\title{
Bioresponsive nanoparticles based on poly(amidoamine)s for protein delivery
}

\section{Grégory Coué}

Ph.D. thesis with references, and summaries in English and Dutch University of Twente, Enschede, The Netherlands

April 2011

The research is this thesis was carried out from 2007 until 2011 in the research group Biomedical Chemistry of the MIRA Institute for Biomedical Technology and Technical Medicine, University of Twente, Enschede, The Netherlands.

This research work is part of the European Project FP6 IP NanoBioPharmaceutics.

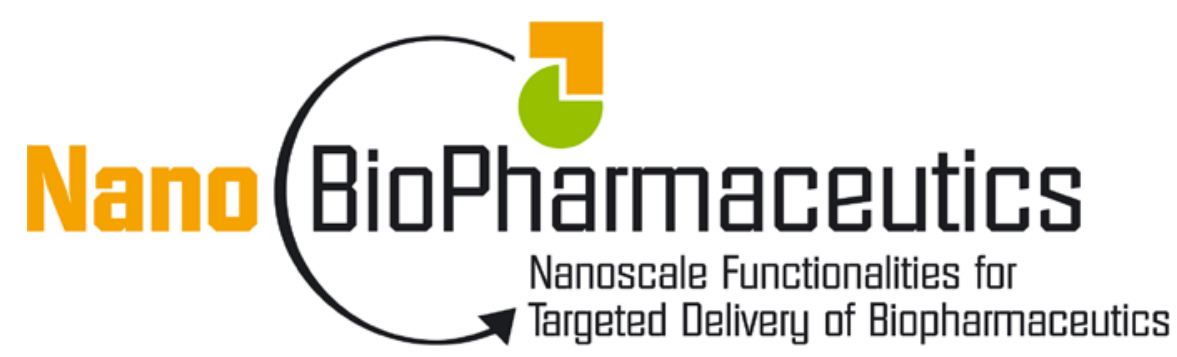

Copyright (C 2011 by Grégory Coué, all rights reserved

The printing of this thesis was financially supported by:

Nederlandse vereniging voor Biomaterialen en Tissue Engineering

Netherlands society for Biomaterials and Tissue Engineering 
Samenstelling van de commissie:

Voorzitter

Prof. Dr. S.G. Lemay

Universiteit Twente, Nederland

Secretaris

Prof. Dr. S.G. Lemay

Universiteit Twente, Nederland

Promotor

Prof. Dr. J.F.J. Engbersen

Universiteit Twente, Nederland

Leden

Prof. Dr. J. Feijen

Universiteit Twente, Nederland

Prof. Dr. D.W. Grijpma

Universiteit Twente, Nederland

Prof. Dr. C. Grandfils

Université de Liège, België

Hoogleraar

Prof. Dr. W.E. Hennink

Universiteit Utrecht, Nederland

Prof. Dr. J.J.L.M. Cornelissen

Universiteit Twente, Nederland

Paranimfen

Can Aran

Samuele De Guido 


\section{BIORESPONSIVE NANOPARTICLES BASED ON POLY(AMIDOAMINE)S FOR Protein Delivery}

\section{Proefschrift}

ter verkrijging van

de graad van doctor aan de Universiteit Twente op gezag van de rector magnificus,

Prof. Dr. H. Brinksma, volgens besluit van het College voor Promoties

in het openbaar te verdedigen

op vrijdag 24 juni 2011 om 16.45 uur

door

\section{Grégory Michel Jean Pierre Charles Coué}

geboren op 20 mei 1983

te Malestroit (Bretagne, Frankrijk) 
Dit proefschrift is goedgekeurd door de promotor:

Prof. Dr. Johan F.J. Engbersen

(c) 2011 Grégory Coué 


\section{Table of Contents}

\section{Chapter 1}

General Introduction

\section{Chapter 2}

Strategies and perspectives on the design of polymeric nanoparticles for protein and peptide delivery: from the delivery issues to the applications of poly(amidoamine)s, a literature review

\section{Chapter 3}

Functionalized linear poly(amidoamine)s are efficient vectors for intracellular protein delivery

\section{Chapter 4}

A protein nanocarrier from charge-reversal poly(amidoamine)s in response to endosomal $\mathrm{pH}$

\section{Chapter 5}

111

Bioreducible insulin-loaded nanoparticles and their interaction with model lipid membranes

\section{Chapter 6}

Bioreducible poly(amidoamine)s as carriers for intracellular protein delivery to intestinal cells

\section{Chapter 7}

In vitro and in vivo evaluation of insulin-loaded poly(amidoamine) nanoparticles for oral protein delivery 
Chapter 8

179

Development of antigen-loaded poly(amidoamine) nanoparticles for nasal applications and their in vitro evaluation

\section{Chapter 9}

Design and physiochemical characterization of poly(amidoamine) nanoparticles and the toxicological evaluation in human endothelial cells: applications to peptide delivery to the brain

Chapter 10

Conclusions

Appendix A

Novel thermo-responsive polymers based on bioreducible poly(amidoamine)s

Appendix B

Attempts of improvement on the stability of bioreducible poly(amidoamine) nanoparticles for protein and peptide delivery

Summary

Samenvatting

Acknowledgments

Resume 


\section{Chapter 1}

\section{General introduction}

\section{Grégory Coué and Johan F.J. Engbersen}

Department of Biomedical Chemistry, MIRA Institute for Biomedical Technology \& Technical Medicine, Faculty of Science and Technology, University of Twente, P.0. Box 217, 7500 AE Enschede, the Netherlands

\section{Background}

The rapid development of genomics and proteomics during the last two decades has led to the discovery of many new proteins that have great therapeutic potential because of their powerful and selective activity in important physiological processes [1]. Several peptide and protein agents such as vaccines, hormones, growth factors and enzymes have the opportunity to be used as highly specific and effective therapeutics to treat a range of chronic diseases, cancers, autoimmune diseases and metabolic disorders [1-6]. The advances in biotechnology now permit the production of numerous proteins on a commercially viable scale. However, whereas production is no longer a major obstacle, the effective delivery of therapeutic proteins to the targeted site of action remains a tremendous challenge. Indeed, the delivery of protein therapeutics is associated with a great number of hurdles that have to be overcome before the protein can exert its therapeutic activity. The bioavailability of many protein drugs is low because of their physical and chemical instability, and as for oral administration these therapeutics suffer from their fast enzymatic degradation and metabolization in the gastrointestinal tract. In addition, negatively-charged cell membranes and mucosa prevent proteins and other drugs with anionic character from entering cells by charge repulsion, and the large size and hydrophilicity of proteins causes their transport through compartmental cellular barriers slow and ineffective [7,8]. Moreover, once internalized, proteins can also be subject to lysosomal degradation. 
Several strategies to overcome these difficulties have been investigated, and the utilization of polymer-based nanocarriers has emerged as a promising and versatile approach because of their facile transformation and possibilities to tune properties including subcellular size, biodegradability, and biocompatibility [9, 10]. Recently, nanosized polyelectrolyte complexes (PECs) resulting from the self-assembly of proteins with natural and synthetic polymers have drawn increasing attention for application in therapeutic protein delivery [11-14]. In this non-covalent method, PECs are formed by simply mixing oppositely charged drug and polymer that will interact by electrostatic-attraction. The PEC formation should then result in optically homogeneous and stable dispersions of nanoparticles possessing cationic charges able to bind to and internalize with cell surface [11].

As cationic carriers, poly(amidoamine)s (PAAs) have high potential in biomedical applications [15, 16]. These polymers are water-soluble, biodegradable and biocompatible, with lower cytotoxicity profiles than other usual polycationic vectors [17-20]. In our group we have previously developed a series of novel linear PAAs containing repetitive disulfide linkages in their backbone (SS-PAAs). These polymers are relatively stable in the extracellular medium but are prone to fast degradation in the reductive intracellular environment due to the cleavage of the disulfide linkages in the polymer chain [21-25], which makes the SS-PAAs very efficient vectors for intracellular gene delivery [26-29]. In general, this property can be favorably exploited in delivery systems that should be stable outside the cell but have to disintegrate into fragments of low molecular weight after uptake into target cells in order to release their therapeutic cargo and to minimize cytotoxic effects.

\section{Aim of this study}

The main aim of the study described in this thesis is the design of carriers for safe and efficient protein delivery, based on functionalized biodegradable PAAs, notably bioreducible SS-PAAs having repetitive disulfide bonds in their main chain that are degradable by intracellular reduction. These polymer systems are expected to be non-toxic and capable to induce efficient intracellular protein delivery via the parenteral route, but are also of interest to be studied as delivery systems via oral and nasal administration, as well as for transport of proteins across the blood-brain barrier. 


\section{Outline of the thesis}

In this thesis, bioreducible PAAs are designed as virtually non-toxic carriers for protein delivery. The structural influences of these polymers on their protein delivery properties, profection capability and cytotoxicity in vitro are discussed in detail. The results on in vivo protein delivery to diabetic rats with the bioreducible PAAs are also described.

In Chapter 2, a literature overview is presented focusing on the strategies that have been followed to design polymers as non-toxic carriers for intracellular protein delivery. This review aims to contribute to the understanding of the current status on polymeric protein carriers and the challenging work that can be achieved in the near future.

In Chapter 3, functionalized linear PAAs are designed and evaluated as efficient vectors for intracellular protein delivery in vitro towards COS-7 cells, using $\beta$-galactosidase as a model protein.

In Chapter 4, protein nanocarriers from bioreducible PAAs containing repetitive disulfide linkages in the main chain and charge-reversal groups in the side chains that respond to acidification in the endosomes are designed and evaluated as non-toxic carriers for intracellular delivery of cationic proteins in vitro towards Huvec cells.

In Chapter 5, we describe the synthesis and properties of insulin-loaded nanoparticles based on bioreducible PAAs. In this study, surface sensitive analytical techniques are used to evaluate the responsiveness of the nanosized insulin-loaded polyelectrolyte complexes when adsorbed to model lipid membranes.

In Chapter 6, the influence of the disulfide bonds in PAAs for intracellular protein delivery, notably for intestinal applications, is described. Formulations of nanoparticles using PAAs as polymer carrier and human serum albumin were studied in vitro towards Caco-2/TC7 cells. The mucoadhesive properties of the polymers were also studied.

Chapter 7 describes the preparation of bioreducible PAA nanoparticles for oral insulin applications. PAA nanoparticles are formulated with human insulin and their proteolytic and chemical stability in vitro were evaluated, as well as their capacity to decrease glucose blood level in vivo in diabetic rats.

In Chapter 8, nanoparticles based on bioreducible PAAs for nasal applications are presented. These nanoparticles contain ovalbumin and p24, the component of the HIV virus particle capsid, as antigens and $\mathrm{CpG}$ oligodeoxynucleotide as adjuvant, and are evaluated in vitro for nasal cell penetration and cytotoxicity using HUVEC cells, the respiratory epithelial $\mathrm{NCI} \mathrm{H} 441$ cells and the endothelial cell line ISO-HAS-1. 
Chapter 9 describes the use of PAAs as non-toxic carriers for protein and peptide therapeutics for delivery to the brain. The physico-chemical properties of these polymers were characterized as well as their potency for efficient profection in hCMEC and Huvec cells.

In Appendix 1, attempts of improvement on the stability of PAA nanoparticle formulations with protein are assessed by ionic gelation or cross-linking.

In Appendix 2, thermo-responsive bioreducible PAAs are designed and synthesized for gene delivery. This preliminary study aims to ascertain the chemical structural effects on the modifications of the side chains in the PAAs on their responsive to an increase of temperature from room temperature to body temperature.

\section{References}

[1] S. Stolnik, K. Shakesheff, Formulations for delivery of therapeutic proteins. Biotechnol. Lett. 31(1) (2009) 1-11.

[2] C. Borghouts, C. Kunz, B. Groner, Current strategies for the development of peptide-based anti-cancer therapeutics. J. Pept. Sci. 11(11) (2005) 713-726.

[3] C. Krejsa, M. Rogge, W. Sadee, Protein therapeutics: new applications for pharmacogenetics. Nat. Rev. Drug Discov. 5(6) (2006) 507-521.

[4] R. Langer, J. Folkman, Polymers for Sustained-Release of Proteins and Other Macromolecules. Nature 263(5580) (1976) 797-800.

[5] A.K. Pavlou, J.M. Reichert, Recombinant protein therapeutics - success rates, market trends and values to 2010. Nat Biotech 22(12) (2004) 1513-1519.

[6] J.E. Talmadge, The Pharmaceutics and Delivery of Therapeutic Polypeptides and Proteins. Adv. Drug Deliv. Rev. 10(2-3) (1993) 247-299.

[7] M.C. Manning, K. Patel, R.T. Borchardt, Stability of Protein Pharmaceuticals. Pharm. Res. 6(11) (1989) 903-918.

[8] Y. Tabata, Y. Ikada, Protein release from gelatin matrices. Adv. Drug Deliv. Rev. 31(3) (1998) 287-301.

[9] M.D. Chavanpatil, A. Khdair, J. Panyam, Nanoparticles for cellular drug delivery: Mechanisms and factors influencing delivery. J. Nanosci. Nanotechnol. 6(9-10) (2006) 2651-2663.

[10] C.O. Weill, S. Biri, A. Adib, P. Erbacher, A practical approach for intracellular protein delivery. Cytotechnology 56(1) (2008) 41-48.

[11] P. Calvo, C. RemunanLopez, J.L. VilaJato, M.J. Alonso, Novel hydrophilic chitosan-polyethylene oxide nanoparticles as protein carriers. J. Appl. Polym. Sci. 63(1) (1997) 125-132.

[12] A. Harada, K. Kataoka, Novel polyion complex micelles entrapping enzyme molecules in the core: Preparation of narrowly-distributed micelles from lysozyme and poly(ethylene glycol)-poly(aspartic acid) block copolymer in aqueous medium. Macromolecules 31(2) (1998) 288-294.

[13] A. Jintapattanakit, V.B. Junyaprasert, S. Mao, J. Sitterberg, U. Bakowsky, T. Kissel, Peroral delivery of insulin using chitosan derivatives: A comparative study of polyelectrolyte nanocomplexes and nanoparticles. Int. J. Pharm. 342(1-2) (2007) 240-249.

[14] Y. Lee, S. Fukushima, Y. Bae, S. Hiki, T. Ishii, K. Kataoka, A protein nanocarrier from charge-conversion polymer in response to endosomal pH. J. Am. Chem. Soc. 129(17) (2007) 5362-5363.

[15] P. Ferruti, M.A. Marchisio, R. Duncan, Poly(amido-amine)s: Biomedical applications. Macromol. Rapid Commun. 23(5-6) (2002) 332-355. 
[16] J. Franchini, E. Ranucci, P. Ferruti, Synthesis, physicochemical properties, and preliminary biological characterizations of a novel amphoteric agmatine-based poly(amidoamine) with RGD-like repeating units. Biomacromolecules 7(4) (2006) 1215-1222.

[17] O. Boussif, F. Lezoualch, M.A. Zanta, M.D. Mergny, D. Scherman, B. Demeneix, J.P. Behr, A Versatile Vector for Gene and Oligonucleotide Transfer into Cells in Culture and in-Vivo Polyethylenimine. Proc. Natl. Acad. Sci. U. S. A. 92(16) (1995) 7297-7301.

[18] C.X. Wu, S.L. Lo, J. Boulaire, M.L.W. Hong, H.M. Beh, D.S.Y. Leung, S. Wang, A peptide-based carrier for intracellular delivery of proteins into malignant glial cells in vitro. J Control Release 130(2) (2008) 140-145.

[19] J.D. Eichman, A.U. Bielinska, J.F. Kukowska-Latallo, J.R. Baker Jr, The use of PAMAM dendrimers in the efficient transfer of genetic material into cells. Pharmaceut Sci Tech Today 3(7) (2000) 232-245.

[20] E. Ranucci, G. Spagnoli, P. Ferruti, D. Sgouras, R. Duncan, Poly(amidoamine)s with potential as drug carriers: degradation and cellular toxicity. J Biomater Sci Polym Ed 2(4) (1991) 303-315.

[21] C. Lin, C.-J. Blaauboer, M.M. Timoneda, M.C. Lok, M. van Steenbergen, W.E. Hennink, Z. Zhong, J. Feijen, J.F.J. Engbersen, Bioreducible poly(amido amine)s with oligoamine side chains: Synthesis, characterization, and structural effects on gene delivery. J Control Release 126(2) (2008) 166-174.

[22] C. Lin, Z. Zhong, M.C. Lok, X. Jiang, W.E. Hennink, J. Feijen, J.F.J. Engbersen, Linear poly(amido amine)s with secondary and tertiary amino groups and variable amounts of disulfide linkages: Synthesis and in vitro gene transfer properties. J Control Release 116(2) (2006) 130-137.

[23] C. Lin, Z. Zhong, M.C. Lok, X. Jiang, W.E. Hennink, J. Feijen, J.F.J. Engbersen, Random and block copolymers of bioreducible poly(amido amine)s with high- and low-basicity amino groups: Study of DNA condensation and buffer capacity on gene transfection. J Control Release 123(1) (2007) 67-75.

[24] C. Lin, Z.Y. Zhong, M.C. Lok, X.L. Jiang, W.E. Hennink, J. Feijen, J.F.J. Engbersen, Novel bioreducible poly(amido amine)s for highly efficient gene delivery. Bioconjugate Chem. 18(1) (2007) 138-145.

[25] M.A. Mateos-Timoneda, M.C. Lok, W.E. Hennink, J. Feijen, J.F.J. Engbersen, Poly(amido amine)s as gene delivery vectors: Effects of quaternary nicotinamide moieties in the side chains. ChemMedChem 3(3) (2008) 478-486.

[26] A. Bernkop-Schnürch, Thiomers: A new generation of mucoadhesive polymers. Adv. Drug Deliv. Rev. 57(11) (2005) 1569-1582.

[27] C. Lin, J.F.J. Engbersen, The role of the disulfide group in disulfide-based polymeric gene carriers. Expert Opin. Drug Deliv. 6(4) (2009) 421-439.

[28] F.H. Meng, W.E. Hennink, Z. Zhong, Reduction-sensitive polymers and bioconjugates for biomedical applications. Biomaterials 30(12) (2009) 2180-2198.

[29] K.C. Rajender, W.L. Frederick, H.K. Michael, M.B. David, G.B.R. Robert, R. Daniel, Plasma cysteine, cystine, and glutathione in cirrhosis. Gastroenterology 87(4) (1984) 770-776. 


\section{Strategies and perspectives on the design of polymeric nanoparticles for protein and peptide delivery: from the delivery issues to the applications of poly(amidoamine)s, a literature review}

\section{Grégory Coué and Johan F.J. Engbersen}

Department of Biomedical Chemistry, MIRA Institute for Biomedical Technology \& Technical Medicine, Faculty of Science and Technology, University of Twente, P.0. Box 217, 7500 AE Enschede, the Netherlands

Part of this review has been published: G. Coué, J.F.J. Engbersen, Perspectives on Nanoparticulate Delivery of Therapeutic Proteins by Oral Administration, NanoLIFE 1 (1-2) (2010) 99-108

\section{Background of Protein Therapeutics}

The rapid development of genomics and proteomics during the last two decades revealed has led to the discovery of many new proteins that have valuable therapeutic potential because of their powerful and selective activity in important physiological processes [1]. Proteins and peptides are increasingly recognized as potential leads for the development of new therapeutics, since several peptide and protein agents such as vaccines, hormones, growth factors and enzymes have the opportunity to be used as highly specific and effective therapeutics to treat a range of chronic diseases, cancers, autoimmune diseases and metabolic disorders [1-6]. The most frequently marketed biopharmaceuticals include monoclonal-antibody-based products for cancer treatment and autoimmune diseases, therapeutic vaccines, insulin for diabetes treatment, human growth hormone for supplementation in hormone deficiency, and interferon- $\alpha$ for treatment of hepatitis B and/or C $[7,8]$. The advances in biotechnology now permit the production of numerous proteins on a commercially viable scale, and these biopharmaceutics comprise an increasing share of the pharmaceutical market. 
However, the effective delivery of therapeutic proteins to the targeted site of action remains a tremendous challenge since the delivery of protein therapeutics is associated with a great number of hurdles that have to be overcome before the protein can exert its therapeutic activity. Their widespread applications are restricted by their physico-chemical properties that make their systemic delivery difficult. Such properties include their particularly high molecular weight and hydrophilicity, which lead to low bioavailability, poor transfer across biological membranes, and low stability in the bloodstream [9-11]. The molecular weight and size of a drug influence its diffusion through the epithelial layer. It is known that bioavailability decreases sharply when its molecular mass increases beyond $700 \mathrm{Da}$. The hydrophilicity of the drug also affects its permeation and transcellular absorption by passive diffusion, which can only occur if the drug is lipophilic, unless transport proceeds via the paracellular pathway, restricted to relatively small molecules (<200 Da) [12-15]. Most therapeutically valuable proteins and peptides typically have large molecular weight (>700 Da) and also hydrophilic $[11,13]$, leading to a generally low bioavailability. In addition, during the preparation of the protein/peptide drugs, manufacturing processes and environmental factors may damage the proteins, reduce their biological activity, induce aggregation, render the proteins immunogenic and lead to their precipitation $[16,17]$. These processes include sterilization and lyophilization while the contributing environment factors are $\mathrm{pH}$, ionic strength, temperature, high pressure, non-aqueous solvents, metal ions, detergents, absorption, agitation and shearing. Protein stability, based on weak non-covalent interactions between secondary, tertiary and quaternary structures of proteins, is crucial to prevent any disruptions that will destabilize the proteins [16].

Directed administration of peptide and protein therapeutics by injection can solve some of these obstacles. Currently, the most common administration route of therapeutic peptides and proteins is injection or intravenous infusion. However, as most peptide and protein drugs appear immunogenic, they have very short half-lives in the bloodstream and as highly vulnerable molecules due to degradation by enzymes and proteases, either at the administration site or en-route to the site of pharmacological action, resulting in poor availability. Therefore repeated doses are demanded to maintain therapeutic levels and this might result in an oscillating concentration of the drug in the blood [14]. Furthermore, injections and intravenous infusions are costly and painful and lead to poor patient compliance. Besides parenteral drug delivery, other non-invasive formulation approaches for peptide and protein drugs have been recently emerging. Recently there has been a shift 
in the pharmaceutical industry towards producing needle-free biopharmaceuticals as alternatives to unfavoured injections, and major efforts and considerable research in academic and industrial laboratories have been directed towards developing new effective forms of therapeutic peptides and proteins. Beyond the parenteral route of administration, a number of routes have been tested with varying degrees of success. Among these, oral, buccal, transdermal, pulmonary, intranasal, intraocular, rectal and vaginal routes are all investigated in protein and peptide delivery. However, even although some of these routes, such as rectal, vaginal, and ocular administration, offer certain advantages, their poor patient acceptability, reserves their use mainly to local, rather than systemic, drug administration.

The oral and nasal routes seem to emerge as the most promising alternatives to administration of proteins by injections.

\section{Oral and Nasal Delivery of Proteins: Advantages and Bottlenecks of these Mucosal Routes}

\subsection{Oral Delivery of Proteins}

In view of its convenience and patient acceptance, the oral route is the most common and preferred route of drug delivery for the majority of patients since it avoids pain and discomfort. However, for the delivery of protein therapeutics this route is also associated with a great number of hurdles that have to be overcome before the protein can exert its therapeutic activity.

The bioavailability of many protein drugs is low because of the physical and chemical instability of proteins and their fast enzymatic degradation and metabolization in the gastrointestinal tract. In addition, negatively-charged cell membranes and mucosa prevent proteins and other drugs with anionic character from entering cells by charge repulsion and the large size and hydrophilicity of proteins causes their transport through compartmental cellular barriers slow and ineffective $[18,19]$. Effective oral delivery is one of the key problems for these therapeutics and the development of efficient drug delivery systems that can overcome this hurdle will greatly contribute to the advancement of their application.

\section{The route from the mouth to the intestine}

A major obstacle for the oral administration of proteins is their vulnerability to proteolytic degradation by digestive enzymes in the gastrointestinal (GI) tract [20]. Whereas 
degradation of proteins during their transit via the mouth, pharynx and esophagus, ileum and colon is minimal, the proteolytic activity is highest in the stomach and duodenum. The digestive juices of the stomach secreted by gastric exocrine glands are responsible for production of hydrochloric acid, pepsinogen and mucus along with other components. Pepsinogen is converted into pepsin by hydrogen chloride secreted by the gastric glands and is responsible for the cleavage of peptide bonds between aromatic amino acids such as phenylalanine, tyrosine and tryptophan. In order to be absorbed, proteins must persist sufficiently long in the intestinal lumen to allow adherence to cell apical surfaces and to be transported into intestinal cells. However, the bioavailability of drugs sharply decreases when the molecular weight increases beyond ca. $700 \mathrm{Da}$, which is far below the molecular weight of most of the proteins used as therapeutics. Their large molecular weight and hydrophilicity causes low mucosal permeability and cellular transport. All these effects lead to bioavailabilities lower than $10 \%$ for orally administered peptides and proteins, and for example as low as $0.05 \%$ for orally delivered insulin [21-23]. Therefore, considerable interest is focused on the development of appropriate carrier formulations that improve the poor oral bioavailability of proteins by protecting the protein from degradation, enhancing its uptake into the intestinal mucosa and increasing the absorption across biological membranes.

\section{Uptake from the intestine into the bloodstream}

One of the most significant factors which affect absorption into the bloodstream is transport across the epithelial cell layer of the intestine. The purpose of the epithelial layer is to absorb only required nutrients such as vitamins and minerals and to exclude unwanted entities such as toxins or viruses. Basically, five different pathways are possible for a drug to reach the bloodstream from the intestinal lumen: the transcellular pathway (through the epithelial cells) by passive diffusion or by binding to transport proteins, the paracellular pathway (in between adjacent cells), the adsorptive- and receptor-mediated endocytotic pathway, and the absorption into the lymphatic circulation via M-cells of Peyer's patches (PPs) (see Figure 2.1). 


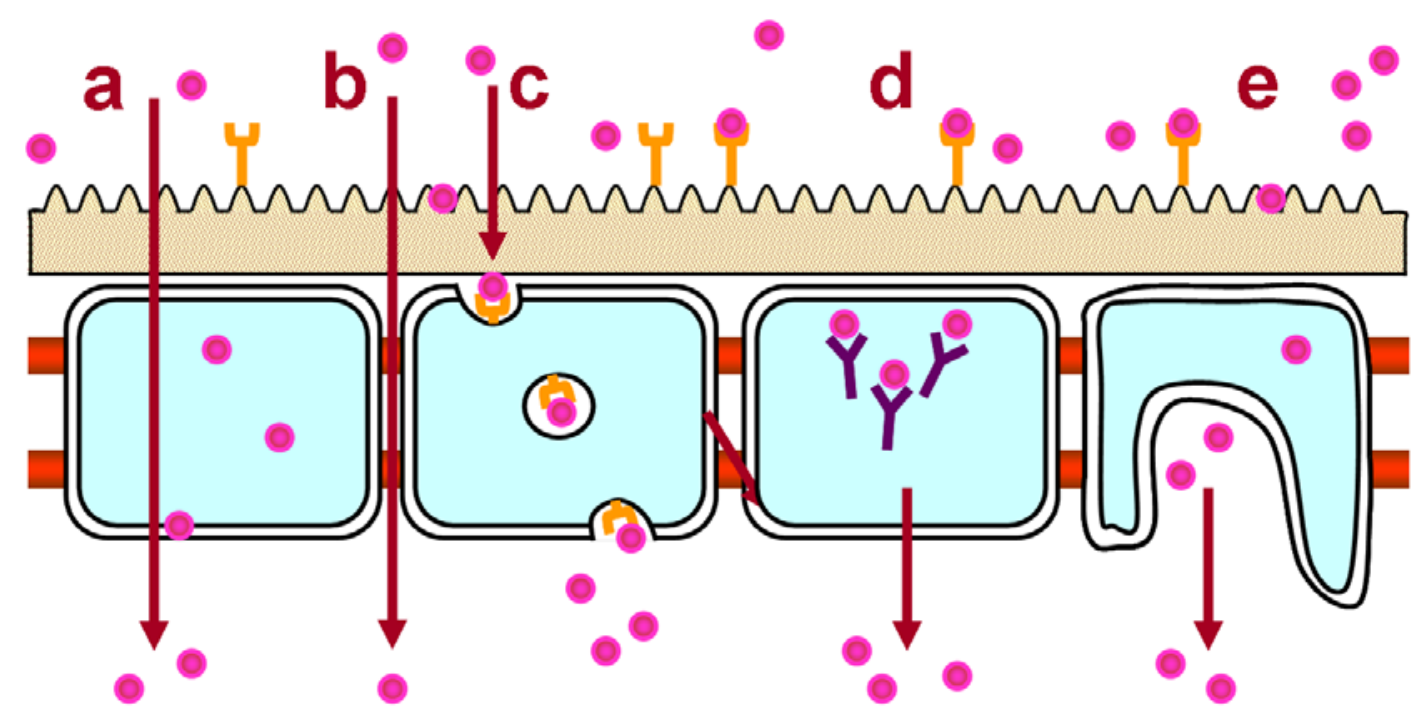

Figure 2.1. Schematic depiction of the intestinal epithelium and the pathways available for drug absorption: (a) transcellular pathway by passive diffusion, (b) paracellular pathway in between cells, (c) adsorptive- and receptor-mediated endocytotic pathway, (d) transcellular pathway by transport proteins, (e) pathway by absorption into the lymphatic circulation via M-cells of Peyer's patches via receptor mediated endocytosis and nonspecific adsorptive mechanisms.

In the transcellular pathway (a), molecules are passing the cell membranes by passive diffusion. Generally, the lipid bilayer of the membranes makes free diffusion across the cells only limited to lipophilic molecules with molecular mass of less than $400 \mathrm{Da}$. Therefore, a minimum of hydrophobicity is needed for macromolecules in order to permeate the epithelium and to be transcellularly absorbed through passive diffusion. However, most therapeutic proteins and peptides are hydrophilic, making them not expectable to follow the transcellular route [24].

The small paracellular space with tight junctions that have to be passed in the paracellular route (b) only permits the transport of relatively small hydrophilic molecules (molecular mass <100-200 Da) $[12,13,15]$. Even in these cases, the absorption capacity is quite limited because the paracellular pathway comprises a very small percentage of the total epithelial surface area. Therefore, the paracellular route is not a possible option for the delivery of macromolecules. For instance, in the case of insulin for which large efforts have been undertaken to develop an oral administration system, evidence for a paracellular route of absorption has not been found by either morphocytochemical or biochemical analyses.

It was demonstrated that insulin absorbed in the apical membrane and was internalized by certain types of endocytosis (c) [25]. In order to open this pathway to macromolecules, it 
will be necessary to alter or disrupt the tight junctions that exist between cells. However, this introduces the strong disadvantage that the transport is nonselective and viruses and toxins can be taken up as well.

In principle, the most natural approach to transport proteins across the epithelial cell layer is by adsorptive or receptor-mediated endocytosis. Some proteins as immunoglobulin and antihypertensive peptides derived from egg proteins have been shown to be actively transported in membrane-bound vesicles after binding to cell-surface receptors or binding sites (route d) [26-28]. However, for some only a tiny fraction released at the basolateral membrane and secreted into the interstitial space in an intact form [26].

Uptake of protein therapeutics may also proceed via absorption into the lymphatic circulation by PPs (route e). PPs are aggregations of lymphoid tissue that are found in the lowest portion of the small intestine ileum and it is generally assumed that uptake of particles is mediated by epithelial $M$ cells. Strategies to improve the interactions of therapeutics with adsorptive enterocytes and M cells of PPs can be classified into those utilizing specific binding to ligands or receptors and nonspecific adsorptive mechanisms.

\subsection{Nasal Delivery of Proteins}

\section{A promising alternative}

Because of the complexity and poor success in the oral delivery of biotherapeutic proteins and peptides, the nasal route offers an interesting option to conventional parenteral routes of administration [29]. It presents numerous benefits as a non-invasive target issue for drug delivery as compared to the oral administration. Several nasal delivery systems for peptides, such as Luteinizing hormone-releasing hormone agonists, are available as licensed products, these peptides are inactive after oral administration, and in this respect nasal delivery is regarded as an attractive alternative to chronic injection therapy. Moreover, some drugs that use the nasal route of administration have also been approved and have reached the market, as calcitonin salmon nasal spray or nasal desmopressin or buserelin [30, 31].

The nasal route of administration has intrigued researchers for several decades, especially in the context of delivering peptides to systemic circulation. It has been shown as a highly efficient mucosal route for the induction of antibody responses in the serum, as well as local and distal mucosal secretions [32-34].

The following biopharmaceutical features have been considered as being potentially relevant for nasal delivery compared to other delivery routes: comparatively high 
bioavailability, rapid kinetics of drug absorption and therapeutic effects comparable to intramuscular or intravenous injections [35].

The nose has a large nasal mucosa area available for drug absorption due to the coverage of the epithelial surface by numerous microvilli, the subepithelial layer is highly vascularized and directly accessible, the venous blood from the nose passes directly into the systemic circulation and therefore avoids the loss of drug by first-pass metabolism in the liver, it offers lower doses, more rapid attainment of therapeutic blood levels, quicker onset of pharmacological activity, fewer side effects, high total blood flow per $\mathrm{cm}^{3}$, porous endothelial basement membrane. It is readily accessible and some aspects of nasal drug administration such as mucosal immunization make this way of administration interesting for the delivery of drugs [36].

Moreover, nasal delivery has been explored as well as an alternative administration route to target drugs directly to the brain along the olfactory nerves [37-42]. Delivery of drug molecules to the brain is one of the most challenging research areas in pharmaceutical sciences because the blood-brain barrier represents an insurmountable obstacle for a large number of important drugs, including antibiotics, and a variety of neuropeptide drugs active in the central nervous system. When a nasal drug formulation is delivered into the nasal cavity, the olfactory mucosa might be reached and drug transport into the brain and/or cerebrospinal fluid via the olfactory fluid can occur [43]. For example, intact vasoactive intestinal peptide can be successfully delivered to the brain using the intranasal route of administration, while its intravenous administration is ineffective [37]. All these parameters make nasal delivery to be considered as a promising method for protein drug delivery, and these benefits maximize patient convenience, comfort and compliance with a simple and painless mode of application [44].

\section{Limitations of the nasal route}

As outlined above, the nasal cavity is an attractive route for administration of proteins and antigens. Nonetheless, despite the high potential of nasal drug delivery, this route also has a number of limitations, and therefore important issues have to be taken into account for the preparation of nasal formulations.

There are three different distinct functional zones in the nasal cavity, namely: vestibular, olfactory, and respiratory areas. The vestibular area serves as a baffle system; it heats and humidifies inspired air and also functions as a filter of airborne particles [45, 46]. The olfactory epithelium is capable of metabolizing drugs [45]. The respiratory mucosa is the 
region where drug absorption is optimal, and is also the region exposing severe limitations for protein/vaccine delivery. This pseudo-stratified columnar epithelium is covered by a thick mucus layer [47]. After the mucus/surfactant layer, the second barrier that proteins encounter in the respiratory tract is a monolayer of epithelial cells tightly sealed by tight intercellular junctions associated with the immunogical active mucosal nasal associated lymphoid tissues (NALT), containing specialized M-like cells similar to those present in the PPs in the gut. The penetration of macromolecules by the paracellular route is limited since the normal diameter of the tight junctions is in the order of 3.9-8.4 $\AA$ [48] and even with the application of an absorption enhancer the diameter would most be likely still less than $15 \mathrm{~nm}$. Larger macromolecules would have to cross the membrane using a transmucosal route, for example, by endocytosis or a carrier- or receptor-mediated transport process.

Bioavailability of nasally administered peptide and protein drugs can be limited because a broad range of metabolic enzymes are located in the nasal mucosal cavity and the epithelial cells lining the cavity, inducing rapid mucociliary clearance and limiting the ability of peptides and proteins to reach the general circulation in therapeutic quantities $[44,49]$. The tightly impermeable epithelial cell layers in the nasal cavity and also covering nasal-associated lymphoid tissues as well as the short residence time of formulations in the nasal cavity due to mucociliary clearance are severe limitations for protein/vaccine delivery in the upper respiratory tract [49-51]. Consequently, the nose functions as a protective system against foreign material [52].

Furthermore, drug doses are limited because of the relatively small area of absorption. Moreover, the potential irritation and possibly irreversible damage of the nasal tissue from the chronic application of nasal drug formulations can also significantly affect its drug absorption potential in the long-term [35, 44].

The physicochemical properties of the drug, nasal mucociliary clearance and nasal absorption enhancers are the main factors that affect drug absorption through the nasal mucosa. One of the greatest limitations of nasal drug delivery is inadequate nasal drug absorption. Several promising drug candidates cannot be exploited via the nasal route if they are not absorbed well enough to produce therapeutic effects. Proper delivery systems are therefore needed to improve absorption/uptake of protein/peptide-loaded carriers from the epithelium and prevent rapid elimination of the formulations from nasal and intestinal cavities. Mucoadhesive delivery systems with absorption-enhancing properties are needed to improve residence and absorption of therapeutic protein drugs. 


\section{The Requirements to Improve Mucosal Protein Delivery}

The high need for better transport and stabilization of protein drugs inside the body and for improvement of controlled and sustained bioavailability at localized or targeted sites in the body, like the intranasal and intestinal mucosal walls, have stimulated much research in the development of efficient peptide and protein delivery systems.

Desired general characteristics for a protein drug carrier are a high biocompatibility, the ability to incorporate high drug payloads, the possibility of targeting of specific cells or tissues, and tunable release kinetics. A prerequisite for all approaches is that the biological activity of the therapeutic protein is maintained in all modifications without giving rise to significant activity loss. Moreover, once inside the body, the transport system must protect the drug from degradation, metabolization, and capture by the host immune system. For instance for oral delivery, such delivery systems can for instance protect from pepsin digestion in the stomach by enteric coating, enable rapid drug release in the duodenum to provide a higher concentration at the epithelial surface, give adhesion to the mucus membrane, or present special molecules that bind only receptors expressed by target cells. The development of such delivery systems is essential to attain a bioavailability that is acceptable in clinical applications $[53,54]$.

Three different strategies can be discerned that have been applied separately or in combination: (i) modification of the physicochemical properties of the proteins, e.g., by attachment of lipophilic moieties [55], (ii) the addition of novel functions to the proteins, such as protease inhibitors, or penetration or absorption enhancers (e.g., bile salts, fatty acids, cyclodextrins or surfactants) [56-58], or (iii) incorporation of the proteins in delivery carriers, notably the encapsulation of the biodrugs in polymeric materials to achieve delayed and controlled release. Among others, polymeric protein delivery systems based on nanoparticles have been developed and employed so far and will be described more extensively further on in this review.

\section{Protein Encapsulation as a Potential Solution to Increase Bioavailability}

\subsection{Polymer nanoparticles}

Several strategies to overcome the difficulties associated to protein delivery have been investigated, and since the latter half of the 1980s, the utilization of polymeric nanoparticles has emerged as potential carriers for proteins. Because of their facile transformation and possibilities, to tune properties including subcellular size, biodegradability and biocompatibility, these systems have emerged as a promising and 
versatile approach to overcome the different hurdles that limit the biological activity of protein therapeutics in the body [59-61].

Polymers can serve as a matrix that can be altered by variation of the degree of polymerization, changing the constituents of monomers, or attachment of functional groups to the polymers. The formulations are typically based on encapsulation or complexation of a therapeutic protein in a biocompatible synthetic polymeric matrix, providing improved stability compared to the free peptides and proteins. Properly designed nanoparticles can selectively target tissues, cells and subcellular compartments such as nucleus and organelles and control the diffusion of the protein out of the formulation for sustained release of protein drugs in therapeutically relevant ranges to the site of action $[62,63]$.

Most strategies for oral and nasal drug delivery rely on systems designed to protect against enzymatic degradation and enhance transfer of drugs across the epithelium mucosa. Nanoparticles can meet these requirements, by for instance protecting fragile protein drugs against enzymatic degradation in the harsh environment of the Gl tract. Moreover, since nanoparticles can be designed to cross the epithelial mucosa or the lymphoid tissues without using penetration enhancers, they have been extensively investigated to enhance the drug bioavailability after oral and intranasal administration [64, 65].

\subsection{Lipid-based particles}

Lipid-based particles, such as liposomes, represent an important class of colloidal formulations that have shown great promise for use with therapeutic proteins [66-68]. They have been delivered by various routes, and have been identified as effective immunological adjuvants [69], and have potential for the intranasal and oral delivery of protein antigen [70], whilst retaining the biological activity of the entrapped drug [71]. They have notably been used to protect proteins from enzymatic degradation and enhance the bioavailability in virtue of their good bioadhesive characteristics since their bilayer structure is similar to the cell membrane.

For instance, Alpar et al. studied the potential adjuvant effect of liposomes on tetanus toxoid, when delivered via the nasal and oral routes compared to delivery in simple solution in relation to the development of a non-parenteral immunization procedure, which stimulates a strong systemic immunity. They found that tetanus toxoid entrapped in distearoyl phosphadylcholine liposomes was stable and efficiently taken up significantly improving the immune response when compared to the free antigen. These results, 
suggest that liposomes, administered through the oral and nasal routes, have considerable potential as mucosal adjuvants and warrant further investigation [70]. Also, nasal delivery of insulin using liposomes was successful, with increased insulin permeability and enhancement of nasal absorption, with insulin bioavailabilities above $13 \%[72,73]$.

Although their use for oral delivery of proteins has shown some success, as for instance a significant decrease of blood glucose levels in mouse models after administration of insulin-loaded liposomes [74], the poor stability of these systems under the diverse physiological conditions typically found in the Gl tract do not offer much perspectives for widespread application in oral delivery [75]. Nevertheless, the coating of liposomes with mucoadhesive polymers like carbopol and chitosan showed significant improvement in the intestinal absorption of protein drugs like insulin and calcitonin [76-78]. Coating liposomes also proved to be successful for nasal insulin delivery $[79,80]$. In one example, Jain et al. investigated the applicability of insulin-containing multi-vesicular liposomes with the addition of novel chitosan and carbopol coating as sustained release protein delivery systems via the nasal route, and those surface-modified liposomes proved to considerably reduce blood glucose levels compared to non-coated liposomes [80].

\subsection{Hydrogel-based particles}

Solid, hydrogel-based particles appear to be better than lipid-based particles for oral delivery. In this respect, $\mathrm{pH}$-sensitive hydrogels are of particular interest as potential carriers because of their ability to respond to the $\mathrm{pH}$ change between the stomach and small intestine, enabling the protection of the protein from release and degradation at the low $\mathrm{pH}$ in the stomach and the release of the protein at the higher $\mathrm{pH}$ in the small intestine. The protection of the drug in the stomach in these systems is due to the collapsed network and the presence of hydrogen bonding complexes between compatible functional groups. One of the most extended investigated hydrogel systems is a copolymer of methacrylic acid (MAA) with grafted polyethylene glycol (PEG) [81, 82]. The system is an anionic hydrogel, swollen in intestinal conditions but collapsed in gastric environment. PEG is incorporated for both its high level of biocompatibility and its ability to form hydrogen bonding complexes with MAA [83]. The combination of MAA with PEG tethers has demonstrated mucoadhesive properties and improved retention times in the small intestine [84]. Further improvement of this system could be achieved by copolymerization of PEG and MAA with for instance modified carboxymethyl starch to enhance the $\mathrm{pH}$ sensitivity of the hydrogels 
[85]. Similar systems have also been engineered by modification of the composition of the hydrogels. For instance, drawbacks induced by the presence of PEG have been eliminated by the replacement of PEG by $\mathrm{N}$-vinyl pyrrolidone, thereby preventing the incomplete protection of the protein at gastric $\mathrm{pH}$ levels and the delay in protein release upon reaching intestinal $\mathrm{pH}$ levels [86]. In another example, anionic complexation hydrogels of poly(itaconic acid) (PIA) with PEG tethers were prepared [87]. This system increases the residence time between the hydrogel and the intestinal mucosa due to both the formation of hydrogen bonds between IA units and mucosal glycoproteins. In addition, PIA hydrogels may prevent proteolytic enzyme activity and increase the permeability of the intestinal epithelial layer because of their high capacity for calcium cation binding [88, 89].

Polyacrylic acid gels were as well successfully used for nasal delivery of proteins. The effect of polyacrylic acid gel on the nasal absorption of insulin and calcitonin was investigated in rats. After nasal administration of insulin its absorption from polyacrylic gel the residence time was increased up to three hours [90]. The effects of putative bioadhesive polymer gels on slowing nasal mucociliary clearance were investigated using a rat model. The results indicate that all the formulations decreased intranasal mucociliary clearance, thus increasing the residence time of the formulations in the nasal cavity [91].

\subsection{Nanoparticles vs. microparticles}

Compared to microparticulate drug delivery systems, the smaller size of nanoparticles can imply problems with respect to lower physical stability due to their larger surface and higher surface energy. However, nanoscale carriers possess more promising properties for protein delivery because of their sub-cellular size, nanosized drug carriers can cross the fenestration of the vascular epithelium and penetrate tissues, then favoring the transport of particles across the mucosal epithelium. Moreover, nanosystems can be confined at the location of choice either by direct application at specific sites or by conjugation to molecules that strongly bind the target cells. Specialized M cells in the intestinal and nasal epithelium serve as portals for diverse particulates [92, 93]. In contrast to oral delivery, particulates are mainly taken up by the M-cells in the NALT via nasal delivery; therefore the particle size is an essential parameter for optimized delivery.

Fattal et al. reported significant discrimination in the uptake of nano- and microparticles of poly(lactic-co-glycolic acid) (PLGA) by PPs in mice [93]. The number of particles of mean diameter around 0.3 and $1 \mu \mathrm{m}$ observed in PPs was much greater than that of particles of diameter average close to $3 \mu \mathrm{m}$. Regarding the uptake by M cells of NALT, several studies 
have shown that microparticles small than $10 \mu \mathrm{m}$ generally show higher uptake than larger ones [94-96]. The size of nanoparticles or 'small' microparticles is therefore more suitable for $M$ cells uptake and translocation to lymphoid organs to initiate antigen-specific immune responses.

Ponchel et al. proposed a particle absorption model with a porous adsorbent for fine particles, such as $200 \mathrm{~nm}$ poly(isobutylcyanoacrylate) nanoparticles or polystyrene latexes with different particle sizes [97]. Fine particles less than $1 \mu \mathrm{m}$ penetrate into the mucus layer, a porous absorbent. On the other hand, larger particles, such as $2 \mu \mathrm{m}$ polystyrene, showed a Langmuir-type absorption. This absorption pattern suggests that absorption involves a monolayer of the particles on the smooth surface. In another typical example, Amidon et al. showed that $100 \mathrm{~nm}$ PLGA particles diffused throughout the submucosal layers, whereas microsized particles were predominantly localized on the epithelial lining of the tissues [98].

\section{Design and Properties of Polymeric Nanoparticles for Mucosal Protein Delivery}

Unlike low molecular weight drugs, proteins possess secondary, tertiary and in some cases quaternary structures with labile bonds and side chains of chemically reactive groups. Disruption of theses structures or modification of side chains can lead to loss of activity. Therefore, the fragile nature of proteins requires that the processes necessary for the fabrication of protein therapeutics must not damage the protein, reduce its biological activity, nor render the protein immunogenic. Moreover, for most of the proteins, aggregated forms have less biological activity than their native monomeric form [20]. Due to the very specific properties of proteins, the set up of a suitable manufacturing process is essential for obtaining an effective delivery system. The tendency of proteins to be structurally altered with loss of bioactivity and inactivation poses severe limits to the reactions that can be performed on the carrier, to the solvents that can be used, and to the environmental conditions adopted during preparation, purification, and storage of the delivery system. Harsh experimental conditions, especially encountered with nanoparticle formulations from hydrophobic polyesters, the use of organic solvents or surfactants, as well as high temperature, pressure, shear forces, and sonification are usually detrimental for protein stability $[75,99]$. Also matrix degradation may induce protein inactivation or generate immunogenic derivatives. Degradation of polyester type of matrices, like those derived from poly(lactic acid) (PLA) and PLGA (co-)polymers, causes a pH decrease that can induce physical or chemical inactivation of entrapped proteins [100]. 
Regarding the composition, nanoparticles have been produced using various biodegradable or non-biodegradable, hydrophilic or hydrophobic, natural or synthetic polymers. Nanoparticles based on chitosan [101, 102], poly(isobutylcyanoacrylate) [103-106], acrylic acid-based copolymers [107-110], and PLA and PLGA [111-115] were for instance reported to give promising results in the oral and nasal delivery of therapeutic proteins and peptides.

Protein molecules contain many functional groups and hydrophobic regions and may exhibit an overall net positive or negative charge at different $\mathrm{pH}$, depending on their isoelectric point. Some proteins are also known to possess overall hydrophobic properties. Therefore, the development of tailor made carrier systems that bind specific proteins based on complementary hydrogen-bonding, electrostatic and hydrophobic interactions is a promising approach for future development.

\subsection{Surface modification of nanoparticles: the dichotomy of need of both hydrophilicity and hydrophobicity}

In general, the in vitro and in vivo behavior of nanoparticles tends to be greatly dominated by their physicochemical properties such as particle size, surface charge, and hydrophilicity-lipophilicity balance [116, 117]. The epithelial cell membranes are strictly limiting the penetration of proteins and a minimum level of lipophilicity is required for particles to pass through the membrane and to be absorbed transcellularly [24]. Although nanoparticles need some lipophilicity to pass through cell membranes, an excess of lipophilicity can be unbeneficial for protein drug carriers. When synthetic hydrophobic and biodegradable polymers are used for protein delivery $[63,118]$, hydrophilic proteins are poorly entrapped into the hydrophobic matrix. Nanoparticles composed of solely hydrophobic materials generally show low loading capacities and inappropriate release profiles; usually a burst release is followed by incomplete release due to non-specific interactions [119]. Various hydrophobic polymers such as polyesters have been functionalized with lower molecular weight hydrophilic moieties, oligomers or polymers to form core-corona type particles. This surface modification improves the physical stability, prevents particle opsonisation and rapid clearance, and improves the protein loading and release profile [59]. Appropriate surface functionalization can be applied to enhance nanoparticle stability in physiological conditions and to improve targeting to specific tissues or cells. Typical examples of these systems are the PEG surface modified polylactide nanoparticles, extensively described in the literature $[111,120,121]$. The 
interaction between nanoparticles and enzymes of the digestive fluids and plasma was considerably reduced by the PEG coating around the particles which provides efficient charge shielding. Incorporation of PEG into the formulation also induced an increase of the release rate of the particle loading and a decrease of the degradation rate of the nanoparticles. The permeability across mucosa and the amount of drug passing to the bloodstream was also improved [111, 122]. Therefore, improved in vitro and in vivo performance can be obtained when hydrophobic polymers are combined with hydrophilic polymers.

The absorption of nanoparticles can also be enhanced by introducing a coating of cationic and mucoadhesive polymers to their surfaces. The surface functionalization of hydrophobic nanoparticles with mucoadhesive materials such as polysaccharides, lectins, or other synthetic polymers may be of particular benefit for mucosal protein delivery systems [123-125]. Lectins are naturally-occurring glycoproteins that have the ability to non-specifically adhere to and be internalized by epithelial cells as has been demonstrated by Naisbett and Woodley [126] and Lehr [123].

The concept of bioadhesion via lectins may be applied not only for the GI tract but also for other biological barriers like the nasal mucosa, the lung, the buccal cavity, the eye and the blood-brain barrier [127]. While there are many studies on the nasal administration of bioadhesive formulations, the emphasis has been on the use of polymers such as chitosan (vide infra), and to date there are few studies using lectins. Using the isolectin B4 from Bandeiraea simplicifolia 1 (BSI-B4) Giannasca et al. demonstrated lectin-mediated targeting of antigen to hamster M-cells, resulting in the production of specific serum IgG, and Kumar et al. have demonstrated that equine nasopharyngeal tonsillar tissue contains M-cells that react with a lectin from Bandeireae simplicifolia $[128,129]$. This latter lectin (GS I-B4) has also been shown to be almost exclusively M-cell specific for rat NALT, in contrast to other lectins tested (UEA-1, DBA, WGA), and it suppressed the uptake of yeast particles by the M-cells [130]. Thus although studies on lectin targeting to the upper respiratory tract are still very preliminary, the possibilities for vaccine administration look interesting.

As a typical example, Delie et al. recently showed that the interaction of particles with Caco-2 cells was clearly dependant on surface hydrophilicity, where coating PLGA nanoparticles with chitosan increased the internalization in cells by a factor 5 [131]. Similarly, Takeuchi et al. reported that the absorption of elcatonin via the Gl tract was enhanced by chitosan-coated PLGA nanoparticles [132]. Sung et al. explored the use of 
chitosan-coated poly(glutamic acid) for insulin delivery and found that the nanoparticles enhanced the intestinal absorption of insulin, providing a prolonged reduction in blood glucose levels, while the bioavailability was ca. 20\% [133]. Another example with promising results for oral applications was shown with dextran-polycaprolactone nanocapsules of size ca. $200 \mathrm{~nm}$ which permitted high loading (ca. 80\%) of lectins and other model proteins [134]. Comparative studies carried out with protein-loaded PLA, chitosan, and PEGylated PLGA nanoparticles demonstrated that both protein loading and transmucosal permeability were strongly increased by the hydrophilicity of the matrix [135].

In recent years, polymeric micelles have also received growing attention as protein carriers with non-covalent polymer-protein interactions [136]. Polymeric micelles are formed through the self-assembly of amphiphilic block copolymers in an aqueous environment. They have a nanoscopic, core-shell structure in which the hydrophobic core acts as a micro-reservoir for the encapsulation of notably hydrophobic drugs. It has been shown that the polymer micelles can cross the intestinal barrier after oral administration [137] and the nasal epithelial membrane $[138,139]$. Consequently, the polymeric micellar systems might also be useful for the oral and nasal delivery of protein therapeutics.

\subsection{The use of mucoadhesive nanocarriers: "the chitosan example"}

The mucoadhesion of colloidal carriers has been reported to represent one of the most important properties to improve the bioavailability of poorly absorptive drugs [62, 75, 140]. Mucoadhesive carriers adhere to the mucus layer present on mucosal membranes and are expected to prolong the residence time at the local site of absorption, leading to increased drug absorption through the intestinal and nasal membranes. As a result, numerous mucoadhesive delivery systems have been proposed, of which polysaccharides being the most chosen material for the carrier. In particular, chitosan nanoparticles have repetitively been reported to have great potential for oral and nasal protein/peptide administration.

Chitosan is a biodegradable and biocompatible natural polymer. It has a low level of toxicity and is degraded in vivo by lysozymes producing $N$-acetyl-glucosamine [141-146]. Chitosan possesses hydroxyl and amino functional groups which allow chemical modification of the molecule, and therefore the possibility to tune its physical properties for the aimed applications, notably to enhance its solubility, mucoadhesiveness, the absorption and/or cellular uptake of peptides and/or the immunostimulatory properties. In 
recent years, soluble and particulate carriers based on chitosan and its derivatives have received particular interest for the delivery of proteins via mucosal administration such as nasal and oral routes. They provide the capacity of intensifying the interaction of proteins with epithelial barriers (cell membranes and mucus), increasing the residence time of formulations at the site of administration, protecting labile proteins from enzymatic degradation and promoting the absorption of the free protein via the paracellular pathway as well as transcytosis of the encapsulated proteins across epithelial cells and $M$ cells [147-164].

Chitosan owes its high capacity to adhere to the mucosa to ionic interactions between the positively charged amino groups in chitosan and the negatively charged mucus gel layers [141]. The primary mechanism of adhesion at the molecular level is therefore effectuated via electrostatic attraction. The interactions are strong at acidic and slightly acidic $\mathrm{pH}$ levels, at which the positive charge density of chitosan is high. Chitosan and its derivatives allow high protein loading and their excellent mucoadhesive properties address for transmucosal drug delivery by paracellular and intracellular pathways [143].

Nanoparticulate systems of chitosan or other charged polysaccharides with proteins may be easily produced by polyelectrolyte complexation, also named coacervation, a procedure involving the polyionic nature of these materials [165]. Nanosized polyelectrolyte complexes (PECs) resulting from the self-assembly of proteins with natural and synthetic polymers have recently drawn increasing attention for application in therapeutic protein delivery $[158,165-174]$. In this non-covalent method, stable intermolecular complexes are spontaneously formed by charge-attraction by simply mixing oppositely charged protein and polymer generally both in aqueous solutions [171]. The presence of excess of polycation results in an optically homogeneous and stable nanodispersion of particles possessing cationic surface charge that enable binding to the negatively charged cell surface and subsequent internalization [165]. This PEC self-assembly has the advantage of not using sonification or organic solvents which are both harmful for proteins and peptides.

In order to improve the stability of polyelectrolyte complexes formed by charge attraction between cationic polymers and negatively-charged proteins, multi-ion-crosslinking or ionic gelation have been applied. In this method, the particles are prepared by ionic crosslinking by self-assembly of chitosan or chitosan derivatives and oppositely charged macromolecules or by addition of a low molecular weight anionic crosslinker, such as 
tripolyphosphate (TPP), magnesium sulfate, sodium alginate or cyclodextrin (CD) derivatives to chitosan solutions. This approach yields high protein encapsulation efficiencies (up to 90\%) and the average colloidal size of these nanosystems can be modulated by varying the concentration, the mass ratios or the molecular weight of the oppositely charged crosslinkers, variables that are also influencing the release rate of protein. The improved hybrid nanocarriers were specifically used for oral delivery of insulin [167, 175-177], and oral administration to diabetic rats resulted in a reduction of their glucose levels to a normal range for more than several hours [101, 102]. Several studies of ionic crosslinked chitosan nanoparticles using CD or TPP have also been done for nasal delivery of therapeutic proteins [155, 178-180]. It has been shown that insulin-loaded ionic-crosslinked chitosan nanoparticles enhanced nasal absorption of proteins to a greater extent that unmodified chitosan nanoparticles [155, 180].

\subsection{Potential use of cell-penetrating peptides (CPPs)}

During the past decade, a class of short cell-penetrating peptides (CPPs), including arginine-rich peptides as TAT peptides, oligoarginine, and amphiphilic peptides like penetratin, has been reported to efficiently internalize different bioactive compounds into cells [181-187]. Moreover, CPPs have been successfully used for intracellular delivery of a broad variety of pharmaceutical carriers such as liposomes, micelles and nanoparticles [188]. Especially for oral administration where the drugs are poorly absorbable in the GI tract, the use of CPPs is expected to represent a powerful tool for overcoming the low permeability of biologicals through epithelial cell membranes. Certain peptides can be tethered to the hydrophilic protein drug of interest and together the construct possesses the ability to translocate across the plasma membrane and deliver the payload intracellularly [188]. Direct conjugation of CPPs to proteins has shown to promote their internalization into the cytoplasm [181-187]. Also the co-administration of CPPs with therapeutic peptides and proteins as a physical mixture has been reported to significantly improve the absorption of the protein drugs. For instance, penetratin was investigated and used as a potential novel delivery vector on the systemic absorption of therapeutic peptides and proteins for transmucosal delivery [189]. The absorption-enhancing feasibility of $\mathrm{I}$ - and d-penetratin was used for glucagon-like peptide-1 (GLP-1), and exendin-4 as novel antidiabetic therapy, in addition to interferon- $\beta$ (IFN- $\beta$ ) as protein biotherapeutic model from nasal and intestinal route of administration was evaluated in rats. Nasal route is the most feasible for the delivery of therapeutic peptides 
coadministered with penetratin whereas the intestinal route appears to be more restricted. The absolute bioavailability values depend on the physichochemical characters of drugs, stereoisomer character of penetratin, and site of administration. Penetratin significantly increased the nasal more than intestinal absorption of GLP-1 and exendin-4, as the bioavailability for nasal and intestinal administration of GLP-1 was $15.9 \%$ and 5\%, and for exendin-4 were $7.7 \%$ and $1.8 \%$, respectively. Moreover, the bioavailability of IFN- $\beta$ coadministered with penetratin was $11.1 \%$ and $0.17 \%$ for nasal and intestinal administration, respectively. From these findings, penetratin is a promising carrier for transmucosal delivery of therapeutic peptides and macromolecules as an alternative to conventional parenteral routes.

In another example, intestinal absorption of therapeutic peptides and proteins in the GI tract was significantly improved by coadministration of oligoarginine such as R6 and R8 and penetratin [190, 191]. Recently, Morishita et al. suggested that the electrostatic interaction between drug and CPP is an important factor governing the enhancing effect of the CPP on the intestinal peptide/protein absorption. It was found that among 16 peptide drugs possessing different isoelectric points that were coadministrated with D-R8 (D-form arginine octamer, a typical (PP) in a physical mixture, only those peptides that bind to D-R8 showed increased intestinal absorption. In contrast, the intestinal absorption of other peptide drugs that did not bind to D-R8 was not affected in the presence of D-R8 [192].

\subsection{Targeting moieties to utilize the endogenous cellular transport systems}

An efficient strategy to increase the intestinal absorption of peptide/protein carriers is the conjugation with moieties that are recognized by the endogenous cellular-transport systems in the GI tract. Targeting moieties can be linked to the surface of nanocarriers to improve endocytosis uptake. In most cases, antibodies and fragments or oligopeptides, carbohydrates, glycolipids, and folic acid were selected to target different organs and tissues, as the intestine [193]. Notably, it has been demonstrated that Vitamin B12 attached to the surface of nanoparticles or conjugated to the protein, usually via spacing units, for oral delivery of peptides and proteins promote uptake by the receptor-mediated endocytosis pathway and therefore its application as targeting moiety has significant potential [194-196]. For example, in oral insulin delivery systems the presence of Vitamin B12, either directly conjugated or used as a coating for nanocarriers, in this case Vitamin B12-coated dextran nanoparticles, has lead to successful drop in plasma glucose levels up to $75 \%$ [197-199]. 
The use of transferrin as a conjugate in the oral delivery of insulin was extensively studied by the group of Peppas. Insulin that is covalently bound to transferrin exhibited increased transport across Caco- 2 monolayers by a factor of 7 relative to pure insulin. The transferrin in the conjugate was shown to stabilize insulin in the presence of intestinal enzymes and promotes transfer across the epithelial barrier by a receptor-mediated transcytosis mechanism. Incorporation of the transferrin-insulin conjugates into hydrogel microparticles composed of poly(methacrylic acid) and PEG further increased the bioavailability of oral insulin due to inhibition of degradation of insulin in the Gl tract and increased transport across the epithelial cell barrier [200, 201].

\section{Poly(amidoamine)s as Potential Polymer Carriers for Protein Delivery}

\subsection{Introduction to Poly(amidoamine)s}

Poly(amidoamine)s (PAAs) represent a unique family of synthetic functional polymers that have been widely developed for use in both biomedical materials and polymer therapeutics.

PAAs are synthetic tert-amino polymers obtained by stepwise polyaddition of primary or secondary aliphatic amines to bisacrylamides [202, 203], as shown in Scheme 2.1. Since the addition polymerization is a stepwise process, equal monomer ratios are used in the synthesis in order to obtain PAAs of highest theoretical molecular weight.

A<smiles>[R1]N([R])C(=O)C=C</smiles><smiles>[R]N</smiles><smiles>[R2]N(C)CCC(=O)N([R1])CN([R2])C(=O)CCC(C)(C)C</smiles>

B<smiles>[R7]N([R])C(=O)C=C</smiles><smiles>[R]N[R]N([R])[2H]</smiles><smiles>[R]N([R])CCC(=O)N([R1])CN([R])C(=O)CCC(C)(C)C</smiles>

Scheme 2.1. General synthesis scheme of PAAs, from primary (A) or secondary (B) amines.

The synthesis of PAAs is performed in solvents carrying mobile protons, such as water or alcohols, at temperatures above $10-15^{\circ} \mathrm{C}$ and generally without added catalysts [202, 204]. High monomer concentrations and relatively low reaction temperatures give the best results. Aprotic solvents, even if highly polar, are unsuitable as reaction media as they yield 
only low molecular weight products. The amino groups react only if present as free base. The synthetic mechanism is a Michael type addition, and is described in Scheme 2.2.
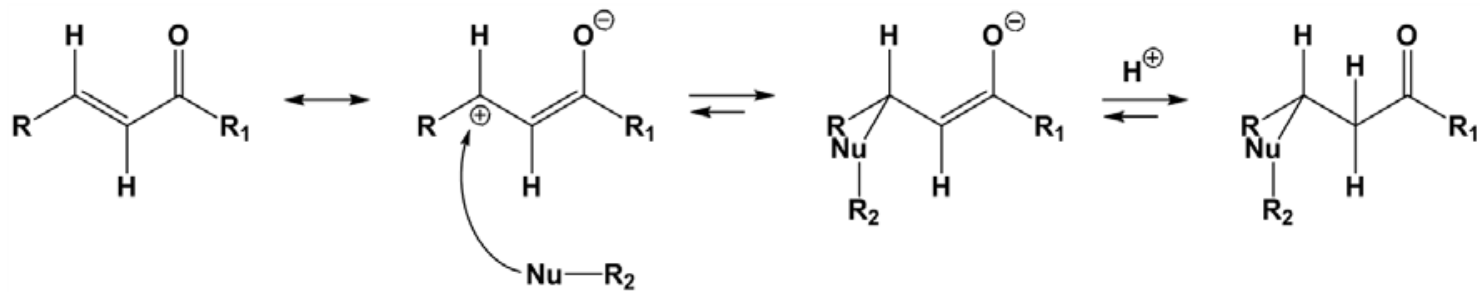

Scheme 2.2. Michael type addition mechanism, $\mathrm{Nu}=$ nucleophile

PAAs are inherently highly functional polymers. However, further functionalization of PAAs may be useful for special purposes. In many cases, the introduction of additional functions in PAAs as side substituents can be simply, directly or indirectly, achieved starting from the corresponding functionalized amine monomers. Moreover, the polymer main chain can be varied by choice of appropriate bisacrylamides.

\subsection{Poly(amidoamine)s for Biomedical Applications}

PAAs have been recognized in literature as polymers with a high potential in biomedical applications [203, 205]. Since they possess tert-amino groups in their main chain, they can be regarded as polyelectrolytes. As generally cationic, these polymers are water-soluble, biodegradable and biocompatible, and can efficiently condense negatively-charged payloads by self-assembly into nanoscaled and positively-charged complexes. This cationic charge permits the nanoparticles to bind on cell membranes and induce endosomal uptake.

PAAs were first investigated in the biomedical field in relation with their ability to form stable complexes with heparin. They were used to neutralize the anticoagulant activity of heparin in solution [206-209], to prepare heparin-absorbing resins [210], and by surface coating of heparin-binding PAAs, to heparinisable materials [211]. More recently, PAAs have been designed as water-soluble polymeric drug carriers, in particularly conjugated with as anticancer agents [212, 213], and as vectors for intracytoplasmic delivery of gene and toxins since these $\mathrm{pH}$-responsive polymers display good endosomolytic characteristics [214].

Effective intracytoplasmic delivery of important macromolecular drugs, particularly proteins and genes, still remains a major challenge restricting their clinical development; a 
challenge that must be overcome if we are able to capitalize on the advances made in the understanding of the molecular basis of diseases [215].

As for gene carriers, the majority of gene therapy clinical trials currently use viral vectors that have major limitations [216]. Although viral vectors mediate effective transfection they have a number of disadvantages, including potential immunogenicity [217-219], potential insertional mutagenesis causing cancers such as leukemia [216], and their pharmacokinetics are not specifically targeted. Many of the alternative non-viral delivery carriers include cationic lipids and polymers such as poly-L-lysine, polyethylenimine and amine terminated PAMAM dendrimers. These carriers have been exploited as oligonucleotide delivery systems, and are generally associated to high toxicity to cells in culture [220-225]. Moreover, they rapidly localize to lung or liver after intravenous administration thus abrogating their ability to target other tissues [226, 227]. Additionally, some of these vectors typically display very poor transfection efficiency [228], this has been attributed to their inability to efficiently permeabilize the endosomal membrane [229]. Efficient cellular targeting and also localization into the appropriate subcellular compartment is vital if these approaches are to be converted into useful medicines. It has been suggested that cationic polymeric transfection agents, such as polyethylenimine, can facilitate vector profection by swelling within the endosome causing membrane rupture, the so-called proton sponge effect [230].

The development of linear PAAs as pH-responsive endosomolytic polymers showed considerable promise. PAAs were found to be significantly less toxic than the previously listed cationic carriers ( $>100$ fold less toxic than polyethylenimine). Moreover, PAAs were able to escape the reticuloendothelial system (RES) clearance after intravenous administration allowing tumor targeting by the enhanced permeability and retention (EPR) effect [230-237]. PAAs have shown to possess the capacity to mediate good gene transfections with transfection efficiencies similar or higher to the golden standards, polyethylenimine and Lipofectamine ${ }^{\circledR}$.

The ability of PAAs to mediate the delivery of proteic macromolecules such as toxins has been investigated, and with gelonin and ricin A-chain as payloads it was shown that these polymers are able to permeabilize the endosomal membrane and thus aid cytoplasmic entry, displaying good results in vitro and in vivo delivery [231, 238-241]. In particular, PAAs were able to restore toxin cytotoxicity, whereas neutral polymers such as dextran were unable to mediate this effect. 


\subsection{Bioreducible Poly(amidoamine)s}

\subsubsection{Introduction to Bioreducible Poly(amidoamine)s}

In our group we have previously developed a series of novel linear PAAs containing repetitive disulfide linkages in their backbone (SS-PAAs). These bioreducible SS-PAA polymers were synthesized via Michael-type polyaddition of the primary amine monomers to $N, N^{\prime}$-cystaminebisacrylamide (CBA) in equimolar monomeric ratios, as shown in Scheme 2.3.A. SS-PAAs were designed to remain relatively stable in extracellular medium but to be prone to fast degradation in the reductive intracellular environment due to the cleavage of the disulfide linkages in the polymer chain [242-245]. This property can be favorably exploited in delivery systems that should be stable outside the cell but have to disintegrate into fragments of low molecular weight after uptake into target cells in order to release therapeutic cargo and minimize cytotoxic effects.

Differently functionalized SS-PAAs were evaluated for their capacity to form nanocomplexes with nucleic acids, and were shown to be very efficient vectors for intracellular gene delivery [246-250]. One example of these successful polymers is $\mathrm{p}(\mathrm{CBA}-\mathrm{ABOL})$, a SS-PAA synthesized by polyaddition of 4-amino-1-butanol (ABOL) to CBA (Scheme 2.3.B). The $\mathrm{p}(\mathrm{CBA}-\mathrm{ABOL})$ polymer possesses, besides repetitive disulfide moieties in the main chain originating from the CBA monomer, hydroxybutyl groups in the side chains originating from the $\mathrm{ABOL}$ units. It has been shown that this hydroxybutyl side group favorably contributes to the efficiency in DNA transfection, presumably by increasing the endosomolytic properties [249].

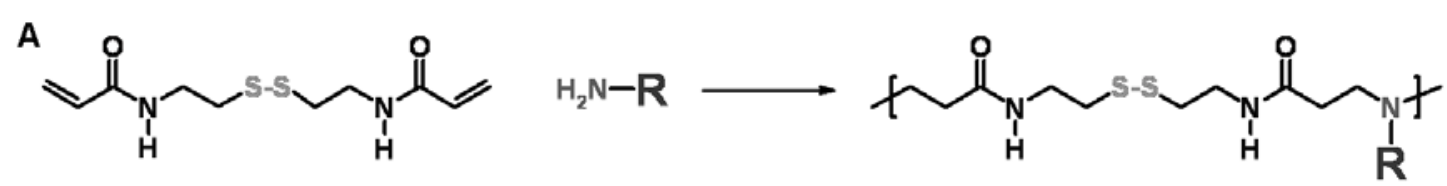

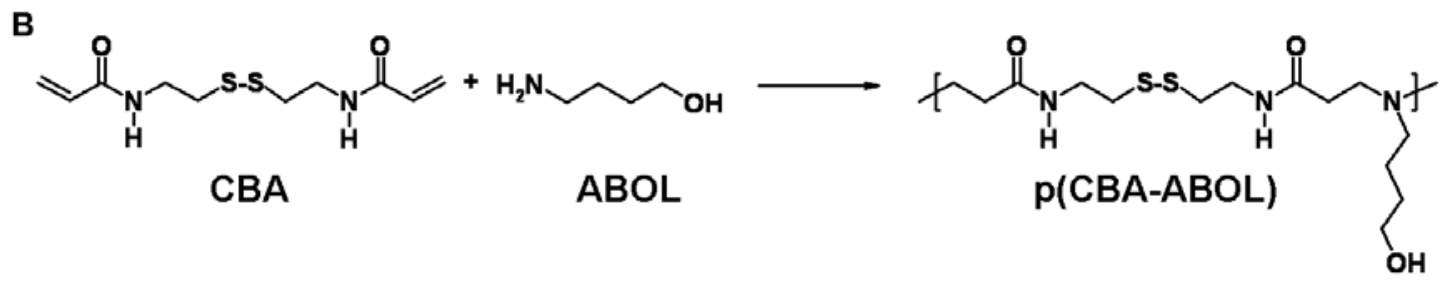

Scheme 2.3. A: General synthesis scheme of SS-PAAs, from Michael type addition of a primary amine to CBA, B: Synthesis scheme of $p(C B A-A B O L)$.

Moreover, the SS-PAAs meet the requirements to possess mucoadhesive properties since the repetitive disulfide linkages in their backbone can react with thiol groups and disulfide groups in the mucus, useful properties for oral and intranasal delivery of nanoparticles made of these polymers [242, 251-254]. 


\subsubsection{Outlook: The Use of Bioreducible Poly(amidoamine)s for Protein Delivery}

The number of biopharmaceutical therapeutics being approved as drugs is constantly increasing, and peptide and proteins therapeutics are becoming more common on the market. The main aim of the study described in this thesis is the design of carriers for safe and efficient protein delivery based on functionalized biodegradable PAAs, notably bioreducible SS-PAAs with disulfide linkages in their main chain that are degradable by intracellular reduction. These polymer systems are expected to possess low toxicity and being capable to induce highly efficient protein delivery via the intracellular pathway. The structural effects of these polymers on their protein delivery properties, profection capability and cytotoxicity have been systematically investigated. Their potency to function as effective protein carriers was further explored for administration via the oral and nasal route, and in a preliminary study as potential carrier to cross the blood-brain barrier.

\section{References}

[1] S. Stolnik, K. Shakesheff, Formulations for delivery of therapeutic proteins. Biotechnol. Lett. 31(1) (2009) 1-11.

[2] C. Borghouts, C. Kunz, B. Groner, Current strategies for the development of peptide-based anti-cancer therapeutics. J. Pept. Sci. 11(11) (2005) 713-726.

[3] C. Krejsa, M. Rogge, W. Sadee, Protein therapeutics: new applications for pharmacogenetics. Nat. Rev. Drug Discov. 5(6) (2006) 507-521.

[4] R. Langer, J. Folkman, Polymers for Sustained-Release of Proteins and Other Macromolecules. Nature 263(5580) (1976) 797-800.

[5] A.K. Pavlou, J.M. Reichert, Recombinant protein therapeutics - success rates, market trends and values to 2010. Nat Biotech 22(12) (2004) 1513-1519.

[6] J.E. Talmadge, The Pharmaceutics and Delivery of Therapeutic Polypeptides and Proteins. Adv. Drug Delivery Rev. 10(2-3) (1993) 247-299.

[7] C. Johnson-Leger, C.A. Power, G. Shomade, J.P. Shaw, A. El Proudfoot, Protein therapeutics - lessons learned and a view of the future. Expert Opin. Biol. Ther. 6(1) (2006) 1-7.

[8] G. Walsh, Biopharmaceutical benchmarks 2006. Nat. Biotechnol. 24(7) (2006) 769-U765.

[9] B.G. Amsden, M.F.A. Goosen, Transdermal Delivery of Peptide and Protein Drugs - an Overview. Aiche J. 41(8) (1995) 1972-1997.

[10] G. Scheuch, R. Siekmeier, Novel approaches to enhance pulmonary delivery of proteins and peptides. J. Physiol. Pharmacol. 58 (2007) 615-625.

[11] R. Singh, S. Singh, J.W. Lillard, Past, present, and future technologies for oral delivery of therapeutic proteins. J. Pharm. Sci. 97(7) (2008) 2497-2523.

[12] M.D. Donovan, G.L. Flynn, G.L. Amidon, Absorption of Polyethylene Glycol-600 through Polyethylene Glycol-2000 - the Molecular-Weight Dependence of Gastrointestinal and Nasal Absorption. Pharm. Res. 7(8) (1990) 863-868.

[13] M.J. Humphrey, P.S. Ringrose, Peptides and Related Drugs - a Review of Their Absorption, Metabolism, and Excretion. Drug Metab. Rev. 17(3-4) (1986) 283-310.

[14] R. Langer, D. Lund, K. Leong, J. Folkman, Controlled release of macromolecules: Biological studies. J. Control. Release 2 (1985) 331-341.

[15] C. McMartin, L.E.F. Hutchinson, R. Hyde, G.E. Peters, Analysis of Structural Requirements for the Absorption of Drugs and Macromolecules from the Nasal Cavity. J. Pharm. Sci. 76(7) (1987) 535-540. 
[16] W. Wang, Protein aggregation and its inhibition in biopharmaceutics. Int. J. Pharm. 289(1-2) (2005) 1-30.

[17] S. Frokjaer, D.E. Otzen, Protein drug stability: A formulation challenge. Nat. Rev. Drug Discov. 4(4) (2005) 298-306.

[18] M.C. Manning, K. Patel, R.T. Borchardt, Stability of Protein Pharmaceuticals. Pharm. Res. 6(11) (1989) 903-918.

[19] Y. Tabata, Y. Ikada, Protein release from gelatin matrices. Adv. Drug Deliv. Rev. 31(3) (1998) 287-301.

[20] H.P. Merkle, New Aspects of Pharmaceutical Dosage Forms for Controlled Drug-Delivery of Peptides and Proteins. Eur. J. Pharm. Sci. 2(1-2) (1994) 19-21.

[21] E. Danforth, R.O. Moore, Intestinal Absorption of Insulin in the Rat. Endocrinology 65(1) (1959) 118-123.

[22] V.H.L. Lee, Enzymatic Barriers to Peptide and Protein-Absorption. Crit Rev Ther Drug Carrier Syst 5(2) (1988) 69-97.

[23] G.M. Pauletti, S. Gangwar, G.T. Knipp, M.M. Nerurkar, F.W. Okumu, K. Tamura, T.J. Siahaan, R.T. Borchardt, Structural requirements for intestinal absorption of peptide drugs. J. Control. Release 41(1-2) (1996) 3-17.

[24] G. Camenisch, J. Alsenz, H. van de Waterbeemd, G. Folkers, Estimation of permeability by passive diffusion through Caco-2 cell monolayers using the drugs' lipophilicity and molecular weight. Eur. J. Pharm. Sci. 6(4) (1998) 313-319.

[25] M. Bendayan, E. Ziv, D. Gingras, R. Bensasson, H. Baron, M. Kidron, Biochemical and Morpho-Cytochemical Evidence for the Intestinal-Absorption of Insulin in Control and Diabetic Rats - Comparison between the Effectiveness of Duodenal and Colon Mucosa. Diabetologia 37(2) (1994) 119-126.

[26] S.E.P. Bastian, P.E. Walton, F.J. Ballard, D.A. Belford, Transport of IGF-I across epithelial cell monolayers. J. Endocrinol. 162(3) (1999) 361-369.

[27] M. Marta, D. Alberto, A.M. María, P. Gema de la, A.L. Miguel, L.-F. Rosina, Transepithelial transport across Caco-2 cell monolayers of antihypertensive egg-derived peptides. PepT1-mediated flux of Tyr-Pro-lle. Mol Nutr Food Res 52(12) (2008) 1507-1513.

[28] R. Rojas, G. Apodaca, Immunoglobulin transport across polarized epithelial cells. Nat. Rev. Mol. Cell Biol. 3(12) (2002) 944-955.

[29] H.R. Costantino, L. Illum, G. Brandt, P.H. Johnson, S.C. Quay, Intranasal delivery: Physicochemical and therapeutic aspects. Int. J. Pharm. 337(1-2) (2007) 1-24.

[30] A. Vegh, Experiences with kryptocur ${ }^{\circledR}$ in the treatment of cryptorchism. Acta Chir Hung 28(4) (1987) 257-261.

[31] P. Peichl, A. Griesmacher, W. Kumpan, R. Schedl, E. Prosquil, H. BrÃ TII, Clinical outcome of salmon calcitonin nasal spray treatment in postmenopausal women after total hip arthroplasty. Gerontology 51(4) (2005) 242-252.

[32] A.J. Almeida, H.O. Alpar, Nasal delivery of vaccines. J. Drug Target. 3(6) (1996) 455-467.

[33] F. Velge-Roussel, P. Marcelo, A.C. Lepage, D. Buzoni-Gatel, D.T. Bout, Intranasal immunization with Taxoplasma gondii SAG1 induces protective cells into both NALT and GALT compartments. Infect. Immun. 68(2) (2000) 969-972.

[34] B. Liang, L. Hyland, S. Hou, Nasal-associated lymphoid tissue is a site of long-term virus-specific antibody production following respiratory virus infection of mice. J. Virol. 75(11) (2001) 5416-5420.

[35] M.I. Ugwoke, N. Verbeke, R. Kinget, The biopharmaceutical aspects of nasal mucoadhesive drug delivery. J. Pharm. Pharmacol. 53(1) (2001) 3-21.

[36] D.T. Ohagan, L. Illum, Absorption of Peptides and Proteins from the Respiratory-Tract and the Potential for Development of Locally Administered Vaccine. Crit. Rev. Ther. Drug Carr. Syst. 7(1) (1990) 35-97.

[37] C. Dufes, J.C. Olivier, F. Gaillard, A. Gaillard, W. Couet, J.M. Muller, Brain delivery of vasoactive intestinal peptide (VIP) following nasal administration to rats. Int. J. Pharm. 255(1-2) (2003) 87-97.

[38] Q.Y. Cheng, J. Feng, J.M. Chen, X.A. Zhu, F.Z. Li, Brain Transport of Neurotoxin-I with PLA Nanoparticles through Intranasal Administration in Rats: A Microdialysis Study. Biopharm. Drug Dispos. 29(8) (2008) 431-439. 
[39] T. Sakane, M. Akizuki, Y. Taki, S. Yamashita, H. Sezaki, T. Nadai, Direct Drug Transport from the Rat Nasal Cavity to the Cerebrospinal-Fluid - the Relation to the Molecular-Weight of Drugs. J. Pharm. Pharmacol. 47(5) (1995) 379-381.

[40] T. Sakane, M. Akizuki, M. Yoshida, S. Yamashita, T. Nadai, M. Hashida, H. Sezaki, Transport of Cephalexin to the Cerebrospinal-Fluid Directly from the Nasal Cavity. J. Pharm. Pharmacol. 43(6) (1991) 449-451.

[41] T. Kissel, U. Werner, Nasal delivery of peptides: An in vitro cell culture model for the investigation of transport and metabolism in human nasal epithelium. J. Control. Release 53(1-3) (1998) 195-203.

[42] D. Ridley, A.C. Perkins, N. Washington, C.G. Wilson, M.L. Wastie, P. Oflynn, A. Blattman, G. Ponchel, D. Duchene, The effect of posture on nasal clearance of bioadhesive starch microspheres. STP Pharma Sci. 5(6) (1995) 442-446.

[43] S.H. Shah, M.J. Shah, J.R. Sharma, An Overview On Brain Targeting Drug Delivery System. Pharm. Rev. 7 (2009).

[44] S. Turker, E. Onur, Y. Ozer, Nasal route and drug delivery systems. Pharm. World Sci. 26(3) (2004) 137-142.

[45] M.A. Sarkar, Drug-Metabolism in the Nasal-Mucosa. Pharm. Res. 9(1) (1992) 1-9.

[46] N. Mygind, R. Dahl, Anatomy, physiology and function of the nasal cavities in health and disease. Adv. Drug Deliv. Rev. 29(1-2) (1998) 3-12.

[47] S.S. Davis, Nasal vaccines. Adv. Drug Deliv. Rev. 51(1-3) (2001) 21-42.

[48] M. Hayashi, T. Hirasawa, T. Muraoka, M. Shiga, S. Awazu, Comparison of Water Influx and Sieving Coefficient in Rat Jejunal, Rectal and Nasal Absorptions of Antipyrine. Chem. Pharm. Bull. 33(5) (1985) 2149-2152.

[49] L. Illum, Nasal drug delivery - possibilities, problems and solutions. J. Control. Release 87(1-3) (2003) 187-198.

[50] R.J. Soane, M. Frier, A.C. Perkins, N.S. Jones, S.S. Davis, L. Illum, Evaluation of the clearance characteristics of bioadhesive systems in humans. Int. J. Pharm. 178(1) (1999) 55-65.

[51] R.J. Soane, A.S. Carney, N.S. Jones, M. Frier, A.C. Perkins, S.S. Davis, L. Illum, The effect of the nasal cycle on mucociliary clearance. Clin. Otolaryngol. 26(1) (2001) 9-15.

[52] B. Brime, M.P. Ballesteros, P. Frutos, Preparation and in vitro characterization of gelatin microspheres containing Levodopa for nasal administration. J. Microencapsul. 17(6) (2000) 777-784.

[53] M. Morishita, N.A. Peppas, Is the oral route possible for peptide and protein drug delivery. Drug Discov. Today 11(19-20) (2006) 905-910.

[54] T.M. Allen, P.R. Cullis, Drug delivery systems: Entering the mainstream. Science 303(5665) (2004) 1818-1822.

[55] R.G. Soderquist, E.D. Milligan, E.M. Sloane, J.A. Harrison, K.K. Douvas, J.M. Potter, T.S. Hughes, R.A. Chavez, K. Johnson, L.R. Watkins, M.J. Mahoney, PEGylation of brain-derived neurotrophic factor for preserved biological activity and enhanced spinal cord distribution. J. Biomed. Mater. Res. Part A 91A(3) (2009) 719-729.

[56] K.S.E. Su, K.M. Campanale, L.G. Mendelsohn, G.A. Kerchner, C.L. Gries, Nasal Delivery of Polypeptides .1. Nasal Absorption of Enkephalins in Rats. J. Pharm. Sci. 74(4) (1985) 394-398.

[57] V.H.L. Lee, Protease Inhibitors and Penetration Enhancers as Approaches to Modify Peptide Absorption. J. Control. Release 13(2-3) (1990) 213-223.

[58] A. Yamamoto, T. Taniguchi, K. Rikyuu, T. Tsuji, T. Fujita, M. Murakami, S. Muranishi, Effects of Various Protease Inhibitors on the Intestinal-Absorption and Degradation of Insulin in Rats. Pharm. Res. 11(10) (1994) 1496-1500.

[59] R. Gref, Y. Minamitake, M.T. Peracchia, V. Trubetskoy, V. Torchilin, R. Langer, Biodegradable Long-Circulating Polymeric Nanospheres. Science 263(5153) (1994) 1600-1603.

[60] M.D. Chavanpatil, A. Khdair, J. Panyam, Nanoparticles for cellular drug delivery: Mechanisms and factors influencing delivery. J. Nanosci. Nanotechnol. 6(9-10) (2006) 2651-2663. 
[61] C.O. Weill, S. Biri, A. Adib, P. Erbacher, A practical approach for intracellular protein delivery. Cytotechnology 56(1) (2008) 41-48.

[62] P. Couvreur, F. Puisieux, Nanoparticles and Microparticles for the Delivery of Polypeptides and Proteins. Adv. Drug Deliv. Rev. 10(2-3) (1993) 141-162.

[63] J. Panyam, V. Labhasetwar, Biodegradable nanoparticles for drug and gene delivery to cells and tissue. Adv. Drug Deliv. Rev. 55(3) (2003) 329-347.

[64] A.T. Florence, The oral absorption of micro- and nanoparticulates: Neither exceptional nor unusual. Pharm. Res. 14(3) (1997) 259-266.

[65] T. Jung, W. Kamm, A. Breitenbach, E. Kaiserling, J.X. Xiao, T. Kissel, Biodegradable nanoparticles for oral delivery of peptides: is there a role for polymers to affect mucosal uptake? Eur. J. Pharm. Biopharm. 50(1) (2000) 147-160.

[66] A. Chonn, P.R. Cullis, Recent Advances in Liposomal Drug-Delivery Systems. Curr. Opin. Biotechnol. 6(6) (1995) 698-708.

[67] C.J.H. Porter, K.M. Wasan, Lipid-based systems for the enhanced delivery of poorly water soluble drugs. Adv. Drug Deliv. Rev. 60(6) (2008) 615-616.

[68] P.P. Constantinides, K.M. Wasan, Advances in lipid-based drug solubilization and targeting - Preface. Adv. Drug Deliv. Rev. 56(9) (2004) 1239-1240.

[69] A.C. Allison, Gregoria.G, Liposomes as Immunological Adjuvants. Nature 252(5480) (1974) 252-252.

[70] H.O. Alpar, J.C. Bowen, M.R.W. Brown, Effectiveness of Liposomes as Adjuvants of Orally and Nasally Administered Tetanus Toxoid. Int. J. Pharm. 88(1-3) (1992) 335-344.

[71] S.M. McAllister, H.O. Alpar, M.R.W. Brown, Antimicrobial properties of liposomal polymyxin B. J. Antimicrob. Chemother. 43(2) (1999) 203-210.

[72] Y. Maitani, S. Asano, S. Takahashi, M. Nakagaki, T. Nagai, Permeability of Insulin Entrapped in Liposome through the Nasal-Mucosa of Rabbits. Chem. Pharm. Bull. 40(6) (1992) 1569-1572.

[73] K. Muramatsu, Y. Maitani, K. Takayama, T. Nagai, The relationship between the rigidity of the liposomal membrane and the absorption of insulin after nasal administration of liposomes modified with an enhancer containing insulin in rabbits. Drug Dev. Ind. Pharm. 25(10) (1999) 1099-1105.

[74] Z. Degim, N. Ünal, D. Essiz, U. Abbasoglu, The effect of various liposome formulations on insulin penetration across Caco-2 cell monolayer. Life Sciences 75(23) (2004) 2819-2827.

[75] J. Kreuter, Peroral Administration of Nanoparticles. Adv. Drug Deliv. Rev. 7(1) (1991) 71-86.

[76] H. Takeuchi, Y. Matsui, H. Yamamoto, Y. Kawashima, Mucoadhesive properties of carbopol or chitosan-coated liposomes and their effectiveness in the oral administration of calcitonin to rats. J. Control. Release 86(2-3) (2003) 235-242.

[77] H. Takeuchi, J. Thongborisute, Y. Matsui, H. Sugihara, H. Yamamoto, Y. Kawashima, Novel mucoadhesion tests for polymers and polymer-coated particles to design optimal mucoadhesive drug delivery systems. Adv. Drug Deliv. Rev. 57(11) (2005) 1583-1594.

[78] H. Takeuchi, H. Yamamoto, Y. Kawashima, Mucoadhesive nanoparticulate systems for peptide drug delivery. Adv. Drug Deliv. Rev. 47(1) (2001) 39-54.

[79] H. Takeuchi, H. Yamamoto, T. Niwa, T. Hino, Y. Kawashima, Enteral absorption of insulin in rats from mucoadhesive chitosan-coated liposomes. Pharm. Res. 13(6) (1996) 896-901.

[80] A.K. Jain, K.B. Chalasani, R.K. Khar, F.J. Ahmed, P.V. Diwan, Muco-adhesive multivesicular liposomes as an effective carrier for transmucosal insulin delivery. J. Drug Target. 15(6) (2007) 417-427.

[81] J.E. Lopez, N.A. Peppas, Effect of poly (ethylene glycol) molecular weight and microparticle size on oral insulin delivery from P(MAA-g-EG) microparticles. Drug Dev. Ind. Pharm. 30(5) (2004) 497-504.

[82] M. Morishita, M. Goto, K. Takayama, N.A. Peppas, Oral insulin delivery systems based on complexation polymer hydrogels. J. Drug Deliv. Sci. Technol. 16(1) (2006) 19-24.

[83] B. Kim, N.A. Peppas, Analysis of molecular interactions in poly(methacrylic acid-g-ethylene glycol) hydrogels. Polymer 44(13) (2003) 3701-3707. 
[84] T. Goto, M. Morishita, N.J. Kavimandan, K. Takayama, N.A. Peppas, Gastrointestinal transit and mucoadhesive characteristics of complexation hydrogels in rats. J. Pharm. Sci. 95(2) (2006) 462-469.

[85] M. Mahkam, Starch-based polymeric carriers for oral-insulin delivery. J. Biomed. Mater. Res. Part A 92A(4) (2010) 1392-1397.

[86] D.A. Carr, N.A. Peppas, Assessment of poly(methacrylic acid-co-N-vinyl pyrrolidone) as a carrier for the oral delivery of therapeutic proteins using Caco-2 and HT29-MTX cell lines. J. Biomed. Mater. Res. Part A 92A(2) (2010) 504-512.

[87] T. Betancourt, J. Pardo, K. Soo, N.A. Peppas, Characterization of pH-responsive hydrogels of poly(itaconic acid-g-ethylene glycol) prepared by UV-initiated free radical polymerization as biomaterials for oral delivery of bioactive agents. J. Biomed. Mater. Res. Part A 93A(1) (2010) 175-188.

[88] F. Madsen, N.A. Peppas, Complexation graft copolymer networks: swelling properties, calcium binding and proteolytic enzyme inhibition. Biomaterials 20(18) (1999) 1701-1708.

[89] I. Shin'ichi, S. Shizuko, Polymerization of itaconic acid derivatives. Adv Polym Sci 5(4) (1967) 689-705.

[90] K. Morimoto, K. Morisaka, A. Kamada, Enhancement of Nasal Absorption of Insulin and Calcitonin Using Polyacrylic-Acid Gel. J. Pharm. Pharmacol. 37(2) (1985) 134-136.

[91] M.P. Zhou, M.D. Donovan, Intranasal mucociliary clearance of putative bioadhesive polymer gels. Int. J. Pharm. 135(1-2) (1996) 115-125.

[92] D.J. Brayden, M.A. Jepson, A.W. Baird, Intestinal Peyer's patch M cells and oral vaccine targeting. Drug Discov. Today 10(17) (2005) 1145-1157.

[93] M. Shakweh, M. Besnard, V. Nicolas, E. Fattal, Poly (lactide-co-glycolide) particles of different physicochemical properties and their uptake by Peyer's patches in mice. Eur. J. Pharm. Biopharm. 61(1-2) (2005) 1-13.

[94] M.D. Donovan, Y. Huang, Large molecule and particulate uptake in the nasal cavity: the effect of size on nasal absorption. Adv. Drug Deliv. Rev. 29(1-2) (1998) 147-155.

[95] J. Brooking, S.S. Davis, L. Illum, Transport of nanoparticles across the rat nasal mucosa. J. Drug Target. 9(4) (2001) 267-279.

[96] J.E. Eyles, V.W. Bramwell, E.D. Williamson, H.O. Alpar, Microsphere translocation and immunopotentiation in systemic tissues following intranasal administration. Vaccine 19(32) (2001) 4732-4742.

[97] G. Ponchel, M.J. Montisci, A. Dembri, C. Durrer, D. Duchene, Mucoadhesion of colloidal particulate systems in the gastro-intestinal tract. Eur. J. Pharm. Biopharm. 44(1) (1997) 25-31.

[98] M.P. Desai, V. Labhasetwar, E. Walter, R.J. Levy, G.L. Amidon, The mechanism of uptake of biodegradable microparticles in Caco-2 cells is size dependent. Pharm. Res. 14(11) (1997) 1568-1573.

[99] H.O. Alpar, S. Somavarapu, K.N. Atuah, V. Bramwell, Biodegradable mucoadhesive particulates for nasal and pulmonary antigen and DNA delivery. Adv. Drug Deliv. Rev. 57(3) (2005) 411-430.

[100] M. van de Weert, W.E. Hennink, W. Jiskoot, Protein instability in poly(lactic-co-glycolic acid) microparticles. Pharm. Res. 17(10) (2000) 1159-1167.

[101] Z.S. Ma, T.M. Lim, L.Y. Lim, Pharmacological activity of peroral chitosan-insulin nanoparticles in diabetic rats. Int. J. Pharm. 293(1-2) (2005) 271-280.

[102] Y. Pan, Y.J. Li, H.Y. Zhao, J.M. Zheng, H. Xu, G. Wei, J.S. Hao, F.D. Cui, Bioadhesive polysaccharide in protein delivery system: chitosan nanoparticles improve the intestinal absorption of insulin in vivo. Int. J. Pharm. 249(1-2) (2002) 139-147.

[103] C. Damge, C. Michel, M. Aprahamian, P. Couvreur, New Approach for Oral-Administration of Insulin with Polyalkylcyanoacrylate Nanocapsules as Drug Carrier. Diabetes 37(2) (1988) 246-251.

[104] C. Damge, C. Michel, M. Aprahamian, P. Couvreur, J.P. Devissaguet, Nanocapsules as Carriers for Oral Peptide Delivery. J. Control. Release 13(2-3) (1990) 233-239. 
[105] C. Michel, M. Aprahamian, L. Defontaine, P. Couvreur, C. Damge, The Effect of Site of Administration in the Gastrointestinal-Tract on the Absorption of Insulin from Nanocapsules in Diabetic Rats. J. Pharm. Pharmacol. 43(1) (1991) 1-5.

[106] M. Roques, C. Damge, C. Michel, C. Staedel, G. Cremel, P. Hubert, Encapsulation of Insulin for Oral-Administration Preserves Interaction of the Hormone with Its Receptor Invitro. Diabetes 41(4) (1992) 451-456.

[107] E. Adriaens, D. Ameye, M.M.M. Dhondt, P. Foreman, J.P. Remon, Evaluation of the mucosal irritation potency of co-spray dried Amioca (R)/poly (acrylic acid) and Amioca (R)/Carbopol (R) 974P mixtures. J. Control. Release 88(3) (2003) 393-399.

[108] R. Herrero-Vanrell, A. Fernandez-Carballido, G. Frutos, R. Cadorniga, Enhancement of the mydriatic response to tropicamide by bioadhesive polymers. J. Ocular Pharmacol. Ther. 16(5) (2000) 419-428.

[109] A.C. Foss, T. Goto, M. Morishita, N.A. Peppas, Development of acrylic-based copolymers for oral insulin delivery. Eur. J. Pharm. Biopharm. 57(2) (2004) 163-169.

[110] S. Sakuma, N. Suzuki, R. Sudo, K. Hiwatari, A. Kishida, M. Akashi, Optimized chemical structure of nanoparticles as carriers for oral delivery of salmon calcitonin. Int. J. Pharm. 239(1-2) (2002) 185-195.

[111] M. Tobio, R. Gref, A. Sanchez, R. Langer, M.J. Alonso, Stealth PLA-PEG nanoparticles as protein carriers for nasal administration. Pharm. Res. 15(2) (1998) 270-275.

[112] J.E. Eyles, G.J.E. Sharp, E.D. Williamson, I.D. Spiers, H.O. Alpar, Intra nasal administration of poly-lactic acid microsphere co-encapsulated Yersinia pestis subunits confers protection from pneumonic plague in the mouse. Vaccine 16(7) (1998) 698-707.

[113] D.T. O'Hagan, M. Singh, R.K. Gupta, Poly(lactide-co-glycolide) microparticles for the development of single-dose controlled-release vaccines. Adv. Drug Deliv. Rev. 32(3) (1998) 225-246.

[114] E.G. Marazuela, N. Prado, E. Morow, H. Fernandez-Garcia, M. Villalba, R. Rodriguez, E. Batanero, Intranasal vaccination with poly(lactide-co-glycolide) microparticles containing a peptide T of Ole e 1 prevents mice against sensitization. Clin. Exp. Allergy 38(3) (2008) 520-528.

[115] H.S. Yoo, T.G. Park, Biodegradable nanoparticles containing protein-fatty acid complexes for oral delivery of salmon calcitonin. J. Pharm. Sci. 93(2) (2004) 488-495.

[116] S. Sakuma, H. Ohshima, T. Kondo, Charge-Distribution in Poly(N,N-L-Lysinediylterephthaloyl) Microcapsule Membranes. J. Colloid Interface Sci. 133(1) (1989) 253-256.

[117] S. Sakuma, H. Ohshima, T. Kondo, Binding Constants of Metal-Cations to and Hamaker Constant for Poly(N,N-L-Lysinediylterephthaloyl) Microcapsules. J. Colloid Interface Sci. 135(2) (1990) 455-460.

[118] A. Sanchez, M. Tobio, L. Gonzalez, A. Fabra, M.J. Alonso, Biodegradable micro- and nanoparticles as long-term delivery vehicles for interferon-alpha. Eur. J. Pharm. Sci. 18(3-4) (2003) 221-229.

[119] D.J.A. Crommelin, G. Storm, W. Jiskoot, R. Stenekes, E. Mastrobattista, W.E. Hennink, Nanotechnological approaches for the delivery of macromolecules. J. Control. Release 87(1-3) (2003) 81-88.

[120] A. Vila, A. Sanchez, C. Evora, I. Soriano, O. McCallion, M.J. Alonso, PLA-PEG particles as nasal protein carriers: the influence of the particle size. Int. J. Pharm. 292(1-2) (2005) 43-52.

[121] L.A. Dailey, T. Kissel, New poly(lactic-co-glycolic acid) derivatives: Modular polymers with tailored properties. Drug Discov Today Technol 2(1) (2005) 7-13.

[122] M. Tobio, A. Sanchez, A. Vila, I. Soriano, C. Evora, J.L. Vila-Jato, M.J. Alonso, The role of PEG on the stability in digestive fluids and in vivo fate of PEG-PLA nanoparticles following oral administration. Colloid Surf. B-Biointerfaces 18(3-4) (2000) 315-323.

[123] C.M. Lehr, Lectin-mediated drug delivery: The second generation of bioadhesives. J. Control. Release 65(1-2) (2000) 19-29.

[124] A. Ludwig, The use of mucoadhesive polymers in ocular drug delivery. Adv. Drug Deliv. Rev. 57(11) (2005) 1595-1639. 
[125] S. Sakuma, M. Hayashi, M. Akashi, Design of nanoparticles composed of graft copolymers for oral peptide delivery. Adv. Drug Deliv. Rev. 47(1) (2001) 21-37.

[126] B. Naisbett, J. Woodley, The Potential Use of Tomato Lectin for Oral-Drug Delivery .1. Lectin-Binding to Rat Small-Intestine in-Vitro. Int. J. Pharm. 107(3) (1994) 223-230.

[127] C. Bies, C.-M. Lehr, J.F. Woodley, Lectin-mediated drug targeting: history and applications. Adv. Drug Deliv. Rev. 56(4) (2004) 425-435.

[128] P.J. Giannasca, J.A. Boden, T.P. Monath, Targeted delivery of antigen to hamster nasal lymphoid tissue with M-cell-directed lectins. Infect. Immun. 65(10) (1997) 4288-4298.

[129] P. Kumar, J.F. Timoney, A.S. Sheoran, M cells and associated lymphoid tissue of the equine nasopharyngeal tonsil. Equine Vet. J. 33(3) (2001) 224-230.

[130] S. Takata, O. Ohtani, Y. Watanabe, Lectin binding patterns in rat nasal-associated lymphoid tissue (NALT) and the influence of various types of lectin on particle uptake in NALT. Arch. Histol. Cytol. 63(4) (2000) 305-312.

[131] M. Gaumet, R. Gurny, F. Delie, Interaction of biodegradable nanoparticles with intestinal cells: The effect of surface hydrophilicity. Int. J. Pharm. 390(1) (2010) 45-52.

[132] Y. Kawashima, H. Yamamoto, H. Takeuchi, Y. Kuno, Mucoadhesive DL-lactide/glycolide copolymer nanospheres coated with chitosan to improve oral delivery of elcatonin. Pharm. Dev. Technol. 5(1) (2000) 77-85.

[133] K. Sonaje, Y.J. Chen, H.L. Chen, S.P. Wey, J.H. Juang, H.N. Nguyen, C.W. Hsu, K.J. Lin, H.W. Sung, Enteric-coated capsules filled with freeze-dried chitosan/poly(gamma-glutamic acid) nanoparticles for oral insulin delivery. Biomaterials 31(12) (2010) 3384-3394.

[134] J.S. Rodrigues, N.S. Santos-Magalhaes, L. Coelho, P. Couvreur, G. Ponchel, R. Gref, Novel core (polyester)-shell(polysaccharide) nanoparticles: protein loading and surface modification with lectins. J. Control. Release 92(1-2) (2003) 103-112.

[135] A. Vila, A. Sanchez, M. Tobio, P. Calvo, M.J. Alonso, Design of biodegradable particles for protein delivery. J. Control. Release 78(1-3) (2002) 15-24.

[136] A. Mahmud, X.B. Xiong, H.M. Aliabadi, A. Lavasanifar, Polymeric micelles for drug targeting. J. Drug Target. 15(9) (2007) 553-584.

[137] F. Mathot, L. van Beijsterveldt, V. Preat, M. Brewster, A. Arien, Intestinal uptake and biodistribution of novel polymeric micelles after oral administration. J. Control. Release 111(1-2) (2006) 47-55.

[138] Z.Z. Shao, A.K. Mitra, Nasal Membrane and Intracellular Protein and Enzyme-Release by Bile-Salts and Bile-Salt Fatty-Acid Mixed Micelles - Correlation with Facilitated Drug Transport. Pharm. Res. 9(9) (1992) 1184-1189.

[139] Z.Z. Shao, A.K. Mitra, Bile-Salt Fatty-Acid Mixed Micelles as Nasal Absorption Promoters .3. Effects on Nasal Transport and Enzymatic Degradation of Acyclovir Prodrugs. Pharm. Res. 11(2) (1994) 243-250.

[140] C.M. Lehr, Bioadhesion Technologies for the Delivery of Peptide and Protein Drugs to the Gastrointestinal-Tract. Crit. Rev. Ther. Drug Carr. Syst. 11(2-3) (1994) 119-160.

[141] M. George, T.E. Abraham, Polyionic hydrocolloids for the intestinal delivery of protein drugs: Alginate and chitosan - a review. J. Control. Release 114(1) (2006) 1-14.

[142] R. Hejazi, M. Amiji, Chitosan-based gastrointestinal delivery systems. J. Control. Release 89(2) (2003) 151-165.

[143] M.M. Issa, M. Köping-Höggård, P. Artursson, Chitosan and the mucosal delivery of biotechnology drugs. Drug Discov Today Technol 2(1) (2005) 1-6.

[144] M. Rinaudo, Chitin and chitosan: Properties and applications. Prog. Polym. Sci. 31(7) (2006) 603-632.

[145] A.K. Singla, M. Chawla, Chitosan: some pharmaceutical and biological aspects - an update. J. Pharm. Pharmacol. 53(8) (2001) 1047-1067.

[146] V.R. Sinha, A.K. Singla, S. Wadhawan, R. Kaushik, R. Kumria, K. Bansal, S. Dhawan, Chitosan microspheres as a potential carrier for drugs. Int. J. Pharm. 274(1-2) (2004) 1-33.

[147] L. Illum, N.F. Farraj, S.S. Davis, Chitosan as a Novel Nasal Delivery System for Peptide Drugs. Pharm. Res. 11(8) (1994) 1186-1189. 
[148] C.M. Lehr, J.A. Bouwstra, E.H. Schacht, H.E. Junginger, Invitro Evaluation of Mucoadhesive Properties of Chitosan and Some Other Natural Polymers. Int. J. Pharm. 78(1) (1992) 43-48.

[149] H.L. Luessen, J.C. Verhoef, G. Borchard, C.M. Lehr, A.G. Deboer, H.E. Junginger, Mucoadhesive Polymers in Peroral Peptide Drug-Delivery .2. Carbomer and Polycarbophil Are Potent Inhibitors of the Intestinal Proteolytic-Enzyme Trypsin. Pharm. Res. 12(9) (1995) 1293-1298.

[150] P. Artursson, T. Lindmark, S.S. Davis, L. Illum, Effect of Chitosan on the Permeability of Monolayers of Intestinal Epithelial-Cells (Caco-2). Pharm. Res. 11(9) (1994) 1358-1361.

[151] G. Borchard, H.L. Luessen, A.G. deBoer, J.C. Verhoef, C.M. Lehr, H.E. Junginger, The potential of mucoadhesive polymers in enhancing intestinal peptide drug absorption .3. Effects of chitosan-glutamate and carbomer on epithelial tight junctions in vitro. J. Control. Release 39(2-3) (1996) 131-138.

[152] N.G.M. Schipper, S. Olsson, J.A. Hoogstraate, A.G. deBoer, K.M. Varum, P. Artursson, Chitosans as absorption enhancers for poorly absorbable drugs .2. Mechanism of absorption enhancement. Pharm. Res. 14(7) (1997) 923-929.

[153] M. Amidi, S.G. Romeijn, G. Borchard, H.E. Junginger, W.E. Hennink, W. Jiskoot, Preparation and characterization of protein-loaded $\mathrm{N}$-trimethyl chitosan nanoparticles as nasal delivery system. J. Control. Release 111(1-2) (2006) 107-116.

[154] P. Calvo, C. RemunanLopez, J.L. VilaJato, M.J. Alonso, Chitosan and chitosan ethylene oxide propylene oxide block copolymer nanoparticles as novel carriers for proteins and vaccines. Pharm Res 14(10) (1997) 1431-1436.

[155] R. Fernandez-Urrusuno, P. Calvo, C. Remunan-Lopez, J.L. Vila-Jato, M.J. Alonso, Enhancement of nasal absorption of insulin using chitosan nanoparticles. Pharm Res 16(10) (1999) 1576-1581.

[156] J.H. Hamman, C.M. Schultz, A.F. Kotze, N-trimethyl chitosan chloride: Optimum degree of quaternization for drug absorption enhancement across epithelial cells. Drug Dev. Ind. Pharm. 29(2) (2003) 161-172.

[157] A.F. Kotze, H.L. Luessen, B.J. deLeeuw, B.G. deBoer, J.C. Verhoef, H.E. Junginger, $\mathrm{N}$-trimethyl chitosan chloride as a potential absorption enhancer across mucosal surfaces: In vitro evaluation in intestinal epithelial cells (Caco-2). Pharm Res 14(9) (1997) 1197-1202.

[158] S.R. Mao, U. Bakowsky, A. Jintapattanakit, T. Kissel, Self-assembled polyelectrolyte nanocomplexes between chitosan derivatives and insulin. J. Pharm. Sci. 95(5) (2006) 1035-1048.

[159] S. Mao, O. Germershaus, D. Fischer, T. Linn, R. Schnepf, T. Kissel, Uptake and transport of PEG-graft-trimethyl-chitosan copolymer-insulin nanocomplexes by epithelial cells. Pharm Res 22(12) (2005) 2058-2068.

[160] M. Thanou, B.I. Florea, M.W.E. Langemeyer, J.C. Verhoef, H.E. Junginger, N-trimethylated chitosan chloride (TMC) improves the intestinal permeation of the peptide drug buserelin in vitro (Caco-2 cells) and in vivo (rats). Pharm Res 17(1) (2000) 27-31.

[161] M. Thanou, M.T. Nihot, M. Jansen, J.C. Verhoef, H.E. Junginger, Mono-N-carboxymethyl chitosan (MCC), a polyampholytic chitosan derivative, enhances the intestinal absorption of low molecular weight heparin across intestinal epithelia in vitro and in vivo. J. Pharm. Sci. 90(1) (2001) 38-46.

[162] I.M. Van der Lubben, F.A.J. Konings, G. Borchard, J.C. Verhoef, H.E. Junginger, In vivo uptake of chitosan microparticles by murine Peyer's patches: Visualization studies using confocal laser scanning microscopy and immunohistochemistry. J. Drug Target. 9(1) (2001) 39-+.

[163] I.M. van der Lubben, J.C. Verhoef, A.C. van Aelst, G. Borchard, H.E. Junginger, Chitosan microparticles for oral vaccination: preparation, characterization and preliminary in vivo uptake studies in murine Peyer's patches. Biomaterials 22(7) (2001) 687-694.

[164] A. Vila, A. Sanchez, K. Janes, I. Behrens, T. Kissel, J.L.V. Jato, M.J. Alonso, Low molecular weight chitosan nanoparticles as new carriers for nasal vaccine delivery in mice. Eur J Pharmacol 57(1) (2004) 123-131. 
[165] P. Calvo, C. RemunanLopez, J.L. VilaJato, M.J. Alonso, Novel hydrophilic chitosan-polyethylene oxide nanoparticles as protein carriers. J. Appl. Polym. Sci. 63(1) (1997) 125-132.

[166] A. Harada, K. Kataoka, Novel polyion complex micelles entrapping enzyme molecules in the core: Preparation of narrowly-distributed micelles from lysozyme and poly(ethylene glycol)-poly(aspartic acid) block copolymer in aqueous medium. Macromolecules 31(2) (1998) 288-294.

[167] A. Jintapattanakit, V.B. Junyaprasert, S. Mao, J. Sitterberg, U. Bakowsky, T. Kissel, Peroral delivery of insulin using chitosan derivatives: A comparative study of polyelectrolyte nanocomplexes and nanoparticles. Int. J. Pharm. 342(1-2) (2007) 240-249.

[168] Y. Lee, S. Fukushima, Y. Bae, S. Hiki, T. Ishii, K. Kataoka, A protein nanocarrier from charge-conversion polymer in response to endosomal pH. J. Am. Chem. Soc. 129(17) (2007) 5362-5363.

[169] M. Alonso-Sande, M. Cuna, C. Remunan-Lopez, Formation of new glucomannan-chitosan nanoparticles and study of their ability to associate and deliver proteins. Macromolecules 39(12) (2006) 4152-4158.

[170] B. Sarmento, A. Ribeiro, F. Veiga, D. Ferreira, Development and characterization of new insulin containing polysaccharide nanoparticles. Colloid Surf. B-Biointerfaces 53(2) (2006) 193-202.

[171] S. Boddohi, N. Moore, P.A. Johnson, M.J. Kipper, Polysaccharide-Based Polyelectrolyte Complex Nanoparticles from Chitosan, Heparin, and Hyaluronan. Biomacromolecules 10(6) (2009) 1402-1409.

[172] M. Huang, S.N. Vitharana, L.J. Peek, T. Coop, C. Berkland, Polyelectrolyte complexes stabilize and controllably release vascular endothelial growth factor. Biomacromolecules 8(5) (2007) 1607-1614.

[173] S.Y. Zhu, F. Qian, Y. Zhang, C. Tang, C.H. Yin, Synthesis and characterization of PEG modified N-trimethylaminoethylmethacrylate chitosan nanoparticles. Eur. Polym. J. 43(6) (2007) 2244-2253.

[174] C. Schatz, A. Bionaz, J.M. Lucas, C. Pichot, C. Viton, A. Domard, T. Delair, Formation of polyelectrolyte complex particles from self-complexation of $\mathrm{N}$-sulfated chitosan. Biomacromolecules 6(3) (2005) 1642-1647.

[175] F.M. Goycoolea, G. Lollo, C. Remunan-Lopez, F. Quaglia, M.J. Alonso, Chitosan-Alginate Blended Nanoparticles as Carriers for the Transmucosal Delivery of Macromolecules. Biomacromolecules 10(7) (2009) 1736-1743.

[176] Y.H. Lin, K. Sonaje, K.M. Lin, J.H. Juang, F.L. Mi, H.W. Yang, H.W. Sung, Multi-ion-crosslinked nanoparticles with $\mathrm{pH}$-responsive characteristics for oral delivery of protein drugs. J. Control. Release 132(2) (2008) 141-149.

[177] M.R. Rekha, C.P. Sharma, Synthesis and evaluation of lauryl succinyl chitosan particles towards oral insulin delivery and absorption. J. Control. Release 135(2) (2009) 144-151.

[178] X. Wang, C. Zheng, Z.M. Wu, D.G. Teng, X. Zhang, Z. Wang, C.X. Li, Chitosan-NAC Nanoparticles as a Vehicle for Nasal Absorption Enhancement of Insulin. J. Biomed. Mater. Res. Part B 88B(1) (2009) 150-161.

[179] D. Teijeiro-Osorio, C. Remunan-Lopez, M.J. Alonso, New Generation of Hybrid Poly/Oligosaccharide Nanoparticles as Carriers for the Nasal Delivery of Macromolecules. Biomacromolecules 10(2) (2009) 243-249.

[180] X.G. Zhang, H.J. Zhang, Z.M. Wu, Z. Wang, H.M. Niu, C.X. Li, Nasal absorption enhancement of insulin using PEG-grafted chitosan nanoparticles. Eur. J. Pharm. Biopharm. 68(3) (2008) 526-534.

[181] D. Derossi, A.H. Joliot, G. Chassaing, A. Prochiantz, The 3rd Helix of the Antennapedia Homeodomain Translocates through Biological-Membranes. J. Biol. Chem. 269(14) (1994) 10444-10450.

[182] S. Futaki, T. Suzuki, W. Ohashi, T. Yagami, S. Tanaka, K. Ueda, Y. Sugiura, Arginine-rich peptides - An abundant source of membrane-permeable peptides having potential as carriers for intracellular protein delivery. J. Biol. Chem. 276(8) (2001) 5836-5840. 
[183] D.J. Mitchell, D.T. Kim, L. Steinman, C.G. Fathman, J.B. Rothbard, Polyarginine enters cells more efficiently than other polycationic homopolymers. J. Pept. Res. 56(5) (2000) 318-325.

[184] I. Nakase, T. Takeuchi, G. Tanaka, S. Futaki, Methodological and cellular aspects that govern the internalization mechanisms of arginine-rich cell-penetrating peptides. Adv. Drug Deliv. Rev. 60(4-5) (2008) 598-607.

[185] R. Trehin, H.P. Merkle, Chances and pitfalls of cell penetrating peptides for cellular drug delivery. Eur. J. Pharm. Biopharm. 58(2) (2004) 209-223.

[186] E. Vives, P. Brodin, B. Lebleu, A truncated HIV-1 Tat protein basic domain rapidly translocates through the plasma membrane and accumulates in the cell nucleus. J. Biol. Chem. 272(25) (1997) 16010-16017.

[187] M. Zorko, U. Langel, Cell-penetrating peptides: mechanism and kinetics of cargo delivery. Adv. Drug Deliv. Rev. 57(4) (2005) 529-545.

[188] V.P. Torchilin, Tat peptide-mediated intracellular delivery of pharmaceutical nanocarriers. Adv. Drug Deliv. Rev. 60(4-5) (2008) 548-558.

[189] E.S. Khafagy, M. Morishita, N. Kamei, Y. Eda, Y. Ikeno, K. Takayama, Efficiency of cell-penetrating peptides on the nasal and intestinal absorption of therapeutic peptides and proteins. Int. J. Pharm. 381(1) (2009) 49-55.

[190] N. Kamei, M. Morishita, Y. Eda, N. Ida, R. Nishio, K. Takayama, Usefulness of cell-penetrating peptides to improve intestinal insulin absorption. J. Control. Release 132(1) (2008) 21-25.

[191] M. Morishita, N. Kamei, J. Ehara, K. Isowa, K. Takayama, A novel approach using functional peptides for efficient intestinal absorption of insulin. J. Control. Release 118(2) (2007) 177-184.

[192] N. Kamei, M. Morishita, K. Takayama, Importance of intermolecular interaction on the improvement of intestinal therapeutic peptide/protein absorption using cell-penetrating peptides. J. Control. Release 136(3) (2009) 179-186.

[193] A. Dembri, M.J. Montisci, J.C. Gantier, H. Chacun, G. Ponchel, Targeting of 3 '-azido 3 '-deoxythymidine (AZT)-loaded poly(isohexylcyanoacrylate) nanospheres to the gastrointestinal mucosa and associated lymphoid tissues. Pharm. Res. 18(4) (2001) 467-473.

[194] R. Fowler, S. Stolnik, C. Alexander, M. Garnett, H. Horsley, B. Smith, Protein delivery through the intestinal epithelium: a vitamin B12-mediated approach. Drug Discov. Today 15(23-24) (2010) 1088-1089.

[195] G.J. Russell-Jones, Use of vitamin B-12 conjugates to deliver protein drugs by the oral route. Crit. Rev. Ther. Drug Carr. Syst. 15(6) (1998) 557-586.

[196] G.J. Russell-Jones, L. Arthur, H. Walker, Vitamin B-12-mediated transport of nanoparticles across Caco-2 cells. Int. J. Pharm. 179(2) (1999) 247-255.

[197] K.B. Chalasani, G.J. Russell-Jones, A.K. Jain, P.V. Diwan, S.K. Jain, Effective oral delivery of insulin in animal models using vitamin B12-coated dextran nanoparticles. J. Control. Release 122(2) (2007) 141-150.

[198] K.B. Chalasani, G.J. Russell-Jones, S.K. Yandrapu, P.V. Diwan, S.K. Jain, A novel vitamin B-12-nanosphere conjugate carrier system for peroral delivery of insulin. J. Control. Release 117(3) (2007) 421-429.

[199] A.K. Petrus, A.R. Vortherms, T.J. Fairchild, R.P. Doyle, Vitamin B-12 as a carrier for the oral delivery of insulin. ChemMedChem 2(12) (2007) 1717-1721.

[200] N.J. Kavimandan, E. Losi, N.A. Peppas, Novel delivery system based on complexation hydrogels as delivery vehicles for insulin-transferrin conjugates. Biomaterials 27(20) (2006) 3846-3854.

[201] J.P. Shofner, M.A. Phillips, N.A. Peppas, Cellular Evaluation of Synthesized Insulin/Transferrin Bioconjugates for Oral Insulin Delivery Using Intelligent Complexation Hydrogels. Macromol. Biosci. 10(3) (2010) 299-306.

[202] P. Ferruti, M.A. Marchisio, R. Barbucci, Synthesis, Physicochemical Properties and Biomedical Applications of Poly(Amido-Amine)s. Polymer 26 (1985) 1336-1348.

[203] P. Ferruti, M.A. Marchisio, R. Duncan, Poly(amido-amine)s: Biomedical applications. Macromol. Rapid Commun. 23(5-6) (2002) 332-355. 
[204] F. Danusso, P. Ferruti, Synthesis of Tertiary Amine Polymers. Polymer 11(2) (1970) 88-113.

[205] J. Franchini, E. Ranucci, P. Ferruti, Synthesis, physicochemical properties, and preliminary biological characterizations of a novel amphoteric agmatine-based poly(amidoamine) with RGD-like repeating units. Biomacromolecules 7(4) (2006) 1215-1222.

[206] P.G. Frick, H. Brogli, Mechanism of Heparin Rebound after Extracorporeal Circulation for Open Cardiac Surgery. Surgery 59(5) (1966) 721-726.

[207] Marchisi.Ma, T. Longo, P. Ferruti, F. Danusso, Preliminary Study of New Blood-Compatible Polymers. Eur. Surg. Res. 3(3-4) (1971) 240-241.

[208] Marchisi.Ma, P. Ferruti, T. Longo, Molecular Deheparinizer Filter. Eur. Surg. Res. 4(4-5) (1972) 312-313.

[209] Marchisi.Ma, T. Longo, P. Ferruti, Selective Deheparinizer Filter Made of New Crosslinked Polymers of a Polyamidoamine Structure. Experientia 29(1) (1973) 93-95.

[210] P. Ferruti, G. Casini, F. Tempesti, R. Barbucci, R. Mastacchi, M. Sarret, Heparinizable Materials .3. Heparin Retention Power of a Poly(Amido-Amine) Either as Crosslinked Resin, or Surface-Grafted on Pvc. Biomaterials 5(4) (1984) 234-236.

[211] W. Marconi, A. Martinelli, A. Piozzi, D. Zane, Synthesis and Physicochemical Characterization of a Hydrophilic Polyurethane Able to Bind Heparin. Biomaterials 13(7) (1992) 432-438.

[212] R. Duncan, N. Malik, S. Richardson, P. Ferruti, Polymer conjugates for anti-cancer agent and DNA delivery. American Chemical Society, Polymer Preprints, Division of Polymer Chemistry, Vol. 39, 1998, p. 180.

[213] P. Ferruti, F. Danusso, G. Franchi, Polentar.N, Garattin.S, Effects of a Series of New Synthetic High Polymers on Cancer Metastases. J. Med. Chem. 16(5) (1973) 496-499.

[214] P.R. Ferruti, S.; Duncan, R., Targeting of drugs: stealth therapeutic systems, G. Gregoriadis, B. McCormack, Eds., Plenum Press New York, 1998, pp. 207-224.

[215] E.M.S. Hersh, A. T., Self-Assembling Complexes for Gene Delivery from Laboratory to Clinical Trial, A. V. Kabanov, P. L. Felgner, L. W. Seymour., Eds., Wiley, New York, 1998, pp. 421-436.

[216] M.H. Porteus, J.P. Connelly, S.M. Pruett, A look to future directions in gene therapy research for monogenic diseases. PLoS Genet. 2(9) (2006) 1285-1292.

[217] T. Kielian, W.F. Hickey, Inflammatory thoughts about glioma gene therapy. Nat. Med. 5(11) (1999) 1237-1238.

[218] D.C. Gorecki, Gene therapy: Prospects and problems. Expert Opin Emerg Drugs 4 (1999) 247-261.

[219] M. Morille, C. Passirani, A. Vonarbourg, A. Clavreul, J.P. Benoit, Progress in developing cationic vectors for non-viral systemic gene therapy against cancer. Biomaterials 29(24-25) (2008) 3477-3496.

[220] S. Choksakulnimitr, S. Masuda, H. Tokuda, Y. Takakura, M. Hashida, In-Vitro Cytotoxicity of Macromolecules in Different Cell-Culture Systems. J. Control. Release 34(3) (1995) 233-241.

[221] B.C.F. Chu, S.B. Howell, Pharmacological and therapeutic properties of carrier bound methotrexate against tumor confined to a third space body compartment. J. Pharmacol. Exp. Ther. 219(2) (1981) 389-393.

[222] G. Citro, C. Szczylik, P. Ginobbi, G. Zupi, B. Calabretta, Inhibition of leukaemia cell proliferation by folic acid-polylysine-mediated introduction of c-myb antisense oligodeoxynucleotides into HL-60 cells. Br. J. Cancer 69(3) (1994) 463-467.

[223] N. Malik, R. Wiwattanapatapee, R. Klopsch, K. Lorenz, H. Frey, J.W. Weener, E.W. Meijer, W. Paulus, R. Duncan, Dendrimers: Relationship between structure and biocompatibility in vitro, and preliminary studies on the biodistribution of I-125-labelled polyamidoamine dendrimers in vivo. J. Control. Release 65(1-2) (2000) 133-148.

[224] D. Lew, S.E. Parker, T. Latimer, A.M. Abai, A. Kuwahararundell, S.G. Doh, Z.Y. Yang, D. Laface, S.H. Gromkowski, G.J. Nabel, M. Manthorpe, J. Norman, Cancer Gene-Therapy Using Plasmid DNA - Pharmacokinetic Study of DNA Following Injection in Mice. Hum. Gene Ther. 6(5) (1995) 553-564. 
[225] A. Katchalsky, D. Danon, A. Nevo, A. Devries, Interactions of Basic Polyelectrolytes with the Red Blood Cell .2. Agglutination of Red Blood Cells by Polymeric Bases. Biochim Biophys Acta 33(1) (1959) 120-138.

[226] M. Nishikawa, Y. Takakura, M. Hashida, Pharmacokinetic considerations regarding non-viral cancer gene therapy. Cancer Sci. 99(5) (2008) 856-862.

[227] M. Nishikawa, Y. Takakura, M. Hashida, Pharmacokinetics of Plasmid DNA-Based Non-viral Gene Medicine. Advances in Genetics, Vol. 53, 2005, pp. 47-68.

[228] F.L. Graham, A.J. Vandereb, New Technique for Assay of Infectivity of Human Adenovirus 5 DNA. Virology 52(2) (1973) 456-467.

[229] A. Kichler, K. Mechtler, J.P. Behr, E. Wagner, Influence of membrane-active peptides on lipospermine/DNA complex mediated gene transfer. Bioconjugate Chem. 8(2) (1997) 213-221.

[230] O. Boussif, F. Lezoualch, M.A. Zanta, M.D. Mergny, D. Scherman, B. Demeneix, J.P. Behr, A Versatile Vector for Gene and Oligonucleotide Transfer into Cells in Culture and in-Vivo Polyethylenimine. Proc. Natl. Acad. Sci. U. S. A. 92(16) (1995) 7297-7301.

[231] N.G. Pattrick, S.C.W. Richardson, M. Casolaro, P. Ferruti, R. Duncan, Poly(amidoamine)-mediated intracytoplasmic delivery of ricin A-chain and gelonin. J. Control. Release 77(3) (2001) 225-232.

[232] S. Richardson, P. Ferruti, R. Duncan, Poly(amidoamine)s as potential endosomolytic polymers: Evaluation in vitro and body distribution in normal and tumour-bearing animals. J. Drug Target. 6(6) (1999) 391-404.

[233] C.X. Wu, S.L. Lo, J. Boulaire, M.L.W. Hong, H.M. Beh, D.S.Y. Leung, S. Wang, A peptide-based carrier for intracellular delivery of proteins into malignant glial cells in vitro. J. Control. Release 130(2) (2008) 140-145.

[234] J.D. Eichman, A.U. Bielinska, J.F. Kukowska-Latallo, J.R. Baker Jr, The use of PAMAM dendrimers in the efficient transfer of genetic material into cells. Pharmaceut Sci Tech Today 3(7) (2000) 232-245.

[235] E. Ranucci, G. Spagnoli, P. Ferruti, D. Sgouras, R. Duncan, Poly(amidoamine)s with potential as drug carriers: degradation and cellular toxicity. J Biomater Sci Polym Ed 2(4) (1991) 303-315.

[236] P. Ferruti, S. Manzoni, S.C.W. Richardson, R. Duncan, N.G. Pattrick, R. Mendichi, M. Casolaro, Amphoteric linear poly(amido-amine)s as endosomolytic polymers: Correlation between physicochemical and biological properties. Macromolecules 33(21) (2000) 7793-7800.

[237] K.W. Wan, B. Malgesini, L. Verpilio, P. Ferruti, P.C. Griffiths, A. Paul, A.C. Hann, R. Duncan, Poly(amidoamine) salt form: Effect on $\mathrm{pH}$-dependent membrane activity and polymer conformation in solution. Biomacromolecules 5(3) (2004) 1102-1109.

[238] N. Lavignac, M. Lazenby, J. Franchini, P. Ferruti, R. Duncan, Synthesis and preliminary evaluation of poly(amidoamine)-melittin conjugates as endosomolytic polymers and/or potential anticancer therapeutics. Int. J. Pharm. 300(1-2) (2005) 102-112.

[239] S.C.W. Richardson, N.G. Pattrick, N. Lavignac, P. Ferruti, R. Duncan, Intracellular fate of bioresponsive poly(amidoamine)s in vitro and in vivo. J. Control. Release 142(1) (2010) 78-88.

[240] N. Lavignac, M. Lazenby, P. Foka, B. Malgesini, I. Verpilio, P. Ferruti, R. Duncan, Synthesis and endosomolytic properties of poly(amidoamine) block copolymers. Macromol. Biosci. 4(10) (2004) 922-929.

[241] S.C.W. Richardson, N.G. Pattrick, Y.K.S. Man, P. Ferruti, R. Duncan, Poly(amidoamine)s as potential nonviral vectors: Ability to form interpolyelectrolyte complexes and to mediate transfection in vitro. Biomacromolecules 2(3) (2001) 1023-1028.

[242] A. Bernkop-Schnürch, Thiomers: A new generation of mucoadhesive polymers. Adv. Drug Delivery Rev. 57(11) (2005) 1569-1582.

[243] C. Lin, J.F.J. Engbersen, The role of the disulfide group in disulfide-based polymeric gene carriers. Expert Opin. Drug Deliv. 6(4) (2009) 421-439.

[244] F.H. Meng, W.E. Hennink, Z. Zhong, Reduction-sensitive polymers and bioconjugates for biomedical applications. Biomaterials 30(12) (2009) 2180-2198. 
[245] K.C. Rajender, W.L. Frederick, H.K. Michael, M.B. David, G.B.R. Robert, R. Daniel, Plasma cysteine, cystine, and glutathione in cirrhosis. Gastroenterology 87(4) (1984) 770-776.

[246] C. Lin, C.-J. Blaauboer, M.M. Timoneda, M.C. Lok, M. van Steenbergen, W.E. Hennink, Z. Zhong, J. Feijen, J.F.J. Engbersen, Bioreducible poly(amido amine)s with oligoamine side chains: Synthesis, characterization, and structural effects on gene delivery. J. Control. Release 126(2) (2008) 166-174.

[247] C. Lin, Z. Zhong, M.C. Lok, X. Jiang, W.E. Hennink, J. Feijen, J.F.J. Engbersen, Linear poly(amido amine)s with secondary and tertiary amino groups and variable amounts of disulfide linkages: Synthesis and in vitro gene transfer properties. J. Control. Release 116(2) (2006) 130-137.

[248] C. Lin, Z. Zhong, M.C. Lok, X. Jiang, W.E. Hennink, J. Feijen, J.F.J. Engbersen, Random and block copolymers of bioreducible poly(amido amine)s with high- and low-basicity amino groups: Study of DNA condensation and buffer capacity on gene transfection. J. Control. Release 123(1) (2007) 67-75.

[249] C. Lin, Z.Y. Zhong, M.C. Lok, X.L. Jiang, W.E. Hennink, J. Feijen, J.F.J. Engbersen, Novel bioreducible poly(amido amine)s for highly efficient gene delivery. Bioconjugate Chem. 18(1) (2007) 138-145.

[250] M.A. Mateos-Timoneda, M.C. Lok, W.E. Hennink, J. Feijen, J.F.J. Engbersen, Poly(amido amine)s as gene delivery vectors: Effects of quaternary nicotinamide moieties in the side chains. ChemMedChem 3(3) (2008) 478-486.

[251] M.H. Dufresne, M.A. Gauthier, J.C. Leroux, Thiol-functionalized polymeric micelles: From molecular recognition to improved mucoadhesion. Bioconjugate Chem. 16(4) (2005) 1027-1033.

[252] A. Bernkop-Schnurch, V. Schwarz, S. Steininger, Polymers with thiol groups: A new generation of mucoadhesive polymers? Pharm. Res. 16(6) (1999) 876-881.

[253] K. Kafedjiiski, F. Foger, A. Bernkop-Schnurch, M. Werle, Evaluation of in vitro enzymatic degradation of various thiomers and cross-linked thiomers. Drug Dev. Ind. Pharm. 33(2) (2007) 199-208.

[254] M.K. Marschutz, P. Caliceti, A. Bernkop-Schnurch, Design and in vivo evaluation of an oral delivery system for insulin. Pharm. Res. 17(12) (2000) 1468-1474. 


\section{Chapter 3}

\section{Functionalized linear poly(amidoamine)s are efficient vectors for intracellular protein delivery}

\section{Grégory Coué and Johan F.J. Engbersen}

Department of Biomedical Chemistry, MIRA Institute for Biomedical Technology \& Technical Medicine, Faculty of Science and Technology, University of Twente, P.O. Box 217, 7500 AE Enschede, the Netherlands

Part of this chapter has been published: G. Coué, J.F.J. Engbersen, Functionalized linear poly(amidoamine)s are efficient vectors for intracellular protein delivery, J. Control. Release (2011), doi:10.1016/j.jconrel.2011.01.023

Abstract: An effective intracellular protein delivery system was developed based on functionalized linear poly(amidoamine)s (PAAs) that form self-assembled cationic nanocomplexes with oppositely charged proteins. Three differently functionalized PAAs were synthesized, two of these having repetitive disulfide bonds in the main chain, by Michael-type polyaddition of 4-amino-1-butanol (ABOL) to cystamine bisacrylamide (CBA), histamine (HIS) to CBA, and ABOL to bis(acryloyl)piperazine (BAP). These water-soluble PAAs efficiently condense $\beta$-galactosidase by self-assembly into nanoscaled and positively-charged complexes. Stable under neutral extracellular conditions, the disulfide-containing nanocomplexes rapidly destabilized in a reductive intracellular environment. Cell-internalization and cytotoxicity experiments showed that the PAA-based nanocomplexes were essentially non-toxic. $\beta$-Galactosidase was successfully internalized into cells, with up to $94 \%$ of the cells showing $\beta$-galactosidase activity, whereas the enzyme alone was not taken up by the cells. The results indicate that these poly(amidoamine)s have excellent properties as highly potent and non-toxic intracellular protein carriers, which should create opportunities for novel applications in protein delivery. 


\section{Introduction}

Modern biotechnology nowadays enables the production of numerous proteins and peptides that are, or have the potential to be, used as highly specific and effective therapeutics agents, like vaccines, hormones, growth factors and enzymes. In this category, enzymes represent an essential group of protein drugs to notably treat chronic diseases, cancers, autoimmune diseases and metabolic disorders [1-6]. Many of these therapeutics should exert their pharmaceutical action inside the cytoplasm or onto individual organelles inside the cell, as for instance cancer-curing toxins (ricin, gelonin) and nucleases, or antibodies like $\alpha$-tubulin [7,8]. Negatively-charged cell membranes prevent proteins and peptides as other therapeutics with anionic character from entering cells by charge repulsion. Moreover, internalized proteins can be subject to lysosomal degradation. Several strategies to overcome these difficulties have been investigated, and the utilization of polymer-based nanocarriers has emerged as a promising and versatile approach because of their facile transformation and possibilities, to tune properties including subcellular size, biodegradability and biocompatibility [9, 10]. Recently, nanosized polyelectrolyte complexes (PECs) resulting from the self-assembly of proteins with natural and synthetic polymers have drawn increasing attention for application in therapeutic protein delivery [11-14]. In this non-covalent method, PECs are formed by simply mixing oppositely charged drug and polymer that will interact by electrostatic-attraction. The PEC formation results in an optically homogeneous and stable dispersions of nanoparticles possessing cationic charges able to bind to and internalize with cell surface [11]. They have the advantage of not using sonification or organic solvents which are both harmful for proteins and peptides and are regularly used for the preparation of nanoparticles notably by the double emulsion technique.

Poly(amidoamine)s (PAAs) can be easily synthesized by Michael-type polyaddition of primary or bis-secondary amines to bis(acrylamide)s [15, 16]. These polymers are water-soluble, biodegradable and biocompatible, with lower cytotoxicity profiles than other usual polycationic vectors [17-20]. PAAs have the advantage to degrade into oligomeric products in aqueous media within days or weeks, depending on their structure [21, 22]. As was shown by the groups of Ferruti and Duncan, these polymers have high potential in biomedical applications $[16,23]$ and have found to be particularly suitable for use as intracytoplasmic and endosomolytic vectors for the delivery of anticancer drugs [24, 25], proteins [7, 26] and nucleic acids [27-29].

In our group we have previously developed a series of novel linear PAAs containing 
repetitive disulfide linkages in their backbone (SS-PAAs) that were very efficient as vectors in intracellular gene delivery. Appropriately functionalized SS-PAAs (e.g. with 4-hydroxybutyl or 4-ethylimidazole side groups) self-assemble with DNA into nanoscaled polyplexes that show transfection efficiencies much higher than obtained with the reference polymer, polyethylenimine (PEI), or the PAA counterparts lacking the disulfide linkages [29-33]. These polymers are relatively stable in extracellular medium but are prone to fast degradation in the reductive intracellular environment due to the cleavage of the disulfide linkages in the polymer chain [34-38]. This property can be favorably exploited in delivery systems that should be stable outside the cell but have to disintegrate into fragments of low molecular weight after uptake into target cells in order to release therapeutic cargo and minimize cytotoxic effects.

In this paper, we present a study that illustrates that functionalized PAAs, and notably SS-PAAs, have great potential as vectors for intracellular protein delivery. Three differently functionalized PAAs have been evaluated for their capacity to form nanocomplexes with proteins that are stable in the extracellular environment, show efficient intracellular uptake, and are sensitive to bioenvironmental triggering to release their therapeutic active protein cargo. The PAAs were synthesized by Michael-type polyaddition of 4-amino-1-butanol (ABOL) to cystamine bisacrylamide (CBA), histamine to $\mathrm{CBA}$, and $\mathrm{ABOL}$ to bis(acryloyl)piperazine (BAP). The $\mathrm{p}(\mathrm{CBA}-\mathrm{ABOL})$ polymer possesses, besides repetitive disulfide moieties in the main chain originating from the CBA monomer, hydroxybutyl groups in the side chains originating from the $A B O L$ units. It has been shown that this hydroxybutyl side group favorably contributes to the efficiency in DNA transfection, presumably by increasing the endosomolytic properties [37]. The $\mathrm{p}(\mathrm{CBA}-\mathrm{HIS})$ polymer also possesses repetitive disulfide linkages in the main chain, but has imidazole moieties in the side chains originating from the histamine monomeric units. These imidazole moieties provide extra cationic charges that give increased charge interaction with the therapeutic payload. Moreover, it provides extra pH-responsiveness since the $\mathrm{pK}_{a}$ of the imidazole residues is in the range of the endosomal acidification ( $\mathrm{pH} 7.4-5.1)$. Besides these two bioreducible SS-PAA polymers, we have also included in the study the $\mathrm{p}(\mathrm{BAP}-\mathrm{ABOL})$ polymer, containing non-reducible bis(acryl)piperazine units in the main chain. We hypothesized that the cationic PAAs could self-assemble with negatively-charged proteins to form cationic nanosized particles by charge attraction, as schematically represented in Scheme 3.1. 


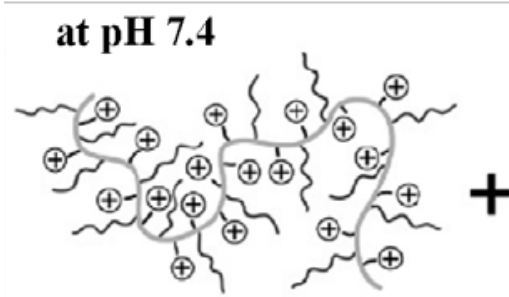

cationic polymer

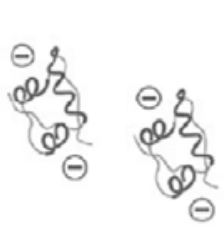

$\beta$-galactosidase

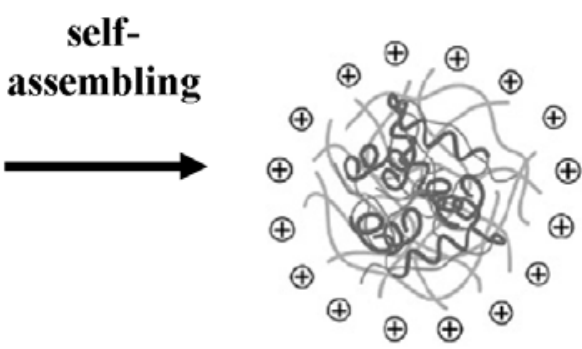

polymer/protein

nanocomplex

Scheme 3.1. Self-assembling formation of nanocomplexes at neutral $\mathrm{pH}$ by charge attraction between a negatively-charged protein ( $\beta$-galactosidase) and a positively-charged polymer (PAA).

The particles described in this work, with their positive charge, were not aimed for intravenous applications since they might aggregate with serum proteins, but were studied as proof of principle for intracellular delivery. Furthermore, these particles could be used for nasal applications for which aggregation is considerably less probable.

To investigate the feasibility of this concept, we selected $\beta$-galactosidase as a model protein. $\beta$-Galactosidase is an essential enzyme in the human body that is able to hydrolyze $\beta$-D-galactosides like lactose. Deficiencies in the protein can result in galactosialidosis or Morquio B syndrome. This large, tetrameric 464-kDa protein has an isoelectric point of $\mathrm{pH} 4.6$, implying an overall negative charge at neutral $\mathrm{pH}[39,40]$. Mixing of appropriate solutions of PAA and $\beta$-galactosidase resulted in the self-assembling formation of nanosized particles. $\beta$-Galactosidase reveals to be a suitable reporter protein since its intracellular presence can be easily detected via its enzymatic activity using ONPG and Bluo-gal assays.

\section{Materials and methods}

\subsection{Materials}

$\beta$-Galactosidase (grade VI from E.coli) was obtained from Sigma. Labeling of $\beta$-Galactosidase with Alexa Fluor ${ }^{\circledR} 488$ carboxylic acid TFP ester was performed according to the procedure provided by the supplier (Invitrogen). All monomers used for the polymer synthesis, 4-amino-1-butanol (ABOL, Aldrich), histamine (HIS, Fluka), Mono-Boc-protected diaminobutane (MBDAB, Fluka), N,N'-cystaminebisacrylamide (CBA, Polysciences), 1,4-bis(acryloyl)piperazine (BAP, Sigma-Aldrich) were purchased in the highest purity available and used without further purification. HEPES (Sigma), 
dithiothreitol (DTT, Sigma-Aldrich), trifluoroacetic acid (TFA, Aldrich), Bluo-gal (Invitrogen), o-nitrophenyl- $\beta$-D-galactopyranoside (ONPG, Sigma), Coomassie Blue (Bio-Rad), agarose (Eurogentec), trypsin (1:250) (Invitrogen) and methanol (MeOH, Biosolve) were used as received. Deionized water (DI water) was obtained from a MilliQ-water purification system.

\subsection{Synthesis of poly(amidoamine)s}

\subsubsection{Polymer synthesis}

The bioreducible PAA polymers, $\mathrm{p}(\mathrm{CBA}-\mathrm{ABOL})$ and $\mathrm{p}(\mathrm{CBA}-\mathrm{HIS})$, indicated together as SS-PAAs, have repetitive disulfide linkages in their main chain and were synthesized via Michael polyaddition of the primary amine monomers, $A B O L$ and HIS respectively, to CBA in equimolar monomeric ratios, as described previously [37]. The PAA polymer analog lacking the disulfide moieties, $\mathrm{p}(\mathrm{BAP}-\mathrm{ABOL})$, was synthesized similarly using BAP and $\mathrm{ABOL}$ as the monomers. Since the addition polymerization is a stepwise process, equal monomer ratios were used in the synthesis in order to obtain PAAs of highest theoretical molecular weight. In a typical experiment, CBA (2.63 g, $10 \mathrm{mmol})$ and ABOL (0.91 g, 10 $\mathrm{mmol}$ ) were added into a brown reaction flask and dissolved in $\mathrm{MeOH} / \mathrm{DI}$ water mixture (5 $\mathrm{ml}, 4 / 1, \mathrm{v} / \mathrm{v})$. Polymerization was carried out in the dark at $45^{\circ} \mathrm{C}$ under nitrogen atmosphere. The reaction mixture became homogeneous in less than two hours. The reaction was allowed to proceed for 10 days yielding to a viscous solution. During the polymerization a gradual increase in viscosity was observed. In all cases gelation did not occur. In a final stage, $10 \mathrm{~mol} \%$ excess ABOL (0.091 g, $1 \mathrm{mmol}$ ) was added to the reaction mixture in order to consume any unreacted acrylamide groups after polymerization and ensure that all potentially toxic acrylamide end groups were consumed, and that polymers contained only amino end groups. Stirring was continued for two days at $45^{\circ} \mathrm{C}$. Subsequently, the resulting solution was diluted with $30 \mathrm{ml}$ DI water, acidified with 4M $\mathrm{HCl}$ aqueous solution to $\mathrm{pH} \sim 5$, and then purified and isolated by ultrafiltration operation (3 kg/mol cut-off) with filtrated acidic DI water ( $\mathrm{pH} \sim 5$ ), followed by freeze-drying. A similar experimental procedure was performed for $\mathrm{p}(\mathrm{CBA}-\mathrm{HIS})$ using HIS as the reactive amine. Also for the synthesis of $\mathrm{p}(\mathrm{BAP}-\mathrm{ABOL})$, the PAA polymer that is lacking the disulfide linkages, BAP and ABOL were used in equimolar ratios; in this case only DI water was used as the solvent. The resulting polymers, collected in their $\mathrm{HCl}$-salt form as white solid powder after freeze-drying, have a good solubility in water. For all three polymers, the yield was ca. $45 \%$ after ultrafiltration and lyophilization. 


\subsubsection{Polymer characterization}

The ${ }^{1 H}$ NMR spectra of the synthesized PAAs in $\mathrm{D}_{2} \mathrm{O}$ were recorded on Varian Inova spectrometer operating at $300 \mathrm{MHz}$.

The molecular weight and polydispersity $\left(M_{w} / M_{n}\right)$ of the synthesized PAAs were determined by GPC relative to PEO standards (Polymer Labs) using a Viscotek GPCMax pump and autoinjector and two thermostated $\left(30^{\circ} \mathrm{C}\right) \mathrm{PL}$ aquagel-OH 30 columns $(8 \mu \mathrm{m}$, $300 \times 7.5 \mathrm{~mm}$, Polymer Labs, with a low-molar-mass separation range (200 40,000)). Data was collected using a TDA302 Tripledetector with RI, Visc and LS (7 and 90 $\left.{ }^{\circ}\right)$ ). 0.3M

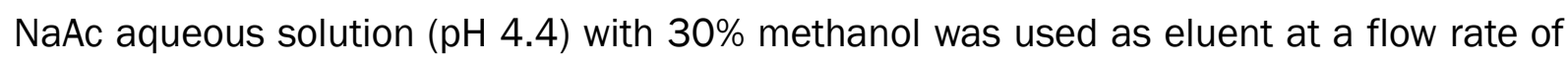
$0.7 \mathrm{ml} / \mathrm{min})$.

\subsection{Characterization of $P A A / \beta$-galactosidase nanoparticles}

\subsubsection{Particle size and zeta-potential measurements}

$\mathrm{PAA} / \beta$-galactosidase nanocomplexes at different polymer/ $\beta$-galactosidase weight ratios were prepared by adding a HEPES buffer solution $(10 \mathrm{mM}, \mathrm{pH} 7.4)$ of PAA $(800 \mu \mathrm{l})$ to a HEPES buffer solution (10 mM, pH 7.4) of $\beta$-galactosidase (200 $\mu \mathrm{l}, 75 \mu \mathrm{g} / \mathrm{ml}$ ), followed by vortexing for 5 seconds and incubating at room temperature for 30 minutes. Particle size and surface charge measurements of the nanocomplexes were determined by dynamic light scattering (DLS) at $25^{\circ} \mathrm{C}$ with a Zetasizer Nano ZS (Malvern Instruments, Malvern) using a wavelength of $532 \mathrm{~nm}$. The value was recorded as the mean of three measurements. The size distribution was given by polydispersity index (PDI, a value between 0 and 1). A PDI of 1 indicates large variations in particle size; a PDI of 0 indicates no variation in particle size (as an ideal monodispersed formulation). As the size of the particles influences the eventual uptake and distribution of the particles inside the cell, their stability was investigated and followed by DLS, at $25^{\circ} \mathrm{C}$ and $37^{\circ} \mathrm{C}$. The results at $25^{\circ} \mathrm{C}$ represent the ability of the nanocomplex solution to be stored at room temperature, whereas the results at $37^{\circ} \mathrm{C}$ indicate the thermal stability in the human body.

\subsubsection{Particle morphology}

The morphology of the nanoparticles was characterized by cryo-TEM and AFM. As for cryo-TEM measurements, a few microliters of suspension were deposited on a bare 700 mesh copper grid. After blotting away the excess of liquid, the grids were plunged quickly into liquid ethane. Frozen-hydrated specimens were mounted in a cryo-holder (Gatan, 
model 626) and observed with a Philips CM 120 electron microscope, operating at 120 KV. Micrographs were recorded under low-dose conditions on a slow-Scan CCD camera (Gatan, model 794). For AFM experiments, a drop of nanoparticular suspension was deposited directly onto the native oxide surface of $1 \times 1 \mathrm{~cm}^{2}$ pieces of a silicon wafer and dried in air. The particles were visualized in air and the sample topography was obtained by imaging the particles in the contact mode. All AFM experiments were performed with a Multimode NanoScope III (Veeco-Digital Instruments, USA). Commercially available triangular silicon nitride cantilevers were used (Veeco, USA).

\subsection{3. $\beta$-Galactosidase condensation and loading efficiency}

Agarose gel electrophoresis experiments were designed to demonstrate the formation of complexation between PAA and $\beta$-galactosidase and to estimate the optimal amount of polymer necessary to completely condense the enzyme. This can be observed by the absence of free protein bands on the gel. To this end, the enzyme (final concentration 15 $\mu \mathrm{M})$ was incubated with different concentrations of PAA for 30 minutes in 10 mM HEPES buffer ( $\mathrm{pH}$ 7.4) before loading of samples into wells. Therefore, nanocomplexes were prepared by adding $8 \mu \mathrm{l}$ of polymer solution (various concentrations in 10mM HEPES buffer $\mathrm{pH}$ 7.4) to $2 \mu \mathrm{l}$ of $\beta$-galactosidase solution ( $75 \mu \mathrm{M}$ in HEPES buffer $\mathrm{pH} 7.4$ ), followed by vortexing for 5 seconds and the dispersions were incubated for 30 minutes at room temperature. After incubation, $3 \mu \mathrm{l}$ of this mixture was applied onto a $0.7 \%$ agarose gel and $5 \mu \mathrm{l}$ of HEPES buffer solution was added and the electrophoresis was run for one hour at 80V. After 30 minutes staining with a Coomassie Blue stain solution, destaining was carried out in DI water containing $10 \% \mathrm{MeOH}$ and $7 \%$ acetic acid, and $\beta$-galactosidase was visualized by the presence of blue bands on the gel.

To estimate the loading efficiency of the nanoparticles at neutral $\mathrm{pH}$, particle solutions of $\mathrm{PAA} / \beta$-galactosidase nanoparticles were prepared at polymer/protein weight ratio ranging from $3 / 1$ to $24 / 1$ using Alexa Fluor ${ }^{\circledR} 488$ labeled $\beta$-galactosidase. The nanoparticles were centrifuged at $14000 \mathrm{rpm}$ for 30 minutes at $4^{\circ} \mathrm{C}$. Aliquots of supernatant were subsequently taken and their protein content determined by fluorescence spectroscopy (Safire ${ }^{2}$, Tecan, Canada) at an emission wavelength of $519 \mathrm{~nm}$ and an excitation wavelength of $495 \mathrm{~nm}$. The actual loading efficiency was indirectly determined by measuring the difference between the total amount of $\beta$-galactosidase added to the solution and the amount of $\beta$-galactosidase in the free form in the supernatant. $A$ calibration curve from solutions of various fluorescently-labeled $\beta$-galactosidase 
concentrations was determined prior to this experiment. It was confirmed that free $\beta$-galactosidase was not precipitated from the solution by centrifugation.

\subsubsection{Release of $\beta$-galactosidase from nanoparticles by disulfide reduction of the SS-PAAS}

The release of protein from the nanoparticles at intracellular mimicking reductive conditions was measured using solutions of SS-PAA/ $\beta$-galactosidase nanoparticles prepared as described before at polymer/protein weight ratio 24/1 using Alexa Fluor ${ }^{\circledR}$ 488 labeled $\beta$-galactosidase. The reducing agent DTT was added to a final concentration of $2.5 \mathrm{mM}$ and the solution was incubated for 30 minutes. Subsequently, the solution was centrifuged at $14000 \mathrm{rpm}$ for 30 minutes at $4^{\circ} \mathrm{C}$. Aliquots of supernatant were taken and their protein content was determined by the measurement of the fluorescence intensity using a prior-determined calibration curve.

Evidence for nanoparticle destabilization caused by the reductive cleavage of the disulfide bonds in the SS-PAA polymer was also obtained by following the particle size signal through DLS measurements of SS-PAA/ $\beta$-galactosidase nanoparticular solutions to which a solution of DTT in HEPES buffer was added to give a final concentration of 2.5 $\mathrm{mM}$ DTT in the resultant solution.

Experiments were performed under conditions mimicking in vitro cellular studies in order to obtain indications of the PAA/ $\beta$-galactosidase nanoparticle stability and enzyme-protecting efficacy, and the recovery of the enzymatic activity upon the reduction of the disulfide linkages in the polymeric nanoparticles. To this aim, PAA/ $\beta$-galactosidase nanoparticles were prepared in HEPES buffer solution $(10 \mathrm{mM}$, pH 7.4) at polymer/protein weight ratio 24/1. Samples of these solutions were diluted with equivalent volume of either HEPES buffer or DMEM medium with or without 10\% Fetal Bovine Serum (FBS), and the enzymatic activity of $\beta$-galactosidase condensed in nanoparticles was determined before and after addition of DTT (2.5 $\mathrm{mM})$ using the ONPG assay [41]. To this end, to $20 \mu \mathrm{l}$ of every nanoparticle solution, treated or untreated with $2.5 \mathrm{mM}$ DTT, was added $180 \mu \mathrm{l}$ ONPG-staining solution $(0.673 \mathrm{mg} / \mathrm{ml}$ in $10 \mathrm{mM}$ HEPES buffer $\mathrm{pH} 7.4$ ), and the mixture was incubated for 20 minutes at $37^{\circ} \mathrm{C}$ and the UV absorbance at $415 \mathrm{~nm}$ was determined using the absorbance at $655 \mathrm{~nm}$ as a reference. The $\beta$-galactosidase activity was calculated by comparison with a linear calibration curve of $\beta$-galactosidase of different concentrations under similar conditions.

Furthermore, the protection efficacy of $\beta$-galactosidase in PAA/ $\beta$-galactosidase 
nanoparticles against protease has been evaluated. Trypsin was selected as the protease enzyme, as it has been reported that $\beta$-galactosidase possesses a limited resistance towards this enzyme [42]. Therefore, $1 \mathrm{ml}$ of the PAA/ $\beta$-galactosidase nanoparticle HEPES buffer solution was mixed with an equal volume of HEPES buffer solution containing trypsin at a concentration similar to that found in human serum.(ca. $200 \mathrm{ng} / \mathrm{ml}$ ) [43]. After 30 minutes of incubation, the solution was centrifuged at $14000 \mathrm{rpm}$ for 30 minutes at $4^{\circ} \mathrm{C}$. Subsequently, the supernatant was replaced by $1 \mathrm{ml}$ of HEPES buffer with or without DTT (2.5 mM), prior to enzymatic activity determination by the ONPG assay as previously described.

\subsubsection{Release of $\beta$-galactosidase by acidification of the nanoparticles}

The effect of $\mathrm{pH}$ decrease from 7.4 to 5.1 (mimicking endosomal $\mathrm{pH}$ decrease) was investigated by DLS measurements. Particle size measurements of the nanocomplexes were performed at $25^{\circ} \mathrm{C}$ with a Zetasizer Nano ZS (Malvern Instruments, Malvern) using a wavelength of $532 \mathrm{~nm}$. Simultaneously, the nanoparticular solution was titrated from $\mathrm{pH} 7.4$ to $\mathrm{pH} 5.1$ by regularly adding small aliquots of $0.25 \mathrm{M} \mathrm{HCl}$ solution using a MTP-2 multipurpose titrator (Malvern Instruments, Malvern). Particle size was determined every half-unit of $\mathrm{pH}$.

In another experiment, the loading capacity of the nanoparticles at intracellular $\mathrm{pH}$ was measured using solutions of $\mathrm{PAA} / \beta$-galactosidase nanoparticles prepared at polymer/protein weight ratio 24/1 as previously, using Alexa Fluor ${ }^{\circledR} 488$ labeled $\beta$-galactosidase. After acidification to $\mathrm{pH} \sim 5$ by addition of $1 \mathrm{M} \mathrm{HCl}$ solution and incubation for 30 minutes, the nanoparticles were centrifuged at $14000 \mathrm{rpm}$ for 30 minutes at $4^{\circ} \mathrm{C}$. Aliquots of supernatant were subsequently taken and their protein content was determined by fluorescence spectroscopy $\left(\lambda_{\mathrm{em}}=519 \mathrm{~nm}, \lambda_{\mathrm{ex}}=495 \mathrm{~nm}\right)$ using a calibration curve. The percentage of loading efficiency was calculated from the difference of the total amount of $\beta$-galactosidase added to the solution and the amount of $\beta$-galactosidase that is determined in the free form in the supernatant.

In order to obtain an indication of the $\beta$-galactosidase release from the nanoparticles upon the acidification of the environment to endosomal values $(\mathrm{pH} \sim 5)$, the enzymatic activity of $\beta$-galactosidase condensed in the nanoparticles was determined using the ONPG assay after acidification to $\mathrm{pH} 5$ [41]. Therefore, to $20 \mu \mathrm{l}$ of PAA/ $\beta$-galactosidase nanoparticle solution acidified at pH 5 for 30 minutes was added $180 \mu$ ONPG-staining solution $(0.673 \mathrm{mg} / \mathrm{ml}$ in $10 \mathrm{mM}$ HEPES buffer $\mathrm{pH} 7.4)$, and the mixture was incubated for 
20 minutes at $37^{\circ} \mathrm{C}$ before measuring the UV absorbance at $415 \mathrm{~nm}$ using the absorbance at $655 \mathrm{~nm}$ as a reference. The $\beta$-galactosidase concentration was calculated by comparison with a linear calibration curve of $\beta$-galactosidase of different concentrations formerly prepared at $\mathrm{pH} 7.4$ and $\mathrm{pH} 5$.

\subsubsection{Cellular uptake and cytotoxicity of NPs in vitro}

In vitro protein transfection (profection) of the PAA/ $\beta$-galactosidase nanoparticles was studied in COS-7 cells (SV-40 transformed African Green monkey kidney cells). The potential for cell-internalization was in a first run followed by Fluorescence-Activated Cell Sorting (FACS) experiments. For this approach, different PAA/ $\beta$-galactosidase weight ratios ranging from $3 / 1$ to $36 / 1(\mathrm{~W} / \mathrm{w})$ were used to prepare nanocomplexes in HEPES buffer $(10 \mathrm{mM}, \mathrm{pH} 7.4)$ using Alexa Fluor ${ }^{\circledR} 488$-labeled $\beta$-galactosidase. COS-7 cells were seeded at a density of $4.0 \times 10^{4}$ cells/well in a 24-well plate and were incubated for 24 hours. Prior to protein transfection, the cells were washed with PBS and incubated in 0.5 $\mathrm{ml}$ of serum-free DMEM media in each well. In brief, the nanocomplexes were prepared by adding a HEPES buffer solution $(10 \mathrm{mM}, \mathrm{pH} 7.4,200 \mu \mathrm{L})$ of PAAs with varying concentrations (from 40 to $600 \mu \mathrm{g} / \mathrm{ml}$ ) to a HEPES buffer solution (10 mM, pH 7.4, $50 \mu \mathrm{L}$ ) of $\beta$-galactosidase $(50 \mu \mathrm{g} / \mathrm{ml})$, followed by vortexing and incubating at room temperature for 30 minutes. In a standard profection experiment, the cells in serum-free DMEM media were incubated with the desired amount of nanocomplexes $(100 \mu \mathrm{L}$ dispersion with $1 \mu \mathrm{g}$ $\beta$-galactosidase per well) for one hour at $37^{\circ} \mathrm{C}$ in a humidified $5 \% \mathrm{CO}_{2}$-containing atmosphere, after which the media was replaced with fresh DMEM containing 10\% FBS and incubated for another 24 hours at $37^{\circ} \mathrm{C}$. The cells were washed with PBS buffer, trypsinized and transferred to sterile tubes followed by centrifugation at $1100 \mathrm{rpm}$ for 5 minutes. The supernatant was poured off, and the cells were resuspended in $0.4 \mathrm{ml}$ of PBS. Then, $10 \mu \mathrm{l}$ of propidium iodide (PI) $(1.0 \mathrm{mg} / \mathrm{ml})$ fluorescent DNA nuclear marker was added to the cells to determine cell viability. Fluorescence for both Alexa Fluor ${ }^{\circledR}$ 488-labeled $\beta$-galactosidase and PI were detected using a Fluorescence Activated Cell Sorting FACScan flow cytometer with excitation wavelengths of 488 and $535 \mathrm{~nm}$, respectively. The instrument was calibrated with a negative control (non-transfected cells) to identify viable cells and then the transfected cells were analyzed from a gated viable population of 10000 cells. In all experiments, the viable cells were gated based on cell exclusion of PI.

Parallel profection series in separate 96 -well plates (ca. $1.0 \times 10^{4}$ cells per well) were 
simultaneously carried out to determine the internalization efficiencies and quantitative protein activities of the released protein, as well as the cell viability. Similar PAA $/ \beta$-galactosidase nanocomplexes as for FACS experiments, but unlabeled, were prepared for these latter steps. To determine $\beta$-galactosidase profection efficiency, after incubation of the cells with the nanoparticles and refreshment of the culture medium, the cells were washed with PBS and fixed using a 4\% p-formaldehyde solution in PBS for 15 minutes at room temperature. Subsequently, the cells were treated with $100 \mu \mathrm{l}$ of $0.2 \%$ Bluo-gal solution (in PBS) and allowed to stain for $\beta$-galactosidase activity at $37^{\circ} \mathrm{C}$ overnight. Using bright-field microscopy (Nikon Eclipse TE300, Nikon, Japan), the percentage cells displaying $\beta$-galactosidase activity was determined by counting the number of active cells per 100 cells on a slide, three times in different fields. The quantitative enzymatic activity of $\beta$-galactosidase inside the cells was further determined by colorimetric assay, measuring the enzyme activity of $\beta$-galactosidase using the ONPG assay [44]. A linear calibration curve using different concentrations $\beta$-galactosidase was used as a reference. The number of viable cells was measured using an XTT assay [45]. The XTT value for untreated cells (i.e. cells not exposed to the transfection systems) was taken as $100 \%$ cell viability. All profection and toxicity assays were carried out in triplicate.

\section{Results and Discussion}

\subsection{Synthesis and characterization of PAAs}

Two different bioreducible PAA polymers with repetitive disulfide linkages in their main chain (SS-PAAs) were synthesized via Michael addition of the corresponding primary amine monomers, ABOL or HIS, to CBA and were coded in terms of the used monomers, as shown in Scheme 3.2. Furthermore, for comparison, a PAA lacking the disulfide linkages was prepared by polyaddition of ABOL to BAP. The polymers were collected in ca. $45 \%$ yield as their $\mathrm{HCl}$-salt after freeze-drying and were well soluble in water.

The ${ }^{1} \mathrm{H}$ NMR spectra of the synthesized PAAs in $\mathrm{D}_{2} \mathrm{O}$ were recorded on Varian Inova spectrometer operating at $300 \mathrm{MHz}$, and were in full accordance with the expected structures. The absence of any proton signals between 5 and 7 ppm shows that the polymer did not contain any residual acrylamide end groups.

p(CBA-ABOL): White solid. Yield: $1.49 \mathrm{~g}(43 \%) .{ }^{1} \mathrm{H}$ NMR $\left(\mathrm{D}_{2} \mathrm{O}\right) \delta(p p m)=1.73\left(\mathrm{CH}_{2} \mathrm{CH}_{2} \mathrm{OH}, 2 \mathrm{H}\right)$; $1.94\left(\mathrm{CH}_{2} \mathrm{CH}_{2} \mathrm{CH}_{2} \mathrm{OH}, 2 \mathrm{H}\right) ; 2.91\left(2 \times \mathrm{NHCOCH}_{2}, 4 \mathrm{H}\right) ; 3.00\left(2 \times \mathrm{SSCH}_{2} \mathrm{CH}_{2}, 4 \mathrm{H}\right) ; 3.36$ $\left(\mathrm{NCH}_{2} \mathrm{CH}_{2} \mathrm{CH}_{2} \mathrm{CH}_{2} \mathrm{OH}, 2 \mathrm{H}\right) ; 3.59\left(\mathrm{CH}_{2} \mathrm{CH}_{2} \mathrm{NCH}_{2} \mathrm{CH}_{2}, 4 \mathrm{H}\right) ; 3.66\left(2 \times \mathrm{SSCH}_{2} \mathrm{CH}_{2}, 4 \mathrm{H}\right) ; 3.75\left(\mathrm{CH}_{2} \mathrm{OH}\right.$, 
$2 \mathrm{H})$.

p(CBA-HIS): White solid. Yield: $1.92 \mathrm{~g}(51 \%) .{ }^{1} \mathrm{H}$ NMR $\left(\mathrm{D}_{2} \mathrm{O}\right) \delta(\mathrm{ppm})=2.77\left(2 \times \mathrm{NHCOCH}_{2}, 4 \mathrm{H}\right)$;

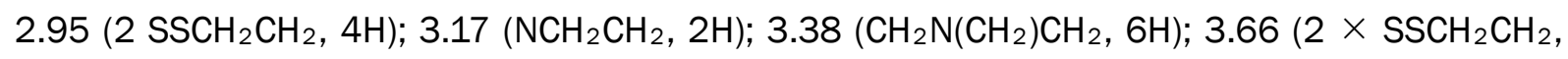
$4 \mathrm{H}) ; 7.26(\mathrm{C}=\mathrm{CH}-\mathrm{N}, 1 \mathrm{H}) ; 8.38(\mathrm{C}-\mathrm{N}=\mathrm{CH}-\mathrm{N}, 1 \mathrm{H})$.

p(BAP-ABOL): White solid. Yield: $1.10 \mathrm{~g}(38 \%) .{ }^{1} \mathrm{H}$ NMR $\left(\mathrm{D}_{2} \mathrm{O}\right) \delta(\mathrm{ppm})=1.58\left(\mathrm{CH}_{2} \mathrm{CH}_{2} \mathrm{OH}, 2 \mathrm{H}\right)$; $1.80\left(\mathrm{CH}_{2} \mathrm{CH}_{2} \mathrm{CH}_{2} \mathrm{OH}, 2 \mathrm{H}\right) ; 2.91\left(2 \times \mathrm{NHCOCH}_{2}, 4 \mathrm{H}\right) ; 3.26\left(\mathrm{NCH}_{2} \mathrm{CH}_{2} \mathrm{CH}_{2} \mathrm{CH}_{2} \mathrm{OH}, 2 \mathrm{H}\right) ; 3.51$ $\left(\mathrm{CH}_{2} \mathrm{CH}_{2} \mathrm{NCH}_{2} \mathrm{CH}_{2}, 4 \mathrm{H}\right) ; 3.49$ and $3.53\left(\mathrm{NCH}_{2} \mathrm{CH}_{2} \mathrm{~N}, 8 \mathrm{H}\right)$; $3.76\left(\mathrm{CH}_{2} \mathrm{OH}, 2 \mathrm{H}\right)$.

The GPC measurements showed that the average molecular weight $\left(M_{w}\right)$ of $p(C B A-A B O L)$, $\mathrm{p}(\mathrm{CBA}-\mathrm{HIS})$ and $\mathrm{p}(\mathrm{BAP}-\mathrm{ABOL})$ was respectively $5.9,8.7$ and $5.5 \mathrm{~kg} / \mathrm{mol}(\mathrm{PDI}=1.13)$.

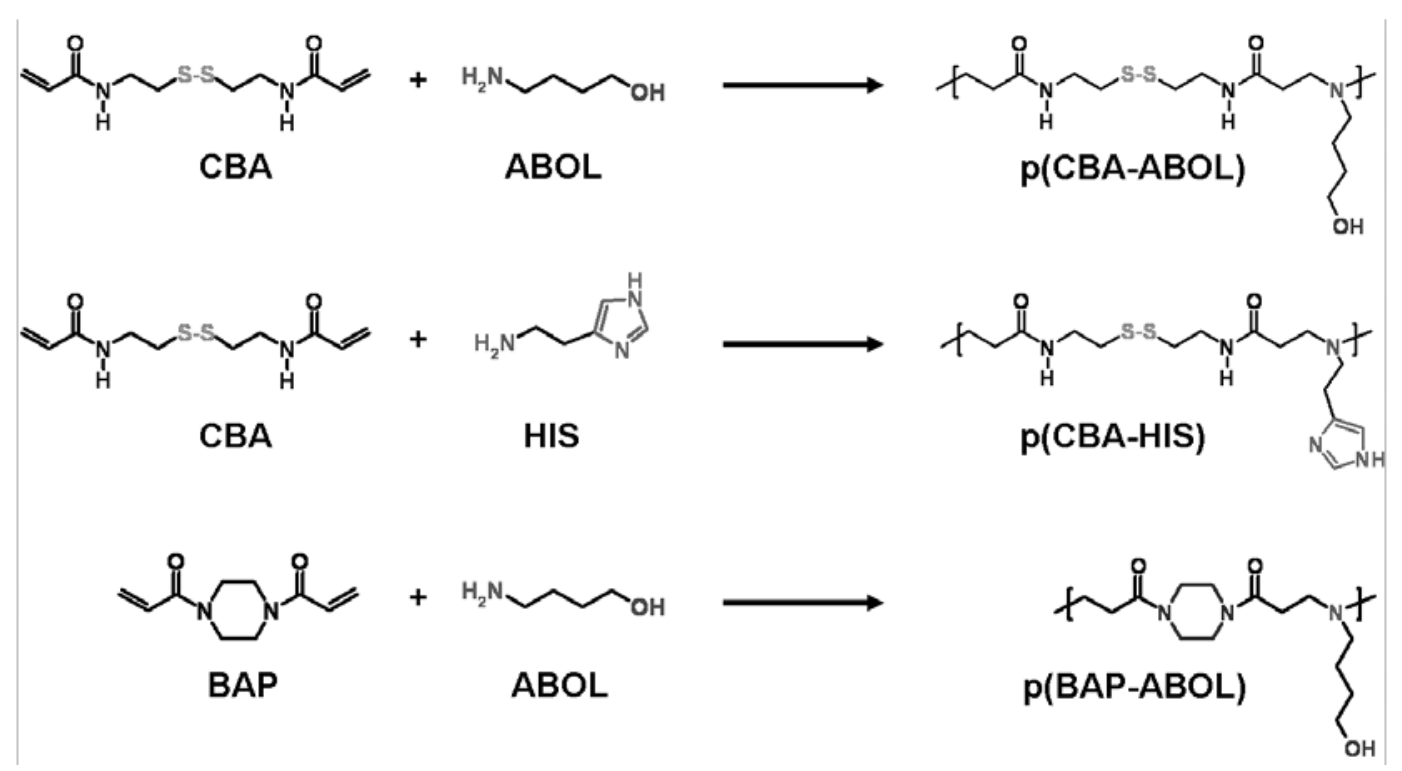

Scheme 3.2. Synthesis scheme of poly(amidoamine)s. The polymers were coded in terms of the used bisacrylamide and primary amine monomer.

\subsection{Protein uptake into the PAA nanoparticles: physical characterization and loading efficiency}

A first requirement for polymers to function as intracellular delivery vectors is that they should be able to condense their content into nanosized particles. At physiological $\mathrm{pH}(\mathrm{pH}$ 7.4), the PAAs are present as polycations due to partial protonation of the tertiary nitrogens in the main chain of the polymer. Charge interaction with $\beta$-galactosidase can be expected since this enzyme, with an isoelectric point of 4.6 , has a net negative charge under these conditions. DLS and zeta-potential measurements showed that all three synthesized polymers are capable to form nanosized polyelectrolyte complexes by self-assembly with $\beta$-galactosidase. The particles have sizes smaller than $150 \mathrm{~nm}$ with 
low polydispersity (PDI < 0.15) and positive surface charge $(>+25 \mathrm{mV})$, in $10 \mathrm{mM}$ HEPES buffer solution pH 7.4 (Figure 3.1). The smallest size $(<100 \mathrm{~nm})$ and highest surface charge $(>35 \mathrm{mV})$ is observed for the nanocomplexes of $\mathrm{p}$ (CBA-HIS), which may be attributed to the presence of the imidazole groups (partially protonated) in this polymer giving rise to stronger interactions with $\beta$-galactosidase. Repetitive size measurements in time show that the nanoparticles formed with $\beta$-galactosidase were stable for more than one month at room temperature and at least 4 days at $37^{\circ} \mathrm{C}$.

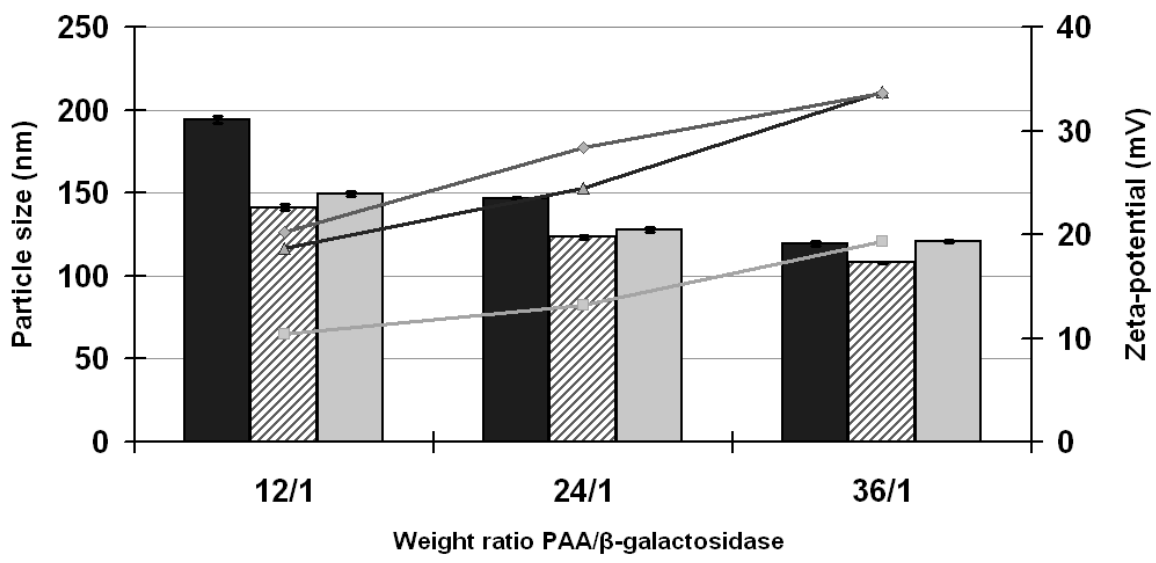

Figure 3.1. Size distributions and zeta-potentials of PAA/ $\beta$-galactosidase nanoparticles measured by DLS at $25^{\circ} \mathrm{C}$ according to the PAA/ $\beta$-galactosidase weight ratio, using $\mathrm{p}(\mathrm{CBA}-\mathrm{ABOL})$ (black bars), $\mathrm{p}(\mathrm{CBA}-\mathrm{HIS}$ ) (striped bars), and $\mathrm{p}(\mathrm{BAP}-\mathrm{ABOL}$ ) (grey bars) as polymeric vector.

Cryo-TEM microscopy and AFM imaging showed a well-shaped spherical structure of the nanocomplexes with sizes comparable to those determined by DLS (Figure 3.2), confirming particle sizes of ca. 10-130 nm.
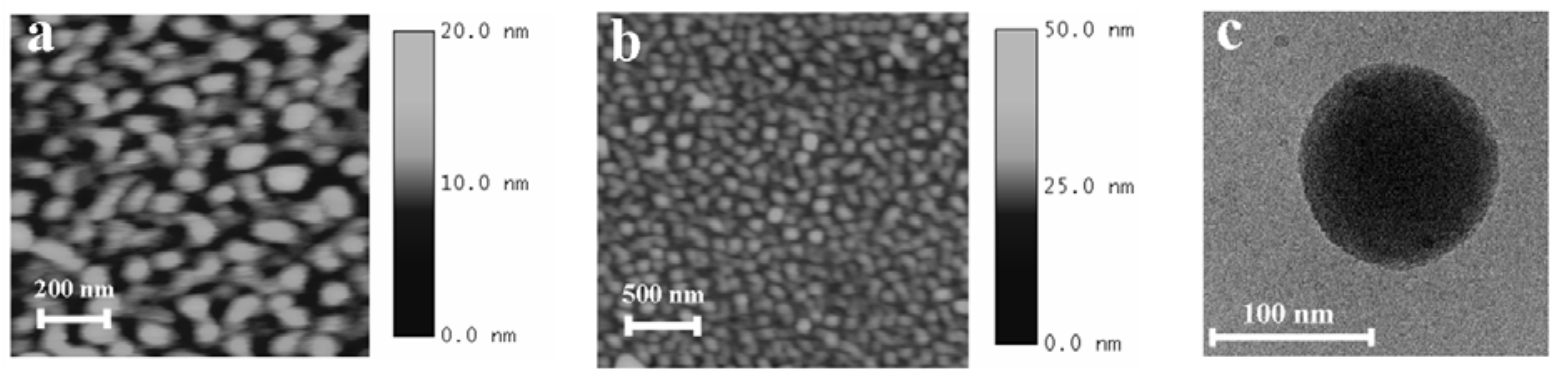

Figure 3.2. (a) and (b) AFM images and heights of $p(C B A-A B O L) / \beta$-galactosidase nanoparticles in HEPES buffer solution pH 7.4 (weight ratio $=24 / 1$ ), (c) Cryo-TEM visualization of $\mathrm{p}(\mathrm{CBA}-\mathrm{ABOL}) / \beta$-galactosidase nanoparticles in HEPES buffer solution $\mathrm{pH} 7.4$ (weight ratio $=24 / 1$ ) 
Agarose gels were run using PAA/ $\beta$-galactosidase nanoparticles prepared at polymer/protein weight ratios ranging from $0.1 / 1$ to $64 / 1$. Pure $\beta$-galactosidase was included in the experiments and was loaded as a control. Although PAGE gels usually give better resolution for proteins, under these conditions the $\mathrm{pH}$ could be better controlled and kept to neutral conditions by using agarose gels. As is shown in Figure 3.3, depicting the results for $p(C B A-A B O L) / \beta$-galactosidase nanoparticles, free $\beta$-galactosidase substantially migrates towards the positive electrode, as expected due to its overall negative charge. However, the presence of positively-charged PAA results in a dramatic decrease of the mobility of the enzyme, which can initially be attributed to a shielding of the negative surface charges on binding of the cationic polymer to the enzyme and at higher ratios to the formation of polyelectrolyte complexes [46].

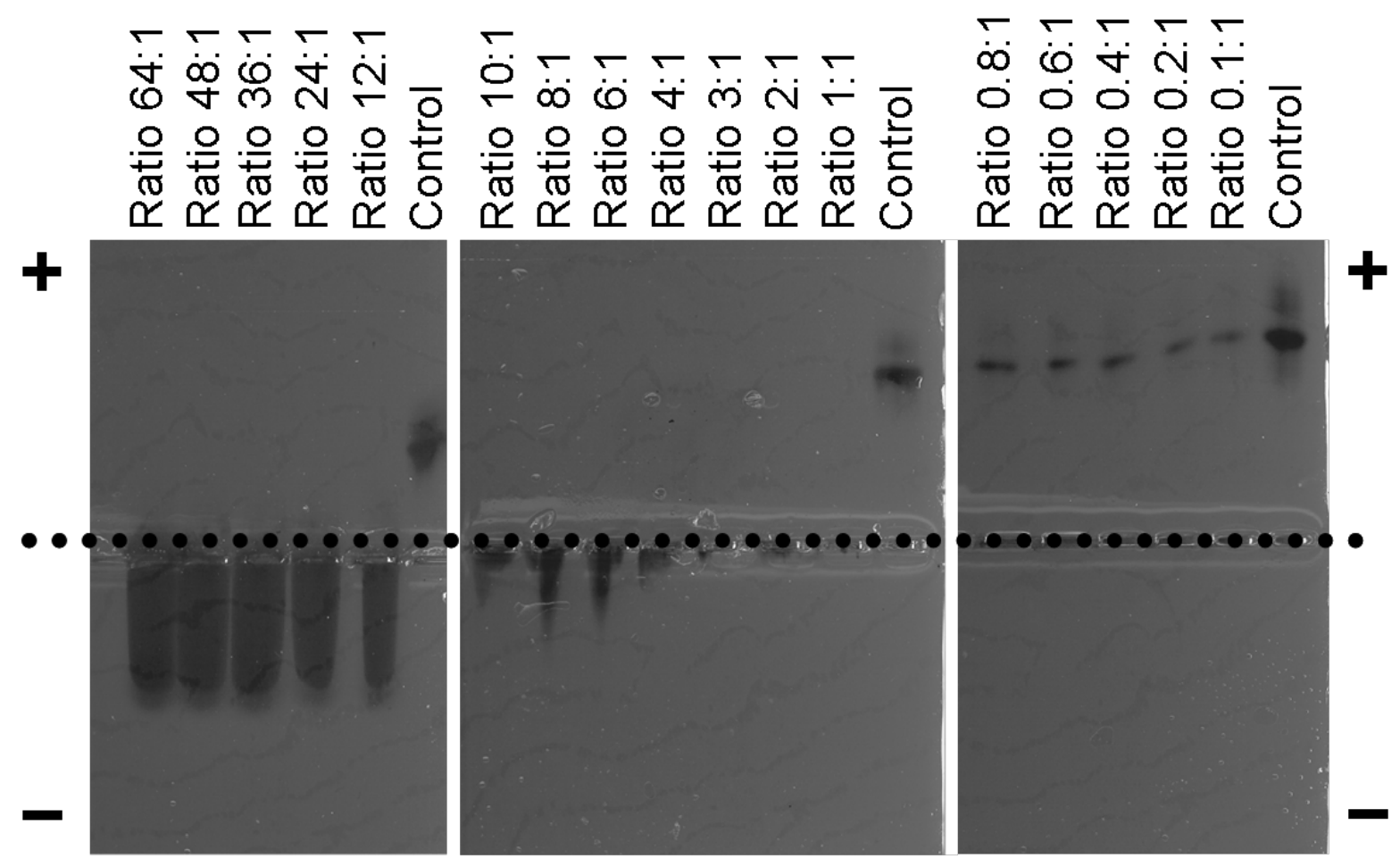

Figure 3.3. Agarose gel electrophoresis obtained after running $p(C B A-A B O L) / \beta$-galactosidase nanoparticles prepared at polymer/protein ratios ranging from $0.1 / 1$ to $64 / 1$. For each gel, the last well on the right side of the plate was loaded with free $\beta$-galactosidase as a control.

At $1 / 1$ ratio of $\mathrm{p}$ (CBA-ABOL)/enzyme, no residual protein band is observed, indicating an approximate $1 / 1(\mathrm{w} / \mathrm{w})$ binding ratio of $\mathrm{p}(\mathrm{CBA}-\mathrm{ABOL})$ to the enzyme molecule. For weight ratios $\mathrm{p}(\mathrm{CBA}-\mathrm{ABOL}) /$ enzyme higher than $4 / 1$, smeared bands were observed towards the negative electrode, which size increases with higher polymer weight ratios, indicating the 
presence of an excess of unbound or loosely bound cationic polymer over negatively-charged enzyme. Similar results were obtained with $p(B A P-A B O L)$ and $\mathrm{p}(\mathrm{CBA}-\mathrm{HIS})$ as polymeric vectors (data not shown). These results are in good accordance with the DLS data where nanosized complexes were formed for weight ratios of $\mathrm{p}(\mathrm{CBA}-\mathrm{ABOL}) / \beta$-galactosidase higher than 4/1.

Table 3.1 gives the loading efficiencies of the PAA/ $\beta$-galactosidase nanoparticles at neutral $\mathrm{pH}$ in HEPES buffer solution $(10 \mathrm{mM}, \mathrm{pH} 7.4)$, as determined by fluorescence spectroscopy measurements using Alexa Fluor ${ }^{\circledR} 488$ labeled $\beta$-galactosidase.

Table 3.1. $\beta$-Galactosidase loading efficiencies of PAA/Alexa Fluor ${ }^{\circledR} 488$ labeled $\beta$-galactosidase nanoparticles prepared using different PAA/ $\beta$-galactosidase weight ratios in HEPES buffer pH 7.4. The reported values were corrected from the protein content determined in the supernatant using free $\beta$-galactosidase.

\begin{tabular}{|c|c|c|}
\hline Polymer & $\begin{array}{c}\text { Polymer } / \beta \text {-galactosidase } \\
\text { weight ratio }\end{array}$ & $\begin{array}{c}\text { B-galactosidase loading } \\
\text { efficiency }(\%)^{*}\end{array}$ \\
\hline \multirow{4}{*}{$\mathrm{p}(\mathrm{CBA}-\mathrm{ABOL})$} & $3 / 1$ & 88.5 \\
\hline & $6 / 1$ & 89.7 \\
\hline & $12 / 1$ & 91.3 \\
\hline & $24 / 1$ & 92.5 \\
\hline \multirow{4}{*}{$\mathrm{p}(\mathrm{CBA}-\mathrm{HIS})$} & $3 / 1$ & 93.4 \\
\hline & $6 / 1$ & 94.1 \\
\hline & $12 / 1$ & 95.5 \\
\hline & $24 / 1$ & 95.6 \\
\hline \multirow{4}{*}{$p(B A P-A B O L)$} & $3 / 1$ & 39.5 \\
\hline & $6 / 1$ & 55.7 \\
\hline & $12 / 1$ & 65.9 \\
\hline & $24 / 1$ & 69.5 \\
\hline
\end{tabular}

* Percentage of $\beta$-galactosidase that is incorporated in the polymeric nanoparticles $(+/-0.5)$. Initial $\beta$-galactosidase concentration is $15 \mu \mathrm{g} / \mathrm{ml}$.

It can be seen that the incorporation of the enzyme in the disulfide polymer nanoparticles of $p(C B A-A B O L)$ and $p(C B A-H I S)$ is very high even under the dilute conditions applied ( $\beta$-galactosidase concentration: $15 \mu \mathrm{g} / \mathrm{ml})$. The $\beta$-galactosidase loading efficiency of the nanoparticles with the HIS pendant groups is slightly higher than those with the $A B O L$ side groups. This slight difference of loading efficiency might be attributed to the slight higher molecular weight from the $\mathrm{p}(\mathrm{CBA}-\mathrm{HIS})$ polymer, moreover it may also be explained 
by the presence of the extra cationic charges in the side chains for the $p$ (CBA-HIS) polymer. Nevertheless, the lower loading efficiency from the $\mathrm{p}(\mathrm{BAP}-\mathrm{ABOL}) / \beta$-galactosidase nanoparticles cannot be attributed to the difference of molecular weight (respectively 5.9 and $5.5 \mathrm{~kg} / \mathrm{mol}$ for $\mathrm{p}(\mathrm{CBA}-\mathrm{ABOL})$ and $\mathrm{p}(\mathrm{BAP}-\mathrm{ABOL})$ ). The $\mathrm{p}(\mathrm{BAP}-\mathrm{ABOL})$ polymer is less efficient in polyelectrolyte complexation of $\beta$-galactosidase. This may be ascribed to the lower conformational flexibility of this polymer, as the polymer has a rigid piperazine moiety instead of the four methylene and disulfide linkages in the monomeric units.

\subsection{Mimicking intracellular degradation by reduction of the SS-PAA/ $\beta$-galactosidase nanoparticles}

A second requirement to function as intracellular delivery vector is that the vector must be capable to efficiently unpack the therapeutic payload once the delivery system has been internalized into the cell. Insufficient unpacking of nanocomplexes inside cells is frequently a major barrier in the transfection process $[47,48]$. The rapid cleavage of disulfide linkages by glutathione and reductase enzymes in the intracellular environment (containing up to $10 \mathrm{mM}$ glutathione) can be favorably exploited here to induce fast degradation of the SS-PAAs in the nanocomplexes resulting in efficient protein release. This concept of reductive particle destabilization in the intracellular environment was supported by DLS measurements of SS-PAA/ $\beta$-galactosidase nanoparticle solutions in the presence of $2.5 \mathrm{mM}$ DTT as the reductive agent in HEPES buffer $\mathrm{pH} 7.4$. In this solution, mimicking the reducing intracellular environment, a rapid increase of the nanoparticle sizes from 100-130 nm to more than $1 \mu \mathrm{m}$ occurs within a few minutes, accompanied by a large decrease of the count rates. In contrast, the size of polyplexes based on the reference polymer $\mathrm{p}(\mathrm{BAP}-\mathrm{ABOL})$, lacking the disulfide linkages, remain stable after addition of DTT (data not shown). 
Table 3.2. $\beta$-Galactosidase release from PAA/Alexa Fluor ${ }^{\circledR} 488$ labeled $\beta$-galactosidase nanoparticles in HEPES buffer pH 7.4 (weight ratio 24/1), column A: after addition of DTT to a final concentration of $2.5 \mathrm{mM}$, column B: after addition of $0.25 \mathrm{M} \mathrm{HCl}$ to drop $\mathrm{pH}$ to $\mathrm{pH} 5.1$.

\begin{tabular}{|c|c|c|}
\hline Polymer & $\begin{array}{c}\text { A: } \\
\beta \text {-galactosidase release } \\
(\%)^{*}\end{array}$ & $\begin{array}{c}\text { B: } \\
\beta \text {-galactosidase release } \\
(\%)^{*}\end{array}$ \\
\hline$p(\mathrm{CBA}-\mathrm{ABOL})$ & 89.1 & 11.0 \\
\hline $\mathrm{p}(\mathrm{CBA}-\mathrm{HIS})$ & 74.8 & 18.3 \\
\hline $\mathrm{p}(\mathrm{BAP}-\mathrm{ABOL})$ & 0.5 & 14.0 \\
\hline
\end{tabular}

* Percentage of $\beta$-galactosidase that is released from the polymeric nanoparticles (+/- 0.5). Initial $\beta$-galactosidase concentration is $15 \mu \mathrm{g} / \mathrm{ml}$.

Table 3.2, column A, gives the percentages of $\beta$-galactosidase that is released from the $\mathrm{PAA} / \beta$-galactosidase nanoparticles after addition of $2.5 \mathrm{mM} \mathrm{DTT}$, as determined by fluorescence measurements of the supernatant after centrifugation using Alexa Fluor ${ }^{\circledR}$ 488 labeled $\beta$-galactosidase. The nanoparticles from the disulfide polymers $p(C B A-A B O L)$ and $\mathrm{p}(\mathrm{CBA}-\mathrm{HIS})$ have released most of the encapsulated enzyme (89\% and $74 \%$ respectively), due to the fast degradation of these polymers, whereas no release of enzyme was measured for the polymer/ $\beta$-galactosidase particles containing the $\mathrm{p}(\mathrm{BAP}-\mathrm{ABOL})$ polymer lacking the disulfide linkages.

In Figure 3.4 the quantitative enzymatic activities of $\beta$-galactosidase are given under conditions that further illustrate the concept of $\beta$-galactosidase protection and inhibition by encapsulation in the PAA nanocomplexes and protein release and reactivation by intracellular reduction of the SS-PAA packing. 

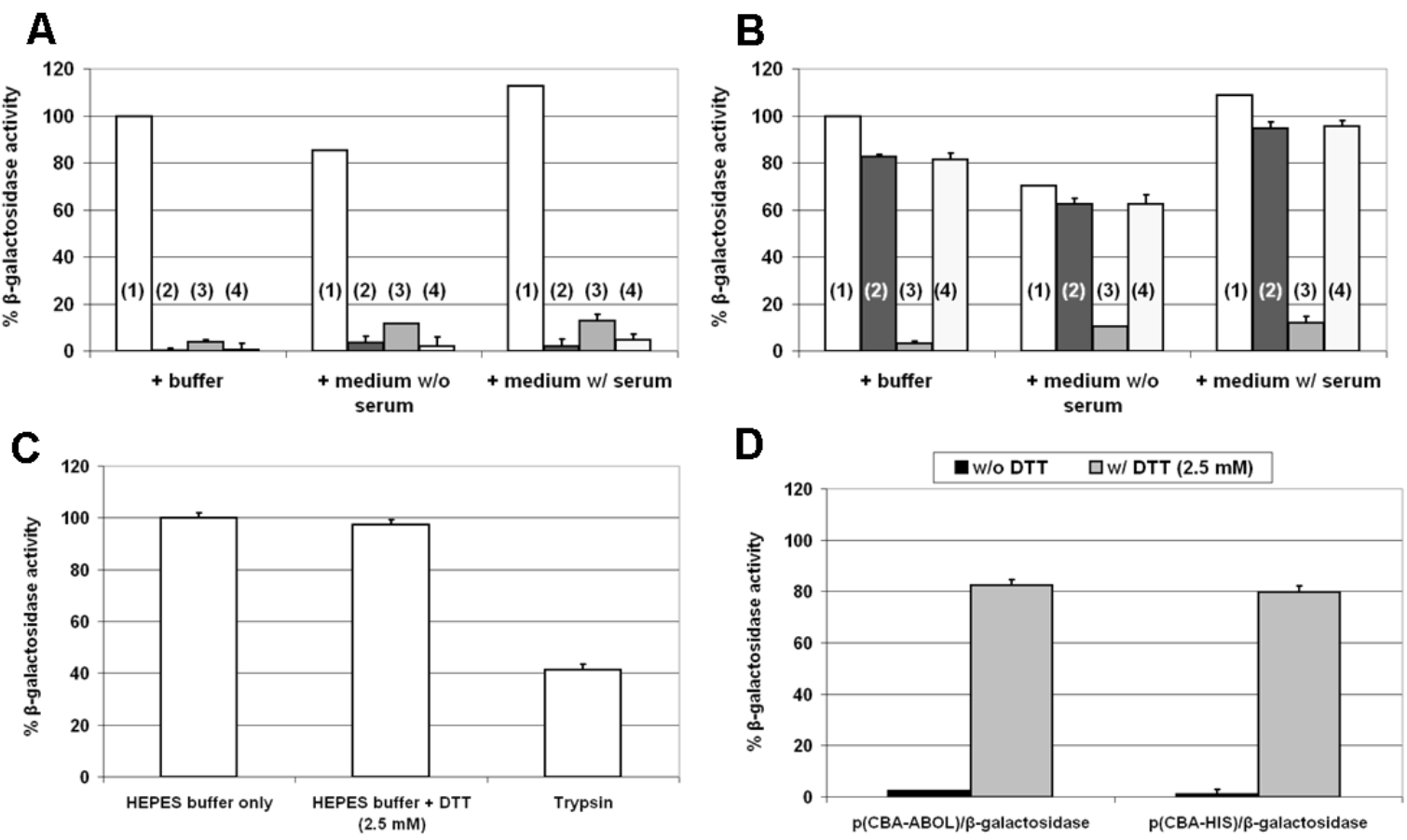

Figure 3.4. (A): Relative $\beta$-galactosidase activities (as determined by ONPG assay) of free enzyme and PAA/ $\beta$-galactosidase nanocomplexes (weight ratio 24/1) in HEPES buffer and in DMEM medium in the absence and presence of $10 \%$ FBS serum. The activity of free enzyme in HEPES buffer was set at 100\%. (B): Relative enzyme activities after addition of DTT to a final concentration of $2.5 \mathrm{mM}$. For (A) and (B): (1): free $\beta$-galactosidase in HEPES buffer solution, (2): $p(C B A-A B O L) / \beta$-galactosidase nanoparticles, (3): $p$ (BAP-ABOL)/ $\beta$-galactosidase nanoparticles, (4): $p(C B A-H I S) / \beta$-galactosidase nanoparticles, (C): Effect of the presence of $2.5 \mathrm{mM}$ DTT (second bar) and trypsin (third bar) on the activity of free $\beta$-galactosidase in HEPES buffer solution. (D): Final enzyme activities of PAA/ $\beta$-galactosidase nanocomplex solutions (weight ratio 24/1) that were incubated with trypsin during $30 \mathrm{~min}$, followed by isolation of the nanocomplexes by centrifugation and redissolution in HEPES buffer in the absence and presence of $2.5 \mathrm{mM}$ DTT.

As is shown in Figure 3.4A, the activity of free $\beta$-galactosidase is almost the same in HEPES buffer and in cell-free solutions akin to those used in the in vitro cellular experiments, i.e. serum-free DMEM medium, DMEM medium with $10 \% \mathrm{FBS}$, whereas the $\beta$-galactosidase activity is almost completely suppressed in PAA/ $\beta$-galactosidase nanoparticles. These results suggest that encapsulation of $\beta$-galactosidase in PAA nanoparticles can prevent the enzyme to display its activity in an extracellular environment. However, after addition of DTT a strong recovery of enzymatic activity (up to $96 \%)$ is observed for the SS-PAA formulations $p(C B A-A B O L)$ and $p(C B A-H I S)$, whereas no significant increase in activity is observed for $p(B A P-A B O L)$ samples containing the polymer vector lacking the disulfide linkages (Figure 3.4B). In a separate control experiment it was confirmed that the presence of $2.5 \mathrm{mM}$ DTT has no influence on the activity of free $\beta$-galactosidase (Figure $3.4 \mathrm{C}$ ), as was indicated by Anfinsen et al. since the 
enzyme lacks disulfide bridges [49]. In contrast, the activity of $\beta$-galactosidase was strongly reduced (to 40\%, Figure 3.4C) when the free enzyme was exposed for 30 min to a $200 \mathrm{ng} / \mathrm{ml}$ solution of trypsin, a digestive protease enzyme that compromises the $\beta$-galactosidase structural integrity [42]. However, Figure 3.4D shows that encapsulation of $\beta$-galactosidase in the polymeric nanoparticles protects the enzyme from trypsin hydrolysis. SS-PAA/ $\beta$-galactosidase nanoparticles that were isolated after trypsin treatment and redissolved in HEPES buffer release $\beta$-galactosidase with almost completely recovered enzymatic activity (83\%) after addition of $2.5 \mathrm{mM}$ DTT. This percentage of recovery of enzyme activity is similar to that found for fresh SS-PAA/ $\beta$-galactosidase nanoparticles that were directly subjected to $2.5 \mathrm{mM}$ DTT in HEPES buffer (Figure 3.4B).

These experiments show that the $\beta$-galactosidase activity in the SS-PAA nanoparticles is almost completely inhibited, even in solutions similar to those used in the in vitro cellular experiments. The results suggest that encapsulation in the SS-PAA polymers will prevent the enzyme to display its activity in the extracellular environment, but once the nanoparticle is internalized by the cell $\beta$-galactosidase activity will be almost complete recovered due to the rapid cleavage of the disulfide linkages of the polymer backbone. This bioresponsive off-on switching of the enzymatic activity in these nanoparticles is a promising property for minimizing off-target effects in targeting delivery.

\subsection{Effect of environmental acidification on the nanoparticles}

Since electrostatic interactions between the positively-charged polymer and the negatively-charged protein are the main driving force for the self assembly into the nanoparticles, it can be anticipated that a decrease in $\mathrm{pH}$, as is occurring during endosomal acidification, will also influence the stability of the nanoparticles. On one hand, a decrease of the $\mathrm{pH}$ will lead to a decrease of negative charge on the protein, but on the other hand, the degree of protonation of the PAAs will be increased. Therefore there is a delicate balance between these effects, but it may be expected that the decrease of overall negative charge on the protein is the dominating factor, since there is already an excess of positive charge present in the nanoparticles at $\mathrm{pH}$ 7.4. Thus, a decrease of the $\mathrm{pH}$ will lead to destabilization and eventually release of the protein from the nanocomplexes. DLS measurements show that the SS-PAA/ $\beta$-galactosidase nanoparticles significantly increase in size from ca. $100-130 \mathrm{~nm}$ to more than $300 \mathrm{~nm}$ when the $\mathrm{pH}$ decreases from 7.4 (extracellular pH) to 5.1 (intracellular pH) (Figure 3.5). In contrast, the 
$\mathrm{p}(\mathrm{BAP}-\mathrm{ABOL})$-containing nanoparticles only slightly respond to $\mathrm{pH}$ decrease which may be attributed to the lower flexibility of the $\mathrm{p}(\mathrm{BAP}-\mathrm{ABOL})$ polymer (vide supra). For all three systems, small peaks in size distribution were observed around 25-50 nm when the $\mathrm{pH}$ drops to values lower than $\mathrm{pH} 6.0$ revealing the presence of small aggregates from free $\beta$-galactosidase, as has been checked in a separate experiment. The increase of particle size while decreasing $\mathrm{pH}$ might also be explained by the capacity of PAA polymers to undergo a conformational change from a coiled structure at $\mathrm{pH} 7.4$ to a more extended one when exposed to acidic $\mathrm{pH}$, as has been indicated by Duncan et al. from pulsed-gradient spin-echo NMR and SANS measurements [50-52].

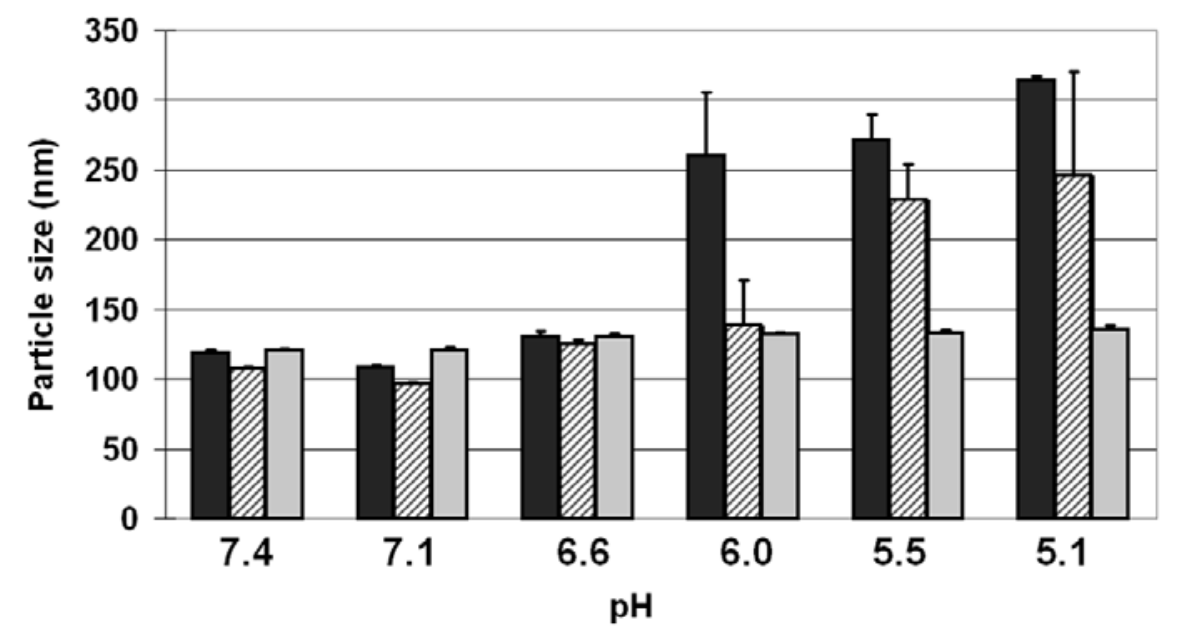

Figure 3.5. Size distributions of PAA/ $\beta$-galactosidase nanoparticles (weight ratio 24/1) during $\mathrm{pH}$ titration of the particle solution from $\mathrm{pH} 7.4$ to $\mathrm{pH} 5.1$ (titration duration: 2 hours), representing the $\mathrm{pH}$ of the extracellular and intracellular environments respectively, using $\mathrm{p}$ (CBA-ABOL) (black bars), $\mathrm{p}(\mathrm{CBA}-\mathrm{HIS})$ (stripped bars), and $\mathrm{p}(\mathrm{BAP}-\mathrm{ABOL}$ ) (grey bars) as polymeric vector.

The release of $\beta$-galactosidase from the PAA/ $\beta$-galactosidase nanoparticles at intracellular $\mathrm{pH}$ after acidification and subsequent centrifugation of the nanoparticles was determined from the supernatant by fluorescence measurements using Alexa Fluor ${ }^{\circledR}$ 488 labeled $\beta$-galactosidase and summarized in Table 3.2, column B. The $\beta$-galactosidase release upon acidification for 30 minutes is in the range of $11-18 \%$, and obviously there is no significant difference between the disulfide-containing polymers and the disulfide-free polymer. These results suggest that endosomal acidification alone may not be sufficient for efficient release of the protein content from the nanocomplexes and that bioreduction of the polymer backbone can importantly contribute to the intracellular release process.

A further interesting aspect is the recovery of the enzymatic activity of $\beta$-galactosidase 
upon destabilization of the system when $\mathrm{pH}$ reaches endosomal values $(\mathrm{pH} \sim 5)$. A control experiment pointed out that pure $\beta$-galactosidase does not have any activity at $\mathrm{pH} 5$ as determined with the ONPG assay (data not shown). Therefore, after acidification of the enzyme-loaded nanoparticles at pH 5 for 30 minutes and subsequent centrifugation, the residual activity of $\beta$-galactosidase in the supernatant solution was determined with the ONPG assay after adjusting the solution to $\mathrm{pH}$ 7.4. Whereas almost no $\beta$-galactosidase activity was retrieved from the $\mathrm{p}(\mathrm{CBA}-\mathrm{ABOL})$ and $\mathrm{p}(\mathrm{CBA}-\mathrm{HIS})$ nanocomplexes, the released protein from the $\mathrm{p}(\mathrm{BAP}-\mathrm{ABOL}$ ) vector still showed residual activity (up to $7 \%$ ). The results indicate a better protection of the enzyme by the $\mathrm{p}(\mathrm{BAP}-\mathrm{ABOL})$ vector during the $\mathrm{pH}$-decrease which corresponds with the DLS results where a smaller increase of particular size was observed while titrating the nanoparticular solution from pH 7.4 to 5.1 .

\subsection{In vitro cellular uptake and cytotoxicity}

To further evaluate the applicability of the PAA vectors for intracellular protein delivery, the delivery and activity of $\beta$-galactosidase were investigated in vitro using COS-7 cells. Profection efficiencies were optimized as a function of polymer/ $\beta$-galactosidase weight ratios, ranging from $3 / 1$ to $36 / 1$.

Cytotoxicity is a relevant factor to assess the safety of vectors. The cytotoxicity of polycations can be caused by polymer aggregation on the cell surface impairing the vital membrane function, as well as interaction with intracellular membranes after internalization, thereby interfering with critical intracellular processes of the cells [53]. In this study, cell viability measurements using the XTT assay after 24 hours of incubation on the cells with these cationic nanosystems showed that cell toxicity was virtually absent; see Figure 3.6A.

The number of cells that have taken up $\beta$-galactosidase, as determined by FACS, after 24 hours of incubation with the polymer/ $\beta$-galactosidase nanocomplexes is more than $80 \%$, as is illustrated in Figure 3.6B. Especially at higher polymer/protein weight ratios where protein is condensed into smaller and more positively-charged nanoparticles, the intracellular uptake is much facilitated. It should be noted that addition of pure $\beta$-galactosidase without polymer did not result in any uptake of this enzyme by the cells (data not shown).

In addition, the profection efficiency of the polymer/ $\beta$-galactosidase nanocomplexes into COS-7 was investigated in vitro. Figure 3.6C depicts the percentages of cells stained intensively blue by the Bluo-gal solution per 100 cells on a slide, expressing enzymatic 
activity in the cells. The median profection efficiency of $\beta$-galactosidase delivered into COS-7 cells was about $80 \%$ and up to $94 \%$ with $\mathrm{p}(\mathrm{CBA}-\mathrm{ABOL})$ at $36 / 1$ polymer/protein weight ratio. These experiments show that PAA/ $\beta$-galactosidase nanoparticles were efficiently taken up inside the cells and release active $\beta$-galactosidase.

Although the Bluo-gal assay permits to estimate the profection efficiency of $\beta$-galactosidase inside cells and is mostly the only assay for evaluation of the protein delivery efficiency that is reported in literature [54, 55], this assay does not provide quantitative information about the enzymatic activity of the delivered protein inside the cells. Therefore, as a supplementary experiment we have attempted to determine the specific enzymatic activity of $\beta$-galactosidase into the COS-7 cells, using an ONPG assay. After incubation of the cells for one hour with PAA/ $\beta$-galactosidase nanocomplexes and incubation in medium for 24 hours, the cells were lysed according to the ONPG procedure and the enzymatic activity was determined. The results given in Figure 3.6D show that about $1 \%$ of the original $\beta$-galactosidase activity as calculated from the enzyme content in the applied nanocomplexes is active in the COS-7 cells.

In the protein activity experiments depicted by the Bluo-gal and ONPG assays, it appeared that the results were not much different for the disulfide-containing polymers, $p(C B A-A B O L)$ and $p(C B A-H I S)$, and the disulfide-free polymer $p(B A P-A B O L)$. This suggests that, under the tested conditions, contrary to our expectations, the intracellular disulfide reduction of the SS-PAAs apparently did not result in more efficient protein release and/or recovery of enzyme activity. 

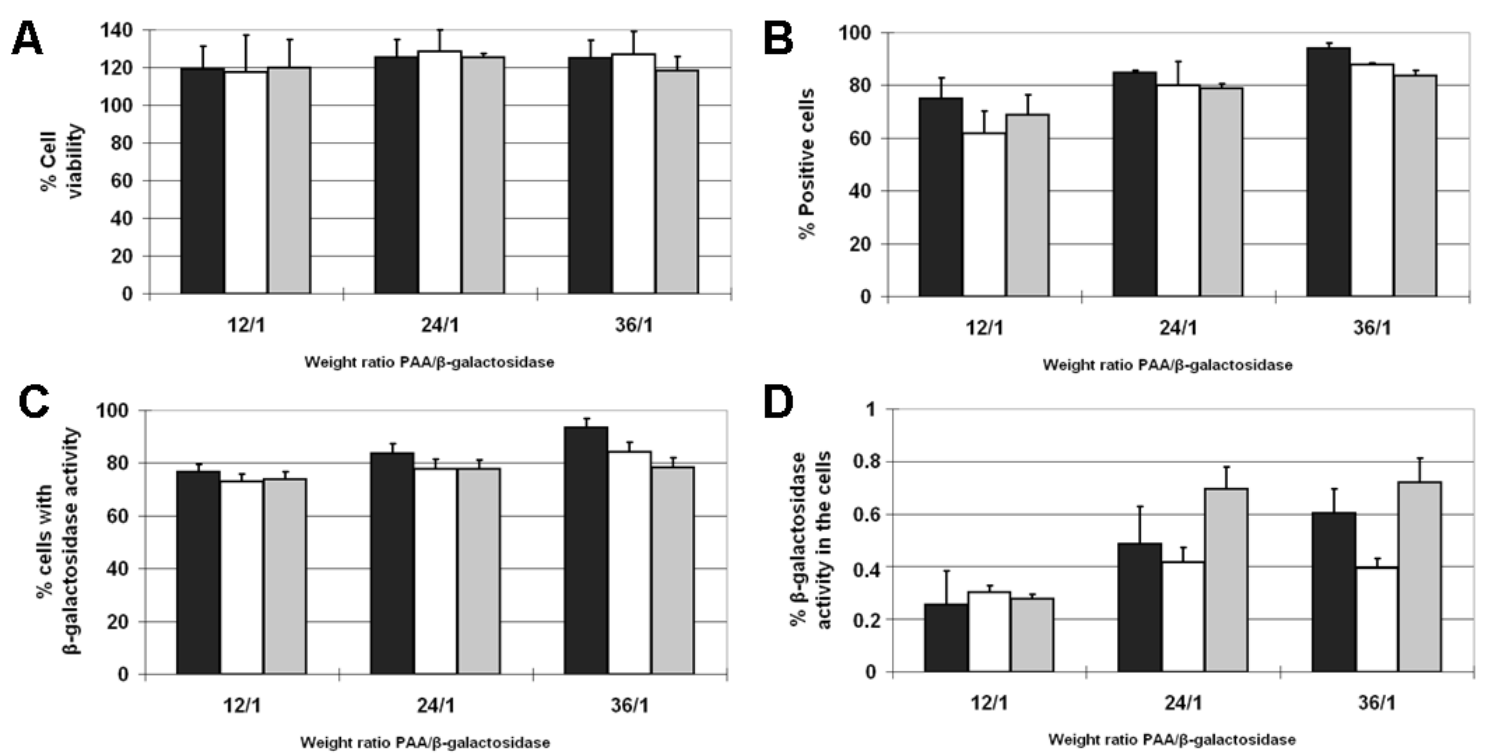

Figure 3.6. Results of the profection efficiency and activity of $\beta$-galactosidase from PAA based nanocomplexes formed at various polymer/ $\beta$-galactosidase weight ratios investigated in vitro using COS-7 cells determined 24 hours after incubation with nanocomplexes containing $1 \mu \mathrm{g}$ $\beta$-galactosidase per well. PAA vectors are $p(C B A-A B O L)$ (black bars), $p(C B A-H I S)$ (white bars), and $p$ (BAP-ABOL) (grey bars). The data is given as mean $\pm S D(n=3)$. A: Cell viabilities as determined by XTT assay. B: Cellular uptake of Alexa Fluor ${ }^{\circledR} 488$ labeled $\beta$-galactosidase as determined by FACS measurements. C: Profection-efficiency in percentage of cells showing $\beta$-galactosidase activity by Bluo-gal assay. D: Quantitative $\beta$-galactosidase enzymatic activity in percentage determined by ONPG assay.

\section{Conclusions}

The three representative examples of the novel family of functionalized linear poly(amidoamine)s, $p(C B A-A B O L), p(C B A-H I S)$, and $p(B A P-A B O L)$, show that this class of polymers have very promising properties to function as vectors for non-toxic and efficient intracellular protein delivery. The synthesis procedure of these polymers is compatible with the use of a variety of functionalized amine monomers, allowing large variation in the structure of the polymers, and tuning of the chemical and biophysical properties that are of significance for efficient protein delivery. It has been shown that the positively-charged PAAs form nanosized complexes with overall negatively-charged $\beta$-galactosidase by a self-assembly process. These nanocomplexes are stable at physiological $\mathrm{pH} 7.4$ for at least several days and efficiently block $\beta$-galactosidase activity in an extracellular environment. Upon acidification of the solution $(\mathrm{pH} \sim 5)$, as occurs after endosomal uptake, the nanocomplexes tend to destabilize as is evidenced form their observed increase in size in DLS experiments. Moreover, for nanocomplexes made from $\mathrm{p}(\mathrm{CBA}-\mathrm{ABOL})$ and $\mathrm{p}(\mathrm{CBA}-\mathrm{HIS})$, containing disulfide linkages in their polymeric backbone, 
fast disintegration and release of the protein payload is observed in reductive solution (2.5 mM DTT), mimicking the intracellular environment, and in in vitro experiments with COS-7 cells. Profection and enzyme activity determinations with COS- 7 cells showed that $\beta$-galactosidase encapsulated in SS-PAA nanoparticles was successfully internalized into cells. After cellular uptake, the protein-containing nanocomplex is dissociated and the protein is released inside the cell with remaining enzymatic activity and excellent cell-viability.

\section{Acknowledgements}

The authors thank Dr. Chao Lin for his assistance with the cell studies, the students Gert-Jan ter Boo and Astrid Hoeppener for their respective synthetic and cell experimental contributions, Mies van Steenbergen for the GPC measurements, Dr. Marc Stuart for the cryo-TEM pictures and Dr. Oya Tagit for her help with the AFM experiments.

This research work is part of the Integrated European project Nanobiopharmaceutics.

\section{References}

[1] C. Borghouts, C. Kunz, B. Groner, Current strategies for the development of peptide-based anti-cancer therapeutics. J. Pept. Sci. 11(11) (2005) 713-726.

[2] C. Krejsa, M. Rogge, W. Sadee, Protein therapeutics: new applications for pharmacogenetics. Nat. Rev. Drug Discov. 5(6) (2006) 507-521.

[3] R. Langer, J. Folkman, Polymers for Sustained-Release of Proteins and Other Macromolecules. Nature 263(5580) (1976) 797-800.

[4] A.K. Pavlou, J.M. Reichert, Recombinant protein therapeutics - success rates, market trends and values to 2010. Nat Biotech 22(12) (2004) 1513-1519.

[5] S. Stolnik, K. Shakesheff, Formulations for delivery of therapeutic proteins. Biotechnol. Lett. 31(1) (2009) 1-11.

[6] J.E. Talmadge, The Pharmaceutics and Delivery of Therapeutic Polypeptides and Proteins. Adv. Drug Delivery Rev. 10(2-3) (1993) 247-299.

[7] N.G. Pattrick, S.C.W. Richardson, M. Casolaro, P. Ferruti, R. Duncan, Poly(amidoamine)-mediated intracytoplasmic delivery of ricin A-chain and gelonin. J Control Release 77(3) (2001) 225-232.

[8] C. O. Weill, S. Biri, A. Adib, P. Erbacher, A practical approach for intracellular protein delivery. Cytotechnology 56(1) (2008) 41-48.

[9] M.D. Chavanpatil, A. Khdair, J. Panyam, Nanoparticles for cellular drug delivery: Mechanisms and factors influencing delivery. J. Nanosci. Nanotechnol. 6(9-10) (2006) 2651-2663.

[10] J. Panyam, V. Labhasetwar, Biodegradable nanoparticles for drug and gene delivery to cells and tissue. Adv. Drug Delivery Rev. 55(3) (2003) 329-347.

[11] P. Calvo, C. RemunanLopez, J.L. VilaJato, M.J. Alonso, Novel hydrophilic chitosan-polyethylene oxide nanoparticles as protein carriers. J. Appl. Polym. Sci. 63(1) (1997) 125-132.

[12] A. Harada, K. Kataoka, Novel polyion complex micelles entrapping enzyme molecules in the core: Preparation of narrowly-distributed micelles from lysozyme and poly(ethylene glycol)-poly(aspartic acid) block copolymer in aqueous medium. Macromolecules 31(2) (1998) 288-294. 
[13] A. Jintapattanakit, V.B. Junyaprasert, S. Mao, J. Sitterberg, U. Bakowsky, T. Kissel, Peroral delivery of insulin using chitosan derivatives: A comparative study of polyelectrolyte nanocomplexes and nanoparticles. Int. J. Pharm. 342(1-2) (2007) 240-249.

[14] Y. Lee, S. Fukushima, Y. Bae, S. Hiki, T. Ishii, K. Kataoka, A protein nanocarrier from charge-conversion polymer in response to endosomal pH. J. Am. Chem. Soc. 129(17) (2007) 5362-5363.

[15] P. Ferruti, M.A. Marchisio, R. Barbucci, Synthesis, Physicochemical Properties and Biomedical Applications of Poly(Amido-Amine)S. Polymer 26 (1985) 1336-1348.

[16] P. Ferruti, M.A. Marchisio, R. Duncan, Poly(amido-amine)s: Biomedical applications. Macromol. Rapid Commun. 23(5-6) (2002) 332-355.

[17] J.D. Eichman, A.U. Bielinska, J.F. Kukowska-Latallo, J.R. Baker Jr, The use of PAMAM dendrimers in the efficient transfer of genetic material into cells. Pharm Sci Tech Today 3(7) (2000) 232-245.

[18] E. Ranucci, G. Spagnoli, P. Ferruti, D. Sgouras, R. Duncan, Poly(amidoamine)s with potential as drug carriers: degradation and cellular toxicity. J Biomater Sci Polym Ed 2(4) (1991) 303-315.

[19] O. Boussif, F. Lezoualch, M.A. Zanta, M.D. Mergny, D. Scherman, B. Demeneix, J.P. Behr, A Versatile Vector for Gene and Oligonucleotide Transfer into Cells in Culture and in-Vivo Polyethylenimine. Proc. Natl. Acad. Sci. U. S. A. 92(16) (1995) 7297-7301.

[20] C.X. Wu, S.L. Lo, J. Boulaire, M.L.W. Hong, H.M. Beh, D.S.Y. Leung, S. Wang, A peptide-based carrier for intracellular delivery of proteins into malignant glial cells in vitro. J Control Release 130(2) (2008) 140-145.

[21] P. Ferruti, E. Ranucci, F. Bignotti, L. Sartore, P. Bianciardi, M.A. Marchisio, Degradation Behavior of Ionic Stepwise Polyaddition Polymers of Medical Interest. J. Biomater. Sci.-Polym. Ed. 6(9) (1995) 833-844.

[22] P. Ferruti, E. Ranucci, L. Sartore, F. Bignotti, M.A. Marchisio, P. Bianciardi, F.M. Veronese, Recent Results on Functional Polymers and Macromonomers of Interest as Biomaterials or for Biomaterial Modification. Biomaterials 15(15) (1994) 1235-1241.

[23] J. Franchini, E. Ranucci, P. Ferruti, Synthesis, physicochemical properties, and preliminary biological characterizations of a novel amphoteric agmatine-based poly(amidoamine) with RGD-like repeating units. Biomacromolecules 7(4) (2006) 1215-1222.

[24] N. Lavignac, M. Lazenby, J. Franchini, P. Ferruti, R. Duncan, Synthesis and preliminary evaluation of poly(amidoamine)-melittin conjugates as endosomolytic polymers and/or potential anticancer therapeutics. Int. J. Pharm. 300(1-2) (2005) 102-112.

[25] N. Lavignac, J.L. Nicholls, P. Ferruti, R. Duncan, Poly(amidoamine) Conjugates Containing Doxorubicin Bound via an Acid-Sensitive Linker. Macromol. Biosci. 9(5) (2009) 480-487.

[26] S.C.W. Richardson, N.G. Pattrick, Y.K.S. Man, P. Ferruti, R. Duncan, Poly(amidoamine)s as potential nonviral vectors: Ability to form interpolyelectrolyte complexes and to mediate transfection in vitro. Biomacromolecules 2(3) (2001) 1023-1028.

[27] S.C.W. Richardson, N.G. Pattrick, N. Lavignac, P. Ferruti, R. Duncan, Intracellular fate of bioresponsive poly(amidoamine)s in vitro and in vivo. J Control Release 142(1) (2010) 78-88.

[28] S. Swaminathan, R. Cavalli, F. Trotta, P. Ferruti, E. Ranucci, I. Gerges, A. Manfredi, D. Marinotto, P.R. Vavia, In vitro release modulation and conformational stabilization of a model protein using swellable polyamidoamine nanosponges of beta-cyclodextrin. J. Incl. Phenom. Macrocycl. Chem. 68(1-2) (2010) 183-191.

[29] R. Cavalli, A. Bisazza, R. Sessa, L. Primo, F. Fenili, A. Manfredi, E. Ranucci, P. Ferruti, Amphoteric Agmatine Containing Polyamidoamines as Carriers for Plasmid DNA In Vitro and In Vivo Delivery. Biomacromolecules 11(10) (2010) 2667-2674.

[30] A. Bernkop-Schnürch, Thiomers: A new generation of mucoadhesive polymers. Adv. Drug Delivery Rev. 57(11) (2005) 1569-1582.

[31] C. Lin, J.F.J. Engbersen, The role of the disulfide group in disulfide-based polymeric gene carriers. Expert Opin. Drug Deliv. 6(4) (2009) 421-439.

[32] F. H. Meng, W. E. Hennink, Z. Zhong, Reduction-sensitive polymers and bioconjugates for biomedical applications. Biomaterials 30(12) (2009) 2180-2198 
[33] K.C. Rajender, W.L. Frederick, H.K. Michael, M.B. David, G.B.R. Robert, R. Daniel, Plasma cysteine, cystine, and glutathione in cirrhosis. Gastroenterology 87(4) (1984) 770-776.

[34] C. Lin, C.-J. Blaauboer, M.M. Timoneda, M.C. Lok, M. van Steenbergen, W.E. Hennink, Z. Zhong, J. Feijen, J.F.J. Engbersen, Bioreducible poly(amido amine)s with oligoamine side chains: Synthesis, characterization, and structural effects on gene delivery. J Control Release 126(2) (2008) 166-174.

[35] C. Lin, Z. Zhong, M.C. Lok, X. Jiang, W.E. Hennink, J. Feijen, J.F.J. Engbersen, Linear poly(amido amine)s with secondary and tertiary amino groups and variable amounts of disulfide linkages: Synthesis and in vitro gene transfer properties. J Control Release 116(2) (2006) 130-137.

[36] C. Lin, Z. Zhong, M.C. Lok, X. Jiang, W.E. Hennink, J. Feijen, J.F.J. Engbersen, Random and block copolymers of bioreducible poly(amido amine)s with high- and low-basicity amino groups: Study of DNA condensation and buffer capacity on gene transfection. J Control Release 123(1) (2007) 67-75.

[37] C. Lin, Z.Y. Zhong, M.C. Lok, X.L. Jiang, W.E. Hennink, J. Feijen, J.F.J. Engbersen, Novel bioreducible poly(amido amine)s for highly efficient gene delivery. Bioconjugate Chem. 18(1) (2007) 138-145.

[38] M.A. Mateos-Timoneda, M.C. Lok, W.E. Hennink, J. Feijen, J.F.J. Engbersen, Poly(amido amine)s as gene delivery vectors: Effects of quaternary nicotinamide moieties in the side chains. ChemMedChem 3(3) (2008) 478-486.

[39] R.H. Jacobson, X.J. Zhang, R.F. DuBose, B.W. Matthews, Three-dimensional structure of [beta]-galactosidase from E. coli. Nature 369(6483) (1994) 761-766.

[40] K. Wallenfels, R. Weil, D.B. Paul, The Enzymes, Vol. Volume 7, Academic Press, 1972, pp. 617-663.

[41] M. Ladero, M.T. Perez, A. Santos, F. Garcia-Ochoa, Hydrolysis of lactose by free and immobilized beta-galactosidase from Thermus sp strain T2. Biotechnol. Bioeng. 81(2) (2003) 241-252.

[42] D. Zahner, R. Hakenbeck, The Streptococcus pneumoniae Beta-Galactosidase Is a Surface Protein. J. Bacteriol. 182(20) (2000) 5919-5921.

[43] G. Lakebakaar, S. McKavanagh, M. Redshaw, T. Wood, J.A. Summerfield, E. Elias, Serum Immunoreactive Trypsin Concentration after a Lundh Meal - Its Value in the Diagnosis of Pancreatic Disease. J. Clin. Pathol. 32(10) (1979) 1003-1008.

[44] J.Y. Cherng, P. vandeWetering, H. Talsma, D.J.A. Crommelin, W.E. Hennink, Effect of size and serum proteins on transfection efficiency of poly((2-dimethylamino)ethyl methacrylate)-plasmid nanoparticles. Pharm Res 13(7) (1996) 1038-1042.

[45] D.A. Scudiero, R.H. Shoemaker, K.D. Paull, A. Monks, S. Tierney, T.H. Nofziger, M.J. Currens, D. Seniff, M.R. Boyd, Evaluation of a Soluble Tetrazolium Formazan Assay for Cell-Growth and Drug Sensitivity in Culture Using Human and Other Tumor-Cell Lines. Cancer Res. 48(17) (1988) 4827-4833.

[46] A. Verma, J.M. Simard, J.W.E. Worrall, V.M. Rotello, Tunable reactivation of nanoparticle-inhibited beta-galactosidase by glutathione at intracellular concentrations. J. Am. Chem. Soc. 126(43) (2004) 13987-13991.

[47] D.W. Pack, A.S. Hoffman, S. Pun, P.S. Stayton, Design and development of polymers for gene delivery. Nat Rev Drug Discov 4(7) (2005) 581-593.

[48] D.V. Schaffer, N.A. Fidelman, N. Dan, D.A. Lauffenburger, Vector unpacking as a potential barrier for receptor-mediated polyplex gene delivery. Biotechnol. Bioeng. 67(5) (2000) 598-606.

[49] G.R. Craven, E. Steers, C.B. Anfinsen, Structural Studies on Beta-Galactosidase. Fed Proc 23(2P1) (1964) 263-\&.

[50] P.C. Griffiths, Z. Khayat, S. Tse, R.K. Heenan, S.M. King, R. Duncan, Studies on the mechanism of interaction of a bioresponsive endosomolytic polyamidoamine with interfaces. 1. Micelles as model surfaces. Biomacromolecules 8(3) (2007) 1004-1012.

[51] P.C. Griffiths, A. Paul, Z. Khayat, K.W. Wan, S.M. King, I. Grillo, R. Schweins, P. Ferruti, J. Franchini, R. Duncan, Understanding the mechanism of action of poly(amidoamine)s as endosomolytic polymers: Correlation of physicochemical and biological properties. Biomacromolecules 5(4) (2004) 1422-1427. 
[52] Z. Khayat, P.C. Griffiths, I. Grillo, R.K. Heenan, S.M. King, R. Duncan, Characterising the size and shape of polyamidoamines in solution as a function of $\mathrm{pH}$ using neutron scattering and pulsed-gradient spin-echo NMR. Int. J. Pharm. 317(2) (2006) 175-186.

[53] D. Fischer, T. Bieber, Y.X. Li, H.P. Elsasser, T. Kissel, A novel non-viral vector for DNA delivery based on low molecular weight, branched polyethylenimine: Effect of molecular weight on transfection efficiency and cytotoxicity. Pharm. Res. 16(8) (1999) 1273-1279.

[54] B.T.F. van der Gun, A. Monami, S. Laarmann, T. Rasko, K. Slaska-Kiss, E. Weinhold, R. Wasserkort, L. de Leij, M.H.J. Ruiters, A. Kiss, P.M.J. McLaughlin, Serum insensitive, intranuclear protein delivery by the multipurpose cationic lipid SAINT-2. J Control Release 123(3) (2007) 228-238.

[55] G.Y. Wu, C.H. Wu, Receptor-Mediated Invitro Gene Transformation by a Soluble DNA Carrier System. J. Biol. Chem. 262(10) (1987) 4429-4432. 


\section{A protein nanocarrier from charge-reversal poly(amidoamine)s in response to endosomal pH}

Grégory Coué1 ${ }^{1}$, Christian Freese ${ }^{2,3}$, Ronald E. Unger2,3, C. James Kirkpatrick ${ }^{2,3}$ and Johan F.J. Engbersen 1

1 Department of Biomedical Chemistry, MIRA Institute for Biomedical Technology \& Technical Medicine, Faculty of Science and Technology, University of Twente, P.0. Box 217, 7500 AE Enschede, the Netherlands

2REPAIR-lab, Institute of Pathology, University Medical Center of the Johannes Gutenberg University, Langenbeckstrasse 1, 55101 Mainz, Germany

${ }_{3}$ European Institute of Excellence on Tissue Engineering and Regenerative Medicine, Mainz, Germany

Part of this chapter has been published: G. Coué, C. Freese, R.E. Unger, C.J. Kirkpatrick, and J.F.J. Engbersen, A protein nanocarrier from charge-reversal poly(amidoamine)s in response to endosomal pH, submitted

Abstract: Effective intracellular vectors were developed for delivery of proteins that have a net positive charge at neutral $\mathrm{pH}$, using bioreducible disulfide-containing poly(amidoamine)s (SS-PAAs) with negatively-charged citraconic side groups giving charge-reversal upon $\mathrm{pH}$ decrease. At neutral $\mathrm{pH}$, these water-soluble and linear polymers efficiently self-assemble with cationic proteins into nanocomplexes by charge attraction. The citraconic amide group functions as a $\mathrm{pH}$-sensitive charge-masking group for primary amines and is hydrolyzed by intramolecular catalysis at acidic $\mathrm{pH}$ under the formation of the protonated amine group. Intracellular-mimicking protein release from the particles is triggered by the inversion of protein-polymer interaction at $\mathrm{pH} 5$ (endosomal $\mathrm{pH}$ ) due to the charge-reversal of the citraconic side group, and by the reduction of polymer disulfide linkages, causing polymer degradation. Cell-internalization and cytotoxicity experiments showed that the SS-PAA-based nanocomplexes were essentially non-toxic, and that 
lysozyme is successfully internalized into Huvec cells. The results indicate that charge-reversal SS-PAAs have excellent properties as potent and non-toxic intracellular delivery systems for cationic proteins.

\section{Introduction}

Smart polymers responding to external signals, like biosignals, changes in reduction potential or $\mathrm{pH}$, are very attractive in the drug delivery field requiring selective controlled release. One of the functions of $\mathrm{pH}$-sensitive polymers can be that they act as a buffer system upon endosomal acidification and that their increasingly cationic charge facilitates the endosomal escape of drugs by disruptive membrane interactions and/or increase of the local osmotic pressure [1, 2]. Another type of $\mathrm{pH}$-sensitive polymers uses acetal, hydrazone or orthoester linkages in their backbone [3-5] to enable degradation in the endosome. However the drug release in response to the $\mathrm{pH}$ in these systems is relatively slow. More active and prompt responses to a small decrease in $\mathrm{pH}$ were obtained by inclusion of derivatives from cis-1,2-cyclohexanedicarboxylic anhydride or citraconic anhydride in the polymer providing a specific release in the early endosome [6, 7].

Citraconic anhydride is an $\alpha$-methyl derivative of maleic anhydride, which has been used to mask the positive charge of proteins [8-12]. After reaction of citraconic anhydride with a primary amine, a citraconic amide derivative is formed that has a negative charge owing to the carboxylate group at the end. The citraconic amide derivative is stable at neutral and basic $\mathrm{pH}$, but it becomes unstable at acidic $\mathrm{pH}$ due to intramolecular catalyzed hydrolysis of the amide group, which promptly degrades back into its cationic primary amine form within less than three hours [13]. It has been reported that the citraconic amide function hydrolyses around $\mathrm{pH} 5$ which corresponds with the eventual endosomal $\mathrm{pH}$ [13]. Because the amide hydrolysis is directly related to charge-inversion of the side chain of the polymer, it could also provide an abrupt change in the interaction with counter-ions and oppositely charged species in the endosomes. Kataoka et al. developed a block copolymer with combtype side groups of citraconic amide as a protein nanocarrier that releases its cargo in the endosomes by the repulsive electrostatic forces generated as a consequence of charge inversion of the side groups of the polymer [6, 14-16]. The group of Park used citraconylated amide linkages to be cleaved under acidic conditions, resulting in the recovery of positively-charged amine groups that enhance the intracellular delivery of quantum dot nanoparticles [17]. 
In this study, we have utilized the principle of charge-reversal in citraconic amide functionalized poly(amidoamine)s for efficient intracellular delivery of cationic proteins.

Poly(amidoamine)s (PAAs) can be easily synthesized by Michael-type polyaddition of primary or bis-secondary amines to bis(acrylamide)s. These polymers are water-soluble, biodegradable and biocompatible, with less cytotoxicity than other usual polycationic vectors [1, 18-20]. PAAs have the advantage to degrade to oligomeric products in aqueous media within days or weeks, depending on their structure [21, 22]. As previously shown by the groups of Ferruti and Duncan, especially for amphoteric PAAs carrying carboxyl groups as side substituents, these polymers have high potential in biomedical applications [23-25]. PAAs have been found to be particularly suitable for a use as intracytoplasmic and endosomolytic vectors for the delivery of anticancer drugs [26, 27] and proteins $[28,29]$.

Recently, we have developed in our group novel linear poly(amidoamine)s containing repetitive disulfide linkages in their backbone (SS-PAAs) that worked as highly efficient intracellularly degradable protein delivery vectors. In previous work, we have shown that the polycationic $p(C B A-A B O L)$, an SS-PAA composed of cystamine bisacrylamide and 4-aminobutanol, was capable to condense negatively-charged $\beta$-galactosidase into nanoscaled, positively-charged and non-toxic nanocomplexes, and that with those nanoparticles enzymatically active protein was successfully internalized into COS-7 cells $[30,31]$. The SS-PAAs have also shown to be efficient vectors for gene delivery, resulting in transfection efficiencies much higher than those of their counterparts lacking disulfide linkages, and the reference polymer, polyethylenimine (PEI) [32-36]. Moreover, these water-soluble, linear SS-PAAs are relatively stable in extracellular medium but, due to the presence of the repetitive disulfide linkages, they are prone to fast degradation in the reductive intracellular environment [37-39]. This property can be used in systems that should be relatively stable during transport outside the cell but should disintegrate in fragments of low molecular weight after uptake into the target cells.

In this work, the favorable physicochemical and biological properties of the SS-PAA polymers are explored to develop efficient carriers for the intracellular delivery of proteins that are positively charged at neutral pH. For this purpose, two different SS-PAA derivatives of citraconic amide, and one SS-PAA derivative of succinic anhydride as a reference polymer, were synthesized. These polymers have negative charges in the side groups owing to the carboxylate groups at the end of the citraconic or succinic amide groups, allowing the formation of nanosized polyelectrolyte complexes by 
charge-attraction with cationic proteins such as lysozyme. In the intracellular environment, the citraconic amide functionalized polymer/protein complexes are expected to become destabilized by both charge-reversal of the side groups of the polymer, as depicted in Scheme 4.1, and by bioreduction of the disulfide linkages in the polymer backbone. However, the succinic amide functionalized analog is stable for amide hydrolysis and therefore is only sensitive for bioreduction.

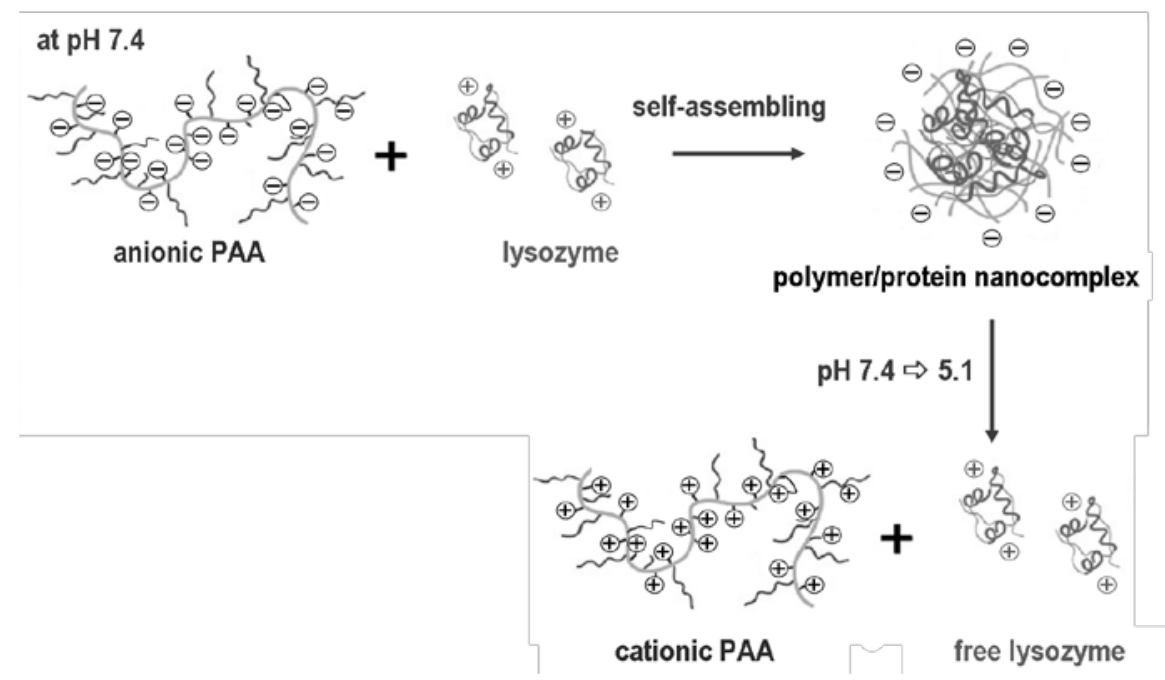

Scheme 4.1. Self-assembly scheme of nanocomplexes at neutral pH by charge attraction between positively-charged protein, in the present case lysozyme, and negatively-charged polymer, and lysozyme release at intracellular $\mathrm{pH}$ due to polymer charge-reversal and polymer-protein repulsion.

Whereas most approaches to cell transfection agents rely on the use of positively charged carriers to ensure cellular uptake, the work of Mirkin et al. on DNA-coated oligonucleotide-gold nanoparticle conjugate has shown that also negatively charged entities can readily enter cells [40-43]. Therefore, it is of additional interest to evaluate the negatively charged SS-PAA/lysozyme nanoparticles for their cellular uptake, as well as intracellular stability and cytotoxicity.

\section{Materials and methods}

\subsection{Materials}

Lysozyme from chicken egg white ( 70,000 units/mg) was obtained from Fluka. Labeling of lysozyme with Alexa Fluor ${ }^{\circledR} 488$ carboxylic acid TFP ester was performed according to the procedure provided by the supplier (Invitrogen). All monomers, mono-Boc-protected diaminobutane (MBDAB, Fluka) and N,N'-cystaminebisacrylamide (CBA, Polysciences) were purchased in the highest purity and used without further purification. Citraconic 
anhydride ( $\geq 98 \%$, Fluka), succinic anhydride ( $\geq 99 \%$, Aldrich), cesium carbonate $\left(\mathrm{Cs}_{2} \mathrm{CO}_{3}\right.$, Aldrich), 4-(2-hydroxyethyl)-1-piperazineethanesulfonic acid (HEPES, Sigma), dithiothreitol (DTT, Sigma-Aldrich), trifluoroacetic acid (TFA, Aldrich), and methanol (MeOH, Biosolve) were used as received. Deionized water (DI water) was obtained from a MilliQ-water purification system (Millipore, France).

\subsection{Monomer and polymer synthesis}

\subsubsection{Synthesis of 2,2-bis(acrylamido)acetic acid}

A solution of glyoxylic acid (100.6 ml 50\% solution, $0.91 \mathrm{~mol})$ in $96 \%$ sulfuric acid $(110 \mathrm{ml}$, $2.058 \mathrm{~mol}$ ) was added drop-wise to a mixture of acrylonitrile $(150 \mathrm{ml}, 2.278 \mathrm{~mol})$ and copper acetate $(0.3 \mathrm{~g})$ contained in a $500 \mathrm{ml}$ three-necked glass flask maintained under nitrogen and maintained in the range $15-30^{\circ} \mathrm{C}$ using a thermostated bath. After this addition, the temperature was allowed to adjust to room temperature and the mixture was maintained under stirring for further 4 hours. The resulting yellowish, viscous solution was then diluted with cold water $(300 \mathrm{ml})$ to give a white precipitate which was left at $4^{\circ} \mathrm{C}$ overnight. After this time, the raw solid was recovered by filtration and purified by dissolving in the stoechiometric amount of sodium hydroxide (3 $\mathrm{M})$, and re-precipitated by the addition of the stoechiometric amount of aqueous $\mathrm{HCl}(37 \%)$. The white precipitate was placed at $4^{\circ} \mathrm{C}$ until being recovered by filtration. The product was washed three times by pouring into cold water $\left(200 \mathrm{ml}, 0^{\circ} \mathrm{C}\right)$ and recovering by filtration, and dried to constant weight at $25^{\circ} \mathrm{C}$ under reduced pressure. Yield $=108.2 \mathrm{~g}(60 \%)$.

$1 \mathrm{H} \operatorname{NMR}\left(\mathrm{D}_{2} \mathrm{O}\right) \delta(\mathrm{ppm})=3.2-4.7(2 \mathrm{H}, \mathrm{NH}) ; 5.67(1 \mathrm{H},=\mathrm{CH}) ; 6.38,6.15(1 \mathrm{H}$ each, $=\mathrm{CH} 2)$ $5.3(1 \mathrm{H}, \mathrm{CH}-\mathrm{COOH}) ; 8.92(2 \mathrm{H}, \mathrm{N}-\mathrm{CH}-\mathrm{N})$.

Titrimetric analysis: theoretical for a molecular weight $198.18 \mathrm{~g} / \mathrm{mol}: 5.05 \mathrm{ml} / \mathrm{g}$ of $1 \mathrm{M}$ $\mathrm{NaOH}$; found: $5.00 \mathrm{ml} / \mathrm{g}$.

\subsubsection{Synthesis of $p(C B A-M B D A B)$ and $p(C B A / B A C-M B D A B) S S-P A A s$}

A series of bioreducible SS-PAA polymers with repetitive disulfide linkages in their main chain were synthesized via Michael polyaddition of MBDAB as specific amine monomer to CBA in equimolar monomeric ratios. Since the addition polymerization is a stepwise process, equal monomer ratios were used in the synthesis in order to obtain polymer chains of highest theoretical molecular weight. In a typical experiment, CBA (2.63 g, 10 mmol) and $\operatorname{MBDAB}(1.94 \mathrm{~g}, 10 \mathrm{mmol})$ were added into a brown reaction flask and dissolved in $\mathrm{MeOH} / \mathrm{DI}$ water mixture $(5 \mathrm{ml}, 4 / 1, \mathrm{v} / \mathrm{v})$. Polymerization was carried out in 
the dark at $45^{\circ} \mathrm{C}$ under nitrogen atmosphere. The reaction mixture became homogeneous in less than two hours. The reaction was allowed to proceed for 10 days yielding to a viscous solution. During the polymerization a gradual increase in viscosity was observed. In all cases, gelation did not occur. In a final stage, $10 \mathrm{~mol} \%$ excess $\operatorname{MBDAB}(0.194 \mathrm{~g}, 1 \mathrm{mmol})$ was added to the reaction mixture in order to consume any unreacted acrylamide groups after polymerization and ensure that all potentially toxic acrylamide end groups were consumed, and that polymers contained only amino end groups. Stirring was continued for two days at $45^{\circ} \mathrm{C}$. Subsequently, the resulting solution was diluted with $30 \mathrm{ml}$ DI water, acidified with $4 \mathrm{M} \mathrm{HCl}$ aqueous solution to $\mathrm{pH} \sim 5$, and then purified and isolated by ultrafiltration operation ( $3 \mathrm{~kg} / \mathrm{mol}$ cut-off) with filtrated acidic $\mathrm{DI}$ water ( $\mathrm{pH} \sim 5$ ), followed by freeze-drying.

Similar polymers were synthesized via Michael polyaddition of MBDAB as specific amine monomer to equal ratios of $\mathrm{CBA}$ and $\mathrm{BAC}$ in equimolar monomeric ratios. The resultant polymer has acetic acid moieties on its backbone providing negative charges at neutral $\mathrm{pH}$.

\subsubsection{Synthesis of $p(C B A-D A B)$ and $p(C B A / B A C-D A B) S S-P A A s$}

Deprotection of Boc-protected amino groups of the side chain of the polymers was performed in a mixture of TFA/MeOH overnight and yielded to polymers with primary amino and hydroxyl groups in the side chains. After deprotection, the solution was diluted with $\mathrm{DI}$ water and adjusted to $\mathrm{pH} \sim 5$ using a $4 \mathrm{M} \mathrm{NaOH}$ solution. The resulting polymer solution was purified by ultrafiltration ( $3 \mathrm{~kg} / \mathrm{mol}$ cut-off) with acidified DI water $(\mathrm{pH} \sim 5$ ) and recovered as a white powder after lyophilization. The p(CBA-DAB) and $\mathrm{p}(\mathrm{CBA} / \mathrm{BAC}-\mathrm{DAB})$ polymers were collected in their $\mathrm{HCl}$-salt form as a solid after freeze-drying.

\subsubsection{Synthesis of $p(C B A-C A), p(C B A / B A C-C A)$, and $p(C B A-S A)$ SS-PAAs}

$\mathrm{p}(\mathrm{CBA}-\mathrm{DAB})\left(50 \mathrm{mg} ; 0.13 \mathrm{mmol}\right.$ of primary amine) and $\mathrm{Cs}_{2} \mathrm{CO}_{3}$ (424 mg, $1.3 \mathrm{mmol}$ ) were dissolved in $\mathrm{MeOH}(5 \mathrm{ml})$, and citraconic anhydride (145 $\mu \mathrm{l}, 1.04 \mathrm{mmol})$ was added dropwise into the solution in 5 equal fractions and stirred overnight at room temperature. The reaction mixture was poured into $5 \% \mathrm{NaHCO}_{3}(40 \mathrm{ml})$, and the mixture was purified by ultrafiltration ( $3 \mathrm{~kg} / \mathrm{mol}$ cut-off) with slightly basified water $(\mathrm{pH} \sim 8)$ and recovered as a white powder after lyophilization.

The same procedure was followed for the citraconic coupling onto $p(C B A / B A C-D A B)$ to 
obtain $\mathrm{p}(\mathrm{CBA} / \mathrm{BAC}-\mathrm{CA})$, and for the synthesis of $\mathrm{p}(\mathrm{CBA}-\mathrm{SA})$ succinic anhydride was used instead of citraconic anhydride.

\subsection{Polymer characterization}

The ${ }^{1} \mathrm{H}$ NMR spectra of the synthesized PAAs in $\mathrm{D}_{2} \mathrm{O}$ were recorded on a Varian Inova spectrometer operating at $300 \mathrm{MHz}$. The molecular weight and polydispersity $\left(\mathrm{M}_{\mathrm{w}} / \mathrm{M}_{\mathrm{n}}\right)$ of the synthesized PAAs were determined by GPC relative to PEO standards (Polymer Labs) using a Viscotek GPCMax pump and autoinjector and two thermostated $\left(30^{\circ} \mathrm{C}\right) \mathrm{PL}$ aquagel-OH 30 columns $(8 \mu \mathrm{m}, 300 \times 7.5 \mathrm{~mm}$, Polymer Labs, with a low-molar-mass separation range (200 40,000)). Data were collected using a TDA302 Tripledetector with RI, Visc and LS (7 and $\left.90^{\circ}\right)$ ). 0.3M NaAc aqueous solution ( $\left.\mathrm{pH} 4.4\right)$ with $30 \%$ methanol was used as eluent at a flow rate of $0.7 \mathrm{ml} / \mathrm{min}$ ).

\subsection{Degradation of citraconic amide}

The degradation of citraconic amide was measured by the fluorescamine method. Fluorescamine is an amine-reactive fluorescence dye with a maximum fluorescence wavelength at $465 \mathrm{~nm}$. After the degradation of citraconic amide in the copolymer, the formed primary amine in the side group reacts with the fluorescamine and the degradation percentage can be calculated from the comparison of the fluorescence before and after exposure of the polymer to acidic conditions. Therefore, each sample of the polymers was dissolved in distilled water at a concentration of $1 \mathrm{mg} / \mathrm{ml}$, and $100 \mu \mathrm{l}$ of this stock solution was mixed with $100 \mu \mathrm{l}$ of $10 \mathrm{mM}$ acetate buffer $\mathrm{pH} 5.5$ or $10 \mathrm{mM}$ HEPES buffer $\mathrm{pH}$ 7.4. This solution was incubated at $37^{\circ} \mathrm{C}$ and $10 \mu \mathrm{l}$ of each sample was diluted into $100 \mu \mathrm{l}$ of $0.1 \mathrm{M}$ borate buffer $\mathrm{pH} 9.1$ every hour. To this mixture was added 10 $\mu \mathrm{l}$ of fluorescamine solution in DMF $(2 \mathrm{mg} / \mathrm{ml})$ and allowed for reaction at room temperature for $10 \mathrm{~min}$. The fluorescence of the solution was measured at emission wavelength $495 \mathrm{~nm}$ and excitation wavelength $390 \mathrm{~nm}$. The fluorescence obtained with the fluorescamine reaction with the $\mathrm{p}(\mathrm{CBA}-\mathrm{DAB})$ and $\mathrm{p}(\mathrm{CBA} / \mathrm{B} A \mathrm{C}-\mathrm{DAB})$ polymers and that of a blank buffer solution was used for calibration (100\% and $0 \%$ free amine groups, respectively).

\subsection{Characterization of SS-PAA/Iysozyme NPS}

\subsubsection{Particle size and zeta-potential measurements}

SS-PAA/lysozyme nanocomplexes at polymer/protein weight ratio 36/1 were prepared by 
adding a HEPES buffer solution (10 mM, pH 7.4) of SS-PAA $(800 \mu \mathrm{l}, 2700 \mu \mathrm{g} / \mathrm{ml})$ to a HEPES buffer solution (10 mM, pH 7.4) of lysozyme (200 $\mu \mathrm{l}, 75 \mu \mathrm{g} / \mathrm{ml})$, followed by vortexing for 5 seconds and incubating at room temperature for 30 minutes. Particle size and surface charge measurements of the nanocomplexes were determined by dynamic light scattering (DLS) at $25^{\circ} \mathrm{C}$ with a Zetasizer Nano ZS (Malvern Instruments, Malvern, UK) using a wavelength of $532 \mathrm{~nm}$. The value was recorded as the mean of three measurements. The size distribution was given by the polydispersity index (PDI, a value between 0 and 1). A PDI of 1 indicates large variations in particle size; a PDI of 0 indicates no variation in particle size (as an ideal monodispersed formulation).

\subsubsection{Lysozyme condensation and loading efficiency}

To estimate the loading efficiency of the nanoparticles at neutral $\mathrm{pH}$, particle solutions of SS-PAA/lysozyme nanoparticles were prepared at polymer/protein weight ratio 36/1 using Alexa Fluor ${ }^{\circledR} 488$ labeled lysozyme. The nanoparticles were centrifuged at 14000 rpm for 30 minutes at $4^{\circ} \mathrm{C}$. Aliquots of supernatant were subsequently taken and their protein content determined by fluorescence spectroscopy (Safire ${ }^{2}$, Tecan, Canada) at an emission wavelength of $519 \mathrm{~nm}$ and an excitation wavelength of $495 \mathrm{~nm}$. The actual loading efficiency was indirectly determined by measuring the difference between the total amount of lysozyme added to the solution and the amount of lysozyme in the free form in the supernatant after centrifugation. A calibration curve from solutions of various fluorescently-labeled lysozyme concentrations was determined prior to this experiment. It was confirmed that free labeled-lysozyme was not precipitated from the solution by centrifugation.

\subsubsection{Stability of the lysozyme-containing nanoparticles mimicking intracellular conditions}

In order to obtain indications of the SS-PAA/lysozyme nanoparticle stability and the enzyme-protecting efficacy in the polymeric nanoparticles, experiments were performed under conditions mimicking the intracellular environment. To this aim, SS-PAA/lysozyme nanoparticles were prepared in HEPES buffer solution $(10 \mathrm{mM}, \mathrm{pH} 7.4)$ at polymer/protein weight ratio 36/1, using Alexa Fluor ${ }^{\circledR} 488$ labeled lysozyme and unlabeled lysozyme respectively. Samples of these solutions were diluted with equivalent volumes of either HEPES buffer or endothelial cell growth medium-2 (EGM-2) (Lonza, Verviers, Belgium) with or without Fetal Bovine Serum (FBS) (2.5 or 7.5\%), and after 
dilution the mixtures were allowed for 30 minute incubation at room temperature. Thereafter, the lysozyme loading in these nanoparticles was determined. The enzymatic activity of lysozyme condensed in the nanoparticles was also determined using the EnzCheck ${ }^{\circledR}$ lysozyme assay (Invitrogen). The assay measures lysozyme activity on Micrococcus lysodeikticus cell walls, which are labeled with fluorescein to such a high degree that auto-quenching occurs. Lysozyme action can relieve this quenching, yielding a dramatic increase in fluorescence that is proportional to lysozyme activity. Therefore, lysozyme-containing experimental samples were diluted with an equivalent volume of reaction buffer (provided in the assay kit), and $50 \mu \mathrm{l}$ of the $50 \mu \mathrm{g} / \mathrm{ml} \mathrm{DQ}$ lysozyme substrate working suspension were added to $50 \mu \mathrm{l}$ of diluted lysozyme-containing SS-PAA nanoparticle samples diluted with buffer solution or medium with or without serum . The mixtures were incubated for 30 minutes at $37^{\circ} \mathrm{C}$, protected from light. The fluorescence intensity of each reaction was measured in a fluorescence microplate reader, subtracting the value derived from the no-enzyme control. Digestion products from the DQ lysozyme substrate have absorption maxima at $\sim 494 \mathrm{~nm}$ and fluorescence emission maxima at $\sim 518 \mathrm{~nm}$. The lysozyme concentration was calculated by comparison with a linear calibration curve of lysozyme of different concentrations formerly prepared in either HEPES buffer or endothelial cell growth medium-2 (EGM-2) with or without FBS (2.5 or $7.5 \%)$.

\subsubsection{Release of lysozyme by acidification of the nanoparticles}

The effect of $\mathrm{pH}$ decrease from 7.4 to 5.1 (mimicking endosomal $\mathrm{pH}$ decrease) was investigated by DLS measurements. Particle size measurements of the nanocomplexes were performed at $25^{\circ} \mathrm{C}$ with a Zetasizer Nano ZS (Malvern Instruments, Malvern, UK) using a wavelength of $532 \mathrm{~nm}$. Simultaneously, the nanoparticle solution was titrated from $\mathrm{pH} 7.4$ to $\mathrm{pH} 5.1$ by regularly adding small aliquots of $0.25 \mathrm{M} \mathrm{HCl}$ solution using a MTP-2 multipurpose titrator (Malvern Instruments, Malvern, UK). Particle sizes were determined every half-unit of $\mathrm{pH}$.

In another experiment, the release of lysozyme from the nanoparticles after exposure at pH 5 (endosomal pH) was determined using solutions of SS-PAA/lysozyme nanoparticles prepared at polymer/protein weight ratio $24 / 1$ as previously ( $\mathrm{pH} 7.4$ ), using Alexa Fluor ${ }^{\circledR}$ 488 labeled lysozyme. After acidification to $\mathrm{pH} 5$ by addition of a small amount of $1 \mathrm{M} \mathrm{HCl}$ solution and incubation for 30 minutes, the nanoparticles were centrifuged at $14000 \mathrm{rpm}$ for 30 minutes at $4^{\circ} \mathrm{C}$. Aliquots of the supernatant were subsequently taken and the 
amount of labeled lysozyme present in the free form in the supernatant was determined by fluorescence spectroscopy $\left(\lambda_{\mathrm{em}}=519 \mathrm{~nm}, \lambda_{\mathrm{ex}}=495 \mathrm{~nm}\right)$ using a calibration curve.

In order to obtain an indication of the residual enzymatic activity of the released lysozyme from the SS-PAA nanoparticles after acidification to $\mathrm{pH} 5$, the enzymatic activity was determined using the EnzCheck ${ }^{\circledR}$ Iysozyme assay. Therefore, the lysozyme-containing SS-PAA nanoparticle samples acidified at $\mathrm{pH} 5$ for 30 minutes were diluted in an equivalent volume of reaction buffer (provided in the assay kit). Then, $50 \mu$ of this solution was added to DQ lysozyme substrate working suspension $(50 \mu \mathrm{g} / \mathrm{ml})$ provided in the assay kit, and the mixtures were incubated for 30 minutes at $37^{\circ} \mathrm{C}$, protected from light. The fluorescence intensity of each reaction was measured in a fluorescence microplate reader, subtracting the value derived from the no-enzyme control. The lysozyme concentration was calculated by comparison with a linear calibration curve of lysozyme of different concentrations formerly prepared at $\mathrm{pH} 7.4$ and $\mathrm{pH} 5$.

\subsubsection{Release of lysozyme from nanoparticles by disulfide reduction of the SS-PAAS}

The release of protein from the nanoparticles at intracellular reductive conditions was measured using solutions of SS-PAA/lysozyme nanoparticles prepared as previously, at polymer/protein weight ratio 36/1 using Alexa Fluor ${ }^{\circledR} 488$ labeled lysozyme. After addition of DTT to a final concentration of $2.5 \mathrm{mM}$ and incubation for 30 minutes, the solution was centrifuged at $14000 \mathrm{rpm}$ for 30 minutes at $4^{\circ} \mathrm{C}$. Aliquots of supernatant were subsequently taken and their protein content was determined by the measurement of the fluorescence intensity (Safire ${ }^{2}$, Tecan, Canada) at an emission wavelength of 519 $\mathrm{nm}$ and an excitation wavelength of $495 \mathrm{~nm}$ using a prior-determined calibration curve. In order to obtain an indication of the efficiency of the protein release caused by the reduction of the disulfide linkages in the polymeric nanoparticles, after adding DTT in HEPES buffer to the SS-PAA/lysozyme nanoparticles to a final concentration of $2.5 \mathrm{mM}$ DTT in the resultant solution, the enzymatic activity was determined using the EnzCheck ${ }^{\circledR}$ lysozyme assay as previously described.

\subsection{Cellular uptake and cytotoxicity of NPs in vitro}

For all the cell experiments described in the following paragraphs, Alexa Fluor 488 labeled lysozyme was used as payload in the SS-PAA/lysozyme nanoparticles.

Besides, cell lines, as for example $\mathrm{CHO}$ or hCMEC are cells that are immortalized. Some of the most important cell specific properties of primary cells are not present anymore in 
this type of cells (as contact inhibition for instance). Therefore, in this study, we used primary cells that express the proteins expressed before the isolation from human tissue. Moreover, we used these primary cells for limited amount of time to ensure that they more closely mimic the in vivo situation.

\subsubsection{Detection of cell viability and cytotoxicity after treatment with SS-PAA/Iysozyme nanoparticles}

Cell viability was determined through the MTS assay by measuring the formation of formazan due to the reduction of a tetrazolium compound that is added to the cells. In this MTS assay, the substrate (3-(4,5-dimethylthiazol-2-yl)-5-(3-carboxymethoxyphenyl)-2(4-sulfophenyl)-2H-tetrazolium, inner salt) is reduced to formazan by dehydrogenase enzymes found in metabolically active cells. When cell viability decreases, cells lose their ability to reduce the tetrazolium compound and the amount of formazan produced, as measured by the absorbance at $492 \mathrm{~nm}$ using a microplate reader, is proportional to the number of viable cells in the culture. human umbilical vein endothelial cells (Huvec) were seeded onto fibronectin-coated 96 -well plates (10,000 cells/well), and cultured with endothelial growth medium-2 (EGM-2) with supplements from the EGM-2 Single Quots kit (both Lonza, Verviers, Belgium) and 1\% penicillin/streptomycin. After confluence, cells were treated with increasing concentrations of SS-PAA/lysozyme nanoparticle for 24 hours. The cell viability was measured by using the CellTiter 96 AQueous non-radioactive assay (Promega, Mannheim, Germany) according to manufacturer's instructions. The supernatant from nanoparticle-treated and untreated cells was removed and the cells were incubated with $100 \mu \mathrm{l}$ cell medium/substrate solution at $37^{\circ} \mathrm{C}$ for 45 minutes.

To further determine whether SS-PAA/lysozyme nanoparticles display any cytotoxic effects, cells were treated with these nanoparticles as above and $50 \mu$ of supernatant was removed at various time points. The LDH release into the medium was detected by using the CytoTox 96 non-radioactive cytotoxicity assay (Promega, Mannheim, Germany) as recommended by the manufacturer. By using this assay, we indirectly measure the leakage of the cell membrane after exposure to the nanoparticle solution, leakages in the cell membrane meaning cell death. The release of LDH of untreated cells was used as control, and the LDH activity of lysed cells was set to $100 \%$. Data were analyzed with GraphPad Prism 5.0 software. 


\subsubsection{Uptake of nanoparticles into human cell types}

Human umbilical vein endothelial cells (Huvec) (50,000 cells/well) were seeded onto fibronectin-coated LabTek chambers (Nunc, Roskilde, Denmark) and cultured until confluent. Cells were treated with $300 \mu \mathrm{g} / \mathrm{ml}$ SS-PAA/lysozyme nanoparticle solution for 24 hours. After removal of the supernatant, cells were washed extensively with $0.2 \%$ BSA in1M HEPES, and then fixed with 3.7\% paraformaldehyde (Merck, Darmstadt, Germany) in CS-buffer (0.1M PIPES, 1mM EGTA, 4\% Polyethylenglycol-8000, 0.1M NaOH, pH 7.0) at room temperature for 20 minutes. Cells were then washed three times with PBS and CD31, which is located in the membrane of endothelial cells, was then stained with mouse anti-human CD31 antibody (DakoCytomation, Glostrup, Denmark) and the appropriate secondary antibody (goat anti-mouse Alexa 546; Molecular Probes, Carlsbad, USA). Cell nuclei were stained with Hoechst dye (Sigma-Aldrich, St. Luis, USA). Stained cells with and without exposure to SS-PAA/lysozyme nanoparticles were mounted with GelMount (Biomeda, Natutec, Germany) and images were collected using a confocal laser scanning microscope (Leica, Germany). In this way, the location of the fluorescently labeled lysozyme from SS-PAA/lysozyme nanoparticles (green channel) could be observed with respect to the cell membrane (red channel) and the cell nuclei (blue channel).

\section{Results and discussion}

\subsection{Synthesis and characterization of the SS-PAAS}

First, two different bioreducible SS-PAA polymers with repetitive disulfide linkages in their main chain were synthesized via Michael addition of the primary amine monomer MBDAB to the bisacrylamides CBA and BAC. These polymers contain disulfide linkages in their main chain and Boc-protected amine in the side chain. The resulting polymers coded in terms of the used monomers, $\mathrm{p}(\mathrm{CBA}-\mathrm{MBDAB})$ and $\mathrm{p}(\mathrm{CBA} / \mathrm{BAC}-\mathrm{MBDAB})$, were collected in their $\mathrm{HCl}$-salt form as white solid powder after freeze-drying, and have a good solubility in water. For both polymers, the yield was ca. 65\% after ultrafiltration and lyophilization. The ${ }^{1} \mathrm{H}$ NMR spectra of the polymers were in full accordance with the expected structures. The absence of any proton signals between 5 and 7 ppm shows that the polymer did not contain any residual acrylamide end groups. The complete removal of the Boc protective groups could be confirmed by the disappearance of the tert-butyl signal at $1.5 \mathrm{ppm}$ in the ${ }^{1} \mathrm{H}$ NMR spectra after addition of TFA to the copolymers, yielding to polymers possessing free primary amine groups in the side chains, $p(C B A-D A B)$ and $\mathrm{p}(\mathrm{CBA} / \mathrm{BAC}-\mathrm{DAB})$. These primary amines in the side chain are the reactive functionalities 
for the coupling reaction with citraconic anhydride and succinic anhydride, respectively. Citraconic anhydride or succinic anhydride were added to the Boc-deprotected polymers and allowed to react with these free primary amines groups to yield the citraconic amide functionalized SS-PAAs, $p(C B A-C A)$ and $p(C B A / B A C-C A)$, and the succinic amide functionalized $p(C B A-S A)$, respectively. In all cases, $100 \%$ of the primary amine groups in the polymers were converted into the amides, as was determined by ${ }^{1} \mathrm{H}$ NMR.

The synthesis route to the citraconic amide functionalized SS-PAAs is given in Scheme 4.2, and the structures of the final citraconic and succinic amide functionalized SS-PAAs are shown in Figure 4.1. Details about the NMR data and molecular weights of the polymers are available in Figures 4.2 and 4.3 and Table 4.1.

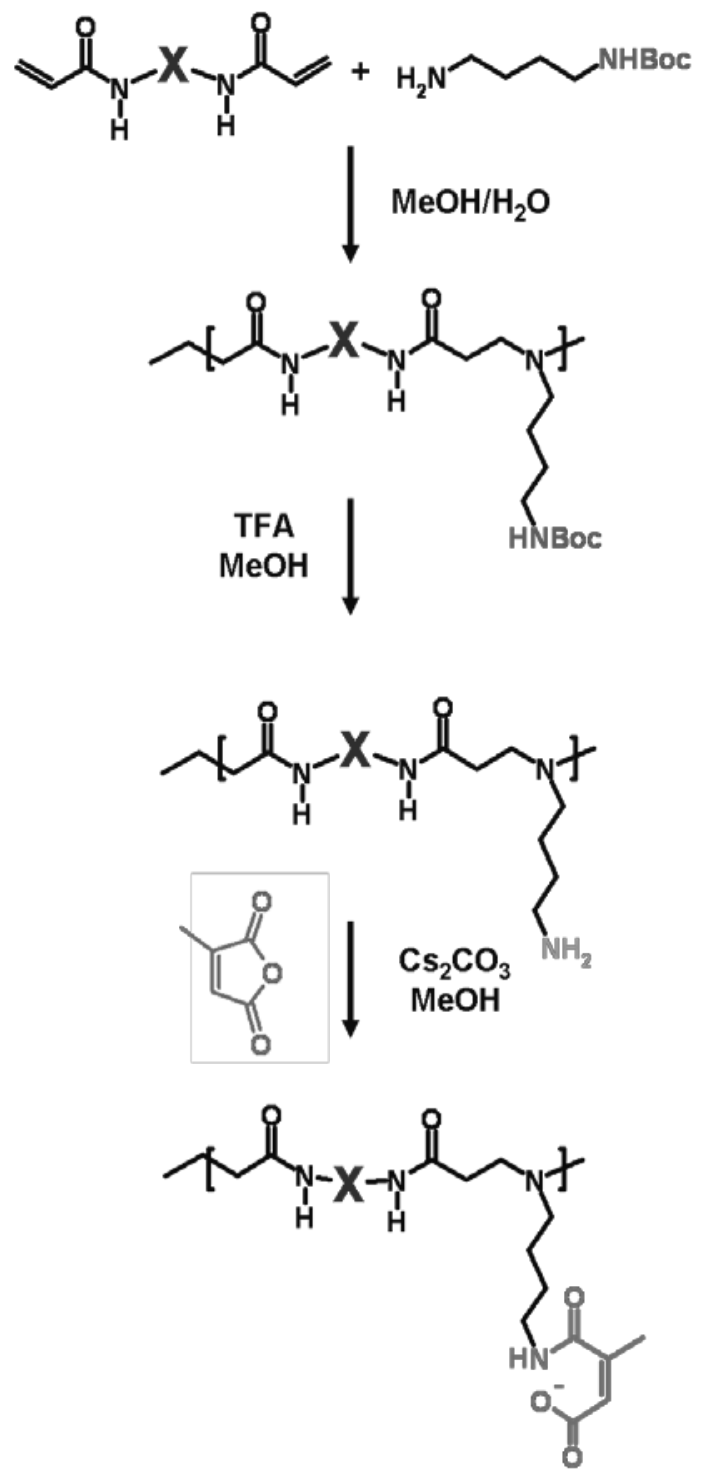

Scheme 4.2. General synthesis scheme of citraconic amide based SS-PAAs. The X structure of the polymer backbone is CBA or BAC, providing disulfide bonds or acetate groups along the polymer main chain, respectively. 


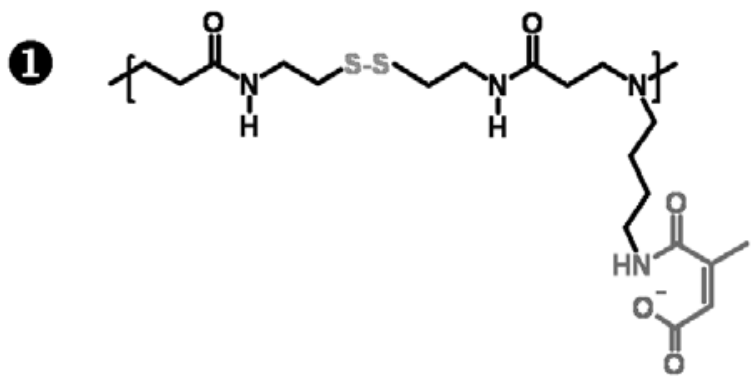

22

3<smiles>CCCCC(=O)NCCSSCCNC(=O)CCN(C)CCCCNC(=O)CCC(=O)[O-]</smiles>

Figure 4.1. Structure of poly(amidoamine)s. 1: $p(C B A-C A), 2: p(C B A / B A C-C A)$ 3: $p(C B A-S A)$. The polymers were coded in terms of the used bisacrylamide and primary amine monomer. 


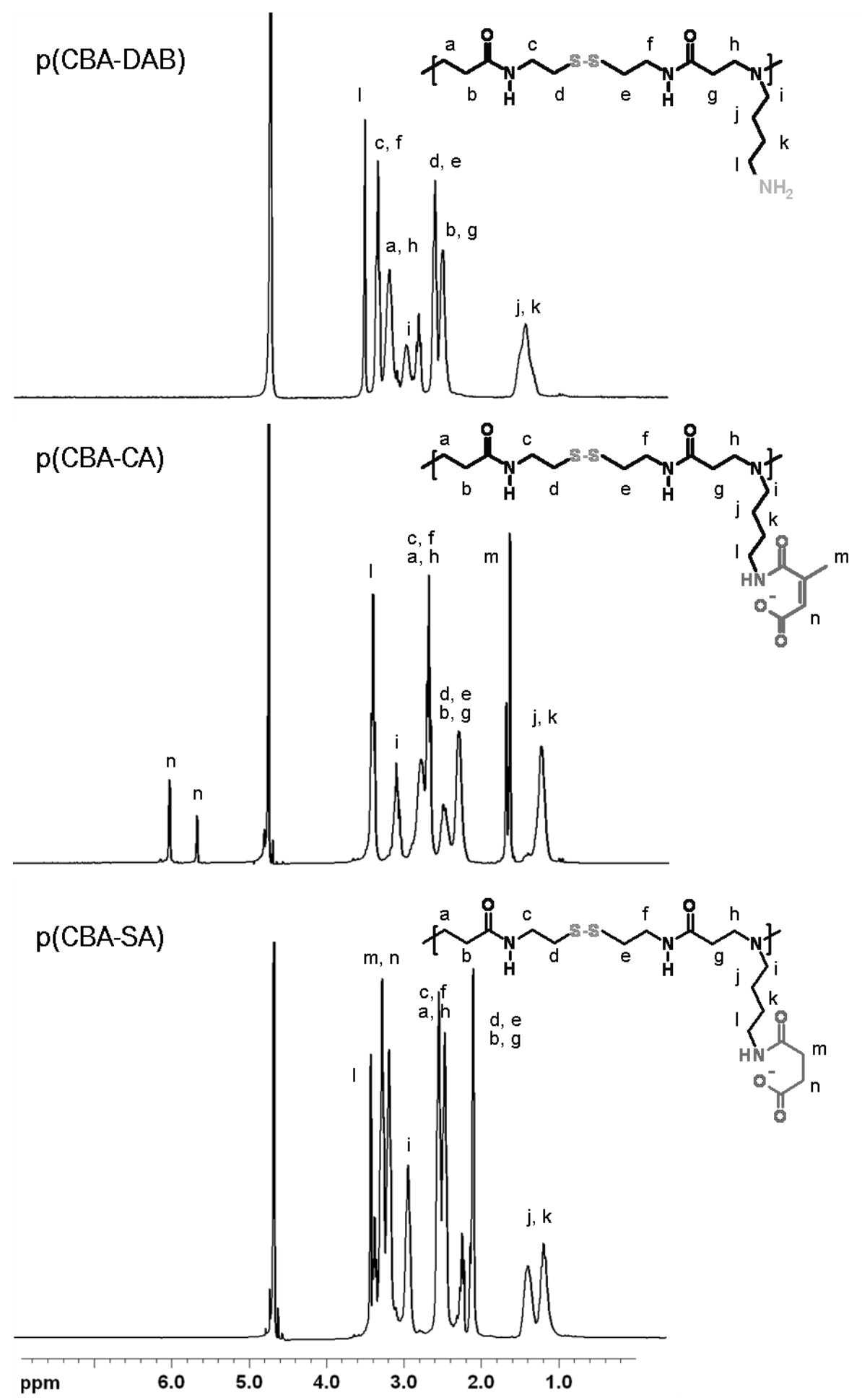

Figure 4.2. ${ }^{1 H}$ NMR spectra of the poly(amidoamine)s: $p(C B A-D A B), p(C B A-C A)$, and $p(C B A-S A)$. 

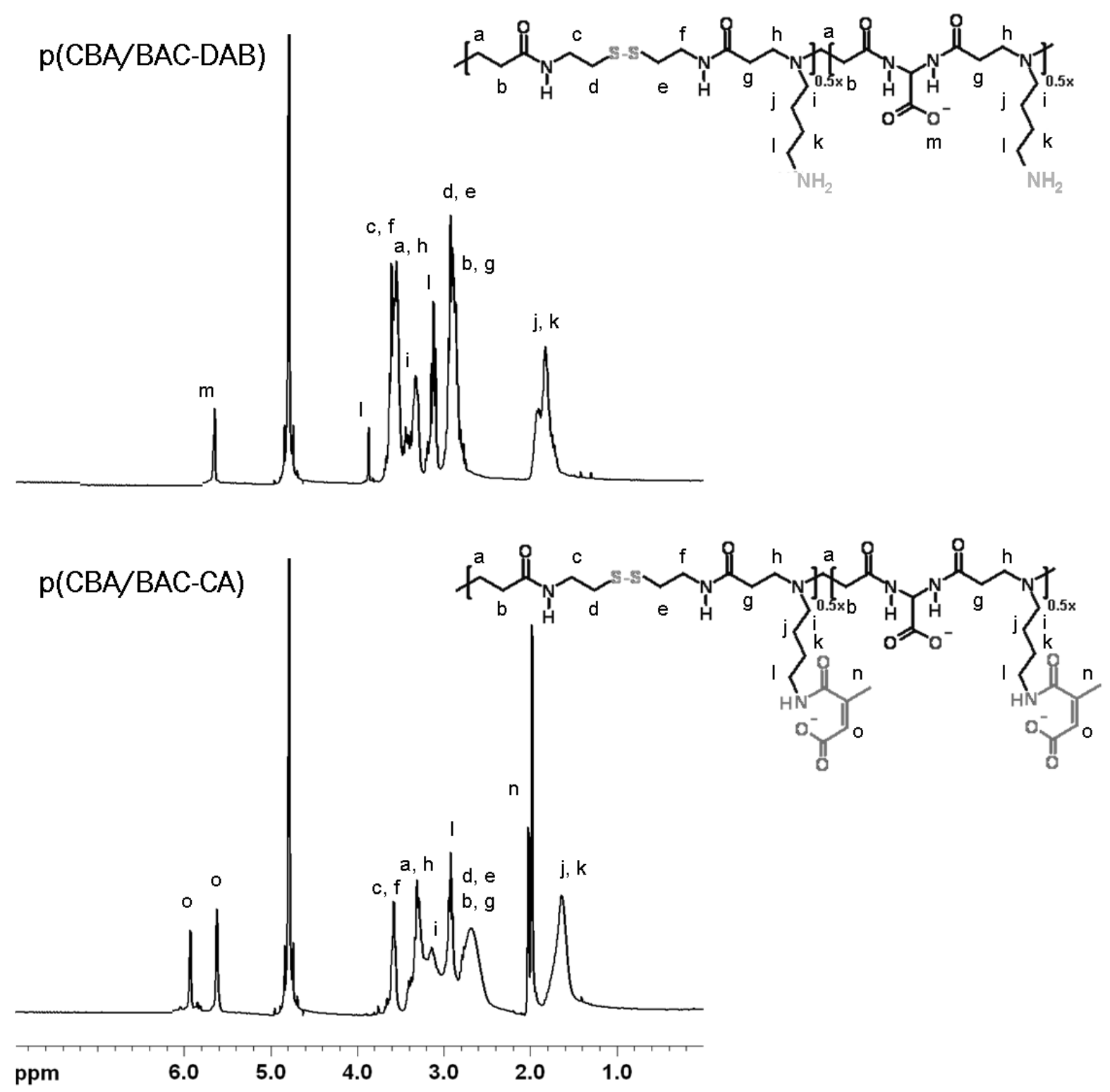

Figure 4.3. ${ }^{1 H}$ NMR spectra of the poly(amidoamine)s: $p(C B A / B A C-D A B)$, and $p(C B A / B A C-C A)$. 
Table 4.1. Characterization of SS-PAAs (homopolymers and copolymer), in terms of molecular weight $\left(\mathrm{M}_{\mathrm{w}}, \mathrm{PDI}\right)$.

\begin{tabular}{|c|c|c|c|}
\hline Polymer & $\begin{array}{c}\text { Composition } \\
\text { CBA/BAC * }\end{array}$ & $\mathrm{M}_{\mathrm{w}} * *$ & $\begin{array}{c}\mathrm{PDI} \\
\left(\mathrm{M}_{\mathrm{w}} / \mathrm{M}_{\mathrm{n}}\right) * *\end{array}$ \\
\hline $\mathrm{p}(\mathrm{CBA}-\mathrm{CA})$ & n.a. & 6.3 & 1.16 \\
\hline $\mathrm{p}\left(\mathrm{CBA}_{50} / \mathrm{BAC}_{50}-\mathrm{CA}\right)$ & $50 / 50$ & 6.8 & 1.23 \\
\hline $\mathrm{p}(\mathrm{CBA}-\mathrm{SA})$ & n.a. & 6.3 & 1.17 \\
\hline
\end{tabular}

n.a.: non applicable, * : determined by integrated peak area from ${ }^{1 H} \mathrm{NMR}\left(\mathrm{D}_{2} \mathrm{O}, 300 \mathrm{MHz}\right)$, ** : average-weight molecular weight $\left(\mathrm{M}_{\mathrm{w}}\right)$ determined by GPC measurement

\subsection{Degradation of citraconic amide in the polymer}

The negatively charged citraconic amide group in the side chains of the SS-PAA polymers is stable at neutral and basic $\mathrm{pH}$, but is rapidly cleaved by intramolecular catalysis at acidic $\mathrm{pH}$ under the formation of positively charged protonated primary amine groups (Scheme 4.3). 

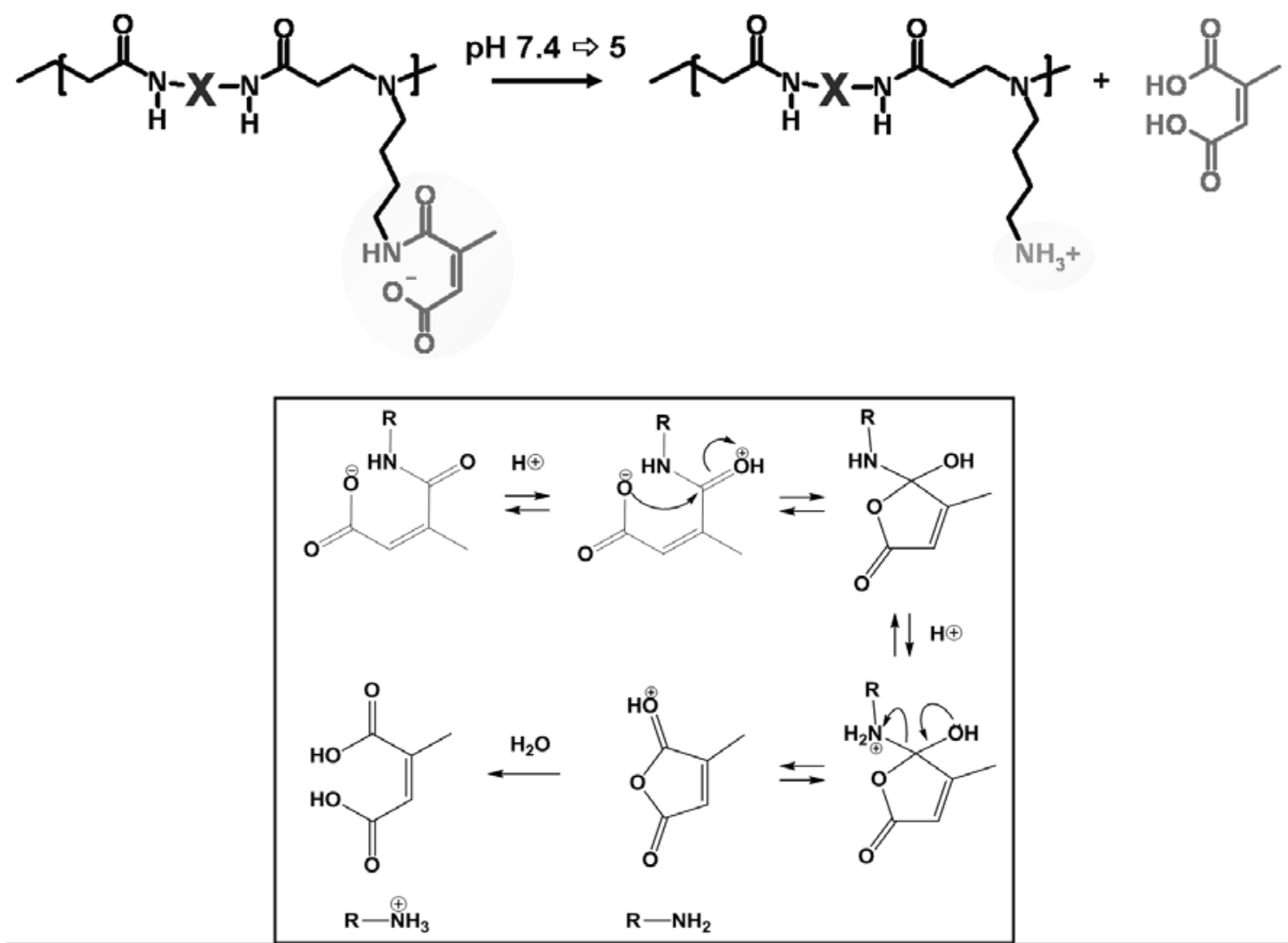

Scheme 4.3. Hydrolysis scheme and mechanism of citraconic anhydride derivative SS-PAA, when $\mathrm{pH}$ drops from 7.4 to $\mathrm{ca}$. 5. The $\mathrm{X}$ structure of the polymer backbone varies depending on the bisacrylamide used for the polymer synthesis, CBA or BAC providing respectively disulfide bonds or acetate groups along the polymer main chain.

The $\mathrm{pH}$-dependent degradation rates of the citraconic amide groups in the SS-PAA polymers are shown in Figure 4.4 . The degradation rate at $37^{\circ} \mathrm{C}$ was calculated by measurement of the change in the primary amine concentration in the solution using the fluorescamine quantification method at a fixed concentration of the polymers [44]. Due to the single $\mathrm{C}-\mathrm{C}$ bond between the amide function and the carboxylate group in the $\mathrm{p}(\mathrm{CBA}-\mathrm{SA})$, this latter group does not provide intramolecular cleavage of the amide bond and therefore the amide bond in this derivative is much more stable under acidic conditions. The experiments in acetate buffer $(\mathrm{pH} 5.5)$ showed that within one hour approximately that $60 \%$ of the citraconic amides were degraded, and after 4 hours incubation at $\mathrm{pH} 5.5$ more than $85 \%$ of the citraconic amides were converted into free amine. In contrast, hydrolysis proceeds only very slowly at pH 7.4 in HEPES buffer and even after 4 hours more than $80 \%$ of the citraconic amides remained intact. As expected, 
no degradation of the succinic amide side groups was observed under these conditions.

$\square p(C B A-C A) \quad \square p(C B A / B A C-C A) \quad \square p(C B A-S A)$
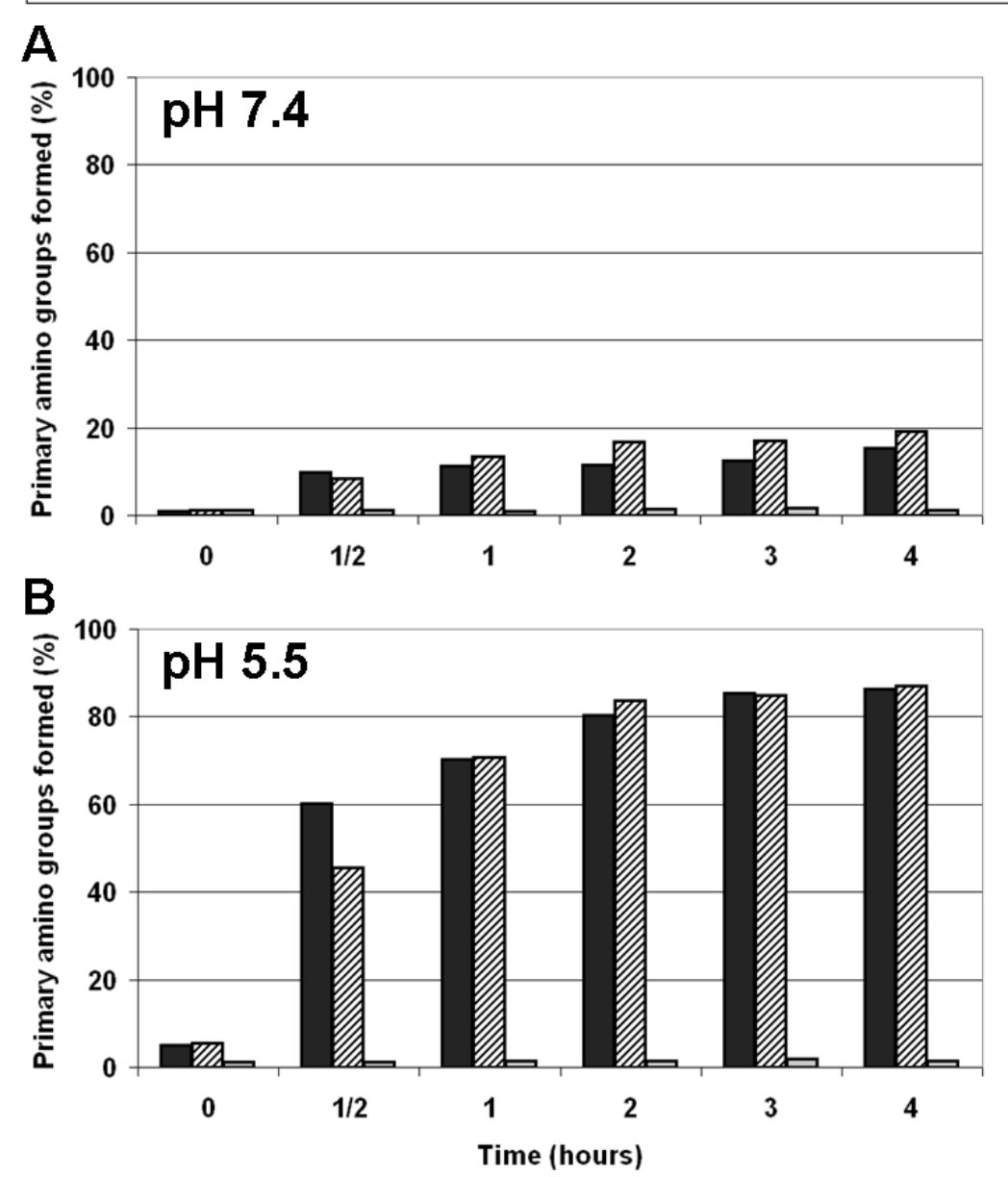

Figure 4.4. Degradation of citraconic amide and succinic amide side groups in the SS-PAAs at (A) $\mathrm{pH} 7.4$ and $(\mathrm{B}) \mathrm{pH}$ 5.5. The data are mean values of three experiments, for $\mathrm{p}(\mathrm{CBA}-\mathrm{CA})$ (black bars), $p(C B A / B A C-C A)$ (striped bars), and $p(C B A-S A)$ (grey bars).

\subsection{Formation of self-assembled polymer/protein nanoparticles: physical} characterization and loading efficiency

The three negatively-charged citraconic amide and succinic amide functionalized SS-PAA polymers are capable to form nanosized polyelectrolyte complexes by self-assembly with positively-charged lysozyme molecules ( $\mathrm{pl}>9$ ), based on electrostatic, hydrophobic, and hydrogen-bonding interactions. DLS and zeta-potential measurements showed that the particles have sizes smaller than $250 \mathrm{~nm}$ (PDI < 0.25) and negative surface charge $(-5 /-15 \mathrm{mV})$ in HEPES buffer solution $\mathrm{pH}$ 7.4. The smallest size (ca. $200 \mathrm{~nm}$ ) and lowest surface charge $(-15 \mathrm{mV})$ were observed for the nanocomplexes of the copolymer 
$\mathrm{p}(\mathrm{CBA} / \mathrm{BAC}-\mathrm{CA})$, which may be explained by the higher negative charge density of this polymer, due to the presence of the acetate groups along the polymer backbone giving rise to stronger interactions with cationic lysozyme.

Table 4.2. Lysozyme loading of SS-PAA/Alexa Fluor® 488 labeled lysozyme nanoparticles prepared at weight ratio 36/1 in HEPES buffer pH 7.4, after dilution with HEPES buffer pH 7.4, medium without serum, medium with $2.5 \%$ FBS serum, and medium with $7.5 \%$ FBS serum. The reported values were derived from the free lysozyme content determined in the supernatant after centrifugation.

\begin{tabular}{|c|c|c|c|c|}
\hline \multirow{2}{*}{ Polymer } & \multicolumn{4}{|c|}{ Lysozyme loading in particles (\%)* } \\
\cline { 2 - 5 } & HEPES buffer & $\begin{array}{c}\text { Medium w/o } \\
\text { serum }\end{array}$ & $\begin{array}{c}\text { Medium w/ } \\
\mathbf{2 . 5 \%} \text { FBS }\end{array}$ & $\begin{array}{c}\text { Medium w/ } \\
7.5 \% \text { FBS }\end{array}$ \\
\hline $\mathrm{p}$ (CBA-CA) & 86 & 82 & 80 & 75 \\
\hline $\mathrm{p}(\mathrm{CBA} / \mathrm{BAC}-\mathrm{CA})$ & 85 & 78 & 77 & 75 \\
\hline $\mathrm{p}(\mathrm{CBA}-\mathrm{SA})$ & 85 & 77 & 77 & 75 \\
\hline
\end{tabular}

* Percentage of lysozyme that is incorporated in the polymeric nanoparticles. Initial lysozyme concentration is $15 \mu \mathrm{g} / \mathrm{ml}$.

Table 4.2 gives the lysozyme loading efficiency of the three different SS-PAA/lysozyme nanoparticles in HEPES buffer solution (10 mM, pH 7.4). It can be seen that all disulfide polymers incorporate into the nanoparticles a high percentage of the enzyme present in solution even under the very dilute conditions applied (lysozyme concentration: 15 $\mu \mathrm{g} / \mathrm{ml})$.

\subsection{Stability of the lysozyme-containing nanoparticles}

The stability of the lysozyme-containing SS-PAA nanoparticles and their efficacy to protect the incorporated enzyme were investigated under conditions akin to the in vitro cellular experiments (vide infra), notably in serum-containing environments that might destabilize the electrostatic interactions between the negatively-charged polymers and the cationic Iysozyme. To this aim, the SS-PAA/lysozyme nanoparticles were diluted with an equivalent volume of either HEPES buffer or serum-free EGM-2 medium with or without FBS (2.5 or $7.5 \%$ ), and both the lysozyme content and the enzymatic activity were determined. The measured lysozyme loading in the nanoparticles under these conditions are shown in Table 4.2. The results show that the nanoparticles still maintain a lysozyme loading of at least $75 \%$, under all serum conditions, indicating that in serum-containing environment the SS-PAA/lysozyme nanoparticles become only slightly destabilized. 
The enzymatic activity of lysozyme was determined after dilution of the SS-PAA/lysozyme nanoparticles with HEPES buffer and in the cell-free solutions akin to those used in the in vitro cellular experiments, i.e serum-free EGM-2 medium, EGM-2 medium with 2.5 and 7.5\% FBS. A separate experiment showed that the activity of free lysozyme is almost the same in all these four cell-free conditions (data not shown). As is shown in Figure 4.5, the lysozyme activity is almost completely suppressed in the SS-PAA/lysozyme nanoparticles in HEPES buffer. These results show that the encapsulation of lysozyme in the SS-PAA nanoparticles prevents the enzyme to display its activity in an extracellular environment. In contrast, the addition of medium with FBS to the SS-PAA/lysozyme nanoparticle solutions induce an increase in enzymatic activity which increases with increasing FBS concentration up to $25 \%$ after 5 hours of exposure. However, since incubation of cells with the nanoparticles is usually no longer than two hours, these experiments show that the lysozyme activity in the SS-PAA nanoparticles can be almost completely inhibited, even in solutions similar to those used in the in vitro cellular experiments. 


\section{DEPES buffer $\square$ medium w/o FBS \\ $\square$ medium $w / 2.5 \%$ FBS $\quad \square$ medium $w / 7.5 \%$ FBS}
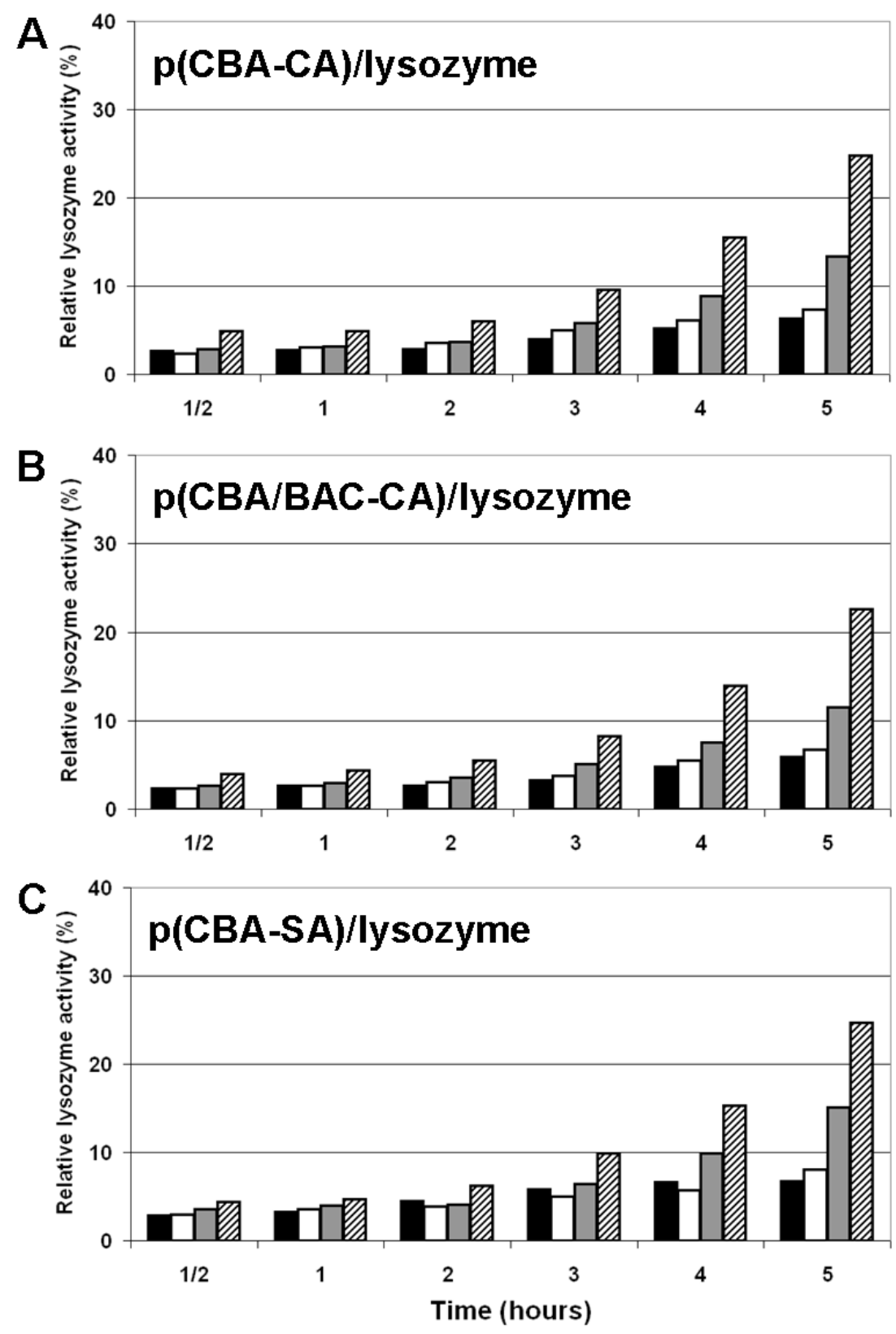

Figure 4.5. Relative lysozyme activity of the SS-PAA/lysozyme nanoparticles, after dilution with HEPES buffer pH 7.4 (dark bars), medium without serum (light bars), medium with 2.5\% FBS serum (dotted bars), and medium with $7.5 \%$ FBS serum (striped bars), using p(CBA-CA) (A), $\mathrm{p}(\mathrm{CBA} / \mathrm{BAC}-\mathrm{CA})(\mathrm{B})$, and $\mathrm{p}(\mathrm{CBA}-\mathrm{SA})(\mathrm{C})$ as polymeric carriers. 


\subsection{Mimicking intracellular release of enzyme loading by $\mathrm{pH}$ triggering and bioreduction} of lysozyme-loaded nanoparticles

\subsection{1 pH-triggered release of enzyme loading from lysozyme-loaded SS-PAA nanoparticles}

Electrostatic interactions between positively-charged enzyme and negatively-charged polymer are the main driving force for the self assembly of these compounds into nanoparticles. In nanoparticles containing the negatively-charged citraconic amide groups the polymer charge is rapidly shifted into the cationic domain due to the intramolecular hydrolysis of these groups under the formation of cationic primary ammonium groups (see Scheme 4.3). DLS measurements showed that the $\mathrm{p}(\mathrm{CBA}-\mathrm{CA}) /$ lysozyme nanoparticles significantly increased in size and surface charge when the $\mathrm{pH}$ is decreased from 7.4 to 5.1 , especially when $\mathrm{pH}$ drops below 6.5 where citraconic hydrolysis occurs (Figure 4.6). This indicates that this type of polymer/protein complexes respond to the $\mathrm{pH}$ decrease that is occurring after endocytosis, whereas the particles containing the succinic amide moieties only slightly increase in size with only slight increase of surface charge at low $\mathrm{pH}$ values, indicating that the succinamide moieties keep intact under these conditions. For the p(CBA/BAC-CA)/lysozyme nanoparticles, first a decrease of particle size and a slight decrease of surface charge were measured upon decrease of the $\mathrm{pH}$ from 7.4 to 6.1, which may be explained by an increase of cationic charge at the lysozyme surface, resulting in an increased interaction with the anionic polymers. At lower $\mathrm{pH}$ values, the $\mathrm{p}(\mathrm{CBA} / \mathrm{BAC}-\mathrm{CA}) / \mathrm{lysozyme}$ nanoparticles increase again in particle size and surface charge due to the conversion of the citraconic amide into free ammonium groups, inducing repulsion between polymer and enzyme. 


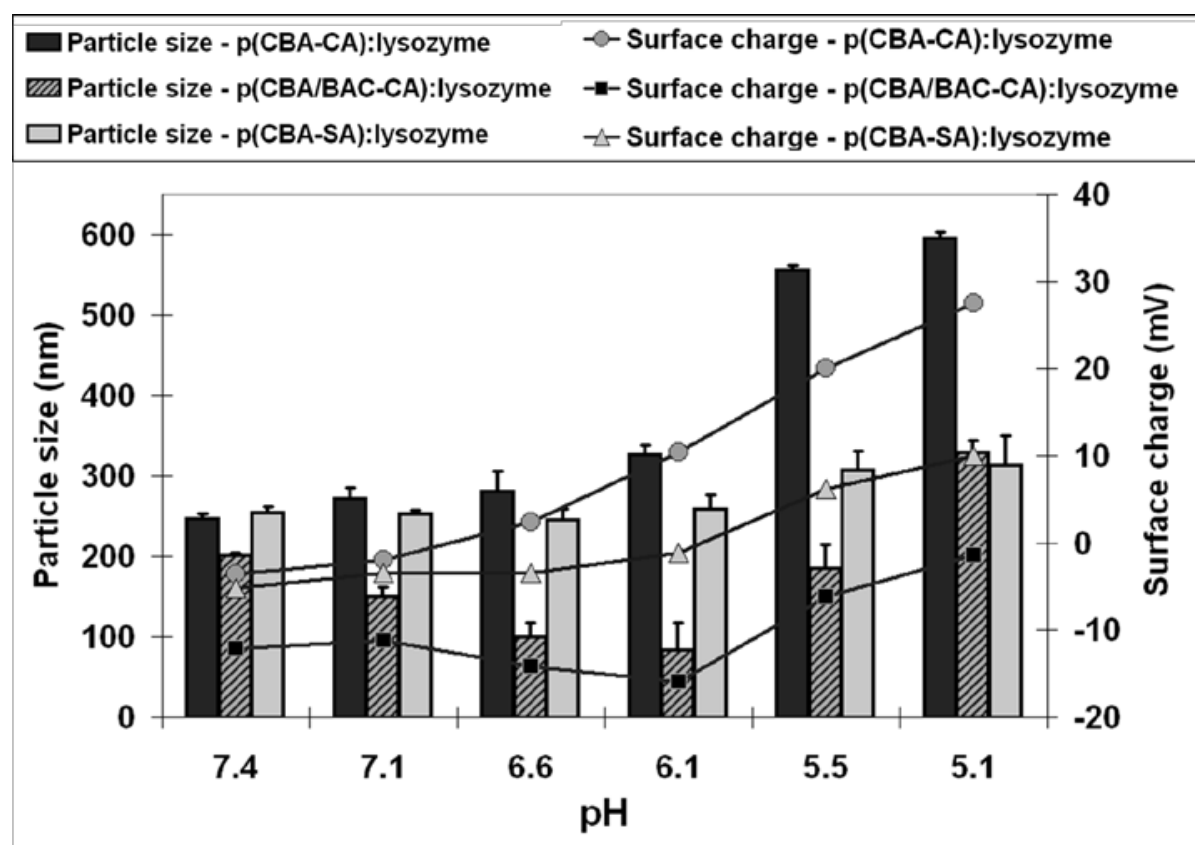

Figure 4.6. Size distributions and surface charges of SS-PAA/lysozyme nanoparticles during the $\mathrm{pH}$ titration of the particles (titration duration: 2 hours), from $\mathrm{pH} 7.4$ to $\mathrm{pH} 5.1$, representing the $\mathrm{pH}$ in the extracellular and intracellular environments, respectively.

The results from the DLS experiments indicate that the $\mathrm{p}(\mathrm{CBA}-\mathrm{CA}) /$ lysozyme and $\mathrm{p}(\mathrm{CBA} / \mathrm{BAC}-\mathrm{CA}) /$ lysozyme nanoparticles will become destabilized upon acidification of the endosomes. In order to evaluate to which extent such destabilization leads to release of enzyme the amount of lysozyme released from the nanoparticles was determined after acidification of the solution to $\mathrm{pH} 5$. As is shown in Table 4.3 column A, after 30 minutes at $\mathrm{pH}$ 5, the lysozyme release from the citraconic amide containing polymeric nanoparticles is in the range of 65\%; whereas from the succinic amide analog the release was only $6 \%$. This confirms that the lysozyme release is due to polymer charge-reversal of the nanoparticle systems based on the SS-PAA derivatives of citraconic anhydride.

\subsubsection{Release of enzyme loading by polymer bioreduction in lysozyme-loaded SS-PAA nanoparticles}

The rapid cleavage of disulfide linkages by glutathione and reductase enzymes in the intracellular environment (which can contain up to $10 \mathrm{mM}$ glutathione) can be favorably exploited to degrade the SS-PAAs and consequently induce fast degradation of the SS-PAAs in the nanocomplexes resulting in efficient protein release. Table 4.3 column $B$ shows the quantity of released labeled-lysozyme from the SS-PAA/lysozyme nanoparticles after the addition of $2.5 \mathrm{mM}$ DTT to the nanoparticle solution. The nanoparticles from 
$\mathrm{p}(\mathrm{CBA}-\mathrm{CA})$ and $\mathrm{p}(\mathrm{CBA}-\mathrm{SA})$ release almost completely their encapsulated enzyme due to the fast cleavage of the disulfide-containing CBA units in these polymers (91\% and $94 \%$ respectively), whereas $\mathrm{p}(\mathrm{CBA} / \mathrm{BAC}-\mathrm{CA})$ containing only half of the content of CBA releases only $49 \%$ of the lysozyme content. An additional factor for retaining a higher percentage of lysozyme can also be the higher negative charge density of $\mathrm{p}(\mathrm{CBA} / \mathrm{BAC}-\mathrm{CA})$ due to the presence of the BAC units in this polymer.

Table 4.3. A+B: Lysozyme release from SS-PAA/Alexa Fluor ${ }^{\circledR} 488$ labeled lysozyme nanoparticles in HEPES buffer pH 7.4 (weight ratio 36/1), column A: after addition of $0.25 \mathrm{M} \mathrm{HCl}$ to drop $\mathrm{pH}$ to $\mathrm{pH} 5$, column B: after addition of DTT to a final concentration of $2.5 \mathrm{mM}$.

\begin{tabular}{|c|c|c|}
\hline Polymer & $\begin{array}{c}\text { A) } \\
\text { Lysozyme release } \\
(\%) \\
\text { at } p H 5\end{array}$ & $\begin{array}{c}\text { B) } \\
\text { Lysozyme release } \\
(\%)\end{array}$ \\
after DTT addition
\end{tabular}

\subsection{Activity of released lysozyme from Iysozyme-loaded SS-PAA nanoparticles}

\subsubsection{After release by $\mathrm{pH}$ triggering of lysozyme-loaded nanoparticles}

The results from the experiments previously described showed that lysozyme is released upon acidification of the $\mathrm{p}(\mathrm{CBA}-\mathrm{CA}) / \mathrm{lys}$ sozyme and $\mathrm{p}(\mathrm{CBA} / \mathrm{BAC}-\mathrm{CA}) / \mathrm{lys}$ sozyme nanoparticles. Figure 4.7 shows the activity of lysozyme from the three different SS-PAA/lysozyme nanoparticles at pH 7.4 and 30 minutes after acidification to $\mathrm{pH}$ 5.1. It can be seen that, whereas the lysozyme activity is almost completely suppressed in lysozyme nanoparticles at $\mathrm{pH}$ 7.4, acidification of the nanoparticle solutions gives an increase of enzymatic activity up to $96 \%$ of the original free enzyme activity after 5 hours of exposure at pH 5 of the citraconic amide-functionalized nanoparticles. As expected, no significant increase of lysozyme enzymatic activity was measured after acidification for the particles containing the succinic amide moieties. These experiments demonstrate that encapsulation of lysozyme in the SS-PAA nanoparticles occurs without loss of intrinsic enzyme activity. Moreover, incubation of the nanocomplexes in mild acidic conditions results in citraconic amide hydrolysis leading to destabilization of the nanoparticles and progressive release of active lysozyme, whereas enzyme release is very slow for the succinic amide derivative. 


\section{$\square \mathrm{pH} 7.4$}

四H $7.4+\mathrm{DTT}$

$\square \mathrm{pH} 5$
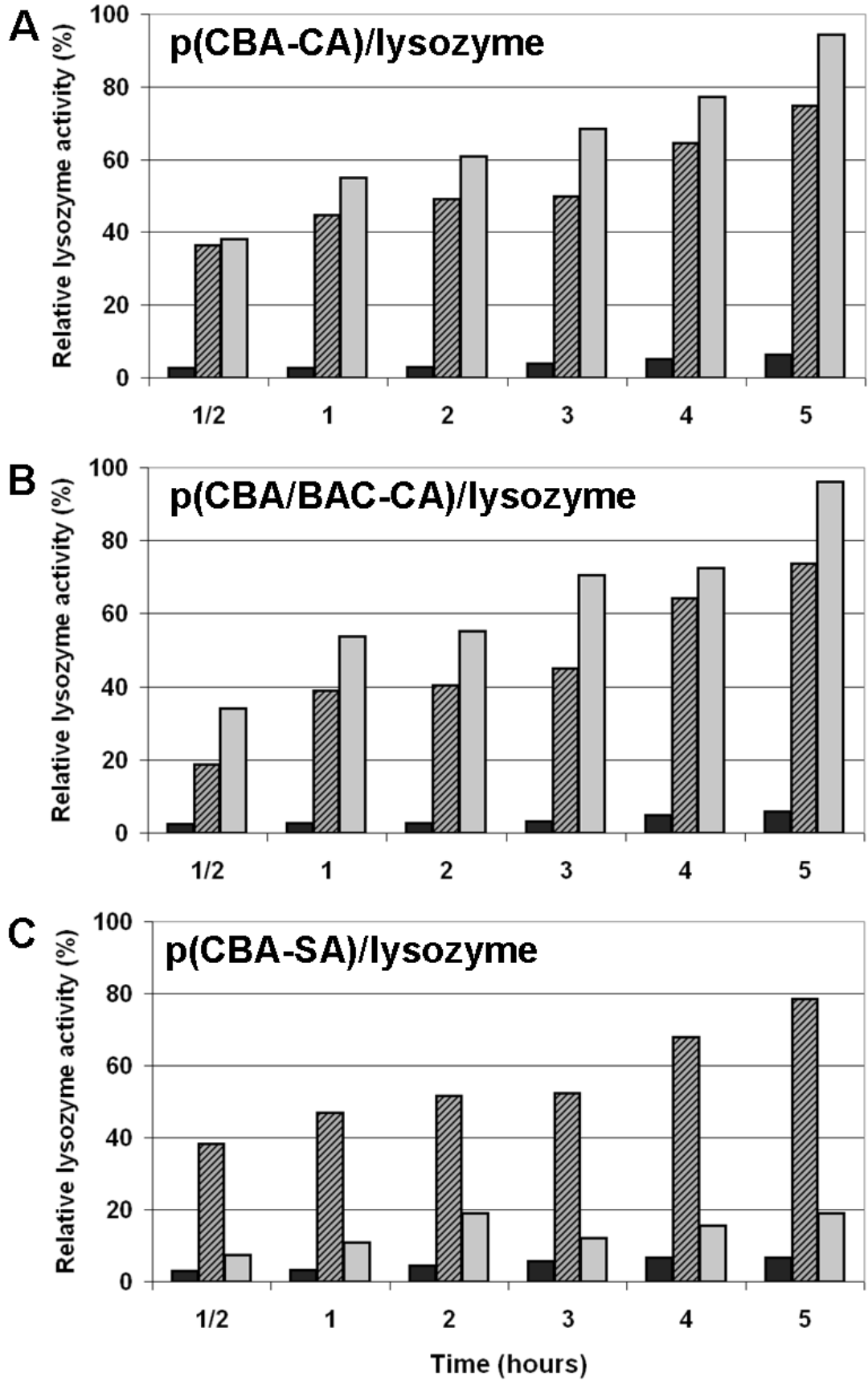

Figure 4.7. Relative lysozyme activity of the SS-PAA/lysozyme nanoparticles, at $\mathrm{pH} 7.4$ (dark bars), at pH 7.4 after addition of DTT to $2.5 \mathrm{mM}$ final concentration (dark striped bars), and at pH 5 (grey bars), measured using the EnzCheck ${ }^{\circledR}$ lysozyme assay, an assay from Invitrogen, using p(CBA-CA) $(\mathrm{A}), \mathrm{p}(\mathrm{CBA} / \mathrm{BAC}-\mathrm{CA})(\mathrm{B})$, and $\mathrm{p}(\mathrm{CBA}-\mathrm{SA})(\mathrm{C})$ as polymeric carriers. 


\subsubsection{After release by polymer bioreduction in lysozyme-loaded nanoparticles}

As shown in Table 4.3 column B, the presence of intracellular reductive agents induces the release of lysozyme from the SS-PAA/lysozyme nanoparticles. The activities of lysozyme released from the nanoparticles after DTT reduction are illustrated in Figure 4.7. As previously noted, almost no lysozyme activity was observed for over 5 hours for all three different nanoparticle systems at $\mathrm{pH} 7.4$ and in the absence of reducing agent. However, after addition of $2.5 \mathrm{mM}$ DTT, mimicking the intracellular reducing activity, the lysozyme released from all three SS-PAA/lysozyme nanoparticles reached an activity of about $80 \%$ of the original activity of free lysozyme in solution after 5 hours. This is an indication that, once the nanoparticles are internalized in the cells, the enzyme is released with almost completely recovered enzymatic activity due to the reduction of the disulfide linkages in the main chain of the SS-PAA polymers.

Hence, from the two previous experiments based on the measurements of the activity of released lysozyme from lysozyme-loaded SS-PAA nanoparticles, it can be concluded that the encapsulation in the citraconic derivative SS-PAA polymers prevents the enzyme to display its activity in a neutral extracellular environment, but once the nanoparticle is internalized in the cell, lysozyme will be released with almost complete recovered activity due to the charge-reversal of the polymer side chains in the endosomes and the polymer degradation by reduction in the cytosol. This bioresponsive off-on switching of the enzymatic activity in these nanoparticles is a promising property for minimizing off-target effects in targeting delivery.

\subsection{Cellular uptake and cytotoxicity of the SS-PAA/Iysozyme nanoparticles in vitro}

\subsubsection{Detection of cell viability and cytotoxicity after treatment with different polymers}

In order to establish the optimal concentration of polymer for the preparation of the nanoparticles for intracellular lysozyme delivery, first the effects of the SS-PAA/lysozyme nanoparticles on cell viability and cytotoxicity on human endothelial cells were determined by using an MTS and LDH assay, measuring the percentage of metabolic active cells, and the percentage of dead cells, respectively.

Therefore, primary umbilical vein endothelial cells (Huvec) were incubated with different

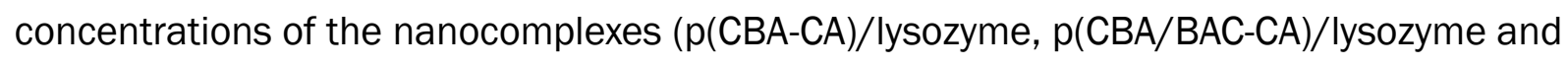
$\mathrm{p}(\mathrm{CBA}-\mathrm{SA}) /$ lysozyme) for 24 hours. No reduction of cell viability after the treatment with SS-PAA/lysozyme nanoparticles with a concentration range from $45 \mu \mathrm{g} / \mathrm{ml}$ to $180 \mu \mathrm{g} / \mathrm{ml}$ was detected. However, at the high concentration of $360 \mu \mathrm{g} / \mathrm{ml}$ of the SS-PAA/lysozyme 
nanoparticles a slight decrease in cell viability was observed with viabilities of $80 \%$ for $\mathrm{p}(\mathrm{CBA}-\mathrm{CA}) /$ lysozyme and $\mathrm{p}(\mathrm{CBA} / \mathrm{BAC}-\mathrm{CA}) /$ lysozyme nanocomplexes and $88 \%$ for $\mathrm{p}(\mathrm{CBA}-\mathrm{SA}) /$ lysozyme nanoparticles, compared to the untreated control (Figure 4.8A). The cytotoxic effect of the SS-PAA/lysozyme nanocomplexes was assessed by examining the release of LDH into the supernatant (Figure 4.8B). The amount of released LDH, as determined by a colorimetric LDH enzyme reaction, is proportional to the number of lysed cells. In this assay no cytotoxic effect (extra LDH release) was observed on the cells compared to the untreated control cells. In addition, Alexa Fluor ${ }^{\circledR} 488$ labeled lysozyme (which was used as carrier model protein) alone did not affect cell viability nor caused cytotoxicity (data not shown).

A

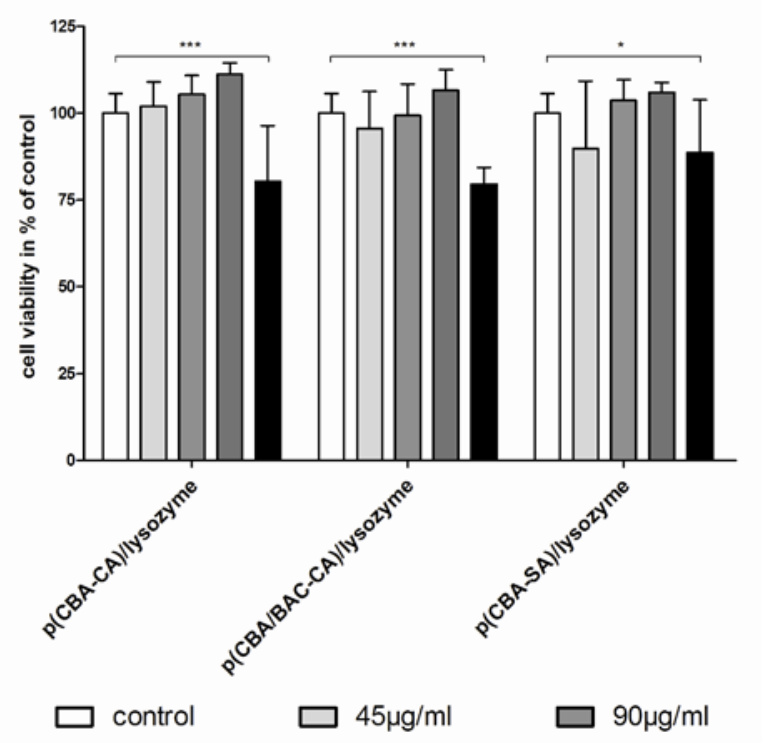

B

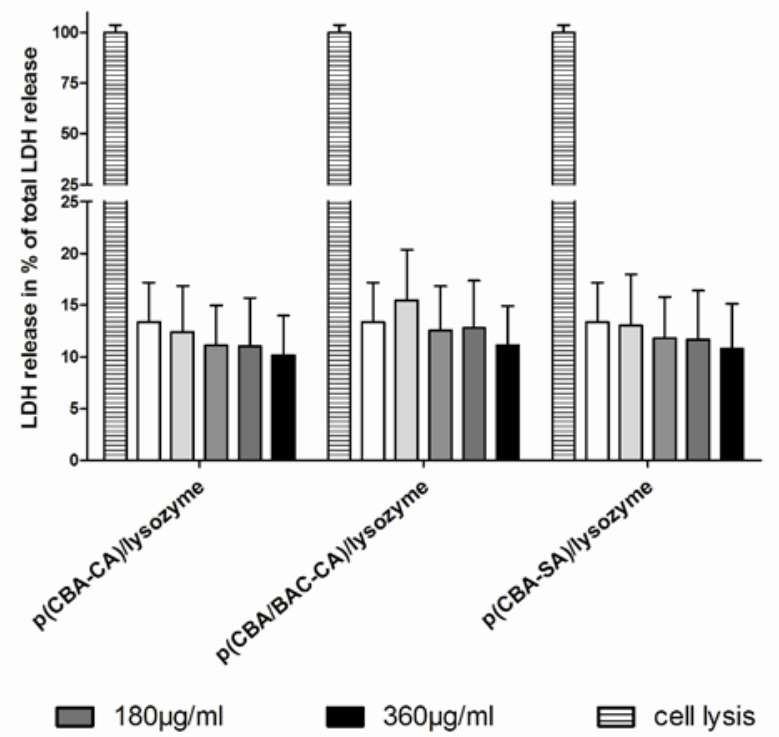

Figure 4.8. Cell viability (A) and cytotoxicity (B) of Huvec cells after treatment with different concentrations of $\mathrm{p}(\mathrm{CBA}-\mathrm{CA}) /$ lysozyme, $\mathrm{p}(\mathrm{CBA} / \mathrm{BAC}-\mathrm{CA}) /$ lysozyme and $\mathrm{p}(\mathrm{CBA}-\mathrm{SA})$ /lysozyme nanocomplexes for 24 hours

(A) 10000 human umbilical vein endothelial cells were incubated with different amounts of polymers. After 24 hours, cell viability was determined by using MTS assay. Untreated cells were used as control and set to $100 \%$ cell viability. (B) After 24 hours the supernatants of the cells were collected and used to determine cytotoxicity by measuring the activity of released lactate dehydrogenases (LDH). The supernatant of untreated cells was used as control (for the amount of spontaneous LDH release), while the supernatant after cell lysis was used for the determination of $100 \%$ cytotoxicity. The results represent the means of three different experiments and three replicates ( \pm standard deviation; $\mathrm{n}=$ at least $7 ; * * *: \mathrm{p}<0.001, *$ : $\mathrm{p}<0,05$; two-way ANOVA, Bonferroni post-tests). 


\subsubsection{Cellular uptake of the different polymers in primary human umbilical vein endothelial cells}

Based on the cell viability assay, a concentration of $300 \mu \mathrm{g} / \mathrm{ml}$ of polymer was chosen in the preparation and use of the SS-PAA/lysozyme nanoparticles for intracellular delivery. The uptake of the different SS-PAA/lysozyme nanoparticles was investigated by confocal laser scanning microscopy. Alexa Fluor 488 labeled lysozyme was used as the payload in the SS-PAA/Iysozyme nanoparticles, and in this way the location of the fluorescently labeled lysozyme could be observed through the green channel. The cell membranes and nuclei were also stained and were visualized through the red and blue channels, respectively. Figure 4.9 shows the results after 30 hours of exposure of Huvec cells to free lysozyme (A) and lysozyme incorporated in nanoparticles of $p(C B A-C A)$ (B), $p(C B A / B A C-C A)(C)$ and $p(C B A-S A)(D)$. As can be seen in Figure 4.9A, free lysozyme was also internalized in the cells, which may be caused by the highly cationic nature of this enzyme. Although the amount of internalized polymers and lysozyme was not quantified, Figures 4.9B, 4.9C and 9D show a significant increase in the amount of internalized lysozyme from the SS-PAA/lysozyme nanocomplexes compared to free lysozyme, especially when applying $\mathrm{p}(\mathrm{CBA} / \mathrm{BAC}-\mathrm{CA}) /$ lysozyme nanoparticles. Therefore, it can be concluded that the complexation of lysozyme in the SS-PAA/lysozyme nanoparticles improves the internalization of the enzyme, compared to unbound lysozyme. Moreover, it was noticed that the lysozyme from the internalized SS-PAA/lysozyme nanoparticles was primarily located in the perinuclear region. In all cases, none of the internalized lysozyme from the nanocomplexes was detected in the nucleus. 

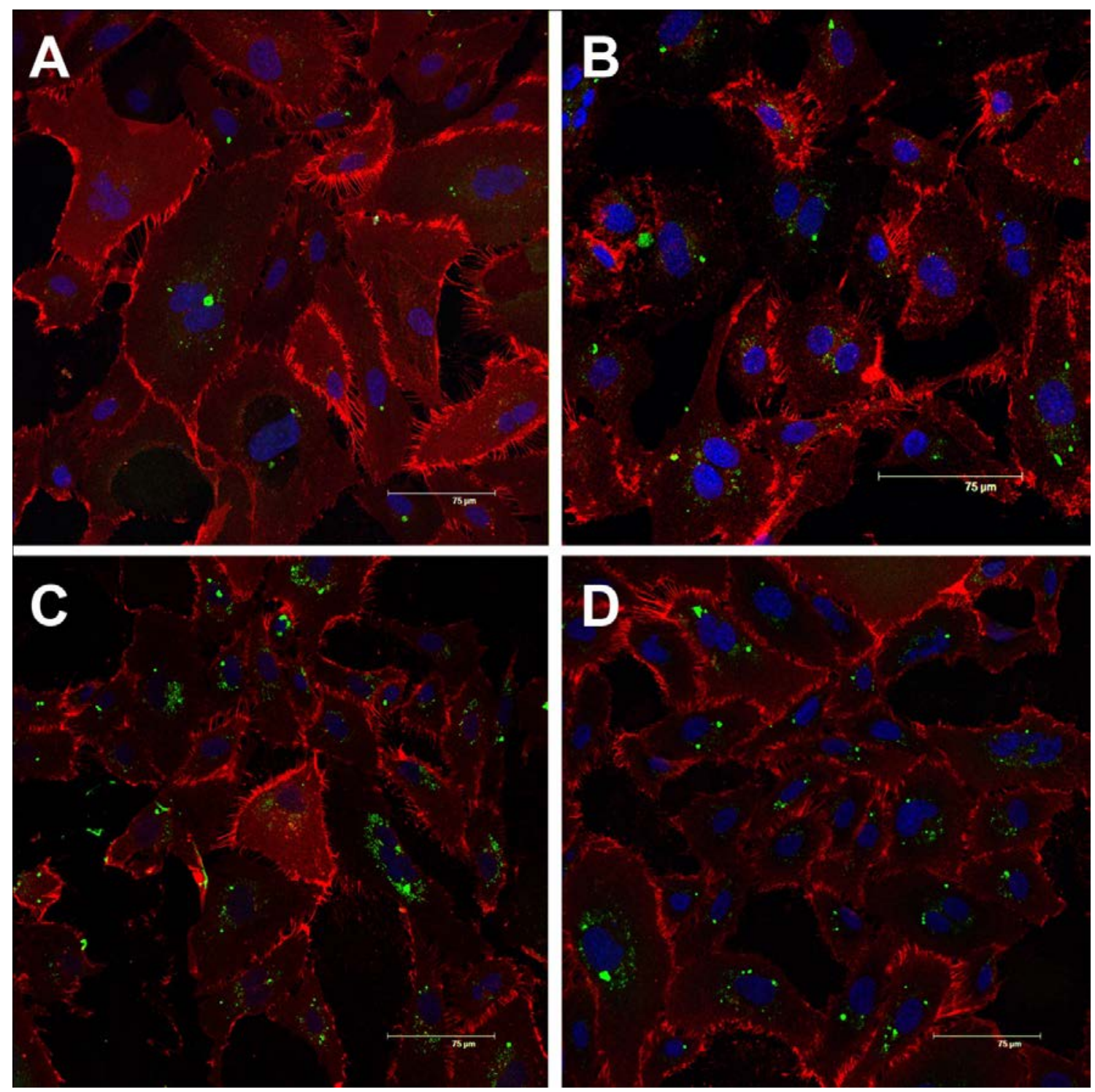

Figure 4.9. Internalization of AF488-lysozyme after 30 hours of exposure to cells. Confocal laser scanning microscopy images (40x); scale bar $75 \mu \mathrm{m}$.

Huvec were exposed to $300 \mu \mathrm{g} / \mathrm{ml}$ of different polymers for 30 hours. Afterwards cells were fixed and the membranes were stained with primary antibody against CD31 and the appropriate Alexa 546 secondary antibody (cell membranes in red). The nuclei were stained with Hoechst dye (blue). The green dots correspond to AF488-lysozyme, which are mostly located around the nuclei. In (A) the cells were just incubated with free AF488-lysozyme. The uptake of AF488-lysozyme from $\mathrm{p}(\mathrm{CBA}-\mathrm{CA}) /$ lysozyme nanoparticles is presented in (B), from $\mathrm{p}(\mathrm{CBA} / \mathrm{BAC}-\mathrm{CA}) /$ lysozyme nanoparticles in $(C)$, while the internalization of AF488-lysozyme from $p(C B A-S A) / l y s o z y m e$ nanoparticles is shown in (D). 


\section{Conclusions}

We have developed novel poly(amidoamine)s with disulfide linkages in their main chain and negatively charged citraconic amide functionalities in the side chain as an attractive category of bioresponsive polymers capable to form stable self-assembling nanoparticles with cationic proteins such as lysozyme at neutral $\mathrm{pH}$ conditions. Once encapsulated in the polymeric nanoparticles the enzyme activity of lysozyme is fully blocked. However, the intrinsic enzyme activity of lysozyme is (almost) fully preserved after encapsulation in the nanoparticles (i.e. no denaturation occurs). Experiments that mimic the chemical properties of the intracellular environment (i.e. pH decrease in the endosomes and high reduction potential inside the cells) have shown the enzyme is readily released with (almost) full recovery of activity due to disintegration of the nanoparticles at acidic $\mathrm{pH}$ by increasing repulsive electrostatic interaction caused by inversion of the charge in the side groups of the polymers from anionic (citraconic amide) to cationic (protonated amine) and the cleavage of the disulfide linkages in the intracellular reducing environment. These properties render these novel polymers very promising in the development of potent intracellular protein delivery systems.

\section{Acknowledgements}

This work is part of the Integrated European project Nanobiopharmaceutics, www.nanobiopharmaceutics.org

\section{References}

[1] O. Boussif, F. Lezoualch, M.A. Zanta, M.D. Mergny, D. Scherman, B. Demeneix, J.P. Behr, A Versatile Vector for Gene and Oligonucleotide Transfer into Cells in Culture and in-Vivo Polyethylenimine. Proc. Natl. Acad. Sci. U. S. A. 92(16) (1995) 7297-7301.

[2] M. Oishi, K. Kataoka, Y. Nagasaki, pH-responsive three-layered PEGylated polyplex micelle based on a lactosylated $\mathrm{ABC}$ triblock copolymer as a targetable and endosome-disruptive nonviral gene vector. Bioconjugate Chem. 17(3) (2006) 677-688.

[3] Y. Bae, S. Fukushima, A. Harada, K. Kataoka, Design of environment-sensitive supramolecular assemblies for intracellular drug delivery: Polymeric micelles that are responsive to intracellular pH change. Angew. Chem.-Int. Edit. 42(38) (2003) 4640-4643.

[4] J. Heller, J. Barr, S.Y. Ng, K.S. Abdellauoi, R. Gurny, Poly(ortho esters): synthesis, characterization, properties and uses. Adv. Drug Deliv. Rev. 54(7) (2002) 1015-1039.

[5] N. Murthy, Y.X. Thng, S. Schuck, M.C. Xu, J.M.J. Frechet, A novel strategy for encapsulation and release of proteins: Hydrogels and microgels with acid-labile acetal cross-linkers. J. Am. Chem. Soc. 124(42) (2002) 12398-12399.

[6] Y. Lee, S. Fukushima, Y. Bae, S. Hiki, T. Ishii, K. Kataoka, A protein nanocarrier from charge-conversion polymer in response to endosomal pH. J. Am. Chem. Soc. 129(17) (2007) 5362-5363.

[7] P.S. Xu, E.A. Van Kirk, Y.H. Zhan, W.J. Murdoch, M. Radosz, Y.Q. Shen, Targeted 
charge-reversal nanoparticles for nuclear drug delivery. Angew. Chem.-Int. Edit. 46(26) (2007) 4999-5002.

[8] A.E. Habibi, K. Khajeh, M. Nemat-Gorgani, Chemical modification of lysine residues in Bacillus licheniformis alpha-amylase: Conversion of an endo- to an exo-type enzyme. J. Biochem. Mol. Biol. 37(6) (2004) 642-647.

[9] S. Mossavarali, S. Hosseinkhani, B. Ranjbar, M. Mirohaei, Stepwise modification of lysine residues of glucose oxidase with citraconic anhydride. Int. J. Biol. Macromol. 39(4-5) (2006) 192-196.

[10] K. Khajeh, H. Naderi-Manesh, B. Ranjbar, A.A. Moosavi-Movahedi, M. Nemat-Gorgani, Chemical modification of lysine residues in Bacillus alpha-amylases: effect on activity and stability. Enzyme Microb. Technol. 28(6) (2001) 543-549.

[11] M.M. Mir, K.M. Fazili, M.A. Qasim, Chemical Modification of Buried Lysine Residues of Bovine Serum-Albumin and Its Influence on Protein Conformation and Bilirubin Binding. Biochim Biophys Acta 1119(3) (1992) 261-267.

[12] J.G. Bindels, L.W. Misdom, H.J. Hoenders, The Reaction of Citraconic Anhydride with Bovine Alpha-Crystallin Lysine Residues - Surface Probing and Dissociation-Reassociation Studies. Biochim Biophys Acta 828(3) (1985) 255-260.

[13] J.K. Shetty, J.E. Kinsella, Ready Separation of Proteins from Nucleoprotein Complexes by Reversible Modification of Lysine Residues. Biochem. J. 191(1) (1980) 269-272.

[14] M. Sanjoh, S. Hiki, Y. Lee, M. Oba, K. Miyata, T. Ishii, K. Kataoka, pDNA/poly(L-lysine) Polyplexes Functionalized with a pH-Sensitive Charge-Conversional Poly(aspartamide) Derivative for Controlled Gene Delivery to Human Umbilical Vein Endothelial Cells. Macromol. Rapid Commun. 31(13) (2010) 1181-1186.

[15] Y. Lee, T. Ishii, H.J. Kim, N. Nishiyama, Y. Hayakawa, K. Itaka, K. Kataoka, Efficient Delivery of Bioactive Antibodies into the Cytoplasm of Living Cells by Charge-Conversional Polyion Complex Micelles. Angew. Chem.-Int. Edit. 49(14) (2010) 2552-2555.

[16] Y. Lee, T. Ishii, H. Cabral, H.J. Kim, J.H. Seo, N. Nishiyama, H. Oshima, K. Osada, K. Kataoka, Charge-Conversional Polyionic Complex Micelles-Efficient Nanocarriers for Protein Delivery into Cytoplasm. Angew. Chem.-Int. Edit. 48(29) (2009) 5309-5312.

[17] H. Mok, J.W. Park, T.G. Park, Enhanced intracellular delivery of quantum dot and adenovirus nanoparticles triggered by acidic $\mathrm{pH}$ via surface charge reversal. Bioconjugate Chem. 19(4) (2008) 797-801.

[18] J.D. Eichman, A.U. Bielinska, J.F. Kukowska-Latallo, J.R. Baker Jr, The use of PAMAM dendrimers in the efficient transfer of genetic material into cells. Pharmaceut Sci Tech Today 3(7) (2000) 232-245.

[19] E. Ranucci, G. Spagnoli, P. Ferruti, D. Sgouras, R. Duncan, Poly(amidoamine)s with potential as drug carriers: degradation and cellular toxicity. J Biomater Sci Polym Ed 2(4) (1991) 303-315.

[20] G.Y. Wu, C.H. Wu, Receptor-Mediated Invitro Gene Transformation by a Soluble DNA Carrier System. J. Biol. Chem. 262(10) (1987) 4429-4432.

[21] P. Ferruti, E. Ranucci, F. Bignotti, L. Sartore, P. Bianciardi, M.A. Marchisio, Degradation Behavior of Ionic Stepwise Polyaddition Polymers of Medical Interest. J. Biomater. Sci.-Polym. Ed. 6(9) (1995) 833-844.

[22] P. Ferruti, E. Ranucci, L. Sartore, F. Bignotti, M.A. Marchisio, P. Bianciardi, F.M. Veronese, Recent Results on Functional Polymers and Macromonomers of Interest as Biomaterials or for Biomaterial Modification. Biomaterials 15(15) (1994) 1235-1241.

[23] J. Franchini, E. Ranucci, P. Ferruti, Synthesis, physicochemical properties, and preliminary biological characterizations of a novel amphoteric agmatine-based poly(amidoamine) with RGD-like repeating units. Biomacromolecules 7(4) (2006) 1215-1222.

[24] P. Ferruti, M.A. Marchisio, R. Duncan, Poly(amido-amine)s: Biomedical applications. Macromol. Rapid Commun. 23(5-6) (2002) 332-355.

[25] J. Franchini, P. Ferruti, Perspectives on: Recent advances in poly(amidoamine)s chemistry. J. Bioact. Compat. Polym. 19(3) (2004) 221-236.

[26] N. Lavignac, M. Lazenby, J. Franchini, P. Ferruti, R. Duncan, Synthesis and preliminary evaluation of poly(amidoamine)-melittin conjugates as endosomolytic polymers and/or 
N. Lavignac, J.L. Nicholls, P. Ferruti, R. Duncan, Poly(amidoamine) Conjugates Containing Doxorubicin Bound via an Acid-Sensitive Linker. Macromol. Biosci. 9(5) (2009) 480-487.

[28] N.G. Pattrick, S.C.W. Richardson, M. Casolaro, P. Ferruti, R. Duncan, Poly(amidoamine)-mediated intracytoplasmic delivery of ricin A-chain and gelonin. J Control Release 77(3) (2001) 225-232.

[29] S.C.W. Richardson, N.G. Pattrick, Y.K.S. Man, P. Ferruti, R. Duncan, Poly(amidoamine)s as potential nonviral vectors: Ability to form interpolyelectrolyte complexes and to mediate transfection in vitro. Biomacromolecules 2(3) (2001) 1023-1028.

[30] G. Coué, J.F.J. Engbersen, Functionalized linear poly(amidoamine)s are efficient vectors for intracellular protein delivery. J Control Release (2011), doi:10.1016/j.jconrel.2011.01.023.

[31] G. Coué, J. Feijen, J.F.J. Engbersen, Development of biodegradable poly(amidoamine)s for protein delivery. J Control Release 132(3) (2008) e2-e3.

[32] C. Lin, C.-J. Blaauboer, M.M. Timoneda, M.C. Lok, M. van Steenbergen, W.E. Hennink, Z. Zhong, J. Feijen, J.F.J. Engbersen, Bioreducible poly(amido amine)s with oligoamine side chains: Synthesis, characterization, and structural effects on gene delivery. J Control Release 126(2) (2008) 166-174.

[33] C. Lin, Z. Zhong, M.C. Lok, X. Jiang, W.E. Hennink, J. Feijen, J.F.J. Engbersen, Linear poly(amido amine)s with secondary and tertiary amino groups and variable amounts of disulfide linkages: Synthesis and in vitro gene transfer properties. J Control Release 116(2) (2006) 130-137.

[34] C. Lin, Z. Zhong, M.C. Lok, X. Jiang, W.E. Hennink, J. Feijen, J.F.J. Engbersen, Random and block copolymers of bioreducible poly(amido amine)s with high- and low-basicity amino groups: Study of DNA condensation and buffer capacity on gene transfection. J Control Release 123(1) (2007) 67-75.

[35] C. Lin, Z.Y. Zhong, M.C. Lok, X.L. Jiang, W.E. Hennink, J. Feijen, J.F.J. Engbersen, Novel bioreducible poly(amido amine)s for highly efficient gene delivery. Bioconjugate Chem. 18(1) (2007) 138-145.

[36] M.A. Mateos-Timoneda, M.C. Lok, W.E. Hennink, J. Feijen, J.F.J. Engbersen, Poly(amido amine)s as gene delivery vectors: Effects of quaternary nicotinamide moieties in the side chains. ChemMedChem 3(3) (2008) 478-486.

[37] C. Lin, J.F.J. Engbersen, The role of the disulfide group in disulfide-based polymeric gene carriers. Expert Opin Drug Deliv 6(4) (2009) 421-439.

[38] A. Bernkop-Schnürch, Thiomers: A new generation of mucoadhesive polymers. Adv. Drug Deliv. Rev. 57(11) (2005) 1569-1582.

[39] E.P. Feener, W.C. Shen, H.J.P. Ryser, Cleavage of Disulfide Bonds in Endocytosed Macromolecules - a Processing Not Associated with Lysosomes or Endosomes. J. Biol. Chem. 265(31) (1990) 18780-18785.

[40] D.A. Giljohann, D.S. Seferos, W.L. Daniel, M.D. Massich, P.C. Patel, C.A. Mirkin, Gold Nanoparticles for Biology and Medicine. Angew. Chem.-Int. Edit. 49(19) (2010) 3280-3294.

[41] D.A. Giljohann, D.S. Seferos, A.E. Prigodich, P.C. Patel, C.A. Mirkin, Gene Regulation with Polyvalent siRNA-Nanoparticle Conjugates. J. Am. Chem. Soc. 131(6) (2009) 2072-+.

[42] N.L. Rosi, D.A. Giljohann, C.S. Thaxton, A.K.R. Lytton-Jean, M.S. Han, C.A. Mirkin, Oligonucleotide-modified gold nanoparticles for intracellular gene regulation. Science 312(5776) (2006) 1027-1030.

[43] M.D. Massich, D.A. Giljohann, A.L. Schmucker, P.C. Patel, C.A. Mirkin, Cellular Response of Polyvalent Oligonucleotide-Gold Nanoparticle Conjugates. ACS Nano 4(10) (2010) 5641-5646.

[44] Udenfrie.S, S. Stein, P. Bohlen, W. Dairman, Fluorescamine - Reagent for Assay of Amino-Acids, Peptides, Proteins, and Primary Amines in Picomole Range. Science 178(4063) (1972) 871-872. 


\section{Chapter 5}

\section{Bioreducible insulin-loaded nanoparticles and their interaction with model lipid membranes}

Rickard Frost ${ }^{1}$, Grégory Coué ${ }^{2}$, Johan F. J. Engbersen², Michael Zäch ${ }^{1}$, Bengt Kasemo ${ }^{1}$ and Sofia Svedhem ${ }^{1}$

1 Department of Applied Physics, Chalmers University of Technology, SE-412 96 Göteborg, Sweden.

2 Department of Biomedical Chemistry, MIRA Institute for Biomedical Technology \& Technical Medicine, Faculty of Science and Technology, University of Twente, P.O. Box 217, 7500 AE Enschede, The Netherlands

Part of this chapter has been published: R. Frost, G. Coué, J.F.J. Engbersen, M. Zäch, B. Kasemo and S. Svedhem, Bioreducible insulin-loaded nanoparticles and their interaction with model lipid membranes, J. Colloid Interface Sci., submitted

Abstract: To improve design processes in the field of nanomedicine, in vitro characterization of nanoparticles with systematically varied properties is of great importance. In this study, surface sensitive analytical techniques were used to evaluate the responsiveness of nano-sized drug-loaded polyelectrolyte complexes when adsorbed to model lipid membranes. Two bioreducible poly(amidoamine)s (PAAs) containing multiple disulfide linkages in the polymer backbone (SS-PAAs) were synthesized and used to form three types of nanocomplexes by self-assembly with human insulin, used as a negatively charged model protein at neutral $\mathrm{pH}$. The resulting nanoparticles collapsed on top of negatively charged model membranes upon adsorption, without disrupting the membrane integrity. These structural rearrangements may occur at a cell surface which would prevent uptake of intact nanoparticles. By the addition of glutathione, the disulfide linkages in the polymer backbone of the SS-PAAs were reduced, resulting in fragmentation of the polymer and dissociation of the adsorbed nanoparticles from the membrane. A decrease in ambient $\mathrm{pH}$ also resulted in destabilization of the nanoparticles 
and desorption from the membrane. These mimics of intracellular environments suggest dissociation of the drug formulation, a process that releases the protein drug load, when reaching the interior of a cell.

\section{Introduction}

The advancement of biotechnology has resulted in the discovery of many therapeutic peptides and proteins which in most of the cases should exert their pharmaceutical action inside the cytoplasm or onto individual organelles inside the cell [1-6]. Negatively charged cell membranes prevent proteins and peptides as other therapeutics with anionic character from entering cells by charge repulsion. Moreover, internalized proteins can be subject to lysosomal degradation. Several strategies to overcome these difficulties have been investigated, and the utilization of polymer-based nanocarriers has emerged as a promising and versatile approach because of their facile transformation and possibilities to tune properties including subcellular size, biodegradability, and biocompatibility $[7,8]$. In particular, positively charged polymeric nanoparticles have been shown to promote transcytosis in epithelial cells [9-11].

Recently, nano-sized polyelectrolyte complexes (PECs) resulting from the self-assembly of proteins with natural or synthetic polymers have attracted increasing attention for applications in therapeutic protein delivery [12-15]. In this non-covalent nanoassembly method, PECs are formed by simply mixing oppositely charged drug and polymer that will interact by electrostatic attraction. For instance, the PEC formation of anionic proteins and cationic polymers can be used for the preparation of homogeneous and stable dispersions of nanoparticles possessing cationic charges in overall, as schematically represented in Scheme 5.1. Moreover, this formulation methodology has the advantage of not requiring sonication or organic solvents which are both harmful for proteins and peptides and are regularly used for the preparation of nanoparticles notably by the double emulsion technique. One attractive class of polymers commonly used for PEC-based drug formulation is poly(aminoamine)s (PAAs), which can be easily synthesized by Michael-type polyaddition of primary or bis-secondary amines to bis(acrylamide)s [16, 17]. These polymers are water-soluble, biodegradable and biocompatible, and less cytotoxic than other common polycationic vectors [18-21]. PAAs have been found to be particularly suitable for use as intracytoplasmic and endosomolytic vectors for the delivery of anticancer drugs [22, 23], proteins [24-26], and nucleic acids [25, 27, 28]. A useful design strategy for drug release inside the cytosol is to introduce repetitive 
disulphide bonds in the polymer backbone [29-31]. Such polymers are relatively stable in extracellular medium but, due to the presence of repetitive disulfide linkages, are prone to fast degradation in the reductive intracellular environment. This property can be used in systems that should be relatively stable during transport outside the cell but should disintegrate in fragments of low molecular weight after uptake into the target cells. Recent studies on gene delivery have shown that novel linear PAAs containing repetitive disulfide linkages in their backbone (SS-PAAs) are able to condense DNA into nano-scaled, positively charged, and non-toxic polyplexes leading to transfection efficiencies much higher than those of the reference polymer (polyethylenimine (PEI)) and their counterparts lacking disulfide linkages [32-36]. Similar functionalized PAAs also have also been investigated for protein delivery, and were shown to have a great potential to function as vectors for intracellular protein delivery [37].
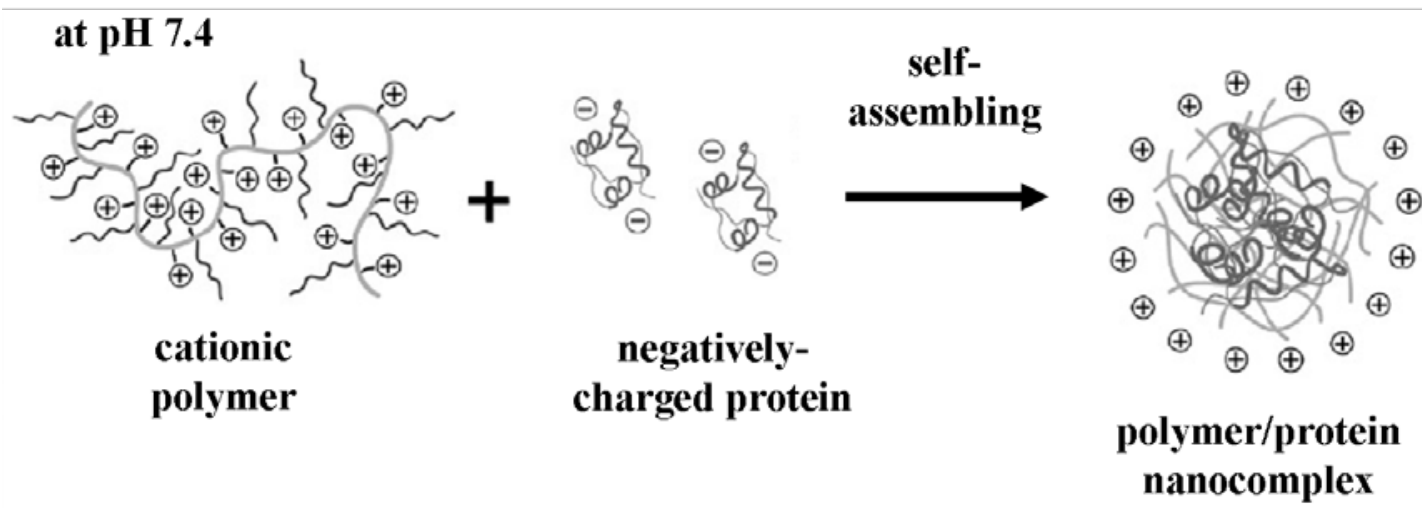

Scheme 5.1. Self-assembly formation of nanocomplexes at neutral $\mathrm{pH}$ by charge attraction between a negatively charged protein and a positively charged polymer, such as cationic PAAs.

In this study we present a series of cationic SS-PAAs which we hypothesized would self-assemble with negatively charged proteins to form nano-sized particles (hereafter referred to as nanoparticles, NPs) by charge attraction, hydrophilic, and hydrophobic interactions. We selected human insulin as a negatively charged model protein at neutral $\mathrm{pH}$. NPs were prepared at pH 7.4 by self-assembly of the model protein and two cationic SS-PAAs, and their properties were evaluated in vitro. The overall design idea is to obtain protein-loaded NPs which are stable in the extracellular environment, which show efficient intracellular uptake, and which eventually release their therapeutic active protein load due to the sensitivity to bioenvironmental triggering, such as endosomal $\mathrm{pH}$ decrease and intracellular degradation. To support this process and to advance the development of 
novel nanodrugs in general, there is a need for better methods for in vitro characterization. Therefore, an important part of the evaluation of the properties of the newly designed NPs uses a platform for real-time monitoring of nanodrug interactions at a model lipid membrane interface, based on surface-sensitive analytical techniques and supported lipid membranes (here negatively charged). The usefulness of this approach to study structural rearrangement of protein-loaded and electrostatically assembled NPs adsorbed to model membranes is demonstrated. The experimental platform has also been applied to evaluate the NP response towards a decrease in ambient pH as well as to the presence of reducing agents, as is occurring after endosomal uptake and exposure to the intracellular environment. The model membranes in this study were designed to mimic the negative charge of native cell membranes and were formed using two common and naturally occurring phospholipids, POPC and POPS. POPC is the most common phospholipid in cell membranes and has a neutral charge, while POPS, which is important for cell signaling, holds a net negative charge. The main methods of analysis have been quartz crystal microbalance with dissipation monitoring (QCM-D) and atomic force microscopy (AFM).

\section{Materials and methods}

\subsection{Materials}

Human insulin was kindly supplied by Novo Nordisk (Denmark). FITC-insulin was obtained from Sigma-Aldrich. All monomers, 4-amino-1-butanol (ABOL, Sigma-Aldrich), alpha-amino-omega-carboxy-poly(ethylene glycol) hydrochloride (PEG $\mathrm{M}_{\mathrm{w}} 3000 \mathrm{~g} / \mathrm{mol}$ ) (cPEG-NH $\mathrm{NH}_{2}$, Iris Biotech $\mathrm{GmbH}$ ), and $N, N^{\prime}$-cystaminebisacrylamide (CBA, Polysciences) were purchased in the highest purity and used without further purification. 4-(2-Hydroxyethyl)-1-piperazineethanesulfonic acid (HEPES, Sigma-Aldrich), glutathione (Sigma-Aldrich), 2-(N-morpholino)ethanesulfonic acid (MES, Sigma-Aldrich), and methanol (Biosolve) were used as received. Phosphate buffered saline (PBS) was prepared from tablets $(0.0015 \mathrm{M}$ potassium dihydrogen phosphate, $0.0081 \mathrm{M}$ disodium hydrogen phosphate, $0.0027 \mathrm{M}$ potassium chloride and $0.137 \mathrm{M}$ sodium chloride, pH 7.4, Sigma Aldrich). Deionized water (DI water) was obtained from a MilliQ-water purification system (Millipore, France). Model lipid membranes were prepared form 1-palmitoyl-2-oleyl-sn-glycero-3-phosphocholine (POPC) and 1-palmitoyl-2-oleyl-sn-glycero-3-phospho-L-serine (POPS) (Avanti Polar Lipids Inc., USA). 


\subsection{Synthesis of SS-PAAs: $p(C B A-A B O L)$ and cPEG-p(CBA-ABOL)}

Two SS-PAA polymers, $p(C B A-A B O L)$ and $c P E G-p(C B A-A B O L)$, were synthesized via Michael polyaddition of the primary amine monomers $\mathrm{ABOL}$ and $\mathrm{CPEG}-\mathrm{NH}_{2}$ to $\mathrm{CBA}$. Equimolar monomeric amine/acrylamide ratios were used to obtain PAAs of highest theoretical molecular weight.

For the synthesis of p(CBA-ABOL), as described in Chapter 3, CBA (2.63 g, $10 \mathrm{mmol}$ ) and $\mathrm{ABOL}(0.91 \mathrm{~g}, 10 \mathrm{mmol})$ were added into a brown reaction flask and dissolved in $\mathrm{MeOH} / \mathrm{DI}$ water mixture $(5 \mathrm{ml}, 4 / 1, \mathrm{v} / \mathrm{v})$.

The co-polymer cPEG-p(CBA-ABOL), with 10\% cPEG side chains relative to the hydroxybutyl groups, was synthesized via Michael polyaddition of the primary amine monomers, $A B O L$ and $\mathrm{CPEG}-\mathrm{NH}_{2}$, to the bisacrylamide CBA. Since the addition polymerization is a stepwise process, equimolar monomeric amine/acrylamide ratios were used in the synthesis in order to obtain SS-PAAs of highest theoretical molecular weight. CBA (2.63 g, $10 \mathrm{mmol}$ ), ABOL $(0.89 \mathrm{~g}, 9.8 \mathrm{mmol})$ and $\mathrm{CPEG}-\mathrm{NH}_{2}(0.67 \mathrm{~g}, 0.2 \mathrm{mmol})$ were added into a brown reaction flask and dissolved in a mixture $\mathrm{MeOH} / \mathrm{DI}$ water (4/1 v/v, $5 \mathrm{ml}$ ). The much lower ratio of $\mathrm{CPEG}-\mathrm{NH}_{2}$ was applied since it has been shown that $\mathrm{CPEG}-\mathrm{NH}_{2}$ has a preferential reactivity in the Michael addition and the PEGylated polymer is preferentially isolated after ultrafiltration.

For both reactions, polymerization was carried out in the dark at $45^{\circ} \mathrm{C}$ under nitrogen atmosphere. The reaction mixture became homogeneous in less than two hours, and the reaction was allowed to proceed for 10 days yielding to a viscous solution. During the polymerization a gradual increase in viscosity was observed. In all cases, gelation did not occur. In a final stage, $10 \mathrm{~mol} \%$ excess $\mathrm{ABOL}(0.09 \mathrm{~g}, 1 \mathrm{mmol})$ was added to the reaction mixture in order to consume any unreacted acrylamide groups after polymerization and ensure that all potentially toxic acrylamide end groups were consumed. Stirring was continued for two days at $45^{\circ} \mathrm{C}$. Subsequently, the resulting solution was diluted with $30 \mathrm{ml} \mathrm{DI}$ water, acidified with $4 \mathrm{M} \mathrm{HCl}$ aqueous solution to $\mathrm{pH} \sim 5$, and then purified and isolated by ultrafiltration operation ( $3 \mathrm{~kg} / \mathrm{mol}$ cut-off for $\mathrm{p}$ (CBA-ABOL), $5 \mathrm{~kg} / \mathrm{mol}$ cut-off for cPEG-p(CBA-ABOL)) with filtrated acidic DI water $(\mathrm{pH} \sim 5)$, followed by lyophilization.

\subsection{Polymer characterization}

The ${ }^{1} \mathrm{H}$ NMR spectra of the synthesized PAAs in $\mathrm{D}_{2} \mathrm{O}$ were recorded on Varian Inova spectrometer operating at $300 \mathrm{MHz}$. The molecular weight and polydispersity $\left(M_{w} / M_{n}\right)$ of the synthesized PAAs were determined by GPC relative to PEO standards (Polymer Labs) 
using a Viscotek GPCMax pump and autoinjector and two thermostated $\left(30^{\circ} \mathrm{C}\right) \mathrm{PL}$ aquagel-OH 30 columns $(8 \mu \mathrm{m}, 300 \times 7.5 \mathrm{~mm}$, Polymer Labs, with a low-molar-mass separation range (200 40,000)). Data was collected using a TDA302 Tripledetector with $\mathrm{RI}$, Visc and LS (7 and $\left.90^{\circ}\right)$ ). 0.3M NaAc aqueous solution ( $\left.\mathrm{pH} 4.4\right)$ with $30 \%$ methanol was used as eluent at a flow rate of $0.7 \mathrm{ml} / \mathrm{min}$ ).

\subsection{Preparation of SS-PAA/insulin nanoparticles}

We investigated the feasibility of nanoparticle formation between the positively charged SS-PAAs and negatively charged insulin by varying the polymer/protein weight ratios in order to obtain nanosystems with the best properties in terms of particle size, surface charge, loading efficiency and stability. SS-PAA/insulin nanocomplexes were prepared at different polymer/protein weight ratios ranging from $2 / 1$ to $48 / 1$ by adding a HEPES buffer solution $(10 \mathrm{mM}, \mathrm{pH}$ 7.4) of polymer $(800 \mu \mathrm{l})$ to a HEPES buffer solution $(10 \mathrm{mM}$, $\mathrm{pH} 7.4)$ of insulin $(200 \mu \mathrm{l}, 0.75 \mathrm{mg} / \mathrm{ml})$. DLS measurements showed that by increasing the polymer/insulin weight ratio, the particle size decrease to reach a plateau value at weight ratios higher than 12/1 (data not shown). These results show that at weight ratios higher than $12 / 1$ there is enough polymers to efficiently encapsulate the insulin. Higher polymer/insulin weight ratio would bring an excess of cationic polymer which might increase the surface charge of the particles and induce cytotoxicity (data not shown).

Based on these results and the experience of former SS-PAA/protein nanoparticles made of SS-PAAs and $\beta$-galactosidase as protein payload [37], we chose for this study to prepare all the SS-PAA/insulin nanocomplexes at polymer/insulin weight ratio $12 / 1$ by adding a HEPES buffer solution $(10 \mathrm{mM}, \mathrm{pH} 7.4)$ of polymer $(800 \mu \mathrm{l}, 2.25 \mathrm{mg} / \mathrm{ml})$ to a HEPES buffer solution $(10 \mathrm{mM}, \mathrm{pH} 7.4)$ of insulin $(200 \mu \mathrm{l}, 0.75 \mathrm{mg} / \mathrm{ml})$. The mixture was vortexed for 5 seconds and incubated at room temperature for 30 minutes. Subsequently, the NP suspensions were stored in $4^{\circ} \mathrm{C}$ and used within 24 hours.

\subsection{Characterization of SS-PAA/insulin nanoparticles}

\subsubsection{Particle size and zeta-potential measurements}

Particle size and zeta-potential measurements of the nanocomplexes were determined by dynamic light scattering (DLS) at $22^{\circ} \mathrm{C}$ with a Zetasizer Nano ZS (Malvern Instruments, Malvern, UK) using a wavelength of $532 \mathrm{~nm}$ and a detection angle of $173^{\circ}$. Presented sizes are based on distributions by intensity. Prior to analysis the NP suspensions were diluted to $90 \mu \mathrm{g} / \mathrm{ml}$ in $10 \mathrm{mM}$ HEPES, $\mathrm{pH}$ 7.4. Three batches of each type of NP were 
analyzed in triplicate.

\subsubsection{Insulin loading efficiency}

To estimate the loading efficiency of the nanoparticles at neutral $\mathrm{pH}$, particle solutions of SS-PAA/insulin nanoparticles were prepared at polymer/protein weight ratio 12/1 using FITC-labeled insulin. The nanoparticles were centrifuged at $14000 \mathrm{rpm}$ for 30 minutes at $4^{\circ} \mathrm{C}$. Aliquots of supernatant were subsequently taken and their protein content determined by fluorescence spectroscopy (Safire ${ }^{2}$, Tecan, Canada) at an emission wavelength of $519 \mathrm{~nm}$ and an excitation wavelength of $495 \mathrm{~nm}$. The actual loading efficiency was indirectly determined by measuring the difference between the total amount of insulin added to the solution and the amount of insulin in the free form in the supernatant. A calibration curve from solutions of various fluorescently-labeled insulin concentrations was determined prior to this experiment. It was confirmed that free insulin was not precipitated from the solution by centrifugation.

\subsubsection{Extrusion of lipid vesicles}

Lipid vesicles were prepared by the extrusion method from a 3:1 mixture of POPC and POPS lipids. A total of $6 \mathrm{mg}$ of lipids dissolved in chloroform was added to a round bottomed flask, and the solvent was evaporated under a flow of nitrogen to give a lipid film distributed around the inner wall of the flask. Residual solvent was removed under vacuum for at least one hour. The dried lipids were rehydrated in $1.2 \mathrm{ml}$ of PBS. The lipid suspension was then extruded 11 times through a $100 \mathrm{~nm}$ polycarbonate membrane and another 11 times through a $30 \mathrm{~nm}$ polycarbonate membrane using a mini extruder (Avanti Polar Lipids Inc., USA). The vesicle solution was stored at $4{ }^{\circ} \mathrm{C}$.

\subsubsection{Fabrication of $\mathrm{SiO}_{2}$-coated QCM-D crystals}

Au-coated QCM-D sensor crystals (Q-Sense, Sweden) with a fundamental resonance frequency of $5 \mathrm{MHz}$ were coated with an $100 \mathrm{~nm}$ adhesive layer of Ti followed, in situ, by $80 \mathrm{~nm}$ of $\mathrm{SiO}_{2}$ by thermal evaporation (HVC 600, AVAC). Prior to evaporation the crystals were cleaned in an ultrasonic bath (5 minutes in 2-propanol and 5 minutes in DI water) and in a microwave plasma system (250 W, 2 minutes, Plasma Strip TePla 300PC (TePla AG, Germany)). Thermal evaporation was initiated at a pressure of $<5 \cdot 10^{-6}$ mbar. Prior to use the crystals were treated with UV-ozone for $>30$ minutes. The sensor crystals were used repeatedly and stored in $10 \mathrm{mM}$ sodium dodecyl sulphate (SDS) between 
measurements.

\subsection{QCM-D experiments}

All QCM-D experiments were performed in an E4-instrument (Q-Sense, Sweden) at $22^{\circ} \mathrm{C}$ in flow mode. After stabilization of the baseline in PBS, a supported lipid membrane was formed using vesicles diluted to $0.1 \mathrm{mg} / \mathrm{ml}$ in PBS with $5 \mathrm{mM} \mathrm{MgCl}$. When the lipid membrane had been formed the buffer was exchanged to $10 \mathrm{mM}$ HEPES, pH 7.4. Next, the flow rate was decreased from $100 \mu \mathrm{l} / \mathrm{min}$ to $50 \mu \mathrm{l} / \mathrm{min}$ and NPs, diluted to $90 \mu \mathrm{g} / \mathrm{ml}$, were flowed over the lipid membrane for one hour before excess and reversibly bound NPs were rinsed away with buffer. NP interactions were mostly analyzed in 10 mM HEPES $(\mathrm{pH} 7.4)$, in some experiments with an addition of $5 \mathrm{mM}$ glutathione ( $\mathrm{pH}$ adjusted to 7.4 using $1 \mathrm{M} \mathrm{NaOH}$ ). NPs were also studied over a $\mathrm{pH}$ gradient from $\mathrm{pH} 7.3$ to 5.1 in a $10 \mathrm{mM}$ MES buffer, lasting for one hour. At the end of each experiment the ambient conditions were changed back to the same as prior to NP adsorption. All QCM-D data was evaluated using Q-tools (Q-Sense, Sweden). Presented frequency and dissipation shifts were recorded at the $9^{\text {th }}$ overtone and normalized by division with 9 . The thickness of the adsorbed NP layer was determined by Voigt based modeling and by the Sauerbrey equation ( $m_{\text {acoustic }}=C * \Delta \mathrm{f}_{\mathrm{z}=9}$ where $\mathrm{C}=-17.7 \mathrm{ng} /\left(\mathrm{cm}^{2} \mathrm{~Hz}\right)$ ) assuming a density of $1000 \mathrm{~kg} / \mathrm{m}^{3}$ of the adsorbed material and a viscosity of the buffer of $0.001 \mathrm{~kg} / \mathrm{ms}$.

\subsection{AFM experiments}

AFM imaging was carried out using a PicoSPM microscope (Agilent/Molecular Imaging Inc., Palo Alto, CA) and MSCT-AUNM MicroLever silicon nitride tips (Veeco Europe, Dourdan, France). The cantilevers used have a spring constant of $30 \mathrm{pN} / \mathrm{nm}$ and the tips a radius of curvature $<20 \mathrm{~nm}$ (according to specifications). Typical scan speeds were in the range 1.8-2.2 lines/s. All experiments were performed in $10 \mathrm{mM}$ HEPES buffer using constant-force contact mode with low imaging force. The fluid cell consisted of an o-ring pressed against the substrate (UV-ozone treated Si-wafer) with a customized holder. The fluid cell contained $300 \mu \mathrm{l}$ of liquid during imaging and all liquid exchanges (addition of vesicles or NPs and buffer rinse) were made by repeatedly adding and withdrawing $300 \mu \mathrm{l}$ of liquid. Images were treated and analyzed using the SPIP software version 3.0.0.9 (Image Metrology Inc., Ljungby, Denmark). Force spectroscopy experiments were performed with a constant approach / retraction speed of $v=280-560 \mathrm{~nm} / \mathrm{s}$, corresponding to a force loading rate $v k=8.40-16.8 \mathrm{nN} / \mathrm{s}$. Deflection-position raw data 
were converted to force-distance curves with SPIP software using specified values for the cantilever spring constant.

\section{Results and discussion}

\subsection{Synthesis and characterization of SS-PAAs}

The SS-PAAs were synthesized via a Michael-type polyaddition reaction of the appropriate primary amines to CBA as bisacrylamide. The general reaction scheme of the polymerization reaction is shown in Scheme 5.2.

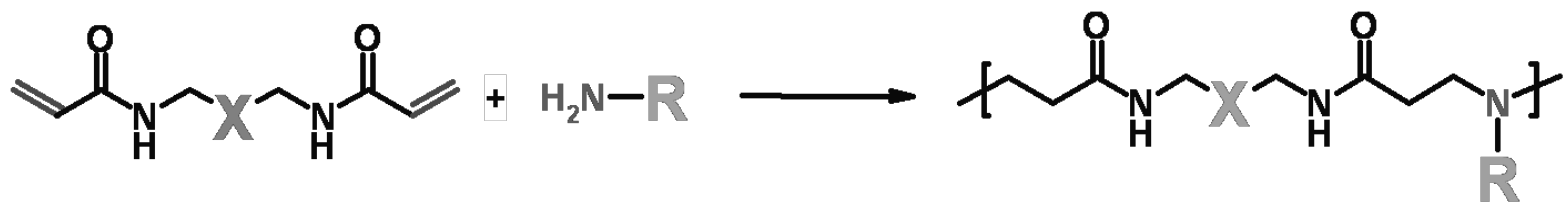

Scheme 5.2. General synthesis scheme of PAAs by Michael-type polyaddition of a bisacrylamide and a primary amine.

In this paper, two differently functionalized SS-PAAs, $p(C B A-A B O L)$, and cPEG-p(CBA-ABOL), were synthesized and were coded in terms of the used bisacrylamide and the primary amine monomers. The chemical structures of the two polymers are presented in Figure 5.1.<smiles>CN(CCCCO)CCC(=O)NCCSCCNC(=O)CCC(C)(C)C</smiles>

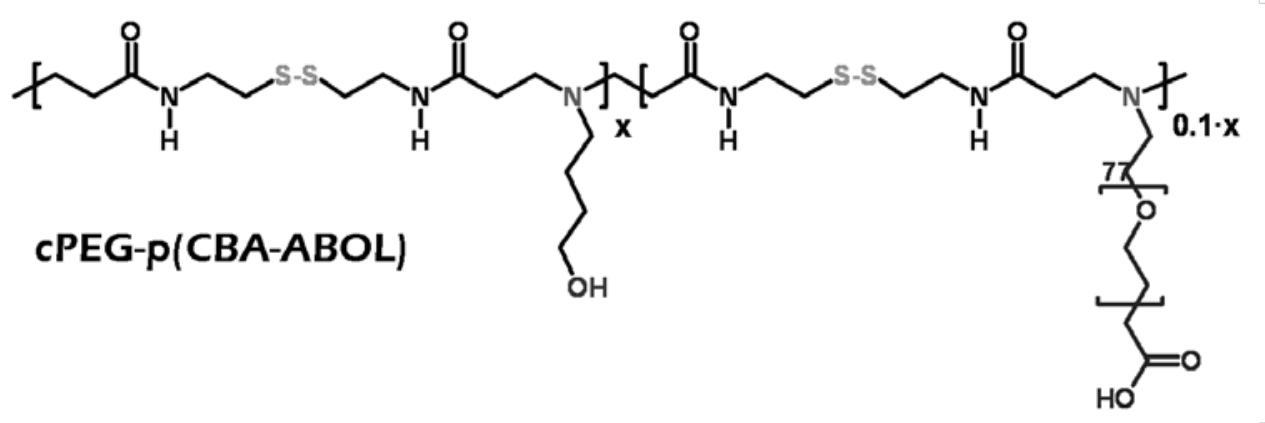

Figure 5.1. Chemical structures of the two SS-PAAs: $p(C B A-A B O L)$, and $c P E G-p(C B A-A B O L)$ that have been used to form nano-sized complexes with insulin. The polymers were coded in terms of the used bisacrylamide and primary amine monomer. 
The $p(C B A-A B O L)$ and $c P E G-p(C B A-A B O L)$ polymer possess, in addition of the repetitive disulfide moieties in the main chain for bioreduction originating from the CBA monomer, butylene side chains terminated by a hydroxyl group originating from the ABOL units. It has been shown that this hydroxybutyl side group favorably contributes to the efficiency in DNA transfection, presumably by increasing the endosomolytic properties [35]. cPEG-NH 2 side chains are included to induce a stealth effect. This stealth effect is disabled when the drug carrier reaches a reductive environment, due to the cleavage of the multiple disulfide linkages in the main chain of the polymer, as is present in the intracellular milieu.

Details about the synthesis and the ${ }^{1} \mathrm{H}$ NMR and GPC data of $\mathrm{p}(\mathrm{CBA}-\mathrm{ABOL})$ are available in

\section{Chapter 3.}

cPEG-p(CBA-ABOL) was synthesized via Michael addition of the corresponding primary amine monomers, $\mathrm{ABOL}$ and $\mathrm{CPEG}-\mathrm{NH}_{2}$, to $\mathrm{CBA}$. The reaction scheme of the polymerization reaction is shown in Scheme 5.3.<smiles></smiles>

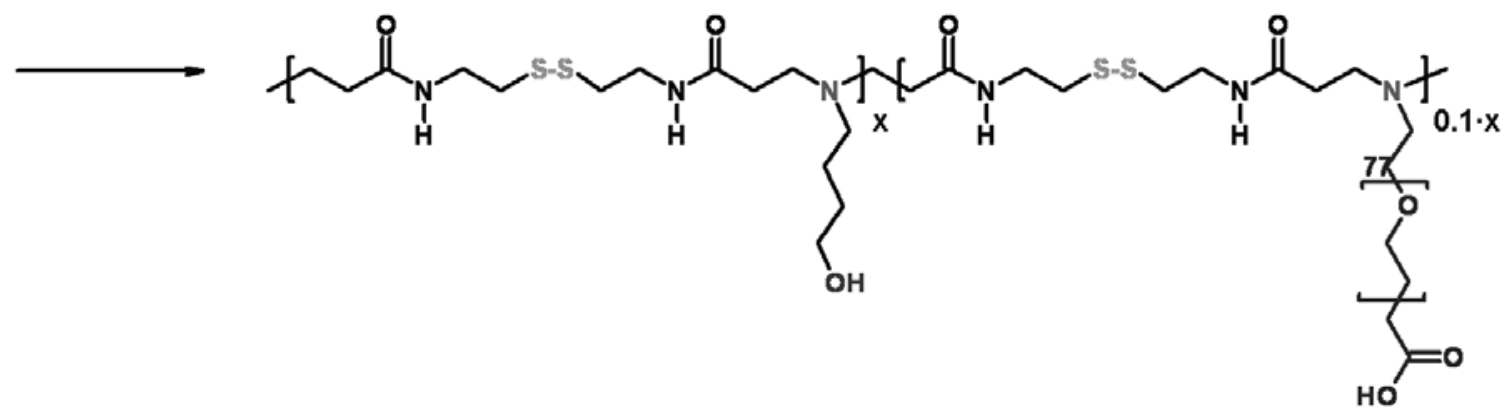

Scheme 5.3. Synthesis scheme of $c P E G-p(C B A-A B O L)$ by Michael-type polyaddition of a CBA, ABOL and $\mathrm{CPEG}-\mathrm{NH}_{2}$.

The synthesized polymer, collected in their $\mathrm{HCl}$-salt form after freeze-drying, has a good solubility in water. The yield was ca. 35\% after ultrafiltration and lyophilization. The ${ }^{1 \mathrm{H}}$ NMR spectrum of cPEG-p(CBA-ABOL) was in full accordance with the expected structure. The absence of any proton signals between 5 and $7 \mathrm{ppm}$ shows that the polymer did not 
contain any residual acrylamide end groups.

The fraction of $c P E G$ chains incorportated in the $c P E G-p(C B A-A B O L)$ polymer was determined by comparing the integrals of the ${ }^{1} \mathrm{H}$ NMR signals attributed to the methylene protons $\left(\mathrm{CH}_{2} \mathrm{CH}_{2} \mathrm{O}\right)$ in the PEG and the methylene protons $\left(\mathrm{CH}_{2} \mathrm{CH}_{2} \mathrm{CH}_{2} \mathrm{OH}\right)$ of the PAA polymer, and was in accordance with the aimed polymer composition i.e. a SS-PAA with 10\% PEG side chains.

The GPC measurements showed that the average molecular weight $\left(\mathrm{M}_{\mathrm{w}}\right)$ of cPEG-p(CBA-ABOL) was $8.8 \mathrm{~kg} / \mathrm{mol}(\mathrm{PDI}=1.3)$.

cPEG-p(CBA-ABOL): White solid. Yield: $1.50 \mathrm{~g}(36 \%){ }^{1} \mathrm{H}$ NMR $\left(\mathrm{D}_{2} \mathrm{O}\right) \delta(\mathrm{ppm})=1.73\left(\mathrm{CH}_{2} \mathrm{CH}_{2} \mathrm{OH}\right.$, 1.8H); $1.94\left(\mathrm{CH}_{2} \mathrm{CH}_{2} \mathrm{CH}_{2} \mathrm{OH}, 1.8 \mathrm{H}\right) ; 2.05\left(\mathrm{CH}_{2} \mathrm{CH}_{2} \mathrm{O}, 15 \mathrm{H}\right) ; 2.77\left(2 \times \mathrm{NHCOCH}_{2}, 4 \mathrm{H}\right) ; 2.95(2 \times$ $\left.\mathrm{SSCH}_{2} \mathrm{CH}_{2}, 4 \mathrm{H}\right) ; 3.17\left(\mathrm{NCH}_{2} \mathrm{CH}_{2}, 2 \mathrm{H}\right) ; 3.38\left(\mathrm{CH}_{2} \mathrm{~N}\left(\mathrm{CH}_{2}\right) \mathrm{CH}_{2}, 6 \mathrm{H}\right) ; 3.60\left(2 \times \mathrm{SSCH}_{2} \mathrm{CH}_{2}, 4 \mathrm{H}\right) ; 3.76$ $\left(\mathrm{CH}_{2} \mathrm{CH}_{2} \mathrm{O}, 15 \mathrm{H}\right) ; 3.91\left(\mathrm{OCH}_{2} \mathrm{COOH}, 0.2 \mathrm{H}\right)$.

\subsection{Nanoparticle characterization}

At physiological $\mathrm{pH}(\mathrm{pH}$ 7.4), the SS-PAAs are present as polycations due to partial protonation of the basic nitrogens in the polymer. Charge interaction with insulin can be expected since this protein, with an isoelectric point ( $\mathrm{pl}$ ) of 5.3, has a net negative charge under these conditions. Three different kinds of nanoparticles were formed and characterized with respect to size, zeta-potential, and insulin loading efficiency. DLS and zeta-potential measurements showed that both synthesized polymers form nanosized polyelectrolyte complexes by self-assembly with insulin, with particle sizes smaller than $200 \mathrm{~nm}$ and with low polydispersity (PDI < 0.2), in 10 mM HEPES buffer solution pH 7.4. All NPs have a positive surface charge, although this charge is reduced as a function of cPEG content. NP2 which is prepared from cPEG-p(CBA ABOL) alone is close to neutral charge, and NP3 which is prepared from a mixture of cPEG-p(CBA ABOL) and $p(C B A A B O L)$ is in between the two. Additional DLS measurements showed that $p(C B A-A B O L)$ and $c P E G-p(C B A-A B O L)$ formed nanoparticles by themselves in solution, at similar concentrations as those used to prepare the SS-PAA/insulin nanoparticles. The sizes of these nanoparticles were about 300 nm (PDI ca. 0.4), in 10 mM HEPES, pH 7.4 (data not shown). Particles of these sizes were not detected during the DLS measurements of the SS-PAA/insulin nanoparticles, proving the absence of nanoparticles non-loaded with insulin.

Very high loading efficiencies of the SS-PAA/insulin nanoparticles were confirmed by 
fluorescence spectroscopy measurements using FITC-insulin (Table 5.1).

Table 5.1. Nanoparticle composition and characteristics in terms of particle size, surface charge (zeta-potential) and insulin loading efficiency.

\begin{tabular}{|c|c|c|c|c|c|c|}
\hline \multirow{2}{*}{$\begin{array}{c}\text { Nanoparticle } \\
\text { nomenclature }\end{array}$} & $\begin{array}{c}\mathrm{p}(\mathrm{CBA}-\mathrm{ABOL}) \\
(\mathrm{mg} / \mathrm{ml})\end{array}$ & $\begin{array}{c}\text { CPEG-p(CBA-ABOL) } \\
(\mathrm{mg} / \mathrm{ml})\end{array}$ & $\begin{array}{c}\text { Insulin } \\
(\mathrm{mg} / \mathrm{ml})\end{array}$ & $\begin{array}{c}\text { Size* } \\
(\mathrm{nm})\end{array}$ & $\begin{array}{c}\text { Zeta-potential } \\
(\mathrm{mV})\end{array}$ & $\begin{array}{c}\text { Insulin } \\
\text { loading } \\
\text { efficiency } \\
(\%)\end{array}$ \\
\hline NP 1 & 1.80 & $/ / /$ & 0.15 & $\begin{array}{c}169 \\
\pm 5\end{array}$ & $+36 \pm 2$ & 99 \\
\hline NP 2 & $/ / /$ & 1.80 & 0.15 & $\begin{array}{c}158 \\
\pm 11\end{array}$ & $+2 \pm 1$ & 95 \\
\hline NP 3 & 1.20 & 0.60 & 0.15 & $\begin{array}{c}192 \\
\pm 7\end{array}$ & $+19 \pm 1$ & 97 \\
\hline
\end{tabular}

*Polydispersity index (PDI) was in all cases $<0.2$

\subsection{Nanoparticle interactions with negatively charged model membranes}

The interactions between the three different NPs and negatively charged model lipid membranes were monitored by the QCM-D technique which detects changes in mass and properties of thin layers adsorbed to surfaces in real-time, measured as frequency and dissipation shifts $(\Delta f$ and $\Delta D$ ). The QCM-D technique is an acoustic technique, which in many aspects is complementary to the more established optical biosensor techniques based on surface plasmon resonance. QCM-D is especially useful for the characterization of highly hydrated structures, and for some systems strong QCM-D responses are obtained when optical signals are very weak [38]. The resonance frequency shift of the piezoelectric quartz crystal is related to the amount of mass adsorbed/desorbed to/from the sensor surface. The dissipation shift is related to the properties of the adsorbed material where soft or loosely attached material give rise to a large response (fast damping of the crystal oscillation at resonance).

The QCM-D frequency responses from a typical series of experiments are shown in Figure 5.2. Note that negative frequency shifts correspond to increase in mass. Here, the model membranes were first formed by vesicle rupture on the $\mathrm{SiO}_{2}$-coated QCM-D sensor surface (indicated by a dip in the frequency shift). This is a well established procedure, resulting in characteristic QCM-D responses for the bilayer-modified sensor surface $(\Delta f \approx$ $26 \mathrm{~Hz}$ and $\Delta D<0.5)[39,40]$. When model membranes on the QCM-D sensor surface are exposed to the positively charged NPs, adsorption of mass to the membranes was 
observed, leading to a decrease in frequency shift (corresponding to mass uptake) and an increase in dissipation shift (corresponding to a less rigid layer). Next, rinsing was performed, before addition of glutathione (see Section 3.4).

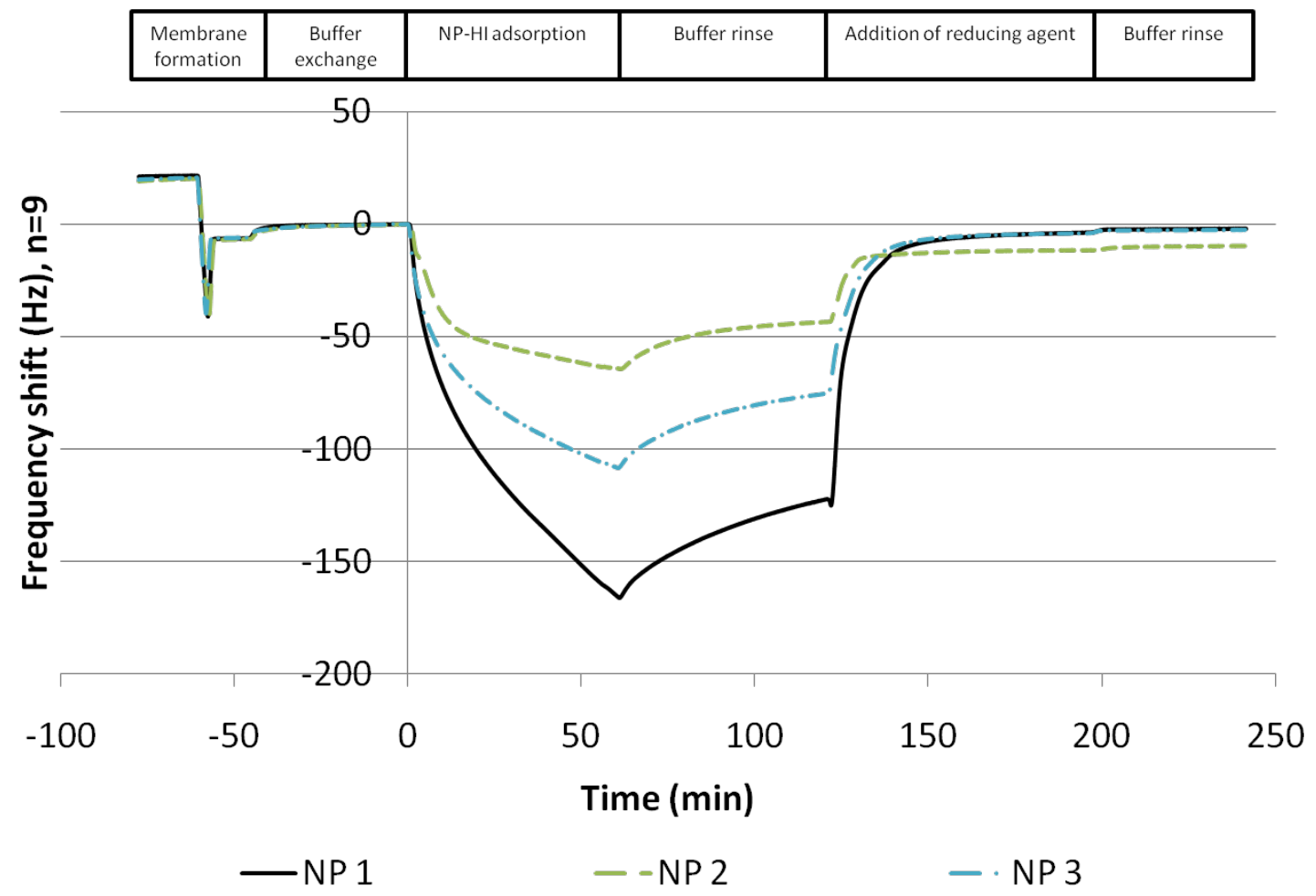

Figure 5.2. QCM-D frequency shifts for experiments where NP 1-3 were adsorbed to POPC:POPS (3:1) membranes and subsequently exposed to a reducing agent ( $5 \mathrm{mM}$ glutathione).

The adsorption of the three NPs was expected due to their positive charge. However, when comparing the QCM-D results for the three different NPS, it was found that the adsorption of NP 1 (based on p(CBA-ABOL)) generated the largest frequency shift followed by NP 3 (based on a mixture of p(CBA-ABOL) and cPEG-p(CBA-ABOL)), and NP 2 (based on $c P E G-p(C B A-A B O L))$. In general, the obtained frequency shifts (corresponding to adsorption of NPs) are smaller than would have been expected for a complete layer of adsorbed, intact NPs. This statement is based on the fact that the modeled thickness of the adsorbed NP 1, using both Voigt based modeling and the Sauerbrey equation, is about $30 \mathrm{~nm}$, i.e. much less than the hydrodynamic diameter of the intact NP. Further, the results showed a relationship between the zeta-potential of the NPs (Table 5.1) and the frequency shift. Figure 5.2 also shows that the material deposited on the membrane during the experiments with NP 1-3 had a reversible component. The fraction of adsorbed material that dissociated from the surface upon rinsing corresponded to approximately 
one third of the total amount. An alternative interpretation of these data would be that structural rearrangements of the adsorbed NPs occur.

The results obtained for NP 2 and NP 3 show that the incorporation of PEG chains into the drug formulation does not introduce a stealth effect since NP adsorption to the model membrane is not completely prevented. It is true that the PEGylated NPs (NP 2 and NP 3) adsorb to a lesser extent, but perhaps more likely due to the fact that these NPs have lower positive charge rather than due to steric repulsion caused by the PEG chains.

To take full advantage of the QCM-D data, both frequency and dissipation shifts need to be taken into account. The relationship between these two responses during NP adsorption to the model membrane is shown in Figure 5.3. The softest structure (corresponding to the highest dissipation shift) was generated by NP 2 which was based on the $c P E G-p(C B A-A B O L)$ polymer. This observation is rationalized by the presence of PEG-chains extending from the polymer backbone. This effect is not obvious for NP 3 where the same polymer is present although in a smaller extent.

As noted above the frequency shifts are generally lower than would have been expected for a layer of intact NPs, and similarly the relation between the dissipation and the frequency shifts (small $|\Delta D / \Delta f|$ ratio), suggest that the NPs collapse into a thin layer upon adsorption to the model membrane, as was also observed previously for other polycationic PECs with insulin [41]. It is also evident that the $\Delta f-\Delta D$ relationships for NP 1-3 consist of two separate phases: one initial phase where the increase in $\Delta D$ was rapid, and a second phase in which an adsorbed unit of mass yield a smaller shift in dissipation. The first, more rapid phase, seems to correspond to NPs adsorbed to the bare POPC:POPS membrane and the second phase to NPs adsorbed to a surface partly of fully covered with NPs.

The similar relationship between $\Delta f$ and $\Delta D$ for NP 1 and NP 3 was seemingly determined by the $p(C B A-A B O L)$ polymer (100\% of NP 1 and $67 \%$ of NP 3$)$, likely because of an enrichment of this polymer at the surface during the adsorption process. In a previous study, adsorption of PECs prepared from mixed polymer compositions was similarly dominated by one of the polymers [41]. Taken together, QCM-D frequency and dissipation data indicate that the main difference between NP 1 and NP 2 was the adsorption kinetics. Thus the desired stealth effect by preparing NPs from a mixture of two polymers, one of which was PEGylated, was only obtained in the sense that the adsorption process was slower. The structure of the adsorbed material remained similar. In contrast, the NPs prepared from the PEGylated polymer alone formed a softer layer on the membrane, 
albeit still collapsed. In order for PEGylation to be an effective means to reduce interactions the PEG chains need to be closely packed and perhaps this requirement is not met for the present particles.

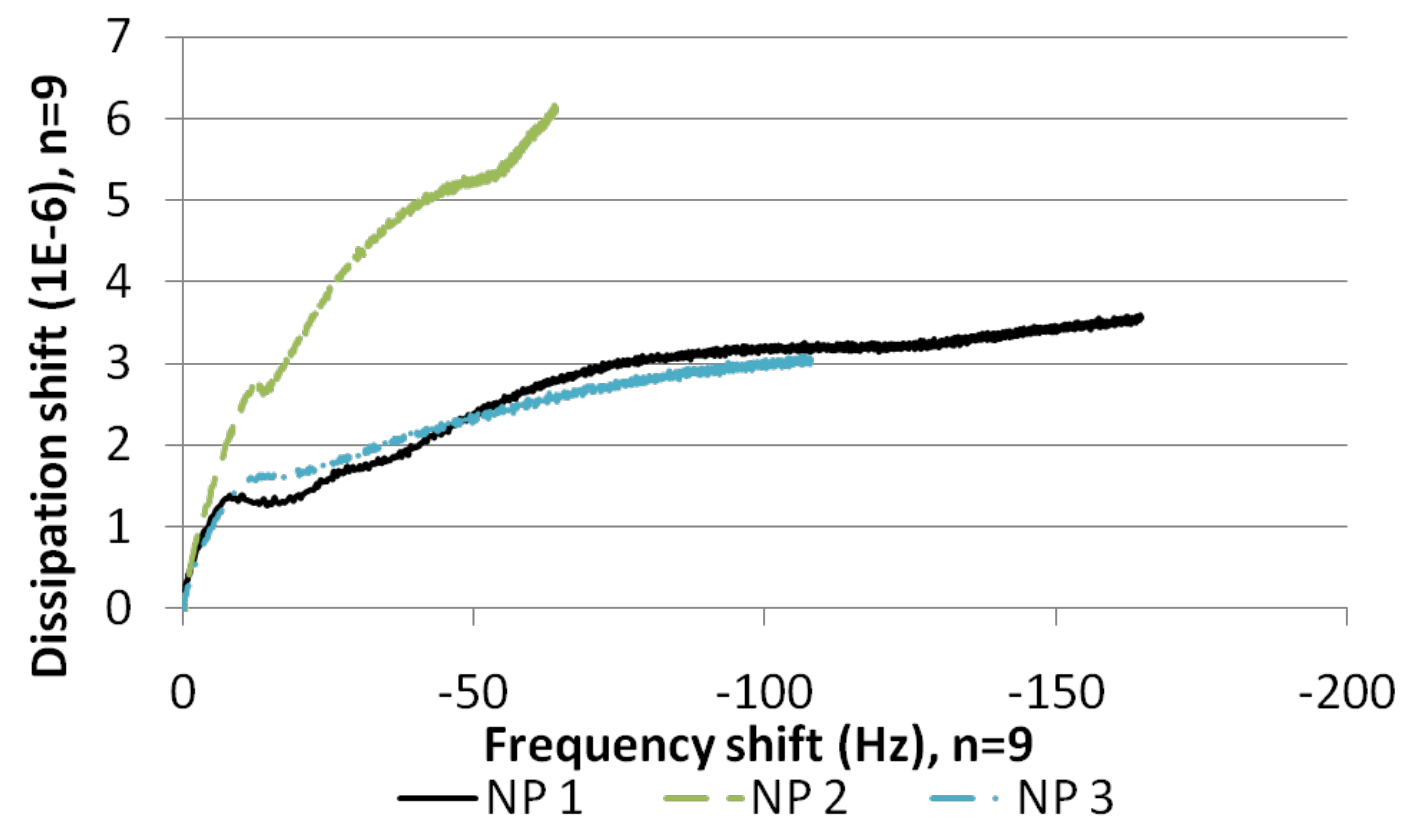

Figure 5.3. $\Delta f$ vs. $\Delta D$ for adsorption of NP 1-3 on POPC:POPS (3:1) model membranes.

\subsection{Response of the adsorbed nanoparticles to reducing agent and decrease in ambient $p H$}

As shown in Figure 5.4A, upon exposing adsorbed NPs based on SS-PAAs to $5 \mathrm{mM}$ glutathione it was evident that material readily dissociated from the model membrane. These results were expected given the polymer structures; glutathione as a cysteine-containing tripeptide abundant in the in the intracellular environment reduced the disulfide bonds present in the backbone of the polymers present in NP 1-3.

Furthermore, the pH-sensitivity of NP 1 was evaluated in a similar manner (Figure 5.4B). After adsorption of NPs to the model membrane and subsequent rinsing, a pH-gradient ranging from 7.3 to 5.1 was applied. The result showed that adsorbed NP 1 came off the surface when the $\mathrm{pH}$ was lowered. The rate of dissociation varied along the $\mathrm{pH}$-gradient but the most rapid dissociation of the NPs from the membrane occurred at approximately $\mathrm{pH}$ 6.2. This can be explained by the increasing protonation of the tertiary amine moieties present in the polymer chains $\left(\mathrm{pK}_{\mathrm{a}} \sim 6-6.5\right)$ and the increase in cationic charge in the insulin structure $(\mathrm{pl} \sim 5.3)$, resulting in a strong decrease of charge interaction between 
polymer and protein upon decreasing $\mathrm{pH}$. Zeta potential measurements of POPC:POPS (3:1) liposomes performed at $\mathrm{pH} 7.3$ and 5.0 showed that the liposomes remained negatively charged at $\mathrm{pH} 5.0$ (data not shown). Hence, the anionic character of the supported membrane remains, despite the low pH used in the experiments. It is assumed that the surface charge of the supported lipid membrane is similar to the surface charge of the corresponding liposomes in bulk.
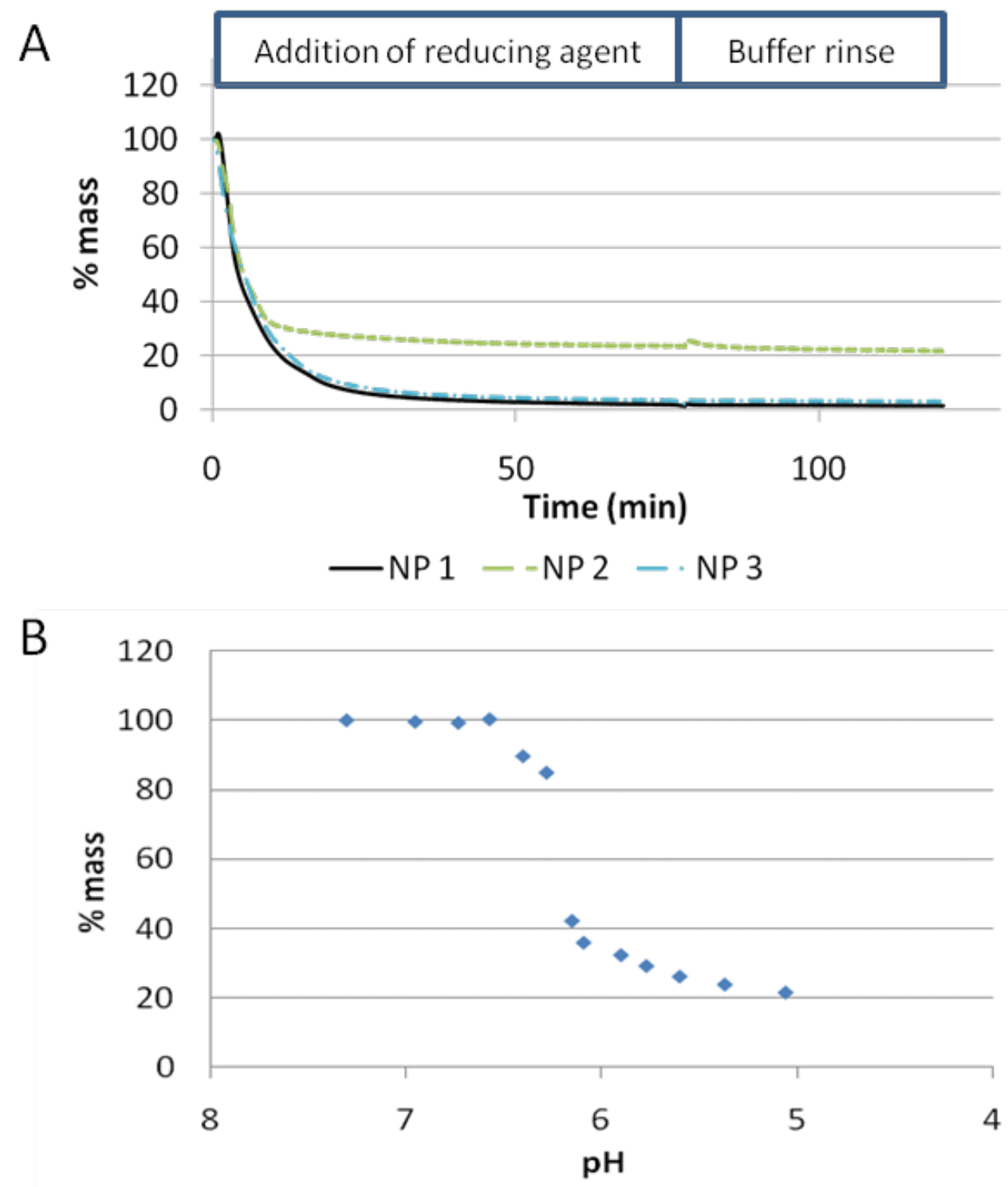

Figure 5.4. Removal of adsorbed NPs when exposed to (A) glutathione (data corrected for small bulk shifts due to the addition of glutathione) and (B) a decrease in $\mathrm{pH}$.

To further investigate the fate of the NPs when adsorbed to the model membrane and exposed to glutathione, liquid-phase AFM imaging was performed. First, the bare 
membrane was imaged and detected by force spectroscopy, yielding results in accordance with previous studies [42]. Second, the surface was imaged after adsorption of NP 1 and subsequent buffer rinse. Finally, the surface was imaged after exposure to glutathione and buffer rinse. The results are presented in Figure 5.5 together with a schematic model of the structure of the material on the surface.

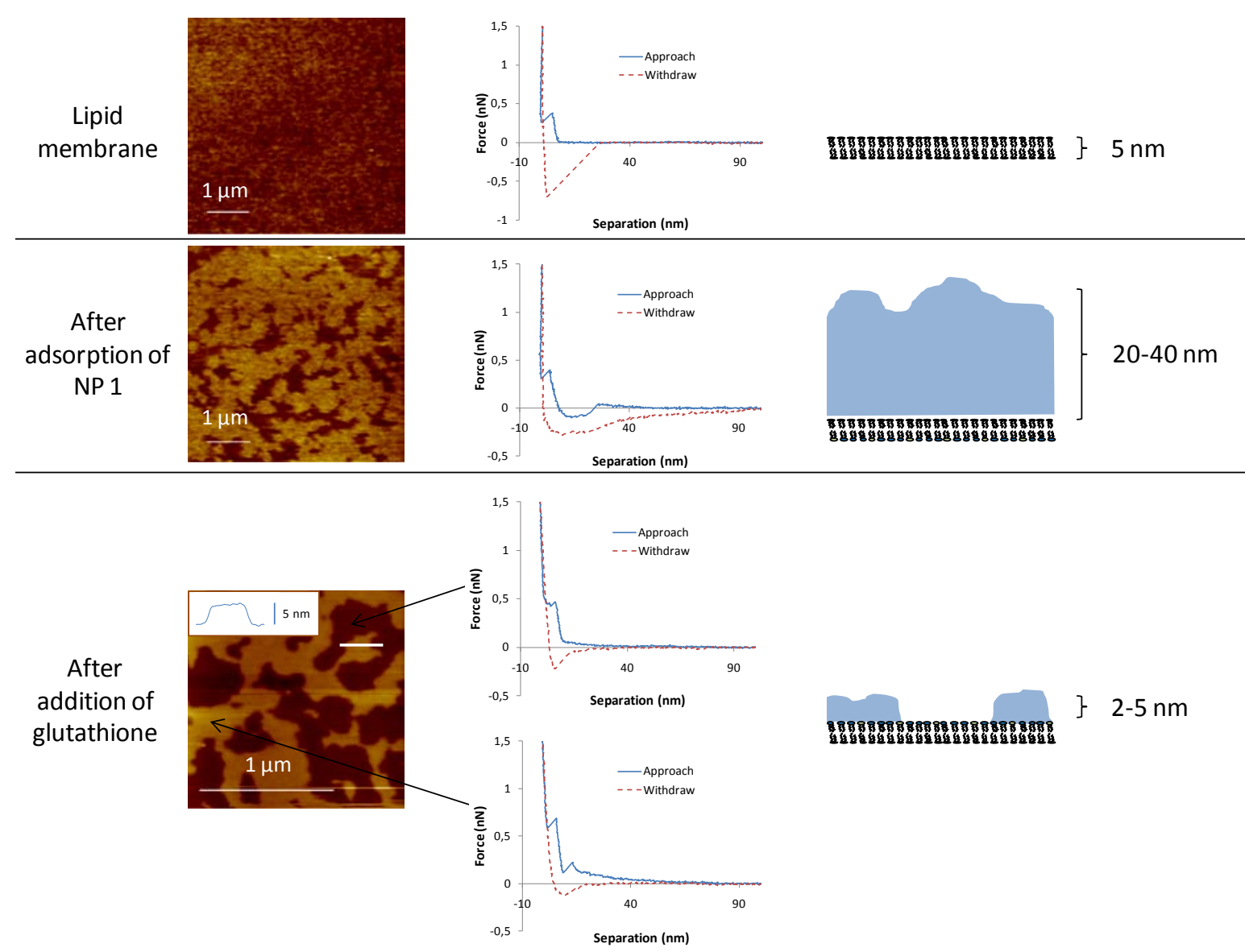

Figure 5.5. AFM images, corresponding force spectra and schematic models (not to scale) of the bare lipid membrane (z-range $1.6 \mathrm{~nm}$ ), after adsorption of NP 1 (z-range $3.0 \mathrm{~nm}$ ) and after addition of glutathione (z-range $10 \mathrm{~nm}$ ). The cross section, shown in the inset, corresponds to the white bar in the image.

The appearance of the initial, lipid-membrane covered surface is homogeneous and flat. A characteristic kink in the force curves indicated the presence of a lipid membrane. After adsorption of NP 1, the AFM image revealed a heterogeneous surface as compared to the initial bare membrane. The force spectra on this rough surface, in both dark and bright regions, were clearly different from the bare membrane although it was still possible to detect the kink associated with the previously formed membrane. The main differences are the appearance of a comparably long-range force interaction and the absence of a 
sharp jump-off event upon separating the tip from the surface. Furthermore, the force spectra reveal the presence of material several tenths of nanometers away from the lipid membrane, independently on where on the surface the force spectra are recorded. We interpret this as a fully covering layer of adsorbed NPs. In accordance with the QCM-D data, these results suggest that the NPs collapse on top of the underlying membrane, which is not disrupted by the adsorption process, and form a layer with a thickness much smaller than their hydrodynamic diameter upon adsorption. To further investigate the thickness of the formed adlayer, the QCM-D data was used to model its thickness. The thickness was calculated from the Sauerbrey equation, which is assumed to be valid due to the rigid structure on the surface (small $|\Delta D / \Delta f|$ ratio), and also determined by Voigt based modeling. In both cases a thickness of about $30 \mathrm{~nm}$ was obtained. The modeled thicknesses were thus in the same range as the range of the adhesive detected by force spectroscopy. In some AFM-experiments flattened circular discs of NPs with a height of about $10 \mathrm{~nm}$ were detected on the surface. After exposure to glutathione, the AFM images showed two distinct regions. Still, the lipid membrane was detected across the entire surface although at this stage no NPs were present in the dark regions. In the bright regions, force spectroscopy showed two separate layers, the underlying membrane and some remaining material from the adsorbed NPs. The continued absence of a well-defined jump-off perhaps indicates the presence of small NP remainders also on the tip. Now the layer corresponding to the NPs was much thinner, about 2-5 nm and only partly covering the surface. At this stage the QCM-D result show almost a complete removal of the adsorbed NP 1. The small amount of NP-material still present in the AFM experiment is likely due to the manual liquid exchange compared to the QCM-D experiments which were performed under a continuous flow.

\subsection{Relevance of surface interaction analysis in nanodrug design}

A limitation with the analytical platform applied in the present study is that the QCM-D and AFM analyses do not allow distinguishing between the two NP constituents, SS-PAA polymer and protein. However, since the NPs deform (indeed collapse into a film of a much thinner than the NP hydrodynamic diameter) upon adsorption to the membrane most of the protein drug load is likely released already during that process. Depending on the protein drug load this initial drug release could in some cases be advantageous. For example, when the protein drug targets extracellular receptors, e.g. in the case of insulin, a local drug release close to the cell surface could be beneficial, just as formulations for 
slow release in general [43]. The quantification of possible drug release upon adsorption of the NPs needs further analyses and is not within the scope of this study.

A second aspect to consider regarding the NP deformation is how it effects the internalization of the NPs into the cell. In this case, the NPs were designed to be relatively stable during transport outside the cell and to disintegrate in fragments of low molecular weight after uptake into the target cells. Based on the present results, it is not likely that the NPs studied here would remain intact long enough to be taken up as NPs by the cell. Also most of the drug load will likely have been released before NPs at the cell surface can be taken up. Therefore, to obtain intracellular delivery of the protein drug load the rigidity of the formulations may need to be increased e.g. by crosslinking the polymers with dithiol linkers after NP complexation. If more rigid NPs were produced, further development of the production protocol could be made to obtain NPs in a size range which is more suitable for cellular uptake through endocytosis and thereby further increase the efficiency of intracellular protein delivery. Moreover, the stealth effect of the NPs needs to be improved to prevent unspecific adsorption to the cell surface e.g. by increasing the density of PEG in the polymer backbone. Despite the fact that the obtained results give rise to additional questions, the designed responsiveness of the NPs has been proven successful and the usefulness of the surface-based platform for in vitro characterization has been shown.

\section{Conclusions}

Two bioreducible PAA polymers with repetitive disulfide linkages in their main chain were successfully synthesized and used to form three types of nano-sized complexes with human insulin. All NPs were positively charged and the two bioreducible polymers yielded NPs with narrow size distributions and mean sizes below $200 \mathrm{~nm}$. By combining results from QCM-D and AFM it was possible to conclude that the NPs collapse upon adsorption to a negatively charged model lipid membrane and form a layer much thinner than the hydrodynamic diameter of the NPs. These structural rearrangements are a concern since common nanodrug design strategies are based on the idea that the nanoparticles need to stay intact at the interface to be taken up as intact objects by the cell. When the adsorbed NPs were exposed to a gradient in the ambient pH ranging from 7.3 to 5.1 they dissociated from the membrane. A similar response was obtained when the adsorbed NPs were exposed to glutathione, i.e. under conditions mimicking an intracellular reductive environment, due to the presence of disulfide linkages in the polymer backbone. 
In all cases the NPs dissolve, and release of insulin from the carrier is expected. These results demonstrate the responsiveness of the SS-PAA based nanodrugs in situ to conditions mimicking different intracellular environments.

\section{Acknowledgements}

This research work is part of the Integrated European FP6 IP NanoBioPharmaceutics. Novo Nordisk is acknowledged for supplying human insulin.

The authors would like to acknowledge Mies van Steenbergen for the GPC measurements.

\section{References}

[1] C. Borghouts, C. Kunz, B. Groner, Current strategies for the development of peptide-based anti-cancer therapeutics. J. Peptide Science 11(11) (2005) 713-726.

[2] C. Krejsa, M. Rogge, W. Sadee, Protein therapeutics: new applications for pharmacogenetics. Nat Rev Drug Discov. 5(6) (2006) 507-521.

[3] R. Langer, J. Folkman, Polymers for Sustained-Release of Proteins and Other Macromolecules. Nature 263(5580) (1976) 797-800.

[4] A.K. Pavlou, J.M. Reichert, Recombinant protein therapeutics - success rates, market trends and values to 2010. Nat Biotech 22(12) (2004) 1513-1519.

[5] S. Stolnik, K. Shakesheff, Formulations for delivery of therapeutic proteins. Biotechnol. Lett. 31(1) (2009) 1-11.

[6] J.E. Talmadge, The Pharmaceutics and Delivery of Therapeutic Polypeptides and Proteins. Adv. Drug Del. Rev. 10(2-3) (1993) 247-299.

[7] M.D. Chavanpatil, A. Khdair, J. Panyam, Nanoparticles for cellular drug delivery: Mechanisms and factors influencing delivery. J. Nanosci. Nanotechnol. 6(9-10) (2006) 2651-2663.

[8] J. Panyam, V. Labhasetwar, Biodegradable nanoparticles for drug and gene delivery to cells and tissue. Adv. Drug Del. Rev. 55(3) (2003) 329-347.

[9] O. Harush-Frenkel, E. Rozentur, S. Benita, Y. Altschuler, Surface charge of nanoparticles determines their endocytic and transcytotic pathway in polarized MDCK cells. Biomacromolecules 9(2) (2008) 435-443.

[10] P. Debbage, Targeted Drugs and Nanomedicine: Present and Future. Curr. Pharm. Des. 15(2) (2009) 153-172.

[11] A.T. Florence, N. Hussain, Transcytosis of nanoparticle and dendrimer delivery systems: evolving vistas. Adv. Drug Del. Rev. 50 (2001) S69-S89.

[12] A. Harada, K. Kataoka, Novel polyion complex micelles entrapping enzyme molecules in the core: Preparation of narrowly-distributed micelles from lysozyme and poly(ethylene glycol)-poly(aspartic acid) block copolymer in aqueous medium. Macromolecules 31(2) (1998) 288-294.

[13] A. Jintapattanakit, V.B. Junyaprasert, S. Mao, J. Sitterberg, U. Bakowsky, T. Kissel, Peroral delivery of insulin using chitosan derivatives: A comparative study of polyelectrolyte nanocomplexes and nanoparticles. Int. J. Pharm. 342(1-2) (2007) 240-249.

[14] Y. Lee, S. Fukushima, Y. Bae, S. Hiki, T. Ishii, K. Kataoka, A protein nanocarrier from charge-conversion polymer in response to endosomal pH. J. Am. Chem. Soc. 129(17) (2007) 5362-5363.

[15] M. Mahkam, Starch-based polymeric carriers for oral-insulin delivery. Journal J Biomed Mater Res A 92A(4) (2010) 1392-1397.

[16] P. Ferruti, M.A. Marchisio, R. Barbucci, Synthesis, Physicochemical Properties and Biomedical Applications of Poly(Amido-Amine)S. Polymer 26 (1985) 1336-1348. 
[17] P. Ferruti, M.A. Marchisio, R. Duncan, Poly(amido-amine)s: Biomedical applications. Macromol Rapid Commun 23(5-6) (2002) 332-355.

[18] J.D. Eichman, A.U. Bielinska, J.F. Kukowska-Latallo, J.R. Baker Jr, The use of PAMAM dendrimers in the efficient transfer of genetic material into cells. Pharm Sci Tech Today 3(7) (2000) 232-245.

[19] E. Ranucci, G. Spagnoli, P. Ferruti, D. Sgouras, R. Duncan, Poly(amidoamine)s with potential as drug carriers: degradation and cellular toxicity. J Biomater Sci Polym Ed 2(4) (1991) 303-315.

[20] O. Boussif, F. Lezoualch, M.A. Zanta, M.D. Mergny, D. Scherman, B. Demeneix, J.P. Behr, A Versatile Vector for Gene and Oligonucleotide Transfer into Cells in Culture and in-Vivo Polyethylenimine. Proc. Natl. Acad. Sci. U. S. A. 92(16) (1995) 7297-7301.

[21] C.X. Wu, S.L. Lo, J. Boulaire, M.L.W. Hong, H.M. Beh, D.S.Y. Leung, S. Wang, A peptide-based carrier for intracellular delivery of proteins into malignant glial cells in vitro. J. Control Release 130(2) (2008) 140-145.

[22] N. Lavignac, M. Lazenby, J. Franchini, P. Ferruti, R. Duncan, Synthesis and preliminary evaluation of poly(amidoamine)-melittin conjugates as endosomolytic polymers and/or potential anticancer therapeutics. Int. J. Pharm. 300(1-2) (2005) 102-112.

[23] N. Lavignac, J.L. Nicholls, P. Ferruti, R. Duncan, Poly(amidoamine) Conjugates Containing Doxorubicin Bound via an Acid-Sensitive Linker. Macromol. Biosci. 9(5) (2009) 480-487.

[24] N.G. Pattrick, S.C.W. Richardson, M. Casolaro, P. Ferruti, R. Duncan, Poly(amidoamine)-mediated intracytoplasmic delivery of ricin A-chain and gelonin. J. Control Release 77(3) (2001) 225-232.

[25] S.C.W. Richardson, N.G. Pattrick, N. Lavignac, P. Ferruti, R. Duncan, Intracellular fate of bioresponsive poly(amidoamine)s in vitro and in vivo. J. Control Release 142(1) (2010) 78-88.

[26] S. Swaminathan, R. Cavalli, F. Trotta, P. Ferruti, E. Ranucci, I. Gerges, A. Manfredi, D. Marinotto, P.R. Vavia, In vitro release modulation and conformational stabilization of a model protein using swellable polyamidoamine nanosponges of beta-cyclodextrin. J. Incl. Phenom. Macrocycl. Chem. 68(1-2) (2010) 183-191.

[27] S.C.W. Richardson, N.G. Pattrick, Y.K.S. Man, P. Ferruti, R. Duncan, Poly(amidoamine)s as potential nonviral vectors: Ability to form interpolyelectrolyte complexes and to mediate transfection in vitro. Biomacromolecules 2(3) (2001) 1023-1028.

[28] R. Cavalli, A. Bisazza, R. Sessa, L. Primo, F. Fenili, A. Manfredi, E. Ranucci, P. Ferruti, Amphoteric Agmatine Containing Polyamidoamines as Carriers for Plasmid DNA In Vitro and In Vivo Delivery. Biomacromolecules 11(10) (2010) 2667-2674.

[29] A. Bernkop-Schnürch, Thiomers: A new generation of mucoadhesive polymers. Adv. Drug Del. Rev. 57(11) (2005) 1569-1582.

[30] C. Lin, J.F.J. Engbersen, The role of the disulfide group in disulfide-based polymeric gene carriers. Expert Opin Drug Deliv 6(4) (2009) 421-439.

[31] K.C. Rajender, W.L. Frederick, H.K. Michael, M.B. David, G.B.R. Robert, R. Daniel, Plasma cysteine, cystine, and glutathione in cirrhosis. Gastroenterology 87(4) (1984) 770-776.

[32] C. Lin, C.-J. Blaauboer, M.M. Timoneda, M.C. Lok, M. van Steenbergen, W.E. Hennink, Z. Zhong, J. Feijen, J.F.J. Engbersen, Bioreducible poly(amido amine)s with oligoamine side chains: Synthesis, characterization, and structural effects on gene delivery. J. Control Release 126(2) (2008) 166-174.

[33] C. Lin, Z. Zhong, M.C. Lok, X. Jiang, W.E. Hennink, J. Feijen, J.F.J. Engbersen, Linear poly(amido amine)s with secondary and tertiary amino groups and variable amounts of disulfide linkages: Synthesis and in vitro gene transfer properties. J. Control Release 116(2) (2006) 130-137.

[34] C. Lin, Z. Zhong, M.C. Lok, X. Jiang, W.E. Hennink, J. Feijen, J.F.J. Engbersen, Random and block copolymers of bioreducible poly(amido amine)s with high- and low-basicity amino groups: Study of DNA condensation and buffer capacity on gene transfection. J. Control Release 123(1) (2007) 67-75.

[35] C. Lin, Z.Y. Zhong, M.C. Lok, X.L. Jiang, W.E. Hennink, J. Feijen, J.F.J. Engbersen, Novel bioreducible poly(amido amine)s for highly efficient gene delivery. Bioconj. Chem. 18(1) (2007) 138-145. 
[36] M.A. Mateos-Timoneda, M.C. Lok, W.E. Hennink, J. Feijen, J.F.J. Engbersen, Poly(amido amine)s as gene delivery vectors: Effects of quaternary nicotinamide moieties in the side chains. ChemMedChem 3(3) (2008) 478-486.

[37] G. Coué, J.F.J. Engbersen, Functionalized linear poly(amidoamine)s are efficient vectors for intracellular protein delivery. J. Control Release (2011), doi:10.1016/j.jconrel.2011.01.023

[38] M. Edvardsson, S. Svedhem, G. Wang, R. Richter, M. Rodahl, B. Kasemo, QCM-D and Reflectometry Instrument: Applications to Supported Lipid Structures and Their Biomolecular Interactions. Anal Chem 81(1) (2009) 349-361.

[39] C.A. Keller, B. Kasemo, Surface specific kinetics of lipid vesicle adsorption measured with a quartz crystal microbalance. Biophys. J. 75(3) (1998) 1397-1402.

[40] R.P. Richter, R. Bérat, A.R. Brisson, Formation of solid-supported lipid bilayers: An integrated view. Langmuir 22(8) (2006) 3497-3505.

[41] R. Frost, C. Grandfils, B. Kasemo, S. Svedhem, Monitoring of surface interactions as a tool for nanoparticle design. J. Control Release 148(1) (2010) e36-e37.

[42] E. Reimhult, M. Zach, F. Hook, B. Kasemo, A multitechnique study of liposome adsorption on Au and lipid bilayer formation on SiO2. Langmuir 22(7) (2006) 3313-3319.

[43] M.S. Mesiha, M.B. Sidhom, B. Fasipe, Oral and subcutaneous absorption of insulin poly(isobutylcyanoacrylate) nanoparticles. Int. J. Pharm. 288(2) (2005) 289-293. 


\section{Bioreducible poly(amidoamine)s as carriers for intracellular protein delivery to intestinal cells}

Grégory Coué1†, Shmuel Cohen²†, Delila Beno², Rafi Korenstein², and Johan F.J. Engbersen 1

1 Department of Biomedical Chemistry, MIRA Institute for Biomedical Technology \& Technical Medicine, Faculty of Science and Technology, University of Twente, Enschede, the Netherlands 2 Department of Physiology and Pharmacology, Sackler Faculty of Medicine, Tel Aviv University, Tel-Aviv, Israel

† Contributed equally

Part of this chapter has been published: G. Coué, S. Cohen, D. Beno, R. Korenstein, and J.F.J. Engbersen, Bioreducible poly(amidoamine)s as carriers for intracellular protein delivery to intestinal cells, submitted

Abstract: An effective intracellular protein delivery system via intestinal uptake was developed based on linear poly(amidoamine)s (PAAs) that form self-assembled cationic nanocomplexes with oppositely charged proteins. Two differently functionalized PAAs were synthesized by Michael-type polyaddition of 4-amino-1-butanol (ABOL) to cystamine bisacrylamide (CBA) and to bisacryloylpiperazine (BAP), yielding to $p(C B A-A B O L)$ and p(BAP-ABOL), respectively. These water-soluble PAAs efficiently condense human serum albumin by self-assembly into stable nanoscaled and positively-charged complexes. $A$ particular property of the disulfide-containing $\mathrm{p}(\mathrm{CBA}-\mathrm{ABOL})$ nanocomplexes is that these particles, while stable under neutral extracellular conditions, are rapidly destabilized in a reductive intracellular environment due to the cleavage of the repetitive disulfide linkages in the CBA units of the polymer. Moreover, the presence of the disulfide groups showed to increase the mucoadhesive properties of the nanoparticles. Human-intestinal epithelial Caco-2/TC7 cells were exposed to these nanoparticles and the extent of their uptake and the localization within endosomal compartments was examined. As the disulfide linkages 
possess high affinity towards mucus, comparison was made between the uptake of nanoparticles made of reducible $p(C B A-A B O L)$ and non-reducible $p$ (BAP-ABOL) using variable amounts of mucus covering the cell membrane, produced by co-cultures of Caco-2/TC7 cells and HT-29 mucus secreting cells.

The essentially non-toxic PAA-based nanocomplexes of human serum albumin were successfully internalized into the cytosol, with a much higher uptake of the $p(C B A-A B O L)$ nanocomplexes than nanocomplexes from $\mathrm{p}(\mathrm{BAP}-\mathrm{ABOL})$, the control polymer lacking the disulfide linkages. An event higher uptake of $p(C B A-A B O L)$ nanocomplexes was observed in a co-culture of Caco-2/TC7 with HT-29 cells, indicating that the high mucoadhesive properties of the $\mathrm{p}(\mathrm{CBA}-\mathrm{ABOL})$ polymer carrier is beneficially contributing to the uptake process. Enhanced uptake of the $\mathrm{p}(\mathrm{CBA}-\mathrm{ABOL})$ nanoparticles was also observed in the presence of $10 \mu \mathrm{M}$ of the non-specific Multi Drug Resistance (MDR) blocker Cyclosporin A (CsA) indicating the possible presence of efflux through MDR transporters. The results show that bioreducible SS-PAAs have excellent properties as potent and non-toxic intracellular protein carriers, which should create opportunities for novel applications in oral protein delivery.

\section{Introduction}

Peroral drug application is considered as the most convenient and preferred route for therapeutic protein administration, especially in long-term treatment. However, this route is associated with a great number of hurdles that have to be overcome before the drug can exert its therapeutic activity. The bioavailability of proteins and other drugs with anionic character via the oral administration route is very low due to (i) physical and chemical instability and fast enzymatic degradation in the gastrointestinal tract [1, 2], (ii) charge repulsion of proteins from negatively-charged cell membranes and mucosa cells, and (iii) slow and ineffective transport of large size and hydrophilic proteins through compartmental cellular barriers [3, 4]. The use of nanocarriers for intracellular transport of proteins presents a possible approach towards overcoming these hurdles. The strategy is based on the use of appropriate biocompatible synthetic polymers that form self-assembled nanocomplexes with peptide or protein drugs of interest that have improved stability and enhanced uptake compared to the free peptides and proteins.

For efficient delivery via the intestine, the mucoadhesion of the colloidal carriers has been reported to be one of the most important properties to improve the bioavailability of poorly absorptive drugs [3-7]. Mucoadhesive carriers which adhere to the mucus layer of 
intestinal mucosal membranes are expected to prolong the residence time at the local site of absorption, leading to increased drug absorption through the intestinal membrane. An interesting possibility to increase the mucoadhesive properties of a polymeric carrier is the introduction of disulfide bonds in the polymer backbone since the repetitive disulfide linkages in the polymer can react with thiol groups and disulfide groups in the mucus [8-12].

In this study we have evaluated two differently functionalized poly(amidoamine)s (PAAs), one PAA comprising repetitive disulfide linkages and one lacking disulfide linkages in their polymer backbone, for their capacity to form nanocomplexes with the model protein human serum albumin (HSA), and their efficacy to deliver this protein in cell lines relevant for uptake via the intestinal route, i.e. human intestinal epithelial Caco-2/TC7 cells, and co-cultures Caco-2/TC7 and HT-29 mucus secreting cells. These cells are widely used across the pharmaceutical industry as a model for the human small intestinal mucosa to predict the absorption of orally administered drugs.

PAAs can be synthesized with a great variety in structure by polyaddition of primary and secondary amines to bisacrylamides. These cationic polymers are water-soluble, biodegradable and biocompatible, and have lower cytotoxicity than other usual polycationic vectors [13-16]. PAAs have been selected as polymeric carriers in this study since these polymers have shown to possess high potential in biomedical applications [17, 18], particularly for use as intracytoplasmic and endosomolytic vectors for the delivery of anticancer drugs [19, 20], proteins [21-23] and nucleotides [24-28].

The tertiary amines in the main chain of the PAAs give these polymers high buffer capacity in the $\mathrm{pH}$ range 5.1-7.4 and this property facilitates PAA nanocomplexes once taken up by cells to escape from the endosomes by increasing polymer-membrane interaction and the proton sponge effect $[13,29,30]$. Consequently, degradation of the therapeutic cargo by lysosomal enzymes is prevented [31].

To evaluate the effect of the presence of repetitive disulfide groups in the main chain of PAAs on the mucoadhesive criteria, we have synthesized the disulfide-containing polymer $p(C B A-A B O L)$ and the reference polymer $p(B A P-A B O L)$, lacking disulfide linkages, by Michael-type polyaddition of 4-amino-1-butanol (ABOL) to cystamine bisacrylamide (CBA) and to bisacryloylpiperazine (BAP), respectively. In addition of expecting to be mucoadhesive due to the presence of the repetitive disulfide linkages, the virtually-nontoxic $p(C B A-A B O L)$ polymer has the advantage that it is relatively stable in the extracellular medium but is prone to fast degradation in the reductive intracellular 
environment $[8,32,33]$. This property can be used in polymeric delivery systems which should be relatively stable during transport outside the cell but should disintegrate into fragments of low molecular weight after uptake into the cytosol of target cells.

By simply mixing negatively-charged protein and positively-charged PAA at neutral $\mathrm{pH}$, self-assembled polyelectrolyte complexes (PECs) with nanosized dimensions are formed as is schematically represented in Scheme 6.1. The PECs possess cationic surface charge, which makes them amenable to bind to and internalize with negatively-charged cell membranes [34].
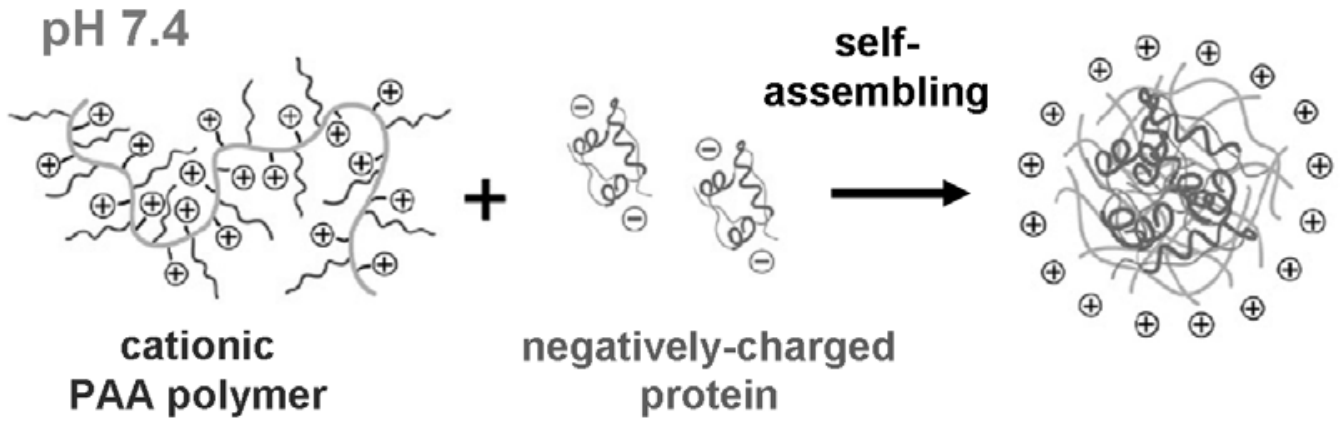

Scheme 6.1. Self-assembling formation of nanocomplexes at neutral pH by charge attraction between a negatively-charged protein (such as human serum albumin) and a positively-charged polymer (PAA).

In this study, we have used fluorescently-labeled HSA to analyze protein loading and release from the nanocomplexes as well as cellular uptake of the protein. HSA has a molecular weight of $67 \mathrm{kDa}$ and an isoelectric point ( $\mathrm{pl}$ ) of 5.3, which gives this protein a net negative charge at physiological $\mathrm{pH}$. Consequently, mixing of appropriate solutions of the positively charged PAA with HSA resulted in the self-assembling formation of nanosized particles. The uptake and intracellular localization of particles were assessed in vitro with Caco-2/TC7 cells. The mucoadhesive properties of the polymers were also studied.

\section{Materials and methods}

\subsection{Materials}

Human albumin-fluorescein isothiocyanate conjugate (FITC-HSA, 10 mol FITC per mol HSA) was obtained from Sigma. All monomers, 4-amino-1-butanol (ABOL, Aldrich), Mono-Boc-protected diaminobutane (MBDAB, Fluka), N,N'-cystaminebisacrylamide (CBA, 
Polysciences, USA), 1,4-bis(acryloyl)piperazine (BAP, Sigma-Aldrich) were purchased in the highest purity and used without further purification. HEPES (Sigma), dithiothreitol (DTT, Sigma-Aldrich), trifluoroacetic acid (TFA, Aldrich), porcine gastric mucus (Sigma), anhydrous dimethylsulfoxide (DMSO, Acros Organics), and methanol (MeOH, Biosolve) were used as received. The amine-reactive Alexa Fluor ${ }^{\circledR} 633$ carboxylic acid, succinimidyl ester (AF633) was purchased from Invitrogen. Deionized water (DI water) was obtained from a MilliQ water purification system (Millipore, France).

\subsection{Synthesis of poly(amidoamine)s (PAAs)}

The polymers $p(C B A-A B O L)$ and $p(B A P-A B O L)$ were synthesized via Michael polyaddition of the primary amine monomer, $\mathrm{ABOL}$, to the bisacrylamide $\mathrm{CBA}$ and $\mathrm{BAP}$, as described in Chapter 3.

\subsection{Synthesis of fluorescently labeled PAAs}

AF633-labeled PAAs were prepared from copolymers having $10 \mathrm{~mol} \%$ of aminobutyl side groups in the main chain. To synthesize these polymers, copolymers of (CBA-ABOL) and p(BAP-ABOL) were prepared by Michael addition of bisacrylamide (CBA or BAP, respectively) to a 9/1 mixture of amines, $A B O L$ and $M B D A B$, followed by Boc-deprotection of the MBDAB units. Typically, $\mathrm{p}(\mathrm{CBA}-\mathrm{ABOL} / \mathrm{MBDAB})$ copolymer was synthesized by adding CBA (2.63 g, $10.75 \mathrm{mmol}), \operatorname{ABOL}(0.88 \mathrm{~g}, 9.67 \mathrm{mmol})$ and MBDAB (0.21 g, $1.08 \mathrm{mmol})$ into a brown reaction flask with $5 \mathrm{ml}$ of a 4/1 (v/v) MeOH/DI water mixture as a solvent. The reaction mixture was allowed to proceed for 10 days at $45^{\circ} \mathrm{C}$ in the dark under nitrogen atmosphere, yielding to a viscous solution. Subsequently, $10 \mathrm{~mol} \%$ excess of ABOL (0.09 g, $0.11 \mathrm{mmol})$ was added to consume any unreacted acrylamide groups and stirring was continued for two days at $45^{\circ} \mathrm{C}$. The $\mathrm{p}(\mathrm{CBA}-\mathrm{ABOL} / \mathrm{MBDAB})$ polymer, containing Boc-protected amine in the side chain, was obtained in ca. $45 \%$ yield after isolation by exhaustive ultrafiltration (3 kg/mol cut-off) with acidified DI water ( $\mathrm{pH} \sim 5$ ), followed by freeze-drying. Deprotection of Boc-protected amino groups of the side chain of the polymer was performed in a mixture of TFA/MeOH overnight, yielding to the copolymers $\mathrm{p}(\mathrm{CBA}-\mathrm{ABOL} / \mathrm{DAB})$ with a $9 / 1$ ratio of hydroxyl and primary amino groups in the side chains. Next, the reaction solution was diluted with $\mathrm{DI}$ water and adjusted to $\mathrm{pH} \sim 5$ using a $4 \mathrm{M} \mathrm{NaOH}$ solution and the resulting polymer solution was purified by ultrafiltration (3 $\mathrm{kg} / \mathrm{mol}$ cut-off) with acidified $\mathrm{DI}$ water $(\mathrm{pH} \sim 5)$. The $\mathrm{p}(\mathrm{CBA}-\mathrm{ABOL} / \mathrm{DAB})$ polymer was recovered in its $\mathrm{HCl}$-salt form as a white solid after lyophilization. The complete removal of 
the Boc protective groups was confirmed by the disappearance of the tert-butyl signal at $1.5 \mathrm{ppm}$ in the ${ }^{1 \mathrm{H}}$ NMR spectra after addition of TFA to the copolymer, yielding to the polymer with the free primary amine groups in the side chains. The primary amines were reacted with the amine-reactive AF633 carboxylic acid, succinimidyl ester, for fluorescent labeling of the polymer. In a typical example, for the synthesis of fluorescently-labeled AF633-p(CBA-ABOL), AF633 (2.5 mg, $2.08 \mu \mathrm{mol})$ in anhydrous DMSO was mixed with the $\mathrm{p}(\mathrm{CBA}-\mathrm{ABOL} / \mathrm{DAB})$ copolymer (146 $\mathrm{mg}, 41.60 \mu \mathrm{mol}$ free $\mathrm{NH}_{2}$ ) in $2 \mathrm{ml}$ of sodium bicarbonate buffer $(0.1 \mathrm{M}, \mathrm{pH}$ 8.3) and the solution was stirred overnight at room temperature. Then, the resultant solution was purified by ultrafiltration ( $1 \mathrm{~kg} / \mathrm{mol}$ cut-off) with DI water. The labeled copolymer was isolated after freeze-drying. A similar experimental procedure was applied in the synthesis of AF633-p(BAP-ABOL).

\subsection{Polymer characterization}

Details about the ${ }^{1} \mathrm{H}$ NMR and GPC data of $p(C B A-A B O L)$ and $p(B A P-A B O L)$ have been described in Chapter 3.

\subsection{Rheological studies}

Rheological measurements were performed with a cone-plate (C35/28) rheometer (RotoVisco RT20, Haake GmbH, Karlsruhe, Germany). p(CBA-ABOL) and p(BAP-ABOL) were fully hydrated in $0.1 \mathrm{M}$ phosphate buffer $\mathrm{pH} 6.8$ to give a concentration of $6 \%(\mathrm{w} / \mathrm{v})$. The polymer solutions were added to an equal volume of the $8 \%(\mathrm{w} / \mathrm{v})$ solution of porcine gastric mucin. After an incubation period of 20 minutes at room temperature, the polymer-mucin incubates were transferred to the viscometer and allowed to equilibrate on the plate for 3 minutes at $25^{\circ} \mathrm{C}$. Dynamic oscillatory tests within the linear viscoelasticity region were performed at $1 \mathrm{~Hz}$ frequency. Frequency sweep measurements were also carried out with a frequency varying from 0.1 to $10 \mathrm{~Hz}$. The storage modulus (G') and the loss modulus ( $G$ ") of the disulfide-containing polymer $\mathrm{p}(\mathrm{CBA}-\mathrm{ABOL})$ and the corresponding control polymer $\mathrm{p}(\mathrm{BAP}-\mathrm{ABOL})$ lacking the disulfide linkages $(3 \% \mathrm{w} / \mathrm{v})$, as well as mixtures of the same polymers with mucin $(4 \% \mathrm{w} / \mathrm{v})$ were determined. Rheological studies were performed with commercially-available mucin instead of native mucus giving more reproducible and comparable results. As references, polymer solutions were prepared in the same way but without adding mucin. 


\subsection{Characterization of PAA/HSA nanoparticles}

\subsubsection{Particle size and zeta-potential measurements}

PAA/HSA nanocomplexes at different polymer/protein weight ratios ranging from $6 / 1$ to 24/1 were prepared by adding a HEPES buffer solution $(10 \mathrm{mM}, \mathrm{pH} 7.4)$ of PAA ( $800 \mu \mathrm{l})$ to a HEPES buffer solution (10 mM, pH 7.4) of HSA (200 $\mu \mathrm{l}, 600 \mu \mathrm{g} / \mathrm{ml})$, followed by vortexing for 5 seconds and incubating at room temperature for 30 minutes. Particle size and surface charge measurements of the nanocomplexes were determined by dynamic light scattering (DLS) at $25^{\circ} \mathrm{C}$ with a Zetasizer Nano ZS (Malvern Instruments, Malvern, UK) using a wavelength of $532 \mathrm{~nm}$. The value was recorded as the mean of three measurements. The size distribution was given by polydispersity index (PDI, a value between 0 and 1). A PDI of 1 indicates large variations in particle size; a PDI of 0 indicates no variation in particle size (i.e. an ideal monodispersed formulation).

\subsubsection{Protein condensation and loading efficiency}

To estimate the loading efficiency of the nanoparticles at neutral $\mathrm{pH}$, solutions of PAA/HSA nanoparticles were prepared at polymer/protein weight ratios ranging from 6/1 to $24 / 1$ according to the procedure described above. The nanoparticles were centrifuged at $14000 \mathrm{rpm}$ for 30 minutes at $4^{\circ} \mathrm{C}$. Aliquots of supernatant were subsequently taken and their protein content determined by fluorescence spectroscopy (Safire2, Tecan, Canada) at an emission wavelength of $519 \mathrm{~nm}$ and an excitation wavelength of $495 \mathrm{~nm}$. The actual loading efficiency was indirectly determined by measuring the difference between the total amount of HSA added to the solution and the amount of HSA in the free form in the supernatant. A calibration curve from solutions of various HSA concentrations was determined prior to this experiment. It was confirmed that free HSA were not precipitated from the solution by centrifugation.

\subsubsection{Protein release from nanoparticles by disulfide reduction of the SS-PAAS}

The release of protein from the nanoparticles at intracellular mimicking reductive conditions was measured using solutions of PAA/HSA nanoparticles prepared as described in section 2.6.1 at polymer/protein weight ratio 24/1. The reducing agent DTT was added to a final concentration of $2.5 \mathrm{mM}$ and the solution was incubated for 30 minutes. Subsequently, the solution was centrifuged at $14000 \mathrm{rpm}$ for 30 minutes at $4^{\circ} \mathrm{C}$. Aliquots of supernatant were taken and their protein content was determined by measurement of the fluorescence intensity using a prior-determined calibration curve. 


\subsubsection{Protein release by acidification of the nanoparticles}

The effect of $\mathrm{pH}$ decrease from 7.4 to 5.1 (mimicking endosomal $\mathrm{pH}$ decrease) on the particle size and surface charge of the nanoparticles was investigated at $25^{\circ} \mathrm{C}$ by DLS measurements using a Zetasizer Nano ZS (Malvern Instruments, Malvern, UK) at a wavelength of $532 \mathrm{~nm}$. The nanoparticle solution was titrated from $\mathrm{pH} 7.4$ to $\mathrm{pH} 5.1$ by regularly adding small aliquots of $0.25 \mathrm{M} \mathrm{HCl}$ solution using a MTP-2 multipurpose titrator (Malvern Instruments, Malvern, UK). Particle size and surface charge were determined every half-unit of $\mathrm{pH}$.

In another experiment, the release of protein from the nanoparticles upon acidification to $\mathrm{pH} 5$, mimicking endosomal $\mathrm{pH}$, was measured using solutions of PAA/HSA nanoparticles prepared at polymer/protein weight ratio 24/1 as previously. After acidification to $\mathrm{pH} 5$ by addition of small amounts of $1 \mathrm{M} \mathrm{HCl}$ solution and incubation for 30 minutes, the nanoparticles were centrifuged at $14000 \mathrm{rpm}$ for 30 minutes at $4^{\circ} \mathrm{C}$. Aliquots of supernatant were subsequently taken and their protein content was determined by fluorescence spectroscopy $\left(\lambda_{\mathrm{em}}=519 \mathrm{~nm}, \lambda_{\mathrm{ex}}=495 \mathrm{~nm}\right)$ using a calibration curve. The percentage of released protein was calculated from the difference of the total amount of HSA originally present in the nanoparticle solution and the amount of HSA that is determined in the free form in the supernatant.

\subsection{In vitro cellular uptake and cytotoxicity of the nanoparticles}

The PAA polymers were labeled with the far-red fluorophore AF633 $\left(\lambda_{\mathrm{em}}=647 \mathrm{~nm}\right)$ since the fluorescence emission of Rhodamine $B\left(\lambda_{e m}=610 \mathrm{~nm}\right)$, a common fluorescent label for detection in the red channel, partly overlaps with the emission of FITC ( $\lambda_{\mathrm{em}}=525 \mathrm{~nm}$ ) from HSA (green channel).

\subsubsection{Fluorescently labeled $p(B A P-A B O L)$ and $p(C B A-A B O L)$ nanoparticles with HSA}

Polymer/protein nanoparticles made of $\mathrm{p}(\mathrm{CBA}-\mathrm{ABOL})$ and $\mathrm{p}$ (BAP-ABOL) polymers and HSA were freshly prepared before every experiment at polymer/protein weight ratio 24/1 by adding 4 volume equivalents of $\mathrm{p}(\mathrm{CBA}-\mathrm{ABOL})$ or $\mathrm{p}(\mathrm{BAP}-\mathrm{ABOL})(3.60 \mathrm{mg} / \mathrm{ml})$ to one equivalent of HSA $(0.60 \mathrm{mg} / \mathrm{ml})$, in $10 \mathrm{mM}$ HEPES buffer. Before cell exposure, these nanoparticle solutions were diluted 1:10 either in DMEM without fetal calf serum (FCS). Hence, the final polymer and protein concentrations for cell exposure experiments were 288 and $12 \mu \mathrm{g} / \mathrm{ml}$, respectively.

Before the FACS uptake studies, the fluorescence emission intensities of FITC-HSA and 
both nanoparticles made of the AF633-PAA polymers were measured at the excitation wavelengths of for FITC (excitation $490 \mathrm{~nm}$, emission $525 \mathrm{~nm}$ ) and AF633 (excitation 632 $\mathrm{nm}$, emission $647 \mathrm{~nm}$ ). It was observed that the fluorescence intensities of HSA in the PAA nanoparticles were similar to those free in solution.

\subsubsection{Cells and toxicity assays}

All cells were used at passages $19-30$, incubated at $37^{\circ} \mathrm{C}$ in a humidified atmosphere of 95\% air and $5 \% \mathrm{CO}_{2}$, and passaged at $80 \%$ confluence in a split ratio of $1 / 5$ with a trypsin-ethylenediamine tetra acetic acid (EDTA) solution. They were routinely grown in 75 $\mathrm{cm}^{2}$ flasks in Dulbecco's modified Eagle's medium supplemented with $20 \%$ fetal bovine serum (FBS), 1\% minimum essential medium (MEM) nonessential amino acids, $2 \mathrm{mM}$ L-glutamine, 10 units $/ \mathrm{ml}$ of penicillin, $10 \mu \mathrm{g} / \mathrm{ml}$ of streptomycin and $1.25 \mathrm{units} / \mathrm{ml}$ nystatin.

Human-intestinal epithelial Caco-2/TC7 cells were used as a model for the intestine epithelial barrier, and were obtained from Dr. Monique Rousset, INSERM U505, Paris, France. HT-29-MTX mucus secreting cells were obtained from Dr. Thécla Lesuffleur, Centre de Recherche Jean-Pierre Aubert- JPARC, INSERM U837, Lille, France.

Toxicity level was determined using the AlamarBlue ${ }^{\circledR}$ test (AbD serotec) and the BCA protein assay (Pierce).

\subsubsection{Flow cytometry analysis}

Uptake studies were conducted two days after cell plating. Caco-2/TC7 cells were exposed to the PAA/HSA nanoparticles as well as to the PAA polymers alone and to free HSA in serum depleted culture medium for two hours, and then the culture medium was replaced by $10 \%$ FCS containing media with the same concentration of polymer/protein nanoparticles, and incubation was continued for an additional 22 hours.

Non-specific blockers of permeability glycoprotein-multi drug resistance (P-gp-MDR) were also applied using exposure media containing $10 \mu \mathrm{M}$ CsA.

After exposure time, uptake was terminated by aspiration removal of the exposure medium and washing the cells twice with ice-cold PBS buffer. Trypsin-EDTA was used to suspend the adherent cells, followed by rinsing with DMEM supplemented with $10 \%$ FCS and suspending in final volume of $250 \mu$ PBS buffer.

For conducting a temperature-dependence study, cells were exposed to nanoparticles at $37^{\circ} \mathrm{C}$ in presence or absence of $10 \%$ FCS DMEM (without phenol red), for various periods 
of time. The extent of adsorption to the cell membrane surface was detected by exposure cells for one hour to nanoparticles at $4^{\circ} \mathrm{C}$. The extent of the reported uptake levels reflects the net results of the uptaken nanoparticles minus the cold treatment results.

The adsorption level in cells exposed at $4^{\circ} \mathrm{C}$ to $\mathrm{HSA}, \mathrm{p}(\mathrm{CBA}-\mathrm{ABOL})$ and $\mathrm{p}(\mathrm{BAP}-\mathrm{ABOL})$, either in complex or alone was found to be very low (comparable to the auto-fluorescence of non-treated cells).

\subsubsection{Confocal microscopic imaging of nanoparticles uptake and localization}

We used fluorescence confocal microscopy to detect internalization and the intracellular fate of the protein from the polymer/protein nanoparticles. Caco-2/TC7 cells were seeded onto 35-mm diameter glass bottomed dishes or cover slips at a density of $10^{5} \mathrm{cells} / \mathrm{cm}^{2}$ for 2-3 days. Cells were exposed to nanoparticles as described above in 2.7.3. Then, cells were rinsed twice in 10\% FCS DMEM and further incubated for 30 minutes at $37^{\circ} \mathrm{C}$ in 10\% FCS medium supplemented with nuclear probe Hoechst 33342 (Invitrogen) and lysosomal staining probe LysoTracker Red DND-99 (Invitrogen) (excitation 577 nm, emission $590 \mathrm{~nm}$ ), rinsed twice with PBS and subjected to confocal microscopy. Alternatively, cells were transiently transfected with Rab5 (early endosome) and Cathepsin D (lysosome) coupled on N-terminal with monomeric RFP (kindly gifted from Dr. Nancy J. Grant, Département de Neurotransmission et Sécrétion Neuroendocrine, Centre de Neurochimie, Strasbourg, France) and exposed to nanoparticles, then rinsed twice and scanned under a Zeiss 510 Meta inverted confocal microscope for estimation of uptake level and location of the nanoparticles. The photomultiplier tube (PMT) voltage was selected to produce images of approximately equal fluorescence intensity.

\section{Results and discussion}

\subsection{Synthesis and characterization of PAAs}

As described in Chapter 3, the SS-PAA polymer $\mathrm{p}(\mathrm{CBA}-\mathrm{ABOL})$ with repetitive bioreducible disulfide linkages in its main chain was synthesized via Michael-type addition of the primary amine monomer $\mathrm{ABOL}$ to $\mathrm{CBA}$. For comparison, p(BAP-ABOL), a PAA lacking disulfide linkages was prepared from polyaddition of $A B O L$ to BAP. The polymers were coded in terms of the used monomers, as shown in Scheme 6.2. 


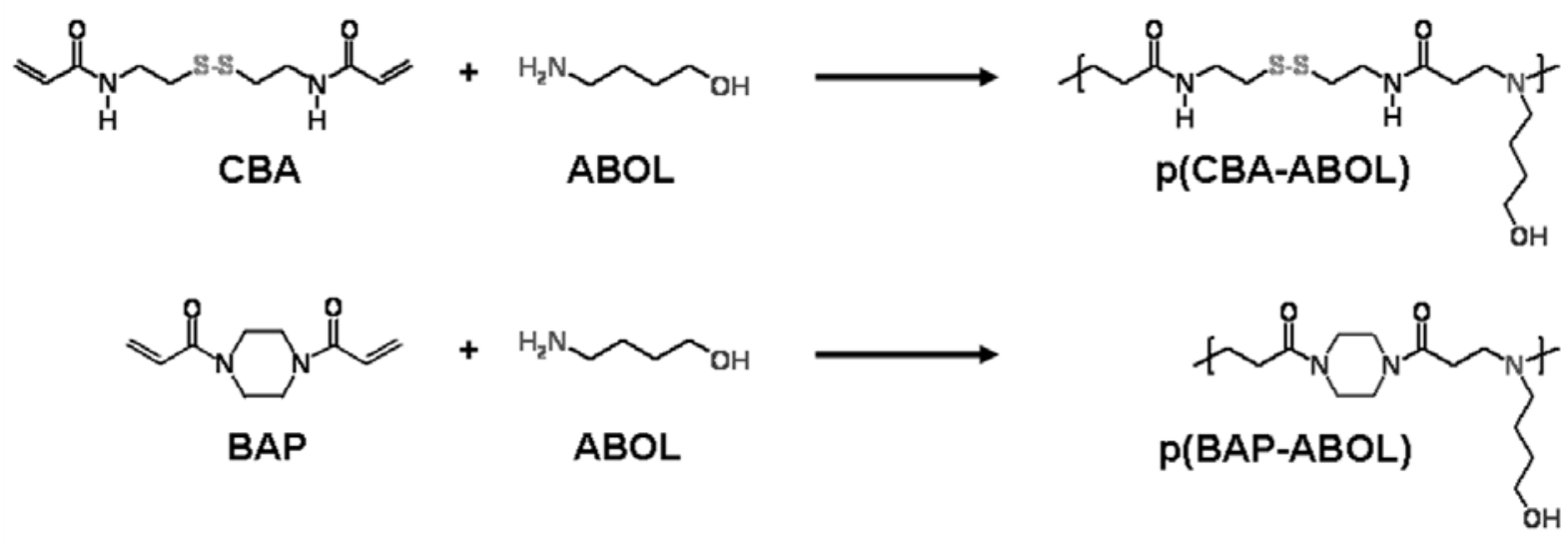

Scheme 6.2. Synthesis scheme of PAAs. The polymers were coded in terms of the used bisacrylamide and primary amine monomer.

The resulting polymers, obtained in ca. $45 \%$ yield in their $\mathrm{HCl}$-salt form as white powders after ultrafiltration and freeze-drying, have a good solubility in water. Details about the ${ }^{1} \mathrm{H}$ NMR and GPC data of $p(C B A-A B O L)$ and $p(B A P-A B O L)$ are available in Chapter 3.

\subsection{Mucoadhesive properties of the $p(C B A-A B O L)$ polymer}

The mucoadhesion of colloidal carriers represents one of the most important properties to improve the bioavailability of poorly absorptive drugs such as proteins. Mucosal surfaces usually have distinct regions of mature mucins which are rich in cysteines, residues participating in establishing disulfide linkages within and among mucin monomers.

We anticipated that the presence of disulfide linkages in $\mathrm{p}(\mathrm{CBA}-\mathrm{ABOL})$ favorably contributes to the mucoadhesive properties of the polymer by disulfide exchange reactions with the thiol and disulfide groups in the mucus. To evaluate this concept, we have carried out rheology experiments of mucin mixed with solutions of the disulfide-containing $\mathrm{p}(\mathrm{CBA}-\mathrm{ABOL})$ and $\mathrm{p}(\mathrm{BAP}-\mathrm{ABOL})$, lacking disulfide bonds. Dynamic oscillatory measurements were performed within the linear viscoelasticity region by measuring the dynamic moduli (storage modulus G' and the loss modulus G") of the mixtures. This analysis provides information about the mechanical properties of the mixtures; increasing values of G' and G" indicating an increase of stiffness. The results are summarized in Figure 6.1. 


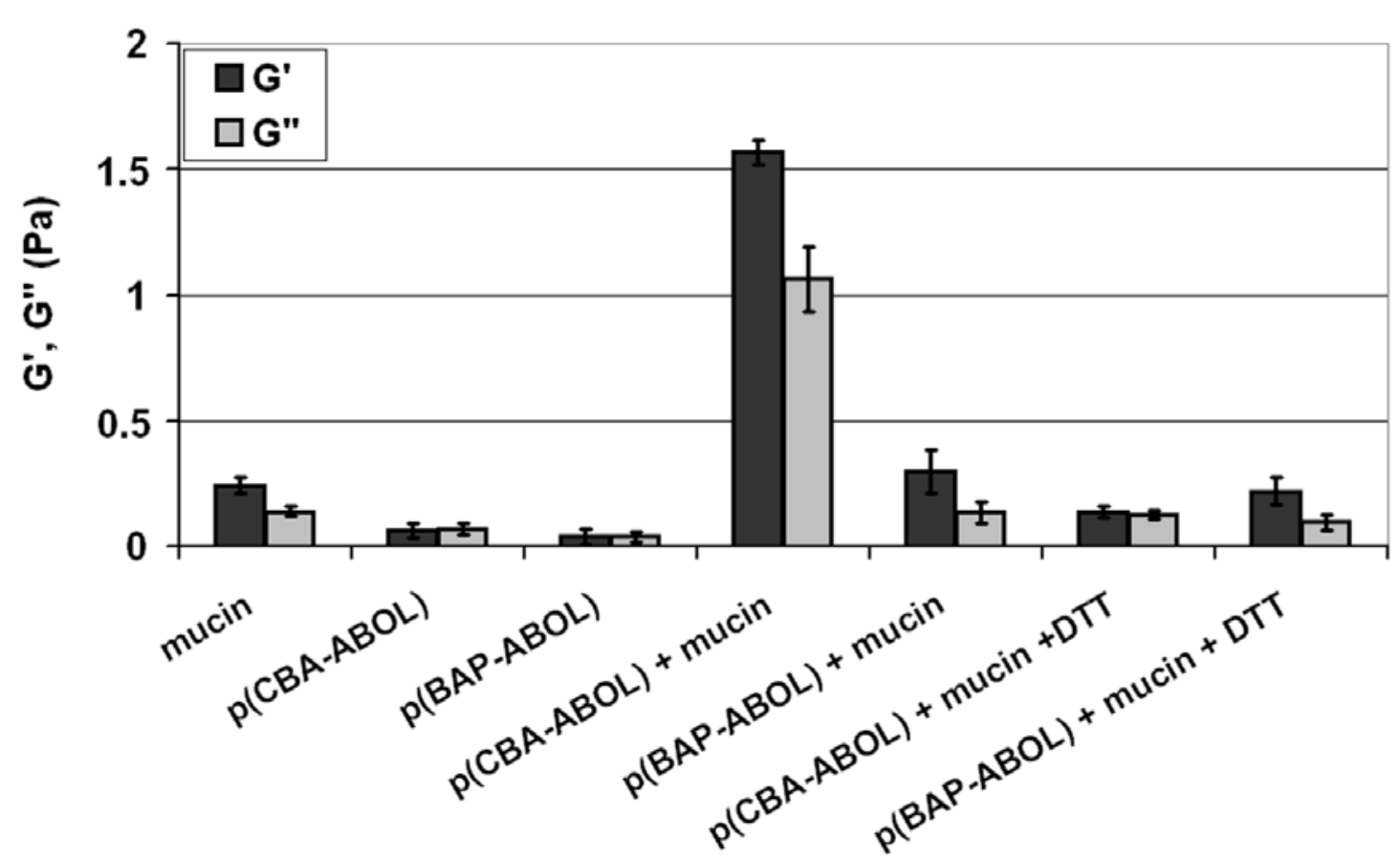

Figure 6.1. Storage modulus G' (black bars) and the loss modulus G" (grey bars) of $3 \%(\mathrm{w} / \mathrm{v})$ $p(C B A-A B O L), p(B A P-A B O L)$ (control) and their mixtures with $4 \%(w / v)$ mucin in the presence or absence of DTT (free thiol). Oscillatory measurements were carried out at $1 \mathrm{~Hz}$ frequency at room temperature after an incubation period of 30 minutes. All indicated values are means of three experiments $+/-$ SD.

A 4\% (w/v) solution of mucin showed moderate viscosity with measured storage and loss moduli of $0.24 \mathrm{~Pa}$ and $0.14 \mathrm{~Pa}$, respectively, whereas $3 \%$ polymer solutions of $p(C B A-A B O L)$ and $p(B A P-A B O L)$ alone almost did not show any increased viscosity, with dynamic moduli close to zero.

However, mixing mucin with $\mathrm{p}(\mathrm{CBA}-\mathrm{ABOL})$ resulted in a $6.5-8$ fold increase in storage and elastic moduli, with G' and G" of $1.57 \mathrm{~Pa}$ and $1.04 \mathrm{~Pa}$, respectively. In contrast, mixing mucin with $\mathrm{p}(\mathrm{BAP}-\mathrm{ABOL})$, the polymer lacking the disulfide linkages, only slightly increased rheological properties of the polymer/mucin mixture were observed.

The different results between $\mathrm{p}(\mathrm{CBA}-\mathrm{ABOL})$ and $\mathrm{p}(\mathrm{BAP}-\mathrm{ABOL})$ suggest that the presence of the disulfide bonds in $\mathrm{p}(\mathrm{CBA}-\mathrm{ABOL})$ is responsible for the stiffer mixture obtained with this polymer. This increase in viscosity might be attributed to disulfide bond formation between the $p(C B A-A B O L)$ polymer and mucin, due to exchange of disulfide linkages from the polymer with free thiol groups present in mucin.

To obtain additional evidence for the formation of disulfide bonds between $p(C B A-A B O L)$ and cysteine residues present in mucin, similar rheology measurements were performed 
in the presence of the disulfide bond reducing agent DTT. As shown in Figure 6.1, addition of $2.5 \mathrm{mM}$ DTT to the $\mathrm{p}(\mathrm{CBA}-\mathrm{ABOL}) /$ mucin mixture resulted in a dramatic decrease of the storage and loss moduli to values even lower than those determined for mucin only. For the $p(B A P-A B O L) / m u c i n$ mixture, only a slight decrease of $G^{\prime}$ and $G$ " is observed, which may also be explained by cleavage of mucus disulfide linkages.

\subsection{Protein loading of the PAA nanoparticles: physical characterization and loading efficiency}

At physiological $\mathrm{pH}(\mathrm{pH}$ 7.4), the PAAs are present as polycations due to partial protonation of the basic tertiary nitrogens in the polymer chain. Charge interaction with HSA can be expected since this protein, with an isoelectric point of 5.3 , has a net negative charge under these conditions. DLS and zeta-potential measurements showed that both synthesized PAA polymers are capable to form nanosized polyelectrolyte complexes by self-assembly with HSA. The particles have sizes $\leq 200 \mathrm{~nm}$ with low polydispersity $(\mathrm{PDI}<0.15)$ and positive surface charge $(+15$ to $+25 \mathrm{mV})$, in $10 \mathrm{mM}$ HEPES buffer solution pH 7.4 (Figure 6.2). Repetitive size measurements in time show that the particles formed with HSA were stable for at least one month at room temperature.

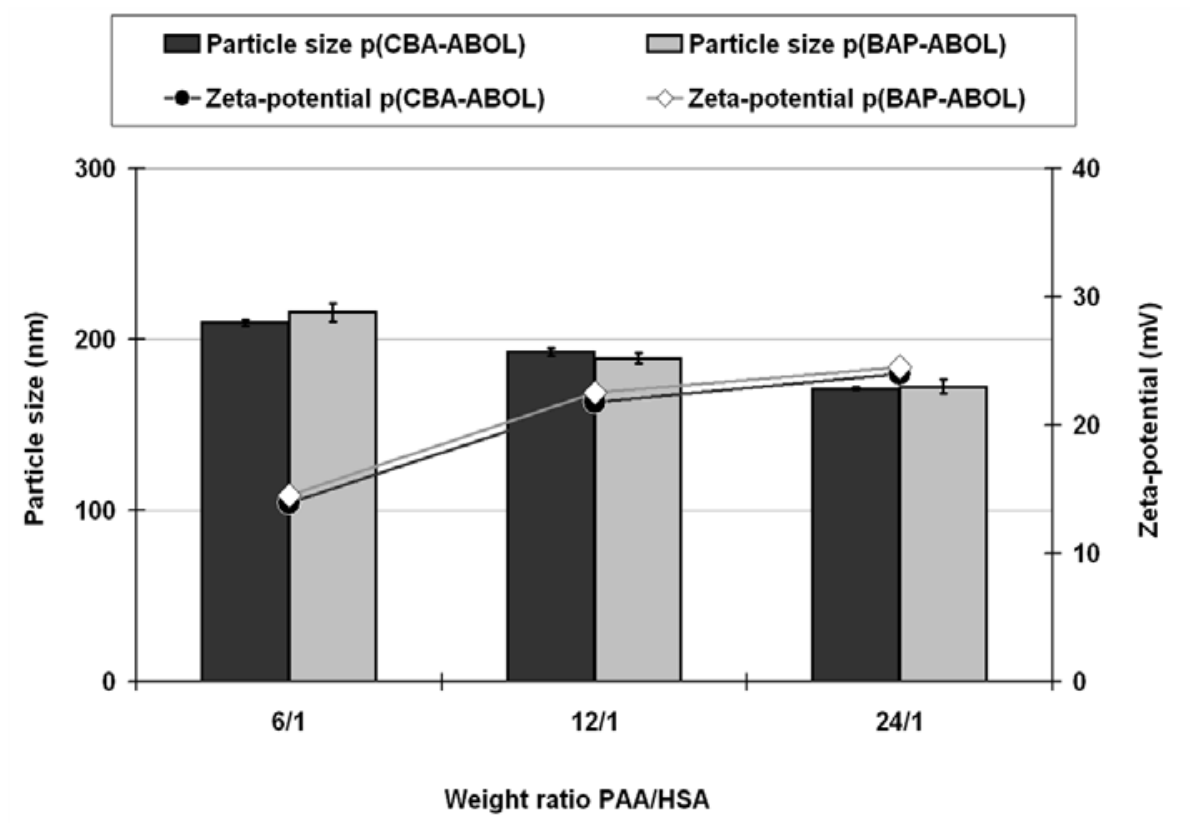

Figure 6.2. Size distributions and zeta-potentials of nanoparticles of PAA/HSA measured by DLS at $25^{\circ} \mathrm{C}$ at different $\mathrm{PAA} / \mathrm{HSA}$ weight ratios, using $\mathrm{p}(\mathrm{CBA}-\mathrm{ABOL}$ ) (black bars) and $\mathrm{p}$ (BAP-ABOL) (grey bars) as polymeric carrier. 
Table 6.1 gives the loading efficiencies of the PAA/HSA nanoparticles at neutral $\mathrm{pH}$ in HEPES buffer solution (10 mM, pH 7.4), as determined by fluorescence spectroscopy measurements. It can be seen that the incorporation of the protein into the polymer nanoparticles is very high under the very dilute conditions applied (HSA concentration is $120 \mu \mathrm{g} / \mathrm{ml})$.

This demonstrates that the PAA polymers are capable to bind this protein with slightly net negative charge with high affinity. The fact that the $p(C B A-A B O L)$ nanoparticles show some higher protein loading efficiency compared to the $p$ (BAP-ABOL) nanoparticles may be due to the higher flexibility of the polymer backbone of the former polymer.

Table 6.1. HSA loading efficiencies of PAA/FITC-HSA nanoparticles prepared using different PAA/HSA weight ratios in HEPES buffer pH 7.4.

\begin{tabular}{|c|c|c|}
\hline Polymer & $\begin{array}{c}\text { Polymer/Protein } \\
\text { weight ratio }\end{array}$ & $\begin{array}{c}\text { FITC-HSA loading } \\
\text { efficiency (\%)* }\end{array}$ \\
\hline \multirow{3}{*}{$\mathrm{p}(\mathrm{CBA}-\mathrm{ABOL})$} & $6 / 1$ & 89 \\
& $12 / 1$ & 94 \\
& $24 / 1$ & 97 \\
\hline $\mathrm{p}(\mathrm{BAP}-\mathrm{ABOL})$ & $6 / 1$ & 73 \\
& $12 / 1$ & 85 \\
& $24 / 1$ & 90 \\
\hline
\end{tabular}

\footnotetext{
* Percentage of HSA incorporated in the PAA nanoparticles (+/- 1)
}

Initial HSA concentration is $120 \mu \mathrm{g} / \mathrm{ml}$.

\subsection{Mimicking the intracellular dissassembly of the $p(C B A-A B O L) /$ protein nanoparticles in reducing environment}

The rapid cleavage of the disulfide linkages in the $p(C B A-A B O L)$ polymer in the intracellular environment due the presence of glutathione and reductase enzymes (containing up to $10 \mathrm{mM}$ glutathione) can be favorably exploited to induce disassembly of the nanocomplexes resulting in efficient protein release.

Table 6.2, column A, gives the percentages of HSA released from the $p(C B A-A B O L)$ and $\mathrm{p}$ (BAP-ABOL) nanoparticles after incubation with $2.5 \mathrm{mM}$ DTT for 30 minutes, as measured by fluorescence of the supernatant solution after centrifugation. The nanoparticles from the disulfide polymer $\mathrm{p}(\mathrm{CBA}-\mathrm{ABOL})$ have released most of the encapsulated protein, due to the fast degradation of these polymers, whereas no release 
of protein was measured for the particles containing $\mathrm{p}(\mathrm{BAP}-\mathrm{ABOL})$, the polymer lacking the disulfide linkages.

Table 6.2. The extent of HSA release from $\mathrm{p}(\mathrm{BAP}-\mathrm{ABOL}) / \mathrm{FITC}-\mathrm{HSA}$ nanoparticles in HEPES buffer pH 7.4 (weight ratio 24/1), after addition: DTT to a final concentration of $2.5 \mathrm{mM}$ (column A) or $0.25 \mathrm{M} \mathrm{HCl}$ to decrease $\mathrm{pH}$ down to $\mathrm{pH} 5.1$ (column B).

\begin{tabular}{|c|c|c|}
\hline Polymer & A (2.5 mM DTT) * & B (pH 5.1) * \\
\hline$p(C B A-A B O L)$ & 93.9 & 14.0 \\
\hline$p(B A P-A B O L)$ & 1.8 & 17.0 \\
\hline
\end{tabular}

* Percentage of HSA that is released from the polymeric nanoparticles (+/- 1). Initial HSA concentration in the nanoparticles is $120 \mu \mathrm{g} / \mathrm{ml}$.

The results from these experiments suggest that once the $\mathrm{p}(\mathrm{CBA}-\mathrm{ABOL})$ nanoparticles have arrived in the reductive environment inside the cell, HSA is released from the nanoparticles, due to the rapid cleavage of the disulfide linkages in the polymer backbone. In contrast, the release from nanoparticles made of $p(B A P-A B O L)$ will be a much slower process, most probably mainly governed by destabilization of the nanoparticles upon acidification (vide infra) and/or the hydrolysis of the polymeric carrier. The distinct difference in protein release between the two polymeric carriers offers opportunities to tune the bioresponsive release by variation of the amount of disulfide linkages in the polymer chain of PAAs [25].

\subsection{Effect of environmental acidification on the nanoparticles}

Since electrostatic interactions between the positively-charged polymer and the negatively-charged protein are an important, if not determining, driving force for the self assembly into the nanoparticles, it can be expected that a decrease of the $\mathrm{pH}$, as occurring during endosomal acidification, will also influence the stability of the nanoparticles. On one hand, a decrease of the $\mathrm{pH}$ will lead to a decrease of the amount of negative charges on the protein. On the other hand, the degree of protonation of the PAAs will be increased. Therefore there is a delicate balance between these effects, in which it is, however, expected that the decrease of overall negative charge on the protein will be the dominating factor, since an excess of positive charge is already present on the polymers in the nanoparticles at $\mathrm{pH}$ 7.4. Then, a decrease of the $\mathrm{pH}$ will lead to destabilization of the nanocomplexes and eventually release of the protein. DLS 
measurements show that the PAA/HSA nanoparticles significantly increase in size from ca. $165 \mathrm{~nm}$ to more than $300 \mathrm{~nm}$ when the $\mathrm{pH}$ decreases from 7.4 (extracellular $\mathrm{pH}$ ) to 5.1 (intracellular pH) (Figure 6.3). For both systems, small peaks in size distribution were observed around $40-50 \mathrm{~nm}$ when the $\mathrm{pH}$ is decreased to values below $\mathrm{pH} 5.3$, revealing the formation of small aggregates of free protein.

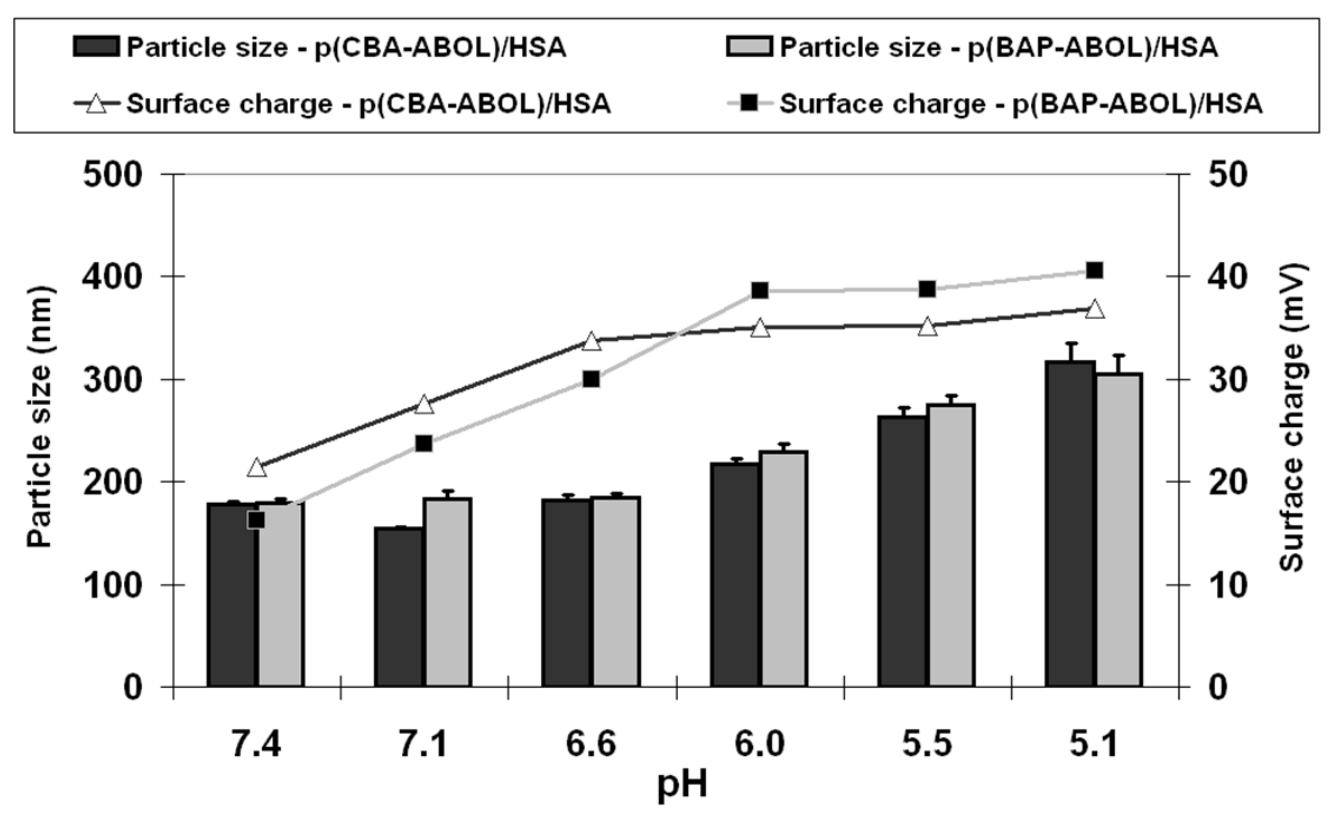

Figure 6.3. Size distributions of nanoparticles of $\mathrm{p}(\mathrm{BAP}-\mathrm{ABOL}) / \mathrm{HSA}$ (weight ratio 24:1) during $\mathrm{pH}$ titration of the particle solution from $\mathrm{pH} 7.4$ to $\mathrm{pH} 5.1$ (titration duration: 2 hours), representing the $\mathrm{pH}$ of the extracellular and intracellular environments respectively, using $\mathrm{p}(\mathrm{CBA}-\mathrm{ABOL})$ (black bars), and $\mathrm{p}$ (BAP-ABOL) (grey bars) as polymeric vector.

The amount of released protein from the PAA/HSA nanoparticles after incubation of the nanoparticle solution for 30 minutes at $\mathrm{pH}$ 5.1, and subsequent centrifugation of the nanoparticles is given in Table 6.2, column B. The HSA release is in the range of $14-17 \%$, and obviously there is no clear difference between the two polymers whether it contains disulfide bonds or not. These results indicate that endosomal acidification alone may not be sufficient to release the protein content from the nanocomplexes and that bioreduction of the polymer backbone can give an essential contribution to the intracellular release process.

\subsection{Cytotoxicity}

BCA and Alamar assays were used to evaluate the viability of Caco-2/TC7 cells after 48 hours of incubation with $p(C B A-A B O L), p(B A P-A B O L)$, free HSA protein, as well as the 
polymer/HSA nanocomplexes.

Figure 6.4 shows that the free HSA and free $p(C B A-A B O L)$ were found to be non cytotoxic, but the $\mathrm{p}$ (BAP-ABOL) polymer induced a toxicity of ca. 15\% after 48 hours of exposure. This cytotoxicity was confirmed by the Alamar blue assay that showed ca. 20\% decrease of cell viability after 4 hours of exposure to p(BAP-ABOL) and ca. $45 \%$ after $24-48$ hours of exposure. The nanoparticles made of the $p(C B A-A B O L)$ and $p(B A P-A B O L)$ polymers exhibited similar toxicity values as the corresponding polymers.

The Caco-2/TC7 cells were also exposed to nanoparticles in the presence of the non-specific multi drug resistance (MDR) blocker cyclosporin A (CsA) to analyze the involvement of the MDR machinery in the PAA/protein nanoparticles effluence (vide infra). The presence of CsA appeared to be not cytotoxic after 4 hours of incubation, but a slightly decreased cell viability of ca. $15 \%$ was found for the nanoparticles, the free polymers and the free protein after 24-48 hours of exposure.

A

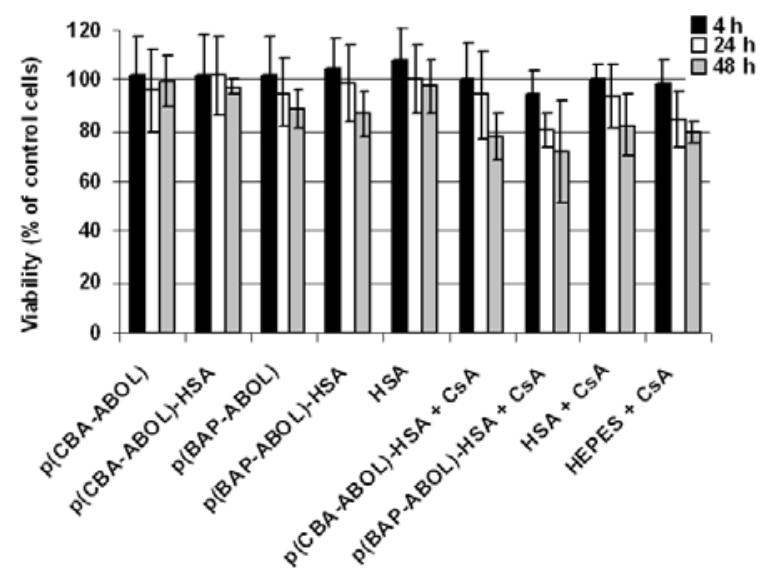

B
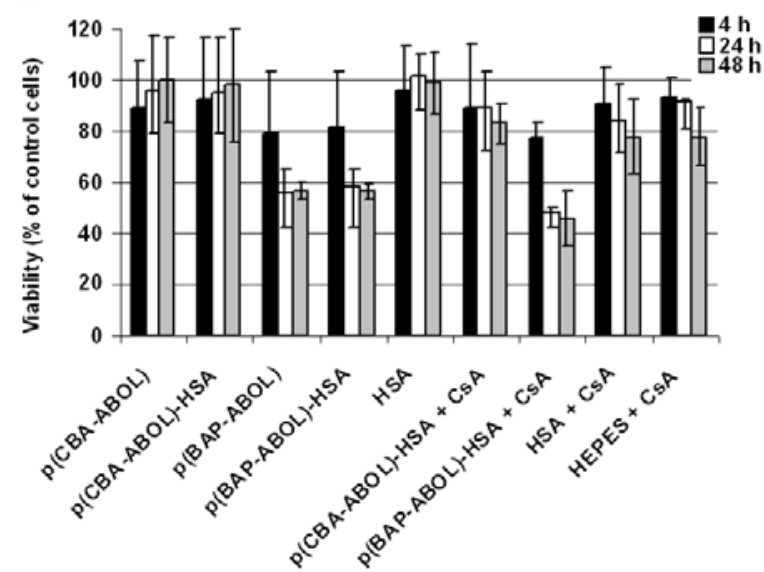

Figure 6.4 Cell viability of Caco-2/TC7 cells after incubation with $p(C B A-A B O L) / H S A$ and $\mathrm{p}(\mathrm{BAP}-\mathrm{ABOL}) / \mathrm{HSA}$ nanoparticles as well as the free polymers and free HSA, as determined by $(\mathrm{A})$ $\mathrm{BCA}$ and (B) Alamar assays. Assays were carried out at $37^{\circ} \mathrm{C}$ in $10 \%$ serum supplemented media in presence or absence of $10 \mu \mathrm{M}$ CsA. Results are given as mean +/- SD of three independent experiments.

\subsection{Uptake of the PAA nanoparticles as determined by flow cytometry}

The uptake of the PAA nanoparticles in Caco-2/TC7 cells was studied by FACS analysis of the cells exposed to the different PAA/HSA nanoparticles for two hours in serum-depleted media, followed by replacement of the medium by 10\% FCS containing media with the same concentration of nanoparticles for an additional 22 hours.

Figure 6.5 shows the relative fluorescent intensities obtained from Caco-2/TC7 cells 
exposed to free HSA and to the two polymer/HSA nanoparticles after 4 and 24 hours of exposure, in the absence and presence of CsA.

As shown in Figure 6.5, very low fluorescence intensities were detected when cells were incubated with solutions of free HSA, indicating a poor uptake of the free protein, as was shown in previous studies [35, 36].

However, a significant increase of fluorescence intensity for HSA uptake was measured when cells were incubated with $\mathrm{p}(\mathrm{CBA}-\mathrm{ABOL}) / \mathrm{HSA}$ nanoparticles. After 4 hours, these cells exhibited ca. 1.5 fold higher fluorescence signal than cells exposed to free HSA, and after 24 hours of exposure this signal was increased to ca. 4 fold. In comparison, the uptake of HSA from the $\mathrm{p}$ (BAP-ABOL)/FITC-HSA nanoparticles was similar to that of free HSA, indicating no improvement of uptake and almost no uptake of these particles.

These results show that the nanoparticles made of the $p(C B A-A B O L)$ polymer have much better capacity to deliver HSA inside the cells, than those of $p(B A P-A B O L)$, the polymer lacking disulfide bonds.

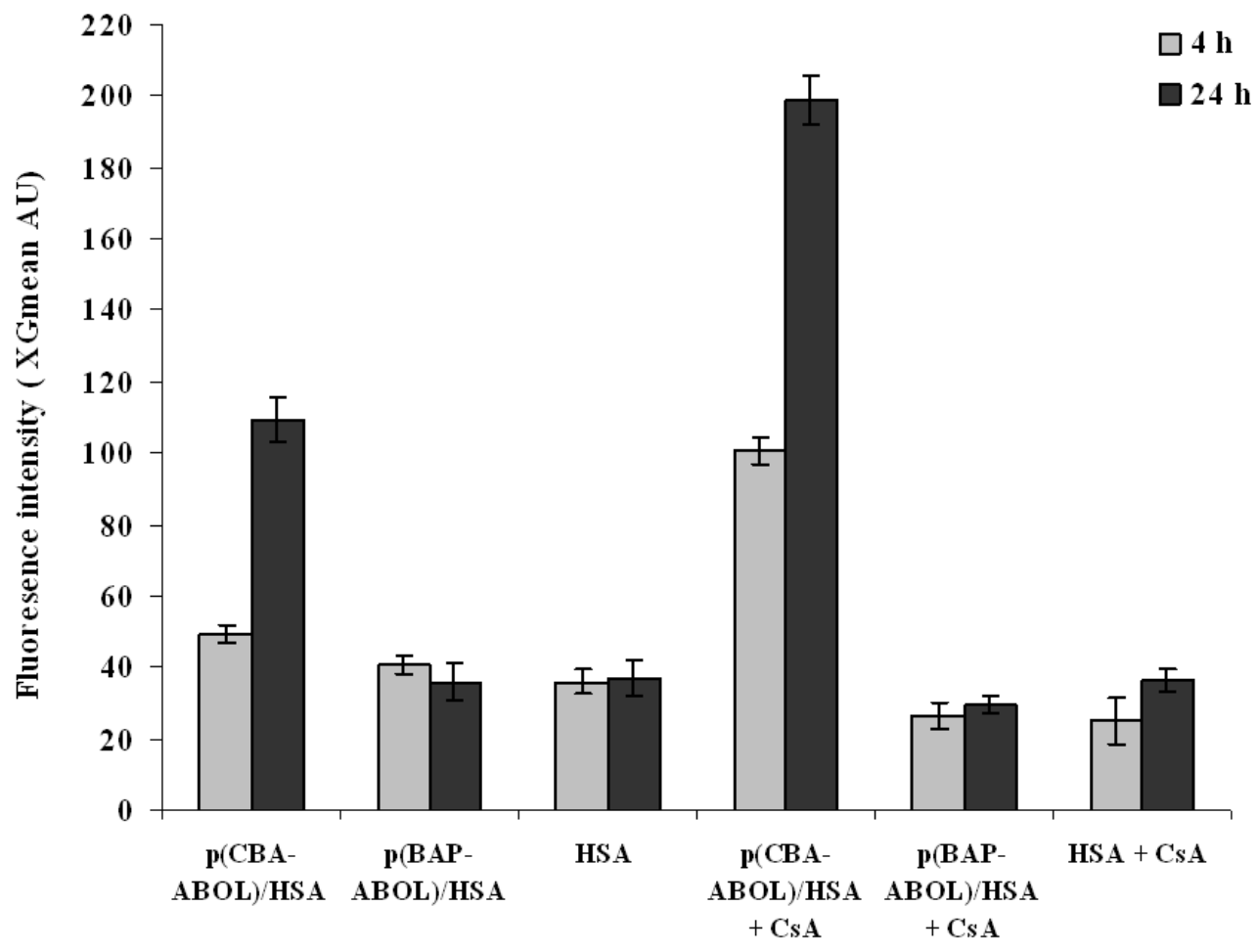

Figure 6.5. Uptake of PAA/HSA nanoparticles by Caco-2/TC7 cells as analyzed by flow cytometry $(n=3)$. Exposure was carried out for 4 and 24 hours at $37^{\circ} \mathrm{C}$ in serum depleted culture medium for two hours and then the culture medium was replaced to $10 \%$ FCS containing media with the same concentration of nanoparticles till the end of the exposure, in the absence or presence of $10 \mu \mathrm{M}$ CsA. 
For analyzing the involvement of the MDR machinery in the PAA/protein nanoparticles efflux, the Caco-2/TC7 cells were exposed to nanoparticles in the presence of the non-specific MDR blocker CsA.

Figure 6.5 shows that exposure to $\mathrm{p}(\mathrm{CBA}-\mathrm{ABOL}) / \mathrm{HSA}$ nanoparticles in the presence of 10 $\mu \mathrm{M}$ CsA yielded a significance increase of the uptake of HSA in comparison to that in the absence of CsA, both after 4 and 24 hours exposure (Figure 6.5). In contrast, the FITC emission intensities of cells that were exposed to $\mathrm{p}$ (BAP-ABOL)/HSA nanoparticles were not affected by the presence of CsA, both after 4 and 24 hours exposure. These FITC signals were as low as from cells incubated with free HSA in presence of CsA, indicating that the very low protein-delivery capability of the $p(B A P-A B O L)$ nanoparticles is not caused by a high efflux mechanism of these particles from the cells, but rather due to a low uptake.

\subsection{Effect of mucus level on the uptake of PAA/protein nanoparticles}

For detection of the mucoadhesive characteristics of the PAA/protein nanoparticles, different ratios of Caco-2/TC7 and HT-29 mucus secreting cells were mixed and the extent of uptake of $\mathrm{p}(\mathrm{CBA}-\mathrm{ABOL}) / \mathrm{HSA}$ nanoparticles as well as $\mathrm{p}$ (BAP-ABOL)/HSA nanoparticles was determined by flow cytometry analysis, after 4 and 24 hours exposure in culture medium similar as in 3.7.

Figure 6.6 shows that the presence of mucus produced by the HT-29 cells did not change the behavior of HSA towards the cells. The very low FITC emission intensities indicate that the free protein remained mainly uninternalized.

However, the uptake of the HSA-loaded p(CBA-ABOL) nanoparticles was significantly higher at all cell compositions, both after 4 hours of exposure (Figure 6.6A) and after 24 hours of exposure (Figure 6.6B), and significantly increased upon increment of the percentage of HT-29 cells in the cell cultures. When HT-29 cells (Caco-2/TC7:HT-29 ratio 0/100) were exposed to these nanoparticles, FITC emission intensities were $>5$ times higher than those of cells exposed to free HSA. In contrast, the extent of uptake of the $\mathrm{p}(\mathrm{BAP}-\mathrm{ABOL}) / \mathrm{HSA}$ nanoparticles was not affected by an increase of HT-29 in the Caco-2/TC7:HT-29 cell culture and remained constant even after 24 hours of exposure, with FITC emission intensities similar or even lower than those of cells exposed to free HSA in solution, illustrating its very poor intracellular delivery capacity.

It may be concluded that both the presence of mucus produced by the HT-29 cells as well as the presence of the disulfide bonds of $p(C B A-A B O L)$ interplay in the enhanced uptake 
of these nanoparticles. These results are in good agreement with the rheological experiments showing that the $p(C B A-A B O L)$ polymer interacts strongly with mucus, in contrast to $\mathrm{p}(\mathrm{BAP}-\mathrm{ABOL})$ lacking disulfide linkages.

A

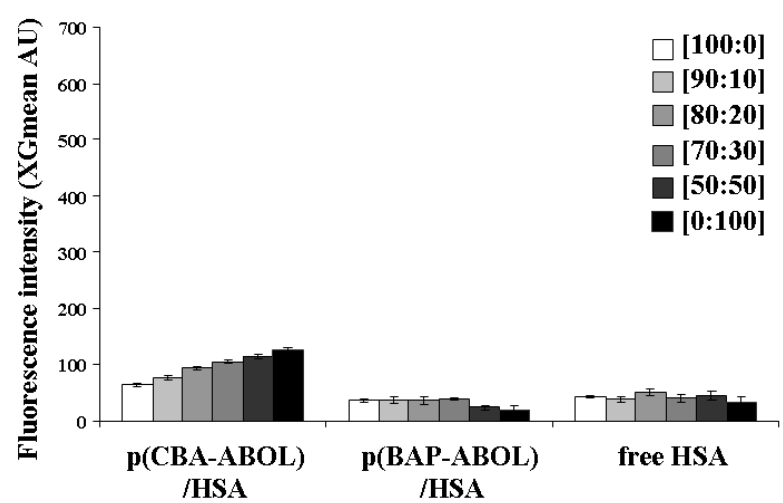

B

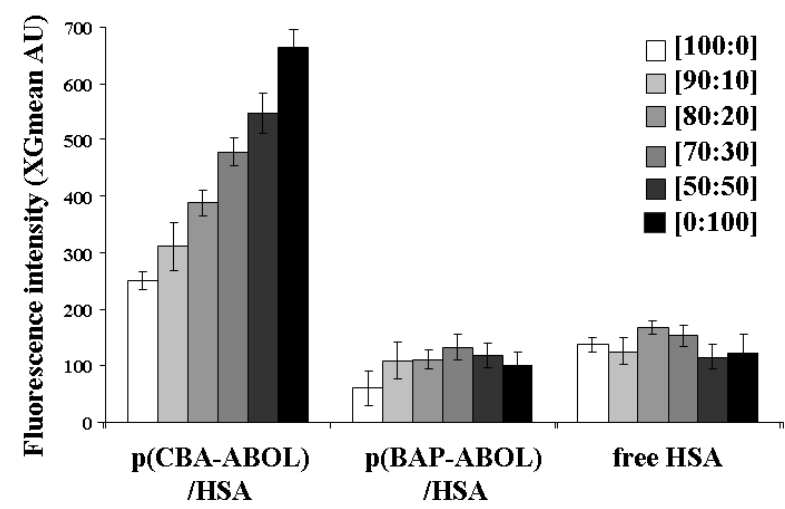

Figure 6.6. FACS analysis of different ratios of Caco-2/TC7:HT-29 co-cultures exposed to $p(C B A-A B O L)$ and $p(B A P-A B O L)$ nanoparticles complexed with HSA for 4 hours (A) and 24 hours (B) at $37^{\circ} \mathrm{C}(n=3)$. The results are normalized to free HSA), AU: arbitrary units.

To verify that the enhanced fluorescence as measured in the FACS analysis is really due to increased uptake of FITC-HSA in the cells and is not caused by residual nanoparticles in (theoretically possible) adhering mucus after the thorough washing procedure, additional confocal microscopy experiments were performed, permitting to follow and localize more accurately the uptake of HSA inside the cells.

\subsection{Confocal microscopy of uptake and compartmental localization of polymer/protein}

\section{nanoparticles}

The uptake of the PAA/HSA nanoparticles and their subsequent localization in Caco-2/TC7 cells were examined by confocal microscopy. HSA labeled with FITC was detectable in the green channel, and the lysosomal compartments stained using Lysotracker ${ }^{\circledR}$ were seen in the red channel. Cells were incubated with free HSA, the $\mathrm{p}(\mathrm{CBA}-\mathrm{ABOL}) / \mathrm{HSA}$ and $\mathrm{p}(\mathrm{BAP}-\mathrm{ABOL}) / \mathrm{HSA}$ nanoparticles, as well as the free $\mathrm{p}(\mathrm{CBA}-\mathrm{ABOL})$ and $\mathrm{p}(\mathrm{BAP}-\mathrm{ABOL})$ polymers, respectively.

The confocal microscopy image of Caco-2/TC7 cells exposed to free FITC-HSA (Figure 6.7B) showed no fluorescent signal, similar to non-treated cells (Figure 6.7A), indicating that free HSA was not taken up by cells. As expected, almost no green signal for FITC-HSA was observed when cells were exposed to the free polymers (Figures 6.7C and 6.7D), and the little fluorescence signal observed for FITC-HSA may result from the overlapping of the 
emission of FITC with the red fluorescent probe Lysotracker®.

Figure 6.7E shows the cellular uptake of HSA from the $\mathrm{p}(\mathrm{CBA}-\mathrm{ABOL})$ nanoparticles. Using this carrier, it can be seen HSA was successfully internalized into the cell cytosol and lysosomal compartments following 24 hours of exposure. The $p(C B A-A B O L) / H S A$ nanocomplexes are seen as green-red co-localized aggregates. In contrast, the $\mathrm{p}$ (BAP-ABOL)/HSA nanoparticles were mainly adsorbed on the cell membrane and were barely detectable, with similar fluorescent signal for FITC-HSA as that found in the cells exposed to the same amount of free FITC-HSA, proving that these nanoparticles were poorly internalized (Figure 6.7F).
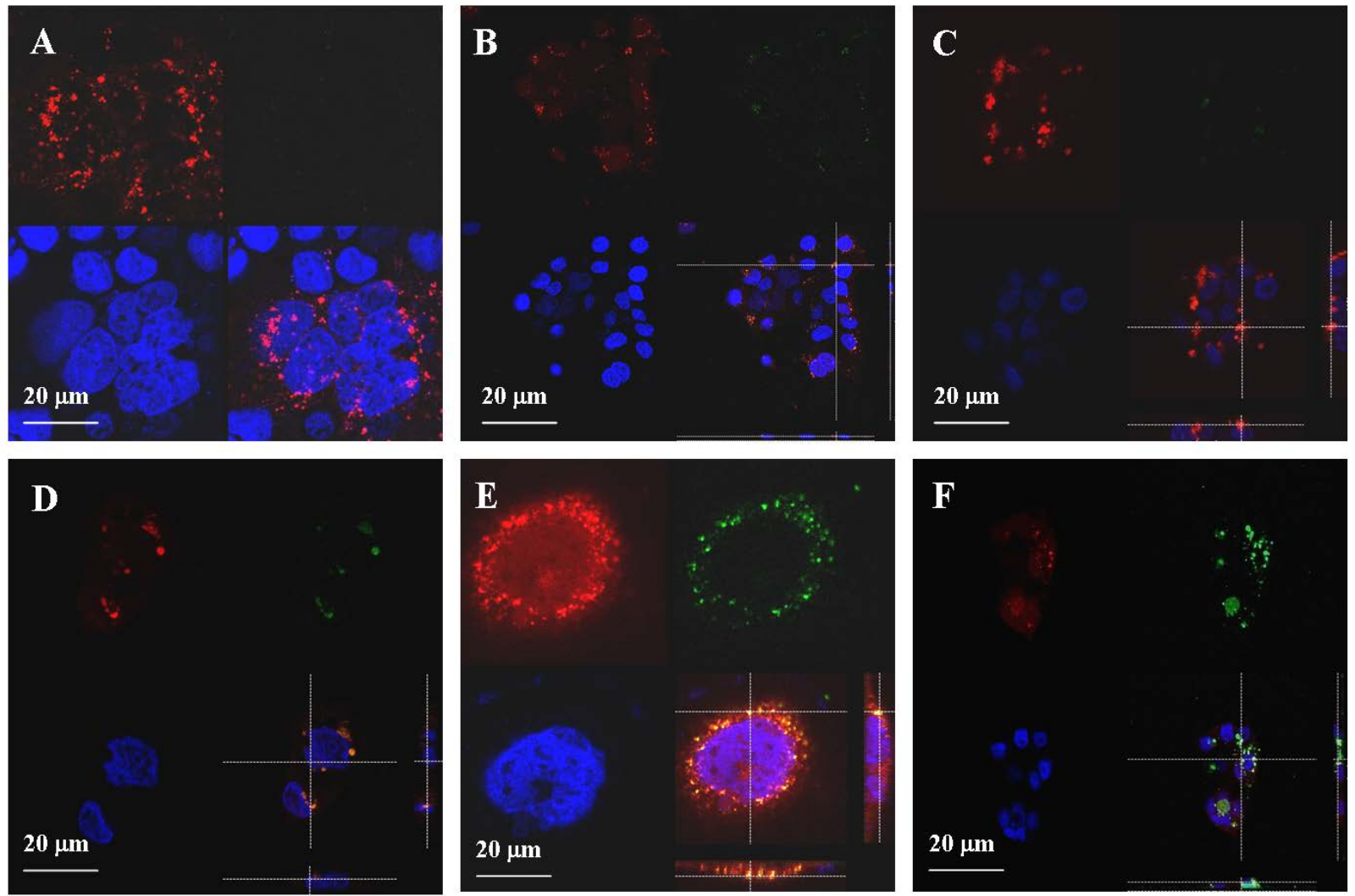

Figure 6.7. Confocal microscope images of Caco-2/TC7 cells exposed to nanoparticles for 24 hours at $37^{\circ} \mathrm{C}$, in serum depleted culture medium for two hours and then the culture medium was replaced to $10 \%$ FCS containing media with the same concentration of nanoparticles till the end of the exposure.

$A:$ non treated cells, B: free HSA, C: free $p(C B A-A B O L), D$ : free $p(B A P-A B O L), E: p(C B A-A B O L) / H S A$ nanoparticles, F: $p$ (BAP-ABOL)/HSA nanoparticles.

Red: LysoTracker probe; Blue: Hoechst nuclear staining; Green: FITC label from HSA. Each picture composed of 3 channels: green, red and blue and an orthogonal Z-section confocal overlay image.

In order to localize the nanoparticles in the different endosomal compartments, early endosomes (Rab-5) and lysosomes (Cathepsin D) were expressed by tagging them with 
red fluorescent protein was examined in Caco-2/TC7 cells. The polymers labeled with AF633 fluorophores were visible as pink in the red channel.

Cells incubated with $\mathrm{p}(\mathrm{CBA}-\mathrm{ABOL}) / \mathrm{HSA}$ nanoparticles showed white aggregates, revealing the localization of the red fluorescence protein from the endosomal and lysosomal compartments, the fluorescently-labeled polymer (seen in pink) and FITC-HSA (seen in green). These small aggregated were significantly present in the cytosol, and also in all the intracellular endosomal and lysosomal compartments (Figures $6.8 \mathrm{~A}-\mathrm{D}$ ). Moreover, when the cells are exposed to HSA-loaded nanoparticles made of the $p(C B A-A B O L)$, their cytoplasm exhibits a much broader spread red pattern (Figures 6.8B and 6.8D) than cells exposed to HSA-loaded nanoparticles made of p(BAP-ABOL) (Figures 6.8F and 6.8H). This distributed red pattern is most likely due to the reduction of the disulfide bonds within $\mathrm{p}(\mathrm{CBA}-\mathrm{ABOL})$ in the cell as a result of the reductive environment prevailing in the cytosol, involving degradation of the polymer. This observation is in good agreement with the results given in Table 6.2A depicting higher intracellular protein release from the nanoparticles made of the $\mathrm{p}(\mathrm{CBA}-\mathrm{ABOL})$ polymers in the presence of the reducing agent DTT.

In contrast, cells exposed to $\mathrm{p}$ (BAP-ABOL)/HSA nanoparticles did not contain any co-localized green-red markers, but only faint green cytoplasmic dots that are not co-localized with endosomal markers indicating that HSA was poorly absorbed into the cells (Figures $6.8 \mathrm{E}-\mathrm{H}$ ).

These results confirm the higher capacity from the $\mathrm{p}(\mathrm{CBA}-\mathrm{ABOL})$ polymer as carrier for intracellular delivery of HSA, in comparison to the $\mathrm{p}(\mathrm{BAP}-\mathrm{ABOL})$ polymer, lacking disulfide bonds. 


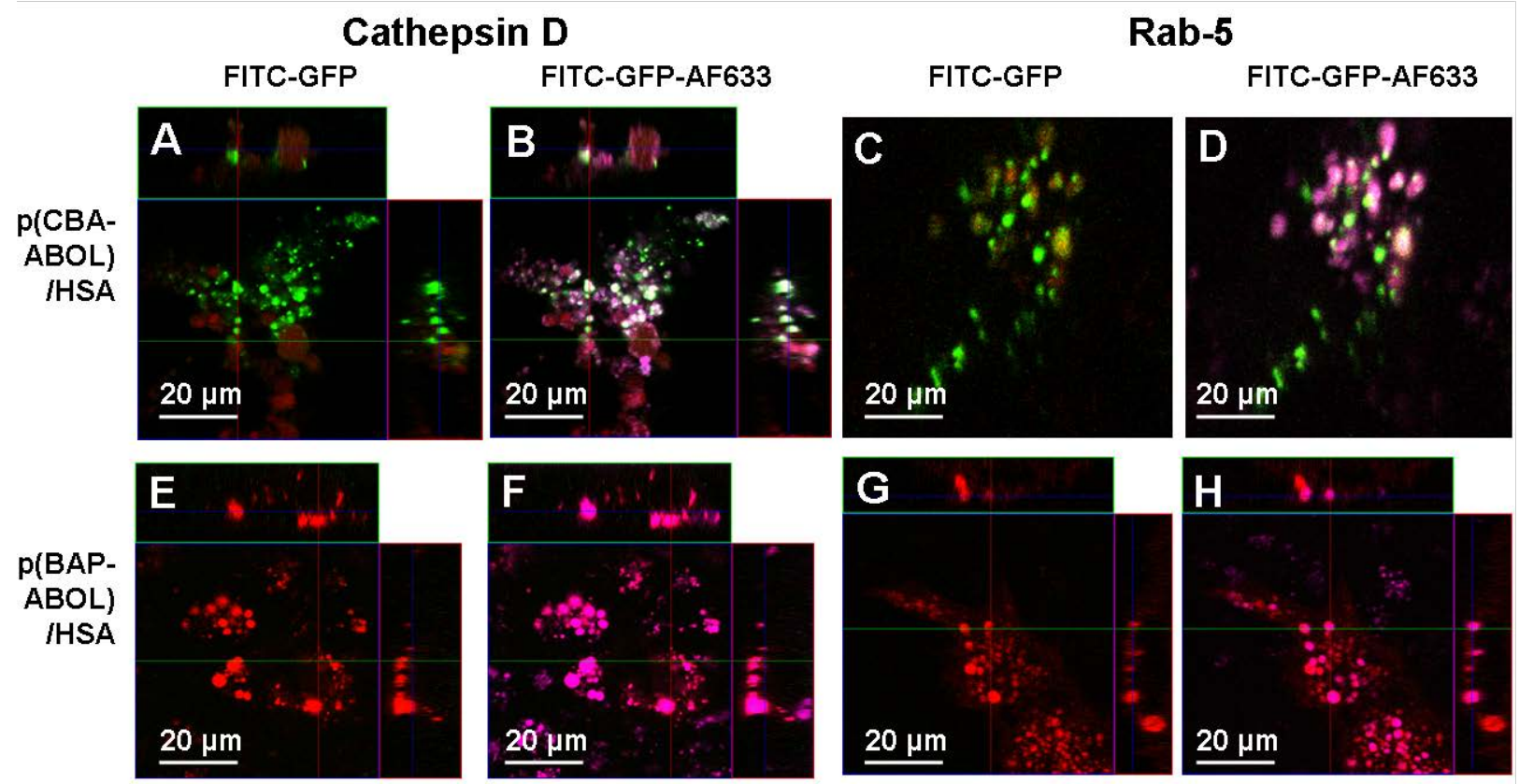

Figure 6.8. Orthogonal confocal images of Caco-2/TC7 cells expressing Cathepsin-D-RFP (A, B; E, F) or Rab-5-RFP (C, D; G, H) exposed to p(CBA-ABOL)/HSA (A, B; C, D) or p(BAP-ABOL)/HSA (E, F; G, H) nanoparticles for 24 hours in presence of $10 \%$ FCS.

Green: FITC-HSA, Red: Red fluorescence protein (RFP), Pink: AF633 label from the polymers, White: colocalization of red, green and pink fluorophores.

\section{Conclusions}

The two positively-charged PAAs, $\mathrm{p}(\mathrm{CBA}-\mathrm{ABOL})$ and $\mathrm{p}(\mathrm{BAP}-\mathrm{ABOL})$, synthesized for this study form stable nanosized complexes with the overall negatively-charged protein, human serum albumin (HSA), by a self-assembly process at physiological pH 7.4. Upon acidification of the solution $(\mathrm{pH}$ 5.1), as occurs after endosomal uptake, the nanocomplexes tend to destabilize as is evidenced form their observed increase in size and the appearance of small protein aggregates in DLS experiments. Moreover, $\mathrm{p}(\mathrm{CBA}-\mathrm{ABOL})$, the polymer containing disulfide linkages in its backbone, shows high mucoadhesion to intestinal mucus compared to $\mathrm{p}(\mathrm{BAP}-\mathrm{ABOL})$, the polymer lacking disulfide linkages, as demonstrated by dynamic rheological experiments. Nanocomplexes made from $\mathrm{p}(\mathrm{CBA}-\mathrm{ABOL})$ show fast disintegration and release of the protein payload in reductive solution mimicking the intracellular environment.

HSA, complexed with PAA polymers, was successfully internalized into Caco-2/TC7 cells. After cellular uptake, the protein-containing $\mathrm{p}(\mathrm{CBA}-\mathrm{ABOL})$ nanocomplexes is disassembled and the protein is released inside the cell with excellent cell viability.

The intracellular protein uptake using $\mathrm{p}(\mathrm{CBA}-\mathrm{ABOL})$ nanoparticles was significantly higher 
than that using $\mathrm{p}(\mathrm{BAP}-\mathrm{ABOL})$ nanoparticles, as was shown by fluorescence cytometry and confocal microscopic analyses. Protein complexed in $\mathrm{p}(\mathrm{CBA}-\mathrm{ABOL})$ nanoparticles was taken up in the cytosol, whereas the results with the $p(B A P-A B O L)$ nanoparticles suggest adsorption of these complexes to the cell membrane rather than intracellular uptake.

The internalization efficiency using $\mathrm{p}(\mathrm{CBA}-\mathrm{ABOL})$ nanoparticles was enhanced with the presence of CsA, suggesting an existing MDR-dependent efflux pathway for these nanoparticles.

A high correlation was observed between the extent of uptake of $p(C B A-A B O L)-b a s e d$ nanoparticles and the mucus level of the cell culture, which was not detected for nanocomplexes made from $\mathrm{p}(\mathrm{BAP}-\mathrm{ABOL})$ lacking the disulfide bonds, suggesting strong association of the disulfide linkages in the main chain of the polymer with the mucus layer and the cell membrane.

In summary, these findings demonstrate the capability of the disulfide-containing poly(amidoamine)s, in this study $\mathrm{p}(\mathrm{CBA}-\mathrm{ABOL})$ in particular, to be used as efficient intracellular protein delivery vehicles for intestinal cells, which is promising for applications in oral delivery systems.

\section{Acknowledgements}

This research work is part of the Integrated European FP6 IP NanoBioPharmaceutics.

\section{References}

[1] D.R. Owens, B. Zinman, G. Bolli, Alternative routes of insulin delivery. Diabetic Med 20(11) (2003) 886-898.

[2] H.P. Merkle, New Aspects of Pharmaceutical Dosage Forms for Controlled Drug-Delivery of Peptides and Proteins. Eur. J. Pharm. Sci. 2(1-2) (1994) 19-21.

[3] M.C. Manning, K. Patel, R.T. Borchardt, Stability of Protein Pharmaceuticals. Pharm. Res. 6(11) (1989) 903-918.

[4] Y. Tabata, Y. Ikada, Protein release from gelatin matrices. Adv. Drug Deliv. Rev. 31(3) (1998) 287-301.

[5] C.M. Lehr, Bioadhesion Technologies for the Delivery of Peptide and Protein Drugs to the Gastrointestinal-Tract. Crit. Rev. Ther. Drug Carr. Syst. 11(2-3) (1994) 119-160.

[6] P. Couvreur, F. Puisieux, Nanoparticles and Microparticles for the Delivery of Polypeptides and Proteins. Adv. Drug Deliv. Rev. 10(2-3) (1993) 141-162.

[7] J. Kreuter, Peroral Administration of Nanoparticles. Adv. Drug Deliv. Rev. 7(1) (1991) 71-86.

[8] A. Bernkop-Schnürch, Thiomers: A new generation of mucoadhesive polymers. Adv. Drug Deliv. Rev 57(11) (2005) 1569-1582.

[9] M.H. Dufresne, M.A. Gauthier, J.C. Leroux, Thiol-functionalized polymeric micelles: From molecular recognition to improved mucoadhesion. Bioconjugate Chem. 16(4) (2005) 1027-1033.

[10] A. Bernkop-Schnurch, V. Schwarz, S. Steininger, Polymers with thiol groups: A new generation of mucoadhesive polymers? Pharm. Res. 16(6) (1999) 876-881. 
[11] K. Kafedjiiski, F. Foger, A. Bernkop-Schnurch, M. Werle, Evaluation of in vitro enzymatic degradation of various thiomers and cross-linked thiomers. Drug Dev. Ind. Pharm. 33(2) (2007) 199-208.

[12] M.K. Marschutz, P. Caliceti, A. Bernkop-Schnurch, Design and in vivo evaluation of an oral delivery system for insulin. Pharm. Res. 17(12) (2000) 1468-1474.

[13] O. Boussif, F. Lezoualch, M.A. Zanta, M.D. Mergny, D. Scherman, B. Demeneix, J.P. Behr, A Versatile Vector for Gene and Oligonucleotide Transfer into Cells in Culture and in-Vivo Polyethylenimine. Proc. Natl. Acad. Sci. U. S. A. 92(16) (1995) 7297-7301.

[14] J.D. Eichman, A.U. Bielinska, J.F. Kukowska-Latallo, J.R. Baker Jr, The use of PAMAM dendrimers in the efficient transfer of genetic material into cells. Pharmaceut Sci Tech Today 3(7) (2000) 232-245.

[15] E. Ranucci, G. Spagnoli, P. Ferruti, D. Sgouras, R. Duncan, Poly(amidoamine)s with potential as drug carriers: degradation and cellular toxicity. J Biomater Sci Polym Ed 2(4) (1991) 303-315.

[16] G.Y. Wu, C.H. Wu, Receptor-Mediated Invitro Gene Transformation by a Soluble DNA Carrier System. J. Biol. Chem. 262(10) (1987) 4429-4432.

[17] J. Franchini, E. Ranucci, P. Ferruti, Synthesis, physicochemical properties, and preliminary biological characterizations of a novel amphoteric agmatine-based poly(amidoamine) with RGD-like repeating units. Biomacromolecules 7(4) (2006) 1215-1222.

[18] P. Ferruti, M.A. Marchisio, R. Duncan, Poly(amido-amine)s: Biomedical applications. Macromol. Rapid Commun. 23(5-6) (2002) 332-355.

[19] N. Lavignac, M. Lazenby, J. Franchini, P. Ferruti, R. Duncan, Synthesis and preliminary evaluation of poly(amidoamine)-melittin conjugates as endosomolytic polymers and/or potential anticancer therapeutics. Int. J. Pharm. 300(1-2) (2005) 102-112.

[20] N. Lavignac, J.L. Nicholls, P. Ferruti, R. Duncan, Poly(amidoamine) Conjugates Containing Doxorubicin Bound via an Acid-Sensitive Linker. Macromol. Biosci. 9(5) (2009) 480-487.

[21] N.G. Pattrick, S.C.W. Richardson, M. Casolaro, P. Ferruti, R. Duncan, Poly(amidoamine)-mediated intracytoplasmic delivery of ricin A-chain and gelonin. J. Control. Release 77(3) (2001) 225-232.

[22] S. Swaminathan, R. Cavalli, F. Trotta, P. Ferruti, E. Ranucci, I. Gerges, A. Manfredi, D. Marinotto, P.R. Vavia, In vitro release modulation and conformational stabilization of a model protein using swellable polyamidoamine nanosponges of beta-cyclodextrin. J. Incl. Phenom. Macrocycl. Chem. 68(1-2) (2010) 183-191.

[23] G. Coué, J.F.J. Engbersen, Functionalized linear poly(amidoamine)s are efficient vectors for intracellular protein delivery. J. Control. Release (2011), doi:10.1016/j.jconrel.2011.01.023

[24] C. Lin, C.-J. Blaauboer, M.M. Timoneda, M.C. Lok, M. van Steenbergen, W.E. Hennink, Z. Zhong, J. Feijen, J.F.J. Engbersen, Bioreducible poly(amido amine)s with oligoamine side chains: Synthesis, characterization, and structural effects on gene delivery. J. Control. Release 126(2) (2008) 166-174.

[25] C. Lin, Z. Zhong, M.C. Lok, X. Jiang, W.E. Hennink, J. Feijen, J.F.J. Engbersen, Linear poly(amido amine)s with secondary and tertiary amino groups and variable amounts of disulfide linkages: Synthesis and in vitro gene transfer properties. J. Control. Release 116(2) (2006) 130-137.

[26] C. Lin, Z. Zhong, M.C. Lok, X. Jiang, W.E. Hennink, J. Feijen, J.F.J. Engbersen, Random and block copolymers of bioreducible poly(amido amine)s with high- and low-basicity amino groups: Study of DNA condensation and buffer capacity on gene transfection. J. Control. Release 123(1) (2007) 67-75.

[27] C. Lin, Z.Y. Zhong, M.C. Lok, X.L. Jiang, W.E. Hennink, J. Feijen, J.F.J. Engbersen, Novel bioreducible poly(amido amine)s for highly efficient gene delivery. Bioconjugate Chem. 18(1) (2007) 138-145.

[28] M.A. Mateos-Timoneda, M.C. Lok, W.E. Hennink, J. Feijen, J.F.J. Engbersen, Poly(amido amine)s as gene delivery vectors: Effects of quaternary nicotinamide moieties in the side chains. ChemMedChem 3(3) (2008) 478-486.

[29] A. Akinc, M. Thomas, A.M. Klibanov, R. Langer, Exploring polyethylenimine-mediated DNA 
transfection and the proton sponge hypothesis. J. Gene. Med. 7(5) (2005) 657-663.

[30] S. Yang, S. May, Release of cationic polymer-DNA complexes from the endosome: A theoretical investigation of the proton sponge hypothesis. J. Chem. Phys. 129(18) (2008) 9.

[31] P. Watson, A.T. Jones, D.J. Stephens, Intracellular trafficking pathways and drug delivery: Fluorescence imaging of living and fixed cells. Adv. Drug Delivery Rev. 57(1 SPEC. ISS) (2005) 43-61.

[32] C. Lin, J.F.J. Engbersen, The role of the disulfide group in disulfide-based polymeric gene carriers. Expert Opin. Drug Deliv. 6(4) (2009) 421-439.

[33] K.C. Rajender, W.L. Frederick, H.K. Michael, M.B. David, G.B.R. Robert, R. Daniel, Plasma cysteine, cystine, and glutathione in cirrhosis. Gastroenterology 87(4) (1984) 770-776.

[34] P. Calvo, C. RemunanLopez, J.L. VilaJato, M.J. Alonso, Novel hydrophilic chitosan-polyethylene oxide nanoparticles as protein carriers. J. Appl. Polym. Sci. 63(1) (1997) 125-132.

[35] S.C. Gu, N. Papadopoulou, E.M. Gehring, O. Nasir, K. Dimas, S.K. Bhavsar, M. Foller, K. Alevizopoulos, F. Lang, C. Stournaras, Functional membrane androgen receptors in colon tumors trigger pro-apoptotic responses in vitro and reduce drastically tumor incidence in vivo. Mol. Cancer 8 (2009) 14.

[36] E.K. Wasan, D. Waterhouse, O. Sivak, M.B. Bally, R.J. Klasa, K.M. Wasan, Plasma protein binding, lipoprotein distribution and uptake of free and lipid-associated BCL-2 antisense oligodeoxynucleotides (G3139) in human melanoma cells. Int. J. Pharm. 241(1) (2002) 57-64. 


\title{
In vitro and in vivo evaluation of insulin-loaded poly(amidoamine) nanoparticles for oral protein delivery
}

\author{
Grégory Coué $^{1}$, Claus Gyrup Nielsen ${ }^{2}$, Peter Kresten Nielsen ${ }^{2}$ and J. F. J. Engbersen ${ }^{1}$ \\ 1 Department of Biomedical Chemistry, MIRA Institute for Biomedical Technology \& Technical \\ Medicine, Faculty of Science and Technology, University of Twente, P.O. Box 217, 7500 AE \\ Enschede, The Netherlands \\ 2 Novo Nordisk A/S, Novo Nordisk Park, DK-2760 Måløv, Denmark
}

\begin{abstract}
To improve the efficiency of insulin via oral administration, several formulations of polyelectrolyte complexes formed by charge-attraction between functionalized linear poly(amidoamine)s and human insulin were prepared. These insulin-loaded nanoparticles were characterized by dynamic light scattering, zeta potential, and their proteolytic and chemical stability. Further on, their hypoglycemic effect was evaluated in vivo in diabetic rats. The poly(amidoamine) nanoparticles were shown to efficiently protect insulin towards proteolytic enzymes and improve its uptake in vivo leading to enhanced oral bioavailability of insulin.
\end{abstract}

\section{Introduction}

About 285 million adults worldwide are currently affected by diabetes mellitus, and this number might increase up to 440 million adults in 2030, diabetes representing the fifth leading cause of death in the U.S.A. [1, 2]. Diabetes is related to the insufficient production of insulin in the pancreas, and the most common treatment is by administration of insulin by subcutaneous injections, despite the inconvenience for the patient. Research on non-invasive methods of insulin delivery such as oral, dermal, nasal and inhalative administration has been extensive for more than 30 years $[3,4]$. The oral route is the most convenient and accepted route of drug administration since it avoids pain and discomfort, especially when repeated dosing is necessary [5-7] as well as being less invasive. However, 
for insulin, oral delivery poses the problem that it is readily degraded under the influence of the low $\mathrm{pH}$ of the gastric medium and the various proteolytic enzymes in the gastric intestinal (Gl) tract. Moreover, its large molecular weight and hydrophilicity causes low mucosal permeability and cellular transport, resulting in a low permeability across the intestinal epithelium [8-19]. All these effects lead to bioavailabilities lower than $10 \%$ for orally administered peptides and proteins, as low as $0.05 \%$ for orally delivered insulin [20-22]. Therefore, there is a need to protect insulin from the harsh environment when given orally [23]. To overcome these problems, delivery systems including nanoparticles, microcapsules, liposomes, and emulsions are used [24, 25].

Some investigators have observed that nanoparticles pass more readily the intestinal epithelium than microspheres and that not only the $M$ cells but also the normal enterocytes are involved in the transport [24, 26, 27]. Despite great progress of the knowledge in this field, oral delivery of protein therapeutics such as insulin still remains a challenging area for researchers. There are still quite a number of limitations in the use of nanoparticles as transmucosal protein delivery systems, including their instability in the GI fluids, limited interaction with intestinal membrane, and limited transport across the mucosal barrier, the use of organic solvent during preparation [28], and the poor absorption of proteins as a result of their high hydrophilicity.

An attractive way to circumvent these problems is through the design of a formulation for the insulin molecules which protects the drug from degradation and releases it the site of action. Recently, nanosized polyelectrolyte complexes (PECs) resulting from the self-assembly of proteins with natural and synthetic polymers have drawn increasing attention for application in therapeutic protein delivery [29-32]. In this non-covalent method, PECs are formed by simply mixing oppositely-charged drug and polymer that will interact by electrostatic-attraction. The PEC formation results in optically homogeneous and stable dispersions of nanoparticles possessing cationic charges able to bind to and internalize with the cell surface. They have the advantage of not using sonification or organic solvents which are both harmful for proteins and peptides and are regularly used for the preparation of nanoparticles notably by the double emulsion technique.

As a requirement of efficient delivery, the mucoadhesion of colloidal carriers has been reported to represent one of the most important properties to improve the bioavailability of poorly absorptive drugs [33-37]. Mucoadhesive carriers adhere to the mucus layer present on intestinal mucosal membranes and are expected to prolong the residence time at the local site of absorption, leading to increased drug absorption through the intestinal 
membrane. Presently, chitosan is widely used as mucoadhesive polymer [38-43], but this. polycation has an intrinsic pKa of 5.5 , which implies that it will lose its charge and precipitate in neutral and basic environment. With carboxyl groups on the glucosamine units of the chitosan structure, carboxylated chitosan has successfully overcome the limited solubility at neutral and weakly alkaline $\mathrm{pH}$ values.

In this study, polyelectrolyte complexes of cationic poly(amidoamine)s and human insulin, have been produced and evaluated in vitro and in vivo. Poly(amidoamine)s (PAAs) are synthetic tert-amino polymers, synthesized by polyaddition of primary amines to bisacrylamides. They are water-soluble, biodegradable and biocompatible, with less cytotoxicity than other usual polycationic vectors [44-48]. PAAs represent a family of functional polymers endowed with a combination of properties that makes them suitable for a variety of biomedical applications related to polymer therapeutics [44, 49].

To answer the mucoadhesive criteria, we have developed in our group novel linear poly(amidoamine)s (PAAs) containing repetitive disulfide linkages in their backbone (SS-PAAs). Those polymeric carriers were previously reported as very efficient as vectors in intracellular gene delivery, resulting in high transfection efficiencies [50-55], and recently it was shown that they are also efficient vectors for intracellular protein delivery [56]. The SS-PAAs meet the requirements to possess mucoadhesive properties since the repetitive disulfide linkages in their backbone can react with thiol groups and disulfide groups in the mucus, useful properties for oral delivery of nanoparticles made of these polymers [57-61]. Moreover, this property can be used in systems that should be relatively stable during transport outside the cell but should disintegrate in fragments of low molecular weight after uptake into the target cells [57, 62-65].

\section{Materials and methods}

\subsection{Materials}

Human insulin (HI) was kindly supplied by Novo Nordisk. FITC-insulin was obtained from Sigma-Aldrich. All monomers, 4-amino-1-butanol (ABOL, Sigma-Aldrich), alpha-amino-omega-carboxy-poly(ethylene glycol) hydrochloride (PEG-M $3000 \mathrm{~g} / \mathrm{mol})$ (cPEG-NH $\mathrm{NH}_{2}$, Iris Biotech $\mathrm{GmbH}$ ), N,N'-cystaminebisacrylamide (CBA, Polysciences), 1,4-bis(acryloyl)piperazine (BAP, Sigma-Aldrich) were purchased in the highest purity and used without further purification. HEPES (Sigma-Aldrich), phosphate buffered saline (PBS, $0.01 \mathrm{M}, \mathrm{pH}$ 7.4, B. Braun, USA), glutathione (Sigma-Aldrich), and methanol ( $\mathrm{MeOH}$, Biosolve) were used as received. Deionized water (DI water) was obtained from a 
MilliQ-water purification system (Millipore, France).

\subsection{Synthesis of PAAs}

The polymers $p(C B A-A B O L), p(B A P-A B O L)$, and the co-polymer cPEG-p(CBA-ABOL), with $10 \%$ cPEG side chains relative to the hydroxybutyl groups, were synthesized via Michael polyaddition of the primary amine monomers, $\mathrm{ABOL}$ and $\mathrm{CPEG}-\mathrm{NH}_{2}$, to the bisacrylamide CBA and BAP, as described in Chapters 3 and 5 , respectively.

\subsection{Polymer characterization}

Details about the ${ }^{1} \mathrm{H}$ NMR and GPC data of the $\mathrm{p}(\mathrm{CBA}-\mathrm{ABOL})$ and $\mathrm{p}(\mathrm{BAP}-\mathrm{ABOL})$ polymers, and the co-polymer cPEG-p(CBA-ABOL), have been described in Chapters 3 and 5.

\subsection{Preparation of PAA/insulin nanoparticles}

Prior to sample preparation, human insulin was expressed recombinantly and purified by chromatographic methods. The purified protein was dried, resulting in a zinc-free powder which can be dissolved to $>50 \mathrm{mg} / \mathrm{ml}$ in water, yielding primarily monomeric active insulin. A series of SS-PAA/insulin and PAA/insulin nanocomplexes were prepared by adding a HEPES buffer solution $(10 \mathrm{mM}, \mathrm{pH} 7.4)$ of PAA $(800 \mu \mathrm{l}, 30 \mathrm{mg} / \mathrm{ml})$ to a HEPES buffer solution $(10 \mathrm{mM}, \mathrm{pH} 7.4)$ of insulin $(200 \mu \mathrm{l}, 10 \mathrm{mg} / \mathrm{ml})$, corresponding to a polymer/protein weight ratio $12 / 1$, followed by vortexing for 5 seconds and incubation at room temperature for 30 minutes.

\subsection{Characterization of PAA/insulin nanoparticles}

\subsubsection{Particle size and zeta-potential measurements}

Particle size and surface charge measurements of the nanocomplexes were determined by dynamic light scattering (DLS) at $25^{\circ} \mathrm{C}$ with a Zetasizer Nano ZS (Malvern Instruments, Malvern) using a wavelength of $532 \mathrm{~nm}$. The value was recorded as the mean of three measurements. The size distribution was given by the polydispersity index (PDI), where a value of 1 indicates large variations in particle size, and a value of 0 indicates no variation in particle size (as an ideal monodispersed formulation). As the size of the particles influences the eventual uptake and distribution of the particles inside the cell, their stability at $25^{\circ} \mathrm{C}$ and $37^{\circ} \mathrm{C}$ was investigated and followed by DLS. The results at $25^{\circ} \mathrm{C}$ represent the ability of the nanocomplex solution to be stored at room temperature, whereas the results at $37^{\circ} \mathrm{C}$ indicate the thermal stability in the human body. 


\subsubsection{Insulin condensation and loading efficiency}

To estimate the loading efficiency of the nanoparticles at neutral $\mathrm{pH}$, solutions of PAA/insulin nanoparticles were prepared at polymer/protein weight ratio 12/1 using FITC-labeled insulin. The nanoparticles were centrifuged at $14000 \mathrm{rpm}$ for 30 minutes at $4^{\circ} \mathrm{C}$. Aliquots of supernatant were subsequently taken and their protein content determined by fluorescence spectroscopy (Safire2, Tecan, Canada) at an emission wavelength of $519 \mathrm{~nm}$ and an excitation wavelength of $495 \mathrm{~nm}$. The actual loading efficiency was indirectly determined by measuring the difference between the total amount of insulin added to the solution and the amount of insulin in the free form in the supernatant. A calibration curve from solutions of various fluorescently-labeled insulin concentrations was determined prior to this experiment. It was confirmed that free insulin was not precipitated from the solution by centrifugation.

\subsubsection{Effect of intracellular conditions on PAA/insulin nanoparticles}

The effect of $\mathrm{pH}$ decrease from 7.4 to 5.1 (mimicking endosomal $\mathrm{pH}$ decrease) was investigated by DLS measurements. Particle size measurements of the nanocomplexes were performed at $25^{\circ} \mathrm{C}$ with a Zetasizer Nano ZS (Malvern Instruments, Malvern, UK) using a wavelength of $532 \mathrm{~nm}$. Simultaneously, the nanoparticular solution was titrated from $\mathrm{pH} 7.4$ to $\mathrm{pH} 5.1$ by regularly adding small aliquots of $0.25 \mathrm{M} \mathrm{HCl}$ solution using a MTP-2 multipurpose titrator (Malvern Instruments, Malvern, UK). Particle size was determined every half-unit of $\mathrm{pH}$.

Evidence for nanoparticle destabilization caused by the reductive cleavage of the disulfide bonds in the SS-PAA polymer was also obtained by following the particle size signal during DLS measurements of SS-PAA/insulin nanoparticular solutions to which a solution of DTT in HEPES buffer was added to give a final concentration of $2.5 \mathrm{mM}$ DTT in the resultant solution.

\subsection{In vitro evaluation of the PAA/insulin nanoparticles}

\subsubsection{Proteolytic stability}

The proteolytic stability was evaluated by mixing the PAA/insulin with a duodenum lumen preparation as a source of intestinal proteinases. The degradation of insulin was followed by quantifying the amount of intact insulin using MALDI-MS. The degradation was quantified as a percentage of insulin remaining compared to undigested insulin. 


\subsubsection{Chemical stability}

The prepared PAA/insulin nanoparticle formulations were aliquoted in multiple vials and left at different temperatures. A control PAA/insulin nanoparticle sample was immediately frozen. Insulin was analyzed by a RP-HPLC C18 column using a simple mobile phase consisting of A: $0.1 \%$ TFA in water and B: $0.085 \%$ TFA and $90 \%$ acetonitrile, with a gradient elution going from $10 \% \mathrm{~B}$ to $90 \% \mathrm{~B}$ over 45 minutes. Flow rate was $1 \mathrm{ml} / \mathrm{min}$ and detection at $215 \mathrm{~nm}$. The degradation of human insulin was determined by comparing peak areas containing intact insulin after incubation with the peak area from an insulin control, and was quantified as a percentage of intact human insulin remaining in the sample.

\subsection{In vivo evaluation: hypoglycemic effect following intra-intestinal administration of insulin loaded PAA nanoparticles in diabetic rats}

To mimic the degradation of insulin (hydrolysis) by intestinal peptides in the stomach, the PAA/insulin nanoparticular solutions were incubated in a 5\% TFA solution. A rapid and complete clearance of the solutions was observed, indicating a destabilization and dissociation of the nanoparticular formulations, leading to release and degradation of insulin. This observation can be explained by the hypothesis of particle formation. The formulations are based on charge interaction between the positively charged PAA and the net negative charged insulin at $\mathrm{pH}$ value above the isoelectric point of insulin. Hence, subjecting the formulations to very low $\mathrm{pH}$ values such as in the acidic environment of the stomach reverses the net charge of insulin to positive resulting in the dissociation of the polymer/insulin complexes and exposing of insulin to the harsh gastric environment.

As the main goal of this study was to evaluate the uptake of insulin through the intestinal wall, the formulations were directly injected in the intestine of the rats, hereby bypassing the gastric environment. To this aim, the nanoformulated PAA/insulin particle solutions were administered to Sprague Dawley rats via a catheter in the mid-jejunum allowing direct interaction with the intestinal wall. The rats were administered $0.8 \mathrm{mg} / \mathrm{kg}$ of the polymer/insulin particle solutions, prepared either in HEPES buffer or in PBS. Blood glucose levels were followed for 6 hours by collecting blood samples at distinct times and the glucose concentration was determined. Blood glucose levels were followed for 6 hours by collecting blood samples at distinct times and after centrifugation the insulin levels in plasma were determined by HPLC analysis. 


\section{Results}

\subsection{Synthesis and characterization of PAAs}

As described in Chapters 3 and 5, the two different bioreducible SS-PAA polymers with repetitive disulfide linkages in their main chain, $p(C B A-A B O L)$ and $c P E G-p(C B A-A B O L)$, were synthesized via Michael addition of the corresponding primary amine monomers, $A B O L$ and $\mathrm{CPEG}-\mathrm{NH}_{2}$, to $\mathrm{CBA}$ and were coded in terms of the used monomers, respectively $p(C B A-A B O L)$ and $c P E G-p(C B A-A B O L)$. Furthermore, a PAA lacking the disulfide linkages was prepared from polyaddition of ABOL to BAP. The general reaction scheme of Michael polyaddition is shown in Scheme 7.1.

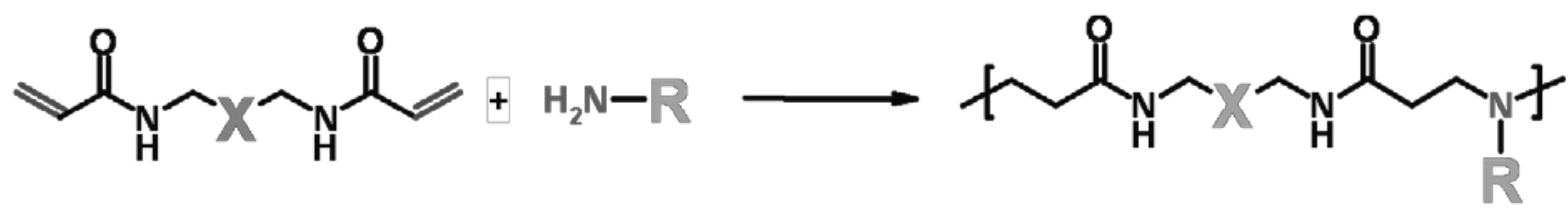

Scheme 7.1. General synthesis scheme of PAAs by Michael-type polyaddition of a bisacrylamide and a primary amine.

The resulting polymers, which structures are depicted in Figure 7.1, collected in their $\mathrm{HCl}-$ salt form as white solid powder after freeze-drying, have a good solubility in water. For all three polymers, the yield was ca. 35-45\% after ultrafiltration and lyophilization.

Details about the ${ }^{1} \mathrm{H}$ NMR and GPC data of $p(C B A-A B O L)$, cPEG-p(CBA-ABOL), and $\mathrm{p}(\mathrm{BAP}-\mathrm{ABOL})$ are available in Chapters 3 and 5. 
<smiles>CN(CCCCO)CCC(=O)NCCSSCCNC(=O)CC(C)(C)C</smiles><smiles>CN(CCCO)CCC(=O)N1CCN(C(=O)CC(C)(C)C)CC1</smiles>

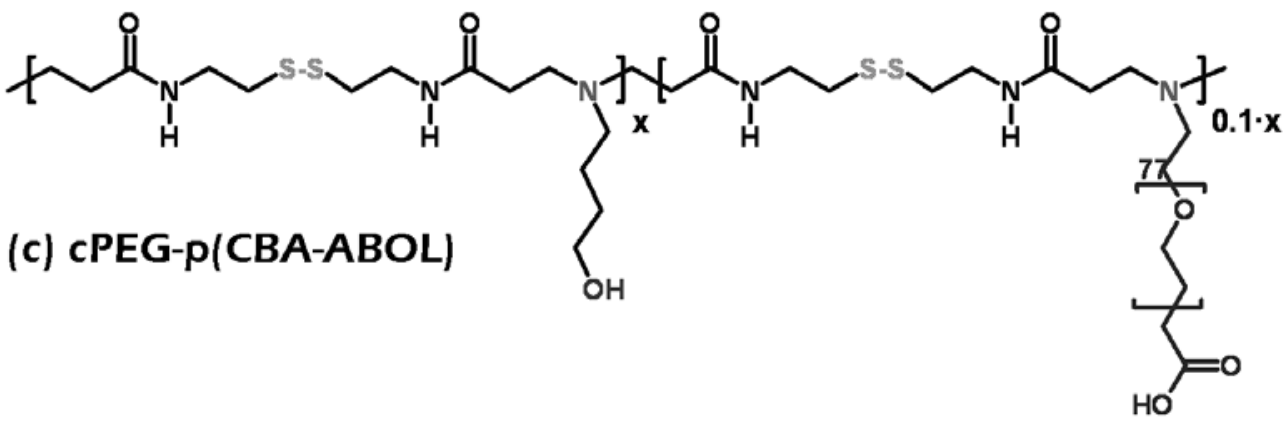

Figure 7.1. Chemical structures of the three PAAs: (a) p(CBA-ABOL), (b) $p$ (BAP-ABOL), and (c) cPEG-p(CBA-ABOL) $(\mathrm{m} / \mathrm{n} \approx 10)$ that have been used to form nano-sized complexes with human insulin. The polymers were coded in terms of the used bisacrylamide and primary amine monomer.

\subsection{Protein condensation into nanoparticles: physical characterization and loading efficiency}

At physiological $\mathrm{pH}$ ( $\mathrm{pH}$ 7.4), the PAAs are present as polycations due to partial protonation of the basic nitrogens in the polymer. Charge interaction with human insulin can be expected, as in Scheme 7.2, since this protein, with an isoelectric point of 5.3, has a net negative charge under these conditions.

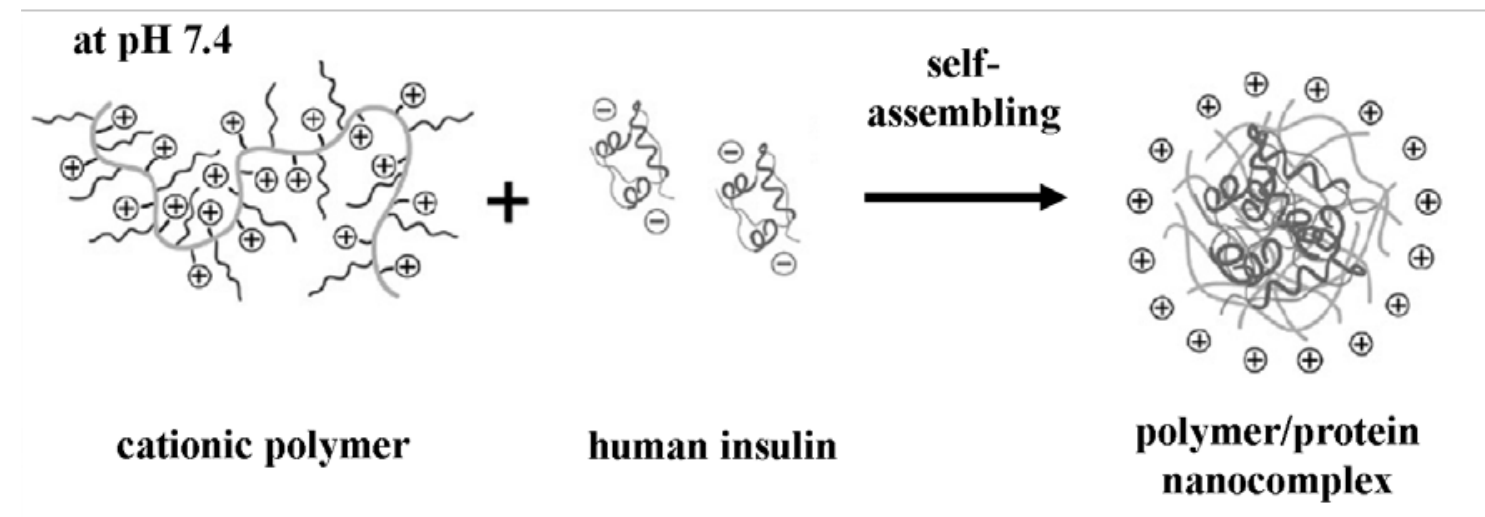

Scheme 7.2. Self-assembly scheme of nanocomplexes at neutral pH by charge attraction between positively-charged polymer, in the present case PAA polymer, and negatively-charged human insulin. 
The nanoparticles that were formed at neutral $\mathrm{pH}$ in HEPES buffer solution $(10 \mathrm{mM}, \mathrm{pH}$ 7.4) were characterized with respect to their size and surface charge. DLS and zeta-potential measurements showed that all the synthesized polymers are capable to form nanosized polyelectrolyte complexes with positive surface charge by self-assembly with human insulin, see Table 7.1. Similar results were obtained when the particles were prepared in PBS (data not shown). Repetitive size measurements in time show that the nanoparticles formed with human insulin were stable for more than one week at room temperature and at least 3 days at $37{ }^{\circ} \mathrm{C}$. Table 7.1 also gives the loading efficiencies of the PAA/insulin nanoparticles at neutral pH in HEPES buffer solution (10 mM, pH 7.4), as determined by fluorescence spectroscopy measurements using FITC-insulin.

Table 7.1. Particle size, surface charge, and loading efficiencies of PAA/insulin nanoparticles measured by DLS at $25^{\circ} \mathrm{C}$ in HEPES buffer $\mathrm{pH} 7.4$.

\begin{tabular}{|c|c|c|c|}
\hline Formulation & $\begin{array}{c}\text { Particle size } \\
(\mathrm{nm})\end{array}$ & $\begin{array}{c}\text { Surface charge } \\
(\mathrm{mV})\end{array}$ & $\begin{array}{c}\text { Insulin loading } \\
\text { efficiency (\%) }\end{array}$ \\
\hline $\mathrm{p}(\mathrm{CBA}-\mathrm{ABOL}) /$ insulin & $265 \pm 4$ & $33 \pm 1$ & 99 \\
\hline $\mathrm{cPEG}-\mathrm{p}(\mathrm{CBA}-\mathrm{ABOL}) /$ insulin & $266 \pm 7$ & $18 \pm 1$ & 95 \\
\hline $\begin{array}{c}2 / 3(\mathrm{p}(\mathrm{CBA}-\mathrm{ABOL}))+1 / 3(\mathrm{cPEG}-\mathrm{p} \\
(\mathrm{CBA}-\mathrm{ABOL})) / \text { insulin }\end{array}$ & $261 \pm 1$ & $25 \pm 1$ & 97 \\
\hline $\mathrm{p}(\mathrm{BAP}-\mathrm{ABOL}) /$ insulin & $283 \pm 19$ & $23 \pm 2$ & 96 \\
\hline
\end{tabular}

* Percentage of insulin that is incorporated in the polymeric nanoparticles. Initial insulin concentration is $2 \mathrm{mg} / \mathrm{ml}$.

\subsection{Mimicking the intracellular fate of the PAA/insulin nanoparticles in intracellular conditions}

Since electrostatic interactions between the positively-charged polymer and the negatively-charged protein are the main driving force for the self assembly into the nanoparticles, it can be anticipated that a decrease in $\mathrm{pH}$, as is occurring during endosomal acidification, will also influence the stability of the nanoparticles. On the one hand, a decrease of the $\mathrm{pH}$ will lead to a decrease of negative charge on the protein, but on the other hand, the degree of protonation of the PAAs will be increased. Therefore there is 
a delicate balance between these effects, but it may be expected that the decrease of overall negative charge on the protein is the dominating factor, since there is already an excess of positive charge present in the nanoparticles at $\mathrm{pH}$ 7.4. Thus, a decrease of the $\mathrm{pH}$ will lead to destabilization of the nanoparticles and eventually the release of the protein from these nanoparticles. DLS measurements show that the SS-PAA/insulin nanoparticles significantly increase in size from ca. $250 \mathrm{~nm}$ to more than $600 \mathrm{~nm}$ when the $\mathrm{pH}$ decreases from 7.4 (extracellular pH) to 5.1 (intracellular pH) (see Figure 7.2).

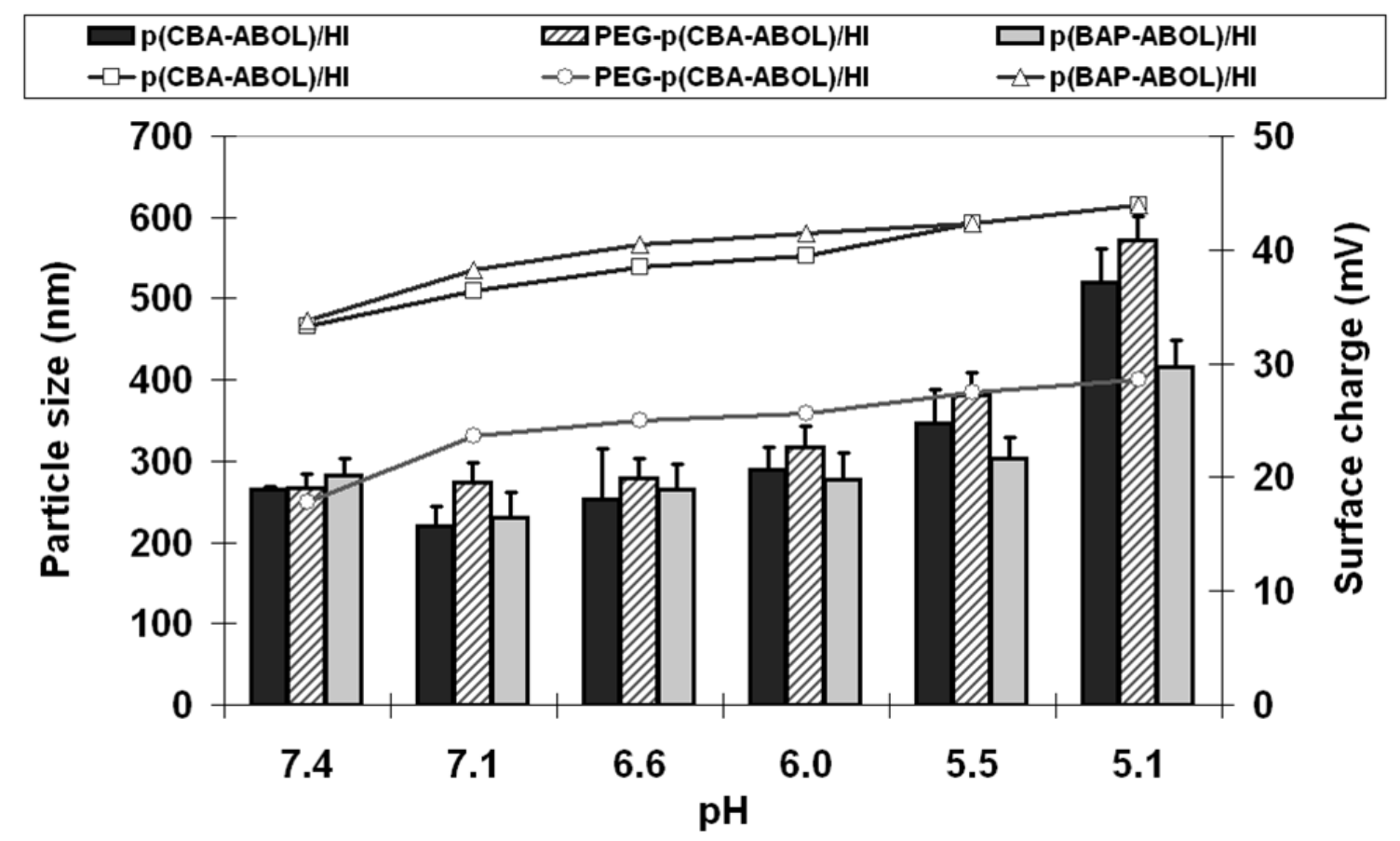

Figure 7.2: Size distributions of PAA/insulin nanoparticles (weight ratio 12/1) during $\mathrm{pH}$ titration of the particle solution from $\mathrm{pH} 7.4$ to $\mathrm{pH} 5.1$ (titration duration: 2 hours), representing the $\mathrm{pH}$ of the extracellular and intracellular environments respectively, using $\mathrm{p}(\mathrm{CBA}-\mathrm{ABOL})$ (black bars), cPEG-p(CBA-ABOL) (stripped bars), and $p(B A P-A B O L)$ (grey bars) as polymeric vector.

The disulfide linkages are rapidly cleaved by glutathione and reductase enzymes in the intracellular environment (containing up to $10 \mathrm{mM}$ glutathione). This physiological process can be favorably exploited to induce efficient protein release by fast degradation of the SS-PAAs in the nanocomplexes. This concept was supported by DLS measurements of SS-PAA/insulin nanoparticle solutions in the presence of $2.5 \mathrm{mM}$ DTT as the reductive agent in HEPES buffer $\mathrm{pH}$ 7.4. In this solution, mimicking the reducing intracellular environment, a rapid increase of the nanoparticle sizes to more than $1 \mu \mathrm{m}$ occurs within a few minutes, accompanied by a large decrease of the count rates. In contrast, the size of polyplexes based on the reference polymer $\mathrm{p}(\mathrm{BAP}-\mathrm{ABOL})$, lacking the disulfide linkages, 
remains stable after addition of DTT (data not shown).

\subsection{Protection of insulin within the PAA nanoparticles}

\subsubsection{Proteolytic stability}

Figure 7.3 shows the percentage of intact insulin after exposure of PAA/insulin nanoparticles and free insulin to intestinal proteolytic enzymes measured using MALDI-TOF. The three PAA/insulin nanoparticles provide protection, with similar effect for the three PAA/insulin formulations, against proteolysis from intestinal proteinases, with more than $80 \%$ of intact protein after 30 minutes of exposure, whereas free human insulin was almost completely degraded after the same exposure time.

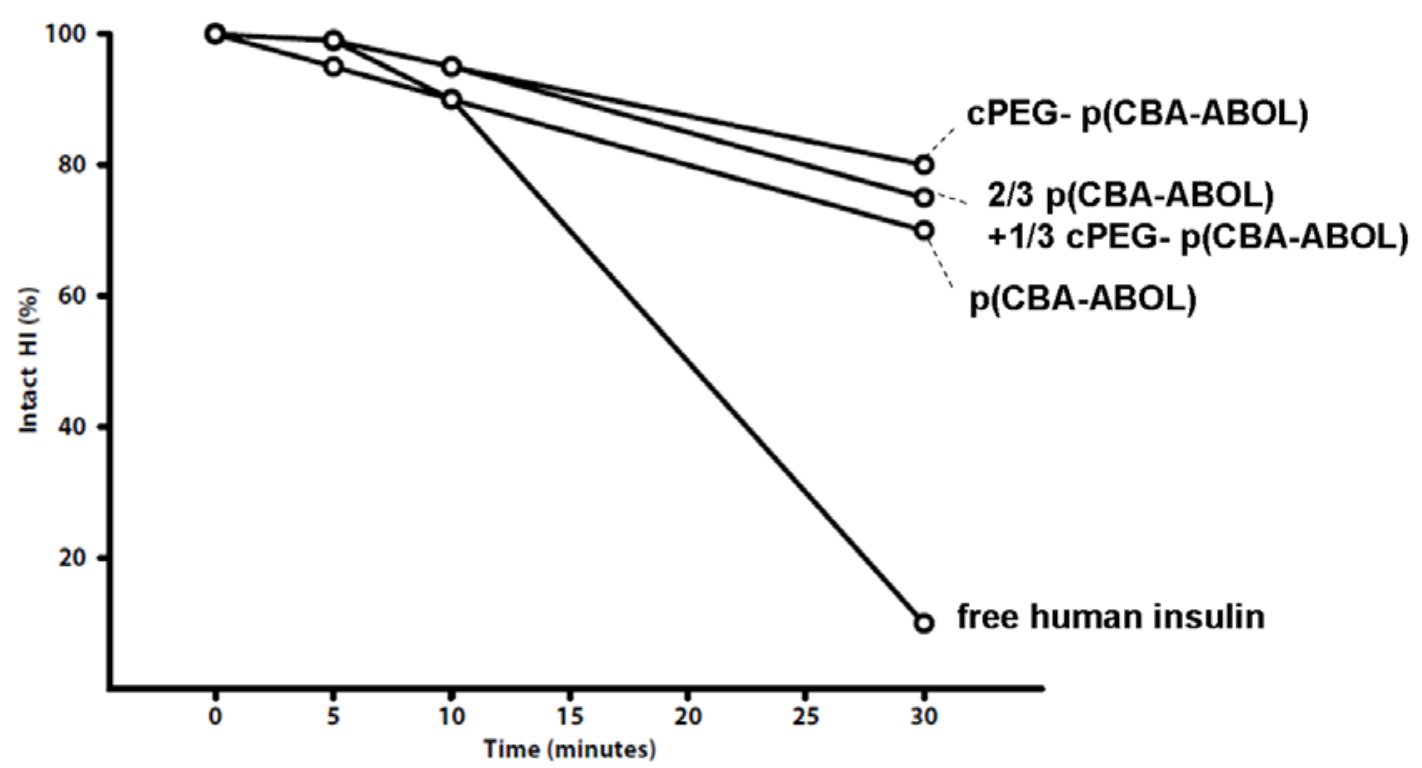

Figure 7.3. Percentage of intact human insulin in PAA/insulin nanoparticles (labeled PAA) compared to free human insulin (labeled HI), as determined by MALDI-MS, after exposure to a duodenum lumen preparation as a source of intestinal proteinases.

\subsubsection{Storage stability}

The PAA/insulin particles were incubated at $4^{\circ} \mathrm{C}$ and $25^{\circ} \mathrm{C}$ for two weeks and their insulin loading were compared to similar particles that were frozen immediately after preparation. These analyses were carried out using an HPLC based approach. The results from these experiments, depicted in Figure 7.4, show that the insulin encapsulated in the PAA/insulin nanoparticles slowly degraded. The PEGylated nanoparticles, with respectively ca. 80-95\% intact insulin left after two weeks incubation at $25^{\circ} \mathrm{C}$, remarkably provide better protection and long-term stability than the nanoparticles not including PEG chains (ca. 60\% insulin 
left after two weeks incubation at $\left.25^{\circ} \mathrm{C}\right)$.

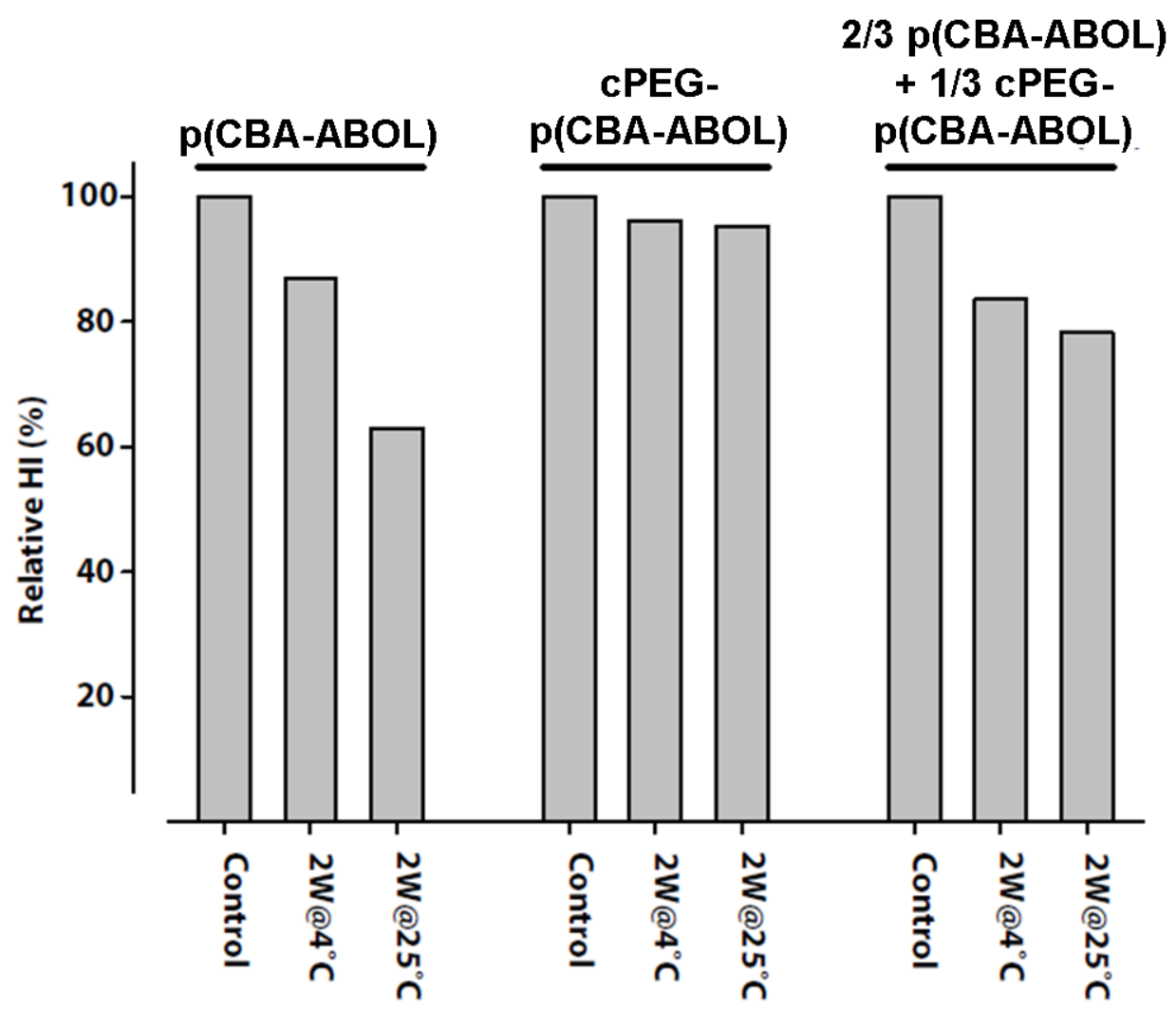

Figure 7.4. Remaining insulin loading in PAA/insulin nanoparticles, after incubated at $4^{\circ} \mathrm{C}$ and $25^{\circ} \mathrm{C}$ for two weeks. The controls are similar particles that were frozen immediately after preparation.

\subsection{In vivo experiments}

In vivo experiments were run with PAA/insulin nanoparticles, formulated either in PBS $\mathrm{pH}$ 7.4 or in $10 \mathrm{mM}$ HEPES buffer $\mathrm{pH}$ 7.4. The nanoparticle formulations were directly administered in the intestine of diabetic rats, hereby bypassing the gastric environment and allowing direct interaction with the intestinal wall. Figures 7.5 and 7.6 show the blood glucose and plasma insulin levels determined after treatment of the rats. 


$\begin{array}{ll}\rightarrow \text { p(CBA-ABOL)/insulin } & \rightarrow \text { 2/3-p(CBA-ABOL)-1/3-cPEG-p(CBA-ABOL)/ insulin } \\ \rightarrow \text { cPEG-p(CBA-ABOL)/insulin } & \rightarrow \text { Control insulin }\end{array}$
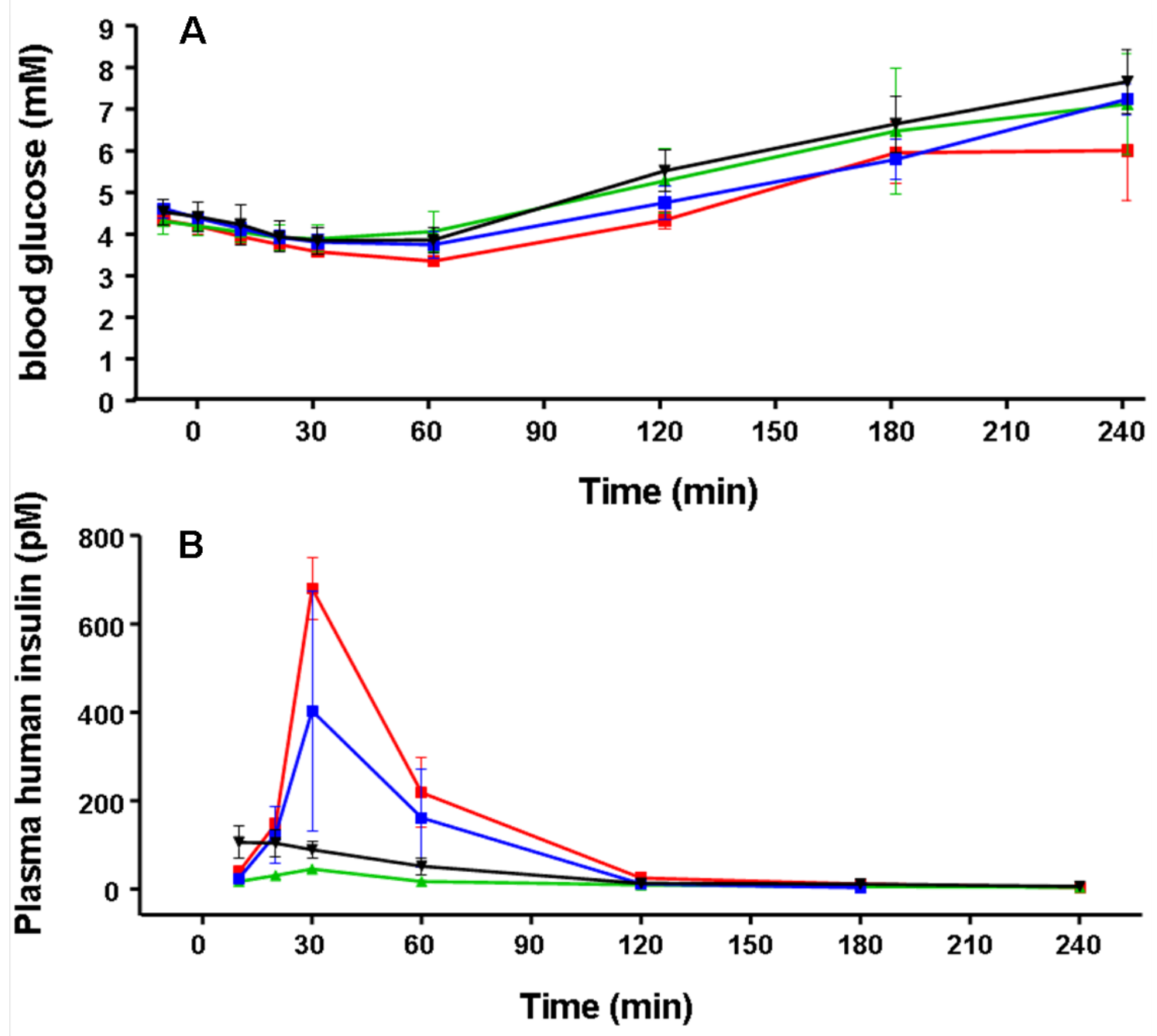

Figure 7.5. Blood glucose $(A)$ and plasma human insulin (B) concentrations after administration of human insulin $(0.8 \mathrm{mg} / \mathrm{kg})$ formulated in PAA nanoparticles, formulated in PBS pH 7.4, into mid-jejunum of fasted male SPRD rats (mean $\pm S E M, n=3$ ). A solution of free insulin was injected as a control. 


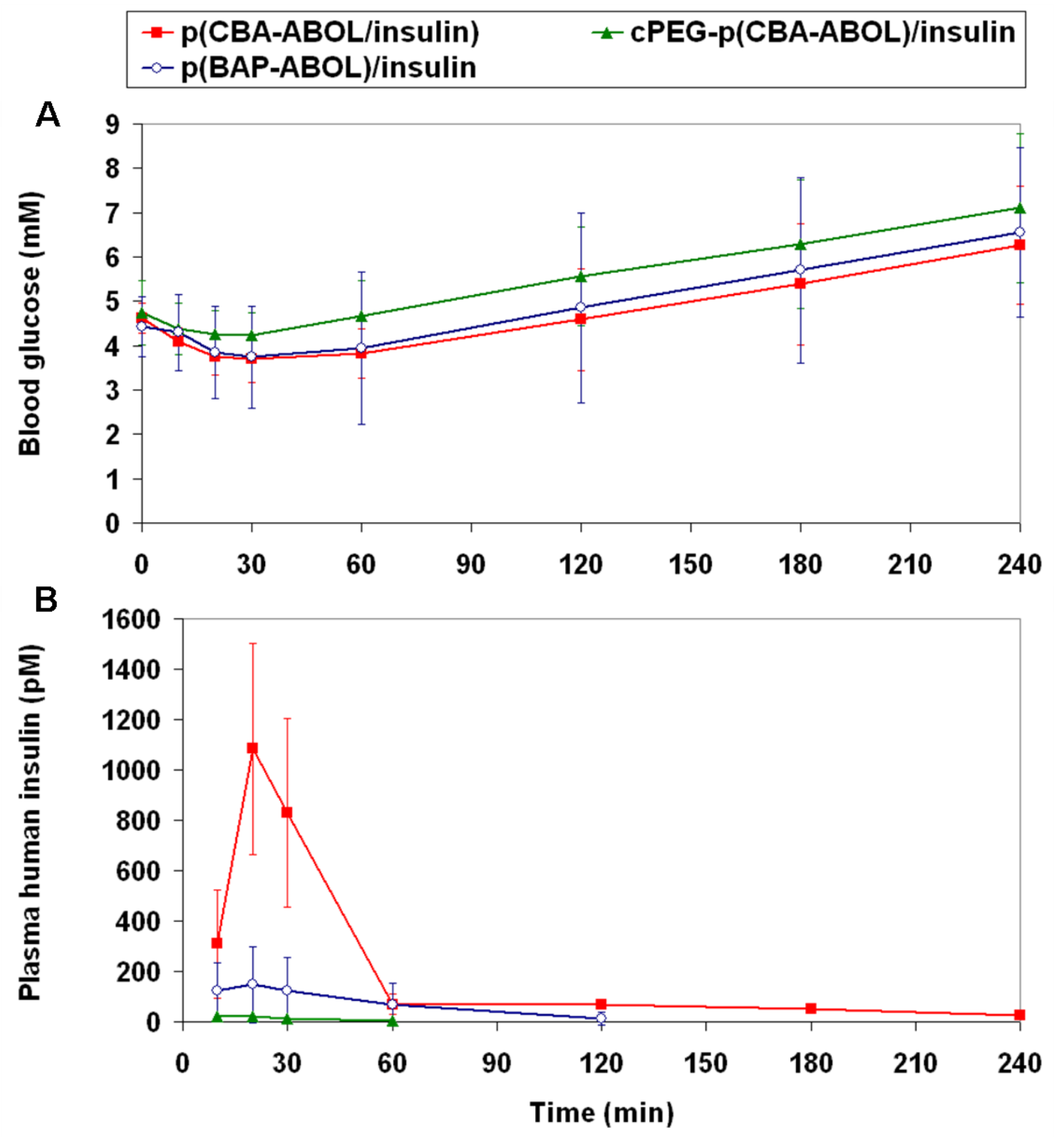

Figure 7.6. Blood glucose (A) and plasma human insulin (B) concentrations after injection of human insulin $(0.8 \mathrm{mg} / \mathrm{kg})$ formulated in PAA nanoparticles, formulated in $10 \mathrm{mM}$ HEPES buffer $\mathrm{pH} 7.4$, into mid-jejunum of fasted male SPRD rats (mean \pm SEM, $n=3$ ).

From the blood glucose measurements it is apparent that the administration of insulin via the $p(C B A-A B O L) /$ insulin nanoparticles induce blood glucose levels below the control samples. Moreover, the plasma insulin concentration profile showed that only the $p(C B A-A B O L) /$ insulin nanoparticles were able to give a significant rise in plasma insulin level over the control samples. The levels peak at 30 minutes, and drops to values close to zero over the next 90 minutes.

The PAA/insulin nanoparticles were prepared both in PBS and HEPES buffer. The particles 
are more stable in HEPES buffer than in PBS, due to the absence of $\mathrm{NaCl}$ salts in this buffer. High salt concentrations tend to destabilize the interactions between cationic polymer and negatively charged protein and provoke faster disintegration of the nanoparticles. This enhanced particle stability seems to have positive effects on the in vivo uptake of insulin uptake via the intestinal wall, especially for $p(C B A-A B O L) /$ insulin nanoparticles, for which the cationic charges of the polymer carrier are not shielded by PEGylation resulting in stronger interactions between polymer and protein. Using $\mathrm{p}(\mathrm{CBA}-\mathrm{ABOL}) /$ insulin nanoparticles in HEPES buffer the plasma insulin concentration reaches ca. $1500 \mathrm{pM}$, value twice higher than when PBS is used to prepare the $\mathrm{p}(\mathrm{CBA}-\mathrm{ABOL}) /$ insulin nanoparticles.

Table 7.2. Bioavailability of human insulin after administration of insulin $(0.8 \mathrm{mg} / \mathrm{kg})$ formulated in PAA nanoparticles, prepared in PBS pH 7.4, into mid-jejunum of fasted male SPRD rats (mean \pm $\mathrm{SEM}, \mathrm{n}=3$ ), relative to intravenous injection of human insulin.

\begin{tabular}{|c|c|}
\hline Formulation & Bioavailability (\%) \\
\hline$p(C B A-A B O L) /$ insulin & $0.17 \pm 0.04$ \\
\hline$c P E G-p(C B A-A B O L) /$ insulin & $0.01 \pm 0.02$ \\
\hline $2 / 3(p(C B A-A B O L))+1 / 3(c P E G-p(C B A-A B O L)) /$ insulin & $0.16 \pm 0.11$ \\
\hline Free human insulin & $0.04 \pm 0.02$ \\
\hline
\end{tabular}

Table 7.2 gives the bioavailability of orally administered insulin for the four formulations, as compared to an intravenous injection of human insulin. The results show that from the PAA/insulin nanoparticles a significant higher percentage of insulin becomes bioavailable than from the orally administered free insulin. Notably the particle formulation using $\mathrm{p}(\mathrm{CBA}-\mathrm{ABOL})$ as carrier for insulin provides the best bioavailability with values ca. $0.2 \%$. In contrast, the presence of the shielding PEG chains at the carrier seems to prevent insulin uptake and bioavailability.

In conclusion, the results show that the PAA polymers, especially $p(C B A-A B O L)$, is a promising carrier for insulin to form self-assembled nanoparticles that protect insulin against proteolytic and chemical degradation, and compare to free insulin improve the uptake of insulin uptake through the intestine, together with its hypoglycemic effect. The 
better results obtained with the $\mathrm{p}(\mathrm{CBA} / \mathrm{ABOL})$ nanoparticles may result from improved adhesion to the mucus layer due to the reaction with the disulfide bonds in the carrier, and therefore leading to increased insulin absorption through the intestinal membrane. The SS-PAA polymers are therefore likely to represent a good template with a great potential for oral insulin delivery, but more studies are required.

Further improvement could be achieved by including targeting agents to the nanoparticles, as an efficient strategy to increase the intestinal adsorption of peptide/protein carriers is the conjugation with moieties that are recognized by the endogenous cellular-transport systems in the Gl tract [24]. Targeting moieties can be linked to the surface of nanocarriers to improve endocytosis uptake. In most cases, antibodies and fragments or oligopeptides, carbohydrates, glycolipids, and folic acid were selected to target different organs and tissues, as the intestine [66]. Notably, it has been demonstrated for oral delivery of peptides and proteins that Vitamin B12, when attached to the surface of nanoparticles or conjugated to the protein, usually via spacing units, promotes the uptake by the receptor-mediated endocytosis pathway. Therefore its application as targeting moiety has significant potential for oral peptide/protein delivery [67-70]. For example, the use of Vitamin B12-coated dextran nanoparticles in oral insulin delivery has lead to successful drop in plasma glucose up to $75 \%$ [71-73].

\section{Conclusions}

Poly(amidoamine) nanoparticles were able to protect insulin against proteolytic and chemical degradation, and to improve insulin uptake through the intestine and its hypoglycemic effect in diabetic rats, as is shown by in vitro and in vivo experiments. Therefore poly(amidoamine)s are potential carriers for oral protein delivery, but further studies have to be performed to improve bioavailability.

\section{Acknowledgements}

This research work is part of the Integrated European project Nanobiopharmaceutics. www.nanobiopharmaceutics.org

\section{References}

[1] S.M. Setter, T.L. Levien, J.L. Iltz, P.S. Odegard, J.J. Neumiller, D.E. Baker, R.K. Campbell, Inhaled dry powder insulin for the treatment of diabetes mellitus. Clin. Ther. 29(5) (2007) 795-813.

[2] P. Zhang, X.Z. Zhang, J. Brown, D. Vistisen, R. Sicree, J. Shaw, G. Nichols, Global healthcare expenditure on diabetes for 2010 and 2030. Diabetes Res. Clin. Pract. 87(3) 
(2010) 293-301.

[3] E.S. Khafagy, M. Morishita, Y. Onuki, K. Takayama, Current challenges in non-invasive insulin delivery systems: A comparative review. Adv. Drug Deliv. Rev. 59(15) (2007) 1521-1546.

[4] C.D. Saudek, Future-Developments in Insulin Delivery Systems. Diabetes Care 16 (1993) 122-132.

[5] J.H. Hamman, G.M. Enslin, A.F. Kotze, Oral delivery of peptide drugs - Barriers and developments. Biodrugs 19(3) (2005) 165-177.

[6] F. Qian, F.Y. Cui, J.Y. Ding, C. Tang, C.H. Yin, Chitosan graft copolymer nanoparticles for oral protein drug delivery: Preparation and characterization. Biomacromolecules 7(10) (2006) 2722-2727.

[7] B. Sarmento, D.C. Ferreira, L. Jorgensen, M. van de Weert, Probing insulin's secondary structure after entrapment into alginate/chitosan nanoparticles. Eur J Pharmacol 65(1) (2007) 10-17.

[8] H.P. Merkle, New Aspects of Pharmaceutical Dosage Forms for Controlled Drug-Delivery of Peptides and Proteins. Eur. J. Pharm. Sci. 2(1-2) (1994) 19-21.

[9] M. Alonso-Sande, M. Cuna, C. Remunan-Lopez, Formation of new glucomannan-chitosan nanoparticles and study of their ability to associate and deliver proteins. Macromolecules 39(12) (2006) 4152-4158.

[10] A. Besheer, K.M. Wood, N.A. Peppas, K. Mader, Loading and mobility of spin-labeled insulin in physiologically responsive complexation hydrogels intended for oral administration. J. Control Rel. 111(1-2) (2006) 73-80.

[11] F. Cui, K. Shi, L.Q. Zhang, A.J. Tao, Y. Kawashima, Biodegradable nanoparticles loaded with insulin-phospholipid complex for oral delivery: Preparation, in vitro characterization and in vivo evaluation. J. Control Rel. 114(2) (2006) 242-250.

[12] A. des Rieux, V. Fievez, M. Garinot, Y.J. Schneider, V. Preat, Nanoparticles as potential oral delivery systems of proteins and vaccines: A mechanistic approach. J. Control Rel. 116(1) (2006) 1-27.

[13] T. Jung, W. Kamm, A. Breitenbach, E. Kaiserling, J.X. Xiao, T. Kissel, Biodegradable nanoparticles for oral delivery of peptides: is there a role for polymers to affect mucosal uptake? Eur J Pharmacol 50(1) (2000) 147-160.

[14] I. Lambkin, C. Pinilla, Targeting approaches to oral drug delivery. Expert Opin Biol Ther 2(1) (2002) 67-73.

[15] M. Mahkam, M. Allahverdipoor, R. Mohammadi, S.O. Ranaei-Simat, M.R. Rashidi, S. Davaran, M. Barshan, S.E. Ranaei-Siadat, An oral delivery system for insulin. J Bioact Compat Pol 21(2) (2006) 135-148.

[16] M. Saffran, B. Pansky, G.C. Budd, F.E. Williams, Insulin and the gastrointestinal tract. J. Control Rel. 46(1-2) (1997) 89-98.

[17] R.J. Schilling, A.K. Mitra, Degradation of Insulin by Trypsin and Alpha-Chymotrypsin. Pharm Res 8(6) (1991) 721-727.

[18] W.C. Shen, Oral peptide and protein delivery: unfulfilled promises? Drug Discov Today 8(14) (2003) 607-608.

[19] K.S. Soppimath, T.M. Aminabhavi, A.R. Kulkarni, W.E. Rudzinski, Biodegradable polymeric nanoparticles as drug delivery devices. J. Control Rel. 70(1-2) (2001) 1-20.

[20] V.H.L. Lee, Enzymatic Barriers to Peptide and Protein-Absorption. Crit Rev Ther Drug Carrier Syst 5(2) (1988) 69-97.

[21] E. Danforth, R.O. Moore, Intestinal Absorption of Insulin in the Rat. Endocrinology 65(1) (1959) 118-123.

[22] G.M. Pauletti, S. Gangwar, G.T. Knipp, M.M. Nerurkar, F.W. Okumu, K. Tamura, T.J. Siahaan, R.T. Borchardt, Structural requirements for intestinal absorption of peptide drugs. J. Control. Release 41(1-2) (1996) 3-17.

[23] G. Borchard, H.L. Luessen, A.G. deBoer, J.C. Verhoef, C.M. Lehr, H.E. Junginger, The potential of mucoadhesive polymers in enhancing intestinal peptide drug absorption .3. Effects of chitosan-glutamate and carbomer on epithelial tight junctions in vitro. J. Control. Release 39(2-3) (1996) 131-138.

[24] G. Coué, J.F.J. Engbersen, Perspectives on Nanoparticulate Delivery of Therapeutic 
Proteins by Oral Administration. Nano LIFE 1(1-2) (2010) 99-108.

[25] A. Graf, K.S. Jack, A.K. Whittaker, S.M. Hook, T. Rades, Protein delivery using nanoparticles based on microemulsions with different structure-types. Eur. J. Pharm. Sci. 33(4-5) (2008) 434-444.

[26] G. Ponchel, J.M. Irache, Specific and non-specific bioadhesive particulate systems for oral delivery to the gastrointestinal tract. Adv. Drug Deliv. Rev. 34(2-3) (1998) 191-219.

[27] K.Y. Win, S.S. Feng, Effects of particle size and surface coating on cellular uptake of polymeric nanoparticles for oral delivery of anticancer drugs. Biomaterials 26(15) (2005) 2713-2722.

[28] A. Vila, A. Sanchez, M. Tobio, P. Calvo, M.J. Alonso, Design of biodegradable particles for protein delivery. J. Control. Release 78(1-3) (2002) 15-24.

[29] A. Harada, K. Kataoka, Novel polyion complex micelles entrapping enzyme molecules in the core: Preparation of narrowly-distributed micelles from lysozyme and poly(ethylene glycol)-poly(aspartic acid) block copolymer in aqueous medium. Macromolecules 31(2) (1998) 288-294.

[30] A. Jintapattanakit, V.B. Junyaprasert, S. Mao, J. Sitterberg, U. Bakowsky, T. Kissel, Peroral delivery of insulin using chitosan derivatives: A comparative study of polyelectrolyte nanocomplexes and nanoparticles. Int. J. Pharm. 342(1-2) (2007) 240-249.

[31] Y. Lee, S. Fukushima, Y. Bae, S. Hiki, T. Ishii, K. Kataoka, A protein nanocarrier from charge-conversion polymer in response to endosomal pH. J. Am. Chem. Soc. 129(17) (2007) 5362-+.

[32] M. Mahkam, Starch-based polymeric carriers for oral-insulin delivery. J. Biomed. Mater. Res. Part A 92A(4) (2010) 1392-1397.

[33] P. Couvreur, F. Puisieux, Nanoparticles and Microparticles for the Delivery of Polypeptides and Proteins. Adv. Drug Deliv. Rev. 10(2-3) (1993) 141-162.

[34] J. Kreuter, Peroral Administration of Nanoparticles. Adv. Drug Deliv. Rev. 7(1) (1991) 71-86.

[35] C.M. Lehr, Bioadhesion Technologies for the Delivery of Peptide and Protein Drugs to the Gastrointestinal-Tract. Crit. Rev. Ther. Drug Carr. Syst. 11(2-3) (1994) 119-160.

[36] M.C. Manning, K. Patel, R.T. Borchardt, Stability of Protein Pharmaceuticals. Pharm. Res. 6(11) (1989) 903-918.

[37] Y. Tabata, Y. Ikada, Protein release from gelatin matrices. Adv. Drug Deliv. Rev. 31(3) (1998) 287-301.

[38] T.W. Wong, Chitosan and Its Use in Design of Insulin Delivery System. Recent Pat Drug Deliv Formul. 3 (2009) 8-25.

[39] F.Y. Cui, F. Qian, Z.M. Zhao, L.C. Yin, C. Tang, C.H. Yin, Preparation, Characterization, and Oral Delivery of Insulin Loaded Carboxylated Chitosan Grafted Poly(methyl methacrylate) Nanoparticles. Biomacromolecules 10(5) (2009) 1253-1258.

[40] M. Thanou, M.T. Nihot, M. Jansen, J.C. Verhoef, H.E. Junginger, Mono-N-carboxymethyl chitosan (MCC), a polyampholytic chitosan derivative, enhances the intestinal absorption of low molecular weight heparin across intestinal epithelia in vitro and in vivo. J. Pharm. Sci. 90(1) (2001) 38-46.

[41] V. Dodane, M.A. Khan, J.R. Merwin, Effect of chitosan on epithelial permeability and structure. Int. J. Pharm. 182(1) (1999) 21-32.

[42] J.X. Gu, W.P. Cheng, J.G. Liu, S.Y. Lo, D. Smith, X.Z. Qu, Z.Z. Yang, pH-triggered reversible "stealth" polycationic micelles. Biomacromolecules 9(1) (2008) 255-262.

[43] L.C. Yin, J.Y. Ding, C.B. He, L.M. Cui, C. Tang, C.H. Yin, Drug permeability and mucoadhesion properties of thiolated trimethyl chitosan nanoparticles in oral insulin delivery. Biomaterials 30(29) (2009) 5691-5700.

[44] P. Ferruti, M.A. Marchisio, R. Duncan, Poly(amido-amine)s: Biomedical applications. Macromol. Rapid Commun. 23(5-6) (2002) 332-355.

[45] O. Boussif, F. Lezoualch, M.A. Zanta, M.D. Mergny, D. Scherman, B. Demeneix, J.P. Behr, A Versatile Vector for Gene and Oligonucleotide Transfer into Cells in Culture and in-Vivo Polyethylenimine. Proc. Natl. Acad. Sci. U. S. A. 92(16) (1995) 7297-7301.

[46] J.D. Eichman, A.U. Bielinska, J.F. Kukowska-Latallo, J.R. Baker Jr, The use of PAMAM dendrimers in the efficient transfer of genetic material into cells. Pharmaceut Sci Tech 
Today 3(7) (2000) 232-245.

[47] E. Ranucci, G. Spagnoli, P. Ferruti, D. Sgouras, R. Duncan, Poly(amidoamine)s with potential as drug carriers: degradation and cellular toxicity. J Biomater Sci Polym Ed 2(4) (1991) 303-315.

[48] G.Y. Wu, C.H. Wu, Receptor-Mediated Invitro Gene Transformation by a Soluble DNA Carrier System. J. Biol. Chem. 262(10) (1987) 4429-4432.

[49] J. Franchini, P. Ferruti, Perspectives on: Recent advances in poly(amidoamine)s chemistry. J. Bioact. Compat. Polym. 19(3) (2004) 221-236.

[50] C. Lin, J.F.J. Engbersen, Effect of chemical functionalities in poly(amido amine)s for non-viral gene transfection. J. Control Rel. 132(3) (2008) 267-272.

[51] C. Lin, Z.Y. Zhong, M.C. Lok, X.L. Jiang, W.E. Hennink, J. Feijen, J.F.J. Engbersen, Novel bioreducible poly(amido amine)s for highly efficient gene delivery. Bioconjugate Chem. 18(1) (2007) 138-145.

[52] C. Lin, C.-J. Blaauboer, M.M. Timoneda, M.C. Lok, M. van Steenbergen, W.E. Hennink, Z. Zhong, J. Feijen, J.F.J. Engbersen, Bioreducible poly(amido amine)s with oligoamine side chains: Synthesis, characterization, and structural effects on gene delivery. J. Control Rel. 126(2) (2008) 166-174.

[53] C. Lin, Z. Zhong, M.C. Lok, X. Jiang, W.E. Hennink, J. Feijen, J.F.J. Engbersen, Linear poly(amido amine)s with secondary and tertiary amino groups and variable amounts of disulfide linkages: Synthesis and in vitro gene transfer properties. J. Control Rel. 116(2) (2006) 130-137.

[54] C. Lin, Z. Zhong, M.C. Lok, X. Jiang, W.E. Hennink, J. Feijen, J.F.J. Engbersen, Random and block copolymers of bioreducible poly(amido amine)s with high- and low-basicity amino groups: Study of DNA condensation and buffer capacity on gene transfection. J. Control Rel. 123(1) (2007) 67-75.

[55] M.A. Mateos-Timoneda, M.C. Lok, W.E. Hennink, J. Feijen, J.F.J. Engbersen, Poly(amido amine)s as gene delivery vectors: Effects of quaternary nicotinamide moieties in the side chains. ChemMedChem 3(3) (2008) 478-486.

[56] G. Coué, J.F.J. Engbersen, Functionalized linear poly(amidoamine)s are efficient vectors for intracellular protein delivery. J. Control Rel. (2011), doi:10.1016/j.jconrel.2011.01.023.

[57] A. Bernkop-Schnürch, Thiomers: A new generation of mucoadhesive polymers. Adv. Drug Delivery Rev. 57(11) (2005) 1569-1582.

[58] M.H. Dufresne, M.A. Gauthier, J.C. Leroux, Thiol-functionalized polymeric micelles: From molecular recognition to improved mucoadhesion. Bioconjugate Chem. 16(4) (2005) 1027-1033.

[59] A. Bernkop-Schnurch, V. Schwarz, S. Steininger, Polymers with thiol groups: A new generation of mucoadhesive polymers? Pharm. Res. 16(6) (1999) 876-881.

[60] K. Kafedjiiski, F. Foger, A. Bernkop-Schnurch, M. Werle, Evaluation of in vitro enzymatic degradation of various thiomers and cross-linked thiomers. Drug Dev. Ind. Pharm. 33(2) (2007) 199-208.

[61] M.K. Marschutz, P. Caliceti, A. Bernkop-Schnurch, Design and in vivo evaluation of an oral delivery system for insulin. Pharm. Res. 17(12) (2000) 1468-1474.

[62] C. Lin, J.F.J. Engbersen, The role of the disulfide group in disulfide-based polymeric gene carriers. Expert Opin. Drug Deliv. 6(4) (2009) 421-439.

[63] G. Saito, J.A. Swanson, K.D. Lee, Drug delivery strategy utilizing conjugation via reversible disulfide linkages: role and site of cellular reducing activities. Adv. Drug Delivery Rev. 55(2) (2003) 199-215.

[64] S. Ganta, H. Devalapally, A. Shahiwala, M. Amiji, A review of stimuli-responsive nanocarriers for drug and gene delivery. J. Control Rel. 126(3) (2008) 187-204.

[65] K.C. Rajender, W.L. Frederick, H.K. Michael, M.B. David, G.B.R. Robert, R. Daniel, Plasma cysteine, cystine, and glutathione in cirrhosis. Gastroenterology 87(4) (1984) 770-776.

[66] A. Dembri, M.J. Montisci, J.C. Gantier, H. Chacun, G. Ponchel, Targeting of 3 '-azido 3 '-deoxythymidine (AZT)-loaded poly(isohexylcyanoacrylate) nanospheres to the gastrointestinal mucosa and associated lymphoid tissues. Pharm. Res. 18(4) (2001) 467-473. 
[67] M. Castelli, D. Wong, K. Friedman, J. Fotso, G. Riley, Significant Enhancement of Vitamin B12 Oral Bioavailability in Healthy Male Subjects. Clin. Pharmacol. Ther. 85 (2009) S87-S87.

[68] G.J. Russell-Jones, Use of vitamin B-12 conjugates to deliver protein drugs by the oral route. Crit. Rev. Ther. Drug Carr. Syst. 15(6) (1998) 557-586.

[69] G.J. Russell-Jones, L. Arthur, H. Walker, Vitamin B-12-mediated transport of nanoparticles across Caco-2 cells. Int. J. Pharm. 179(2) (1999) 247-255.

[70] A.K. Petrus, T.J. Fairchild, R.P. Doyle, Traveling the Vitamin B12 Pathway: Oral Delivery of Protein and Peptide Drugs. Angew. Chem. Int. Ed. 48(6) (2009) 1022-1028.

[71] K.B. Chalasani, G.J. Russell-Jones, A.K. Jain, P.V. Diwan, S.K. Jain, Effective oral delivery of insulin in animal models using vitamin B12-coated dextran nanoparticles. J. Control. Release 122(2) (2007) 141-150.

[72] K.B. Chalasani, G.J. Russell-Jones, S.K. Yandrapu, P.V. Diwan, S.K. Jain, A novel vitamin B-12-nanosphere conjugate carrier system for peroral delivery of insulin. J. Control. Release 117(3) (2007) 421-429.

[73] A.K. Petrus, A.R. Vortherms, T.J. Fairchild, R.P. Doyle, Vitamin B-12 as a carrier for the oral delivery of insulin. ChemMedChem 2(12) (2007) 1717-1721. 


\section{Development of antigen-loaded poly(amidoamine) nanoparticles for nasal applications and their in vitro evaluation}

Grégory Coué1†, Iris Hermanns ${ }^{2,3 \dagger}$, Ronald E. Unger 2,3 , C. James Kirkpatrick ${ }^{2,3}$ and Johan F.J. Engbersen ${ }^{1}$

${ }_{1}$ Department of Biomedical Chemistry, MIRA Institute for Biomedical Technology \& Technical Medicine, Faculty of Science and Technology, University of Twente, P.O. Box 217, 7500 AE Enschede, the Netherlands

2 REPAIR-lab, Institute of Pathology, University Medical Center of the Johannes Gutenberg University, Langenbeckstrasse 1, 55101 Mainz, Germany

${ }_{3}^{3}$ European Institute of Excellence on Tissue Engineering and Regenerative Medicine, Mainz, Germany

† Contributed equally

Part of this chapter has been published: G. Coué, I. Hermanns, R.E. Unger, C.J. Kirkpatrick, and J.F.J. Engbersen, Development of antigen-loaded poly(amidoamine) nanoparticles for nasal applications and their in vitro evaluation, submitted

Abstract: To develop therapeutic protein formulations for improved efficiency of antigen administration via the intranasal route, poly(amidoamine) nanoparticles were prepared, and were loaded with the model proteins: p24 and ovalbumin, the first being a component of the HIV virus particle capsid. The oligodeoxynucleotide CpG with phosphorothioate bases was used as adjuvant. The vaccine-loaded nanoparticles were characterized in term of particle size, surface charge and loading efficiency. In addition, their capacity to pass through epithelial and endothelial cell layers was evaluated in vitro using a novel cellular model, simulating the respiratory mucosa. Formulations of polyelectrolyte complexes formed by charge-attraction between a functionalized linear poly(amidoamine) and the model proteins showed to be non toxic and to efficiently 
improve their uptake in vitro in the respiratory epithelial $\mathrm{NCl} \mathrm{H} 441$ cells and the endothelial cell line ISO-HAS-1, indicating that this delivery system is very promising to achieve enhanced bioavailability of antigens.

\section{Introduction}

Nasal immunization has emerged as a promising and attractive route because it is easy and cheap to administer to large populations [1]. It does not require needles which are a potential source of pain and infection [1, 2]. Moreover, the intranasal route can induce both mucosal and systemic immune responses, which is an advantage because it has been shown as highly efficient for the induction of antibody responses in the blood serum [1, 3-9].

The nasal route of administration has intrigued researchers for several decades, especially in the context of delivering peptides to systemic circulation. The nose is readily accessible and has a large nasal mucosa area available for drug absorption due to the coverage of the epithelial surface by numerous microvilli. The subepithelial layer is highly vascularized with a high total blood flow per $\mathrm{cm}^{3}$ and the venous blood from the nose passes directly into the systemic circulation and therefore avoids the loss of drug by first-pass metabolism in the liver. The nasal cavities allow lower doses, and the more rapid attainment of therapeutic blood levels through the endothelial basement membrane gives a quicker onset of pharmacological activity and fewer side effects. These benefits combined with the better patient compliance compared to intramuscular or intravenous injection make nasal delivery being considered as a promising approach for protein drug delivery [10-12].

Nonetheless, despite the high potential of nasal drug delivery, this route has also a number of limitations, and therefore important issues have to be taken into account for the preparation of nasal formulations. The tightly impermeable epithelial cell layers in the nasal cavity and nasal-associated lymphoid tissues are severe limitations for the delivery of macromolecules such as proteins used as vaccines via the upper respiratory tract [13-15]. Consequently, the nose functions as a protective system against foreign material [16]. Moreover, the bioavailability of nasally administered peptide and protein drugs can be limited because a broad range of metabolic enzymes are located in the nasal mucosal cavity and the epithelial cells lining the cavity, inducing rapid mucociliary clearance and limiting the ability of peptides and proteins to reach the general circulation in therapeutic quantities $[2,3,12,13]$. 
Several promising drug candidates cannot be exploited via the nasal route if they are not absorbed well enough to produce therapeutic effects. Proper delivery systems are therefore needed to improve absorption/uptake from the epithelium and to prevent rapid elimination of the formulations from nasal cavities. In the development of polymeric carriers for nasal administration, mucoadhesion of the carrier system has been reported as one of the most important properties to improve the bioavailability of poorly absorptive drugs [17-20]. Such mucoadhesive carriers adhere to the mucus layer present on mucosal membranes and are expected to prolong the residence time at the local site of absorption, leading to increased drug absorption through the nasal membrane.

Recently, nanosized polyelectrolyte complexes (PECs) formed by self-assembly of proteins with natural and synthetic polymers have drawn increasing attention for application in therapeutic protein delivery [21-27]. In this non-covalent method, upon electrostatic attraction, PECs are formed by mixing oppositely-charged drug and polymer. PEC formation can give a homogeneous and stable dispersion of nanoparticles with cationic surface charge capable to bind to the cell surface and to internalize into the cell [28]. PEC formation has the advantage of not using sonification or organic solvents which are both harmful for proteins and peptides, conditions that are frequently applied in the preparation of nanoparticles, e.g. in the double emulsion method.

A mucoadhesive polymer that has been extensively investigated in drug delivery is chitosan [29, 30]. Due to protonation of the amino groups, chitosan behaves as a polycation with an intrinsic $\mathrm{pK}_{a}$ of 5.5. However, in neutral and basic environment the cationic charges will be lost leading to a dramatical decrease in solubility and eventual precipitation. Chitosan derivatives with higher solubility than chitosan itself, like $\mathrm{N}$-trimethyl chitosan (TMC) and mono- $N$-carboxymethyl chitosan (MCC) have been reported to be suitable for antigen delivery, and have been shown to exert mucoadhesive properties and excellent absorption enhancing effects even at neutral pH [31-36]. Nanoparticles prepared using TMC and MCC were shown to be promising for nasal immunization against tetanus toxoid [37, 38].

As an attractive alternative to chitosan, poly(amidoamine)s (PAAs) represent a family of functional polymers endowed with a combination of properties that makes them suitable for a variety of biomedical applications related to polymer therapeutics [39, 40]. PAAs can be easily synthesized with a broad spectrum of structural and functional variation by polyaddition of primary amines and bis-secondary amines to bisacrylamides. Generally, they are water-soluble, biodegradable and biocompatible, and show less cytotoxicity than 
other usual polycationic vectors [39, 41-44].

Besides the charge interaction of the protonated tert-amino groups in the PAA backbone with the negative sites in the mucus, additional mucoadhesiveness can be obtained by using PAAs containing repetitive disulfide linkages in their backbone (SS-PAAs). Mucosal surfaces usually have distinct regions of mature mucins which are rich in cysteines, residues participating in establishing disulfide linkages within and among mucin monomers. The disulfide linkages in the SS-PAAs can react with these cysteine residues by disulfide exchange reactions with the thiol and disulfide groups, and therefore increase the residence time of polymer on the mucus [45-48]. In addition, cationic nanoparticles of PAAs have been shown to bind to the cell surface and to internalize into the cell by endocytosis [28]. In particular, polymeric SS-PAA carriers were previously found to be very efficient vectors in intracellular gene delivery, yielding high transfection efficiencies [49-54]. Recently, it has been demonstrated that these polymers were also efficient as vectors for intracellular protein delivery [55]. Due to the presence of the repetitive disulfide linkages, these virtually-nontoxic SS-PAAs are relatively stable in extracellular medium but they are prone to fast degradation in the reductive intracellular environment $[45,56-59]$. This property can be used in carrier systems that should be relatively stable during transport outside the cell but have to disintegrate into fragments of low molecular weight after uptake into the target cells, in order to release their bioactive payload and minimize cytotoxicity effects.

In this study, we describe the development and evaluation of the biomedical in vitro properties of antigen-loaded nanoparticles for nasal application based on the self-assembly and formation of polyelectrolyte complexes of the PEGylated SS-PAA polymer cPEG-p(CBA-ABOL) with the antigen p24 or ovalbumin (OVA), and the adjuvant oligodeoxynucleotide CpG (Scheme 8.1). 

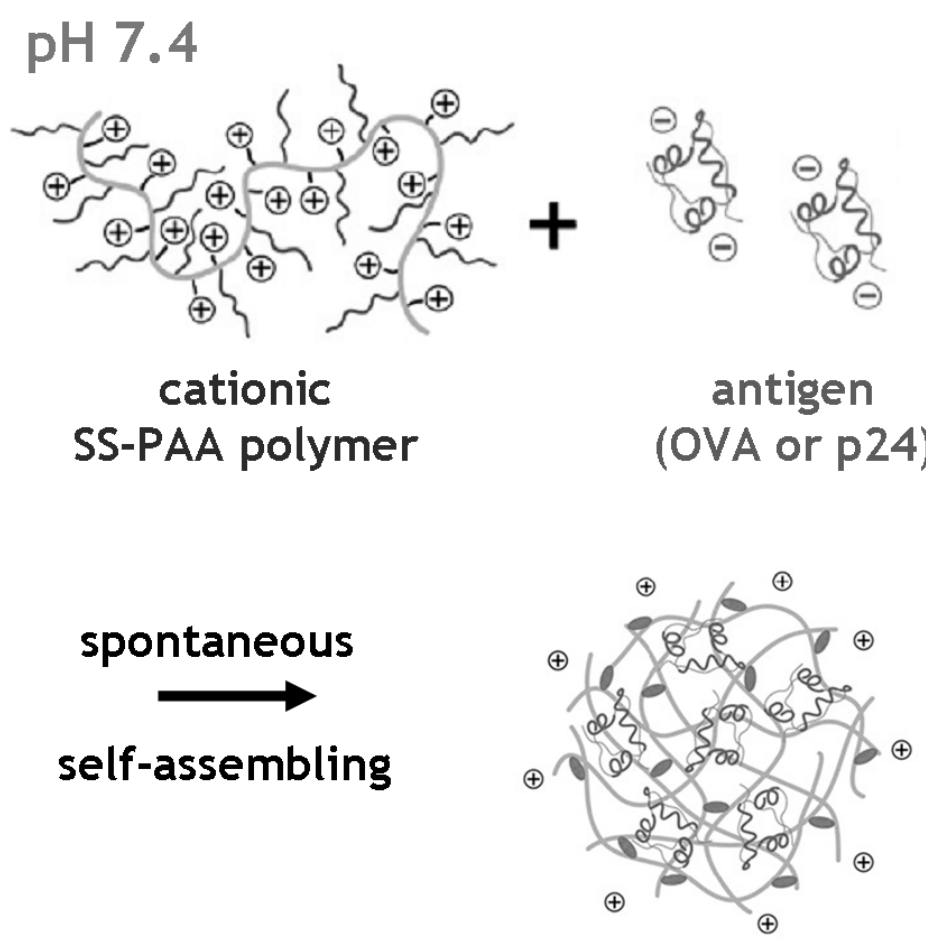

Scheme 8.1. Self-assembling formation of nanocomplexes at neutral $\mathrm{pH}$ by charge attraction between negatively-charged antigen (p24 or OVA) and adjuvant $\mathrm{CpG}$, and a positively-charged polymer (SS-PAA).

We chose to use a PEGylated polymer as carrier since it has been reported that PEGylation serves to provide high stability and stealth properties to the nanocomplexes, and was shown to improve their delivery via the nasal pathway [60-63]. Since many cationic groups have been found to be toxic which has been attributed to the high interactions with the plasma membrane [64], we selected a PEG chain with a carboxylate end group. Based on the results obtained with MCC as carrier, this negatively charged end group should provide good cell viability. Once the nanoparticles reach a reductive environment, and the multiple disulfide linkages in the main chain of the polymer are cleaved, as is present in the intracellular milieu, the nanoparticles with their PEG corona become disassembled.

The $c$ PEG-p(CBA-ABOL) polymer possess, in addition of the repetitive disulfide moieties in the main chain, originating from the cystaminebisacrylamide (CBA) monomer, also hydroxybutylene side chains, originating from the 4-aminobutanol (ABOL) monomer. It has been shown that these hydroxybutyl side groups favorably contribute to the efficiency in intracellular delivery, presumably by increasing the endosomolytic properties of the polymer [50, 55]. 
Regarding the choice of adjuvant, synthetic oligodeoxynucleotides containing immunostimulatory CpG motifs are effective adjuvants when delivered by mucosal or systemic immunization routes and have demonstrated significant stimulation of the immune system [65-67].

The nanoparticles were characterized in terms of particle size, surface charge and loading efficiency, and evaluated in vitro for nasal applications. To this end, the capacity of the nanoparticles to pass through epithelial and endothelial cell layers was evaluated using a novel cellular model simulating the respiratory mucosa.

\section{Materials and methods}

\subsection{Materials}

The peptide p24 was kindly supplied by GlaxoSmithKline Vaccines (Rixensart, Belgium). Labeling of p24 with Alexa Fluor ${ }^{\circledR} 488$ carboxylic acid TFP ester (AF488) was performed according to the procedure provided by the supplier (Invitrogen). Ovalbumin (OVA, Albumin from chicken egg white, Grade VII) and FITC-ovalbumin (FITC-OVA) were obtained from Sigma and Invitrogen, respectively. All monomers, 4-amino-1-butanol (ABOL, Sigma-Aldrich), alpha-amino-omega-carboxy-poly(ethylene glycol) hydrochloride (cPEG-NH $\mathrm{N}_{2} \mathrm{M}_{\mathrm{w}} 3000 \mathrm{~g} / \mathrm{mol}$, Iris Biotech $\mathrm{GmbH}$ ), and N,N'-cystaminebisacrylamide (CBA, Polysciences) were purchased in the highest purity and used without further purification. The oligodeoxynucleotide ODN 1826, tIrl-modn-5 (CpG, Invivogen), phosphate buffered saline (PBS, $0.01 \mathrm{M}, \mathrm{pH} 7.4$, B. Braun, USA) and methanol (MeOH, Biosolve) were used as received. Deionized water (DI water) was obtained from a MilliQ-water purification system (Millipore, France).

\subsection{Synthesis of $C P E G-p(C B A-A B O L)$}

The co-polymer cPEG-p(CBA-ABOL), with 10\% cPEG side chains relative to the hydroxybutyl groups, was synthesized via Michael polyaddition of the primary amine monomers, $A B O L$ and $\mathrm{CPEG}-\mathrm{NH}_{2}$, to the bisacrylamide CBA, as described in Chapter 5.

\subsection{Polymer characterization}

Details about the ${ }^{1 H}$ NMR and GPC data of $c P E G-p(C B A-A B O L)$ have been described in Chapter 5. 


\subsection{Characterization of polymer/antigen/CpG nanoparticles}

\subsubsection{Particle size and zeta-potential measurements}

Nanoparticles using cPEG-p(CBA-ABOL) as polymer carrier, p24 $(0.20 \mathrm{mg} / \mathrm{ml})$ or OVA $(0.25$ $\mathrm{mg} / \mathrm{ml})$ as antigen, and $\mathrm{CpG}(0.08 \mathrm{mg} / \mathrm{ml})$ as adjuvant, were prepared at polymer/(antigen+adjuvant) weight ratio 12/1. To this aim, for the p24 delivery system, cPEG-p(CBA-ABOL)/p24/CpG nanocomplexes were prepared by adding successively 100 $\mu \mathrm{l}$ of a PBS buffer solution (pH 7.4) of CpG $(0.8 \mathrm{mg} / \mathrm{ml})$ and $697 \mu \mathrm{l}$ of a PBS buffer solution $(\mathrm{pH} 7.4)$ of polymer $(4.82 \mathrm{mg} / \mathrm{ml})$ to $203 \mu \mathrm{l}$ of a PBS buffer solution (pH 7.4) of p24 (0.985 $\mathrm{mg} / \mathrm{ml}$ ), followed by vortexing for 5 seconds and incubating at room temperature for 30 minutes. For the OVA delivery system, cPEG-p(CBA-ABOL)/OVA/CpG nanocomplexes were prepared by adding successively a PBS buffer solution ( $\mathrm{pH} 7.4)$ of $\mathrm{CpG}(0.8 \mathrm{mg} / \mathrm{ml})$ and a PBS buffer solution ( $\mathrm{pH} 7.4$ ) of polymer $(4.95 \mathrm{mg} / \mathrm{ml}$ ) to a PBS buffer solution $(\mathrm{pH} 7.4)$ of ovalbumin $(2.5 \mathrm{mg} / \mathrm{ml})$, followed by vortexing for 5 seconds and incubating at room temperature for 30 minutes.

Particle size and surface charge measurements of the nanocomplexes were determined by dynamic light scattering (DLS) at $25^{\circ} \mathrm{C}$ with a Zetasizer Nano ZS (Malvern Instruments, Malvern) using a wavelength of $532 \mathrm{~nm}$. The value was recorded as the mean of three measurements. The size distribution was given by polydispersity index (PDI, a value between 0 and 1). A PDI of 1 indicates large variations in particle size; a PDI of 0 indicates no variation in particle size (as an ideal monodispersed formulation).

As the size of the particles influences the eventual uptake and distribution of the particles inside the body, their stability was investigated and followed by DLS, at $25^{\circ} \mathrm{C}$ and $37^{\circ} \mathrm{C}$. The results at $25^{\circ} \mathrm{C}$ represent the ability of the nanocomplex solution to be stored at room temperature, whereas the results at $37^{\circ} \mathrm{C}$ indicate the thermal stability in the human body.

\subsubsection{Antigen condensation and loading efficiency}

To estimate the loading efficiency of the nanoparticles at neutral $\mathrm{pH}$, particle solutions of SS-PAA/antigen/CpG nanoparticles were prepared at polymer/(antigen+adjuvant) weight ratio $12 / 1$, similarly as previously described using respectively AF488-labeled p24 or FITC-OVA (see in 2.4.1). After incubation, the nanoparticles were centrifuged at $14000 \mathrm{rpm}$ for 30 minutes at $4^{\circ} \mathrm{C}$. Aliquots of supernatant were subsequently taken and their protein content determined by fluorescence spectroscopy (Safire ${ }^{2}$, Tecan, Canada) at an emission wavelength of $519 \mathrm{~nm}$ and an excitation wavelength of $495 \mathrm{~nm}$. The actual 
loading efficiency was indirectly determined by measuring the difference between the total amount of labeled antigen added to the solution and the amount of labeled antigen in the free form in the supernatant. A calibration curve from solutions of various fluorescently-labeled antigen concentrations was determined prior to this experiment. In all cases, it was confirmed that free antigen was not precipitated from the solution by centrifugation.

The content of $\mathrm{CpG}$ in the formulation was determined by HPLC.

\subsection{Cytotoxicity and endotoxin measurements}

Cytotoxicity was determined on the different endothelial cell types in monoculture by detecting mitochondrial enzymatic perturbation (MTS-Assay, Promega). 10000 cells were seeded on a 96-well plate and cultivated for 40 hours at $37^{\circ} \mathrm{C}$. The subconfluent monolayer was treated with different amounts of nanoparticle formulations (dilution 1:10; 1:50 and 1:100) for 4, 24 and 48 hours. After the incubation viability was examined by MTS assay. Untreated cells were set to $100 \%$ and results are depicted as percentage of untreated control. For detection of E-selectin a cell based Enzyme Immuno Assay (EIA) was used on cells fixed after exposure to nanoparticles to quantify the E-selectin expression. Nanoparticles were added for 4 or 24 hours to human umbilical vein endothelial cells (HUVEC). The assay is based on the detection of a chromogen that is formed after primary (E-selectin) antibody has bound with the secondary enzyme-coupled antibody. As controls for E-selectin positive cells HUVEC were exposed to concentrations of $1 \mathrm{\mu g} / \mathrm{ml}, 200 \mathrm{ng} / \mathrm{ml}, 100 \mathrm{ng} / \mathrm{ml}$ Lipopolysaccaride from E. Coli (LPS) and $300 \mathrm{U} / \mathrm{ml}, 60$ $\mathrm{U} / \mathrm{ml}, 30 \mathrm{U} / \mathrm{ml}$ tumor necrosis factor- $\alpha(T N F-\alpha)$. The E-selectin expression is measured after addition of the chromogen OPD and $2 \mathrm{~N} \mathrm{H}_{2} \mathrm{SO}_{4}$ at $492 \mathrm{~nm}$.

\subsection{In vitro transport studies}

For in vitro transport studies a co-culture model of respiratory epithelial cells and endothelial cells grown on both sides of a transwell filter membrane over 10 days was used. The assembly of that model was described previously [68]. Both, the respiratory epithelial NCl H441 cells and the endothelial cell line ISO-HAS-1 in co-culture establish contact inhibited monolayers. Maximum transbilayer electrical resistance (TER) values were found after 10 to 12 days of co-cultivation and averaged $500 \mathrm{Ohm} \cdot \mathrm{cm}^{2}$. At that time point $\mathrm{NCl} \mathrm{H} 441$ cells show a continuous, circumferential immunostaining of the tight junctional protein, ZO-1 and the adherent junction proteins, like E-Cadherin, alpha- and 
ß-Catenin. In vitro transport studies (apical to basolateral) were performed by exposing the respiratory epithelial cells over 4 or 24 hours with carrier formulations. After different time points (30 minutes, 1, 2, 4, 6 and 24 hours) samples were taken from the lower well of the transwell unit to monitor release kinetics of the loaded antigen. Additionally, after exposure time the remaining amount of drug load was detected in the upper well. This proceeding allows detecting the amount of carrier formulation that was not attached to or uptaken by the respiratory epithelium within exposure time. An additional sample acquisition in the lower (basolateral) well was performed after 48 hours. Therewith a potential decelerated release/transport of the antigen load should be taken into account. Peptides/proteins released by the epithelial cells might interfere with the amount of antigen/adjuvant that could be transported. Regarding sensitivity and specificity a bioassay for p24 (Perkin Elmer) or OVA (Seramun Diagnostica $\mathrm{GmbH}$ ) was chosen to measure a possible drug transport.

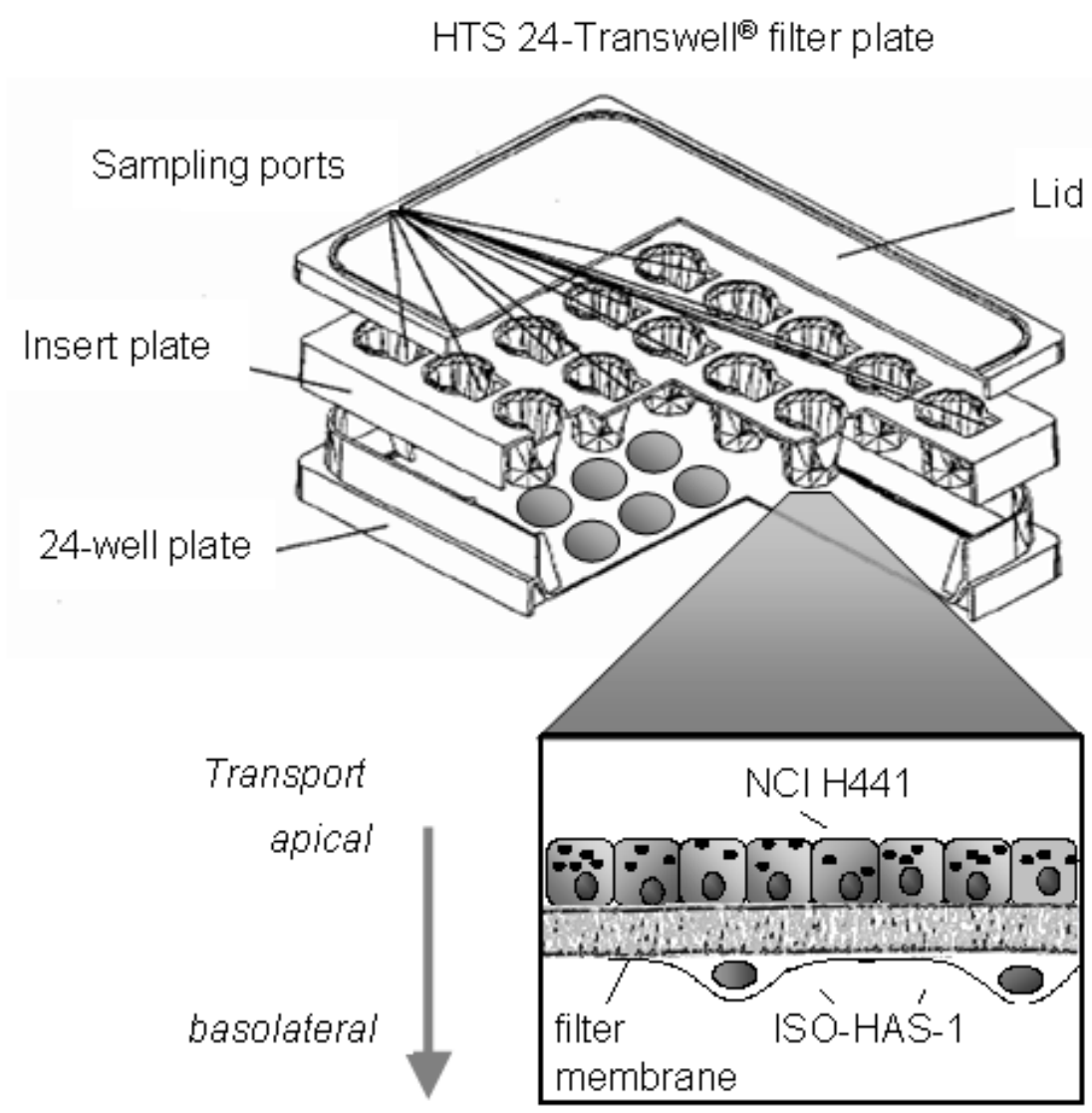

Figure 8.1. Assembly of the in vitro co-culture model. 


\section{Results and Discussion}

\subsection{Synthesis and characterization of $c P E G-p(C B A-A B O L)$}

In this study, cPEG-p(CBA-ABOL) (see structure in Figure 8.2), a bioreducible PAA polymer with repetitive disulfide linkages in their main chain (SS-PAA) was synthesized via Michael addition of the corresponding primary amine monomers, $\mathrm{ABOL}$ and $\mathrm{CPEG}-\mathrm{NH}_{2}$, to $\mathrm{CBA}$, as described in Chapter 5.

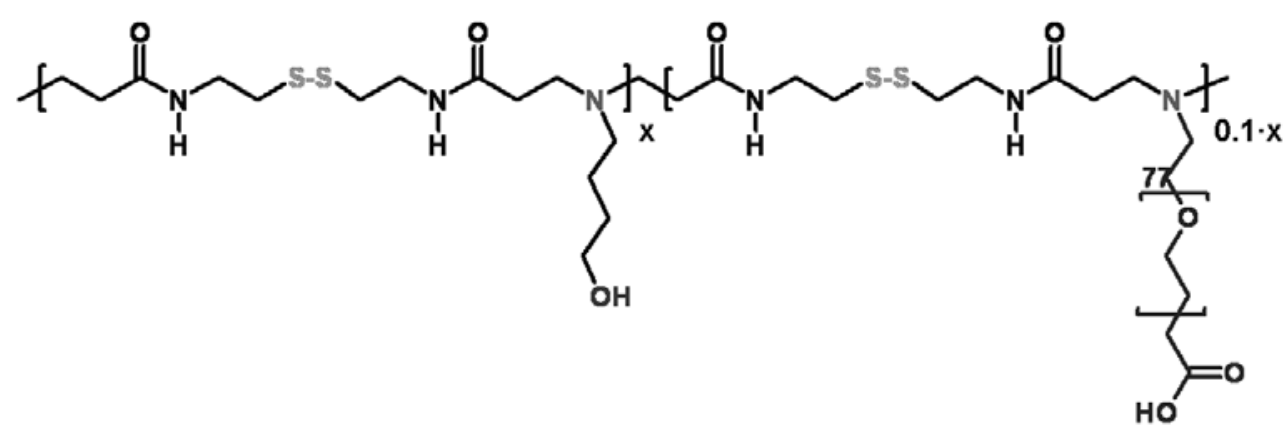

Figure 8.2. Structure of $c P E G-p(C B A-A B O L)$ synthesized by Michael-type polyaddition of a $C B A$, $\mathrm{ABOL}$ and $\mathrm{CPEG}-\mathrm{NH}_{2}$.

Details about the ${ }^{1} \mathrm{H}$ NMR and GPC data of cPEG-p(CBA-ABOL) are given in Chapter 5.

\subsection{Antigen uptake into the PAA nanoparticles: physical characterization}

At physiological $\mathrm{pH}(\mathrm{pH} 7.4)$, the PAAs are present as polycations due to partial protonation of the tertiary nitrogens in the main chain of the polymer. Charge interaction with the negatively-charged antigen ( $\mathrm{p} 24$ : $\mathrm{pl}=5.9$, OVA: $\mathrm{pl}=4.6$ ) and adjuvant (CpG with phosphorothioate bases) can be expected since these entities have a net negative charge under these conditions. DLS and zeta-potential measurements showed that the cPEG-p(CBA-ABOL) polymer is capable to form nanosized polyelectrolyte complexes by self-assembly with both antigens, p24 and OVA, and adjuvant. The particles have sizes smaller than $200 \mathrm{~nm}$ with low polydispersity (PDI < 0.15) and slightly positive surface charge (ca. $+2 \mathrm{mV}$ ) in PBS buffer solution $\mathrm{pH} 7.4$. 
Table 8.1. Size distributions and zeta-potentials of cPEG-p(CBA-ABOL)/p24/CpG and cPEG-p(CBA-ABOL)/OVA/CpG nanoparticles measured by DLS at $25^{\circ} \mathrm{C}$.

\begin{tabular}{|c|c|c|c|}
\hline Nanoparticle & $\begin{array}{c}\text { Particle size } \\
(\mathrm{nm})\end{array}$ & $\begin{array}{c}\text { Surface charge } \\
(\mathrm{mV})\end{array}$ & $\begin{array}{c}\text { Antigen } \\
\text { loading } \\
\text { efficiency (\%) } \\
\text { * }\end{array}$ \\
\hline cPEG-p(CBA-ABOL)/p24/CpG & $112 \pm 1$ & $2.4 \pm 0.2$ & 91 \\
\hline cPEG-p(CBA-ABOL)/OVA/CpG & $169 \pm 1$ & $2.0 \pm 0.2$ & 92 \\
\hline
\end{tabular}

* Percentage of fluorescently-labeled antigen that is incorporated in the polymeric nanoparticles $(+/-1)$. Initial antigen concentration is $0.25 \mathrm{mg} / \mathrm{ml}$ and $0.20 \mathrm{mg} / \mathrm{ml}$ for $\mathrm{p} 24$ and OVA, respectively.

The content of CpG in the formulation was determined by HPLC, and it was shown that the loading efficiency of $\mathrm{CpG}$ in the formulations was $\geq 88 \%$ of an initial concentration of 0.08 $\mathrm{mg} / \mathrm{ml}$, which corresponds to antigen/adjuvant ratios of $2.6 / 1$ and 3.3/1 for p24/CpG and OVA/CpG, respectively.

To evaluate the role of the adjuvant in the formulation, a comparable formulation was prepared with similar polymer and antigen concentrations, but without CpG. DLS measurements showed that, without CpG, particles with ununiform size with high PDI were formed (data not shown), whereas in the presence of CpG a well-defined size distribution with low PDI was obtained. Therefore, the presence of CpG as adjuvant revealed to be important for the formation and the stability of the cPEG-p(CBA-ABOL)/antigen/CpG nanocomplexes.

Repetitive size measurements in time show that the nanoparticles formed with p24 and OVA were stable for more than one month at room temperature. Figure 8.3 represents the particle size of the $\mathrm{cPEG}-\mathrm{p}(\mathrm{CBA}-\mathrm{ABOL}) /$ antigen/CpG nanocomplexes at $37^{\circ} \mathrm{C}$. The particle size of the cPEG-p(CBA-ABOL)/p24/CpG and of cPEG-p(CBA-ABOL)/OVA/CpG nanoparticles slightly increased during the first 12 hours from ca. 115 and $155 \mathrm{~nm}$ to 155 and $185 \mathrm{~nm}$, respectively, and then stayed stable for at least 10 days. 


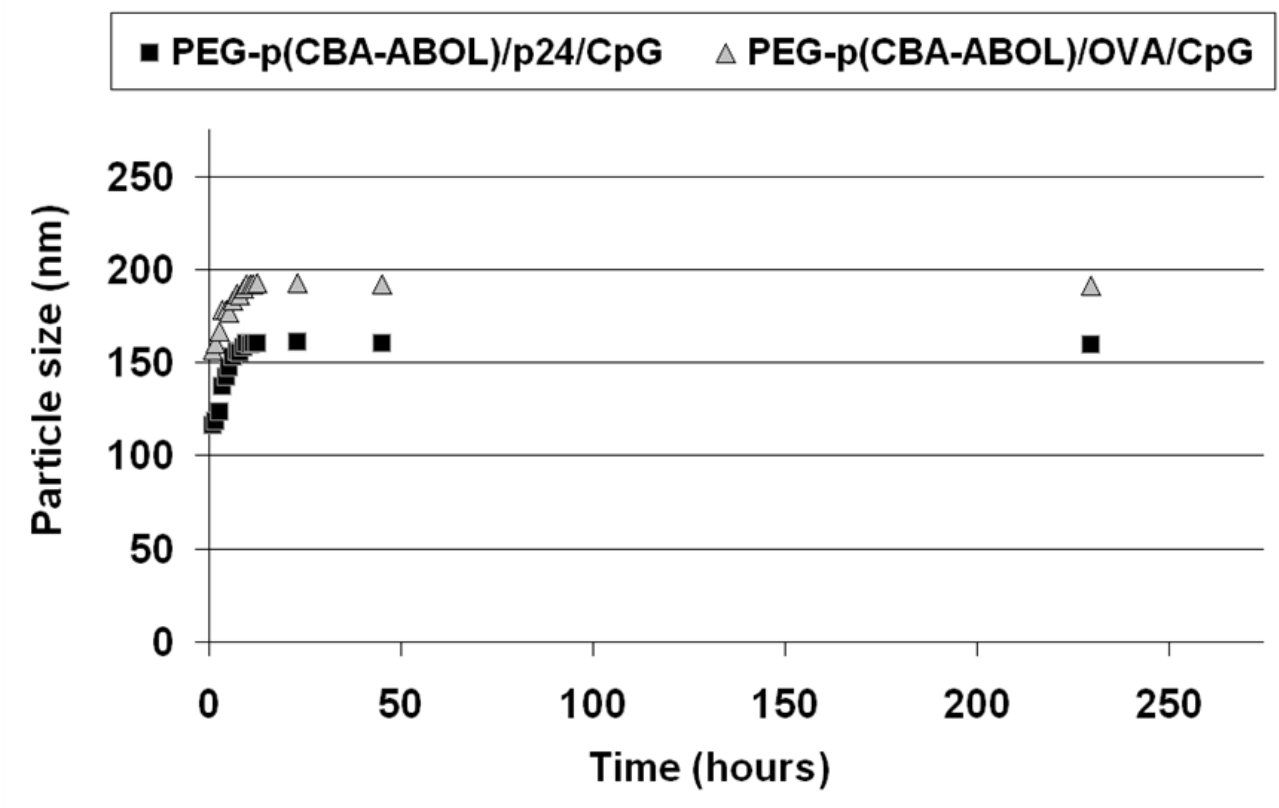

Figure 8.3. Evolution in time of the particle size of $c P E G-p(C B A-A B O L) / p 24 / C p G$ and cPEG-p(CBA-ABOL)/OVA/CpG nanoparticles measured by DLS at $37^{\circ} \mathrm{C}$.

\subsection{In vitro cytotoxicity and cellular uptake}

\subsubsection{Cytotoxicity and endoxotin-testing}

The effect of the nanoparticles on the cell viability of endothelial cells was determined by MTS assay, measuring the percentage of metabolic active cells, and the endotoxin contamination was determined by measuring E-selectin expression. The results are presented in Figure 8.4, and are expressed for single components and complete nanoparticle formulations containing p24 and OVA. 
A
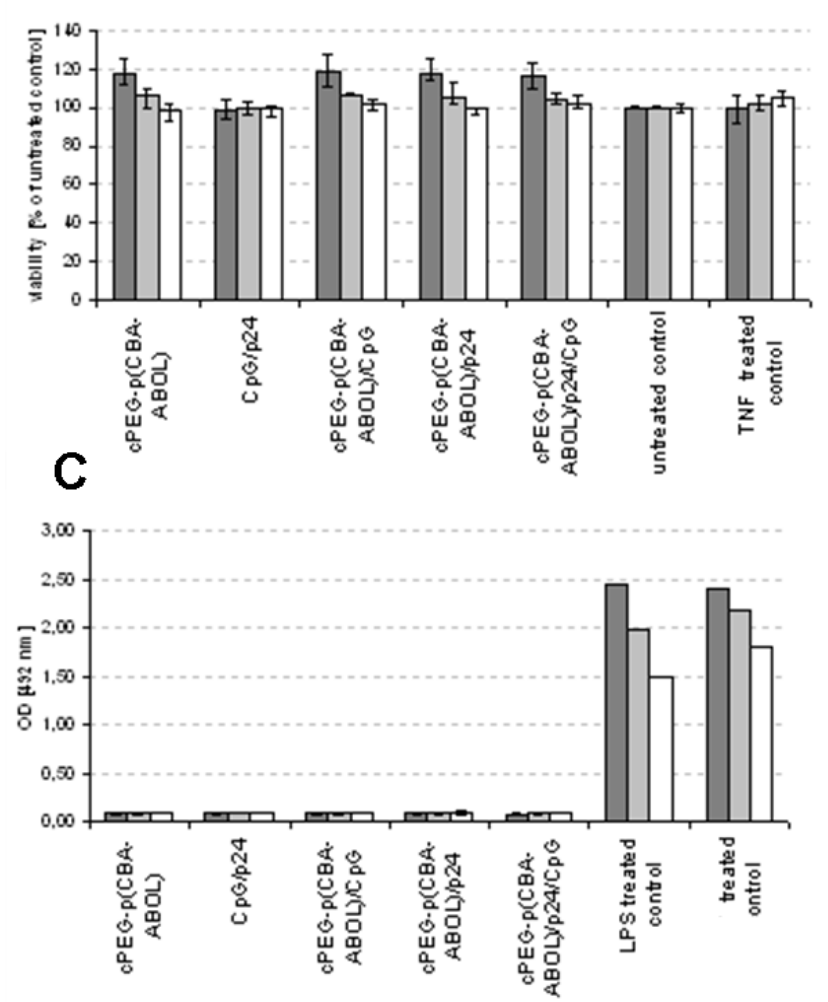

B
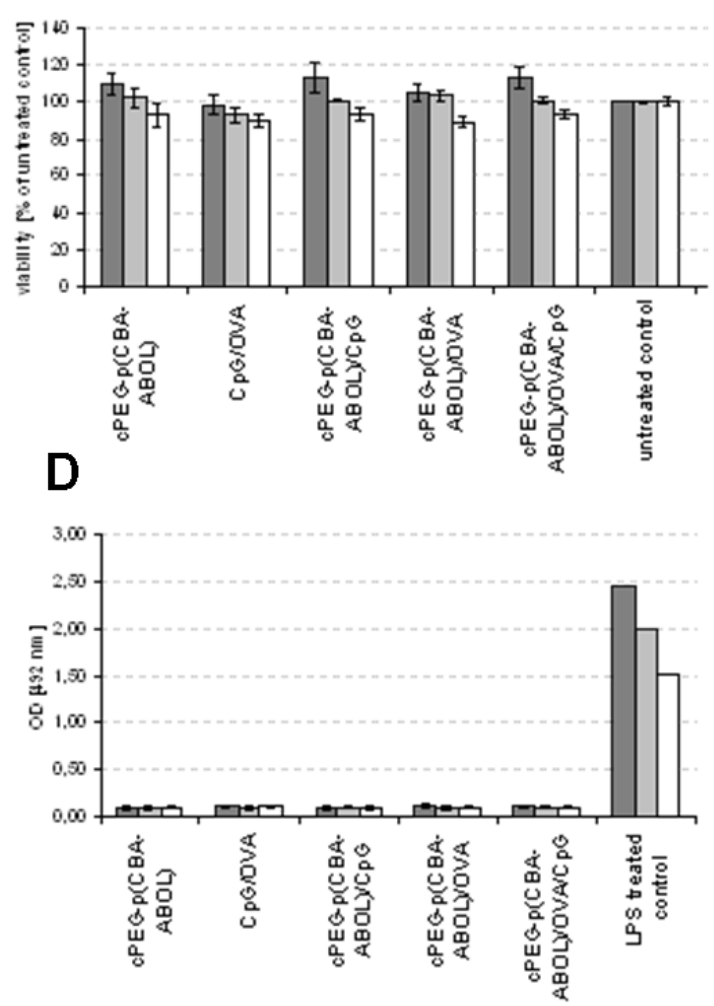

Figure 8.4. Cell viability measured by the MTS assay after 24 hour exposure to single components and nanoparticle formulations containing p24 (A) and OVA (B). E-selection expression after 4 hour exposure to single components and nanoparticle formulations containing p24 (C) and OVA (D). Positive controls for E-selectin induction LPS $(1 \mu \mathrm{g} / \mathrm{ml}, 200 \mathrm{ng} / \mathrm{ml}, 100 \mathrm{ng} / \mathrm{ml})$ and TNF- $\alpha$ (300 $\mathrm{U} / \mathrm{ml}, 60 \mathrm{U} / \mathrm{ml}, 30 \mathrm{U} / \mathrm{ml})$.

The results of the in vitro cytotoxicity testing by MTS show that the single components of the nanoparticle formulations, i.e. cPEG-p(CBA-ABOL), CpG, p24 and OVA, as well as the cPEG-p(CBA-ABOL)/antigen/CpG nanocomplexes are non-toxic (Figures 8.4A and 8.4B). Additionally, all tested components can be regarded as endotoxin-free, because they did not cause an induction of E-selectin after 4 hours of exposure to endothelial cells (Figures 8.4C and 8.4D). In contrast, the positive controls for E-selectin induction, LPS and TNF- $\alpha$, showed the expected concentration dependent increase in E-selectin expression after 4 hours of exposure.

\subsubsection{Cellular transport}

To evaluate the capacity of the nanoparticles to pass through epithelial and endothelial cell layers, we developed and used a novel cellular model simulating the respiratory mucosa. To this aim, a co-culture model of respiratory epithelial cells and endothelial cells 
grown on both sides of a transwell filter membrane, in which both, the respiratory

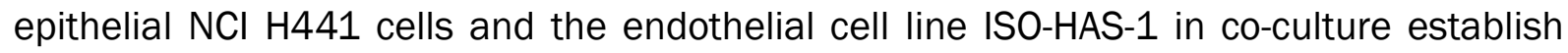
contact inhibited monolayers, was used. The respiratory epithelial cells were exposed to the cPEG-p(CBA-ABOL)/antigen/CpG nanoparticle solutions for 24 hours, as well as the free antigen and $\mathrm{CpG}$. The amount of antigen load was detected in the lower well after different time points during 48 hours, permitting to simulate and follow potential antigen release through the nasal membrane.

Prior to transport studies, we insured that there was not any damage in the cellular barrier. Since the transport of macromolecules could be just achieved simply due to the breakdown of the barrier, an intact cellular barrier is a positive control for an intact transport system. For this reason, the Transepithelial Electrical Resistance (TER) was measured after different times during the 48 hours of exposure of the single components and the nanoparticle formulations containing p24 and OVA to the respiratory epithelial $\mathrm{NCl} \mathrm{H} 441$ cells and the endothelial cell line ISO-HAS-1 in co-culture grown on both sides of a transwell filter membrane.

As shown in Figure 8.5, the TER value of the respiratory tract model did not significantly vary during the full time of the experiments and was comprised between 100 and 150\% compared to the untreated control sample. These results indicate that within an exposure time of 48 hours the TER value was not influenced by the different nanoparticle formulations or the single components used for nanoparticle assembly, either formulated with p24 (Figure 8.5.A) or OVA (Figure 8.5.B). This proves that the barrier of the respiratory cell co-culture model is kept intact, and means that the nanoparticle formulations did not cause any harm on the respiratory co-culture barrier. 

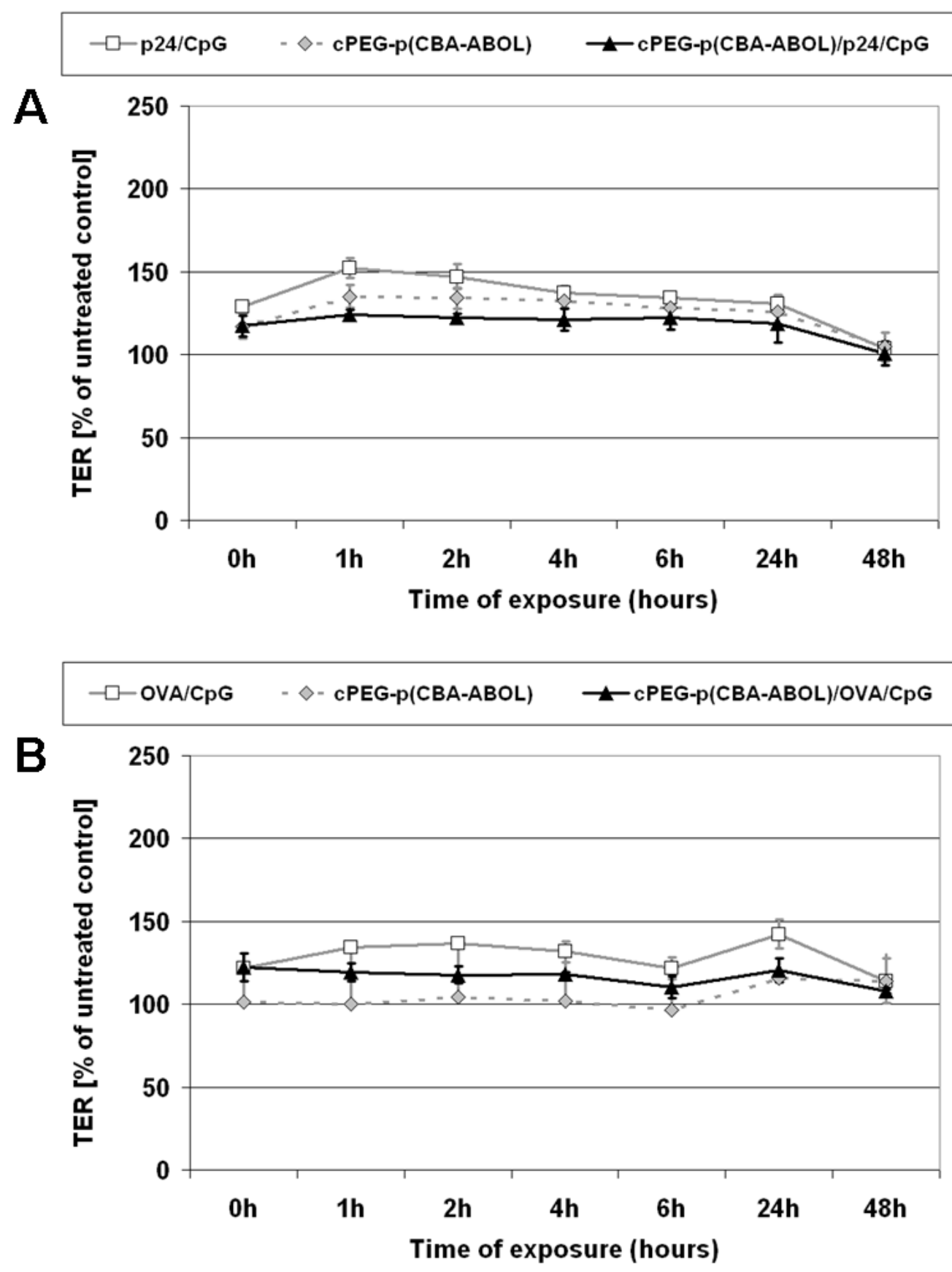

Figure 8.5. Transepithelial Electrical Resistance (TER) measurement for nanoparticle formulations containing p24 (A) and OVA (B).

The amount of antigen in the lower well during apical exposure to the nanoparticle formulations containing p24 and OVA was measured using ELISA techniques after different times of exposure. As a control, a solution containing adjuvant and antigen was also loaded, and the amount of antigen in the basolateral chamber was measured in time. 
Calibration curves were generated with samples of known antigen concentrations, and for both antigens, p24 and OVA, a transport through the respiratory barrier model was detected, as shown in Figures 8.6A and 8.6B, respectively.
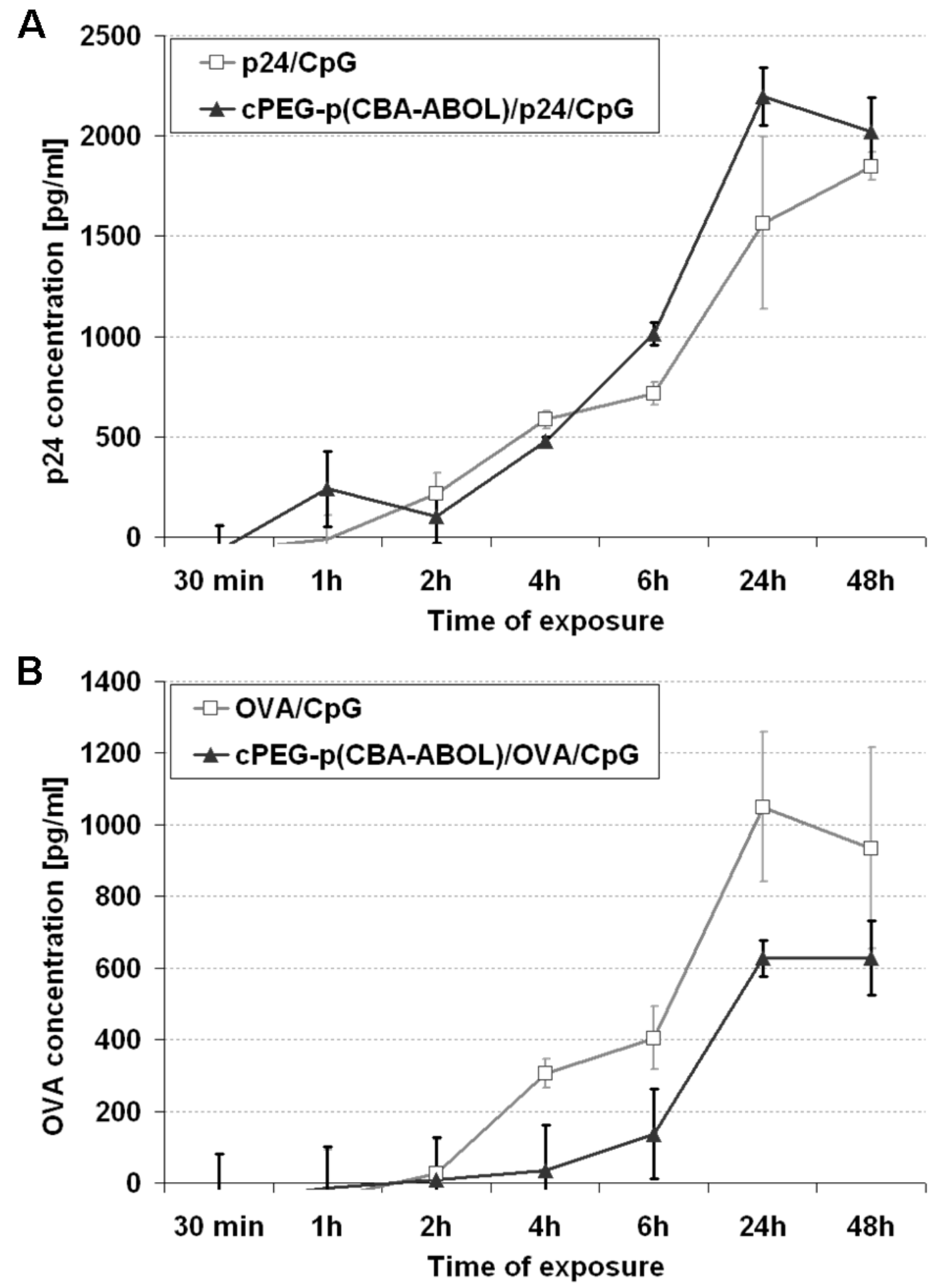

Figure 8.6. Amount of antigen in the lower well during apical exposure to nanoparticle formulations containing p24 (A) and OVA (B). As a control, a solution containing adjuvant and antigen was also loaded. 
Figure 8.6 shows that during the 24 first hours of exposure, for both p24 and OVA, a gradient increase of antigen concentration in the lower well was measured and reached a maximum after 24 hours of exposure. After removal of the nanoparticle formulations from the upper well after 24 hours of exposure, no further increase in antigen concentration was detected, and the measured p24 or OVA concentrations after 48 hours of exposure are approximately the same than after 24 hours. This means that no transport has taken place during the next 24 hours (with a total time of exposure of 48 hours), implying that no decelerated release/transport of the antigen load has occurred. After 24 hours of exposure, no antigen stays inside of the cells and is released with time delay into the lower well.

The measured concentrations of p24 in the basolateral chamber were considerably higher (> 140\%) for the p24-nanoparticle formulation than for free p24, indicating a significant improvement of uptake/transport when the antigen is loaded into the cPEG-p(CBA-ABOL) nanoparticles, therefore enhancing the permeability of p24.

In contrast, already after two hours of exposure a higher concentration of OVA was transported over the respiratory barrier model using the mixture OVA/CpG compared to OVA incorporated in the cPEG-p(CBA-ABOL) nanoparticles (Figure 8.6A). Compared to OVA/CpG, only $60 \%$ of the OVA content of the nanoparticles was transported after 24 hours.

The absorption of free albumin across the alveolar epithelial cell monolayers via transcytosis, as described by Kim et al. [69], might explain these results. It was shown that the transport of albumin is highly dependent upon its size, and that net saturable absorption of albumin across tight rat alveolar epithelial cell monolayers appears to occur predominantly via transcytosis $[69,70]$, instead of via passive diffusion, translocation of albumin across the alveolar epithelial barrier via nonspecific adsorptive endocytosis [71], or endocytosis through adsorption of ligands [72]. Therefore, although the PAA nanocarrier inducing endocytosis inside the cells showed detectable transport through the respiratory barrier model, this delivery system might not be optimal to transport OVA through epithelial cell monolayers.

Moreover, CpG associated to OVA was shown by Fujihashi et al. to promote significant increase of immunoresponse for OVA compared to free OVA [73].

Even if a non-negligible concentration of OVA was transported while complexed in cPEG-p(CBA-ABOL) nanoparticles, internalization of OVA did not provide as good results as the OVA/CpG mixture. One way to improve the transport of OVA is by the inclusion of a 
targeting ligand such as the Flt3 ligand [73, 74].

\section{Conclusions}

A novel bioreducible poly(amidoamine) (SS-PAA) containing disulfide linkages was synthesized and evaluated as carrier for the delivery of antigens through a respiratory epithelial and endothelial cell bilayer model. The linear polymer efficiently condensed the antigens into nanoscaled complexes by electrostatic and hydrophobic interactions. The capacity of the nanoparticles to pass through epithelial and endothelial cell layers was evaluated using a novel cellular model simulating the respiratory mucosa, and the nanoparticles were shown to enhance the permeability of p24 compared to free antigen, with remaining excellent cell-viability and without endotoxin contamination.

The results indicate that bioreducible poly(amidoamine)s have potential to serve as functional and nontoxic antigen carriers for nasal delivery.

\section{Acknowledgements}

The authors wish to thank Mrs E. Stahr for her excellent assistance with the cell culture. GlaxoSmithKline Vaccines is acknowledged for supplying p24 and measuring the content of CpG by HPLC. This research work is part of the European FP6 IP NanoBioPharmaceutics.

\section{References}

[1] J. Holmgren, C. Czerkinsky, Mucosal immunity and vaccines. Nat. Med. 11(4) (2005) S45-S53.

[2] S.S. Davis, Nasal vaccines. Adv. Drug Deliv. Rev. 51(1-3) (2001) 21-42.

[3] I.M. van der Lubben, G. Kersten, M.M. Fretz, C. Beuvery, J.C. Verhoef, H.E. Junginger, Chitosan microparticles for mucosal vaccination against diphtheria: oral and nasal efficacy studies in mice. Vaccine 21(13-14) (2003) 1400-1408.

[4] M. Iqbal, W. Lin, I. Jabbal-Gill, S.S. Davis, M.W. Steward, L. Illum, Nasal delivery of chitosan-DNA plasmid expressing epitopes of respiratory syncytial virus (RSV) induces protective CTL responses in BALB/c mice. Vaccine 21(13-14) (2003) 1478-1485.

[5] L. Illum, S.S. Davis, Nasal vaccination: a non-invasive vaccine delivery method that holds great promise for the future. Adv. Drug Deliv. Rev. 51(1-3) (2001) 1-3.

[6] D.T. Ohagan, L. Illum, Absorption of Peptides and Proteins from the Respiratory-Tract and the Potential for Development of Locally Administered Vaccine. Crit. Rev. Ther. Drug Carr. Syst. 7(1) (1990) 35-97.

[7] A.J. Almeida, H.O. Alpar, Nasal delivery of vaccines. J. Drug Target. 3(6) (1996) 455-467.

[8] F. Velge-Roussel, P. Marcelo, A.C. Lepage, D. Buzoni-Gatel, D.T. Bout, Intranasal immunization with Taxoplasma gondii SAG1 induces protective cells into both NALT and GALT compartments. Infect. Immun. 68(2) (2000) 969-972.

[9] B. Liang, L. Hyland, S. Hou, Nasal-associated lymphoid tissue is a site of long-term virus-specific antibody production following respiratory virus infection of mice. J. Virol. 75(11) (2001) 5416-5420. 
[10] H.R. Costantino, L. Illum, G. Brandt, P.H. Johnson, S.C. Quay, Intranasal delivery: Physicochemical and therapeutic aspects. Int. J. Pharm. 337(1-2) (2007) 1-24.

[11] M.I. Ugwoke, N. Verbeke, R. Kinget, The biopharmaceutical aspects of nasal mucoadhesive drug delivery. J. Pharm. Pharmacol. 53(1) (2001) 3-21.

[12] S. Turker, E. Onur, Y. Ozer, Nasal route and drug delivery systems. Pharm. World Sci. 26(3) (2004) 137-142.

[13] L. Illum, Nasal drug delivery - possibilities, problems and solutions. J Control Release 87(1-3) (2003) 187-198.

[14] R.J. Soane, M. Frier, A.C. Perkins, N.S. Jones, S.S. Davis, L. Illum, Evaluation of the clearance characteristics of bioadhesive systems in humans. Int. J. Pharm. 178(1) (1999) 55-65.

[15] R.J. Soane, A.S. Carney, N.S. Jones, M. Frier, A.C. Perkins, S.S. Davis, L. Illum, The effect of the nasal cycle on mucociliary clearance. Clin. Otolaryngol. 26(1) (2001) 9-15.

[16] B. Brime, M.P. Ballesteros, P. Frutos, Preparation and in vitro characterization of gelatin microspheres containing Levodopa for nasal administration. J. Microencapsul. 17(6) (2000) 777-784.

[17] P. Couvreur, F. Puisieux, Nanoparticles and Microparticles for the Delivery of Polypeptides and Proteins. Adv. Drug Deliv. Rev. 10(2-3) (1993) 141-162.

[18] J. Kreuter, Peroral Administration of Nanoparticles. Adv. Drug Deliv. Rev. 7(1) (1991) 71-86.

[19] C.M. Lehr, Bioadhesion Technologies for the Delivery of Peptide and Protein Drugs to the Gastrointestinal-Tract. Crit. Rev. Ther. Drug Carr. Syst. 11(2-3) (1994) 119-160.

[20] M.C. Manning, K. Patel, R.T. Borchardt, Stability of Protein Pharmaceuticals. Pharm. Res. 6(11) (1989) 903-918.

[21] B. Sarmento, A. Ribeiro, F. Veiga, P. Sampaio, R. Neufeld, D. Ferreira, Alginate/Chitosan nanoparticles are effective for oral insulin delivery. Pharm Res 24(12) (2007) 2198-2206.

[22] A. Harada, K. Kataoka, Novel polyion complex micelles entrapping enzyme molecules in the core: Preparation of narrowly-distributed micelles from lysozyme and poly(ethylene glycol)-poly(aspartic acid) block copolymer in aqueous medium. Macromolecules 31(2) (1998) 288-294.

[23] A. Jintapattanakit, V.B. Junyaprasert, S. Mao, J. Sitterberg, U. Bakowsky, T. Kissel, Peroral delivery of insulin using chitosan derivatives: A comparative study of polyelectrolyte nanocomplexes and nanoparticles. Int. J. Pharm. 342(1-2) (2007) 240-249.

[24] Y. Lee, S. Fukushima, Y. Bae, S. Hiki, T. Ishii, K. Kataoka, A protein nanocarrier from charge-conversion polymer in response to endosomal pH. J. Am. Chem. Soc. 129(17) (2007) 5362-5363.

[25] S.J. Shu, X.G. Zhang, D.Y. Teng, Z. Wang, C.X. Li, Polyelectrolyte nanoparticles based on water-soluble chitosan-poly (L-aspartic acid)-polyethylene glycol for controlled protein release. Carbohydr. Res. 344(10) (2009) 1197-1204.

[26] F.M. Goycoolea, G. Lollo, C. Remunan-Lopez, F. Quaglia, M.J. Alonso, Chitosan-Alginate Blended Nanoparticles as Carriers for the Transmucosal Delivery of Macromolecules. Biomacromolecules 10(7) (2009) 1736-1743.

[27] P. Rivera-Gil, S. De Koker, B.G. De Geest, W.J. Parak, Intracellular Processing of Proteins Mediated by Biodegradable Polyelectrolyte Capsules. Nano Lett. 9(12) (2009) 4398-4402.

[28] M.D. Chavanpatil, A. Khdair, J. Panyam, Nanoparticles for cellular drug delivery: Mechanisms and factors influencing delivery. J. Nanosci. Nanotechnol. 6(9-10) (2006) 2651-2663.

[29] M. Amidi, E. Mastrobattista, W. Jiskoot, W.E. Hennink, Chitosan-based delivery systems for protein therapeutics and antigens. Adv. Drug Deliv. Rev. 62(1) (2010) 59-82.

[30] V. Dodane, M.A. Khan, J.R. Merwin, Effect of chitosan on epithelial permeability and structure. Int. J. Pharm. 182(1) (1999) 21-32.

[31] I.M. van der Lubben, J.C. Verhoef, G. Borchard, H.E. Junginger, Chitosan and its derivatives in mucosal drug and vaccine delivery. Eur J Pharm Sci 14(3) (2001) 201-207.

[32] M. Amidi, S.G. Romeijn, J.C. Verhoef, H.E. Junginger, L. Bungener, A. Huckriede, D.J.A. 
Crommelin, W. Jiskoot, N-Trimethyl chitosan (TMC) nanoparticles loaded with influenza subunit antigen for intranasal vaccination: Biological properties and immunogenicity in a mouse model. Vaccine 25(1) (2007) 144-153.

[33] J.H. Hamman, M. Stander, A.F. Kotze, Effect of the degree of quaternisation of $\mathrm{N}$-trimethyl chitosan chloride on absorption enhancement: in vivo evaluation in rat nasal epithelia. Int. J. Pharm. 232(1-2) (2002) 235-242.

[34] M. Thanou, M.T. Nihot, M. Jansen, J.C. Verhoef, H.E. Junginger, Mono-N-carboxymethyl chitosan (MCC), a polyampholytic chitosan derivative, enhances the intestinal absorption of low molecular weight heparin across intestinal epithelia in vitro and in vivo. J. Pharm. Sci. 90(1) (2001) 38-46.

[35] A.F. Kotze, M.M. Thanou, H.L. Luessen, B.G. de Boer, J.C. Verhoef, H.E. Junginger, Effect of the degree of quaternization of $\mathrm{N}$-trimethyl chitosan chloride on the permeability of intestinal epithelial cells (Caco-2). Eur. J. Pharm. Biopharm. 47(3) (1999) 269-274.

[36] M. Thanou, J.C. Verhoef, H.E. Junginger, Oral drug absorption enhancement by chitosan and its derivatives. Adv Drug Deliv Rev 52(2) (2001) 117-126.

[37] B. Sayln, S. Somavarapu, X.W. Li, D. Sesardic, S. Senel, O.H. Alpar, TMC-MCC (N-trimethyl chitosan-mono-N-carboxymethyl chitosan) nanocomplexes for mucosal delivery of vaccines. Eur J Pharm Sci 38(4) (2009) 362-369.

[38] B. Sayin, S. Somavarapu, X.W. Li, M. Thanou, D. Sesardic, H.O. Alpar, S. Senel, Mono-N-carboxymethyl chitosan (MCC) and N-trimethyl chitosan (TMC) nanoparticles for non-invasive vaccine delivery. Int. J. Pharm. 363(1-2) (2008) 139-148.

[39] P. Ferruti, M.A. Marchisio, R. Duncan, Poly(amido-amine)s: Biomedical applications. Macromol Rapid Commun 23(5-6) (2002) 332-355.

[40] J. Franchini, P. Ferruti, Perspectives on: Recent advances in poly(amidoamine)s chemistry. J. Bioact. Compat. Polym. 19(3) (2004) 221-236.

[41] O. Boussif, F. Lezoualch, M.A. Zanta, M.D. Mergny, D. Scherman, B. Demeneix, J.P. Behr, A Versatile Vector for Gene and Oligonucleotide Transfer into Cells in Culture and in-Vivo Polyethylenimine. Proc. Natl. Acad. Sci. U. S. A. 92(16) (1995) 7297-7301.

[42] J.D. Eichman, A.U. Bielinska, J.F. Kukowska-Latallo, J.R. Baker Jr, The use of PAMAM dendrimers in the efficient transfer of genetic material into cells. Pharmaceut Sci Tech Today 3(7) (2000) 232-245.

[43] E. Ranucci, G. Spagnoli, P. Ferruti, D. Sgouras, R. Duncan, Poly(amidoamine)s with potential as drug carriers: degradation and cellular toxicity. J Biomater Sci Polym Ed 2(4) (1991) 303-315.

[44] G.Y. Wu, C.H. Wu, Receptor-Mediated Invitro Gene Transformation by a Soluble DNA Carrier System. J. Biol. Chem. 262(10) (1987) 4429-4432.

[45] A. Bernkop-Schnürch, Thiomers: A new generation of mucoadhesive polymers. Adv Drug Deliv Rev 57(11) (2005) 1569-1582.

[46] M.H. Dufresne, M.A. Gauthier, J.C. Leroux, Thiol-functionalized polymeric micelles: From molecular recognition to improved mucoadhesion. Bioconjugate Chem. 16(4) (2005) 1027-1033.

[47] A. Bernkop-Schnurch, V. Schwarz, S. Steininger, Polymers with thiol groups: A new generation of mucoadhesive polymers? Pharm. Res. 16(6) (1999) 876-881.

[48] K. Kafedjiiski, F. Foger, A. Bernkop-Schnurch, M. Werle, Evaluation of in vitro enzymatic degradation of various thiomers and cross-linked thiomers. Drug Dev. Ind. Pharm. 33(2) (2007) 199-208.

[49] C. Lin, J.F.J. Engbersen, Effect of chemical functionalities in poly(amido amine)s for non-viral gene transfection. J Control Release 132(3) (2008) 267-272.

[50] C. Lin, Z.Y. Zhong, M.C. Lok, X.L. Jiang, W.E. Hennink, J. Feijen, J.F.J. Engbersen, Novel bioreducible poly(amido amine)s for highly efficient gene delivery. Bioconjug Chem 18(1) (2007) 138-145.

[51] C. Lin, C.-J. Blaauboer, M.M. Timoneda, M.C. Lok, M. van Steenbergen, W.E. Hennink, Z. Zhong, J. Feijen, J.F.J. Engbersen, Bioreducible poly(amido amine)s with oligoamine side chains: Synthesis, characterization, and structural effects on gene delivery. J Control Release 126(2) (2008) 166-174.

[52] C. Lin, Z. Zhong, M.C. Lok, X. Jiang, W.E. Hennink, J. Feijen, J.F.J. Engbersen, Linear 
poly(amido amine)s with secondary and tertiary amino groups and variable amounts of disulfide linkages: Synthesis and in vitro gene transfer properties. J Control Release 116(2) (2006) 130-137.

[53] C. Lin, Z. Zhong, M.C. Lok, X. Jiang, W.E. Hennink, J. Feijen, J.F.J. Engbersen, Random and block copolymers of bioreducible poly(amido amine)s with high- and low-basicity amino groups: Study of DNA condensation and buffer capacity on gene transfection. J Control Release 123(1) (2007) 67-75.

[54] M.A. Mateos-Timoneda, M.C. Lok, W.E. Hennink, J. Feijen, J.F.J. Engbersen, Poly(amido amine)s as gene delivery vectors: Effects of quaternary nicotinamide moieties in the side chains. ChemMedChem 3(3) (2008) 478-486.

[55] G. Coué, J.F.J. Engbersen, Functionalized linear poly(amidoamine)s are efficient vectors for intracellular protein delivery. J Control Release (2011), doi:10.1016/j.jconrel.2011.01.023.

[56] C. Lin, J.F.J. Engbersen, The role of the disulfide group in disulfide-based polymeric gene carriers. Expert Opin. Drug Deliv. 6(4) (2009) 421-439.

[57] G. Saito, J.A. Swanson, K.D. Lee, Drug delivery strategy utilizing conjugation via reversible disulfide linkages: role and site of cellular reducing activities. Adv Drug Deliv Rev 55(2) (2003) 199-215.

[58] S. Ganta, H. Devalapally, A. Shahiwala, M. Amiji, A review of stimuli-responsive nanocarriers for drug and gene delivery. J Control Release 126(3) (2008) 187-204.

[59] K.C. Rajender, W.L. Frederick, H.K. Michael, M.B. David, G.B.R. Robert, R. Daniel, Plasma cysteine, cystine, and glutathione in cirrhosis. Gastroenterology 87(4) (1984) 770-776.

[60] S.R. Mao, U. Bakowsky, A. Jintapattanakit, T. Kissel, Self-assembled polyelectrolyte nanocomplexes between chitosan derivatives and insulin. J. Pharm. Sci. 95(5) (2006) 1035-1048.

[61] M. Tobio, R. Gref, A. Sanchez, R. Langer, M.J. Alonso, Stealth PLA-PEG nanoparticles as protein carriers for nasal administration. Pharm Res 15(2) (1998) 270-275.

[62] N. Csaba, M. Koping-Hoggard, E. Fernandez-Megia, R. Novoa-Carballal, R. Riguera, M.J. Alonso, lonically Crosslinked Chitosan Nanoparticles as Gene Delivery Systems: Effect of PEGylation Degree on In Vitro and In Vivo Gene Transfer. J. Biomed. Nanotechnol. 5(2) (2009) 162-171.

[63] X.G. Zhang, H.J. Zhang, Z.M. Wu, Z. Wang, H.M. Niu, C.X. Li, Nasal absorption enhancement of insulin using PEG-grafted chitosan nanoparticles. Eur. J. Pharm. Biopharm. 68(3) (2008) 526-534.

[64] S. Choksakulnimitr, S. Masuda, H. Tokuda, Y. Takakura, M. Hashida, In vitro cytotoxicity of macromolecules in different cell culture systems. J Control Release 34(3) (1995) 233-241.

[65] A.M. Krieg, H.L. Davis, Enhancing vaccines with immune stimulatory CpG DNA. Curr. Opin. Mol. Ther. 3(1) (2001) 15-24.

[66] B. Maletto, A. Ropolo, V. Moron, M.C. Pistoresi-Palencia, CpG-DNA stimulates cellular and humoral immunity and promotes Th1 differentiation in aged BALB/c mice. J. Leukoc. Biol. 72(3) (2002) 447-454.

[67] B.M. Manning, E.Y. Enioutina, D.M. Visic, A.D. Knudson, R.A. Daynes, CpG DNA functions as an effective adjuvant for the induction of immune responses in aged mice. Exp. Gerontol. 37(1) (2001) 107-126.

[68] M.I. Hermanns, R.E. Unger, K. Kehe, K. Peters, C.J. Kirkpatrick, Lung epithelial cell lines in coculture with human pulmonary microvascular endothelial cells: development of an alveolo-capillary barrier in vitro. Lab. Invest. 84(6) (2004) 736-752.

[69] K.J. Kim, A.B. Malik, Protein transport across the lung epithelial barrier. Am J Physiol Lung Cell Mol Physiol 284(2 28-2) (2003) L247-L259.

[70] K.J. Kim, V. Ratten, P. Oh, J.E. Schnitzer, V.K. Kalra, E.D. Crandall, Specific albumin-binding protein in alveolar epithelial cell monolayers. Am J Respir Crit Care Med 151(A190) (1995).

[71] M.C. Williams, Endocytosis in alveolar type II cells: Effect of charge and size of tracers. Proc Nat Acad Sci USA 81(19 I) (1984) 6054-6058.

[72] Y. Matsukawa, H. Yamahara, V.H.L. Lee, E.D. Crandall, K.J. Kim, Horseradish peroxidase 
transport across rat alveolar epithelial cell monolayers. Pharm Res 13(9) (1996) 1331-1335.

[73] T. Fukuiwa, S. Sekine, R. Kobayashi, H. Suzuki, K. Kataoka, R.S. Gilbert, Y. Kurono, P.N. Boyaka, A.M. Krieg, J.R. McGhee, K. Fujihashi, A combination of Flt3 ligand cDNA and CpG ODN as nasal adjuvant elicits NALT dendritic cells for prolonged mucosal immunity. Vaccine 26(37) (2008) 4849-4859.

[74] K. Kataoka, J.R. McGhee, R. Kobayashi, K. Fujihashi, S. Shizukuishi, Nasal Flt3 ligand cDNA elicits $\mathrm{CD} 11 \mathrm{c}(+) \mathrm{CD} 8(+)$ dendritic cells for enhanced mucosal immunity. J. Immunol. 172(6) (2004) 3612-3619. 


\section{Design and physiochemical characterization of poly(amidoamine) nanoparticles and the toxicological evaluation in human endothelial cells: applications to peptide delivery to the brain}

Grégory Coué1, Christian Freese ${ }^{2,3}$, Ronald E. Unger ${ }^{2,3}$, C. James Kirkpatrick ${ }^{2,3}$, Karin E. Pickl$^{4}$, Frank M. Sinner ${ }^{4}$, and Johan F.J. Engbersen ${ }^{1}$

${ }^{1}$ Department of Biomedical Chemistry, MIRA Institute for Biomedical Technology \& Technical Medicine, Faculty of Science and Technology, University of Twente, P.O. Box 217, 7500 AE Enschede, the Netherlands

2 REPAIR-lab, Institute of Pathology, University Medical Center of the Johannes Gutenberg University, Langenbeckstrasse 1, 55101 Mainz, Germany

${ }^{3}$ European Institute of Excellence on Tissue Engineering and Regenerative Medicine, Mainz, Germany

4 Joanneum Research, Institute of Medical Technologies and Health Management, Stiftingtalstrasse 24, $8010 \mathrm{Graz}$, Austria

Part of this chapter has been published: G. Coué, C. Freese, R.E. Unger, C.J. Kirkpatrick, K.E. Pickl, F.M. Sinner, and J.F.J. Engbersen, Design and physiochemical characterization of poly(amidoamine) nanoparticles and the toxicological evaluation in human endothelial cells: applications to peptide delivery to the brain, submitted

Abstract: In this study, we investigated nanoparticles formulated by self-assembly of a biodegradable poly(amidoamine) (PAA) and a fluorescently-labeled peptide, in their capacity to internalize in endothelial cells and deliver the peptide, with possible applications for brain drug delivery. The nanoparticles were characterized in terms of size, surface charge, and loading efficiency, and were applied on human cerebral microvascular endothelial cells (hCMEC/D3) and human umbilical vein endothelial cells 
(Huvec) cells. Cell-internalization and cytotoxicity experiments showed that the PAA-based nanocomplexes were essentially non-toxic, and the peptide was successfully internalized into cells. The results indicate that these PAAs have excellent properties as non-toxic carriers for intracellular protein delivery, and provide opportunities for novel applications in protein delivery through the blood-brain barrier.

\section{Introduction}

Diseases of the central nervous system (CNS) are presently one of the five most serious diseases in humans, concerning over 1.5 billion people worldwide suffering from CNS diseases or disorders, including Alzheimer's disease, brain tumor, Parkinson's disease, white matter dystrophy symptom, Creutzfeldt-Jacob disease, meningitis, and encephalitis. Progress in neurosciences and pharmacology has resulted in greater knowledge of CNS diseases and of potential therapies. In this context, peptides and proteins have become important targets in neuropharmaceutical drug design for the treatment of a wide variety of CNS disorders [1-6].

While finding ways to get therapeutics drugs to the CNS is becoming more important than ever, it is also a great challenge because the brain tissue benefits from a very efficient protective barrier. Material transport from the blood compartment to the brain is restricted by the unique structure of the cerebral blood vessels posing a blood-brain barrier (BBB) that acts as the major barrier for the passage and absorption of active molecules to the brain. The same mechanisms that protect the brain from foreign substances also restrict the entry of many potential therapeutic agents $[7,8]$.

The BBB is located at the level of brain capillaries, where there is a convergence of different cell types: endothelial cells, pericytes, astrocytes and microglias (perivascular macrophages). The brain microvessel endothelial cells (BMEC), separating the brain from the rest of the body, display important morphological characteristics such as the presence of tight junctions between the cells, the absence of fenestrations and a diminished pinocytic activity $[9,10]$. The tight junctions provide significant transendothelial electrical resistance to the BMEC and impede the penetration of a large number of drugs, such as antibiotics, antineoplastic agents, neuropeptides and other active drugs from the blood into the extracellular environment of the brain [11-13]. Furthermore, BMEC express a variety of enzymes, both cytosolic and on the extracellular membrane, which also contribute to the restrictive nature of the BBB [14].

This has made evident the urgent need to develop new strategies to improve drug delivery 
to this vital organ. The diffusion of drugs from the blood into the brain depends mainly upon the ability of the biologically active molecules to traverse lipid membranes. The BBB allows mostly only high lipid-soluble molecules under a threshold of 400-600 Da to penetrate $[15,16]$. Therefore, numerous drugs do not have adequate physicochemical characteristics, which are necessary to succeed in crossing the BBB [17]. This is the reason why several strategies have been developed to overcome the BBB including invasive (e.g., direct injection) and noninvasive techniques (e.g., use of prodrugs, nasal route) [12]. Among noninvasive techniques, the use of colloidal carriers appears a promising strategy. In general, colloidal drug carriers include micelles, dendrimers, emulsions, liposomes and nanoparticles. It is noteworthy that only liposomes and nanoparticles have been largely exploited for brain drug delivery.

Among the colloidal carriers, biodegradable polymeric nanoparticulate systems have been investigated as potential candidates for CNS-targeted drug delivery. For instance, using biodegradable polymeric poly(alkylcyanoacrylate) nanoparticles, significant drug delivery was achieved to the brain in in vivo experiments [18]. In particular, surface modification of this type of nanoparticles by polysorbate 80 increased the effective drug delivery to the brain [19-23]. Among the biodegradable polymers, poly(lactide) (PLA) and poly(D,L-lactic-co-glycolic acid) (PLGA), as being approved by the FDA for certain human clinical uses, were also considered as safe carriers for brain delivery [23, 24].

Recently, another type of nanoparticles, polyelectrolyte complexes (PECs), resulting from the self-assembly by electrostatic attraction of natural or synthetic polymers with oppositely charged therapeutics, have attracted increasing attention for applications in drug delivery [25-28]. The formulation methodology has the advantage of not requiring sonication or organic solvents which are both harmful for proteins and peptides, and are regularly used for the preparation of nanoparticles notably by the double emulsion technique [25]. The essentially non toxic, polycationic class of poly(amidoamine)s (PAAs) is an attractive class of polymers to be explored for PEC-based drug formulation. These polymers, which can be easily synthesized by Michael-type polyaddition of primary or secondary amines to bisacrylamides [29, 30], are water-soluble, biodegradable and biocompatible, and have generally less cytotoxicity than other common polycationic vectors [31-34]. These favorable properties make that these polymers have high potential in biomedical applications $[30,35]$. In our group, we previously developed a series of novel linear PAAs containing repetitive disulfide linkages in their backbone (SS-PAAs) that were very efficient as vectors in intracellular gene delivery with transfection efficiencies 
much higher than obtained with the PAA counterparts lacking the disulfide linkages and the reference polymer, polyethylenimine (PEI) [36-40]. Similar functionalized SS-PAAs have also shown great potential to function as vectors for intracellular protein delivery [41]. These polymers are relatively stable in extracellular medium but are prone to fast degradation in the reductive intracellular environment due to the cleavage of the disulfide linkages in the polymer chain [42-45]. In general, this property can be favorably exploited in delivery systems that should be stable outside the cell but have to disintegrate into fragments of low molecular weight after uptake into target cells in order to release their therapeutic cargo and minimize cytotoxic effects.

In this study, nanoparticles were prepared by self-assembly of a PEGylated PAA as polymer carrier and a fluorescently labeled peptide as a detectable loading. These nanoparticles were characterized in terms of size, surface charge, and loading efficiency, and were applied on human cerebral microvascular endothelial cells (hCMEC/D3) and were examined in vitro as a model drug delivery system with potential applications to delivery to the brain. As a control, the nanoparticles were also applied on human umbilical vein endothelial cells (Huvec), cell line closely mimicking the in vivo situation.

AGBBB5A, a D-peptide, which structure is depicted in Figure 9.1, consisting of a sequence of 14 amino acids with a molecular weight of ca. $1.76 \mathrm{kDa}$, was used in this study as a model peptide. The sequence of AGBBB5A is based on the idea to have a stable peptide with identical sequence to that of NAP, a peptide with known neuroprotective properties, which sequence (napvsipq) derives from activity-dependent neuroprotective protein [46-49]. The AGBBB5A peptide is labeled with biotin and fluorescein, facilitating its detection by ELISA and fluorescence spectroscopy, respectively.

\section{biotin-napvsipqKGGC FITC}

Figure 9.1. Structure of the peptide AGBBB5A ( $\left.\mathrm{M}_{\mathrm{w}}: 1753.4 \mathrm{Da}\right)$.

\section{Materials and methods}

\subsection{Materials}

The fluorescently-labeled peptides, AGBBB5A and AGBBB5D (a stable isotope-labeled 
peptide with identical sequence to that of AGBBB5A with both glycine labeled with ${ }^{13} \mathrm{C}$ and ${ }^{15} \mathrm{~N}$, used as internal standard for LC/MS analysis), were kindly gifted by AplaGen.

All monomers, 4-amino-1-butanol (ABOL, Sigma-Aldrich), alpha-amino-omega-carboxy-poly(ethylene glycol) hydrochloride $\quad\left(\mathrm{cPEG}-\mathrm{NH}_{2} \quad \mathrm{M}_{\mathrm{w}}\right.$ $3000 \mathrm{~g} / \mathrm{mol}$, Iris Biotech $\mathrm{GmbH}$ ), and N,N'-cystaminebisacrylamide (CBA, Polysciences) were purchased in the highest purity and used without further purification. Phosphate buffered saline (PBS, $0.01 \mathrm{M}, \mathrm{pH}$ 7.4, B. Braun, USA), ethanol (EtOH, Emsure), methanol $(\mathrm{MeOH}$, Biosolve), acetonitrile (ACN, Sigma-Aldrich), trifluoroacetic acid (TFA, Sigma-Aldrich), and ascorbic acid (AA, Sigma-Aldrich) were used as received. Deionized water (DI water) was obtained from a MilliQ-water purification system (Millipore, France).

\subsection{Synthesis of $c P E G-p(C B A-A B O L)$}

The co-polymer cPEG-p(CBA-ABOL), with 10\% cPEG side chains relative to the hydroxybutyl $\mathrm{ABOL}$ groups, was synthesized via Michael-type polyaddition of the primary amine monomers, ABOL and cPEG-NH 2 , to the bisacrylamide CBA, as described in Chapter 5.

\subsection{Polymer characterization}

Details about the ${ }^{1} \mathrm{H}$ NMR and GPC data of $c P E G-p(C B A-A B O L)$ have been described in Chapter 5.

\subsection{Preparation of $c P E G-p(C B A-A B O L) / A G B B B 5 A$ nanoparticles}

Since the peptide AGBBB5A is poorly soluble in aqueous solution, $40 \%$ of EtOH was added in order to increase its solubility.

We investigated the feasibility of nanoparticle formation between the $c P E G-p(C B A-A B O L)$ polymer and the AGBBB5A peptide by varying the polymer/peptide weight ratios in order to obtain nanosystems with optimal properties in terms of particle size, surface charge, loading efficiency and stability. cPEG-p(CBA-ABOL)/AGBBB5A nanoparticles were prepared at different polymer/peptide weight ratios ranging from $2 / 1$ to $48 / 1$ by adding a PBS solution $(10 \mathrm{mM}, \mathrm{pH} 7.4)$ of polymer $(800 \mu \mathrm{l})$ to a PBS/EtOH solution $(3 / 2, \mathrm{v} / \mathrm{v})$ of AGBBB5A (200 $\mu \mathrm{l}, 2 \mathrm{mg} / \mathrm{ml})$. DLS measurements showed that by increasing the polymer/peptide weight ratio, the particle size decreases to reach a plateau value at weight ratios higher than 12/1 with particle sizes of ca. $200 \mathrm{~nm}$ (data not shown). These results show that at weight ratios higher than $12 / 1$ there is enough polymer to efficiently 
encapsulate the peptide. Higher polymer/peptide ratios would introduce an excess of cationic polymer in solution, which might induce cytotoxicity (data not shown).

Based on these results and the experience of former SS-PAA/protein nanoparticles using for instance $\beta$-galactosidase as protein payload [41], we chose for this study to prepare all the cPEG-p(CBA-ABOL)/AGBBB5A nanoparticles at polymer/peptide weight ratio 12/1. cPEG-p(CBA-ABOL)/AGBBB5A nanoparticle solutions were prepared by adding a PBS solution (10 mM, pH 7.4) of cPEG-p(CBA-ABOL) $(800 \mu l, 6 \mathrm{mg} / \mathrm{ml})$ to a PBS/EtOH solution $(3 / 2 \mathrm{v} / \mathrm{v})$ of peptide AGBBB5A $(200 \mu \mathrm{l}, 2 \mathrm{mg} / \mathrm{ml})$, corresponding to a polymer/peptide weight ratio $12 / 1$, followed by vortexing for 5 seconds and incubating at room temperature for 30 minutes.

\subsection{Characterization of $c P E G-p(C B A-A B O L) / A G B B B 5 A$ nanoparticles}

\subsubsection{Particle size and zeta-potential measurements}

Particle size and zeta potential measurements of the nanocomplexes were determined by dynamic light scattering (DLS) at $25^{\circ} \mathrm{C}$ with a Zetasizer Nano ZS (Malvern Instruments, Malvern, UK) using a wavelength of $532 \mathrm{~nm}$. The values of both size and zeta potential were recorded as the mean of three measurements.

\subsubsection{Peptide condensation and loading efficiency}

A capillary LC/MS setup consisting of an Ultimate 3000 System (Dionex, LC Packings) coupled to a TSQ Quantum Ultra AM mass spectrometer (Thermo Finnigan) was used for specific detection of the AGBBB5A peptide in the nanoparticle formulation to identify the preservation of the peptide integrity and the loading efficiency. The chromatographic setup consisted of a C3 reversed phase precolumn (Zorbax SB-C3, $5 \times 0.5 \mathrm{~mm}$ ) in combination with a C4 reversed phase analytical column (ACE 4, $250 \times 0.3 \mathrm{~mm}$ ). Sample loading was performed at $100 \mu \mathrm{l} / \mathrm{min}$; elution at $4 \mu \mathrm{l} / \mathrm{min}$. Chromatographic separation was carried out at $50^{\circ} \mathrm{C}$. Acetonitrile-water mobile phases with $1 \%$ acetic acid and $0.05 \%$ TFA were used for sample loading, for sample elution $0.1 \%$ formic acid was used as mobile phase additive. Detection was performed in positive ESI mode with a nanoESI source using SRM (891.6-341.1, 412.2 and 608.3 for AGBBB5A, 880.5-412.2, 341.1 and 952.4 for the internal standard AGBBB5D). Prior to LC/MS analysis, the nanoparticle formulation was prepared freshly as previously described (see 2.5). Sample preparation included the dilution to $20000 \mathrm{ng} / \mathrm{ml}$ using $8 \%$ ethanol in PBS, followed by a dilution to $800 \mathrm{ng} / \mathrm{ml}$ using $0.5 \%$ human serum albumin in loading mobile phase (ACN: $\mathrm{H}_{2} \mathrm{O}: \mathrm{AA}: \mathrm{TFA}$ 
5:95:1:0.05 (v:v)). Finally $10 \mu \mathrm{l}$ of TCEP solution $(100 \mathrm{mM})$ and $10 \mu \mathrm{l}$ of internal standard (15 $\mathrm{\mu g} / \mathrm{ml}$ AGBBB5D in 0.5\% human serum albumin in loading mobile phase) was added to $180 \mu \mathrm{l}$ of the diluted solution and incubated at $60^{\circ} \mathrm{C}$ for $20 \mathrm{~min}$ in order to ensure that the total amount of the peptide in the formulation is measured. A pure AGBBB5A peptide solution was treated analogously in order to serve as a reference standard.

To estimate the loading efficiency of the nanoparticles at neutral $\mathrm{pH}$, particle solutions of the nanoparticles were centrifuged at $16100 \mathrm{~g}$ for 20 minutes at room temperature. Aliquots of supernatant were subsequently taken and their protein content determined by the LC/MS technique previously described. The actual loading efficiency was indirectly determined by measuring the difference between the total amount of AGBBB5A added to the solution and the amount of AGBBB5A in the free form in the supernatant.

\subsection{Cell experiments}

For the cell experiments described in the following sections, human cerebral microvascular endothelial cells (hCMEC/D3) were used as a model cell line to evaluate the cPEG-p(CBA-ABOL)/AGBBB5A nanoparticles as carrier for the delivery to the brain.

Cell lines like hCMEC are cells that are immortalized, and some important cell specific properties of primary cells are not present anymore in this type of cells (as contact inhibition for instance). Therefore, we also used in this study human umbilical vein endothelial cells (Huvec), which are primary cells expressing the proteins pronounced before the isolation from human tissue. We used these primary cells for limited amount of time (the cells were grown only for three passages) to ensure that they more closely mimic the in vivo situation.

\subsubsection{Detection of cell viability and cytotoxicity after treatment with AGBBB5A nanoparticles}

15,000 Huvec or hCMEC/D3 cells were seeded onto fibronectin-coated 96-well plates and were cultured to confluence using endothelial growth medium-2 (EGM-2) with supplements from the EGM-2 Single Quots kit (both Lonza, Verviers, Belgium), 5\% additional Fetal Bovine Serum (Sigma Aldrich, Germany) and 1\% (v/v) 10,000 U/ml penicillin and 10,000 U/ml streptomycin (Invitrogen Corporation, Germany). Cells were treated for 4 and 24 hours with increasing concentrations of nanoparticle solutions ( 0 to $500 \mu \mathrm{g} / \mathrm{ml}$ ), which were diluted in the cell culture medium. The cell viability was measured by using the CellTiter $96 \mathrm{AQ}_{\text {ueous }}$ non-radioactive assay (Promega, Mannheim, 
Germany) according to the instructions from the manufacturer. The supernatant from nanoparticle-treated and untreated cells was removed and the cells were incubated with $100 \mu \mathrm{l}$ cell medium/MTS-substrate solution at $37^{\circ} \mathrm{C}$ for 45 minutes. The amount of the formazan product was determined by measuring the absorbance in a microplate reader at 492 nm (GeniosPlus, Tecan, Männedorf, Switzerland).

$\mathrm{LDH}$ release of nanoparticle-treated untreated control cells into the supernatant was detected by CytoTox 96 non-radioactive cytotoxicity assay (Promega, Mannheim, Germany) and was used as recommended by the manufacturer. An increased amount of LDH in the supernatant is an indicator for cytotoxicity. The release of LDH of untreated cells was used as control (spontaneous release), the LDH activity of lysed cells were set to $100 \%$.

\subsubsection{Uptake of nanoparticles into human endothelial cell types}

hCMEC/D3 and Huvec cells were seeded onto fibronectin-coated Ibidi $\mu$-slide chambers (Ibidi, Martinsried, Germany) and were treated with $250 \mu \mathrm{g} / \mathrm{ml}$ nanoparticle suspension for 24 hours. After removing the supernatant, cells were washed extensively with $1 \mathrm{M}$ HEPES including $0.2 \% \mathrm{BSA}$ and then fixed with $3.7 \%$ paraformaldehyde (Merck, Darmstadt, Germany) in CS-buffer (0.1 M PIPES, 1mM EGTA, 4\% Polyethylenglycol-8000, $0.1 \mathrm{M} \mathrm{NaOH}, \mathrm{pH}$ 7.0) at room temperature for 20 minutes. After washing cells with PBS, cell membranes were stained with mouse anti-human CD31 antibody (DakoCytomation, Glostrup, Denmark) and the appropriate secondary antibody (goat anti-mouse Alexa546; Molecular Probes, Carlsbad, USA). Afterwards, cell nuclei were stained with Hoechst dye (Sigma-Aldrich, St. Luis, USA). Stained cells were mounted with Ibidi mounting media (Ibidi, Martinsried, Germany) and images were collected using a fluorescent microscope (Olympus IX71 with Delta Vision, Olympus, Germany). In this way, the location of the peptide from the cPEG-p(CBA-ABOL)/AGBBB5A nanoparticles (green) could be observed with respect to the cell membrane (red) and the cell nuclei (blue).

\section{Results and discussion}

\subsection{Synthesis and characterization of $c P E G-p(C B A-A B O L)$}

In this study, cPEG-p(CBA-ABOL) (see structure in Figure 9.2), a bioreducible SS-PAA polymer with repetitive disulfide linkages in their main chain was synthesized via Michael-type addition of the primary amine monomers, $\mathrm{ABOL}$ and $\mathrm{CPEG}-\mathrm{NH}_{2}$, to $\mathrm{CBA}$, as described in Chapter 5.

As been described in Chapter 5, the hydroxybutyl side groups originating from the $A B O L$ 
units favorably contribute to the efficiency in DNA transfection, presumably by increasing the endosomolytic properties [39]. cPEG side chains are included to induce a stealth effect. This stealth effect is disabled when the drug carrier reaches a reductive environment, due to the cleavage of the multiple disulfide linkages in the main chain of the polymer, as is present in the intracellular milieu.

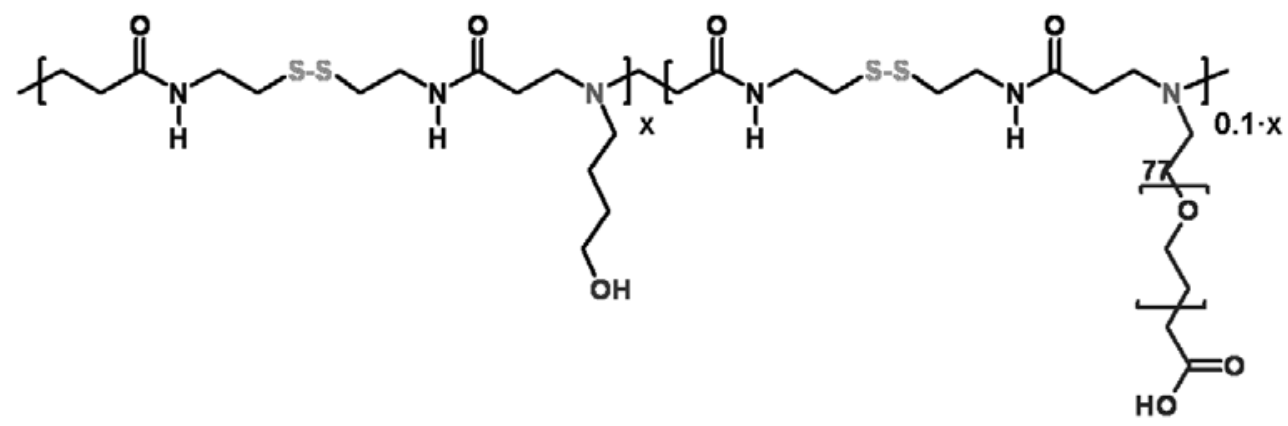

Figure 9.2. Structure of $c P E G-p(C B A-A B O L)$ synthesized by Michael-type polyaddition of a $C B A$, $\mathrm{ABOL}$ and $\mathrm{CPEG}-\mathrm{NH}_{2}$.

Details about the synthesis and the ${ }^{1} \mathrm{H}$ NMR and GPC data of cPEG-p(CBA-ABOL) are available in Chapter 5.

\subsection{Peptide condensation in nanoparticles: physical characterization and loading efficiency}

At physiological $\mathrm{pH}(\mathrm{pH}$ 7.4), interaction between the cPEG-p(CBA-ABOL) polymer and the AGBBB5A peptide can be expected, as depicted in Scheme 9.1. 


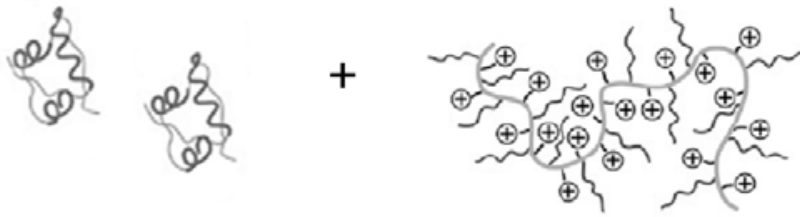

Peptide

AGBBB5A

$(20 \mathrm{w} / \mathrm{w} \%)$

\section{PAA polymer $(80 \mathrm{w} / \mathrm{w} \%)$}

charge attraction

self-assembly

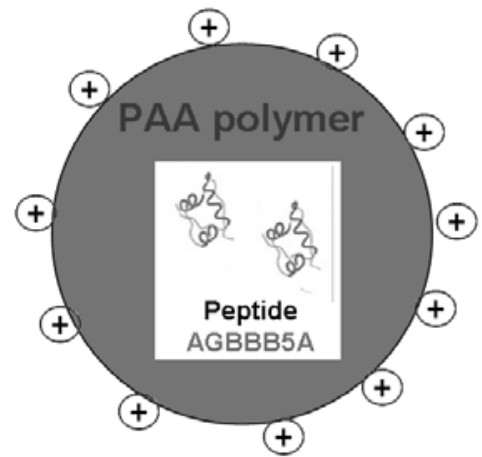

Cartoon 1

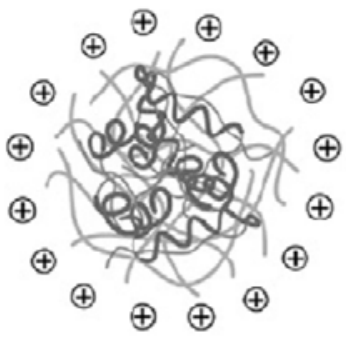

Cartoon 2

Scheme 9.1. Self-assembly formation of nanocomplexes at neutral $\mathrm{pH}$ between the AGBBB5A peptide, and the cPEG-p(CBA-ABOL) polymer

DLS and zeta-potential measurements showed that cPEG-p(CBA-ABOL) is capable to form nanosized complexes by self-assembly with AGBBB5A. The particles have sizes of ca. 200 $\mathrm{nm}$ with low polydispersity (PDI 0.25) and slightly positive surface charge (ca. $5 \mathrm{mV}$ ), in 10 mM PBS buffer solution pH 7.4 (Table 9.1).

Table 9.1. Nanoparticle characterization in terms of particle size, surface charge (zeta-potential) and peptide loading efficiency of cPEG-p(CBA-ABOL)/AGBBB5A nanoparticles measured at polymer/peptide weight ratio 12/1.

\begin{tabular}{|c|c|c|}
\hline $\begin{array}{c}\text { Particle size } \\
(\mathrm{nm})\end{array}$ & $\begin{array}{c}\text { Zeta-potential } \\
(\mathrm{mV})\end{array}$ & $\begin{array}{c}\text { AGBBB5A } \\
\text { loading } \\
\text { efficiency }(\%)^{*}\end{array}$ \\
\hline $201 \pm 1$ & $6.6 \pm 0.2$ & 65 \\
\hline
\end{tabular}

* Percentage of AGBBB5A that is incorporated in the cPEG-p(CBA-ABOL)/AGBBB5A nanoparticles (+/- 1). Initial AGBBB5A concentration is $0.4 \mathrm{mg} / \mathrm{ml}$.

LC/MS spectrometry experiments were run to identify the preservation of the AGBBB5A 
peptide integrity in the nanoparticles. The results from these experiments, summed up in Table 9.2, show that the investigated nanoparticles correspond well with the reference AGBBB5A solution. Therefore, no significant loss or degradation of AGBBB5A was detected after preparation of the nanoparticles, indicating that the intact AGBBB5A peptide is present in the nanoparticle formulation.

Table 9.2. Evaluation of AGBBB5A loading in the cPEG-p(CBA-ABOL)/AGBBB5A nanoparticles by $\mathrm{LC} / \mathrm{MS}$ analysis, in comparison to standard solutions of AGBBB5A.

\begin{tabular}{|c|c|c|c|}
\hline & Reference & $\begin{array}{c}\text { Free } \\
\text { AGBBB5A } \\
\text { solution }\end{array}$ & $\begin{array}{c}\text { cPEG-p(CBA-ABOL) } \\
\text { /AGBBB5A } \\
\text { nanoparticles }\end{array}$ \\
\hline $\begin{array}{c}\text { Relative } \\
\text { area ratio* }\end{array}$ & $100 \pm 11$ & $103 \pm 11$ & $101 \pm 6$ \\
\hline
\end{tabular}

* Relative peak area ratio: (sample value)/(mean of reference value)

\subsection{Cytotoxicity and in vitro cellular uptake}

\subsubsection{Cytotoxicity}

The effect of cPEG-p(CBA-ABOL)/AGBBB5A nanoparticles on the cell viability of Huvec and hCMEC/D3 was determined by MTS assay after various incubation times.

It was demonstrated that the cPEG-p(CBA-ABOL)/AGBBB5A nanoparticles, even at higher concentrations $(500 \mu \mathrm{g} / \mathrm{ml})$ did not affect cell viability after treatment for 4 and 24 hours (see Figure 9.3). 

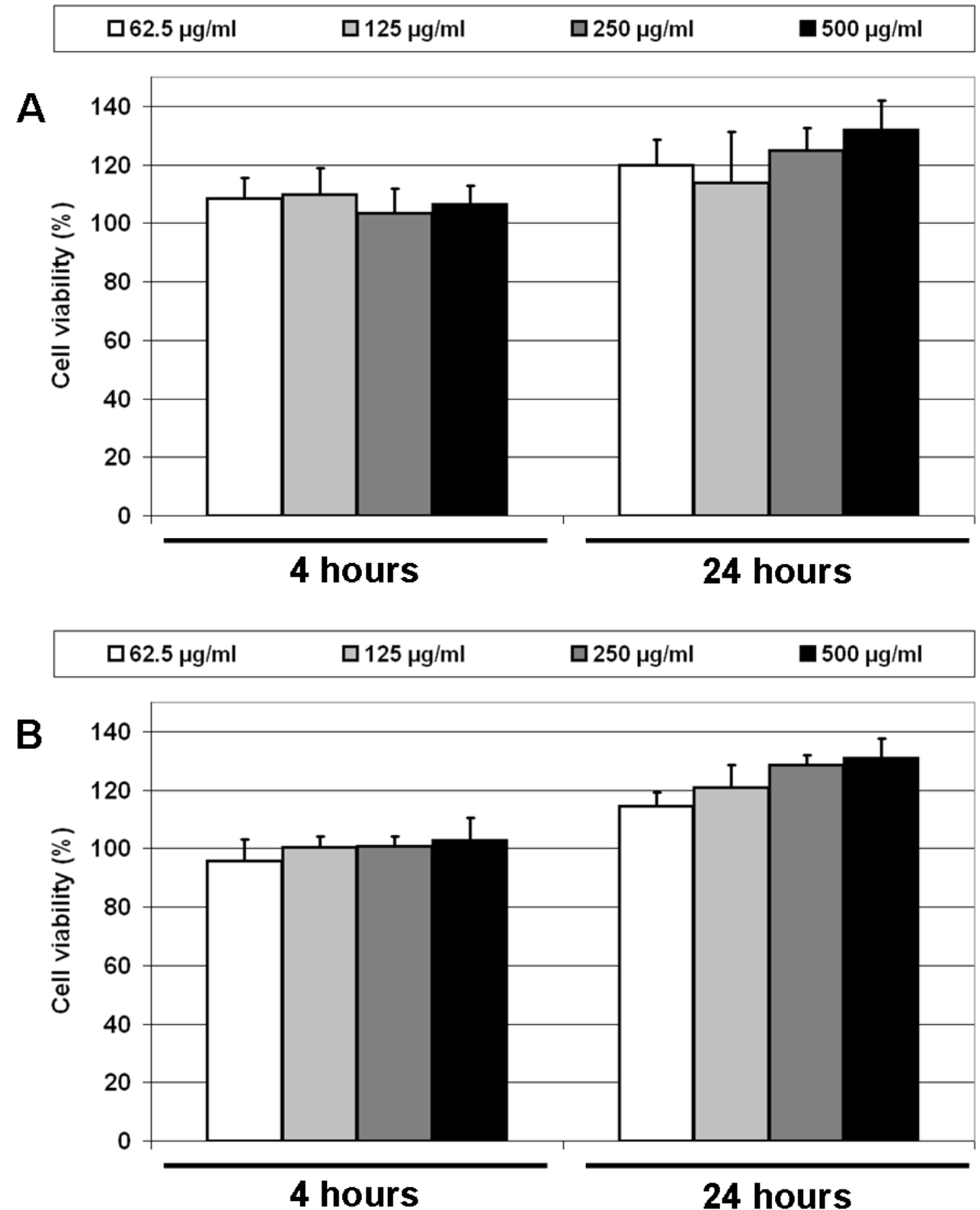

Figure 9.3. Determination of cell viability of different endothelial cells after exposure to PAA/AGBBB5A nanoparticles after 4 and 24 hours. After the treatment of hCMEC/D3 (A) and Huvec (B) with different concentrations of cPEG-p(CBA-ABOL)/AGBBB5A nanoparticles. Cell viability was detected by MTS assay after 4 and 24 hours. The viability of the untreated control cells was set to $100 \%$ viability. The results represent the means of three different experiments each performed in triplicates ( \pm standard deviation; $n \geq 6$ ).

Besides the cell viability measured by the formation of formazan, cytotoxicity was also not induced, as determined by measuring the LDH content in the supernatant (Figure 9.4). Due to the unchanged level of LDH level in the treated samples even after 24 hours, no cytotoxicity could be measured in hCMEC/D3 as well as in the primary cells (Huvec), 
which cell line is the one mimicking the most the in vivo situation.
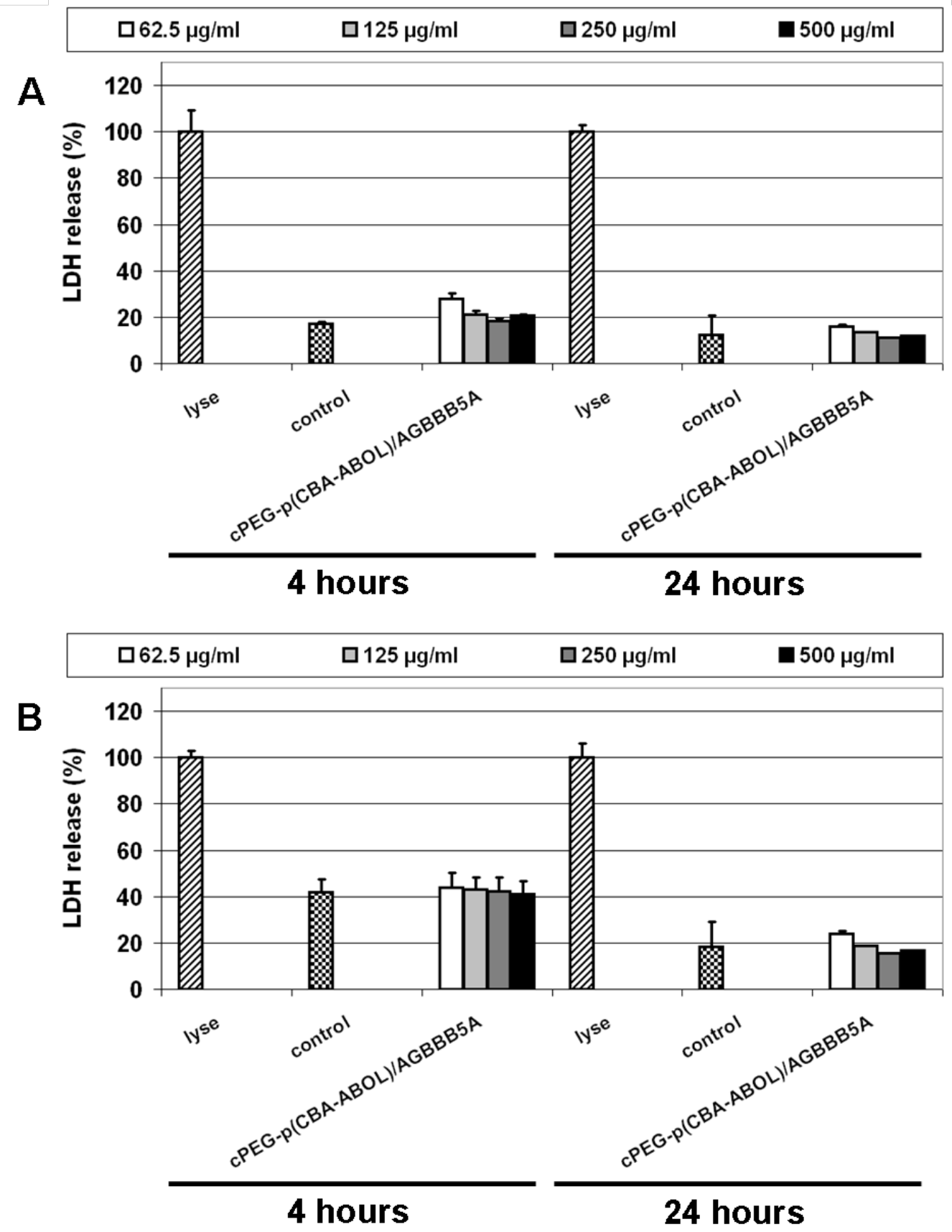

Figure 9.4. Cytotoxicity of (A) hCMEC/D3 and (B) Huvec endothelial cells after 4 and 24 hours treatment with different concentrations of cPEG-p(CBA-ABOL)/AGBBB5A nanoparticles. After the treatment of $\mathrm{hCMEC} / \mathrm{D} 3$ (A) and Huvec (B) cells with different concentrations of cPEG-p(CBA-ABOL)/AGBBB5A nanoparticles, cytotoxicity was determined by LDH assay after 4 and 24 hours. The LDH content after cell lyses was set to $100 \%$. The untreated control represents the spontaneous release of LDH into the supernatant. The results represent the means of three different experiments each performed triplicates ( \pm standard deviation; $n \geq 6$ ) 


\subsubsection{Uptake and compartmental localization of polymer/protein nanoparticles}

To determine if the AGBBB5A peptide incorporated in the cPEG-p(CBA-ABOL) nanoparticles is internalized in the endothelial cells, confluent hCMEC/D3 and Huvec cells were treated for 24 hours with solutions of free AGBBB5A peptide and cPEG-p(CBA-ABOL)/AGBBB5A nanoparticles. Representative fluorescent microscopy images of the internalized peptide $(250 \mu \mathrm{g} / \mathrm{ml})$ are depicted in Figure 9.5.

In all cases, the AGBBB5A peptide could be mostly detected within the perinuclear region of the Huvec and hCMEC/D3 cells, but was not detected within the nuclei.

From the Figures $9.5 \mathrm{~A}$ and $9.5 \mathrm{~B}$, it can be seen that free AGBBB5A peptide in solution was uptaken into both types of endothelial cells in a low extent. It is noticeable that the peptide formed small clusters inside the cells with sizes $\leq 120 \mathrm{~nm}$. This clusterization can be explained by the poor solubility of the AGBBB5A peptide in aqueous solution.

When cells were exposed to the cPEG-p(CBA-ABOL)/AGBBB5A nanoparticles, clusters of similar size were visualized into both types of endothelial cells, in a much higher amount than in the case of incubation with the free peptide, indicating an increased uptake of the nanoparticles (Figures 9.5C and 9.5D). The size of these clusters was ranging between 50 and $150 \mathrm{~nm}$, which is lower than the particle size of the cPEG-p(CBA-ABOL)/AGBBB5A nanoparticles as was determined by DLS measurements (ca. $200 \mathrm{~nm}$, see section 3.2). This indicates that these clusters can most probably also be assigned to aggregated free AGBBB5A peptide, released from the cPEG-p(CBA-ABOL) nanoparticles, rather than from intact cPEG-p(CBA-ABOL)/AGBBB5A nanoparticles. From the results of these microscopy experiments, we may conclude that, using cPEG-p(CBA-ABOL)/AGBBB5A nanoparticles as the carrier, the AGBBB5A peptide could be successfully internalized and released in both types of macrovascular endothelial cells with a much higher efficiency than incubation of these cells with free peptide. 


\section{free AGBBB5A peptide}
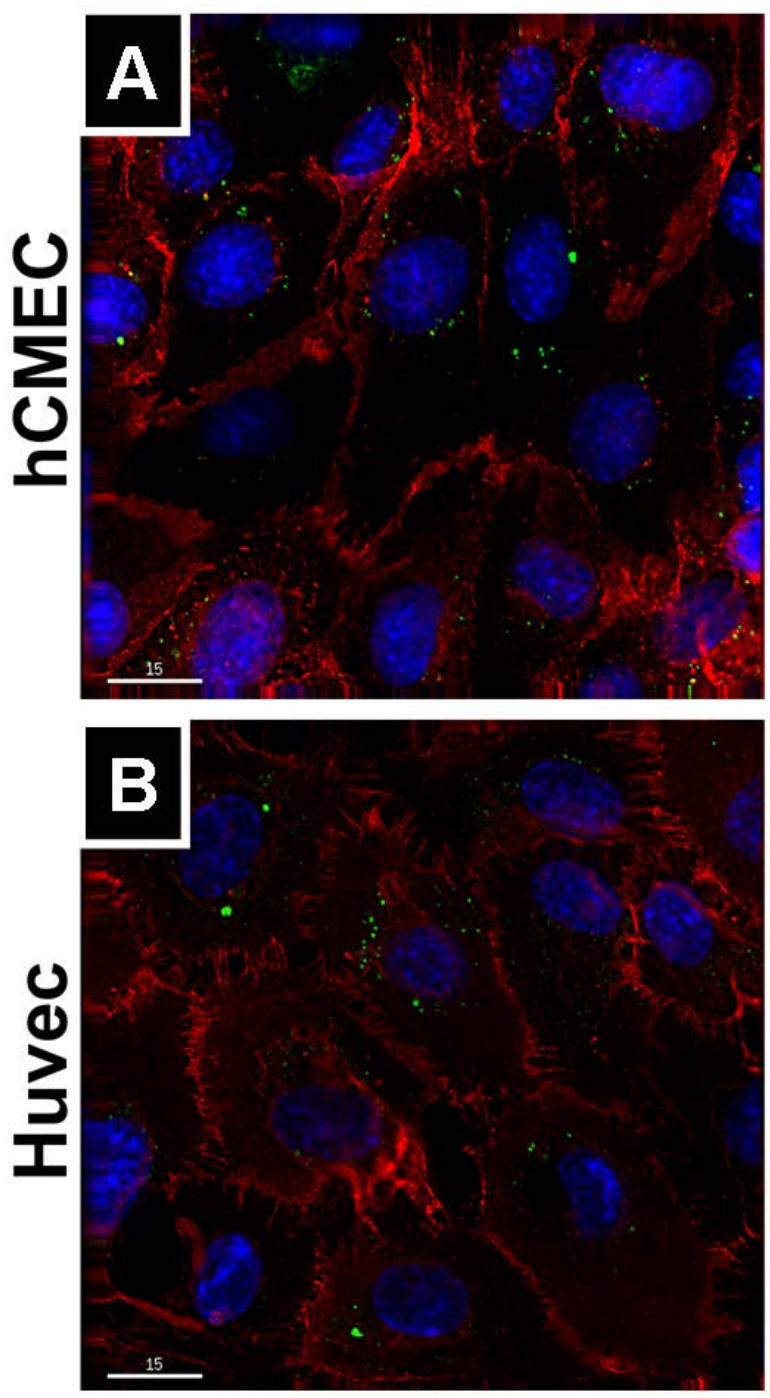

cPEG-p(CBA-ABOL)/AGBBB5A nanoparticles
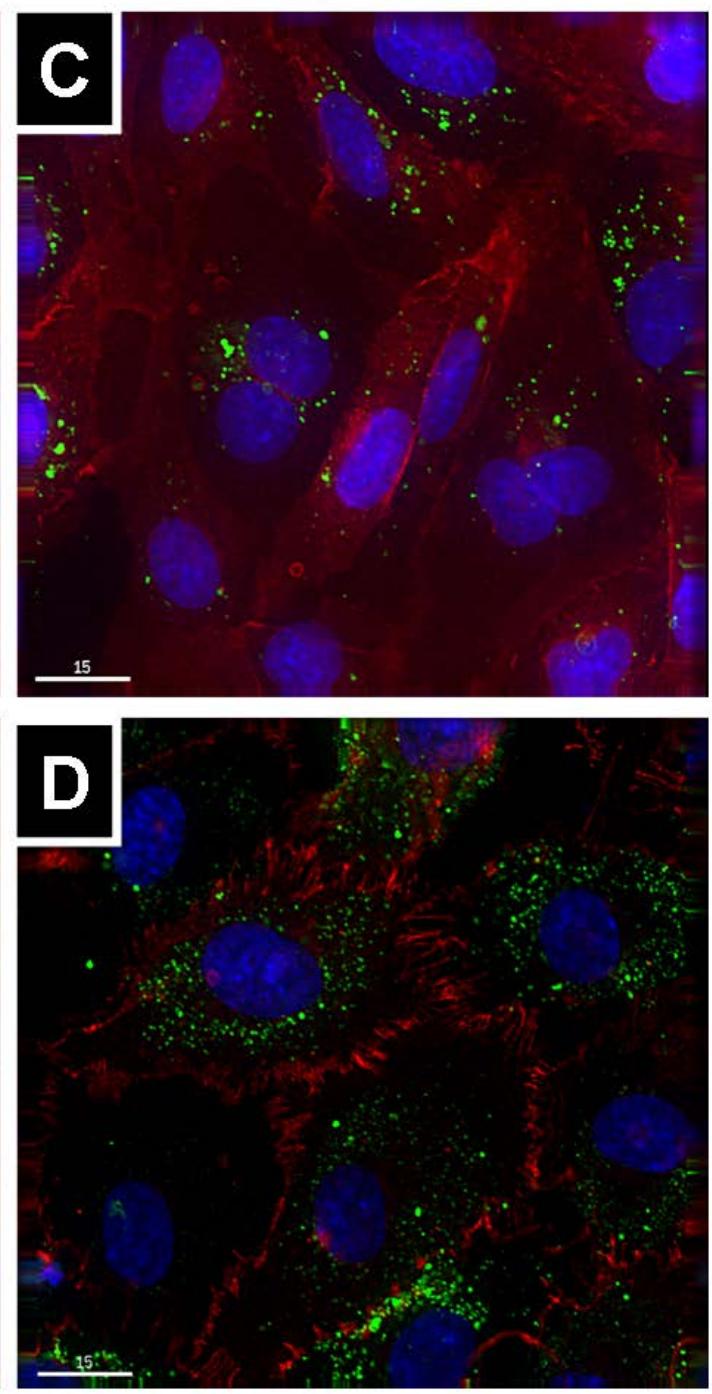

Figure 9.5. Internalization of AGBBB5A into human endothelial cells after 24 hours of treatment visualized by fluorescent microscopy. hCMEC/D3 (A, C) and Huvec $(B, D)$ cells were treated with $250 \mu \mathrm{g} / \mathrm{ml}$ of AGBBB5A peptide (A, B) or cPEG-p(CBA-ABOL)/AGBBB5A nanoparticles (C, D) for 24 hours. Cell membranes were stained in red, nuclei in blue, while the green fluorescence represents the internalized AGBBB5A from cPEG-p(CBA-ABOL)/AGBBB5A nanoparticles (Fluorescent microscopy, Delta Vision, 40x, scale bar $15 \mu \mathrm{m}$ )

\section{Conclusions}

A novel bioreducible poly(amidoamine), cPEG-p(CBA-ABOL), was synthesized and evaluated as carrier for the delivery of peptides in endothelial cells. The linear polymer efficiently condensed AGBBB5A, a model peptide, into nanoscaled complexes.

No cytotoxicity effect was caused by cPEG-p(CBA-ABOL)/AGBBB5A nanoparticles to Huvec 
and hCMEC/D3 endothelial cells as was assessed by the MTS and LDH assays. Using cPEG-p(CBA-ABOL)/AGBBB5A nanoparticles as the carrier, the AGBBB5A peptide could be successfully internalized in both macrovascular endothelial cells (Huvec) and in microvascular endothelial cells from the brain (hCMEC/D3). Therefore, the polymer $c P E G-p(C B A-A B O L)$ shows significant promise as carrier and intracellular delivery agent for the delivery of peptides to endothelial cells of the brain. However; further investigations have to be done to verify if transport over the BBB might be possible.

\section{Acknowledgements}

This research work is part of the European FP6 IP NanoBioPharmaceutics.

\section{References}

[1] A. Balasubramaniam, Clinical potentials of neuropeptide $Y$ family of hormones. Am. J. Surg. 183(4) (2002) 430-434.

[2] A. Binaschi, G. Bregola, M. Simonato, On the role of somatostatin in seizure control: Clues from the hippocampus. Rev. Neurosci. 14(3) (2003) 285-301.

[3] A. Strohle, F. Holsboer, Stress responsive neurohormones in depression and anxiety. Pharmacopsychiatry 36 (2003) S207-S214.

[4] S.J. Claes, Corticotropin-releasing hormone (CRH) in psychiatry: from stress to psychopathology. Ann. Med. 36(1) (2004) 50-61.

[5] P. Datar, S. Srivastava, E. Coutinho, G. Govil, Substance P: Structure, function, and therapeutics. Curr. Top. Med. Chem. 4(1) (2004) 75-103.

[6] L. Gentilucci, New trends in the development of opioid peptide analogues as advanced remedies for pain relief. Curr. Top. Med. Chem. 4(1) (2004) 19-38.

[7] G.W. Goldstein, A.L. Betz, The Blood-Brain-Barrier. Sci.Am. 255(3) (1986) 74-83.

[8] B. Schlosshauer, The Blood-Brain-Barrier - Morphology, Molecules, and Neurothelin. Bioessays 15(5) (1993) 341-346.

[9] W.M. Pardridge, Blood-brain barrier biology and methodology. J. Neurovirol. 5(6) (1999) 556-569.

[10] N.J. Abbott, L. Ronnback, E. Hansson, Astrocyte-endothelial interactions at the blood-brain barrier. Nat. Rev. Neurosci. 7(1) (2006) 41-53.

[11] E.H. Lo, A.B. Singhal, V.P. Torchilin, N.J. Abbott, Drug delivery to damaged brain. Brain Res. Rev. 38(1-2) (2001) 140-148.

[12] E. Garcia-Garcia, K. Andrieux, S. Gil, P. Couvreur, Colloidal carriers and blood-brain barrier (BBB) translocation: A way to deliver drugs to the brain? Int. J. Pharm. 298(2) (2005) 274-292.

[13] Q.R. Smith, S.I. Rapoport, Cerebrovascular Permeability Coefficients to Sodium, Potassium, and Chloride. J. Neurochem. 46(6) (1986) 1732-1742.

[14] N. Bodor, P. Buchwald, Recent advances in the brain targeting of neuropharmaceuticals by chemical delivery systems. Adv. Drug Deliv. Rev. 36(2-3) (1999) 229-254.

[15] W.M. Pardridge, The blood-brain barrier: Bottleneck in brain drug development. NeuroRx 2(1) (2005) 3-14.

[16] V.A. Levin, Relationship of Octanol-Water Partition-Coefficient and Molecular-Weight to Rat-Brain Capillary-Permeability. J. Med. Chem. 23(6) (1980) 682-684.

[17] W.M. Pardridge, Drug and gene delivery to the brain: The vascular route. Neuron 36(4) (2002) 555-558.

[18] J. Kreuter, Nanoparticulate systems for brain delivery of drugs. Adv. Drug Delivery Rev. 47(1) (2001) 65-81. 
[19] P. Ramge, R.E. Unger, J.B. Oltrogge, D. Zenker, D. Begley, J. Kreuter, H. von Briesen, Polysorbate-80 coating enhances uptake of polybutylcyanoacrylate (PBCA)-nanoparticles by human and bovine primary brain capillary endothelial cells. Eur. J. Neurosci. 12(6) (2000) 1931-1940.

[20] J. Kreuter, P. Ramge, V. Petrov, S. Hamm, S.E. Gelperina, B. Engelhardt, R. Alyautdin, H. von Briesen, D.J. Begley, Direct evidence that polysorbate-80-coated poly ( butylcyanoacrylate) nanoparticles deliver drugs to the CNS via specific mechanisms requiring prior binding of drug to the nanoparticles. Pharm. Res. 20(3) (2003) 409-416.

[21] J. Kreuter, Influence of the surface properties on nanoparticle-mediated transport of drugs to the brain. J. Nanosci. Nanotechnol. 4(5) (2004) 484-488.

[22] C.X. Wang, L.S. Huang, L.B. Hou, L. Jiang, Z.T. Yan, Y.L. Wang, Z.L. Chen, Antitumor effects of polysorbate- 80 coated gemcitabine polybutylcyanoacrylate nanoparticles in vitro and its pharmacodynamics in vivo on C6 glioma cells of a brain tumor model. Brain Res. 1261 (2009) 91-99.

[23] K. Tahara, Y. Miyazaki, Y. Kawashima, J. Kreuter, H. Yamamoto, Brain targeting with surface-modified poly(d,I-lactic-co-glycolic acid) nanoparticles delivered via carotid artery administration. Eur. J. Pharm. Sci. (2010) doi:10.1016/j.ejpb.2010.11.002

[24] S. Gelperina, O. Maksimenko, A. Khalansky, L. Vanchugova, E. Shipulo, K. Abbasova, R. Berdiev, S. Wohlfart, N. Chepurnova, J. Kreuter, Drug delivery to the brain using surfactant-coated poly(lactide-co-glycolide) nanoparticles: Influence of the formulation parameters. Eur. J. Pharm. Sci. 74(2) (2010) 157-163.

[25] P. Calvo, C. RemunanLopez, J.L. VilaJato, M.J. Alonso, Novel hydrophilic chitosan-polyethylene oxide nanoparticles as protein carriers. J. Appl. Polym. Sci. 63(1) (1997) 125-132.

[26] A. Harada, K. Kataoka, Novel polyion complex micelles entrapping enzyme molecules in the core: Preparation of narrowly-distributed micelles from lysozyme and poly(ethylene glycol)-poly(aspartic acid) block copolymer in aqueous medium. Macromolecules 31(2) (1998) 288-294.

[27] A. Jintapattanakit, V.B. Junyaprasert, S. Mao, J. Sitterberg, U. Bakowsky, T. Kissel, Peroral delivery of insulin using chitosan derivatives: A comparative study of polyelectrolyte nanocomplexes and nanoparticles. Int. J. Pharm. 342(1-2) (2007) 240-249.

[28] Y. Lee, S. Fukushima, Y. Bae, S. Hiki, T. Ishii, K. Kataoka, A protein nanocarrier from charge-conversion polymer in response to endosomal pH. J. Am. Chem. Soc. 129(17) (2007) 5362-5363.

[29] P. Ferruti, M.A. Marchisio, R. Barbucci, Synthesis, Physicochemical Properties and Biomedical Applications of Poly(Amido-Amine)S. Polymer 26 (1985) 1336-1348.

[30] P. Ferruti, M.A. Marchisio, R. Duncan, Poly(amido-amine)s: Biomedical applications. Macromol. Rapid Commun. 23(5-6) (2002) 332-355.

[31] O. Boussif, F. Lezoualch, M.A. Zanta, M.D. Mergny, D. Scherman, B. Demeneix, J.P. Behr, A Versatile Vector for Gene and Oligonucleotide Transfer into Cells in Culture and in-Vivo Polyethylenimine. Proc. Natl. Acad. Sci. U. S. A. 92(16) (1995) 7297-7301.

[32] C.X. Wu, S.L. Lo, J. Boulaire, M.L.W. Hong, H.M. Beh, D.S.Y. Leung, S. Wang, A peptide-based carrier for intracellular delivery of proteins into malignant glial cells in vitro. J Control Release 130(2) (2008) 140-145.

[33] J.D. Eichman, A.U. Bielinska, J.F. Kukowska-Latallo, J.R. Baker Jr, The use of PAMAM dendrimers in the efficient transfer of genetic material into cells. Pharmaceutical Science and Technology Today 3(7) (2000) 232-245.

[34] E. Ranucci, G. Spagnoli, P. Ferruti, D. Sgouras, R. Duncan, Poly(amidoamine)s with potential as drug carriers: degradation and cellular toxicity. J Biomater Sci Polymer Ed 2(4) (1991) 303-315.

[35] J. Franchini, E. Ranucci, P. Ferruti, Synthesis, physicochemical properties, and preliminary biological characterizations of a novel amphoteric agmatine-based poly(amidoamine) with RGD-like repeating units. Biomacromolecules 7(4) (2006) 1215-1222.

[36] C. Lin, C.-J. Blaauboer, M.M. Timoneda, M.C. Lok, M. van Steenbergen, W.E. Hennink, Z. Zhong, J. Feijen, J.F.J. Engbersen, Bioreducible poly(amido amine)s with oligoamine side 
chains: Synthesis, characterization, and structural effects on gene delivery. J Control Release 126(2) (2008) 166-174.

[37] C. Lin, Z. Zhong, M.C. Lok, X. Jiang, W.E. Hennink, J. Feijen, J.F.J. Engbersen, Linear poly(amido amine)s with secondary and tertiary amino groups and variable amounts of disulfide linkages: Synthesis and in vitro gene transfer properties. J Control Release 116(2) (2006) 130-137.

[38] C. Lin, Z. Zhong, M.C. Lok, X. Jiang, W.E. Hennink, J. Feijen, J.F.J. Engbersen, Random and block copolymers of bioreducible poly(amido amine)s with high- and low-basicity amino groups: Study of DNA condensation and buffer capacity on gene transfection. J Control Release 123(1) (2007) 67-75.

[39] C. Lin, Z.Y. Zhong, M.C. Lok, X.L. Jiang, W.E. Hennink, J. Feijen, J.F.J. Engbersen, Novel bioreducible poly(amido amine)s for highly efficient gene delivery. Bioconjugate Chem. 18(1) (2007) 138-145.

[40] M.A. Mateos-Timoneda, M.C. Lok, W.E. Hennink, J. Feijen, J.F.J. Engbersen, Poly(amido amine)s as gene delivery vectors: Effects of quaternary nicotinamide moieties in the side chains. ChemMedChem 3(3) (2008) 478-486.

[41] G. Coué, J.F.J. Engbersen, Functionalized linear poly(amidoamine)s are efficient vectors for intracellular protein delivery. J Control Release (2011), doi:10.1016/j.jconrel.2011.01.023.

[42] F.H. Meng, W.E. Hennink, Z. Zhong, Reduction-sensitive polymers and bioconjugates for biomedical applications. Biomaterials 30(12) (2009) 2180-2198.

[43] K.C. Rajender, W.L. Frederick, H.K. Michael, M.B. David, G.B.R. Robert, R. Daniel, Plasma cysteine, cystine, and glutathione in cirrhosis. Gastroenterology 87(4) (1984) 770-776.

[44] A. Bernkop-Schnürch, Thiomers: A new generation of mucoadhesive polymers. Adv. Drug Delivery Rev. 57(11) (2005) 1569-1582.

[45] C. Lin, J.F.J. Engbersen, The role of the disulfide group in disulfide-based polymeric gene carriers. Expert Opin. Drug Deliv. 6(4) (2009) 421-439.

[46] Y. Matsuoka, Y. Jouroukhin, A.J. Gray, L. Ma, C. Hirata-Fukae, H.F. Li, L. Feng, L. Lecanu, B.R. Walker, E. Planel, O. Arancio, I. Gozes, P.S. Aisen, A neuronal microtubule-interacting agent, NAPVSIPQ, reduces tau pathology and enhances cognitive function in a mouse model of Alzheimer's disease. J. Pharmacol. Exp. Ther. 325(1) (2008) 146-153.

[47] R.R. Leker, A. Teichner, N. Grigoriadis, H. Ovadia, D.E. Brenneman, M. Fridkin, E. Giladi, J. Romano, I. Gozes, NAP, a femtomolar-acting peptide, protects the brain against ischemic injury by reducing apoptotic death. Stroke 33(4) (2002) 1085-1092.

[48] I. Gozes, B.H. Morimoto, J. Tiong, A. Fox, K. Sutherland, D. Dangoor, M. Holser-Cochav, K. Vered, P. Newton, P.S. Aisen, Y. Matsuoka, C.H. van Dyck, L. Thal, NAP: Research and development of a peptide derived from activity-dependent neuroprotective protein (ADNP). CNS Drug Rev. 11(4) (2005) 353-368.

[49] I. Gozes, I. Divinsky, I. Pilzer, M. Fridkin, D.E. Brenneman, A.D. Spier, From vasoactive intestinal peptide (VIP) through activity-dependent neuroprotective protein (ADNP) to NAP - A view of neuroprotection and cell division. J. Mol. Neurosci. 20(3) (2003) 315-322. 


\section{Chapter 10}

\section{Conclusions}

In this thesis study we designed and developed multifuctional poly(amidoamine)s (PAAs) that are capable to form self-assembled nanocomplexes with peptides and proteins and can function in this form as bioresponsive vectors for protein delivery to targeting cells in vitro and in vivo.

We have shown that representative examples of this novel family of water-soluble PAAs have very promising properties to function as vectors for highly potent and non-toxic intracellular protein delivery. The synthesis procedure of these polymers is compatible with the use of a variety of functionalized amine monomers, allowing large variation in the structure of the polymers, and tuning of the chemical and biophysical properties that are of significance for efficient protein delivery.

We have designed positively-charged PAAs that are able to form nanosized complexes at neutral $\mathrm{pH}$ by a self-assembly process with overall negatively-charged model proteins, such as $\beta$-galactosidase, human serum albumin, and human insulin. In another system, we have developed novel PAAs with negatively charged citraconic amide functionalities in the side chain as an attractive category of bioresponsive polymers capable to form stable self-assembling nanoparticles with cationic proteins such as lysozyme at neutral $\mathrm{pH}$ conditions. Both types of nanocomplexes are stable at physiological pH 7.4 for at least several days and efficiently protect protein integrity. The activity of enzymes incorporated in the nanoparticles is completely suppressed after encapsulation in the extracellular environment, and it is (almost) fully retained after release of the enzyme from the nanoparticles (i.e. no denaturation occurs). Upon acidification of the solution ( $\mathrm{pH} \sim 5$ ), as occurs after endosomal uptake, the $\mathrm{pH}$ decrease and consequently the increase of positive charge on the protein (charge shifting) or the charge-reversal in the side groups of the polymers turning from anionic (citraconic amide) to cationic (protonated amine) leads to decreased protein-polymer interaction and thus a tendency for the nanoparticles to destabilize, as evidenced by DLS from their observed increase in size. Moreover, for nanocomplexes made from PAAs containing disulfide linkages in their polymeric 
backbone (SS-PAAs), fast disintegration of the complexes and release of the protein payload is observed in reductive solution (2.5 mM DTT), mimicking the intracellular environment. Profection experiments showed that proteins encapsulated in PAA nanoparticles were successfully internalized into cells. After cellular uptake, the protein-containing nanocomplexes are dissociated and the protein is released inside the cell with remaining activity and excellent cell-viability. In addition of providing intracellular bioreduction, the presence of the disulfide groups also showed to increase the mucoadhesive properties of the nanoparticles. In the presence of mucus secreting cells, we showed that the SS-PAA-based nanocomplexes were capable to successfully internalize protein into the cell cytosol with a much higher extent than nanoparticles based on PAAs lacking disulfide linkages, proving the high mucoadhesive potency of the SS-PAA carriers. These properties render these novel polymers very promising in the development of potent intracellular protein delivery systems.

Applications of these intracellular protein carriers based on SS-PAAs were investigated for properties important for oral and nasal administration, as well as delivery to the brain. SS-PAA nanoparticles were able to protect insulin against proteolytic and chemical degradation, and to improve insulin uptake through the intestine and its hypoglycemic effect in diabetic rats, as shown by in vitro and in vivo experiments. Formulations of polyelectrolyte complexes formed by charge-attraction between functionalized linear SS-PAAs and model vaccine proteins (ovalbumin, p24) and a model peptide showed to be non-toxic and to efficiently improve their uptake in vitro in the respiratory epithelial $\mathrm{NCl}$ H441 cells and the brain endothelial hCMEC cells, respectively. Therefore, this delivery system is very promising to achieve enhanced bioavailability of proteins, for improved efficiency of antigen administration via the intranasal route and for peptide delivery to the brain.

The results described in this thesis indicate that PAAs have excellent properties which should create opportunities for novel applications in protein delivery. Further in vivo studies have to be performed to improve their potency and bioavailability. This could be for instance achieved by the inclusion of targeting molecules or peptides. 


\title{
Novel thermo-responsive polymers based on bioreducible poly(amidoamine)s
}

\author{
Grégory Coué, Sebastian Ulrich and Johan F.J. Engbersen \\ Department of Biomedical Chemistry, MIRA Institute for Biomedical Technology \& Technical \\ Medicine, Faculty of Science and Technology, University of Twente, P.O. Box 217, 7500 AE \\ Enschede, the Netherlands
}

\begin{abstract}
A series of novel thermo-responsive poly(amidoamine)s with repetitive disulfide linkages in their backbone for intracellular bioreduction (SS-PAAs) were synthesized by varying amounts of thermo-responsive groups such as NIPAAm in their architecture. The thermo-responsive and $\mathrm{pH}$-responsive properties of these polymers could be tuned by variation of the structure of the SS-PAA backbone and the amount of NIPAAm in the side groups. These water-soluble polymers efficiently condense pDNA by self-assembly into nanoscaled and positively-charged polyplexes. These thermo-responsive and biodegradable SS-PAAs show promising properties for application as thermo- and $\mathrm{pH}$-responsive systems for drug delivery.
\end{abstract}

\section{Introduction}

The structures and properties of stimuli-responsive polymers can change with environmental conditions such as temperature, $\mathrm{pH}$, and ionic strengths, which make such smart polymers interesting for various biomedical applications [1-11].

Among those, thermo-reversible polymers have attracted strong attention in the pharmaceutical industry due to their potential to act as novel carriers of therapeutic macromolecules, such as proteins and nucleic acids. The thermo-reversible character (i.e. temperature-dependent solubility) of a thermo-reversible drug delivery system allows to carry out many desired manipulations in a solution state before administration, such as 
mixing, injecting and macromolecule conjugation, but eventually enables to induce a phase separation simply by increasing the temperature above the solubility limit of the polymers.

Polymers of $\mathrm{N}$-isopropylacrylamide (PNIPAAm) have been the most commonly studied thermo-reversible polymers, and PNIPAAm-based smart micelles, hydrogels, and bioconjugates have been exploited for various biomedical applications, notably in drug delivery and tissue engineering [9-13].

A PNIPAAm homopolymer exhibits a lower critical solution temperature (LCST: temperature for soluble $\leftrightarrow$ insoluble transition) of $30-32^{\circ} \mathrm{C}$ in water [14]. The LCST is believed to represent the temperature at which hydrophobic forces (due to interaction of $-\mathrm{N}(\mathrm{H})-\mathrm{CH}\left(\mathrm{CH}_{3}\right)_{2}$ groups), causing insolubility in an aqueous environment, are balanced by $\mathrm{H}$-bonding between water and $-\mathrm{HN}-$ and $-\mathrm{C}=0$ groups that retain the polymer in solution. Above the LCST, the hydrated polymers collapse to a globular state forming micelles. The LCST of PNIPAAm can be efficiently controlled by incorporating charged units, such as methacrylic acid, as well as hydrophobic units, such as butyl methacrylates [15-17]. Therefore the LCST of PNIPAAm can be feasibly tuned to be around biological temperature [18].

Nevertheless, the non-biodegradability of PNIPAAm renders unavoidable hurdles to their applications. As an alternative, instead of radical polymerization, NIPAAm units can be grafted to biodegradable polymers. For instance, $\mathrm{Wu}$ et al. showed that NIPAAm-g-poly(aminoester)s have thermo-responsive behavior similar to PNIPAAm, even with their relatively lower density of NIPAAm units along the hydrophilic backbones. Moreover, the poly(aminoester) backbone is degradable, pH-responsive, and feasible for further applications [19]. In another example, Recillas et al. synthesized a series of chitosan-g-NIPAAm, resulting in water-soluble polymers showing thermo-reversibility with a sharp LCST [20].

Based on these results, we hypothesized that grafting of NIPAAm moieties to poly(amidoamine)s (PAAs) could introduce thermo-responsible properties to these polymers that can be exploited for biomedical applications, e.g. in temperature controlled drug delivery.

PAAs can be easily synthesized by Michael-type polyaddition of primary or secondary amines to bis(acrylamide)s [21, 22]. These polymers are water-soluble, biodegradable and biocompatible, with lower cytotoxicity profiles than other usual polycationic vectors [23-26]. PAAs have high potential in biomedical applications $[22,27]$ and have found to be 
particularly suitable for use as intracytoplasmic and endosomolytic vectors for the delivery of anticancer drugs [28, 29], proteins [30,31] and nucleic acids [32, 33]. PAAs have the advantage to degrade into oligomeric products in aqueous media within days or weeks, depending on their structure $[34,35]$. These polymers are hydrolytically much more stable than poly(aminoester)s and important improvement of the extracellular stability is obtained with these polymers. The degradation of PAAs under physiological conditions is, however, very slow and it can be expected that amide hydrolysis does not contribute to the intracellular release of macromolecules from nanoparticles made of this polymer.

In our group, we have recently developed a series of novel linear PAAs containing repetitive disulfide linkages in their backbone (SS-PAAs) that have shown to be very efficient as vectors in intracellular gene delivery. Appropriately functionalized SS-PAAs (e.g. with 4-hydroxybutyl or 4-imidazolylethyl side groups) self-assemble with DNA into nanoscaled polyplexes that show transfection efficiencies much higher than obtained with the PAA counterparts lacking the disulfide linkages, or the reference polymer, polyethylenimine (PEI) [36-40]. These polymers are relatively stable in extracellular medium but are prone to fast degradation in the reductive intracellular environment due to the cleavage of the disulfide linkages in the polymer chain [41-44]. This property can be favorably exploited in delivery systems that should be stable outside the cell but have to disintegrate into fragments of low molecular weight quickly after uptake into target cells in order to release therapeutic cargo and minimize cytotoxic effects.

The objective of this study was to include structures similar to NIPAAm in the SS-PAA structure in order to obtain SS-PAA nanoparticles with thermo-responsive behavior. The objective was to obtain materials with LCST between 20 and $37^{\circ} \mathrm{C}$, making them suitable for biomedical applications, notably for drug and gene delivery.

A series of novel SS-PAAs were synthesized with varying amounts of thermo-responsive monomer, and the thermo-responsibility of these polymers was studied. Furthermore, the capacity of these SS-PAAs to encapsulate plasmid DNA into nanoparticles was investigated.

\section{Materials and methods}

\subsection{Materials}

All monomers used for the polymer synthesis, 4-amino-1-butanol (ABOL, Aldrich), 3-amino- $N$-isopropylpropanamide hydrochloride (3ANIPAAm, Akos), 1-(2-aminoethyl) piperazine (AEP, Aldrich), and N,N'-cystaminebisacrylamide (CBA, Polysciences) were 
purchased in the highest purity available and used without further purification. $\mathrm{N}$-isopropylacrylamide (NIPAAm) was ordered from Sigma-Aldrich, and was purified three times by recristallization in $n$-hexane (Biosolve).

MES (Sigma-Aldrich), dithiothreitol (DTT, Sigma-Aldrich), triethylamine (TEA, Sigma-Aldrich), SYBR safe (Invitrogen), agarose (Eurogentec), and methanol ( $\mathrm{MeOH}$, Biosolve) were used as received. The plasmid pDNA (pCMV-LacZ, containing a bacterial LacZ gene preceded by a nuclear localization signal under control of a CMV promoter) was purchased from Plasmid Factory (Bielefeld, Germany). Deionized water (DI water) was obtained from a MilliQ-water purification system (Millipore, France).

\subsection{Synthesis of thermo-responsive SS-PAA poly(amidoamine)s}

A series of bioreducible PAA co-polymers, $p\left(C B A-A B O L_{m} / 3 A N I P P A m_{n}\right)$, indicated as SS-PAA, possess repetitive disulfide linkages in its main chain and various amounts of ABOL and 3ANIPPAm, was synthesized by Michael-type polyaddition of the primary amine monomers ABOL and 3ANIPPAm to CBA. Since the addition polymerization is a stepwise process, equal monomer ratios monomeric amine/bisacrylamide were used in the synthesis in order to obtain PAAs of highest theoretical molecular weight. The amine monomeric ratio $\mathrm{m} / \mathrm{n}$ of $\mathrm{ABOL}$ and 3ANIPPAm used were $\mathrm{m} / \mathrm{n}=100 / 0,50 / 50$, and 25/75. For each polymerization, 10. $\mathrm{m} \mathrm{mmol}$ of ABOL and 10. $\mathrm{n}$ mmol of 3ANIPPAm were added into a brown reaction flask and dissolved in $\mathrm{MeOH} / \mathrm{DI}$ water mixture $(5 \mathrm{ml}, 4 / 1 \mathrm{v} / \mathrm{v})$. Since 3ANIPPAm was supplied in the protonated ammonium state, an equimolar amount of the base TEA was added to the polymerization mixture to ensure the presence of unprotonated 3ANIPPAm as reactive primary amine.

All polymerizations were carried out under magnetic stirring in the dark at $45^{\circ} \mathrm{C}$ under nitrogen atmosphere. The reaction mixture became homogeneous in less than two hours. The reaction was allowed to proceed for 10-14 days yielding to a viscous solution. During the polymerization a gradual increase in viscosity was observed. In all cases gelation did not occur. In a final stage, $10 \mathrm{~mol} \%$ excess $\mathrm{ABOL}(0.09 \mathrm{~g}, 1 \mathrm{mmol})$ was added to the reaction mixture and stirring was continued for two days at $45^{\circ} \mathrm{C}$ in order to ensure that all potentially toxic acrylamide end groups are consumed and the polymers contain only amino end groups. Subsequently, the resulting solution was diluted with $30 \mathrm{ml}$ DI water, acidified with $4 \mathrm{M} \mathrm{HCl}$ aqueous solution to $\mathrm{pH} \sim 5$, and then purified and isolated by ultrafiltration operation ( $3 \mathrm{~kg} / \mathrm{mol}$ cut-off) with filtrated acidic DI water ( $\mathrm{pH} \sim 5$ ), followed by freeze-drying. 
Another SS-PAA polymer, NIPAAm-g-p(CBA-AEP), was synthesized via the synthesis of $p(C B A-A E P)$ followed by grafting with NIPAAm. To this end, $p(C B A-A E P)$ was synthesized by Michael-type polyaddition of the secondary amine monomer AEP to CBA in equimolar AEP/CBA ratio. Therefore, CBA (0.64 g, $2.46 \mathrm{mmol})$ and AEP (0.32 g, $2.46 \mathrm{mmol})$ were added into a brown reaction flask with $\mathrm{MeOH}$ as a solvent $(2.5 \mathrm{ml})$. Polymerization was carried out in the dark at $45^{\circ} \mathrm{C}$ under nitrogen atmosphere. The reaction mixture became homogeneous in less than one hour and the reaction was allowed to proceed for 6 days yielding a viscous solution. Subsequently, $10 \mathrm{~mol} \%$ excess AEP (0.03 g, $0.2 \mathrm{mmol}$ ) was added to consume any unreacted acrylamide groups and stirring was continued for 2 days at $45{ }^{\circ} \mathrm{C}$. The resulting solution was diluted with water to about $30 \mathrm{ml}$, acidified with $4 \mathrm{M}$ $\mathrm{HCl}$ to $\mathrm{pH} \sim 5$, and then dialyzed through a dialysis membrane $(1 \mathrm{~kg} / \mathrm{mol}$ cut-off $)$ with acidic DI water ( $\mathrm{pH} \sim 5)$. After freeze-drying, the $\mathrm{p}(\mathrm{CBA}-\mathrm{AEP})$ polymer was collected as the HCl-salt. This polymer possesses secondary amine groups that are able to react with NIPAAm by Michael addition to the acrylamide double bond. Grafting of NIPAAm was performed by dissolving $\mathrm{p}$ (CBA-AEP) $(0.50 \mathrm{~g}, 1.3 \mathrm{mmol})$ in $\mathrm{MeOH}(5 \mathrm{ml})$ in the presence of $0.36 \mathrm{ml}$ of TEA (2 eq.), to deprotonate the secondary amines in the polymer, and the addition of $0.29 \mathrm{mg}$ of NIPAAm (2.6 mmol). The reaction mixture was stirred at $45^{\circ} \mathrm{C}$ in the dark under nitrogen atmosphere for two days. Afterwards, the product was purified by ultrafiltration $(1 \mathrm{~kg} / \mathrm{mol}$ cut-off) with DI water, and the resultant polymer was collected after freeze-drying.

\subsection{Polymer characterization}

The ${ }^{1} \mathrm{H}$ NMR spectra of the synthesized PAAs in $\mathrm{D}_{2} \mathrm{O}$ were recorded on Varian Inova spectrometer operating at $300 \mathrm{MHz}$. The molecular weight and polydispersity $\left(\mathrm{M}_{\mathrm{w}} / \mathrm{M}_{\mathrm{n}}\right)$ of the synthesized PAAs were determined by GPC relative to PEO standards (Polymer Labs) using a Viscotek GPCMax pump and autoinjector and two thermostated $\left(30^{\circ} \mathrm{C}\right) \mathrm{PL}$ aquagel-OH 30 columns $(8 \mu \mathrm{m}, 300 \times 7.5 \mathrm{~mm}$, Polymer Labs, with a low-molar-mass separation range (200 40,000)). Data was collected using a TDA302 Tripledetector with RI, Visc and LS ( 7 and $\left.90^{\circ}\right)$. 0.3M NaAc aqueous solution ( $\mathrm{pH} 4.4$ ) with $30 \%$ methanol was used as eluent at a flow rate of $0.7 \mathrm{ml} / \mathrm{min}$ ).

\subsection{SS-PAA/PDNA polyplex formation and characterization: particle size and surface charge of the SS-PAA/PDNA polyplexes}

SS-PAA/pDNA polyplexes at different polymer/pDNA weight ratios were prepared by adding a MES buffer solution (15 mM, pH 6.7, $5 \mathrm{wt} \%$ glucose) of SS-PAA (800 $\mu$ l) to a MES buffer 
solution (15 mM, pH 6.7, $5 \mathrm{wt} \%$ glucose) of pDNA $(200 \mu \mathrm{l}, 75 \mu \mathrm{g} / \mathrm{ml})$, followed by vortexing for 5 seconds and incubating at room temperature for 30 minutes. Particle size and surface charge measurements of the nanocomplexes were determined by dynamic light scattering (DLS) at $20^{\circ} \mathrm{C}$ with a Zetasizer Nano ZS (Malvern Instruments, Malvern) using a wavelength of $532 \mathrm{~nm}$. The value was recorded as the mean of three measurements. The size distribution was given by the PDI (polydispersity index), a value between 0 and 1, a PDI of 1 indicating large variations in particle size and a PDI of 0 indicating no variation in particle size as an ideal monodispersed formulation.

\subsection{Agarose gel retardation}

Polyplexes at different polymer/nucleotide weight ratios were prepared by adding a MES buffer solution (15 mM, pH 6.7, 5 wt\% glucose) of polymer (32 $\mu$ ) to a MES buffer solution (15 mM, pH 6.7, 5 wt\% glucose) of pDNA ( $8 \mu \mathrm{l}, 100 \mu \mathrm{g} / \mathrm{ml})$, followed by vortexing for 5 seconds and incubating at room temperature for 30 minutes. DTT was used to mimic glutathione intracellular reduction and was added after 30 minutes of incubation obtaining a final concentration of $2.5 \mathrm{mM}$. After another 30 minutes (with or without DTT incubation), polyplexes were loaded on a 0.8 wt\% agarose gel containing $1.25 \mu \mathrm{M}$ SYBR safe. Electrophoresis was performed for 60 minutes at $90 \mathrm{~V}$ in a TAE running buffer $(40 \mathrm{mM}$ tris(hydroxymethyl)aminomethane, $20 \mathrm{mM}$ acetic acid, $10 \mathrm{mM}$ EDTA, pH 8.0) supplemented with 1.25 $\mu \mathrm{M}$ SYBR safe. After electrophoresis, pictures were taken on a Biorad Gel Doc 2000 under UV illumination and analyzed using Biorad Multi Analyst software version 1.1.

\subsection{Responsivity of the SS-PAA polymers and SS-PAA/PDNA nanoparticles to temperature increase}

\subsection{LCST measurements}

Aqueous solutions of SS-PAAs at different concentrations of 2.5-5 wt\% in MES buffer solution (15 mM, 5 wt\% glucose) and SS-PAA/pDNA nanoparticles at different polymer/DNA weight ratios were prepared in MES buffer solution (15 mM, pH 6.7, 5 wt\% glucose). The transmittance of visible light $(\lambda=500 \mathrm{~nm})$ was recorded as a function of temperature from 15 to $60{ }^{\circ} \mathrm{C}$ using a Varian Cary 300 Bio UV-visible spectrophotometer. Before each measurement, the spectrophotometer was calibrated with pure MES buffer solution (15 mM, 5 wt\% glucose), respectively. 


\subsection{Temperature trend response}

Changes in the morphology of the SS-PAA/pDNA nanoparticles upon increase of temperature and crossing the LCST of the nanosystems were followed by temperature-dependant DLS experiments. SS-PAA/pDNA nanoparticles were prepared at polymer/DNA weight ratio 12/1 in MES buffer solution (15 mM, pH 6.7, 5 wt\% glucose. Particle size measurements of the nanocomplexes were performed with a Zetasizer Nano ZS (Malvern Instruments, Malvern) using a wavelength of $532 \mathrm{~nm}$. Simultaneously, the temperature was increased from 15 to $60^{\circ} \mathrm{C}$, particle size was determined every Celsius degree.

\section{Results and discussion}

\subsection{Synthesis and characterization of SS-PAAs}

A series of bioreducible SS-PAAs polymers, $p\left(C B A-A B O L_{m} / 3 A N I P P A m_{n}\right)$, with repetitive disulfide linkages in their main chain and various amounts of NIPAAm moieties were synthesized via Michael addition of the corresponding primary amine monomers, ABOL and BANIPAAm, to CBA and were coded in terms of the used monomers, and molar amino monomer $(m / n)$ ratio used. Furthermore, another SS-PAA, NIPAAm-g-p(CBA-AEP), was prepared via the synthesis of $p(C B A-A E P)$, synthesized by polyaddition of AEP to CBA, followed by grafting with NIPAAm.

All the polymers were collected in ca. 35-45\% yield as their $\mathrm{HCl}$-salt after ultrafiltration and freeze-drying and were well soluble in water. The polymer structures of these polymers are summarized in Figure A.1. 
<smiles>CC(C)NC(=O)CCN(CCC(=O)NCCSSCCNC(=O)CCC(C)(C)N(CCCCO)CCC(=O)NNCCSSCCN(C(=O)O)C(=O)CCC(C)(C)C)C(=O)O</smiles>

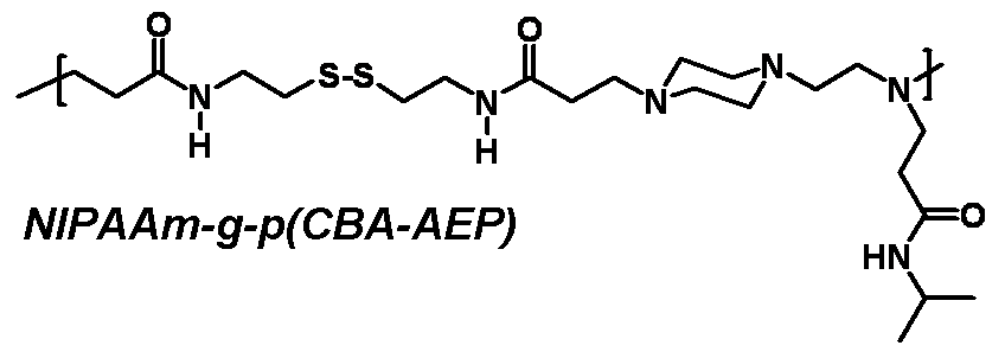

Figure A.1. Structure of the poly(amidoamine)s used in this study. The polymers were coded in terms of the used bisacrylamide and primary amine monomer. As for $p$ (CBA-ABOLm/3ANIPAAmn), $\mathrm{m} / \mathrm{n}=100 / 0,50 / 50,25 / 75$.

The ${ }^{1} \mathrm{H}$ NMR spectra of the synthesized PAAs in $\mathrm{D}_{2} \mathrm{O}$ were recorded on Varian Inova spectrometer operating at $300 \mathrm{MHz}$, and were in full accordance with the expected structures. The absence of any proton signals between 5 and 7 ppm shows that the polymer did not contain any residual acrylamide end groups. Typical examples of the ${ }^{1} \mathrm{H}$ NMR spectra are shown in Figure A.2. 


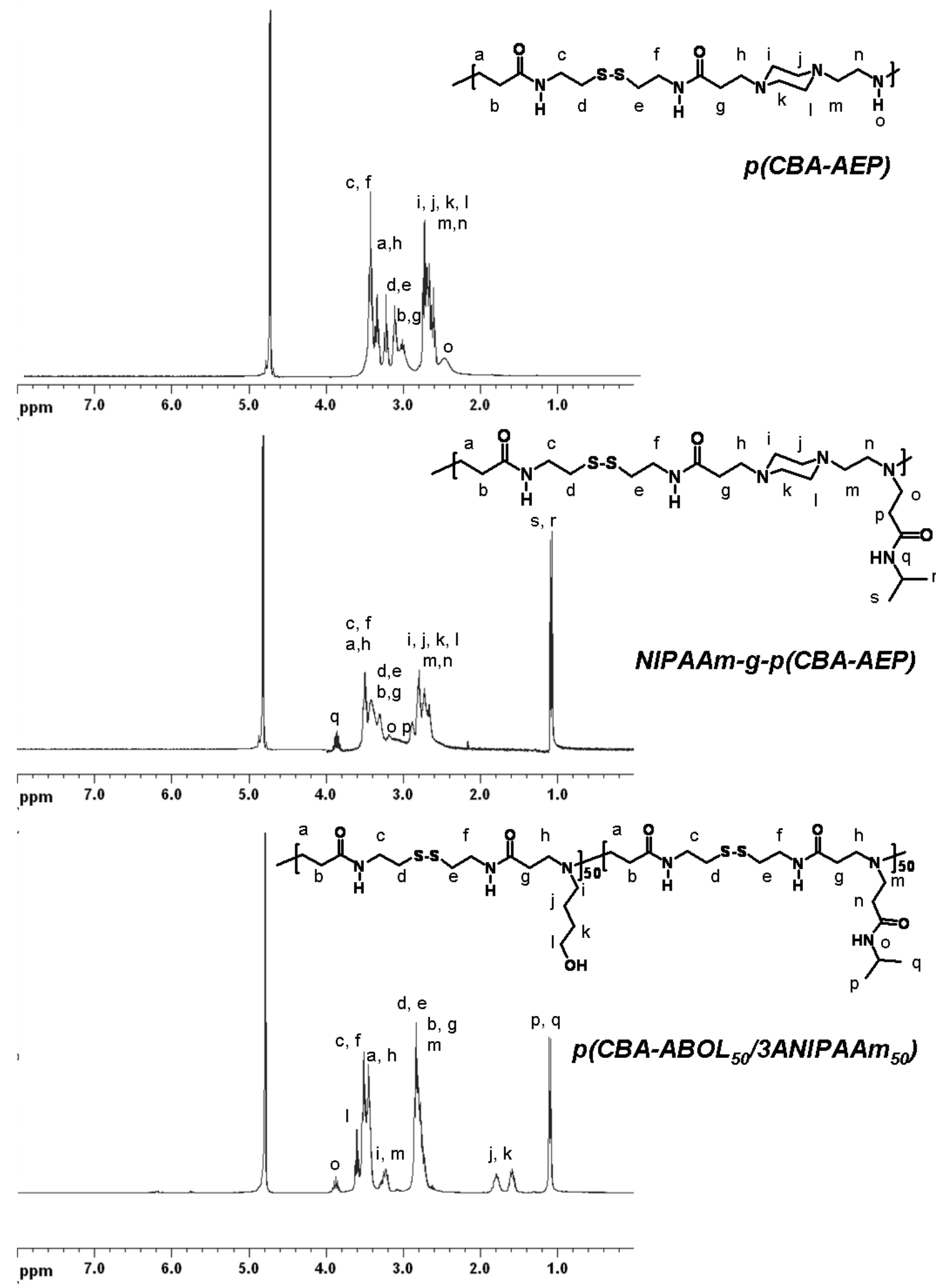

Figure A.2. ${ }^{1 H}$ NMR spectra $\left(\mathrm{D}_{2} \mathrm{O}, 300 \mathrm{MHz}\right)$ of $\mathrm{p}(\mathrm{CBA}-\mathrm{AEP})$, NIPAAm-g-p(CBA-AEP) and p(CBA-ABOL50/3ANIPAAm 50)

Gel permeation chromatography (GPC) measurements showed that the weight-average molecular weight $\left(\mathrm{M}_{\mathrm{w}}\right)$ of $\mathrm{p}(\mathrm{CBA}-\mathrm{ABOL})$ and NIPAAm-g-p(CBA-AEP) were 5.9 and 8.9 
$\mathrm{kg} / \mathrm{mol}$, respectively, with polydispersity index PDI $=1.2$.

Due to solubility reasons under the conditions used for the GPC experiments, the molecular weight of $\mathrm{p}\left(\mathrm{CBA}_{\mathrm{ABO}} \mathrm{L}_{50} / \mathrm{BANIPAA}_{50}\right)$ and $\mathrm{p}\left(\mathrm{CBA}-\mathrm{ABOL}_{25} / \mathrm{BANIPAA}_{75}\right)$ could not be determined. However, based on our experience in the synthesis of functionalized PAAs and their characterization in terms of yield and molecular weight, we may expect molecular weights with values approaching those of the homopolymer $\mathrm{p}(\mathrm{CBA}-\mathrm{ABOL})$.

Table A.1. Characterization of SS-PAAs (homopolymers and copolymers), in terms of composition, molecular weight $\left(\mathrm{M}_{\mathrm{w}}, \mathrm{PDI}\right)$.

\begin{tabular}{|c|c|c|c|}
\hline Polymer & $\begin{array}{c}\text { Composition } \\
\text { ABOL/3ANIPAAm * }\end{array}$ & $\mathrm{M}_{\mathrm{w}} * *$ & $\begin{array}{c}\text { PDI } \\
\left(M_{w} / M_{n}\right) * *\end{array}$ \\
\hline $\mathrm{p}(\mathrm{CBA}-\mathrm{ABOL})$ & $100 / 0$ & 5.9 & 1.2 \\
\hline $\mathrm{p}\left(\mathrm{CBA}-\mathrm{ABOL}_{25} / 3 \mathrm{ANIPAAm}_{75}\right)$ & $75 / 25$ & n.d. & n.d. \\
\hline $\mathrm{p}\left(\mathrm{CBA}-\mathrm{ABOL}_{50} / 3 \mathrm{ANIPAAm}_{50}\right)$ & $50 / 50$ & n.d. & n.d. \\
\hline NIPAAm-g-p(CBA-AEP) & n.a. & 8.9 & 1.2 \\
\hline
\end{tabular}

n.d. : not determined, * : determined by integrated peak area from ${ }^{1 \mathrm{H}} \mathrm{NMR}\left(\mathrm{D}_{2} \mathrm{O}, 300 \mathrm{MHz}\right)$ ** : average-weight molecular weight $\left(\mathrm{M}_{\mathrm{w}}\right)$ determined by GPC measurement

\section{2. pDNA uptake into the SS-PAA nanoparticles: physical characterization}

A requirement for cationic polymers to function as gene delivery vectors is that they are able to condense pDNA into nanosized polyplexes. In previous work, the polymers $p(C B A-A B O L)$ and $p(C B A-A E P)$ were shown to efficiently condense pDNA into nanosized polyplexes of 110-120 nm [37, 39]. In this study we have investigated the capacity of these novel SS-PAAs, for which the polymer architecture has been modified to include NIPAAm-like groups, on their behavior to condense pDNA as a function of temperature and $\mathrm{pH}$.

DLS measurements show that four of the SS-PAAs already condense pDNA at polymer/pDNA weight ratio 12/1 into polyplexes with small particle size $(<130 \mathrm{~nm})$ and positive surface charge (> $20 \mathrm{mV}$ ) (Figure A.3). Remarkably small polyplexes with sizes < $40 \mathrm{~nm}$ were observed for polyplexes of $\mathrm{p}\left(\mathrm{CBA}_{\mathrm{ABOL}}{ }_{25} /\right.$ 3ANIPAAm $\left._{75}\right)$ and $\mathrm{p}\left(\mathrm{CBA}_{\mathrm{ABOL}} \mathrm{F}_{5} / \mathrm{BANIPAAm}_{50}\right)$ containing both thermo-responsive 3ANIPAAm and 
hydroxybutanol groups as side chains.

\begin{tabular}{|c|c|c|}
\hline$\square$ Size $\mathrm{p}\left(\mathrm{CBA}-\mathrm{ABOL}_{25}-3 \mathrm{ANIPAAm}_{75}\right) / \mathrm{pDNA}$ & $\square$ & Size $\mathrm{p}\left(\mathrm{CBA}-\mathrm{ABOL}_{50}-3\right.$ ANIPAAm $\left._{50}\right) / \mathrm{pDNA}$ \\
\hline$\square$ Size NIPAAm-g-p(CBA-AEP)/pDNA & שב & Size $p(C B A-A B O L) / p D N A$ \\
\hline 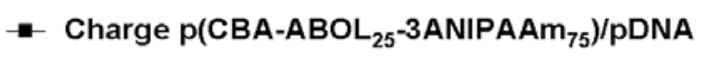 & $-\mathbf{x}$ & Charge $\mathrm{p}\left(\mathrm{CBA}-\mathrm{ABOL}_{50}-3 \mathrm{ANIP}\right.$ \\
\hline -o Charge NIPAAm-g-p(CBA-AEP)/pDNA & $\triangle-$ & Charge $\mathrm{p}(\mathrm{CBA}-\mathrm{ABOL}) / \mathrm{pDNA}$ \\
\hline
\end{tabular}

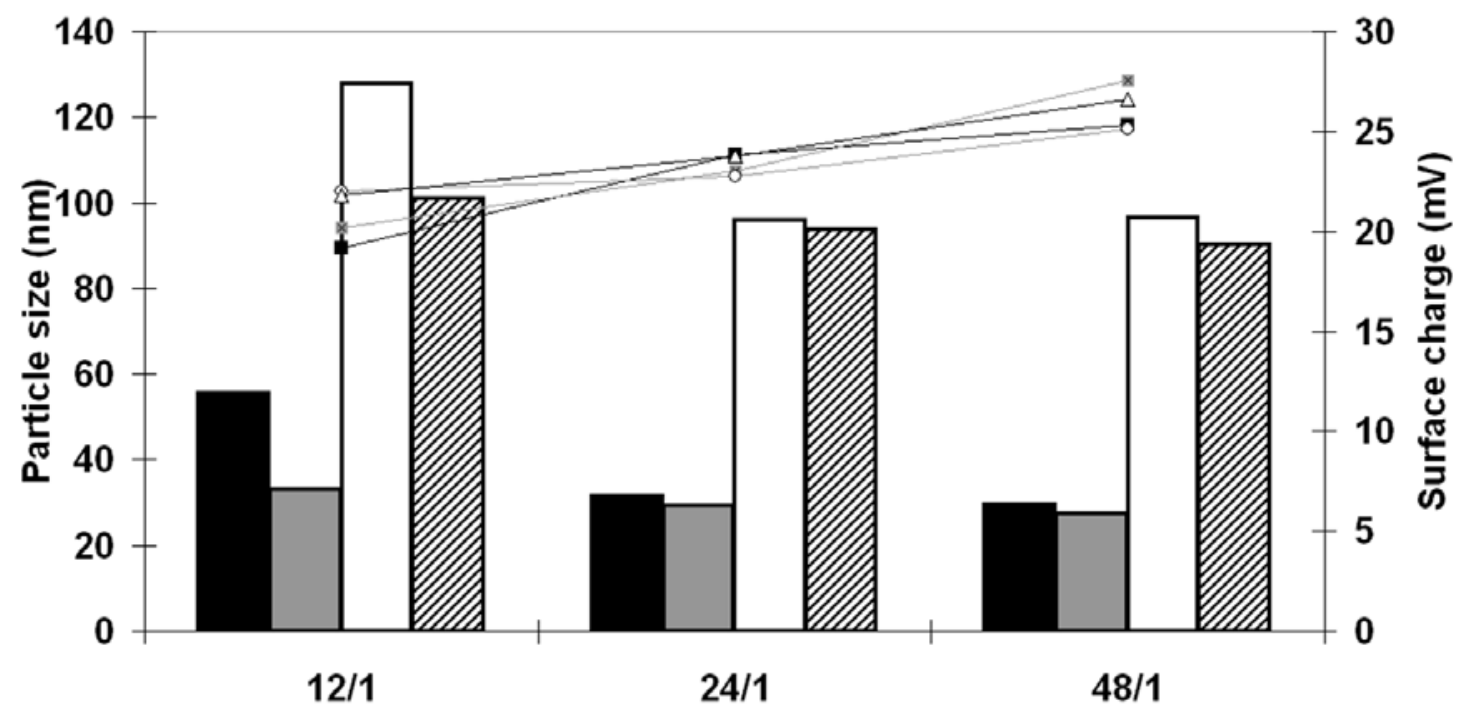

Polymer/pDNA weight ratio

Figure A.3. Size distributions and zeta-potentials of SS-PAA/pDNA polyplexes measured by DLS at $20^{\circ} \mathrm{C}$ according to the SS-PAA/pDNA weight ratio, using $\mathrm{p}\left(\mathrm{CBA}-\mathrm{ABOL}_{25} / 3 \mathrm{ANIPAAm}_{75}\right.$ ) (black bars), $p$ (CBA-ABOL50/3ANIPAAm 50) (grey bars), NIPAAm-g-p(CBA-AEP) (white bars), and p(CBA-ABOL) (striped bars) as polymeric vector.

Agarose gel electrophoresis experiments demonstrate the complexation between SS-PAA and pDNA and allow estimating the minimal amount of polymer necessary to completely condense pDNA. This can be observed by the absence of free pDNA bands on the gel. Agarose gels were run using SS-PAA/pDNA polyplexes prepared at polymer/pDNA weight ratios ranging from $12 / 1$ to $48 / 1$. Naked DNA was included in the experiments and was loaded as a control. As is shown in Figure A.4, naked DNA substantially migrates towards the positive electrode, as expected due to its overall negative charge. However, the presence of positively-charged SS-PAA results in a dramatic decrease of the mobility of pDNA, which can initially be attributed to a shielding of the negative surface charges on binding of the cationic polymer and at higher ratios to the formation of polyplexes. Complete migration is already retarded for the $p(C B A-A B O L)$ and $\mathrm{p}\left(\mathrm{CBA}_{\mathrm{ABOL}} \mathrm{F}_{0} / \mathrm{BANIPAAm}_{50}\right)$ at polymer/DNA weight ratios $12 / 1$, whereas for $p\left(\right.$ CBA-ABOL $_{25} /$ 3ANIPAAm $\left._{75}\right)$ and NIPAAm-g-p(CBA-AEP), migration is only retarded for 
polymer/DNA weight ratios above 24/1. These results show that the inclusion of NIPAAm structure in the architecture of the SS-PAA may decrease the polymer capacity to efficiently condense pDNA, and therefore more polymer is needed to enhance condensation.

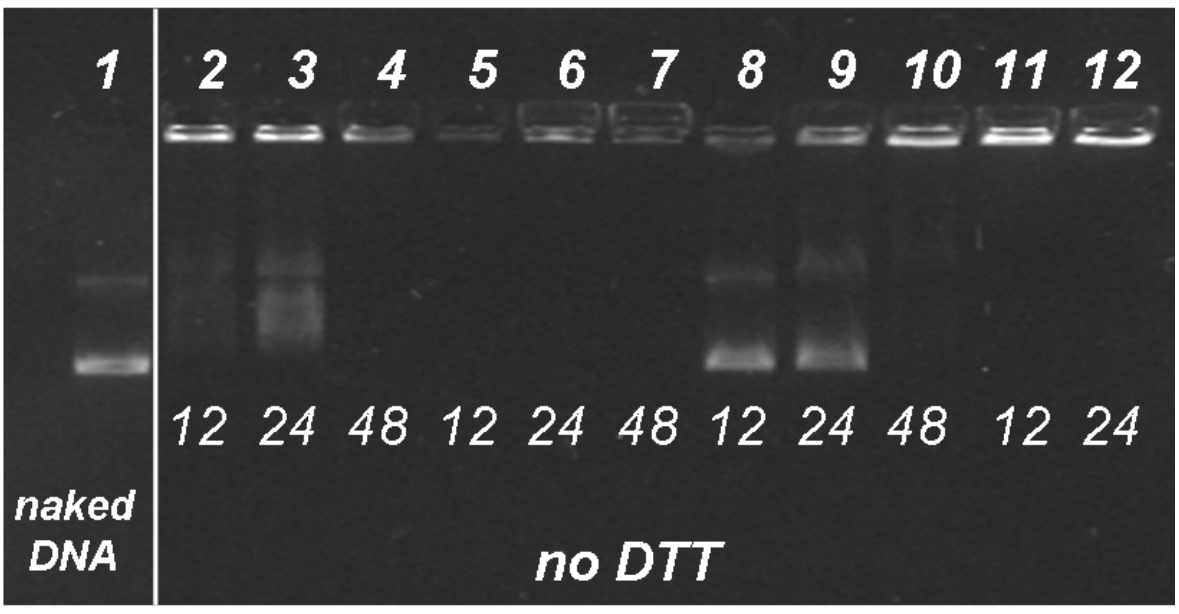

Figure A.4. Agarose gel electrophoresis of SS-PAA/pDNA polyplexes prepared at different SS-PAA/pDNA weight ratios ranging from $12 / 1$ to $48 / 1$, in $15 \mathrm{mM}$ MES buffer pH 6.7 containing $5 \%$ glucose. 1: naked pDNA as a control, 2-12: SS-PAA/pDNA polyplexes using $p$ (CBA-ABOL 25 /3ANIPAAm $\left._{75}\right)$ (2-4), $\quad$ (CBA-ABOL ${ }_{50}$ /3ANIPAAm $\left._{50}\right)$ (5-7), NIPAAm-g-p(CBA-AEP) (8-10), and $p(C B A-A B O L)(11-12)$ as polymeric vector.

\subsection{Thermo-responsivity of the SS-PAA polymers and SS-PAA/PDNA nanoparticles}

The inclusion of 3ANIPAAm in the architecture of the SS-PAAs induces thermo-responsivity, as is clearly shown when the temperature is increased from room temperature to $50^{\circ} \mathrm{C}$. Polymer solutions of $2.5 \mathrm{wt} \% \mathrm{p}\left(\mathrm{CBA}^{-\mathrm{ABOL}_{25}}\right.$ /3ANIPAAm $\left._{75}\right)$, in MES buffer solution $\mathrm{pH} 6.7$, changed for clear to milky, which indicates a transition to a less soluble state of the polymer (Figure A.5). Similar behavior was observed using $\mathrm{p}\left(\mathrm{CBA}-\mathrm{ABOL}_{50} /\right.$ 3ANIPAAm $\left._{50}\right)$ and NIPAAm-g-p(CBA-AEP). 


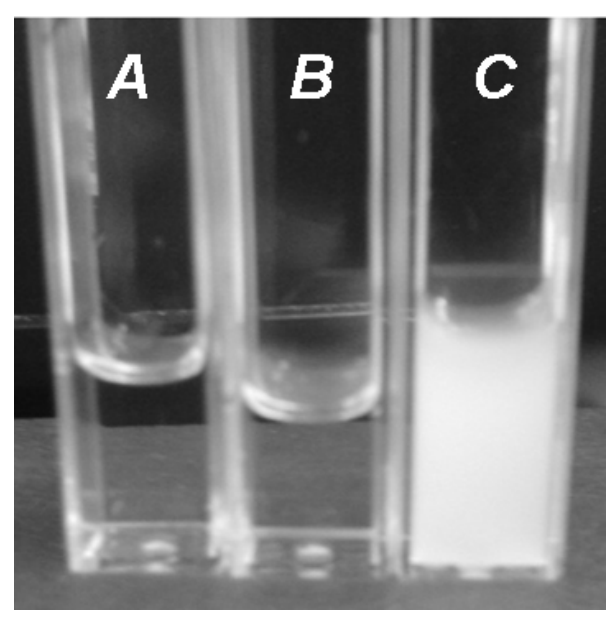

Figure A.5. Photograph of (A) 2.5 wt $\%$ aqueous solution of $p(C B A-A B O L)$ in MES buffer solution $p H$ 6.7 at $50^{\circ} \mathrm{C}$, (B, C) $2.5 \mathrm{wt} \%$ aqueous solution of $\mathrm{p}\left(\mathrm{CBA}-\mathrm{ABOL}_{25} / 3 \mathrm{ANIPAAm}_{75}\right)$ in MES buffer solution $\mathrm{pH} 6.7$, at $15^{\circ} \mathrm{C}(\mathrm{B})$ and at $50^{\circ} \mathrm{C}(\mathrm{C})$.

\subsubsection{Dependency on $\mathrm{pH}$ and polymer concentration}

Figure A.6 shows the temperature dependence of transmittance of $2.5-5 \mathrm{wt} \%$ solutions of $p$ (CBA-ABOL $50 / 3$ ANIPAAm 50 ), $p$ (CBA-ABOL 25 /3ANIPAAm $_{75}$ ), and NIPAAm-g-p(CBA-AEP) at $500 \mathrm{~nm}$, at different $\mathrm{pH}$ values. All these three polymers exhibit thermo-response with complete reduction of the transmittance when temperature is increased.

This thermo-responsive behavior is $\mathrm{pH}$ dependent. The transmittance of $2.5 \mathrm{wt} \%$ and 5 $w t \%$ aqueous solution of $p\left(C B A-A B O L_{50} / 3 A_{N}\right.$ IPAAm $\left._{50}\right)$, showed in Figures A.6A and A.6B, respectively, sharply decreases when temperature is raised at $\mathrm{pH}$ values from 6.6 , demonstrating a thermo-responsive behavior as these $\mathrm{pH}$ values. In contrast, the transmittance is reduced by only $5 \%$ up to $60^{\circ} \mathrm{C}$ at $\mathrm{pH} 5.8$ and 6.3 .

The 5 wt $\%$ aqueous solutions of $p\left(\mathrm{CBA}^{-A_{B O L}}{ }_{25}\right.$ /3ANIPAAm $\left._{75}\right)$ and NIPAAm-g-p(CBA-AEP), which transmittance trend through temperature increase is depicted in showed in Figures A.6C and A.6D, respectively, show thermo-responsive behavior at all $\mathrm{pH}$ values evaluated ranging from 6.3 and 7.4 , with a sharp decrease of transmittance when temperature is raised.

As seen on Figures A.6B and A.6C, it is remarkable that the LCST values decreases with increasing $\mathrm{pH}$, with a decrease from $36^{\circ} \mathrm{C}$ to $18^{\circ} \mathrm{C}$ for the 5 wt $\%$ aqueous solution of $\mathrm{p}\left(\mathrm{CBA}_{\mathrm{ABOL}} \mathrm{F}_{5} / \mathrm{BANIPAAm}_{50}\right)$ when $\mathrm{pH}$ is increased from 6.6 to 6.9. Similarly, the LCST of the 5 wt\% aqueous solution of $p\left(\mathrm{CBA}-\mathrm{ABOL}_{25} /\right.$ BANIPAAm $\left._{75}\right)$ drops from $30^{\circ} \mathrm{C}$ to $19^{\circ} \mathrm{C}$ when $\mathrm{pH}$ is increased from 6.4 to 6.7. However, only a very subtle decrease of LCST was observed while increasing $\mathrm{pH}$ from 6.7 to 6.9. 
This pH-dependency is mainly due to the increased hydrophilic nature of the backbone induced by the higher degrees of protonation of the amino groups, therefore decreasing the thermo-responsive hydrophobic forces causing insolubility.
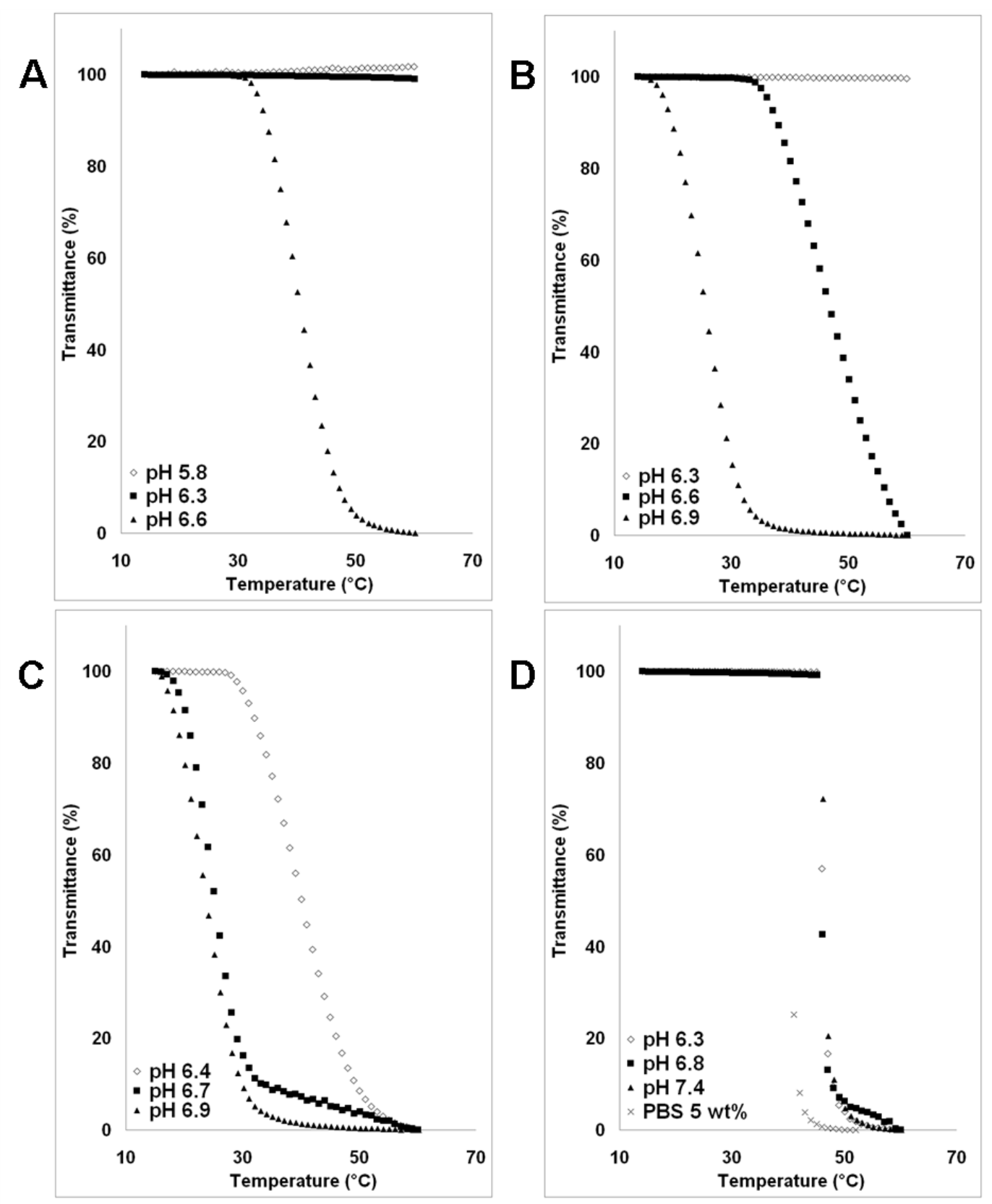

Figure A.6. Temperature and $\mathrm{pH}$ dependencies of the transmittance of aqueous solutions of $\mathrm{p}$ (CBA-ABOL $50 / 3$ ANIPAAm 50 ) (A: $5 \mathrm{wt} \%, \mathrm{~B}: 2.5 \mathrm{wt} \%$ ), and $2.5 \mathrm{wt} \%$ aqueous solution of $p\left(\right.$ CBA-ABOL $_{25} /$ BANIPAAm $\left._{75}\right)$, and NIPAAm-g-p(CBA-AEP), in MES buffer solution.

The thermo-responsivity of the SS-PAAs containing NIPAAm moieties does not seem dependent on the polymer concentration at the concentrations tested. As compared the thermo-responsivity of $\mathrm{p}\left(\mathrm{CBA} \mathrm{ABOL}_{50} / \mathrm{BANIPAAm}_{50}\right)$ in aqueous solution, both $2.5 \mathrm{wt} \%$ 
and $5 \mathrm{wt} \%$ solution of this polymer show thermo-responsivity at pH 6.6 show similar LCST and transmittance decrease.

\subsubsection{Dependency on particle loading}

We investigated the temperature dependence of solubility of solutions of $\mathrm{p}\left(\mathrm{CBA}_{\mathrm{ABOL}} \mathrm{F}_{5} /\right.$ 3ANIPAAm $\left._{50}\right)$ and $\mathrm{p}\left(\mathrm{CBA}_{\mathrm{ABO}} \mathrm{ABO}_{25}\right.$ /3ANIPAAm $\left._{75}\right)$, free in solution or present as polymer carrier in pDNA polyplexes, by the measure of their transmittance. Polyplexes were prepared at different SS-PAA/pDNA weight ratios in 15 mM MES buffer (pH 6.7, 5 $w t \%$ glucose). The concentrations of polymers free in solution were similar to those used for the preparation of the polyplexes. The results are summarized in Figure A.7.

Both polymers, $p\left(C_{B A}-A_{B O L}{ }_{50} 3_{3 A N I P A A m}{ }_{50}\right)$ and $p\left(C_{B A}-A_{B O L}{ }_{25} / 3 A N I P A A m_{75}\right)$, free in solution or used as polymer carrier of SS-PAA/pDNA polyplexes, showed thermo-responsivity with decrease of solubility when the temperature is increased from 20 to $50^{\circ} \mathrm{C}$, whereas the $\mathrm{p}(\mathrm{CBA}-\mathrm{ABOL})$ polymer lacking the NIPAAm moieties does not show any decrease in transmittance (data not shown in Figure A.7).

Figures A.7.A and A.7.C show that the LCST of the (CBA-ABOL $\left.{ }_{50} / 3 A N I P A A m_{50}\right)$ and $\mathrm{p}\left(\mathrm{CBA}_{\mathrm{ABOL}}{ }_{25}\right.$ /3ANIPAAm $\left._{75}\right)$ is not changed upon increasing the concentration of the polymers used (LCST ca. $40-42^{\circ} \mathrm{C}$ ). These results confirm the outcome described in 3.3.1, showing that at the concentrations tested the thermo-responsivity of the SS-PAAs containing NIPAAm moieties does not depend on the polymer concentration. However, at lower polymer concentrations (polymer/pDNA weight ratio 12/1), the decrease of transmittance is less sharp with a broader transition. 

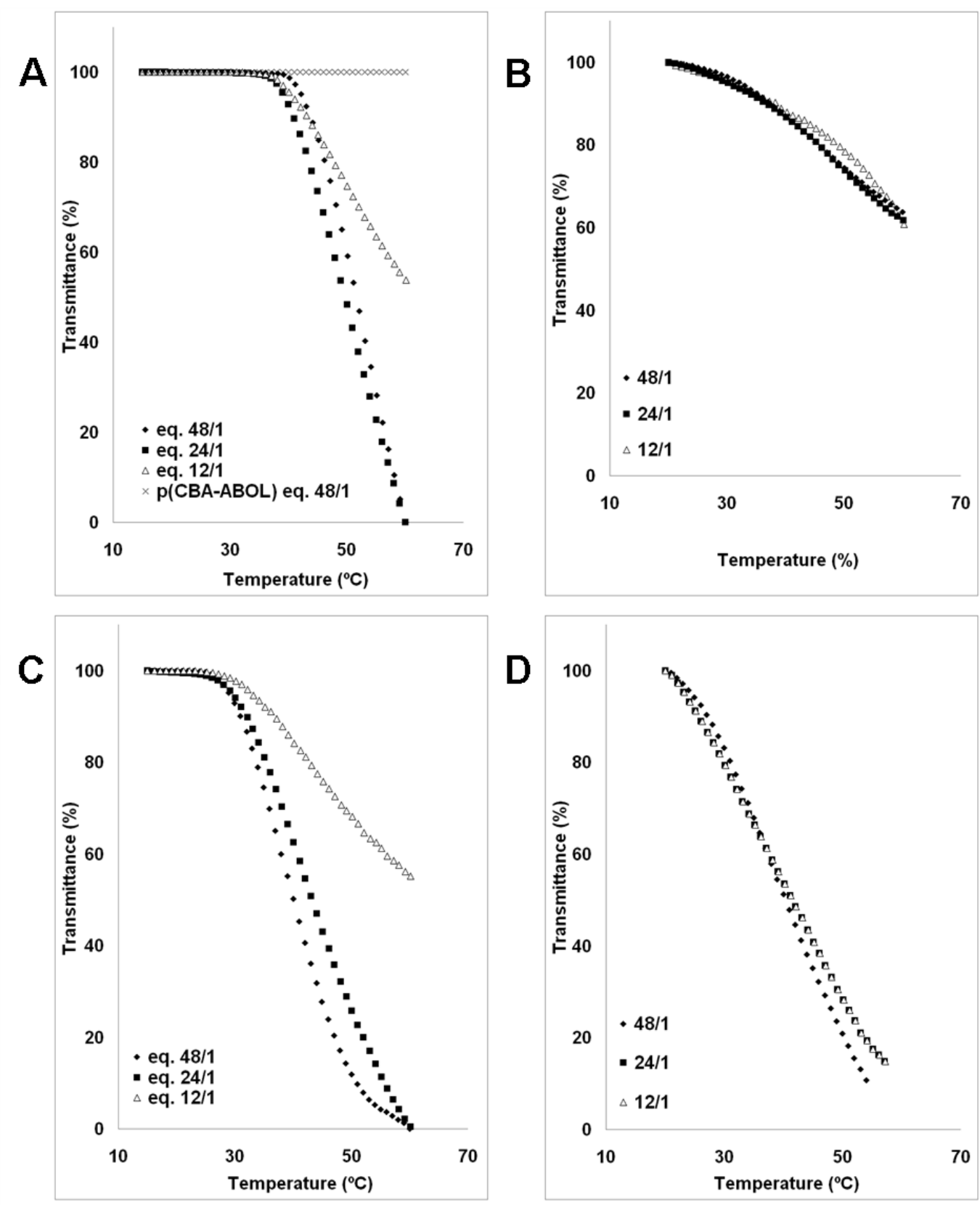

Figure A.7. Temperature and $\mathrm{pH}$ dependencies of the transmittance of aqueous solutions of $p\left(\right.$ CBA-ABOL $_{50} /$ 3ANIPAAm $\left._{50}\right)$ (A, B) and p(CBA-ABOL $25 / 3$ ANIPAAm $\left._{75}\right)(C, D)$ in $15 \mathrm{mM}$ MES buffer (pH 6.7, $5 \mathrm{wt} \%$ glucose), free in solution (A, C) or condensed with pDNA into polyplexes at different polymer/pDNA weight ratios $(B, D)$.

Remarkably, the formation of polyplexes of these polymers with DNA shows a considerable impact on the thermo-responsibility of the SS-PAAs, resulting in a drastic decrease of the LCST values. At similar polymer concentrations, with DNA loading, the LCST passes from $40-42^{\circ} \mathrm{C}$ to $23-25^{\circ} \mathrm{C}$ and from $30-32^{\circ} \mathrm{C}$ to $22-23^{\circ} \mathrm{C}$ for the polymers $\mathrm{p}\left(\mathrm{CBA}_{\mathrm{ABOL}} \mathrm{F}_{5} / \mathrm{BANIPAAm}_{50}\right)$ and $\mathrm{p}\left(\mathrm{CBA}_{\mathrm{ABO}} \mathrm{ABO}_{25}\right.$ /3ANIPAAm $\left._{75}\right)$, respectively, with however 
a much slower gradient of decrease of solubility.

The decrease of solubility is due to the increased hydrophobic nature of the thermo-responsive moieties in the polymer structure. Since pDNA is a hydrophilic macromolecule, the inclusion of pDNA in polyplexes increases the hydrophilic nature of the SS-PAAs. That is the reason why the decrease of transmittance is slower, with a broader transition, in presence of pDNA.

\subsubsection{Effects of temperature on the particle size}

We investigated the temperature dependency of the particle size of pDNA polyplexes made of $p$ (CBA-ABOL 25 /3ANIPAAm 75 ), NIPAAm-g-p(CBA-AEP) and $p$ (CBA-ABOL). Polyplexes were prepared at SS-PAA/pDNA weight ratio 12/1 in 15 mM MES buffer (pH 6.7, 5 wt\% glucose), and their particle size was followed by DLS while temperature was raised from 15 to $60^{\circ} \mathrm{C}$. The results are summarized in Figure A.8.

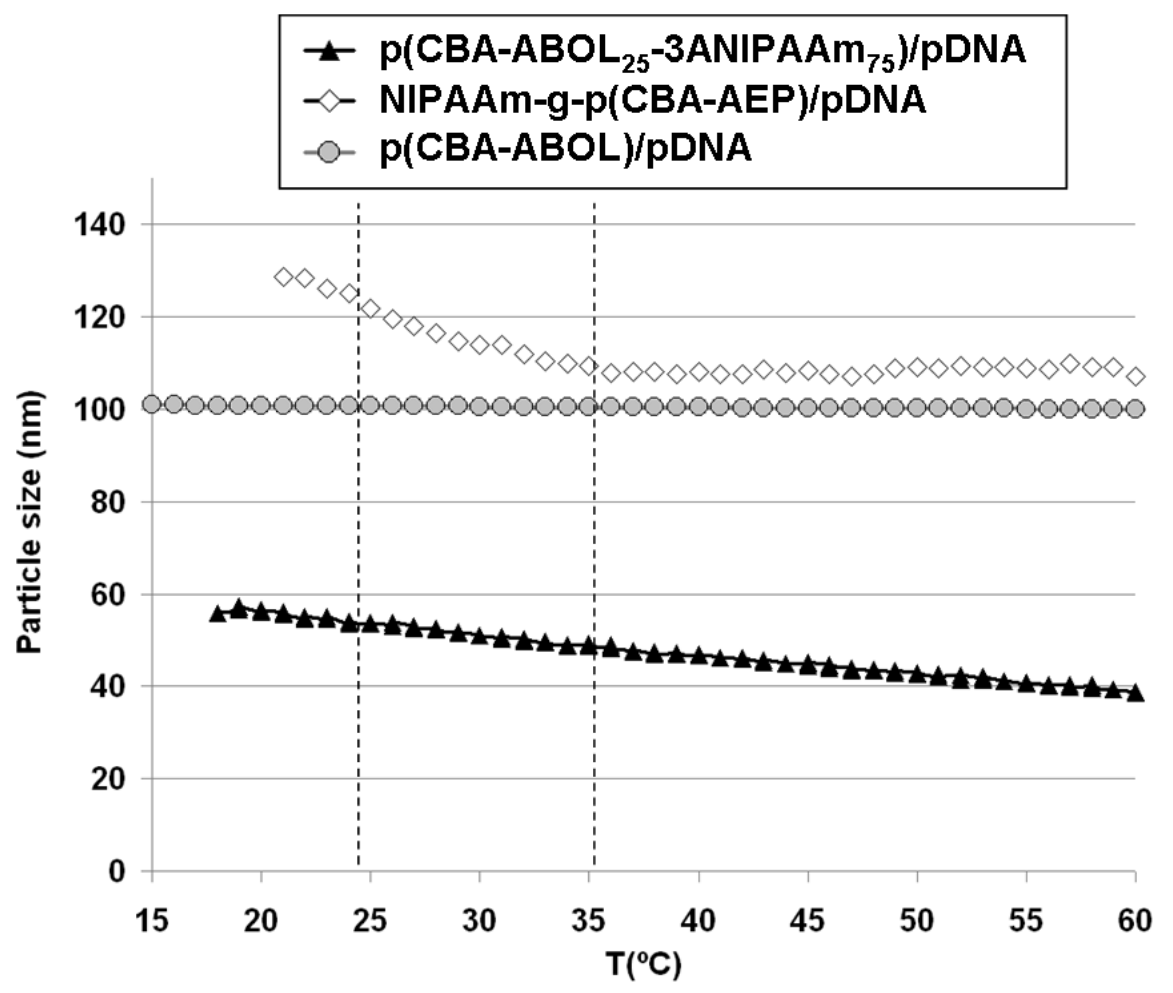

Figure A.8. Temperature dependency of particle size of aqueous solutions of $\mathrm{p}\left(\mathrm{CBA}^{-A_{B O L}}{ }_{25} /\right.$ SANIPAAm $\left._{75}\right) / \mathrm{pDNA}, \quad$ NIPAAm-g-p(CBA-AEP)/pDNA and $p$ (CBA-ABOL)/pDNA polyplexes prepared at SS-PAA/pDNA weight ratio 12/1 in $15 \mathrm{mM}$ MES buffer $(\mathrm{pH} 6.7,5 \mathrm{wt} \%$ glucose).

As shown on Figure A.8, while increasing temperature from 15 to $60^{\circ} \mathrm{C}$, the particle size of $\mathrm{p}\left(\mathrm{CBA}-\mathrm{ABOL}_{25} / \mathrm{BANIPAAm}_{75}\right) / \mathrm{pDNA}$ and NIPAAm-g-p(CBA-AEP)/pDNA polyplexes 
decreased of ca. 20-30\%, with a remarkable more pronounced decrease of particle size until temperature reaches values ca. $25-30^{\circ} \mathrm{C}$, temperatures corresponding to the LCST of the polyplexes. This is caused by the increased hydrophobic nature of the thermo-responsive moieties present in the polymer architecture, responsible for the shrinkage of the particles in aqueous solution. In contrast, the particle size of $\mathrm{p}(\mathrm{CBA}-\mathrm{ABOL}) / \mathrm{pDNA}$ polyplexes formed with the polymer lacking thermo-responsive groups only decreased ca. $1 \%$.

These results confirm the thermo-responsivity of SS-PAAs including NIPAAm moieties in their side chains. When temperature is increased, smaller nanocomplexes are formed. If no loss of particle loading occurs, the payload might consequently be internalized in more compact nanoparticles, resulting eventually in better protection of the particle loading.

\subsection{PDNA release from the SS-PAA nanoparticles}

For efficient gene transfer, pDNA should eventually be released from the polymeric vector. It has been reported that insufficient unpacking of polyplexes can form a major barrier in the transfection process $[45,46]$. Consequently, the rapid cleavage of the disulfide linkages in the intracellular reductive environment (containing $0.1 \sim 10 \mathrm{mM}$ glutathione) is biologically relevant to induce fast dissociation of SS-PAAs based polyplexes and efficient DNA release, leading to increased levels of gene expression. In order to proof the concept of efficient release of DNA from the polyplexes upon disulfide reduction, the complexation-decomplexation behavior of polyplexes based on the four SS-PAAs was investigated by agarose gel retardation.

As expected, for all the SS-PAA/pDNA polyplexes, incubation of the polyplexes for 30 minutes to dithiothreitol (DTT, $2.5 \mathrm{mM}$ ), mimicking the reducing intracellular environment, resulted in total DNA release (Figure A.9). 


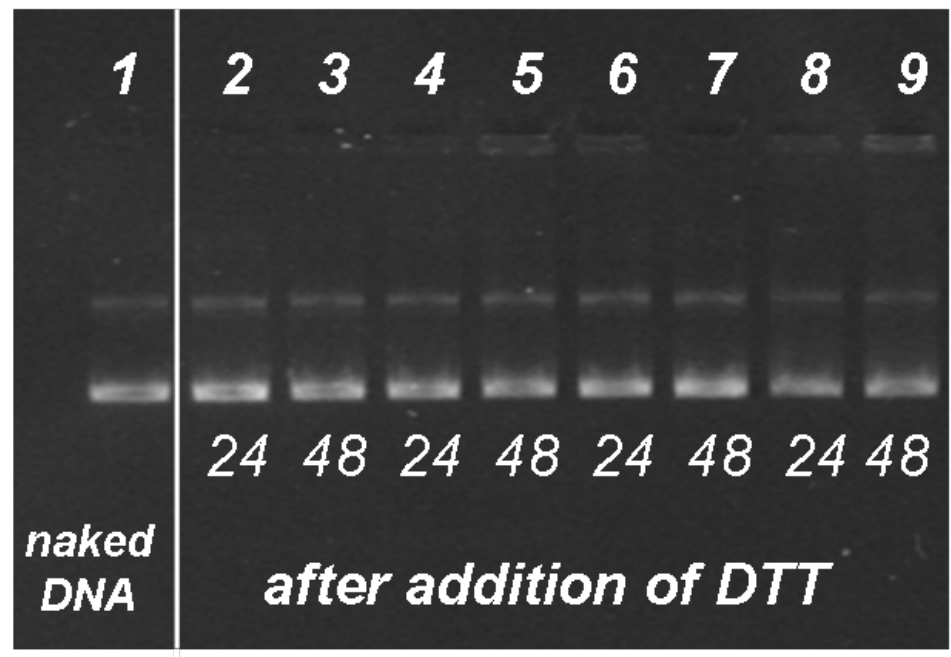

Figure A.9. Agarose gel electrophoresis of SS-PAA/pDNA polyplexes prepared at different SS-PAA/pDNA weight ratios ranging from $12 / 1$ to $48 / 1$, in $15 \mathrm{mM}$ MES buffer pH 6.7 containing $5 \%$ glucose. 1: naked pDNA as a control, 2-9: SS-PAA/pDNA polyplexes using

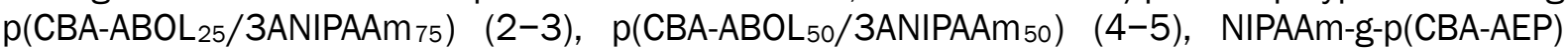
$(6-7)$, and $p(C B A-A B O L)(8-9)$ as polymeric vector, after addition of DTT to final concentration 2.5 $\mathrm{mM}$.

\section{Conclusions}

Introduction of NIPAAm moieties into SS-PAA polymers adds thermo-responsive properties to these polymers, in addition to their intrinsic $\mathrm{pH}$-responsive and bioreduction properties. The PAA backbone and the degree of NIPAAm functionalization can be adjusted to tune the thermo- and $\mathrm{pH}$ responsive properties. Hence thermo-responsive SS-PAAs are promising platform materials for the fabrication of biodegradable thermo- and $\mathrm{pH}$-responsive systems for drug delivery. However, more experiments have to be performed, as for instance in vitro drug release and cytotoxicity experiments, in order to better characterize these novel polymers and better estimate their potency for further use for biomedical applications.

\section{Acknowledgments}

The authors thank Kirsten van Leijenhorst-Groener for her assistance with the gel electrophoresis studies, and Mies van Steenbergen for the GPC measurements.

This research work is part of the Integrated European project Nanobiopharmaceutics.

\section{References}

[1] T. Miyata, N. Asami, T. Uragami, A reversibly antigen-responsive hydrogel. Nature 399(6738) (1999) 766-769. 
[2] D. Schmaljohann, Thermo- and pH-responsive polymers in drug delivery. Adv. Drug Deliv. Rev. 58(15) (2006) 1655-1670.

[3] E.S. Gil, S.M. Hudson, Stimuli-reponsive polymers and their bioconjugates. Prog. Polym. Sci. 29(12) (2004) 1173-1222.

[4] C.D.H. Alarcon, S. Pennadam, C. Alexander, Stimuli responsive polymers for biomedical applications. Chem. Soc. Rev. 34(3) (2005) 276-285.

[5] S. Nayak, L.A. Lyon, Soft nanotechnology with soft nanoparticles. Angew. Chem.-Int. Edit. 44(47) (2005) 7686-7708.

[6] E.R. Gillies, T.B. Jonsson, J.M.J. Frechet, Stimuli-responsive supramolecular assemblies of linear-dendritic copolymers. J. Am. Chem. Soc. 126(38) (2004) 11936-11943.

[7] E.R. Gillies, J.M.J. Frechet, pH-responsive copolymer assemblies for controlled release of doxorubicin. Bioconjugate Chem. 16(2) (2005) 361-368.

[8] Y. Bae, S. Fukushima, A. Harada, K. Kataoka, Design of environment-sensitive supramolecular assemblies for intracellular drug delivery: Polymeric micelles that are responsive to intracellular pH change. Angew. Chem.-Int. Edit. 42(38) (2003) 4640-4643.

[9] G.H. Chen, A.S. Hoffman, Graft-Copolymers That Exhibit Temperature-Induced Phase-Transitions over a Wide-Range of Ph. Nature 373(6509) (1995) 49-52.

[10] C.M. Schilli, M.F. Zhang, E. Rizzardo, S.H. Thang, Y.K. Chong, K. Edwards, G. Karlsson, A.H.E. Muller, A new double-responsive block copolymer synthesized via RAFT polymerization: Poly(N-isopropylacrylamide)-block-poly(acrylic acid). Macromolecules 37(21) (2004) 7861-7866.

[11] G.Y. Li, L.Q. Shi, R.J. Ma, Y.L. An, N. Huang, Formation of complex micelles with double-responsive channels from self-assembly of two diblock copolymers. Angew. Chem.-Int. Edit. 45(30) (2006) 4959-4962.

[12] A. Chilkoti, M.R. Dreher, D.E. Meyer, Design of thermally responsive, recombinant polypeptide carriers for targeted drug delivery. Adv. Drug Deliv. Rev. 54(8) (2002) 1093-1111.

[13] P.S. Stayton, T. Shimoboji, C. Long, A. Chilkoti, G.H. Chen, J.M. Harris, A.S. Hoffman, Control of Protein-Ligand Recognition Using a Stimuli-Responsive Polymer. Nature 378(6556) (1995) 472-474.

[14] H.G. Schild, Probes of the Lower Critical Solution Temperature of Poly(N-Isopropylacrylamide). Acs Symposium Series 467 (1991) 249-260.

[15] H. Feil, Y.H. Bae, J. Feijen, S.W. Kim, Effect of Comonomer Hydrophilicity and Ionization on the Lower Critical Solution Temperature of N-Isopropylacrylamide Copolymers. Macromolecules 26(10) (1993) 2496-2500.

[16] C.S. Brazel, N.A. Peppas, Synthesis and Characterization of Thermomechanically and Chemomechanically Responsive Poly(N-Isopropylacrylamide-Co-Methacrylic Acid) Hydrogels. Macromolecules 28(24) (1995) 8016-8020.

[17] M. Hahn, E. Gornitz, H. Dautzenberg, Synthesis and properties of ionically modified polymers with LCST behavior. Macromolecules 31(17) (1998) 5616-5623.

[18] H.G. Schild, Poly (N-Isopropylacrylamide) - Experiment, Theory and Application. Prog. Polym. Sci. 17(2) (1992) 163-249.

[19] D.C. Wu, Y. Liu, C.B. He, Thermal- and pH-responsive degradable polymers. Macromolecules 41(1) (2008) 18-20.

[20] M. Recillas, L.L. Silva, C. Peniche, F.M. Goycoolea, M. Rinaudo, W.M. Arguelles-Monal, Thermoresponsive behavior of chitosan-g-N-isopropylacrylamide copolymer solutions. Biomacromolecules 10(6) (2009) 1633-1641.

[21] P. Ferruti, M.A. Marchisio, R. Barbucci, Synthesis, Physicochemical Properties and Biomedical Applications of Poly(Amido-Amine)S. Polymer 26 (1985) 1336-1348.

[22] P. Ferruti, M.A. Marchisio, R. Duncan, Poly(amido-amine)s: Biomedical applications. Macromol. Rapid Commun. 23(5-6) (2002) 332-355.

[23] C.X. Wu, S.L. Lo, J. Boulaire, M.L.W. Hong, H.M. Beh, D.S.Y. Leung, S. Wang, A peptide-based carrier for intracellular delivery of proteins into malignant glial cells in vitro. J Control Release 130(2) (2008) 140-145. 
[24] O. Boussif, F. Lezoualch, M.A. Zanta, M.D. Mergny, D. Scherman, B. Demeneix, J.P. Behr, A Versatile Vector for Gene and Oligonucleotide Transfer into Cells in Culture and in-Vivo Polyethylenimine. Proc. Natl. Acad. Sci. U. S. A. 92(16) (1995) 7297-7301.

[25] J.D. Eichman, A.U. Bielinska, J.F. Kukowska-Latallo, J.R. Baker Jr, The use of PAMAM dendrimers in the efficient transfer of genetic material into cells. Pharmaceut Sci Tech Today 3(7) (2000) 232-245.

[26] E. Ranucci, G. Spagnoli, P. Ferruti, D. Sgouras, R. Duncan, Poly(amidoamine)s with potential as drug carriers: degradation and cellular toxicity. J Biomater Sci Polym Ed 2(4) (1991) 303-315.

[27] J. Franchini, E. Ranucci, P. Ferruti, Synthesis, physicochemical properties, and preliminary biological characterizations of a novel amphoteric agmatine-based poly(amidoamine) with RGD-like repeating units. Biomacromolecules 7(4) (2006) 1215-1222.

[28] N. Lavignac, M. Lazenby, J. Franchini, P. Ferruti, R. Duncan, Synthesis and preliminary evaluation of poly(amidoamine)-melittin conjugates as endosomolytic polymers and/or potential anticancer therapeutics. Int. J. Pharm. 300(1-2) (2005) 102-112.

[29] N. Lavignac, J.L. Nicholls, P. Ferruti, R. Duncan, Poly(amidoamine) Conjugates Containing Doxorubicin Bound via an Acid-Sensitive Linker. Macromol. Biosci. 9(5) (2009) 480-487.

[30] N.G. Pattrick, S.C.W. Richardson, M. Casolaro, P. Ferruti, R. Duncan, Poly(amidoamine)-mediated intracytoplasmic delivery of ricin A-chain and gelonin. J Control Release 77(3) (2001) 225-232.

[31] S.C.W. Richardson, N.G. Pattrick, Y.K.S. Man, P. Ferruti, R. Duncan, Poly(amidoamine)s as potential nonviral vectors: Ability to form interpolyelectrolyte complexes and to mediate transfection in vitro. Biomacromolecules 2(3) (2001) 1023-1028.

[32] S.C.W. Richardson, N.G. Pattrick, N. Lavignac, P. Ferruti, R. Duncan, Intracellular fate of bioresponsive poly(amidoamine)s in vitro and in vivo. J Control Release 142(1) (2010) 78-88.

[33] S. Swaminathan, R. Cavalli, F. Trotta, P. Ferruti, E. Ranucci, I. Gerges, A. Manfredi, D. Marinotto, P.R. Vavia, In vitro release modulation and conformational stabilization of a model protein using swellable polyamidoamine nanosponges of beta-cyclodextrin. J. Incl. Phenom. Macrocycl. Chem. 68(1-2) (2010) 183-191.

[34] P. Ferruti, E. Ranucci, F. Bignotti, L. Sartore, P. Bianciardi, M.A. Marchisio, Degradation Behavior of Ionic Stepwise Polyaddition Polymers of Medical Interest. J. Biomater. Sci.-Polym. Ed. 6(9) (1995) 833-844.

[35] P. Ferruti, E. Ranucci, L. Sartore, F. Bignotti, M.A. Marchisio, P. Bianciardi, F.M. Veronese, Recent Results on Functional Polymers and Macromonomers of Interest as Biomaterials or for Biomaterial Modification. Biomaterials 15(15) (1994) 1235-1241.

[36] C. Lin, C.-J. Blaauboer, M.M. Timoneda, M.C. Lok, M. van Steenbergen, W.E. Hennink, Z. Zhong, J. Feijen, J.F.J. Engbersen, Bioreducible poly(amido amine)s with oligoamine side chains: Synthesis, characterization, and structural effects on gene delivery. J Control Release 126(2) (2008) 166-174.

[37] C. Lin, Z. Zhong, M.C. Lok, X. Jiang, W.E. Hennink, J. Feijen, J.F.J. Engbersen, Linear poly(amido amine)s with secondary and tertiary amino groups and variable amounts of disulfide linkages: Synthesis and in vitro gene transfer properties. J Control Release 116(2) (2006) 130-137.

[38] C. Lin, Z. Zhong, M.C. Lok, X. Jiang, W.E. Hennink, J. Feijen, J.F.J. Engbersen, Random and block copolymers of bioreducible poly(amido amine)s with high- and low-basicity amino groups: Study of DNA condensation and buffer capacity on gene transfection. J Control Release 123(1) (2007) 67-75.

[39] C. Lin, Z.Y. Zhong, M.C. Lok, X.L. Jiang, W.E. Hennink, J. Feijen, J.F.J. Engbersen, Novel bioreducible poly(amido amine)s for highly efficient gene delivery. Bioconjugate Chem. 18(1) (2007) 138-145.

[40] M.A. Mateos-Timoneda, M.C. Lok, W.E. Hennink, J. Feijen, J.F.J. Engbersen, Poly(amido amine)s as gene delivery vectors: Effects of quaternary nicotinamide moieties in the side chains. ChemMedChem 3(3) (2008) 478-486.

[41] A. Bernkop-Schnürch, Thiomers: A new generation of mucoadhesive polymers. Adv. Drug Delivery Rev. 57(11) (2005) 1569-1582. 
[42] C. Lin, J.F.J. Engbersen, The role of the disulfide group in disulfide-based polymeric gene carriers. Expert Opin. Drug Deliv. 6(4) (2009) 421-439.

[43] F.H. Meng, W.E. Hennink, Z. Zhong, Reduction-sensitive polymers and bioconjugates for biomedical applications. Biomaterials 30(12) (2009) 2180-2198.

[44] K.C. Rajender, W.L. Frederick, H.K. Michael, M.B. David, G.B.R. Robert, R. Daniel, Plasma cysteine, cystine, and glutathione in cirrhosis. Gastroenterology 87(4) (1984) 770-776.

[45] D.W. Pack, A.S. Hoffman, S. Pun, P.S. Stayton, Design and development of polymers for gene delivery. Nat. Rev. Drug Discov. 4(7) (2005) 581-593.

[46] D.V. Schaffer, N.A. Fidelman, N. Dan, D.A. Lauffenburger, Vector unpacking as a potential barrier for receptor-mediated polyplex gene delivery. Biotechnol. Bioeng. 67(5) (2000) 598-606. 


\title{
Attempts of improvement on the stability of bioreducible poly(amidoamine) nanoparticles for protein and peptide delivery
}

\author{
Grégory Coué, Ewa Swiesciak and Johan F.J. Engbersen \\ Department of Biomedical Chemistry, MIRA Institute for Biomedical Technology \& Technical \\ Medicine, Faculty of Science and Technology, University of Twente, P.O. Box 217, 7500 AE \\ Enschede, the Netherlands
}

\begin{abstract}
Nanoparticular delivery systems based on biodegradable polymers have emerged as a promising approach for protein delivery. $\mathrm{p}(\mathrm{CBA}-\mathrm{ABOL})$, a poly(amidoamine) (PAA) was synthesized by Michael-type polyaddition of 4-amino-1-butanol (ABOL) to cystamine bisacrylamide (CBA). This water-soluble PAA efficiently condenses insulin by self-assembly into nanoscaled and positively-charged complexes. Stable under neutral extracellular conditions, the disulfide-containing nanocomplexes rapidly destabilized in a reductive intracellular environment. Modified nanosized polyelectrolyte complexes were prepared by ionic gelation after addition of molecules such as tripolyphosphate or DNA to the previous nanoparticles, and their properties were evaluated in terms of size, surface charge, loading efficiency, stability in some biologically relevant environments, compared to the non-modified particles.
\end{abstract}

\section{Introduction}

Modern biotechnology nowadays enables the production of numerous proteins and peptides that are, or have the potential to be, used as highly specific and effective therapeutics agents, as vaccines, hormones, growth factors and enzymes, to notably treat chronic diseases, cancers, autoimmune diseases and metabolic disorders [1-6]. However, negatively-charged cell membranes prevent proteins, peptides, and other therapeutics with anionic character from entering cells due to charge repulsion. Furthermore, peptides 
and proteins can be subject to degradation; for instance in oral administration for which it is well known that their bioavailability is very low due to their instability in the gastrointestinal tract and their low permeability through the intestinal mucosa [7]. Several strategies to overcome these difficulties have been investigated, and the utilization of polymer-based nanocarriers, particularly mucoadhesive nanoparticles has emerged as a promising and versatile approach because of their facile transformation and possibilities to tune properties including subcellular size, biodegradability and biocompatibility [8-11]. Moreover, mucoadhesive properties also play an important role by prolonging the residence time of drug carriers and also increasing the intimacy of contact between drug and membrane at the absorption sites, thus enhancing the permeability as well as reducing degradation of drugs.

Recently, nanosized polyelectrolyte complexes (PECs) resulting from the self-assembly of proteins with natural and synthetic polymers have drawn increasing attention for application in therapeutic protein delivery [12-15]. In this non-covalent method, PECs are formed by simply mixing oppositely charged drug and polymer that will interact by electrostatic-attraction. The PEC formation results in an optically homogeneous and stable dispersions of nanoparticles possessing cationic charges able to bind to and internalize with cell surface [13]. They have the advantage of not using sonification or organic solvents which are both harmful for proteins and peptides and are regularly used for the preparation of nanoparticles notably by the double emulsion technique.

Moreover, several protein-loaded nanoparticles, in particular insulin-loading nanoparticles, have been prepared by ionotropic gelation with tripolyphosphate (TPP) counterions [16-20]. This type of particles has emerged as a promising approach for insulin delivery, especially for oral administration.

In this study, the influence of process parameters on the properties of the polyelectrolyte complexes of cationic poly(amidoamine)s (PAAs) and human insulin was investigated, especially how TPP in the nanoparticular formulations affects the properties of the particles compared to the non-modified polyelectrolyte complexes.

PAAs are synthetic tert-amino polymers, synthesized by polyaddition of primary amines to bisacrylamides. They are water-soluble, biodegradable and biocompatible, with less cytotoxicity than other usual polycationic vectors [21-25]. PAAs represent a family of functional polymers endowed with a combination of properties that makes them very suitable for a variety of biomedical applications related to polymer therapeutics $[22,26]$. 
To answer the mucoadhesive criteria for cell or mucosa adhesion improvement, we have developed in our group novel linear PAAs containing repetitive disulfide linkages in their backbone (SS-PAAs). Those polymeric carriers have been previously reported to be very efficient as vectors in intracellular gene delivery [27-31], but also vectors for protein delivery [32, 33]. Moreover, due to the presence of the repetitive disulfide linkages, those virtually-nontoxic SS-PAAs are relatively stable in extracellular medium but they are prone to fast degradation in the reductive intracellular environment [34-39]. This property can be used in systems that should be relatively stable during transport outside the cell but should disintegrate in fragments of low molecular weight after uptake into the target cells to release their therapeutic cargo.

In this study, we have selected $\mathrm{p}(\mathrm{CBA}-\mathrm{ABOL})$ as a model SS-PAA. The $\mathrm{p}$ (CBA-ABOL) polymer possesses, besides repetitive disulfide moieties in the main chain originating from the CBA monomer, hydroxybutyl groups in the side chains originating from the ABOL units. It has been shown that this hydroxybutyl side group favorably contributes to the efficiency in DNA transfection, presumably by increasing the endosomolytic properties [30]. At physiological $\mathrm{pH}(\mathrm{pH}$ 7.4), $\mathrm{p}(\mathrm{CBA}-\mathrm{ABOL})$ is present as a polycation due to partial protonation of part of the tertiary nitrogens in the main chain of the polymer. Charge interaction with insulin can be expected since this protein, with an isoelectric point of 5.3 , has a net negative charge under these conditions, and polyelectrolyte complexes are spontaneously formed as represented in Figure B.1.
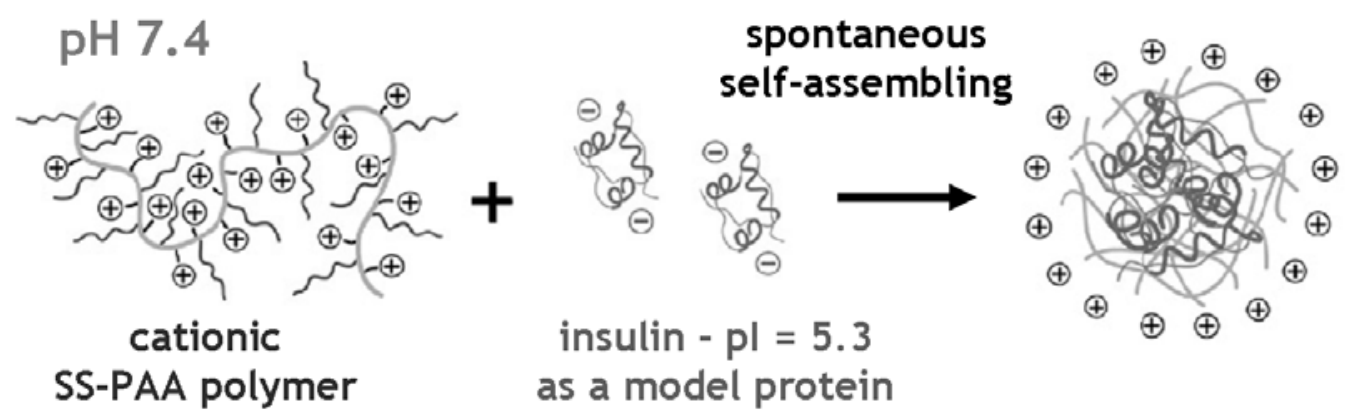

Figure B.1. Self-assembling formation of polyelectrolyte complexes at neutral $\mathrm{pH}$ by charge attraction between a negatively-charged protein (insulin) and a positively-charged polymer $(p(C B A-A B O L))$.

We have also investigated the effects of ionic gelation on the stabilization of the $\mathrm{p}(\mathrm{CBA}-\mathrm{ABOL}) /$ insulin nanoparticles. The formation of nanoparticles is dictated by two 
major steps: first the spontaneous self-assembly of oppositely charged polymer and protein into nanosized complexes governed by charge attraction, followed by the ionic crosslinking of the positively-charged polymer in the nanoparticles with the negatively-charged polyions TPP and DNA to form compact nanoparticles, as represented in Figure B.2.
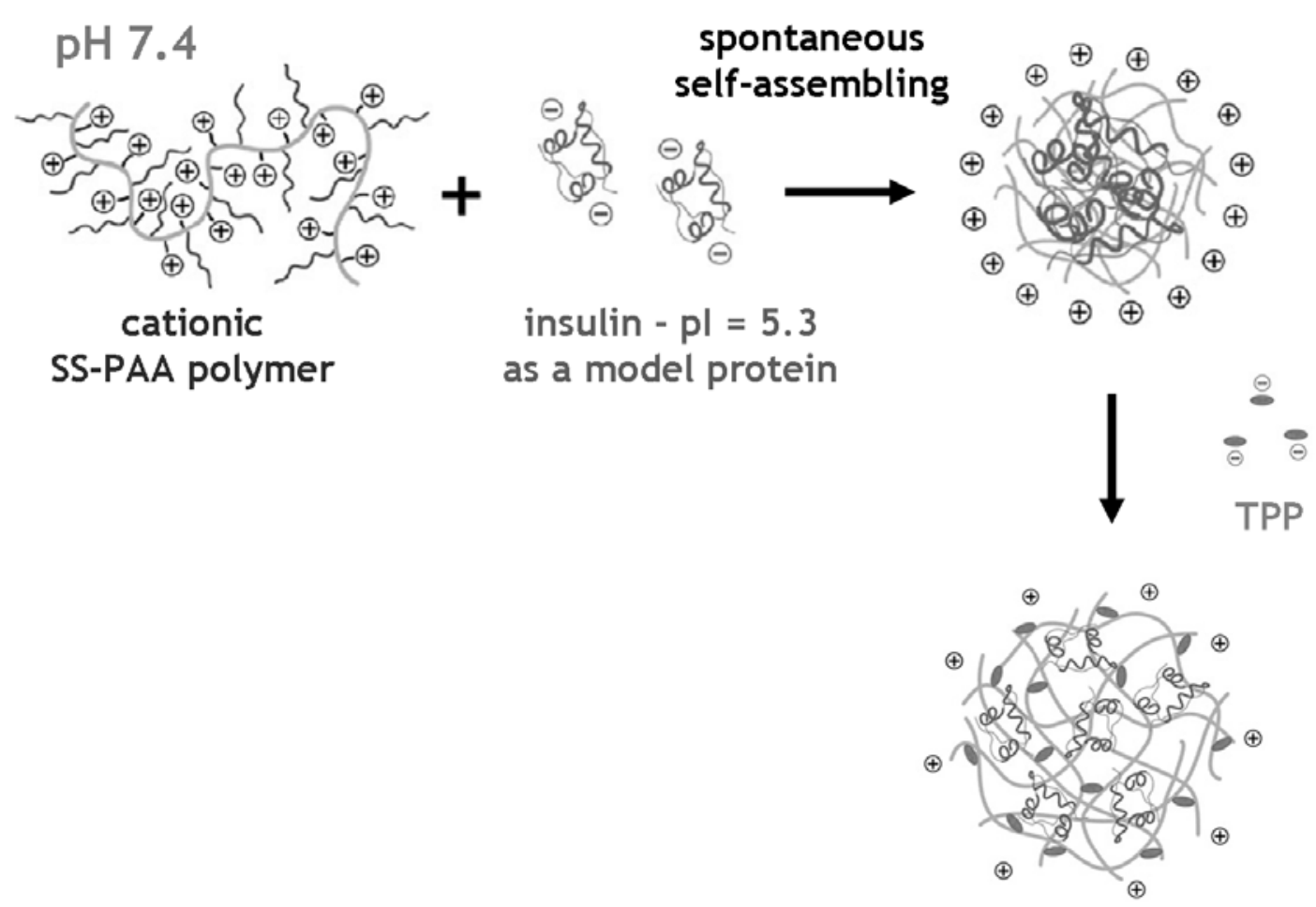

Figure B.2. Schematic representation of insulin nanoparticle formation by self-assembling formation of TPP-crosslinked nanoparticles at neutral $\mathrm{pH}$ by charge attraction between a negatively-charged protein (insulin) and a positively-charged polymer ( $p(C B A-A B O L))$.

Ionic crosslinks were performed using the polyions TPP and deoxyribonucleic acid (DNA). The significant differences between these two entities are their molecular size and their amount of available crosslinking phosphate groups.

TPP is a small molecule, with five hydroxyl groups, which in principle could be deprotonated (see structure in Figure B.3.).

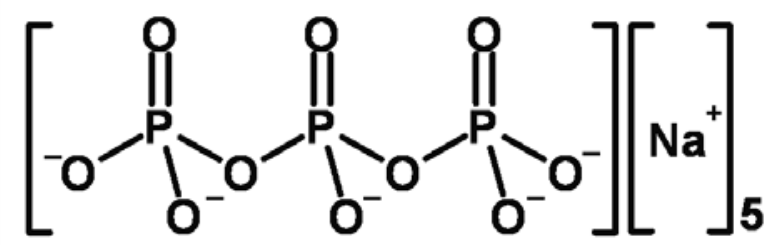

Figure B.3. Structure of sodium triphosphate pentabasic (TPP) 
DNA is a large polyphosphate, which notorious helix structure is composed of bases linked together on the inside and sugar phosphate backbone on the outside.

As a comparison to these two ionic gelation systems, chemically crosslinked nanoparticles were prepared by addition of trimethylolpropane tris 3-mercaptopropionate (3SH). 3SH contains three thiol groups reactive to form covalent bonds with the disulfide linkages present in the main chain of SS-PAAs. In this way, a compact network structure of nanoparticles can be obtained.

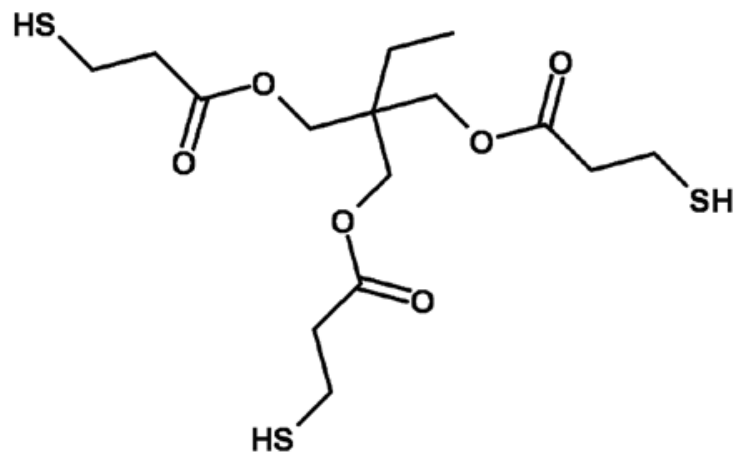

Figure B.4. Structure of trimethylolpropane tris 3-mercaptopropionate (3SH)

\section{Materials and methods}

\subsection{Materials}

Human insulin was kindly supplied by Novo Nordisk. FITC-insulin was obtained from Sigma-Aldrich. All monomers used for the polymer synthesis, 4-amino-1-butanol (ABOL, Aldrich) and N,N'-cystaminebisacrylamide (CBA, Polysciences) were purchased in the highest purity available and used without further purification.

4-(2-hydroxyethyl)-1-piperazineethanesulfonic acid (HEPES, Sigma), dithiothreitol (DTT, Sigma-Aldrich), sodium triphosphate pentabasic (TPP, Sigma-Aldrich), deoxyribonucleic acid sodium salt type 1 from calf thymus (DNA, Sigma-Aldrich), trimethylolpropane tris 3-mercaptopropionate (3SH, Sigma-Aldrich) and methanol ( $\mathrm{MeOH}$, Biosolve) were used as received. Deionized water (DI water) was obtained from a MilliQ-water purification system (Millipore, France).

\subsection{Synthesis of $p(C B A-A B O L)$}

The bioreducible polymer $\mathrm{p}(\mathrm{CBA}-\mathrm{ABOL})$ was synthesized via Michael polyaddition of the primary amine monomer, $\mathrm{ABOL}$, to the bisacrylamide $\mathrm{CBA}$, as described in Chapter 3 . 


\subsection{Polymer characterization}

Details about the ${ }^{1 H}$ NMR and GPC data of $\mathrm{p}(\mathrm{CBA}-\mathrm{ABOL})$ have been described in Chapter 3.

\section{$2.4 p(C B A-A B O L) /$ insulin polyelectrolyte complex formation}

$\mathrm{p}(\mathrm{CBA}-\mathrm{ABOL}) /$ insulin nanocomplexes at different polymer/protein weight ratios were prepared by adding a HEPES buffer solution $(10 \mathrm{mM}, \mathrm{pH} 7.4)$ of $\mathrm{p}(\mathrm{CBA}-\mathrm{ABOL})(800 \mu \mathrm{l}$, ranging from 18.75 to $150 \mu \mathrm{g} / \mathrm{ml}$ ) to a HEPES buffer solution (10 mM, pH 7.4) of insulin (200 $\mu \mathrm{l}, 75 \mu \mathrm{g} / \mathrm{ml})$, followed by vortexing for 5 seconds and incubating at room temperature for 30 minutes.

\subsection{Modification of $p(C B A-A B O L)$ /insulin nanoparticles by ionic gelation or chemical crosslink}

Solutions of TPP, DNA and 3SH were prepared at different concentrations in 10mM HEPES buffer $\mathrm{pH}$ 7.4. The concentration of agent added depends on the polymer concentration in the solution; therefore it varies for every polymer/insulin ratio used. To investigate the optimal final composition, for polymer/insulin solution prepared as previously described in 2.4, different crosslinking agent/polymer weight ratios ranging from $0.1 / 1$ to $3 / 1$ were used. The crosslinked nanoparticles were prepared by adding $10 \%$ crosslinking agent solution to the previously prepared polymer/insulin particle solutions, and the final mixture was incubated at room temperature for additional 30 minutes.

\subsection{Characterization of post-modified $p(C B A-A B O L)$ /insulin nanoparticles}

\subsubsection{Particle size and zeta-potential measurements}

Particle size and surface charge measurements of the nanocomplexes were determined by dynamic light scattering (DLS) at $25^{\circ} \mathrm{C}$ and at $37^{\circ} \mathrm{C}$ with a Zetasizer Nano ZS (Malvern Instruments, Malvern, UK) using a wavelength of $532 \mathrm{~nm}$. The value was recorded as the mean of three measurements. The size distribution was given by polydispersity index (PDI, a value between 0 and 1). A PDI of 1 indicates large variations in particle size; a PDI of 0 indicates no variation in particle size (as an ideal monodispersed formulation).

As the size of the particles influences the eventual uptake and distribution of the particles inside cells, their stability was investigated and followed by DLS, measured at $25^{\circ} \mathrm{C}$ and $37^{\circ} \mathrm{C}$. The results at $25^{\circ} \mathrm{C}$ represent the ability of the nanocomplex solution to be stored at room temperature, whereas the results at $37^{\circ} \mathrm{C}$ give an indication about the thermal stability of the particles in the human body. 


\subsubsection{Insulin condensation and loading efficiency}

To estimate the loading efficiency of the nanoparticles at neutral $\mathrm{pH}$, particle solutions of $\mathrm{p}(\mathrm{CBA}-\mathrm{ABOL}) /$ insulin nanoparticles were prepared at polymer/protein weight ratio ranging from 1/1 to 24/1 using FITC-labeled insulin. The nanoparticles were centrifuged at 14000 rpm for 30 minutes at $4^{\circ} \mathrm{C}$. Aliquots of supernatant were subsequently taken and their protein content determined by fluorescence spectroscopy (Safire ${ }^{2}$, Tecan, Canada) at an emission wavelength of $519 \mathrm{~nm}$ and an excitation wavelength of $495 \mathrm{~nm}$. The actual loading efficiency was indirectly determined by measuring the difference between the total amount of insulin added to the solution and the amount of insulin in the free form in the supernatant. A calibration curve from solutions of various fluorescently-labeled insulin concentrations was determined prior to this experiment. It was confirmed that free insulin was not precipitated from the solution by centrifugation.

\subsubsection{Stability of $p(C B A-A B O L) /$ insulin after addition of ionic or chemical crosslinking agent}

Particle stability was evaluated for two polymer/insulin weight ratios: $1 / 1$ and $2 / 1$. For each polymer/insulin ratio, the TPP/polymer ratios of $0 / 1,0.1 / 1,0.2 / 1$ and $0.4 / 1$ were used. Moreover, particle stability after addition of DNA and TPP was tested for the polymer/insulin weight ratio of $2 / 1$ and DNA/polymer weight ratios of $0.75 / 1,1 / 1,1.5 / 1$, $2 / 1$ and $3 / 1$, and $3 \mathrm{SH} /$ polymer weight ratios of $0.1 / 1,0.2 / 1,0.4 / 1$ and $0.8 / 1$. Samples were incubated at $25^{\circ} \mathrm{C}$ and $37^{\circ} \mathrm{C}$ and particle size was followed. Between the measurements, the samples were stored at room temperature for the samples measured at $25^{\circ} \mathrm{C}$, or stored in an incubator at $37^{\circ} \mathrm{C}$.

\subsubsection{Release of insulin from nanoparticles by disulfide reduction of $p(C B A-A B O L)$}

The release of protein from the nanoparticles at intracellular mimicking reductive conditions was measured using solutions of $\mathrm{p}(\mathrm{CBA}-\mathrm{ABOL}) /$ insulin nanoparticles at polymer/protein weight ratio 2/1 using FITC-labeled insulin. The reducing agent DTT was added to a final concentration of $2.5 \mathrm{mM}$ and the solution was incubated for 30 minutes at room temperature. Subsequently, the solution was centrifuged at $14000 \mathrm{rpm}$ for 30 minutes at $4^{\circ} \mathrm{C}$. Aliquots of supernatant were taken and their protein content was determined by the measurement of the fluorescence intensity using a prior-determined calibration curve. 


\subsubsection{Release of insulin by acidification of the nanoparticles}

The effect of $\mathrm{pH}$ decrease from 7.4 to 5.1 (mimicking endosomal pH decrease) was investigated by DLS measurements. Particle size and surface charge measurements of the nanocomplexes were performed at $25^{\circ} \mathrm{C}$ with a Zetasizer Nano ZS (Malvern Instruments, Malvern) using a wavelength of $532 \mathrm{~nm}$. Simultaneously, the nanoparticular solution was titrated from $\mathrm{pH} 7.4$ to $\mathrm{pH} 5.1$ by regularly adding small aliquots of $0.25 \mathrm{M} \mathrm{HCl}$ solution using a MTP-2 multipurpose titrator (Malvern Instruments, Malvern). Particle size and surface charge were determined every half-unit of $\mathrm{pH}$.

\section{Results and Discussion}

\subsection{Synthesis and characterization of $p(C B A-A B O L)$}

As described in Chapter 3, the bioreducible SS-PAA polymer, p(CBA-ABOL), with repetitive disulfide linkages in their main chain was synthesized via Michael addition of the corresponding primary amine monomer, $\mathrm{ABOL}$, to $\mathrm{CBA}$. The resulting polymer, collected in its $\mathrm{HCl}$-salt form as white solid powder after freeze-drying, has a good solubility in water. The yield was ca. $45 \%$ after ultrafiltration and lyophilization. Details about the ${ }^{1} \mathrm{H}$ NMR and GPC data of $\mathrm{p}(\mathrm{CBA}-\mathrm{ABOL})$ are available in Chapter 3.

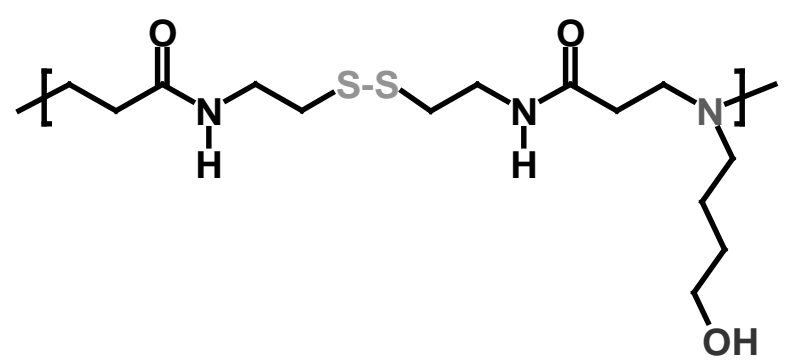

Figure B.5. Chemical structure of the SS-PAA $p(C B A-A B O L)$.

\subsection{Protein uptake into the $p(C B A-A B O L)$ nanoparticles: physical characterization, loading efficiency and optimal polymer/insulin ratio}

At physiological $\mathrm{pH}(\mathrm{pH} 7.4), \mathrm{p}(\mathrm{CBA}-\mathrm{ABOL})$ is present as a polycation due to the partial protonation of the tertiary nitrogens in the main chain of the polymer. Charge interaction with insulin can be expected since this enzyme, with an isoelectric point of 5.3, has a net negative charge under these conditions. DLS and zeta-potential measurements showed that $\mathrm{p}(\mathrm{CBA}-\mathrm{ABOL})$ is capable to form nanosized polyelectrolyte complexes by self-assembly 
with insulin. The particles have sizes smaller than $180 \mathrm{~nm}$ with low polydispersity (PDI < 0.15) and positive surface charge (Figure B.6).

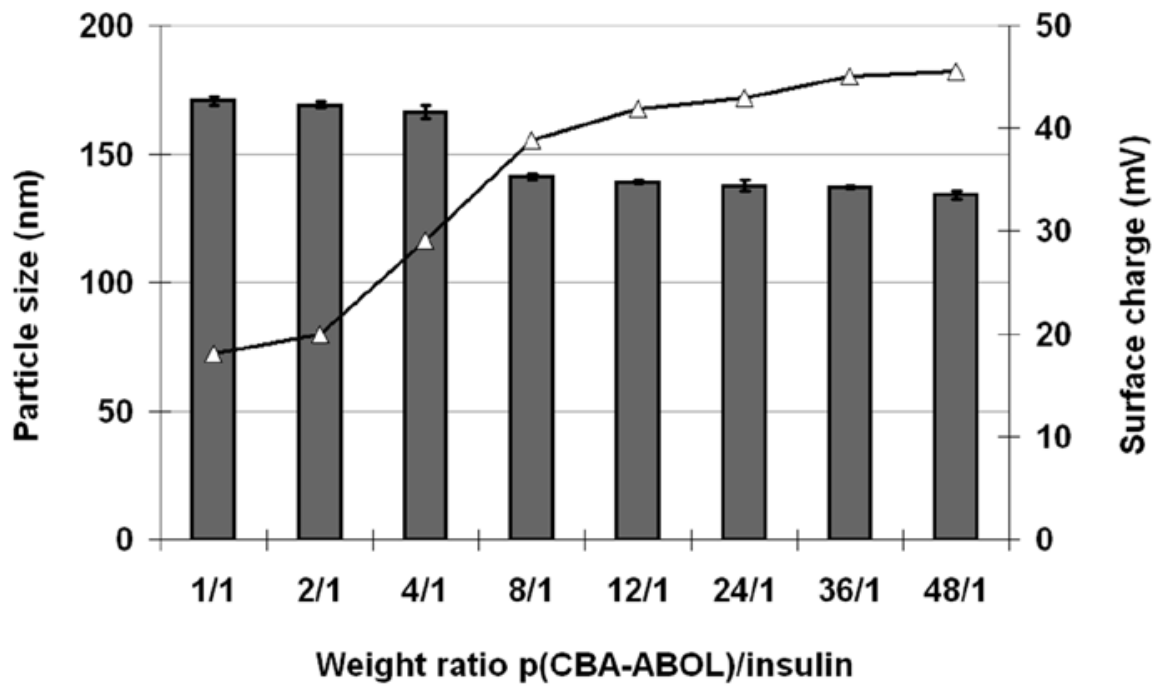

Figure B.6. Size distributions and zeta-potentials of $p(C B A-A B O L) /$ insulin nanoparticles in $10 \mathrm{mM}$ HEPES buffer $\mathrm{pH} 7.4$, measured by DLS at $25^{\circ} \mathrm{C}$ according to the polymer/protein weight ratio.

Table B.1 gives the loading efficiencies of the $p(C B A-A B O L) /$ insulin nanoparticles at neutral $\mathrm{pH}$ in HEPES buffer solution $(10 \mathrm{mM}, \mathrm{pH} 7.4)$, as determined by fluorescence spectroscopy measurements using FITC-labeled insulin. It can be seen that the incorporation of insulin in the disulfide polymer nanoparticles of $p(C B A-A B O L)$ is complete even under the dilute conditions applied (insulin concentration: $15 \mu \mathrm{g} / \mathrm{ml}$ ) for each polymer/insulin weight ratio measured.

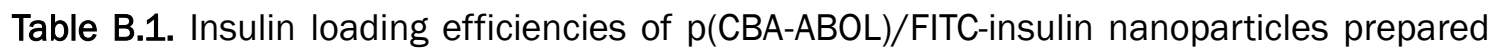
using different $\mathrm{p}$ (CBA-ABOL)/FITC-insulin weight ratios in HEPES buffer $\mathrm{pH}$ 7.4. The reported values were corrected from the protein content determined in the supernatant using free FITC-insulin.

\begin{tabular}{|c|c|}
\hline $\begin{array}{c}\text { Polymer/insulin weight } \\
\text { ratio }\end{array}$ & $\begin{array}{c}\text { Insulin loading efficiency } \\
(\%)^{*}\end{array}$ \\
\hline $1 / 1$ & 100 \\
\hline $2 / 1$ & 100 \\
\hline $4 / 1$ & 100 \\
\hline $8 / 1$ & 100 \\
\hline
\end{tabular}

* Percentage of insulin that is incorporated in the polymeric nanoparticles +/- 0.5. Initial insulin concentration is $15 \mu \mathrm{g} / \mathrm{ml}$. 
3.3 Modification of $p(C B A-A B O L) /$ insulin nanoparticles by addition of ionic or chemical crosslinker: physical characterization and loading efficiency

\subsubsection{Post-modification of $p(C B A-A B O L)$ /insulin nanoparticles using TPP}

Particles of $\mathrm{p}(\mathrm{CBA}-\mathrm{ABOL}) /$ insulin modified by the succeeding addition of TPP were prepared at different polymer/protein weight ratios using various TPP/polymer weight ratios, in $10 \mathrm{mM}$ HEPES buffer solution $\mathrm{pH}$ 7.4. DLS and zeta-potential measurements showed an increase in particle size, notably at high TPP/polymer weight ratios, and a decrease of surface charge from 20-40 $\mathrm{mV}$ to values close to 2-3 $\mathrm{mV}$ after addition of TPP to $\mathrm{p}(\mathrm{CBA}-\mathrm{ABOL}) /$ insulin nanoparticles (Figure B.7).

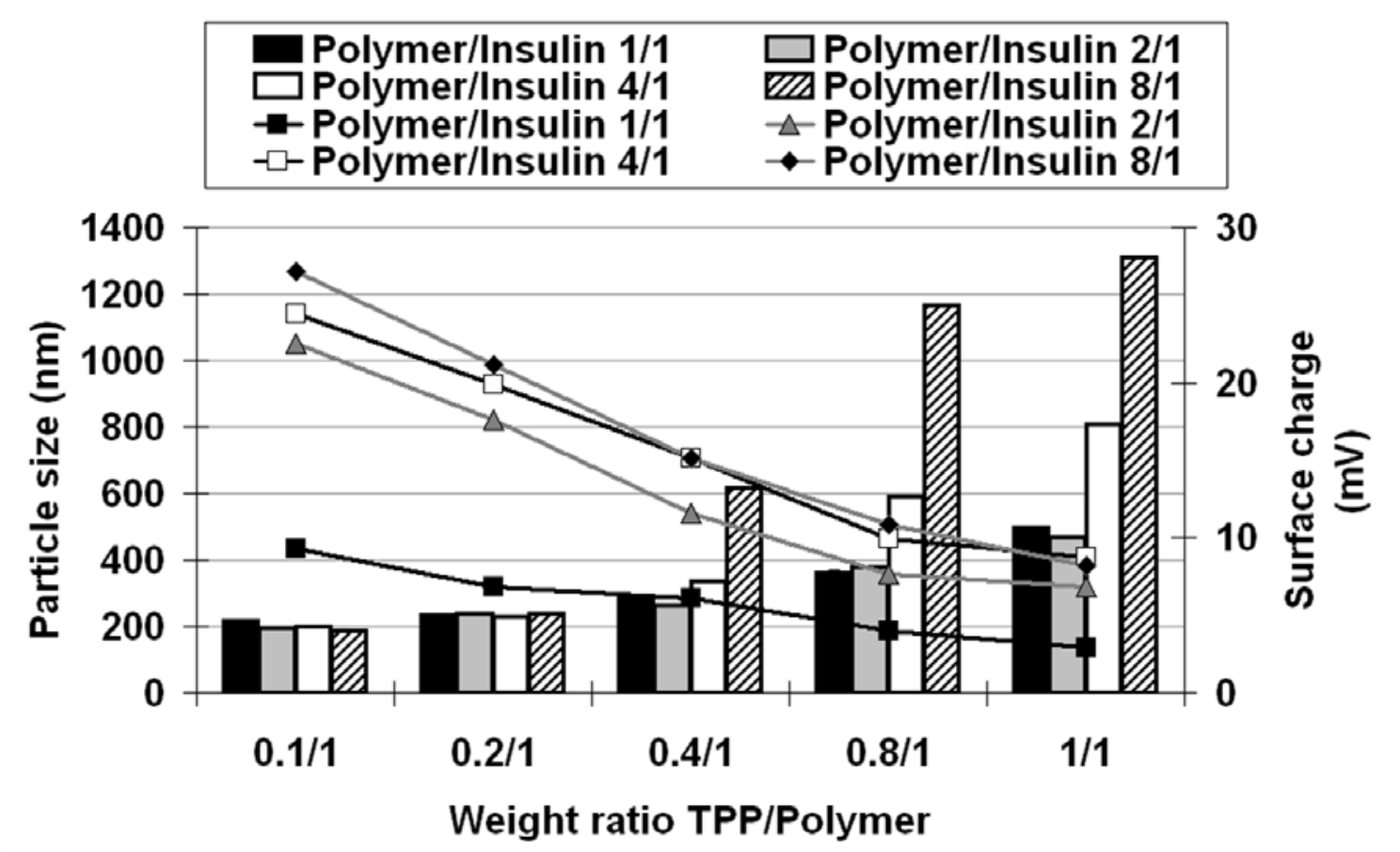

Figure B.7. Size distributions and zeta-potentials of $p(C B A-A B O L) /$ insulin nanoparticles in $10 \mathrm{mM}$ HEPES buffer pH 7.4 after addition of TPP at different polymer / protein ratios, measured by DLS at $25^{\circ} \mathrm{C}$ according to the TPP/polymer weight ratio.

The particles prepared at $\mathrm{p}(\mathrm{CBA}-\mathrm{ABOL})$ /insulin weight ratio 2/1 and TPP/polymer weight ratios 0.2-0.4/1 gave interesting results in term of size and surface charge with particle size similar to the unmodified particles and considerably lower surface charge, but still with residual cationic charge. These results would be valuable for instance for intravenous administration where serum proteins are notoriously known to aggregate on positively charged particles. A decrease in surface charge would then prevent this undesirable phenomenon. Moreover, for those particles, it can be seen that the 
incorporation of insulin in the disulfide polymer nanoparticles is very high even under the dilute conditions applied (insulin concentration: $15 \mu \mathrm{g} / \mathrm{ml}$ ) and similar to the unmodified particles (Table B.2).

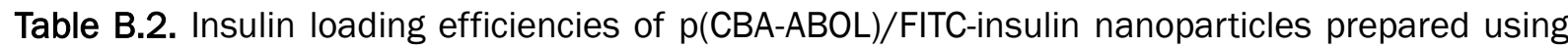
polymer/insulin weight ratio $2 / 1$ in HEPES buffer $\mathrm{pH} 7.4$, modified with TPP at various TPP/polymer weight ratios and compared to the unmodified particles. The reported values were corrected from the protein content determined in the supernatant using free insulin.

\begin{tabular}{|c|c|c|}
\hline $\begin{array}{c}\text { Nanoparticle } \\
\text { crosslinker }\end{array}$ & TPP/polymer weight ratio & Loading efficiency (\%) * \\
\hline no crosslinker & $0 / 1$ & 100 \\
\hline \multirow{3}{*}{ TPP } & $0.1 / 1$ & 93 \\
\cline { 2 - 3 } & $0.2 / 1$ & 91 \\
\cline { 2 - 3 } & $0.4 / 1$ & 91 \\
\cline { 2 - 3 } & $0.8 / 1$ & 90 \\
\hline
\end{tabular}

* Percentage of insulin that is incorporated in the polymeric nanoparticles (+/- 1). Initial insulin concentration is $15 \mu \mathrm{g} / \mathrm{ml}$.

\subsubsection{Post-modification of $p(C B A-A B O L)$ /insulin nanoparticles using DNA}

Particles of $\mathrm{p}(\mathrm{CBA}-\mathrm{ABOL}) /$ insulin with subsequent addition of DNA in the particle formulation were prepared at polymer/protein weight ratio 2/1 using various DNA/polymer weight ratios. DLS and zeta-potential measurements showed that these modified particles have similar particle size, but have a reversed charge (ca. $-30 /-55 \mathrm{mV}$ ) compared to unmodified $\mathrm{p}(\mathrm{CBA}-\mathrm{ABOL})$ /insulin nanoparticles (Figure B.8). 


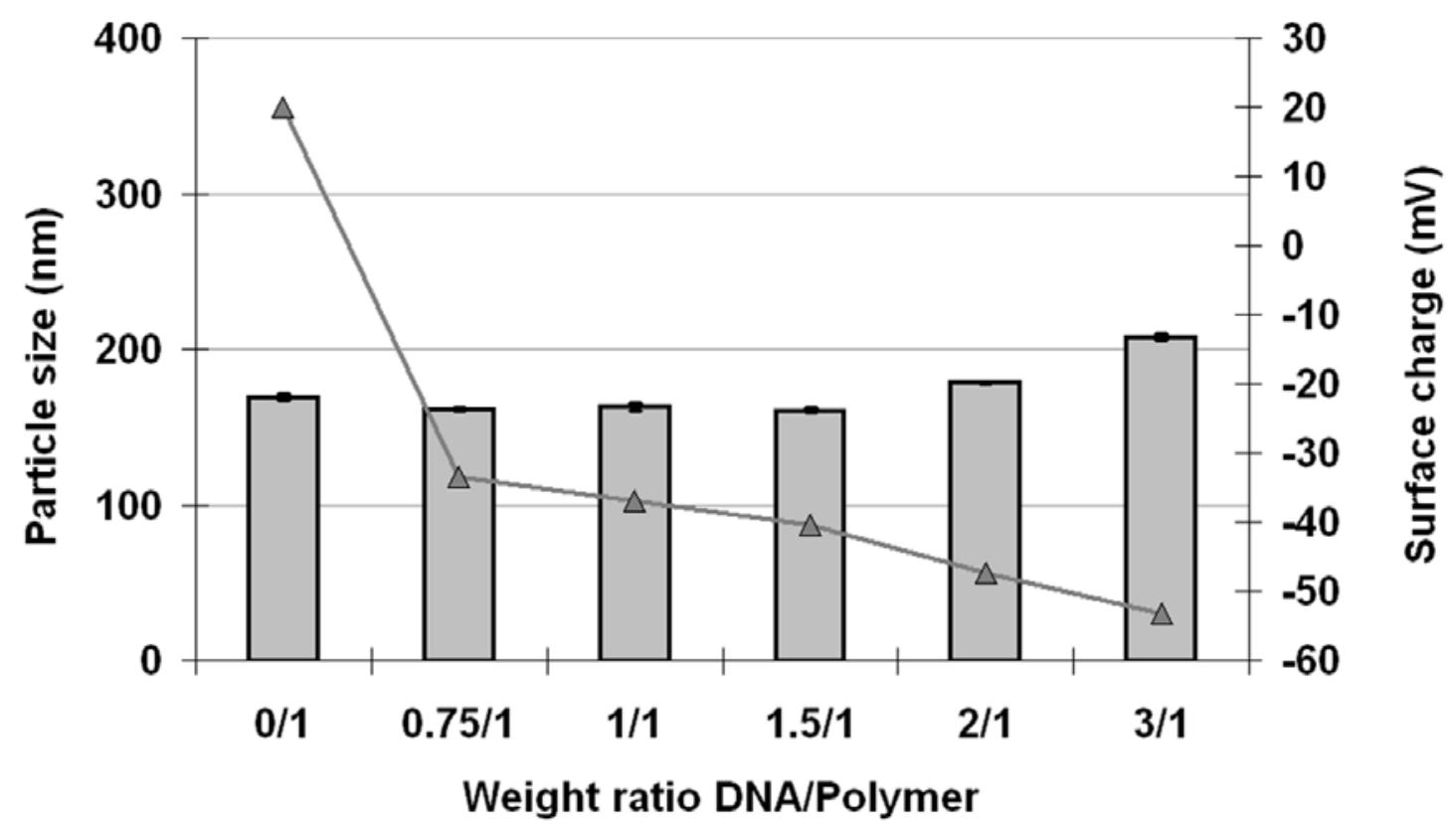

Figure B.8. Size distributions and zeta-potentials of $p(C B A-A B O L) /$ insulin nanoparticles in $10 \mathrm{mM}$ HEPES buffer $\mathrm{pH} 7.4$ after addition of DNA at polymer / protein ratio 2/1, measured by DLS at $25^{\circ} \mathrm{C}$ according to the DNA/polymer weight ratio.

The highly negative surface charges indicate a distinctly different architecture of these particles compared to the unmodified particles. The cationic charge of the unmodified $\mathrm{p}(\mathrm{CBA}-\mathrm{ABOL}) /$ insulin nanoparticles prove that the polymer is exposed on the outside of the particle and may form a shell around the condensed insulin molecules. The presence of highly negative charges in the modified particles demonstrates that either the insulin or the DNA used for the modification of the $\mathrm{p}(\mathrm{CBA}-\mathrm{ABOL}) /$ insulin is now present at the exterior of the particle, therefore minimizing the protection of the insulin loading if insulin is at the outside. 
Table B.3. Insulin loading efficiencies of $\mathrm{p}$ (CBA-ABOL)/FITC-insulin nanoparticles prepared using polymer/insulin weight ratio 2/1 in HEPES buffer $\mathrm{pH} 7.4$, modified with DNA at various DNA/polymer weight ratios and compared to the unmodified particles The reported values were corrected from the protein content determined in the supernatant using free insulin.

\begin{tabular}{|c|c|c|}
\hline $\begin{array}{c}\text { Nanoparticle } \\
\text { crosslinker }\end{array}$ & DNA/polymer weight ratio & Loading efficiency (\%) * \\
\hline no crosslinker & $0 / 1$ & 100 \\
\hline \multirow{5}{*}{ DNA } & $0.8 / 1$ & 99 \\
\cline { 2 - 3 } & $1 / 1$ & 90 \\
\cline { 2 - 3 } & $1.5 / 1$ & 88 \\
\cline { 2 - 3 } & $2 / 1$ & 86 \\
\hline & $2.5 / 1$ & 79 \\
\hline
\end{tabular}

* Percentage of insulin that is incorporated in the polymeric nanoparticles (+/- 1). Initial insulin concentration is $15 \mu \mathrm{g} / \mathrm{ml}$.

It can be seen that the incorporation of the protein in the disulfide polymer nanoparticles of $p(C B A-A B O L)$ is also in this case very high under the dilute conditions applied (insulin concentration: $15 \mu \mathrm{g} / \mathrm{ml}$ ) but somewhat lower than in unmodified $\mathrm{p}(\mathrm{CBA}-\mathrm{ABOL}) /$ insulin nanoparticles.

\subsubsection{Post-modification of $p(C B A-A B O L) /$ insulin nanoparticles using $3 S H$}

Particles of $\mathrm{p}(\mathrm{CBA}-\mathrm{ABOL}) /$ insulin with posterior addition of $3 \mathrm{SH}$ were prepared at polymer/insulin weight ratio $2 / 1$ using various $3 \mathrm{SH} /$ polymer weight ratios in $10 \mathrm{mM}$ HEPES buffer solution pH 7.4. DLS and zeta-potential measurements showed that these modified particles have slightly increased particle size, and lower surface charges compared to unmodified p(CBA-ABOL)/insulin nanoparticles (Figure B.9).

Similar to DNA addition to the $\mathrm{p}(\mathrm{CBA}-\mathrm{ABOL})$ /insulin nanoparticles, the negative surface charges of the nanoparticles obtained at higher $3 \mathrm{SH} /$ polymer ratios shows that in these particles the insulin might be present at the surface of the particle. 


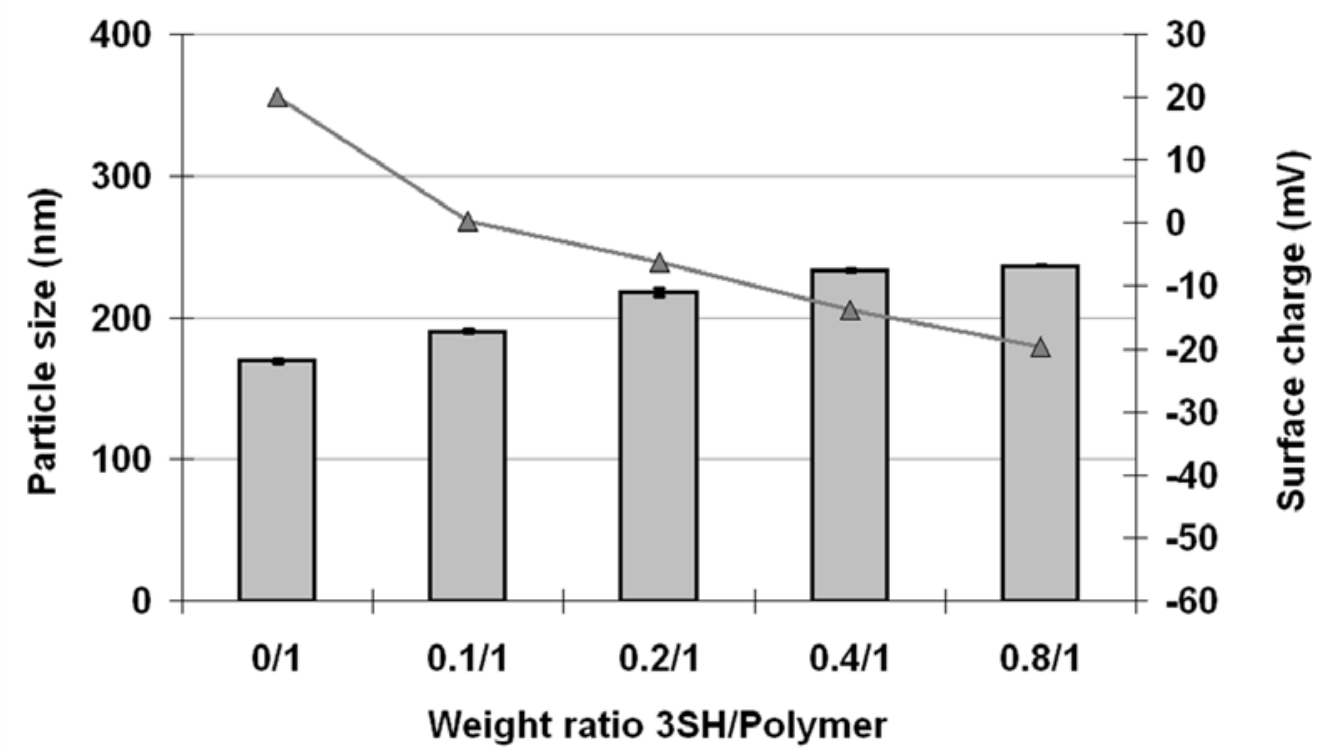

Figure B.9. Size distributions and zeta-potentials of $p(C B A-A B O L) /$ insulin nanoparticles in $10 \mathrm{mM}$ HEPES buffer $\mathrm{pH} 7.4$ after addition of $3 \mathrm{SH}$ at polymer /protein ratio 2/1, measured by DLS at $25^{\circ} \mathrm{C}$ according to the $3 \mathrm{SH} /$ polymer weight ratio.

The incorporation of insulin in the disulfide polymer nanoparticles of $p(C B A-A B O L)$ is high but lower than compared to unmodified $p(C B A-A B O L) /$ insulin nanoparticles, with a $20 \%$ decrease of loading efficiency at highest 3SH/polymer weight ratios (Table B.4).

Table B.4. Loading efficiency (LE) of nanoparticles crosslinked with DNA, 3SH and without crosslinker (PEC).

\begin{tabular}{|c|c|c|}
\hline $\begin{array}{c}\text { Nanoparticle } \\
\text { crosslinker }\end{array}$ & $\begin{array}{c}\text { Crosslinker/polymer } \\
\text { weight ratio }\end{array}$ & Loading efficiency (\%) * \\
\hline no crosslinker & $0 / 1$ & 100 \\
\hline \multirow{3}{*}{$3 S H$} & $0.1 / 1$ & 92 \\
\cline { 2 - 3 } & $0.2 / 1$ & 92 \\
\cline { 2 - 3 } & $0.4 / 1$ & 83 \\
\cline { 2 - 3 } & $0.8 / 1$ & 80 \\
\hline
\end{tabular}

* Percentage of insulin that is incorporated in the polymeric nanoparticles (+/-1). Initial insulin concentration is $15 \mu \mathrm{g} / \mathrm{ml}$.

\subsection{Stability of the post-modified $p(C B A-A B O L) /$ insulin nanoparticles}

Samples were incubated at $25^{\circ} \mathrm{C}$ and $37^{\circ} \mathrm{C}$ and particle size was followed to access the 
stability of the particles respectively at room and body temperature. The results are shown in Figures B.10 and B.11. The self-assembly of only $p(C B A-A B O L)$ and insulin result in unstable nanoparticles, for which particle size rapidly increases reaching and passing over the micron size after two days of incubation. The addition of TPP seems to fasten the destabilization of the particles with a faster increase of particle size (Figures B.10 and B.11, $A$ and $B)$.
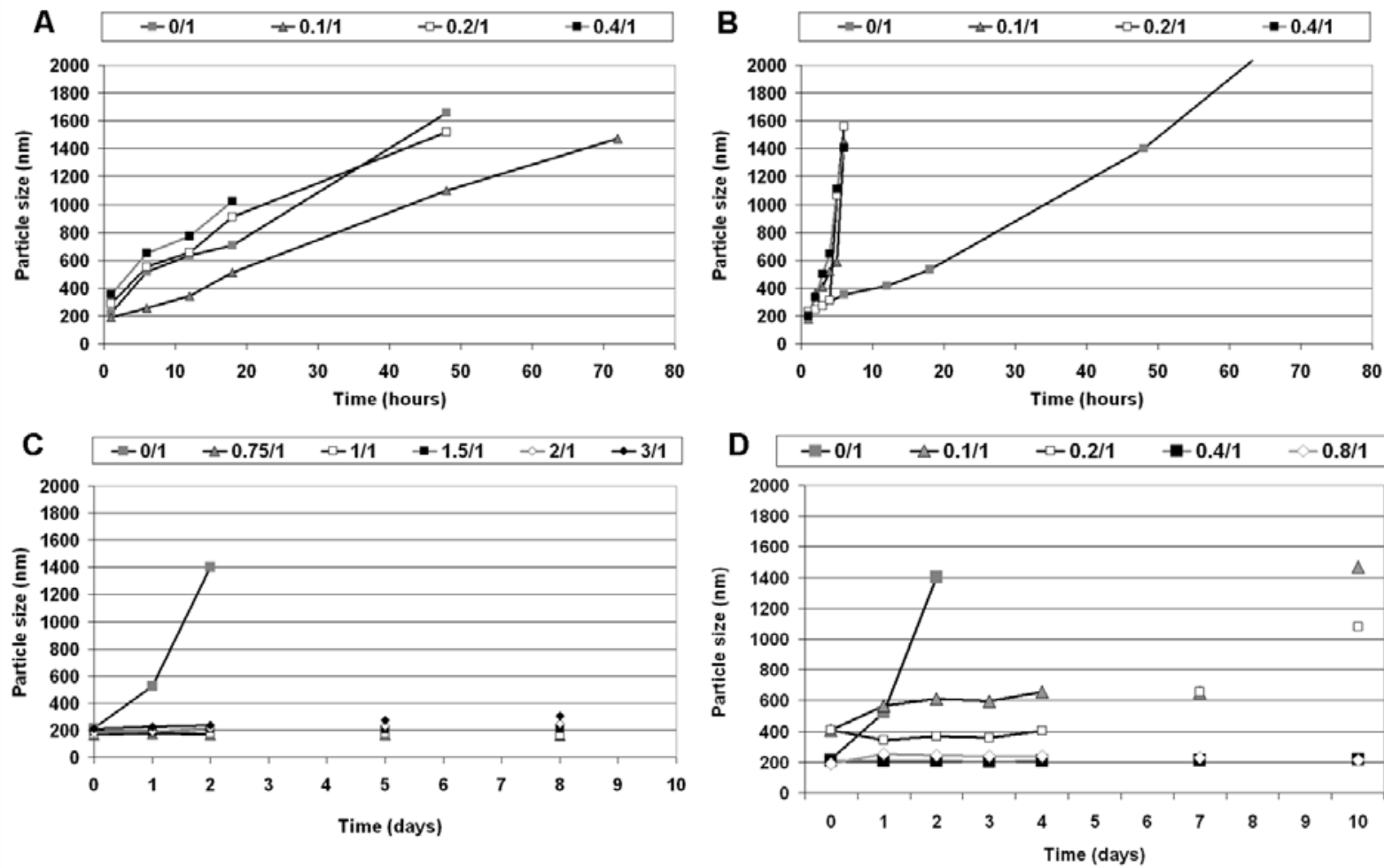

Figure B.10. Evolution of particle size of $p(C B A-A B O L) /$ insulin nanoparticles in 10mM HEPES buffer $\mathrm{pH} 7.4$, respectively after addition of TPP at polymer /protein ratio 1/1 (A) and polymer /protein ratio 2/1 (B), after addition of DNA (C) and $3 S H(D)$ at polymer/protein ratio 2/1, measured by DLS at $25^{\circ} \mathrm{C}$ according to the DNA/polymer weight ratio.

However, while adding DNA and $3 \mathrm{SH}$ to the $\mathrm{p}(\mathrm{CBA}-\mathrm{ABOL}) /$ insulin nanoparticle formulation results in stable nanoparticles with stable particle size more than one week after preparation of the particles both at room and body temperature (Figures B.10 and B.11, C and D). 

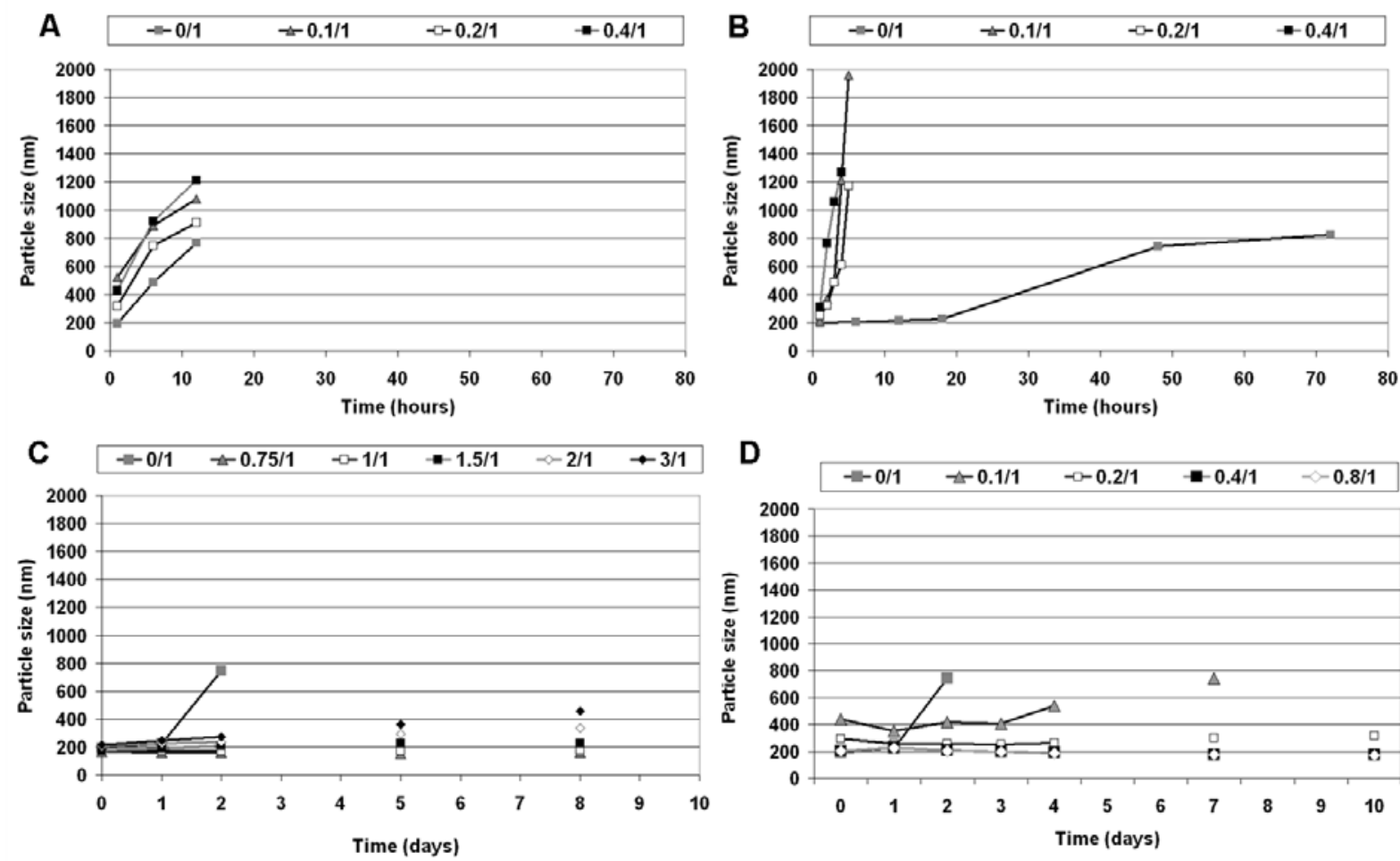

Figure B.11. Evolution of particle size of $p$ (CBA-ABOL)/insulin nanoparticles in 10mM HEPES buffer $\mathrm{pH} 7.4$, respectively after addition of TPP at polymer /protein ratio 1/1 (A) and polymer /protein ratio 2/1 (B), after addition of DNA (C) and $3 S H(D)$ at polymer/protein ratio 2/1, measured by DLS at $37^{\circ} \mathrm{C}$ according to the DNA/polymer weight ratio.

\subsection{Mimicking intracellular degradation by bioreduction of the $p(C B A-A B O L) /$ insulin nanoparticles}

Table B.5 gives the percentages of insulin that is released from the different unmodified and modified $\mathrm{p}(\mathrm{CBA}-\mathrm{ABOL})$ /insulin nanoparticles after addition of $2.5 \mathrm{mM} \mathrm{DTT}$, as determined by fluorescence measurements of the supernatant after centrifugation using FITC labeled insulin. The nanoparticles directed formed from the disulfide polymer $p(C B A-A B O L)$ and insulin have released most of the encapsulated protein, due to the fast degradation of the polymers. Same results were observed once TPP was added to the nanoparticle formulation. 
Table B.5. Insulin release from $\mathrm{p}(\mathrm{CBA}-\mathrm{ABOL}) / \mathrm{FITC}$-insulin nanoparticles in HEPES buffer $\mathrm{pH} 7.4$ (weight ratio 2/1), post-modified with TPP, DNA or DNA, or unmodified, after addition of DTT to a final concentration of $2.5 \mathrm{mM}$.

\begin{tabular}{|c|c|c|}
\hline $\begin{array}{c}\text { Nanoparticle } \\
\text { crosslinker }\end{array}$ & $\begin{array}{c}\text { Crosslinker/polymer } \\
\text { weight ratio }\end{array}$ & Insulin release (\%) \\
\hline no crosslinker & $0 / 1$ & 95 \\
\hline \multirow{4}{*}{ TPP } & $0.1 / 1$ & 93 \\
\cline { 2 - 3 } & $0.2 / 1$ & 91 \\
\cline { 2 - 3 } & $0.4 / 1$ & 89 \\
\cline { 2 - 3 } & $0.8 / 1$ & 89 \\
\hline \multirow{5}{*}{ DNA } & $1 / 1$ & 88 \\
\cline { 2 - 3 } & $0.8 / 1$ & 34 \\
\cline { 2 - 3 } & $1 / 1$ & 35 \\
\cline { 2 - 3 } & $1.5 / 1$ & 48 \\
\cline { 2 - 3 } & $2 / 1$ & 35 \\
\cline { 2 - 3 } & $2.5 / 1$ & 34 \\
\hline \multirow{5}{*}{$3 S \mathrm{H}$} & $3 / 1$ & 40 \\
\cline { 2 - 3 } & $0.1 / 1$ & 7 \\
\cline { 2 - 3 } & $0.2 / 1$ & 3 \\
\cline { 2 - 3 } & $0.4 / 1$ & 14 \\
\hline
\end{tabular}

Nevertheless, a drastic decrease of release was observed when DNA and 3SH were added to the $p(C B A-A B O L) /$ insulin nanoparticle formulation. This might be explained by the difference in particle self-assembly. Since for these two types of particles, surface charge was highly negatively charged, the protein and protein may self-assemble with the polymer shielded in the core of the particles and the protein on the shell, therefore exposing its negative charges on the surface. Consequently, in this conformation, the polymer is shielded and protected from degradation and reduction by DTT, preventing insulin release 


\subsection{Mimicking intracellular acidification of the $p(C B A-A B O L) /$ insulin nanoparticles}

Since electrostatic interactions between the positively-charged polymer and the negatively-charged protein are the main driving force for the self assembly into nanoparticles at neutral $\mathrm{pH}$, it can be anticipated that a decrease in $\mathrm{pH}$ as is occurring while entering in more acidic environments, such as during endosomal acidification $(\mathrm{pH}$ 5) or encountered when entering the stomach ( $\mathrm{pH} \sim 1-2)$, will also influence the stability of the nanoparticles. On one hand, a decrease of the $\mathrm{pH}$ will lead to a decrease of negative charge on the protein, but on the other hand, the degree of protonation of the $\mathrm{p}(\mathrm{CBA}-\mathrm{ABOL})$ polymer will be increased. Therefore there is a delicate balance between these effects, but it may be expected that the decrease of overall negative charge on the protein is the dominating factor, since there is already an excess of positive charge present in the nanoparticles at $\mathrm{pH}$ 7.4. Thus, a decrease of the $\mathrm{pH}$ will lead to destabilization and eventually release of the protein from the nanocomplexes. DLS measurements show that the $p(C B A-A B O L) /$ insulin nanoparticles significantly increase in size from ca. $150 \mathrm{~nm}$ to more than $1000 \mathrm{~nm}$ and surface charge from ca. $25 \mathrm{mV}$ to $40 \mathrm{mV}$ when the $\mathrm{pH}$ decreases from 7.4 (extracellular $\mathrm{pH}$ ) to 2 (stomach $\mathrm{pH}$ ) (Figure B.12), with an higher increase of particle size after reaching $\mathrm{pH} 5$, therefore titrating the particles to $\mathrm{pH}$ values lower than the isoelectric point of insulin. 


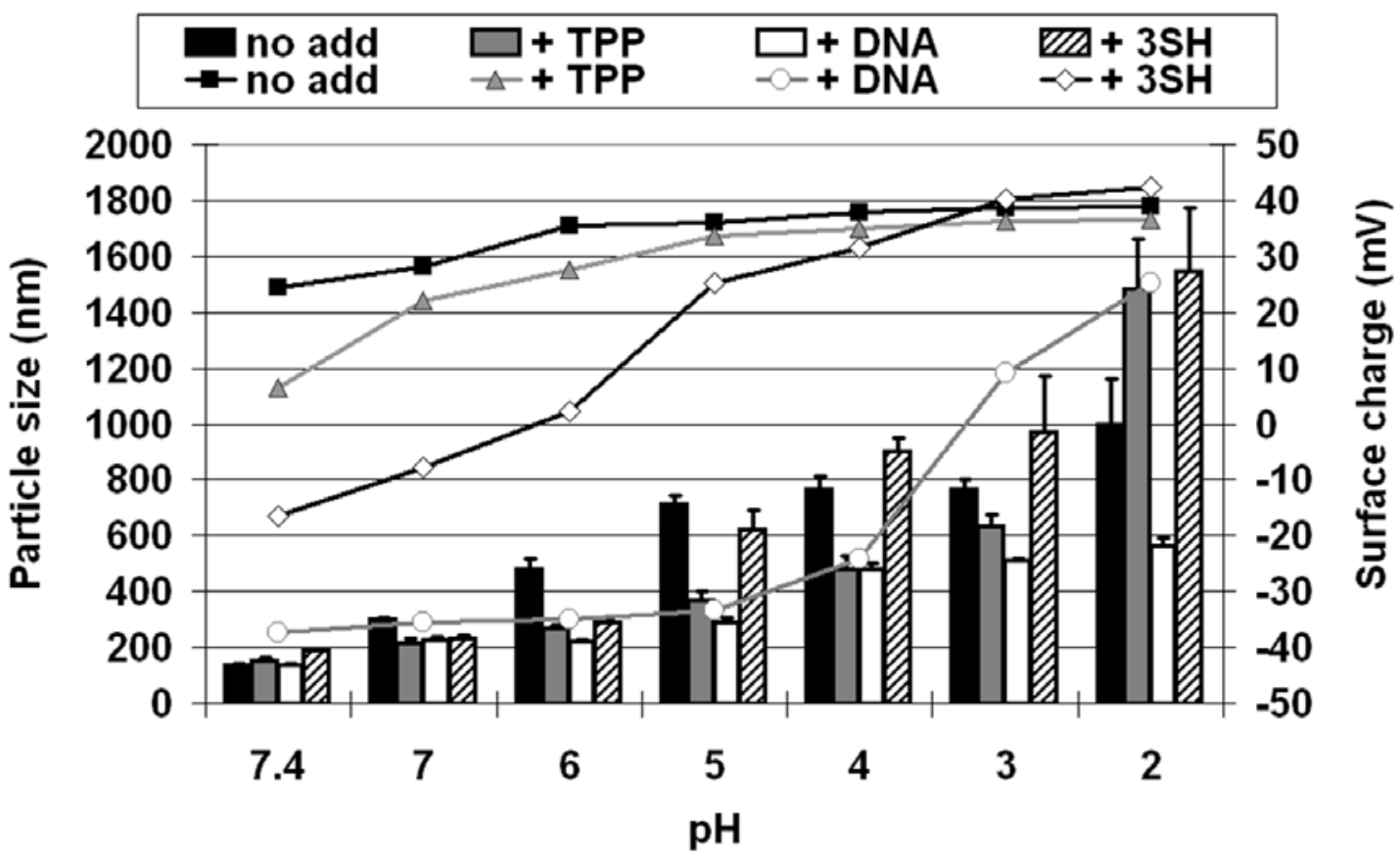

Figure B.12. Size distributions (left y-axis) and surface charges (right y-axis) of $p(C B A-A B O L) /$ insulin nanoparticles (weight ratio 2/1) during $\mathrm{pH}$ titration of the particle solution from $\mathrm{pH} 7.4$ to $\mathrm{pH} 2$ (titration duration: 3.5 hours), representing the $\mathrm{pH}$ of the extracellular and intracellular environments respectively, without modification (black bars, black squares) after modification with addition of TPP (grey bars, grey triangles), DNA (white bars, white circles) or 3SH (stripped bars, white diamonds).

The addition of TPP, DNA and 3SH in the formulation has almost no influence in the stability of the particles while decreasing $\mathrm{pH}$, a large increase of particle size and surface charge were observed notably while decreasing $\mathrm{pH}$ values lower than 5-6 (see Figure B.12), even if less drastic increase in size and charge was initially observed while adding DNA.

\section{Conclusions and perspectives.}

Self-assembled insulin polyelectrolyte complexes and nanoparticles were formed using $\mathrm{p}(\mathrm{CBA}-\mathrm{ABOL})$ a bioreducible poly(amidoamine) polymer. Nanoparticles were formed by addition of a third agent to the formulation: TPP, DNA and 3SH, to either induce ionic gelation or crosslink. The addition of this third component did not significantly change the particle sizes, however decreased the surface charge, the loading efficiency and the capacity of the nanoparticles to release insulin under reductive conditions. Moreover, no significant influence in particle size was observed while titrating the nanoparticles from neutral $\mathrm{pH}$ to endosomolytic $\mathrm{pH}$ or typical $\mathrm{pH}$ as in the stomach. 
Additional experiments could be performed in future studies to assess the influence of the addition of the third component of the formulation towards stability of insulin inside the nanoparticles, particularly in various simulated physiological conditions, or in the presence of trypsin for instance. The mucoadhesive properties of those particles could also be further studied.

\section{Acknowledgements}

This research work is part of the Integrated European project Nanobiopharmaceutics.

\section{References}

[1] C. Borghouts, C. Kunz, B. Groner, Current strategies for the development of peptide-based anti-cancer therapeutics. J. Pept. Sci. 11(11) (2005) 713-726.

[2] C. Krejsa, M. Rogge, W. Sadee, Protein therapeutics: new applications for pharmacogenetics. Nat. Rev. Drug Discov. 5(6) (2006) 507-521.

[3] R. Langer, J. Folkman, Polymers for Sustained-Release of Proteins and Other Macromolecules. Nature 263(5580) (1976) 797-800.

[4] A.K. Pavlou, J.M. Reichert, Recombinant protein therapeutics - success rates, market trends and values to 2010. Nat Biotech 22(12) (2004) 1513-1519.

[5] S. Stolnik, K. Shakesheff, Formulations for delivery of therapeutic proteins. Biotechnol. Lett. 31(1) (2009) 1-11.

[6] J.E. Talmadge, The Pharmaceutics and Delivery of Therapeutic Polypeptides and Proteins. Adv. Drug Delivery Rev. 10(2-3) (1993) 247-299.

[7] D.R. Owens, B. Zinman, G. Bolli, Alternative routes of insulin delivery. Diabetic Med. 20(11) (2003) 886-898.

[8] N.G. Pattrick, S.C.W. Richardson, M. Casolaro, P. Ferruti, R. Duncan, Poly(amidoamine)-mediated intracytoplasmic delivery of ricin A-chain and gelonin. J. Control Rel. 77(3) (2001) 225-232.

[9] C.O. Weill, S. Biri, A. Adib, P. Erbacher, A practical approach for intracellular protein delivery. Cytotechnology 56(1) (2008) 41-48.

[10] G. Ponchel, J.M. Irache, Specific and non-specific bioadhesive particulate systems for oral delivery to the gastrointestinal tract. Adv. Drug Deliv. Rev. 34(2-3) (1998) 191-219.

[11] H. Takeuchi, H. Yamamoto, Y. Kawashima, Mucoadhesive nanoparticulate systems for peptide drug delivery. Adv. Drug Deliv. Rev. 47(1) (2001) 39-54.

[12] P. Calvo, C. RemunanLopez, J.L. VilaJato, M.J. Alonso, Novel hydrophilic chitosan-polyethylene oxide nanoparticles as protein carriers. J. Appl. Polym. Sci. 63(1) (1997) 125-132.

[13] M.D. Chavanpatil, A. Khdair, J. Panyam, Nanoparticles for cellular drug delivery: Mechanisms and factors influencing delivery. J. Nanosci. Nanotechnol. 6(9-10) (2006) 2651-2663.

[14] A. Harada, K. Kataoka, Novel polyion complex micelles entrapping enzyme molecules in the core: Preparation of narrowly-distributed micelles from lysozyme and poly(ethylene glycol)-poly(aspartic acid) block copolymer in aqueous medium. Macromolecules 31(2) (1998) 288-294.

[15] J. Panyam, V. Labhasetwar, Biodegradable nanoparticles for drug and gene delivery to cells and tissue. Adv. Drug Deliv. Rev. 55(3) (2003) 329-347.

[16] A. Grenha, B. Seijo, C. Remunan-Lopez, Microencapsulated chitosan nanoparticles for lung protein delivery. Eur. J. Pharm. Sci. 25(4-5) (2005) 427-437.

[17] Y. Pan, J.M. Zheng, H.Y. Zhao, Y.J. Li, H. Xu, G. Wei, Relationship between drug effects 
and particle size of insulin-loaded bioadhesive microspheres. Acta Pharmacol. Sin. 23(11) (2002) 1051-1056.

[18] Y. Pan, Y.J. Li, H.Y. Zhao, J.M. Zheng, H. Xu, G. Wei, J.S. Hao, F.D. Cui, Bioadhesive polysaccharide in protein delivery system: chitosan nanoparticles improve the intestinal absorption of insulin in vivo. Int. J. Pharm. 249(1-2) (2002) 139-147.

[19] Z.S. Ma, H.H. Yeoh, L.Y. Lim, Formulation pH modulates the interaction of insulin with chitosan nanoparticles. J. Pharm. Sci. 91(6) (2002) 1396-1404.

[20] A.M. Dyer, M. Hinchcliffe, P. Watts, J. Castile, I. Jabbal-Gill, R. Nankervis, A. Smith, L. Illum, Nasal delivery of insulin using novel chitosan based formulations: A comparative study in two animal models between simple chitosan formulations and chitosan nanoparticles. Pharm. Res. 19(7) (2002) 998-1008.

[21] O. Boussif, F. Lezoualch, M.A. Zanta, M.D. Mergny, D. Scherman, B. Demeneix, J.P. Behr, A Versatile Vector for Gene and Oligonucleotide Transfer into Cells in Culture and in-Vivo Polyethylenimine. Proc. Natl. Acad. Sci. U. S. A. 92(16) (1995) 7297-7301.

[22] P. Ferruti, M.A. Marchisio, R. Duncan, Poly(amido-amine)s: Biomedical applications. Macromol. Rapid Commun. 23(5-6) (2002) 332-355.

[23] C.X. Wu, S.L. Lo, J. Boulaire, M.L.W. Hong, H.M. Beh, D.S.Y. Leung, S. Wang, A peptide-based carrier for intracellular delivery of proteins into malignant glial cells in vitro.

J. Control Rel. 130(2) (2008) 140-145.

[24] J.D. Eichman, A.U. Bielinska, J.F. Kukowska-Latallo, J.R. Baker Jr, The use of PAMAM dendrimers in the efficient transfer of genetic material into cells. Pharmaceut Sci Tech Today 3(7) (2000) 232-245.

[25] E. Ranucci, G. Spagnoli, P. Ferruti, D. Sgouras, R. Duncan, Poly(amidoamine)s with potential as drug carriers: degradation and cellular toxicity. J Biomater Sci Polym Ed 2(4) (1991) 303-315.

[26] J. Franchini, P. Ferruti, Perspectives on: Recent advances in poly(amidoamine)s chemistry. J. Bioact. Compat. Polym. 19(3) (2004) 221-236.

[27] C. Lin, C.-J. Blaauboer, M.M. Timoneda, M.C. Lok, M. van Steenbergen, W.E. Hennink, Z. Zhong, J. Feijen, J.F.J. Engbersen, Bioreducible poly(amido amine)s with oligoamine side chains: Synthesis, characterization, and structural effects on gene delivery. J. Control Rel. 126(2) (2008) 166-174.

[28] C. Lin, Z. Zhong, M.C. Lok, X. Jiang, W.E. Hennink, J. Feijen, J.F.J. Engbersen, Linear poly(amido amine)s with secondary and tertiary amino groups and variable amounts of disulfide linkages: Synthesis and in vitro gene transfer properties. J. Control Rel. 116(2) (2006) 130-137.

[29] C. Lin, Z. Zhong, M.C. Lok, X. Jiang, W.E. Hennink, J. Feijen, J.F.J. Engbersen, Random and block copolymers of bioreducible poly(amido amine)s with high- and low-basicity amino groups: Study of DNA condensation and buffer capacity on gene transfection. J. Control Rel. 123(1) (2007) 67-75.

[30] C. Lin, Z.Y. Zhong, M.C. Lok, X.L. Jiang, W.E. Hennink, J. Feijen, J.F.J. Engbersen, Novel bioreducible poly(amido amine)s for highly efficient gene delivery. Bioconjugate Chem. 18(1) (2007) 138-145.

[31] M.A. Mateos-Timoneda, M.C. Lok, W.E. Hennink, J. Feijen, J.F.J. Engbersen, Poly(amido amine)s as gene delivery vectors: Effects of quaternary nicotinamide moieties in the side chains. ChemMedChem 3(3) (2008) 478-486.

[32] G. Coué, J.F.J. Engbersen, Bioreducible poly(amidoamine)s with charge-reversal properties for intracellular protein delivery, J. Control Rel. 148(1) (2010) e9-e11

[33] G. Coué, J.F.J. Engbersen, Functionalized linear poly(amidoamine)s are efficient vectors for intracellular protein delivery. J. Control Rel. (2011) doi:10.1016/j.jconrel.2011.01.023

[34] A. Bernkop-Schnürch, Thiomers: A new generation of mucoadhesive polymers. Adv. Drug Delivery Rev. 57(11) (2005) 1569-1582.

[35] C. Lin, J.F.J. Engbersen, The role of the disulfide group in disulfide-based polymeric gene carriers. Expert Opin. Drug Deliv. 6(4) (2009) 421-439.

[36] K.C. Rajender, W.L. Frederick, H.K. Michael, M.B. David, G.B.R. Robert, R. Daniel, Plasma cysteine, cystine, and glutathione in cirrhosis. Gastroenterology 87(4) (1984) 770-776.

[37] S. Ganta, H. Devalapally, A. Shahiwala, M. Amiji, A review of stimuli-responsive 
nanocarriers for drug and gene delivery. J. Control Rel. 126(3) (2008) 187-204.

[38] G. Saito, J.A. Swanson, K.D. Lee, Drug delivery strategy utilizing conjugation via reversible disulfide linkages: role and site of cellular reducing activities. Adv. Drug Deliv. Rev. 55(2) (2003) 199-215.

[39] F.H. Meng, W.E. Hennink, Z. Zhong, Reduction-sensitive polymers and bioconjugates for biomedical applications. Biomaterials 30(12) (2009) 2180-2198. 
This thesis describes the design and development of bioreducible poly(amidoamine)s as bioresponsive vectors for protein delivery in vitro and in vivo. The structural influences of these polymers on their physico-chemical properties and protein delivery, intracellular profection capability, and cytotoxicity in vitro are discussed in detail.

A general introduction to the thesis and the relevant scientific background information regarding this study is given in the first two chapters. In Chapter 1, a general background with regard to the work in this thesis is presented. Chapter 2 reviews the current literature on the strategies used in the design of polymeric nanoparticles for therapeutic protein and peptide delivery. In this chapter fundamental knowledge about polymer-mediated protein delivery, notably via oral and nasal routes of administration, is given. After a description of the extra- and intracellular barriers to the delivery pathway, the strategies to overcome these barriers by the design of cationic polymers with low cytotoxicity, in particular poly(amidoamine)s (PAAs) for protein delivery, are outlined. Special attention has been given to poly(amidoamine)s with repetitive disulfide linkages in their backbone (SS-PAAs) that can undergo intracellular bioreduction.

Chapter 3 describes the development of an effective intracellular protein delivery system was developed based on functionalized linear PAAs that form self-assembled cationic nanocomplexes with oppositely charged proteins. These water-soluble PAAs efficiently condense $\beta$-galactosidase by self-assembly into nanoscaled and positively-charged complexes. Cell-internalization and cytotoxicity experiments showed that the PAA-based nanocomplexes were essentially non-toxic. $\beta$-Galactosidase was successfully internalized into COS-7 cells, with almost complete $\beta$-galactosidase activity, whereas the enzyme alone was not taken up by the cells.

The development of effective intracellular vectors for the delivery of proteins that have a net positive charge at neutral $\mathrm{pH}$ is described in Chapter 4. Therefore, SS-PAAs were designed with negatively-charged citraconic side groups that give charge-reversal upon $\mathrm{pH}$ decrease. At neutral $\mathrm{pH}$, these water-soluble and linear polymers efficiently self-assemble with cationic proteins into nanocomplexes by charge attraction. In this study, lysozyme was used as a positively charged model protein. Intracellular-mimicking 
lysozyme release from the nanoparticles is triggered by reduction of polymer disulfide linkages as well as by the inversion of protein-polymer charge interaction at $\mathrm{pH} 5$ (endosomal $\mathrm{pH}$ ) caused by hydrolysis of the citraconic side group leading to the charge-reversal of the polymer side group from negative to positive. Cell-internalization and cytotoxicity experiments showed that the SS-PAA-based nanocomplexes successfully internalized lysozyme into Huvec cells and were essentially non-toxic.

Chapter 5 describes the use of surface-sensitive analytical techniques to evaluate the responsiveness of nanosized protein-loaded polyelectrolyte complexes when adsorbed to model lipid membranes. Two SS-PAAs were synthesized and used to form different nanocomplexes by self-assembly with human insulin that is used as a negatively charged model protein at neutral $\mathrm{pH}$. The resulting nanoparticles collapsed on top of negatively charged model membranes upon adsorption, without disrupting the membrane integrity. These structural rearrangements may occur at a cell surface which may have implications for the uptake of nanoparticles.

In Chapter 6, an effective intracellular protein delivery system for oral administration is described based on a linear water-soluble SS-PAA that efficiently condenses human serum albumin by self-assembly into stable nanoscaled and positively-charged complexes. In addition of providing intracellular bioreduction, the presence of the disulfide groups was shown to increase the mucoadhesive properties of the nanoparticles. It was shown that the SS-PAA-based nanocomplexes were capable to successfully internalize human serum albumin into the cell cytosol of co-cultures of Caco-2/TC7 and HT-29 mucus secreting cells, with a much higher extent than nanoparticles based on the control PAA lacking disulfide linkages, with enhanced uptake with higher amount of HT-29 cells, proving the high mucoadhesive potency of the SS-PAA carriers.

In Chapter 7, the preparation of several formulations of polyelectrolyte complexes formed by charge-attraction between functionalized linear PAAs and human insulin is described to improve the efficiency of insulin via oral administration. These insulin-loaded nanoparticles were characterized by dynamic light scattering, zeta potential, and their proteolytic and chemical stability. Further on, their hypoglycemic effect was evaluated in vivo in diabetic rats. The PAA nanoparticles were shown to efficiently protect insulin towards proteolytic enzymes and improve its uptake in vivo leading to enhanced oral bioavailability of insulin.

The PAA nanoparticles described in Chapter 8 were prepared to develop therapeutic protein formulations for improved efficiency of antigen administration via the intranasal 
route. These nanoparticles were loaded with the model proteins, ovalbumin and p24, and the oligodeoxynucleotide $\mathrm{CpG}$, having phosphorothioate bases, was used as adjuvant. The vaccine-loaded nanoparticles were characterized in term of particle size, surface charge and loading efficiency. In addition, their capacity to pass through epithelial and endothelial cell layers was evaluated in vitro using a novel cellular model, simulating the respiratory mucosa. Polyelectrolyte complexes formed by charge-attraction between a functionalized linear PAA and the model proteins showed to be non toxic and to efficiently improve their uptake in vitro in the respiratory epithelial $\mathrm{NCl} \mathrm{H} 441$ cells and the endothelial cell line ISO-HAS-1, indicating that this delivery system is very promising to achieve enhanced bioavailability of antigens.

Chapter 9 describes a preliminary investigation of nanoparticles, formulated by self-assembly of a PAA with a fluorescently-labeled reporter peptide, for targeting central nervous system diseases. The nanoparticles were characterized in terms of size, surface charge, and loading efficiency. Cytotoxicity and cell-internalization experiments using hCMEC and Huvec cells showed that the essentially non-toxic PAA-based nanocomplexes were capable to successfully internalize the reporter peptide into these cells.

In Chapter 10, we give a general review of the results obtained in this work and we conclude that bioreducible poly(amidoamine)s are very versatile polymers in the development of highly potent and non-toxic intracellular protein carriers, due to their many favorable properties important for protein delivery, i.e. good water solubility, easy synthesis and modification, good protein condensation ability, facilitated vector unpacking for protein release, low cytotoxicity, and high profection capability. The results indicate that these PAAs create great opportunities for novel applications in protein delivery.

Appendix A describes a preliminary study of the design and synthesis of a series of novel thermo-responsive SS-PAAs with the inclusion of varying amounts of thermo-responsive groups such as NIPAAm in their architecture. The chemistry of the polymer backbone and the thermo-responsive groups inclusion degree could be adjusted to tune the thermo- and $\mathrm{pH}$ responsive properties. These water-soluble polymers efficiently condense pDNA by self-assembly into nanoscaled and positively-charged polyplexes.

In Appendix B, preliminary studies to further increase the storage and processing stability of SS-PAA nanoparticles are described. Modified nanosized polyelectrolyte complexes were prepared by ionic gelation after addition of molecules such as tripolyphosphate or DNA to the previous nanoparticles, and their properties were evaluated in terms of size, surface charge, loading efficiency, stability in some biologically relevant environments, 
compared to the non-modified particles.

Page | 268 


\section{Samenvatting}

Deze scriptie beschrijft het ontwerp en de ontwikkeling van bioreduceerbare poly(amidoamine)s als bioresponsieve vectoren voor de in-vitro en in-vivo afgifte van therapeutische eiwitten. De invloed van de structuur van deze polymeren op hun fysico-chemische eigenschappen, het vermogen om eiwitten nanodeeltjes te vormen, de bio-gestimuleerde afgifte van eiwitten uit deze nanodeeltjes, de intracellulaire profectiecapaciteit, en de cytotoxiciteit in vitro worden in detail behandeld.

Een algemene introductie op deze scriptie en de relevante wetenschappelijke achtergrondinformatie betreffende dit onderzoek staan beschreven in de eerste twee hoofdstukken. In Hoofdstuk 1 wordt de algemene achtergrond met betrekking tot deze scriptie geschetst. Hoofdstuk 2 geeft een overzicht van de strategiën in het ontwerp van polymere nanodeeltjes voor therapeutische eiwit- en peptidenafgifte zoals beschreven in de huidige literatuur. In dit hoofdstuk behandelt fundamentele kennis over polymeer-gecontroleerde eiwitafgifte, en dan met name via orale- en nasale toediening. $\mathrm{Na}$ een beschrijving van de extra- en intracellulaire barrières die optreden bij deze afgifte routes worden methoden beschreven om deze barrières te omzeilen met behulp van cationische polymeren met lage cytotoxiciteit, en dan met name poly(amidoamine)s (PAAs). De aandacht gaat hierbij in het bijzonder uit naar poly(amidoamine)s die de repetitieve disulfide bindingen in hun hoofdketen (SS-PAAs) bevatten, welke worden gereduceerd in intracellulaire milieu.

In Hoofdstuk 3 wordt een effectief intracellulair eiwit afgiftesysteem beschreven dat werd ontwikkeld op basis van gefunctionaliseerde liniaire PAAs die zelf-assemblerende cationische nanocomplexen vormen met tegengesteld geladen eiwitten. Deze wateroplosbare PAAs zijn in staat om het negatief geladen enzym $\beta$-galactosidase efficiënt te condenseren onder vorming van positief geladen nanocomplexen. Celopname experimenten en cytotoxiciteitstesten toonden aan dat deze op PAA gebaseerde nanocomplexen in essentie niet toxisch zijn. Met gebruik van deze nanocomplexen werd $\beta$-galactosidase succesvol opgenomen in cos-7 cellen, waarbij de $\beta$-galactosidase activiteit bijna volledig werd behouden. Dit in tegenstelling tot het vrije enzym, dat in het geheel niet werd opgenomen door de cellen. 
De ontwikkeling van effectieve intracellulaire vectoren voor de afgifte van positief geladen eiwitten bij neutrale pH staat beschreven in Hoofdstuk 4. Hier werd gebruik gemaakt van SS-PAAs waarvan de zijgroepen via een amidebinding negatief geladen citraconzuurzijgroepen bevatten. De citraconzuurgroepen splitsen af wanneer de $\mathrm{pH}$ omlaag gaat (zoals in de endosomen van de cel), waarbij dan positief geladen amino-groepen ontstaan. Bij neutrale $\mathrm{pH}$ vindt bij deze wateroplosbare lineaire polymeren efficiente zelfassemblage plaats met cationische eiwitten, waardoor er nanocomplexen worden gevormd doordat de tegengestelde ladingen elkaar aantrekken. In deze experimenten werd Lysozym gebruikt als positief geladen cationisch eiwit. Naast de reductie van de disulfide bindingen in de polymeer hoofdketen, werd de intracellulaire lysozyme afgifte nagebootst door het bewerkstelligen van een omkering van de elektrostatische eiwit-polymeer interactie bij $\mathrm{pH} 5$ ( $\mathrm{pH}$ in een endosoom) door de afsplitsing van een citraconzuurgroep, hetgeen leidt tot omkering van de lading op de polymeerzijketens. Cytotoxiciteit en celopname experimenten toonden aan dat die SS-PAA gebaseerde nanocomplexen niet toxisch worden en dat Lysozym succesvol werd opgenomen in HUVEC cellen.

Hoofdstuk 5 beschrijft het gebruik van oppervlakte-gevoelige kwarts microbalans technieken voor analyse van effecten van eiwitgeladen polyelectrolytcomplexen als deze adsorberen aan model lipide membranen. Twee verschillende SS-PAAs werden gesynthetiseerd en hiermee werden verschillende nanocomplexen gevormd door middel van zelfassemblage met humaan insuline, dat werd gebruikt als een negatief geladen modeleiwit bij neutrale $\mathrm{pH}$. Uit de metingen bleek dat de gevormde nanopartikels tijdens absorptie aan de negatief geladen modelmembranen, zonder dat de membraanintegriteit werd verstoord. Deze structurele herschikkingen zouden tevens op een celoppervlak plaats kunnen vinden, waardoor de opname van intacte nanopartikels wordt belemmerd.

In hoofdstuk 6, staat de ontwikkeling beschreven van een effectief intracellulair eiwitafgiftesysteem voor orale toediening op basis van lineaire wateroplosbare SS-PAAs, die in staat zijn om humaan serum albumine efficiënt te condenseren in stabiele positief geladen nanocomplexen. Naast het verschaffen van intracellulaire bioreductie, zorgt de aanwezigheid van disulfide groepen voor een toename in de mucoadhesiviteit van de nanopartikels. Er werd aangetoond dat op SS-PAA gebaseerde nanocomplexen in staat waren om humaan serum albumine succesvol op te laten nemen in het cytosol van co-culturen van Caco-2/TC7 en HT-29 mucus-secreterende cellen. De opname vond plaats in veel grotere mate dan bij de controlegroep, PAAs zonder disulfide binding in de 
keten. Een verhoogde opname werd waargenomen bij een hogere verhouding aan HT-29 cellen, waaruit het belang van de goede mucoadhesiviteit van SS-PAA dragers blijkt.

In hoofdstuk 7 wordt het vervaardigen van verschillende polyelectrolytcomplexen door middel van ladingsaantrekking tussen de gefunctionaliseerde lineaire PAAs en humaan insuline beschreven. Deze polyplexen werden vervaardigd om de doelmatigheid van oraal toegediende insuline te vergroten. Deze insuline-geladen nanopartikels werden gekarakteriseerd met behulp van dynamische lichtverstrooiing, zeta-potentiaal, en hun proteolytische en chemische stabiliteit. Verder werd hun hypoglykemische effect in vivo bestudeerd in diabetische ratten. Aangetoond werd dat PAA nanopartikels insuline effectief beschermen tegen proteolytische enzymen en de opname in vivo bevorderen zodat de orale biobeschikbaarheid verhoogd werd.

Op PAA gebaseerde nanopartikels voor de ontwikkeling van therapeutische eiwit formules om de antigen afgifte efficiëntie via de nasale route te bevorderen zijn beschreven in Hoofdstuk 8. Deze nanopartikels werden respectievelijk met de volgende modeleiwitten beladen: ovalbumine en p24, en de oligodesoxynucleotide CpG met phosphorothioaat basen werd gebruikt als adjuvant. De met vaccin beladen nanopartikels werden gekarakteriseerd op basis van hun deeltjesgrootte, oppervlaktelading en hun laad-efficiëntie. Tevens werd een nieuw celmodel gebruikt om het vermogen van de nanopartikels om de epitheel- en endotheelcel lagen te passeren te onderzoeken. Dit celmodel is een simulatie van het slijmvlies dat het ademhalingsstelsel bedekt. De gevormde polyelectrolytcomplexen van de gefunctionaliseerde lineaire PAAs met de modeleiwitten bleken niet toxisch te zijn. Verder bleken deze complexen de in vitro opname te bevorderen in respiratoire epitheel $\mathrm{NCl}-\mathrm{H} 441$ cellen en in de endotheel cellijn ISO-HAS-1, wat aangeeft dat dit een veelbelovend afgiftesysteem is om de biobeschikbaarheid van antigenen te vergroten.

In Hoofdstuk 9 worden nanopartikels, gevormd door zelfassemblage van PAAs en fluorescent gelabelede reporterpeptiden, beschreven die dienen voor het targeten van aandoeningen die het centraal zenuwstelsel aantasten. De nanopartikels werden gekarakteriseerd op basis van grootte, oppervlaktelading en hun beladingsefficiëntie. Celopname experimenten en cytotoxiciteitstesten, waarbij gebruikt werd gemaakt van hCMEC en HUVEC cellen toonden aan dat ook deze PAA-gebaseerde nanocomplexen niet toxisch zijn. Verder werd aangetoond dat het in de PAA nanogecomplexeerde reporterpeptide succesvol werd opgenomen in de cellen.

Ten slotte wordt er in Hoofdstuk 10 geconcludeerd dat bioreduceerbare 
poly(amidoamine)s veelbelovend zijn voor de ontwikkeling van potente en niet-toxische nano-systemen voor intracellulaire afgifte van therapeutische eiwitten, omdat ze beschikken over zeer gunstige eigenschappen zoals een goed water oplosbaarheid, eenvoudige synthese en mogelijkheden voor modificatie, goede eiwitcondensatie, bio-gestimuleerde uitpakking van de vector ten behoeve van de eiwitafgifte, lage cytotoxiciteit en hoge profectiecapaciteit.

Appendix A beschrijft het ontwerp en de synthese van een serie nieuwe thermo-responsieve SS-PAAs met variërende hoeveelheden thermo-responsieve groepen, zoals NIPAAm, in de architectuur. De structuur van de polymere hoofdketen en de hoeveelheid van thermo-responsieve groepen kan worden gevarieerd om de eigenschappen te tunen. De voorlopige resultaten laten zien dat deze wateroplosbare polymeren pDNA condenseren door middel van zelfassemblage in positief geladen polyplexen met afmetingen op de nanoschaal.

In Appendix B worden voorlopige studies ten behoeve van het verder vergroten van de opslag- en verwerkingsstabiliteit van nanocomplexen van SS-PAAs met DNA beschreven. Gemodificeerde polyelectrolytcomplexen op nanoschaal werden bereid door middel van ionische gelatie na toevoeging van tripolyphosphaat of DNA aan de SS-PAA nanopartikels. Vervolgens werden de eigenschappen van de nanopartikels bekeken op deeltjesgrootte, oppervlaktelading, beladingsefficiëntie, en stabiliteit in relevant biologische omgevingen en vergeleken met de ongemodificeerde nanopartikels. 


\section{Acknowledgments}

At the end of 2006, after 2 internships in the Netherlands, I decided to come back to this country for another experience to do my Ph.D. at the Biomedical Chemistry (BMC) group. That is how I started in February 2007, and now after a bit more than four years I am almost there! It has been a long time with lots of achievements, lots of ideas and hypotheses, hard work, interesting discussions, lots of friendships and last but not least a lot of fun! Of course the Ph.D. life is not always a bed of roses, but in overall I will keep a good memory, with some great results and also friends with whom I know our friendship is made to last. In this long journey, I met many people from whom I received valuable support. Now, I would like to take the opportunity to thank the people who helped me to make this work and my life better with their support.

First of all, I would like to express my sincere gratitude to my promotor Prof. Johan Engbersen for giving me the opportunity to pursue my Ph.D. course at the BMC group. Thank you very much for your trust in me and for your continuous support. I very much appreciate your guidance during the last four years. You have always been available for discussion. I just needed to knock at the door and there was always a way to find a moment to discuss. You were very generous in sharing your knowledge and experience with me, not only about science but also about life in general. I will always remember the pizzas and beers we had during our semi-annual trips within the Nanobiopharmaceutics consortium project. You were always optimistic and constructive. I learned a lot from you about doing research and writing in a scientific manner and I still have a lot to learn.

Most parts of the work presented in this thesis could have never been completed without the contributions of our collaborators. Firstly, I would like to thank Christian Freese, Dr. Iris Hermanns and Dr. Ron Unger from the University Medical Center of the Johannes Gutenberg University, in Mainz (Germany). Other fruitful collaborations were with Dr. Shmuel Cohen and Prof. Rafi Korenstein from the Tel-Aviv University (Israel), and also with Rickard Frost and Prof. Sofia Svedhem from Chalmers University in Göteborg (Sweden). I really appreciate your input and valuable suggestions during the different projects we run jointly. We did a lot of work together, I cannot count the number of emails we exchanged, and in the end almost everything we did results in five chapters in this thesis, which are 
also meant to be published soon in good journals.

I also would like to thank the other partners from the Nanobiopharmaceutics project with whom I have collaborated: Prof. Christian Grandfils (Université de Liège, Belgium), Dr. Karin Pickl (Joanneum Research, Graz, Austria), Prof. Eleonore Fröhlich (Medizinische Universität Graz, Graz, Austria), Dr. Claus Gyrup Nielsen, Dr. Kristian Bak-Jensen and Dr. Peter Kresten Nielsen (Novo Nordisk, Måløv, Denmark), Dr. Abdelatif Elouahabi and Dr. Sandrine Wouters (GSK, Rixensart, Belgium).

Next, I cannot go without mentioning the help and support from the PBM-BMC-BST staff. Karin, from the beginning with my application phase until the last days, you have always kindly helped me in all the administrative work in the best way you could. Thanks a lot! I also would like to thank Hetty for her help in solving all financial and IT problems, Marc for ensuring a safe and enjoyable work environment, and Zlata for ordering chemicals and labware.

Throughout the last four years, I had the chance to supervise bachelor and master students, and some really leaved me very good memories. Gert-Jan, you were my first student, and you turned out to be a really hard-working bachelor student. It was a great experience for me to supervise a student like you. Also thanks for the translation of my samenvatting. Astrid, all the experiments we tried to perform did not work out, but in the end some are included in this thesis, and we had lots of fun in the lab together. Ewa, it was a pleasure to help you with your French lessons. Sebastian, you arrived during the last months of my Ph.D. project and you had the tough mission to perform work in the lab and explore some of the last ideas I had while I was already starting to write my thesis. Even if we experienced a lot of uncontrollable material issues, we still managed to achieve good results reported here in this thesis.

Next, come my colleagues from the PBM-BMC-BST group. Siggi and Ingrid, thanks for your efforts to get me introduced and to make me feel comfortable in the group during my first weeks. Miguel (Señor Mateos), thanks a lot for your help in the lab, you were always available to answer my questions, even the most stupid ones! Erhan (and Arzu), thanks for sharing Turkish food, drinks and culture with me. Jeffrey (Big Jeff, the King of Salsa), good luck with your new life in A'dam. Sytze and Janine, our study tour to London and Cambridge was a great success! During the last years, I also had good times with the other members of the PBM-BMC-BST. Thanks for the times shared together, in the lab and during the borrels, conferences, group events, triathlons and the study tours in Belgium-Germany and in England. 
I also would like to mention some people who have played important roles in my life during the last years.

Tiago, Sara, Ana Banana, Nazely, Schwan, Gerard, Ramazan, Oya, Sandra/Juan, Mayur/Shraddha, Jigar/Falguni: Thanks for all the nice dinners, nights out, BBQs, beers, drinks and other parties shared together! Shaun, it's a pity we couldn't have gone out more often, but I'm confident that it will come in a near future! Anyway, your beer chicken will always stay in my memory! Opa Jacob, it was always a pleasure to meet you for a chat in the corridor! Suleyman and Gianini, my gym mates, thanks for training with me, good luck for the future!

Can and Laura, my apple cake lovers and weekend evening fellows, thanks for the great times shared together, all the French-Turkish-Catalan dinners, without forgetting the snipper, and others. Samuele (Samu Titirez), my unconditional Italian coffee-breaker, it was nice to travel with you, the next time I won't forget to pay the gasoline! We are both keen on cooking, we did a lot of dinners together with our favourite Romanian girls, and you seriously got me addicted to Italian food! Can (Legend), non rien de rien non je ne regrette rien, we share a common passion for scuba diving and Latin girls, let's keep the best: Edith Piaf, a cigar, fish on the BBQ, a glass of Rakı or Pastis, and always a good conversation! Fede, thanks for the good times shared together in the lab and outside either during our wild nights in Enschede, or in Milan where I always feel like at home. Geraldine, my French connection in Enschede, thanks for all the coffee breaks, it was always good to speak French at some times, we could share things that no one except the two of us could understand, and that was more than enjoyable! Good luck with your new job Madame la directrice, I am sure you will have lots of success!

Special thanks also to my dear friends Mathilde, Santiague, Julie, and Daniel, who always gave me support even we were living far away from each other.

And, of course, I could not forget to greet my sisters and my parents, who have always supported and tried to help me in the best way they could whatever the direction I could have followed. Merci pour tout!

\section{Grégory}

April 2011 


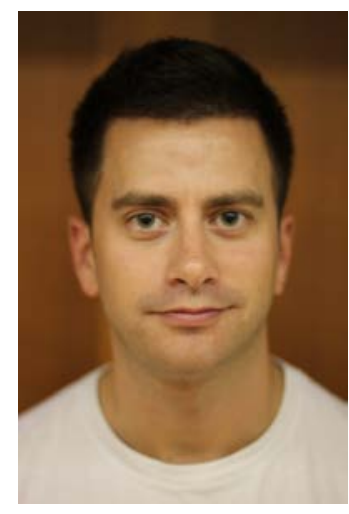

Grégory Coué was born on the 20 $0^{\text {th }}$ of May 1983 in Malestroit (Brittany, France). He was raised in La Gacilly (Brittany, France) and he lived in this lovely village until 2001. That year, he obtained his "Baccalauréat Scientifique" with honors and started to follow a two-year program of Higher Education in Mathematics, Physics and Chemistry in Rennes (Brittany, France), leading to nation-wide selective, competitive examination. As from 2003, he followed a three-year program in Chemistry, Material Science, Physics and Computer Science at the Graduate School of Chemistry and Physics of Bordeaux (ENSCPB, France), with a specialization in Polymer Science, leading to a nation-wide engineer's degree successfully obtained in 2006 . The same year he also obtained a Research Master of Science degree with a specialty in Polymer Science (Université de Bordeaux I, France). In February 2007, he joined the Biomedical Chemistry group at the University of Twente, Enschede, The Netherlands, as a Ph.D. student. During his Ph.D. study, he worked under the supervision of Prof. Dr. Johan F.J. Engbersen. The results of his research are presented in this thesis. As from May 2011, he has been working as a post-doctoral researcher at Sagetis Biotech and at the Institut Químic de Sarrià, Universitat Ramon Llull in Barcelona (Catalunya, Spain), under the supervision of Prof. Dr. Salvador Borrós. 
